\title{
Chipped Stone and Adobe: A Cultural Resources Assessment of the Proposed Applewhite Reservoir, Bexar County, Texas
}

\author{
A. Joachim McGraw
}

Kay Hindes

Follow this and additional works at: https://scholarworks.sfasu.edu/ita

Part of the American Material Culture Commons, Archaeological Anthropology Commons, Environmental Studies Commons, Other American Studies Commons, Other Arts and Humanities Commons, Other History of Art, Architecture, and Archaeology Commons, and the United States History Commons

Tell us how this article helped you.

This Article is brought to you for free and open access by the Center for Regional Heritage Research at SFA ScholarWorks. It has been accepted for inclusion in Index of Texas Archaeology: Open Access Gray Literature from the Lone Star State by an authorized editor of SFA ScholarWorks. For more information, please contact cdsscholarworks@sfasu.edu. 
Chipped Stone and Adobe: A Cultural Resources Assessment of the Proposed Applewhite Reservoir, Bexar County, Texas

\section{Creative Commons License}

\section{(c) (1) (8)}

This work is licensed under a Creative Commons Attribution-NonCommercial 4.0 International License 
CHIPPED STONE AND ADOBE:

A CULTURAL RESOURCES ASSESSMENT OF THE PROPOSED

APPLEWHITE RESERVOIR, BEXAR COUNTY, TEXAS

A. Joachim McGraw and Kay Hindes

With contributions by Glen Evans, Joe1 Gunn, Jana Hellier, Gilberto Hinojosa, Cristi Assad Hunter, and Beverly Van Note

Center for Archaeological Research The University of Texas at San Antonio ${ }^{\circledR}$

Archaeological Survey Report, No. 163 
Pen and ink cover illustration courtesy of Linda Eppright Crowel1, Ruins at 41 BX 669. 


\section{ABSTRACT}

Cultural resources investigations conducted during 1981 and 1984 for the proposed Applewhite Reservoir of southwest Bexar County, Texas, identified a total of 78 archaeological sites. Additionally, seven previously recorded sites in the Medio Creek confluence area were revisited and reassessed, bringing the total number of sites within the proposed reservoir to 85 . Descriptions of these sites, evaluations of their significance, and recommendations for further work are presented in the report. Events and cultural changes related to the project area are also summarized. Limited testing data from 13 sites first identified in 1981 and recommended for further work in the 1984 studies are detailed. 


\section{TABLE OF CONTENTS}

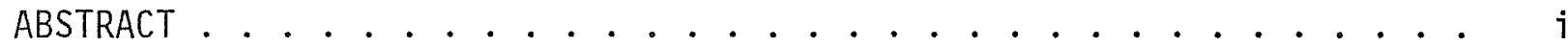

LIST OF FIGURES . . . . . . . . . . . . . . . . . . . . . . . vi

LIST OF TABLES . . . . . . . . . . . . . . . . . . . . . . . . . . viii

ACKNOWLEDGMENTS ............................. . . . . . . . $\mathrm{x}$

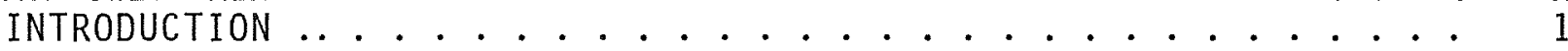

Project Description...................... . . . . 1

Scope of Work . . . . . . . . . . . . . . . . . . . . 5

Special Studies....................... . . . . . 6

RESEARCH DESIGN AND METHODOLOGY . . . . . . . . . . . . . . . . . . 8

Research Design . . . . . . . . . . . . . . . . . . . 8

Testing ............................ 11

Historic Overview Studies . . . . . . . . . . . . . . 11

Testable Hypotheses . . . . . . . . . . . . . . . . 14

Methodology ....................... . . . . 16

1981 Operations ..................... . . . 16

1984 0perations . . . . . . . . . . . . . . . . . . 17

Fluctuations in Methodology Research, 1981-1984 . . . . . . 20

Supplemental Project Operations ................ 20

ENVIRONMENTAL SETTING . . . . . . . . . . . . . . . . . . . 22

Introduction ......................... 22

Geology .......................... . . . . 22

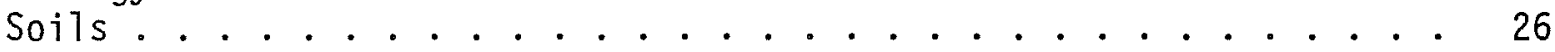

Geomorphology . . . . . . . . . . . . . . . . . . . 28

Hydrology .. . . . . . . . . . . . . . . . . . 36

Climate......................... . . . . . 37

Biota............................ 38

Paleoenvironment . . . . . . . . . . . . . . . . . . 39

ARCHAEOLOGICAL BACKGROUND . . . . . . . . . . . . . . . . . . 43

Introduction ............................. . . . . . . . . . . . . . 43

Paleo-Indian Period . . . . . . . . . . . . . . . . . 43

Archaic Period . . . . . . . . . . . . . . . . . . . 46

Late Prehistoric Period . . . . . . . . . . . . . . . . 48

Historic Period... . . . . . . . . . . . . . . . . . . 48

Indigenous and/or Intrusive Protohistoric-Historic Indian Groups . 49

Pastia and Pampopa . . . . . . . . . . . . . . . . . 50

SuTujam, Sigames, Siupam, and Chayopines(?). . . . . . . . . . . 51

Payaya . . . . . . . . . . . . . . . . . . . 51

Apache . . . . . . . . . . . . . . . . . . . . 54

Comanche, Wichita Groups, and Tonkawa . . . . . . . . . 55

Occupation Patterns ................... . . . 56

Previous Archaeological Research in Bexar County . . . . . . . . . . 58

Previous Archaeological Work in the Study Area . . . . . . . . . . . . 60

Problem Areas of Current Research . . . . . . . . . . . . . . . 60

HISTORICAL OVERVIEW . . . . . . . . . . . . . . . . . . . . . . . 63

Introduction .......................... . . . . . 63

Spanish Exploration and Settlement . . . . . . . . . . . . . . . . . . 63

Mexican Statehood . . . . . . . . . . . . . . . . . . . . 82

Texas Republic . . . . . . . . . . . . . . . . . . . . . . . . . . 88

Early Statehood and Antebellum . . . . . . . . . . . . . . . . . 94

Civil War . . . . . . . . . . . . . . . . . . . . . . . . . 98

Post Civil War--Industrialization . . . . . . . . . . . . . . . . 100 
Site 41 BX 569

Site 41 BX 652

Site 41 BX 653

Site 41 BX 654

Site 41 BX 655

Site 41 BX 656

Site 41 BX 657

Site 41 BX 658

Site 41 BX 659

Site 41 BX 660

Site 41 BX 661

Site 41 BX 662

Site 41 BX 664

Site 41 BX 665

Site 41 BX 666

Site 41 BX 667

Site 41 BX 668

Site 41 BX 669

Site 41 BX 670

Site 41 BX 671

Site 41 BX 672

Site 41 BX 673

Site 41 BX 674

Site 41 BX 675

Site 41 BX 676

Site 41 BX 680

Site 41 BX 681

Site 41 BX 682

Site 41 BX 697

MATERIAL CULTURE ............................ 263

Historic Materials . . . . . . . . . . . . . . . . 263

Ceramics........ . . . . . . . . . . . . . . 264

Miscellaneous ........................ 280

Metal Artifacts .. . . . . . . . . . . . . . . . 280

Glass........................... 281

She11.......................... 285

Chipped Stone ....................... . . 285

Prehistoric Materials . . . . . . . . . . . . . . . . 285

Thick Bifaces . . . . . . . . . . . . . . . . . . 286

Thin Bifaces... . . . . . . . . . . . . . . . . . 298

Projectile Points . . . . . . . . . . . . . . . . 303

Distally Beveled Tools . . . . . . . . . . . . . . . 322

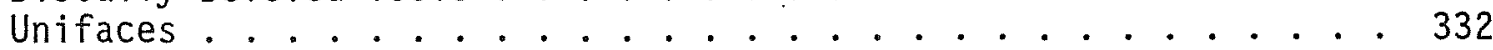

Perforators . . . . . . . . . . . . . . . . . . . 333

Utilized and/or Modified Chipped Stone . . . . . . . . . . . . 333

Battered, Ground, Pecked, and Notched Stone . . . . . . . . . 335

Lithic Debris . . . . . . . . . . . . . . . . . 338

Ceramics.......................... 339

SUMMARY AND INTERPRETATIONS . . . . . . . . . . . . . . . . . . 346

Project Summary . . . . . . . . . . . . . . . . . . . . . 346

Prehistoric Sites Summary . . . . . . . . . . . . . . . . . 354

Prehistoric Sites Interpretations . . . . . . . . . . . . . . . 361

Geomorphological and Paleoenvironmental Considerations . . . . . 361 
Historical Summary .. . . . . . . . . . . . . . . . . 102

INVENTORY OF RESOURCES . . . . . . . . . . . . . . . . . . . 104

Introduction ....................... 104

Site 41 BX 273 ......................... . . 107

Site 41 BX 274. . . . . . . . . . . . . . . . . . . . 108

Site 41 BX 277 . . . . . . . . . . . . . . . . . . . 126

Site 41 BX 343 . . . . . . . . . . . . . . . . . . . . . . . . . 127

Site 41 BX 344 . . . . . . . . . . . . . . . . . . . . . . . . 129

Site 41 BX 346 A. . . . . . . . . . . . . . . . . . . . 137

Site 41 BX 346B.......................... . . . . 139

Site 41 BX 347 ........................ 140

Site 41 BX 348 ....................... . . . 142

Site 41 BX 350 ......................... . . . . . 143

Site 41 BX 515 . . . . . . . . . . . . . . . . . . . 144

Site 41 BX 516 . . . . . . . . . . . . . . . . . . . 145

Site 41 BX 517 . . . . . . . . . . . . . . . . . . . . . . . 146

Site 41 BX 518 . . . . . . . . . . . . . . . . . . . . . . . . . 148

Site 41 BX 519 . . . . . . . ................ 149

Site 41 BX 520 ......................... . . . . . . 151

Site 41 BX 521 . . . . . . . . . . . . . . . . . . . 152

Site 41 BX 522 . . . . . . . . . . . . . . . . . . . . 156

Site 41 BX 523 . . . . . . . . . . . . . . . . . . . . 157

Site 41 BX 524 . . . . . . . . . . . . . . . . . . . 157

Site 41 BX 525 ........................ 159

Site 41 BX 526 . . . . . . . . . . . . . . . . . . . 160

Site 41 BX 527 . . . . . . . . . . . . . . . . . . . . 161

Site 41 BX 528 . . . . . . . . . . . . . . . . . 169

Site 41 BX 529 . . . . . . . . . . . . . . . . . . . . 170

Site 41 BX 530 . . . . . . . . . . . . . . . . . . . 171

Site 41 BX 531 . . . . . . . . . . . . . . . . . . 173

Site 41 BX 532 . . . . . . . . . . . . . . . . . . . . . . . 176

Site 41 BX 533 . . . . . . . . . . . . . . . . . . 178

Site 41 BX 534 . . . . . . . . . . . . . . . . . . . 179

Site 41 BX 535 . . . . . . . . . . . . . . . . . . . . 180

Site 41 BX 536 . . . . . . . . . . . . . . . . . . . 182

Site 41 BX 537 . . . . . . . . . . . . . . . . . . . 183

Site 41 BX 538 . . . . . . . . . . . . . . . . . . . . . 184

Site 41 BX 539 . . . . . . . . . . . . . . . . . . . . . 188

Site 41 BX 540 . . . . . . . . . . . . . . . . . . . . . . . 191

Site 41 BX 541 .. . . . . . . . . . . . . . . . . . . 192

Site 41 BX 542 . . . . . . . . . . . . . . . . . . . . . 194

Site 41 BX 543 ....................... . . . . 195

Site 41 BX 544 . . . . . . . . . . . . . . . . . . . . . . 196

Site 41 BX 545 . . . . . . . . . . . . . . . . . . . . 197

Site 41 BX 546 . . . . . . . . . . . . . . . . . . . . . . 199

Site 41 BX 547 . . . . . . . . . . . . . . . . . . . . 200

Site 41 BX 548 . . . . . . . . . . . . . . . . . . . . . . . 201

Site 41 BX 549 . . . . . . . . . . . . . . . . . . . . . . . 202

Site 41 BX 550 . . . . . . . . . . . . . . . . . . . . . 206

Site 41 BX 552 . . . . . . . . . . . . . . . . . . . . . . . . . . . 207

Site 41 BX 553 . . . . . . . . . . . . . . . . . . . . . . 208

Site 41 BX 554 . . . . . . . . . . . . . . . . . . . . . . . 209

Site 41 BX 568 . . . . . . . . . . . . . . . . . . . 210 
Prehistoric Activities . . . . . . . . . . . . . . . 363

Paleo-Indian Occupation ................ 364

Archaic 0ccupation ............... . . . . 365

Late Prehistoric 0ccupation . . . . . . . . . . . . 365

Historic Indian 0ccupation . . . . . . . . . . . 367

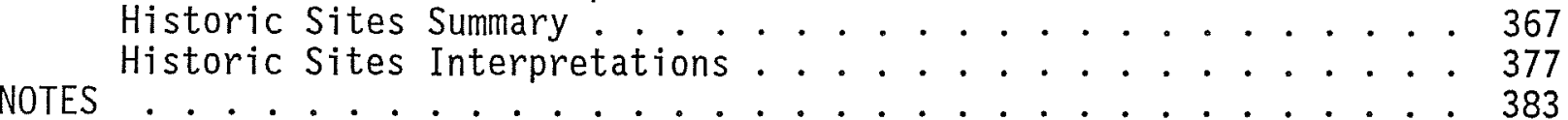

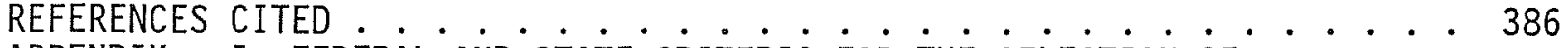

APPENDIX I. FEDERAL AND STATE CRITERIA FOR THE SELECTION OF NATIONAL REGISTER SITES AND TEXAS HISTORIC LANDMARKS . . . 411

APPENDIX II. GLOSSARY ................... 413

APPENDIX III. IDENTIFIED HEADRIGHTS AND/OR GRANTS IN THE STUDY AREA • . 415

APPENDIX IV. SITE SURVEY FORMS FOR 1981 AND $1984 \ldots \ldots . . \ldots . . . . \quad 419$

APPENDIX V. PREVIOUSLY IDENTIFIED SITES ALONG MEDIO CREEK . . . . . 427

APPENDIX VI. FAUNAL REMAINS FROM 41 BX 274

(Cristi Assad Hunter and Jana Hel1ier) . . . . . . . . 436

APPENDIX VII. AN EXPERIMENTAL DATING OF A POSSIBLE SPANISH COLONIAL

BUILDING IN THE PROPOSED APPLEWHITE RESERVOIR AREA

(Joel Gunn) . . . . . . . . . . . . . 460 


\section{LIST OF FIGURES}

1. General Map of the Study Area . . . . . . . . . . . . 2

2. General Location of Surveyed and Unsurveyed Areas during 1981 and 1984........................ 4

3. Research Design ... . . . . . . . . . . . . 9

4. Research Methodology of Site Descriptions ........... 9

5. Ethnohistorical Perspective of the 1984 Archival/Historical Research. . . . . . . . . . . . . . 12

6. Functional Elements of Historic Site Components ......... 13

7. Transect Intervals During Intensive Survey Operations . . . . . . . 18

8. Environment in the Study Area . . . . . . . . . . . . . 23

9. Geologic Map of the Study Area ..... . . . . . . . . . . 24

10. Soils in the Study Area . . . . . . . . . . . . . . . 27

11. Identified Geomorphological Changes (Post-Pleistocene) in the Study Area .. . . . . . . . . . . . . . . 32

12. Postulated Terrace Remnants Associated with Early Archaic Occupation Sites in the Western Portion of the Study Area . . . . . 33

13. Postulated Terrace Remnants Associated with Early Archaic Sites in the Eastern Portion of the Study Area. . . . . . . . . 34

14. Early Routes in the Study Area ..... . . . . . . . . . . . . 69

15. Spanish Colonial and Early Mexican Ranches in the Study Area . . 73

16. Property Ownerships Within the Study Area, Texas Republic . . . . . 91

17. Surveyor's Map I17ustrating Ignacio Pérez's Claim of Four Leagues Along the Southern Banks of the Medina River. . . . . . . . 112

18. Sma11-Scale Contour Map and Overlying Sampling Grid at 41 BX 274, Historic Component . . . . . . . . . . . . . 115

19. General Locations of Test Units at $41 \mathrm{BX} 274$, Prehistoric Component . . . . . . . . . . . . . . . 117

20. Feature 1 at 41 BX 274 ................ 119

21. Backhoe Trenching in Progress at 4I BX 274 . . . . . . . . . 125

22. P1astered Stone Structure at 41 BX 344 . . . . . . . . . . . . 132

23. Stuccoed Frame Structure at 41 BX 344 . . . . . . . . . . . . . . 133

24. Views of Two Structures at 41 BX $344 \ldots \ldots . . . . . . . .134$

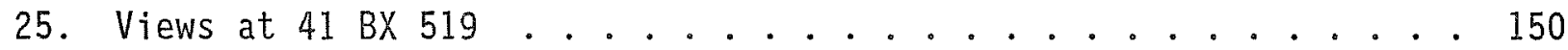

26. Early Historical Military Stirrup from 41 BX $520 \ldots . . . . . . .153$

27. Views of the 0ak Is land Church, 41 BX $521 \ldots . . . . . . .155$

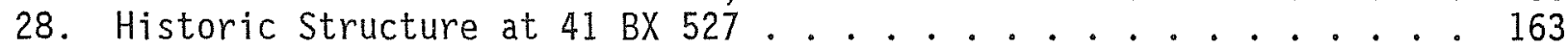

29. Exterior Views of Historic Structure at 41 BX $527 \ldots . . . . . .165$

30. Views of Barn Structure at 41 BX 527 . . . . . . . . . . 167

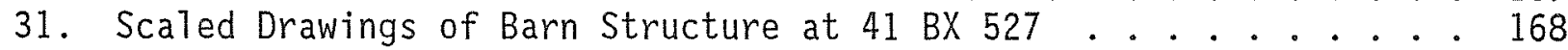

32. Location of Sites 41 BX 530, 41 BX 531, 41 BX 537, 41 BX 538, $41 \mathrm{BX} 539,41 \mathrm{BX} 540$, and 41 BX 669 Along the Eastern Margins of the Proposed Reservoir . . . . . . . . . . . . . . . 174

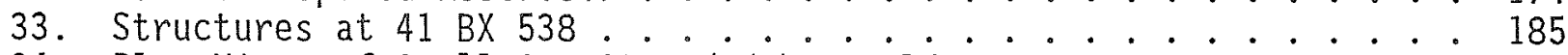

34. P1an Views of Sma17 Cut Stone/Adobe Building at 41 BX 538 . . . . . 186

35. Chapel at 41 BX 549, Linn Ranch Home Headquarters . . . . . . . . 203

36. Plan Views of 41 BX 661, Early 20th-Century Tenant 0ccupation . . 224

37. Brick Kiln Remains at 41 BX 662 . . . . . . . . . . . 226

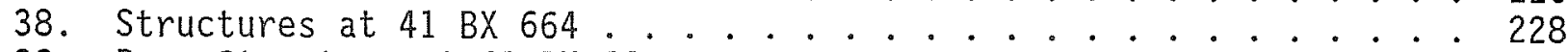

39. Barn Structure at 41 BX $664 \ldots . . . . . . . . . . .2230$

40. Views of Historic Structure at 41 BX $666 \ldots \ldots$. . . . . . . . . . 237

41. Stone Ruins at 41 BX 669 . . . . . . . . . . . . . . . . 244 
42. Views of Historic Structures at 41 BX $672 \ldots . . . . . . . .251$

43. View of Large Wooden Gates at 41 BX 672 . . . . . . . . . . . 252

44. Evidence of Stone-Lined Roadway Leading to Tálon Crossing, 41 BX 680 ..................... . . 258

45. Soft Paste Earthenwares . . . . . . . . . . . . . . 267

46. Hard Paste Earthenwares . . . . . . . . . . . . . . . . . 273

47. Hard Paste Earthenwares, Stoneware, Porcelain, and Clay Marble

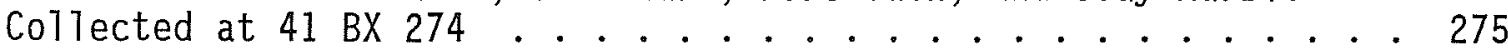

48. Metal Artifacts . . . . . . . . . . . . . . . . . . 283

49. Details of Selected Artifacts from Limited Testing at 41 BX 274 . . 284

50. Collected Lithic Materials from 41 BX 669 ............ . 291

51. Collected Lithic Materials from Prehistoric Sites in Project Area . 295

52. Thick Bifaces, Distally Beveled Tools, and Uniface . . . . . . . . 297

53. Surface Collected Artifacts from 41 BX 665 . . . . . . . . . . . . 301

54. Artifacts from 41 BX 274 . . . . . . . . . . . . . . . . . . . 302

55. Surface Collected Artifacts from 41 BX 528 . . . . . . . . . . . . 305

56. Collected Lithic Materials from 41 BX 274 . . . . . . . . . . . . 311

57. Collected Dart Points . . . . . . . . . . . . . . . . . . . . . 315

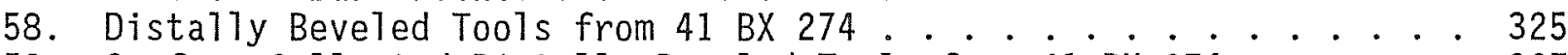

59. Surface Collected Dista77y Beveled Tools from 41 BX 274 . . . . . 327

60. Distally Beveled Tools Recovered from Limited Testing at

41 BX 274 . . . . . . . . . . . . . . 329

61. Utilized/Modified Chipped Stone and Sandstone ......... 334

62. Miscellaneous Artifacts from 41 BX 528 and 41 BX 534 . . . . . . . 337 


\section{LIST OF TABLES}

1. Terrace Soils and Related Cultural Deposits........... 29

2. Climate Data Summary for Bexar County . . . . . . . . . . . . . 37

3. Paleoenvironmental Data Compared to Cultural Chronologies . . . . . 40

4. Local Chronological Cultural Sequence.............. 44

5. Regional Radiocarbon Assays . . . . . . . . . . . . . . . 45

6. Intrusive and Indigenous Indian Groups Identified Along the Medina and San Antonio Rivers and Vicinity . . . . . . . . . . . 57

7. Identified Headrights, Bounty, and Donation Grants for Properties Within the Proposed Reservoir Area . . . . . . . . . . . 89

8. Provenience of Collected Materials from Feature 4, Test Group 4,

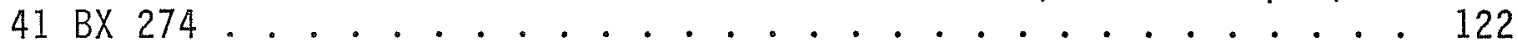

9. List of Data Recorded from Tombstones at 41 BX 667 . . . . . . . 241

10. Provenience of Collected Historic Materials . . . . . . . . . . . 268

11. Prehistoric Artifacts, Morphological Groups and Forms . . . . . . . 287

12. Provenience of Collected Prehistoric Materials . . . . . . . . . 289

13. Summary of Prehistoric and Historic Site Recommendations . . . . 347

14. Listing of Prehistoric Sites in the Conservation Pool Level, Maximum Flood Pool Level, and Adjacent to the Maximum Flood Pool Level ...... . . . . . . . . . . . . 355

15. Prehistoric Sites Believed to be Eligible for Listing on the National Register of Historic Places, by Elevation . . . . . . 357

16. Prehistoric Sites Potentially Eligible for Listing on the National Register of Historic Places, by Elevation . . . . . . 357

17. Prehistoric Sites in Which the Site Significance is Unknown (Further Work Needed), by Elevation . . . . . . . . . . 358

18. Prehistoric Sites Not at this Time Potentially Eligible for the National Register of Historic Places (No Further Work Recommended), by Elevation .............. 359

19. Prehistoric Sites not Eligible for Listing on the National Register of Historic Places, by Elevation . . . . . . . . . 360

20. Listing of Historic Sites/Components in the Conservation Pool Level, Maximum Flood Pool Level, and Adjacent to the Maximum Flood Pool Level ....... 368

21. Historic Sites Believed to be Eligible for Listing on the National Register of Historic Places . . . . . . . .

22. Historic Sites Adjacent to Maximum Flood Pool or in Area of Leon Creek Diversion Dam and Channel with Estimated Secondary Impacts and/or Primary Impact by Projected Construction.

23. Historic Sites Potentially Eligible for Listing on the National Register of Historic Places .. . . . . . . . . . . . 373

24. Historic Sites/Components Not Eligible for Listing on the National Register of Historic Places, by Elevation

25. Historic Churches in the Area of the Proposed Applewhite Reservoir, by Elevation ................ 375

26. Identified Cemeteries in the Area of the Proposed Applewhite Reservoir, by Elevation ............... 376

27. Summary of Sites Previously Recorded Along the Medio CreekMedina River Confluence. . . . . . . . . . . . . . 428

28. Faunal Remains from 41 BX 274 ........... . . 437

29. Frequencies and Percentages of the Taxa from 41 BX $274 \ldots . . .443$

30. Evidence of Modifications Found on the Taxa . . . . . . . 445 
31. The Frequency, Weight in Grams, and Average Specimen Weight by Unit of the Faunal Remains . . . . . . . . . . . . . 446

32. Comparison of the Taxa Found at 41 BX 274 and Rancho de $7 a s$ Cabras ................. . . . 447

33. Comparison of the 41 BX 274 and Rancho de las Cabras Bos and Caprine Elements . . . . . . . . . . . . . 450

34. Ring Measurements in Approximately Half Millimeters and Standard Deviations from the Mean . . . . . . . . . . . . . 465

35. Tree Ring Dates by Various Methods . . . . . . . . . . . 466 


\section{ACKNOWLEDGMENTS}

The authors are deeply indebted to a great many persons for their assistance during the course of the 1981 and 1984 Applewhite Reservoir studies.

\section{FIELD CREW/LABORATORY STAFF}

Sylvia Bento Coleman 1981

Bill Chandler 1984

George Deaton 1984

Courtenay Jones 1981

Joe Labadie 1984

HISTORICAL RESEARCH

Anne Fox 1981

Linda Wooten 1984

HISTORICAL CONSULTANT

Dr. GiTberto Hinojosa, UTSA

OFFICE STAFF

Mary Lou E11 is

Kathy Hodgin

Mary Lehr

EDITOR

Sharon Quirk

GEOLOGICAL AND

GEOMORPHOLOGICAL CONSULTANTS

Glen Evans

Dr. W. W. Hammond

Vance Holliday
Betty Markey 1981

Cecil Peel 1981, 1984

Joan Sherwood 1981

Joe Tovar 1984

Beverly Marshal1 Van Note 1981

DRAFTING/GRAPHICS

Richard Baring

Ken Brown

Verdi Cook

Linda Epright Crowe11

Bruce ElTis

Cathy Dodt Ellis

FAUNAL ANALYSIS

Jana Hellier

Cristi Assad Hunter

TYPISTS

Mary Lou Ellis

Sandra Holland

Ann Young

DENDROCHRONOLOGICAL STUDIES

Dr. Joel Gunn, UTSA

SUPPLEMENTAL OPERATIONS ASSISTANCE

Colonel Bill Bless

Colonel Ben Cheaney
Philip Hindes

Hank Roybal1 
MATERIALS CONSERVATION LABORATORY

Paul Storch
PHOTOGRAPHY

Beth Craig

John Poindexter

Milton Bel1

\section{SOIL CONSERVÃTION SERVICE \\ (Aerial Photographs)}

David Potter

DEPARTMENT OF THE ARMY
FORT WORTH DISTRICT, CORPS OF ENGINEERS

Mr. Robert J. Burton

Ms. Daphne Derven

TEXAS HISTORICAL COMMISSION

Dr. LaVerne Herrington

Nancy Kenmotsu

Paul White
Mr. L. M. Hawkins

Mr. Robert F. Scott IV

SOUTHWEST RESEARCH INSTITUTE

Mr. Steven Durocher 1981
SAN ANTONIO CITY WATER BOARD

Robert Van Dyke
FREESE AND NICHOLS, INC.

Mr. David R. Gattis

In such a large survey and assessment of the proposed Applewhite Reservoir, the success of the work depended greatiy upon the cooperation and assistance of a great number of private 1 andowners, local residents, and informants-many of whom are direct descendants of the original landowners and have owned and 7 ived on the 1 and within the study area for ca. 200 years. We were fortunate to meet and come to know a great many of these individuals. Through oral history interviews we learned from them and about them--family histories, family genealogies, oral traditions, construction techniques of the pioneer settlers, site locations, and a great many other things. To these individuals, we extend a very special thank you and hope that they approve of our work.

Dr. Felix Almaraz

Camille Boyer

Mary Castro

Ernest Chacon

John W. Clark, Jr.

Margaret Condra

Kit Corbin

Bury1 Day

Earl S. Doderer
Annie Mae Gass

Adolph Huizar

Adolph Herrera

Lance Hubbard

Mary Hubbard

LeRoy Johnson

Louise Jones, Kelly and Shannon

James D. Mahan

$\mathrm{Mr}$. Mc0scar 
Billy Mitchel1

Brett Mitche11

Mr. and Mrs. Ike Mullens

Carol ine Munguia

Hayes 0'Quinn

Jeff and Kay 0'Quinn

$M r$. and Mrs. Pax

Carl Pfeiffer

David Picard
J. 0. Powe11

Willis Riggs

Patricia Small

Ed and Mary Walsh

Bi11 Wheaton

Mary Yturri

Dr. Frank W. Weir

Tommie Zunker

The authors would also like to thank some very special people for their assistance with the historical research for the Applewhite Reservoir. To each of these individuals we offer our sincere gratitude.

John Leal, archivist, Bexar County Archives

Dora Guerra, librarian, Special Collections, John Peace Library, UTSA

Sharon Crutchfield, Bernice Strong, Jeanette Phinney, and Sandi Hood, librarians, Daughters of the Republic of Texas Research Library, The Alamo Galen Greaser, Texas General Land Office, Spanish Collection

Tom Shelton, The University of Texas at San Antonio Institute of Texan cultures

Colleen Munds, genealogist, Texas State Library, Aust in

Dr. Thomas R. Hester, director of the Center for Archaeological Research, and Jack Eaton, associate director of the CAR, offered their support and encouragement throughout the duration of the 1981 and 1984 projects. Waynne Cox and Anne Fox of the CAR assisted in the identification of the historic artifacts. Jake Ivey, historical archaeologist, National Park Service, aided in evaluating the Spanish colonial gates found on the Adolph Herrera property during the course of field work. Mr. Robert (Bob) Thonoff willingly spent several hours with us discussing his research on the Battle of Medina. Richard Garay offered valuable leads on the locations of several important historical documents.

Jack Jackson shared portions of his research with us on the locations of the early ranches along the Medina River. Mr. Robert (Bob) Benavides, chairman, Texas Independence Week Committee, a subcommittee of the San Antonio Sesquicentennial Celebration, and vice governor of the Granaderos de Galvez, was instrumental in securing funding for the stabilization and/or preservation of the Spanish colonial gates found on the Adolph Herrera property. Mr. Gary Foreman was instrumental in the same. Mr. Tom Guderjan and Mr. Gerald Poyo of The University of Texas at San Antonio Institute of Texan Cultures provided the catalyst for the removal and storage of the gates to a safe location at the Institute. 


\section{INTRODUCTION}

\section{PROJECT DESCRIPTION}

The cultural resources investigations conducted in 1981 and 1984 by the Center for Archaeological Research (CAR), The University of Texas at San Antonio (UTSA), for the proposed Applewhite Reservoir on the Medina River in southwestern Bexar County, Texas, are detailed herein. The proposed reservoir is planned to "provide a dependable municipal water supply for the city of San Antonio and surrounding communities" (Corps of Engineers 1984; Fig. 1). The dam will create a reservoir which wi17 inundate 2500 acres of 1 and at the conservation pool 1evel of 536 feet above mean sea 7 evel (ms 7 ) with an additional 4729 acres inundated at the maximum flood pool level of 555.3 feet above ms1 (ibid.). A diversion dam on Leon Creek, which would divert high flows from that creek into the reservoir, is also proposed.

The 1981 field work was initiated following an approval of the research proposal, as stated in a letter dated January 30, 1981, from Mr. Steven Durocher of Southwest Research Institute (SWRI) to Dr. Thomas R. Hester, principal investigator and director of UTSA's Center for Archaeological Research. During February and March 1981, personnel from the Center for Archaeological Research conducted the preliminary assessment of prehistoric and historic cultural resources within portions of the proposed reservoir. A. Joachim McGraw of the CAR staff directed survey operations. The field crew consisted of Betty Markey, Cecil Peel, Beverly Marshall Van Note, Joan Sherwood, Courtenay Jones, and Sylvia Bento Coleman. Anne Fox was responsible for historical research and the interpretation of historic sites.

The 1981 work resulted in approximately $50 \%$ of the total project area (as defined by the maximum flood pool level of 555.3 feet above ms1; Fig. 2) being surveyed. Approximately 1250 acres of the conservation pool level and ca. 2289 acres of the maximum flood pool level were surveyed, a total of ca. 3539 acres. Due to difficulties in access to various locations, as well as poor ground visibility due to dense brush in some areas, the remaining $50 \%$ was not surveyed. In 1981, a total of 50 previously unrecorded sites was recorded in the area of the proposed Applewhite Reservoir. One additional site, 41 BX 551, originally identified in 1981 was reassessed in 1984 when access was granted into this area. Survey work determined that site 41 BX 551 was the westward continuation of site 41 BX 346, therefore, site 41 BX 551 was reassigned to site 41 BX 346 . The resulting report from the 1981 study included interpretations of the sites' significance and recommendations for further work.

In the fal1 1984, work to survey previously unsurveyed areas, to conduct limited testing at selected locations, and to compile a historical overview of the area was initiated. The 1984 work was begun following an approval of a research proposal in a 1etter dated August 7, 1984, from David Gattis of Freese and Nichols, Inc., Fort Worth, to Jack Eaton, as sociate director of the CAR-UTSA. Principal investigator for the study was Dr. Thomas R. Hester, director of the CAR-UTSA, and Jack Eaton and A. J. McGraw served as coprincipal investigators. Project director was A. J. McGraw of the CAR-UTSA staff. The field crew consisted of Bill Chandler, George Deaton, Joe Labadie, Joe Tovar, and Cecil Peel. Laboratory processing was conducted by 
This page has been

redacted because it

contains restricted

information. 
Kay Hindes, Cecil Peel, and A. J. McGraw. Historical research, historic site description/interpretation as well as an extensive historical overview of the area were initiated and prepared by Kay Hindes. Field photographers were A. J. McGraw, Beth Craig, and Kay Hindes of the CAR staff.

In 1984, approximately $98 \%$ of the remaining acreage of the total proposed reservoir area (as defined by the maximum flood pool level of 555.3 feet above ms 1) was surveyed. Surveyed were ca. 1225 acres within the conservation pool level and ca. 2314 acres in the maximum flood pool level. In 1984, a total of 28 previously unrecorded sites was recorded in the area of the proposed Applewhite Reservoir. Two sites (4I BX 274 and 41 BX 277) previously identified were also surveyed. Additionally, the 1984 recorded site, 41 BX 663, the historic Pérez Rancho, was reassessed during the course of field work and reassigned to site 41 BX 274. This was done when it was determined that the site margins overlapped and contained both a prehistoric and historic component. Archival research and oral history interviews, performed prior and concurrent with the field work, identified a number of historic sites which were then confirmed by on-site survey. Additionally, most of the sites recorded in 1981 were revisited in 1984, resulting in reevaluations of many of the previously recorded sites. After archival research, two of these sites (41 BX 344 and 41 BX 524) were confirmed by resurvey to have a historic component present. Also during the 1984 investigations, 1 imited testing and/or archival research at 12 sites previously recommended (in 1981) for further work were completed. Site 41 BX 549, because of its sensitive location near a proposed diversion channel, was also reassessed in 1984. Seven previously recorded sites in the vicinity of the Medio Creek-Medina River confluence (McGraw 1977) were revisited and reevaluated in both 1981 and 1984 .

The 1981 and 1984 work was deemed necessary to fulfill the application requirements to the Department of the Army, Corps of Engineers for a 404 Permit for the proposed Applewhite Reservoir and Dam construction. All work to date follows the requirements set forth in the National Historic Preservation Act of 1966, as amended, and the Standards and Guidelines for Archeology and Historic Preservation set forth by the Secretary of the Interior (1983). Assessments of all recorded sites are based upon their potential eligibility for listing on the National Register of Historic Places and as State Archeological Landmarks (see Appendix I). At present, a Texas Antiquities Permit is not required since all affected properties are privately owned; should such lands be acquired in fee a permit would become necessary.

A total of 78 sites has been recorded in the study area of the proposed Applewhite Reservoir during the 1981 and 1984 surveys. An additional seven sites along Medio Creek, originally recorded in 1977 (McGraw 1977) were also revisited and reassessed because of their location in and/or adjacent to the study area. Data from the 1981 and 1984 surveys and limited testing operations from 1984 are presented in the Inventory of Resources section of this report. The Medio Creek sites are presented in Appendix $V$ and are included in the Summary and Interpretations section along with all sites surveyed during the 1981 and 1984 work. 


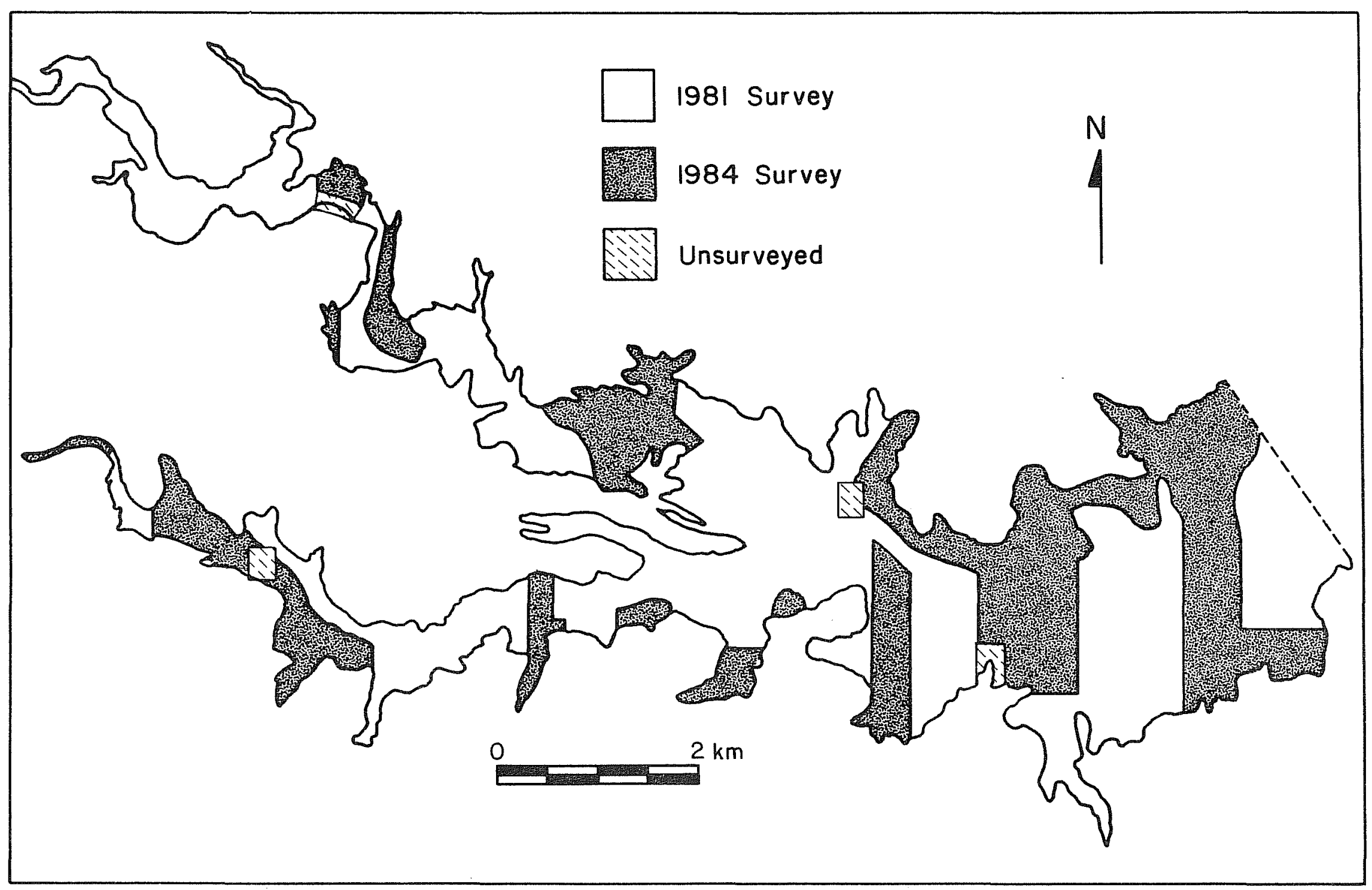


Applewhite/Introduction

\section{SCOPE OF WORK}

The 1981 work (CAR-UTSA 1980) was to be an intensive survey of about 6000 acres of land (as defined by the maximum flood pool 1evel) along the Medina River in southwest Bexar County. The survey was designed to meet four major goals: (1) to perform a complete, on-the-ground survey of the reservoir area; (2) to identify and properly record any and a 11 prehistoric and/or historic cultural resources; (3) to prepare a preliminary evaluation of these sites, utilizing field data and comparative archaeological information available to the Center and historical research (archival, deed searches, etc.); and (4) to present concrete recommendations for possible Phase Two (testing and final evaluations) and Phase Three (mitigation) phases within the reservoir basin.

A draft report resulting from this study by $A$. J. McGraw and Beverly J. Marshall Van Note provided a preliminary assessment of prehistoric and historic cultural resources in the area. The findings and evaluations of this 1981 report are incorporated into the present report.

The 1984 investigations centered around three primary objectives: (1) an intensive survey of areas not surveyed during earlier operations; (2) the testing and evaluation of prehistoric and historic sites identified in the 1981 study as potentially eligible for nomination to the National Register of Historic Places; and (3) the preparation of a historic overview of the region and the project area for a clear assessment of individual site significance and areal cultural developments. Such a systematic investigative process to date has resulted in a more accurate assessment of any cultural resources within the path of future modifications of the area, thus allowing for sitespecific recommendations regarding future mitigation, nonmitigation, or avoidance of identified cultural resources.

To accomplish Objective 1, an intensive surface survey, encompassing $100 \%$ ground coverage, if possible, of areas not surveyed in 1981 was initiated. Special emphasis was placed on areas where extensive subsurface modifications were foreseen: the dam site, spillway, borrow areas, highway and utility relocations, the Leon Creek diversion channel, channel damsite, raw water pump station, water treatment plant, and disposal area. Other localities considered significant were all lands to be acquired in fee, the new pipeline route, raw water pumpline, and transmission line. Only brief project specific information concerning many of these localities was supplied to the investigators by the contracting agencies thereby hampering investigations in these areas.

Objective 2 was the testing and assessment of 12 prehistoric and historic sites identified during the 1981 study as being potentially eligible to the National Register of Historic P1aces: 41 BX 274, 41 BX 519, 41 BX 520, 41 BX 529, 41 BX 530, 41 BX 531, 41 BX 532, 41 BX 533, 41 BX 538, 41 BX 539, $41 \mathrm{BX} 540$, and $41 \mathrm{BX} 544$. The investigations consisted of limited testing, in the form of mechanical (backhoe trenching) and hand-excavated test units, a variety of special application techniques, including judgmental grid sampling, 2-cm contour interval mapping, and special sample collections. The emphasis for this objective was focused on site-specific localities rather than the broad areal perspective of Objective 1. 
Objective 3 of the 1984 investigations was the compilation of a historical overview of the region and the impacted area. Archaeological information, published and unpublished sources, and archival data were reviewed on a local, county, and state level. Archival sources investigated were the Texas General Land Office; the Barker Texas History Center, The University of Texas at Austin; the Texas State Archives, Austin; the Bexar Archives translations, Bexar County Courthouse; Bexar Archives microfilm rolls, John Peace Library, The University of Texas at San Antonio; Bexar County Archives and Deed and Probate Records, Bexar County Courthouse; data at the Daughters of the Republic of Texas Research Library at the Alamo; the special collections at the John Peace Library, UTSA; and The University of Texas at San Antonio Institute of Texan Cultures Research Library. Oral history interviews were conducted with descendants of early, prominent families, local historians, and present landowners. The Texas Historical Commission's (1973:50-53) Historic Preservation in Texas: The Comprehensive Statewide Historic Preservation for Texas was helpful in architectural documentation of selected resources. A detailed description of the historic background to the proposed reservoir is presented in the Historical Overview section, complemented by a descriptive review of associated, historically prominent families.

At the conclusion of the 1981 and 1984 studies, archaeological research at the proposed Applewhite Reservoir has resulted in the identification of a significant number of prehistoric and historic cultural resources. We believe the descriptive data, interpretations, and recommendations presented in this report will offer significant contributions to $10 \mathrm{cal}$ and regional archaeological studies. This research constitutes the first systematic large-scale riverine cultural resources investigation in Bexar county. The area's rich historical background, combined with the opportunity to evaluate extensive prehistoric riparian zones along the environmental transition of the Edwards Plateau and the expanse of the Gulf Coastal Plain should offer a valuable contribution to the history of early Texas and San Antonio.

\section{SPECIAL STUDIES}

As applicable, the archaeological and historical research were supplemented by the specialized study of selected materials and/or aspects of the project area. This work was on three separate areas of interest: (1) a detailed analysis of faunal materials systematically recovered from subsurface testing; (2) experimental efforts toward local dendrochronological research and its direct applicability to sites within the project area; and (3) a preliminary assessment of the potential for and inferences of geomorphological studies. The last element of these studies was considered to be most helpful in gaining a broader insight into the development and effects of natural processes on archaeological sites within the proposed Applewhite Reservoir.

The faunal analyses were conducted by Cristi Assad Hunter and Jana Hellier, under the supervision of D. Gentry Steele, Texas A\&M University, College Station (Appendix VI). Tree-ring studies (Appendix VII) were initiated by Dr. Joel Gunn, Department of Anthropology, The University of Texas at San Antonio (UTSA). Dr. W. W. Hammond, assistant professor, Division of Earth and Physical Sciences, UTSA, was consulted for the background to the local 
geological setting. Vance Holliday, University of Wisconsin, also reviewed the general pattern of geomorphological development in the study area and offered his comments. An actual on-site field inspection of the project location and specific site areas was conducted by geologist, Glen Evans, Austin. Geomorphological data are detailed in the Environmental Setting section.

No radiocarbon material was assayed or wood species identification initiated due to the paucity and almost total absence of charcoal at tested sites. 


\section{RESEARCH DESIGN AND METHODOLOGY}

\section{RESEARCH DESIGN}

During 1981 and 1984, the purpose of the cultural resources study of the proposed Applewhite Reservoir area was the identification and assessment of al1 known prehistoric and historic resources with particular emphasis on their potential eligibility to the National Register of Historic Places.

Research strategy for intensive survey in 1981 was based on a systematic investigative process designed to maximize data collection. The purpose of the 1981 survey operation was threefold: (1) to define cultural resources within the proposed area of modification; (2) to assess the prehistoric and historic significance of these sites; and (3) to recommend courses of further action where necessary.

To accomplish the 1981 study, several additional objectives were formulated:

1. A11 cultural materials within accessible portions of the study area were systematically recorded.

2. Surface extent of sites and distribution of materials were accurately determined, where possible.

3. If identified, inter- and intrasite patterns were defined.

4. Important environmental elements that may have been related to past occupational and subsistence activities were identified.

These data were combined with available ethnographical, historical, and ethnohistorical information.

To aid in preliminary site evaluation, the areal distribution of various technological processes reflected in the surface archaeological record (Figs. 3 and 4) was determined. This examination of sites from a cultural and environmental perspective was considered a more accurate reflection of the nature and importance of each site.

As noted in the Introduction to this report, the 1984 studies addressed three specific goals: (1) an intensive survey of areas not surveyed during 1981; (2) the testing and evaluation of sites (identified in 1981) that were potentially eligible for National Register status; and (3) the preparation of a historical overview of the region and study area to aid in the evaluation of recorded sites. Combined with 1981 work, the completion of 1984 investigations consisted of, as completely as possible, a $100 \%$ surface survey of impacted areas of the proposed reservoir and the testing and evaluation of a series of sites identified in 1981 as potentially eligible for nomination to the National Register of Historic Places. Additionally, a historical overview of the area related current project-specific information to a regional perspective of historical and cultural development.

To accomplish the scope of work of the 1981 and 1984 objectives, this section will review the elements of the research design that relates to pertinent 


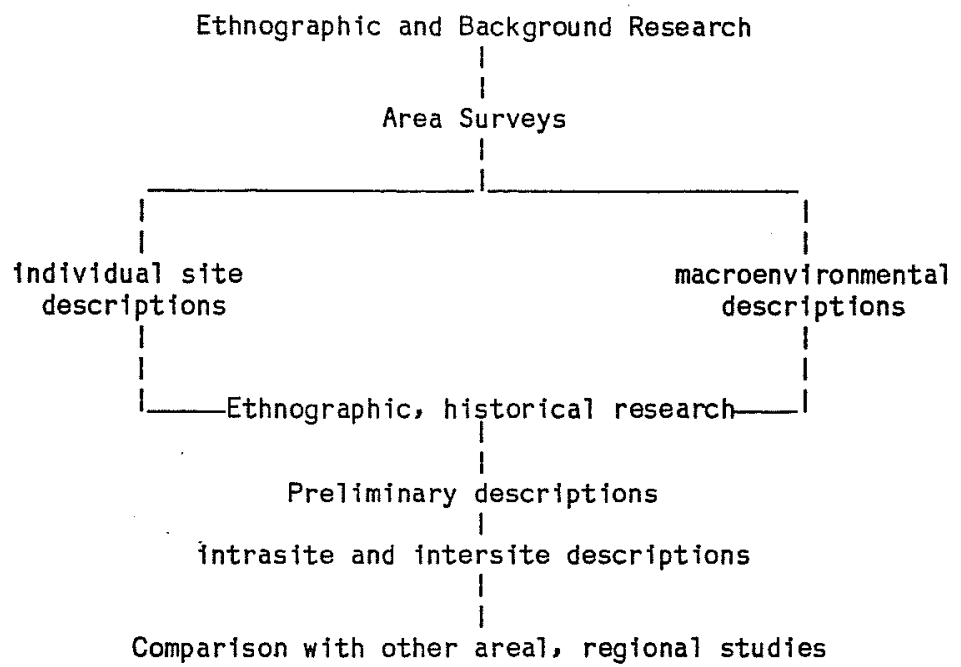

Figure 3. Research Design.

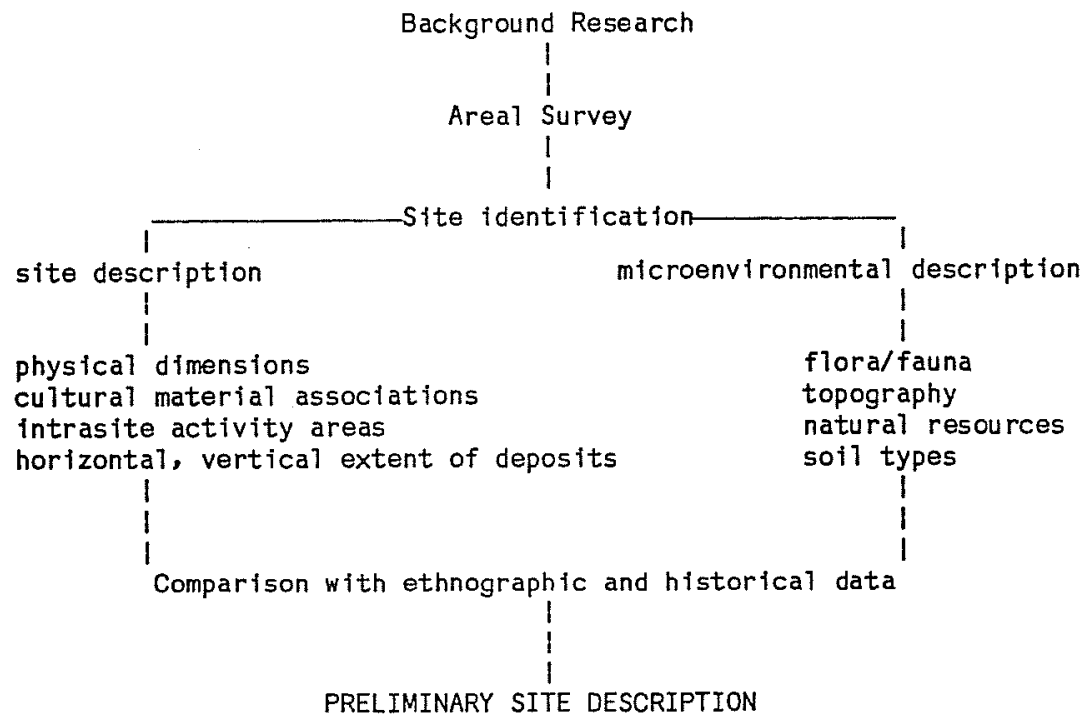

Figure 4. Research Methodology of Site Descriptions. 
regional and $10 \mathrm{cal}$ research questions and demonstrates an understanding of the archaeological record. It will define basic research questions relevant to the project area specifically and the south-central and/or southern Texas region in general. The research design, as presented, was intentionally flexible to become expandable as research data were accumulated. The basic objective of this research design was the formulation of a systematic, detailed plan of work that could be used to accurately identify and determine the significance of cultural resources within the proposed reservoir.

The resulting work of the 1981 and 1984 operations meets the standards and requirements set forth in the National Historic Preservation Act of 1966, as amended, and the Secretary of the Interior's (1983) Standards and Guidelines for Archeology and Historic Preservation. Additional1y, a11 work follows the guidelines presented in the Council of Texas Archeologists (CTA 1981) performance standards. As noted, the research has not required a Texas Antiquities Committee permit since all studied properties are privately owned; should such lands be purchased, a permit will be required.

Cultural resource management studies and guidelines have been discussed in some detail in the Council of Texas Archeologists' Guidelines for the Content of Cultural Resources Management Reports (Bruseth and Thurmond 1981), and this report will briefly review pertinent aspects of these guidelines to define the scope and orientation of the current work.

Current work in the proposed reservoir area is a combined operation of three separate but related cultural resources studies: (1) an archaeological survey; (2) a report overview; and (3) testing of previously identified sites. Such work is thus defined as a combination of (1) a synthesis, evaluation, and interpretation of sites found during survey; (2) a summary and assessment of the existing base of information, including archaeological, historical, and architectural data, as identified from archival and literature searches; and (3) an intrasite as well as intersite information synthesis, evaluation, and interpretation of tested sites (CTA 1981:10-15).

The 1981 and 1984 surveys consisted of four specific elements. First, a priority system of survey operations was initiated based upon differing potentials of certain areas to contain archaeological sites. Since it was recognized that archaeological sites do not occur uniformly across the landscape, it was obvious that certain portions of the study area would have a higher potential for significant site locations. Given the constraints of scheduling, manpower, and funding, different topographic localities were selected and rank-ordered according to estimated potential. These localities were: (1) the modern terraces above the Medina River; (2) the postulated positions of fossil terraces at some distance from the modern river channel; (3) the terraces of tributary creeks; and (4) adjacent upland areas.

A second major element of the survey and the research design was the systematic reconnaissance of formerly uninvestigated areas. Weekly and daily survey operations were outlined in advance to facilitate logistics, accessibility, and efficiency.

Another key element during survey operations was the emphasis on cumulative data interpretation; as information was gathered during daily surveys, the 
Applewhite/Research Design and Methodology

investigation strategy as well as field interpretations were modified to fit existing conditions and to most advantageously study developing patterns of site distributions.

A final element of not only the survey operations but also the later data analysis was the emphasis on testable hypotheses developed from the local and regional archaeological record. These were used to guide investigative strategies and to act as a basis for data interpretation. Testable hypotheses are discussed in this section.

\section{TESTING}

The research design of 1 imited testing operations in the proposed reservoir area was directed toward the accurate interpretation and assessment of specific sites identified as having a potential National Register status. The selection of testing procedures at individual site locations was preceded by estimates of intrasite activity areas, possible impacts to the site's integrity, and relationships to neighboring sites. Assessments of site significance and archaeological potential were made following the evaluation and interpretation of cultural materials on an intra- and intersite level of data synthesis.

\section{HISTORIC OVERVIEW STUDIES}

Prior to and also concurrent with field work for the 1981 and 1984 studies, previous archaeological reports, historical records searches, archival studies, and data interpretations were conducted (Figs. 5 and 6). These operations were designed not only to give project archaeologists a working familiarity with the character of the survey area but also to identify potential site locations. Archival sources, as noted in the Introduction, included the Texas General Land Office and the Texas State Archives, Austin; the files of the Bexar County Archives; information from the Daughters of the Republic of Texas Research Library, the Alamo; and The University of Texas at San Antonio John Peace Library Special Collections. An extensive literature search of published works was used to establish the framework of a regional historical background. Additionally, unpublished local histories and unpublished data on file at the Center Taboratory, UTSA, were reviewed. Oral history interviews were initiated with descendants of early prominent families, including the Walsh, Herrera, and Applewhite families. Informants and local inhabitants were also informally interviewed for background knowledge of specific locations. Dr. Gilberto Hinojosa, assistant professor of history, UTSA, was consulted and contributed to the identification of many of the historical trends in the overview. Architectural documentation of historical structures follows the period descriptions found in the Texas Historical Commission's (1973:50-53) Historic Preservation in Texas: The Comprehensive Statewide Historic Preservation for Texas.

We have purposefully attempted to present a detailed summary of the regional and local historical data to be utilized as an interpretive tool in the understanding of local sites' significance and the character of their former 


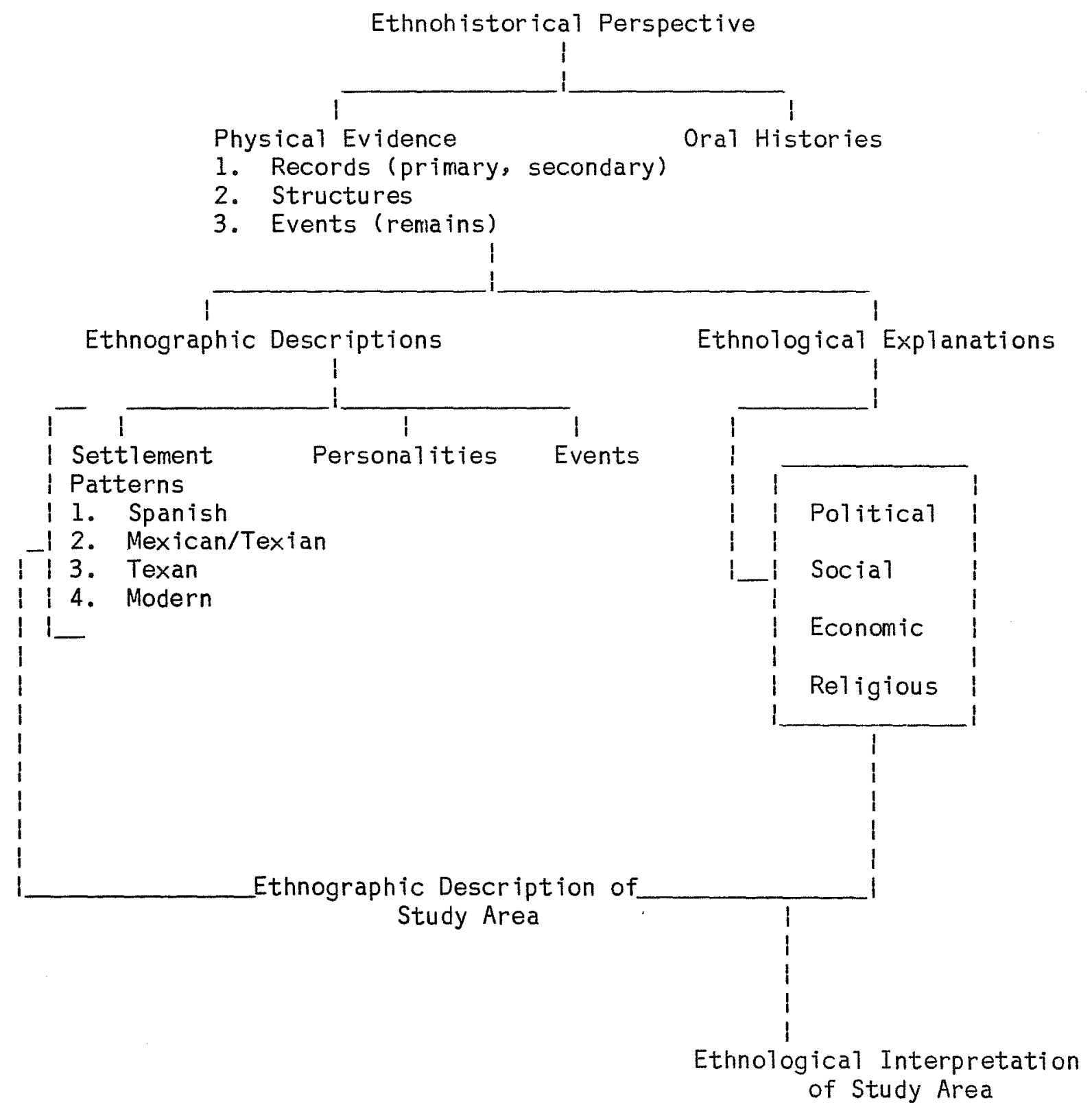

Figure 5. Ethnohistorical Perspective of the 1984 Archival/Historical Research. 


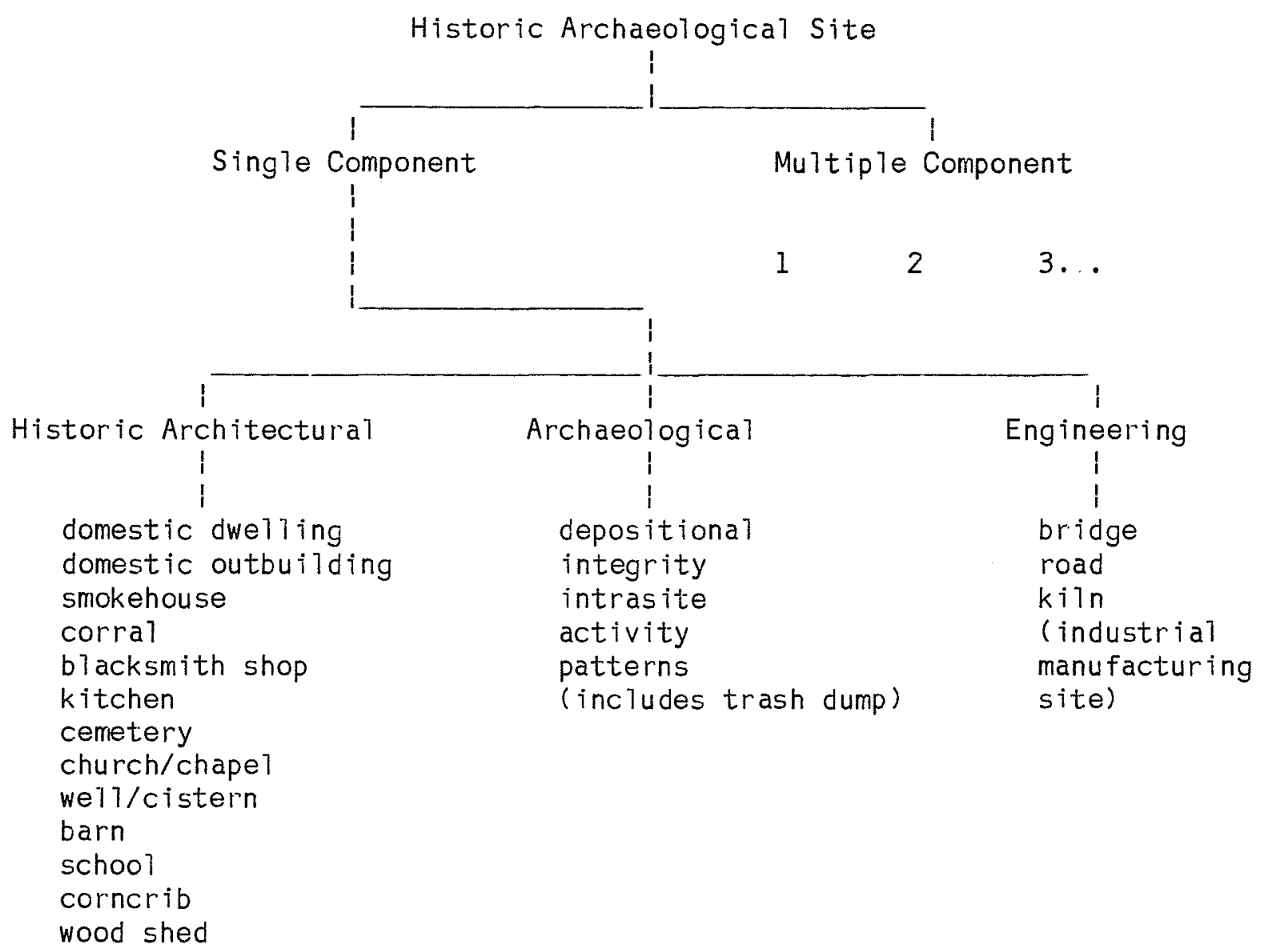

Figure 6. Functional Elements of Historic Site Components. 
inhabitants, particularly when this information can be combined with artifactual materials from tested sites.

We have not, however, attempted to formally describe this as an ethnohistory (or title it as such; although similar works in other unrelated publications have done so) as much of the information presented is a compilation of historical data and its interpretation. As Dobyns (1967:62-67) has pointed out, this does not become an ethnohistory unless it is related to a theory of culture change. As we have not uncovered local research which identifies, describes, or hints of the specific cultural processes of this time period and its complexity of interrelated cultural groups, we would demur on an ethnohistorical review of the same. Additionally, whatever ethnohistory is defined as (from historical, anthropological, or archaeological perspectives), it is currently fraught with subjective and often contradictory concepts. The reader is referred to McGraw (n.d.) for a more 1engthy and tedious discussion of ethnohistory and its implications toward anthropological and/or archaeological research.

Interestingly, an "ethnoarchaeological" perspective is employed for interpretation (problem solving) of the historical component of $41 \mathrm{BX} 274$ (see Inventory of Resources section, 41 BX 274). Particular types of recovered ceramic wares were inferred to represent identifiable types of social behavior during a specific time. From such a perspective, the occurrence of status-oriented items was associated with the individual's economic and social position; background documentary research (including the historical overview) and interviews with descendants basically supported the suppositions otherwise based on Timited archaeological inventories.

\section{TESTABLE HYPOTHESES}

Postulations on the distribution, patterns, and former activities of site locations in the study area are based on both the 1981 studies and interpretive data from nearby study areas. The work to date along the lower Medina River offers a detailed contrast to earlier work conducted in the county along the upper Salado Creek drainage; this latter work (BIack and McGraw 1985) will be reviewed generally to provide a background for the theoretical aspects of the current research.

Information from over 163 sites as we11 as published and unpublished data was reviewed during the Salado Creek study of Panther Springs Creek (41 BX 228), approximately $40 \mathrm{~km}$ from the study area. While, perhaps, not surprisingly, some of this information was contradictory, several significant points should be noted regarding the investigations of the local archaeological record.

1. Site locations within the upper Salado Creek drainage suggest that individual site physiology (excluding proximity to a water source) is less important in major occupation areas than their general location within an ecotone or ecotonal area. The prehistoric exploitation of these elements of the ecotone may be a key to understanding the pattern of 1ocal site distributions as well as better determining the variability of individual site locations. 
2. Local studies of site distributions as well as the excavated contexts of five separate, major occupation sites within the Salado Creek drainage suggest that the regional concept of a prehistoric chronological sequence may be too inflexible to apply to the local archaeological record. With the confusion over what constitutes a definable region as well as controversies and inaccuracies over identifiable chronological phases, past attempts at describing the regional prehistoric record have met with only partial success.

Recent studies by the CAR-UTSA, suggest that a sequence of chronological "local periods" may more accurately reflect the general pattern and direction of a regional chronology but may be qualitatively distinct from the latter. We believe the sensitive dependence of past hunting and gathering groups upon natural resources created a complex of specific adaptive strategies on a subregional and perhaps $10 \mathrm{ca} 7 \mathrm{leve1}$, such as the ecotone of the Balcones Escarpment-Gulf Coastal Plain margins.

In summary, the sequence of known prehistoric occupations within Bexar County generally follows the regional chronologies proposed by others (Weir 1976; Prewitt 1981). Because of the diversity of environmental systems which significantly and qualitatively affected localized hunting and gathering patterns, the phase concept has not been used in formulating a local chronological sequence; instead, local periods are utilized, identified by diagnostic horizon markers. The local periods, more accurate at this interpretive level, do not attempt to identify the complex series of traits on which archaeological phases (Willey and Phillips 1958) are based. Instead, they represent only the apparent climax of horizon markers such as diagnostic projectile points, ceramics, distinctive lithic tools, or specific features.

In the current study area, background information suggests that potential archaeological sites would be similar in context and character to other sites in the environmental transition zone. As such, this would be reflected by: (1) Late Prehistoric and Late Archaic occupations and activity sites concentrated along terraces and floodplains of the modern Medina River channe1; (2) a predominance of large occupation zones suggesting locations of multifunctional and multicomponent activities over a long span of time; (3) a chronological sequence that should be similar to that proposed locally by BT ack and McGraw (1985); (4) a frequent occurrence of moderately to deeply buried sites; and (5) a pattern of occupations that is defined in intensity and distribution by specific local natural resource areas associated with a riverine riparian zone. Additionally, geological and topographic data suggested possible major shifts of mainstream and tributary channel movements in recent times. If true, this should be reflected by: (1) chronologically distinct sites situated on different drainage locations; (2) interdrainage heterogeneity of site distribution and occupations; and (3) general1y, a more complex picture of prehistoric site distributions that regional or previous local studies have suggested. 


\section{METHODOLOGY}

Three basic forms of methodology were employed during the 1981 and 1984 projects: field, laboratory, and analytical. Each will be briefly discussed.

\section{OPERATIONS}

Actual survey of the reservoir area focused on identification of sites, site limits, features, and artifact concentrations. A11 surveyed properties were defined by county block/parcels on maps furnished by Mr. Steven Durocher of Southwest Research Institute, San Antonio. Prior to any field work, the proposed reservoir boundaries, which generally followed the 549 feet above ms 1 contour lines, were plotted on field and 1 aboratory copies of $7.5^{\prime}$ USGS topographic maps. These were used to record all observed site locations.

Complete coverage was achieved by use of a series of systematic on-ground transects. Where topography and ground cover allowed, survey personnel walked on parallel compass courses to traverse both upland and lowland areas as thoroughly as possible. Individual study areas were often divided into smaller parcels as determined by roads or distinctive topographic features in order to simplify the survey process. Each of these localities was then individually transected to insure accurate coverage.

Special surface collections were made in selected areas to aid in detailed examination of such cultural elements as prehistoric lithic characteristics. All collected materials were bagged and Tabeled according to provenience, date of collection, and name of collector.

Data on al1 surveyed sites were recorded on standard site survey forms used by the CAR-UTSA. Elevations and distances of sites from water sources or other natural resources were noted. Identified sites were numbered and plotted on field copies of 1:24000 USGS topographic maps.

In addition to the customary ground survey, several other methods were used for additional perspective. The use of a 12-foot johnboat simplified investigation of high, steep bluffs along the river that were almost inaccessible by overland routes. Low-level, slow-moving aerial reconnaissance of selected locations was also useful. Finally, a preliminary literature search was employed to view the sites from the perspective of cultural and environmental relationships and to more accurately reflect the character and importance of each site.

Laboratory methodology consisted of a comprehensive analysis of collected materials. Artifacts were cleaned, cataloged, cross-inventoried, and identified according to standard Center laboratory techniques. Selected artifacts were cleaned with a nonphosphate detergent in an ultrasonic cleaner, rather than hand-washed.

Following preliminary classification, materials were qualitatively and quantitatively analyzed. The majority of collected materials were lithic or ceramic. Lithic materials fell into three groups: (1) formed stone tools-- 
projectile points, bifaces, unifaces; (2) Tithic debris--cores, flakes; and (3) ground and pecked stone tools and fragments. Ceramic sherds were classified according to morphological characteristics such as gross measurements, color range, exterior and interior surface qualities, core, temper, and paste. The structure of the laboratory process was intended to systematically organize and interpret cultural as well as nonartifactual data.

\section{OPERATIONS}

Field methodology was designed to systematically and effectively identify and assess newly recorded sites. Actual survey work was accomplished by individuals working in teams of two or larger groups, depending upon the daily survey area. Transects along simple north-south or east-west azimuths were employed whenever possible with survey personnel spaced at $100-$ to $150-\mathrm{m}$ intervals, again dependent upon topography and ground cover.

A significant feature of the general survey methodology was a considered variation in the spacing of personnel during survey transects. Distance intervals varied from 25,50 , or $100 \mathrm{~m}$ or more between individuals based upon the visibility and accessibility of the specific area. Areas of extremely dense brush or otherwise difficult to transect required smaller spacing for effective coverage and observations of surface detai1. These areas required a maximum interval of 25-50 m. Localities of high visibility, e.g., flat, broad, plowed fields with no vegetation cover, could be no less effectively inspected with personnel spaced at larger intervals, most usually 75-100 m, or occasionally, up to $150 \mathrm{~m}$. Personnel awareness of site characteristics was increased by the use of walkie-talkies during survey operations, and this contributed to the effectiveness of transect work. Transect intervals employed during survey work are presented as Figure 7 . Regardless of transect interval, each individual, while following a compass azimuth, was required to move 1 aterally across the width of the transect "corridor" to insure complete survey coverage. The UTSA 1984 proposal for work (Hester, Eaton, and McGraw n.d.:17), outlining field methodology and approved by the Texas Historical Commission and the U.S. Department of the Army Corps of Engineers in 1984, specifies survey intervals up to $175 \mathrm{~m}$, dependent upon topography and ground cover.

Shovel testing in the form of $50-\mathrm{cm}^{2}$ units was utilized judgmentally at individual locations to more accurately estimate the potential for shallow subsurface cultural deposits. The material was screened through $1 / 4-i n c h$ wire mesh. The employment and results of this informal testing during intensive survey operations are discussed under individual site descriptions.

Each individual, in addition to assorted personal equipment, was required to carry a compass, canteen, walkie-talkie, machete, topographic map with the survey location and transects clearly marked, a snake bite kit, and various common survey items, including collection bags, flagging tape, field forms, etc.

A11 sites were recorded in the field and plotted on a base map at the field headquarters. Located sites were revisited several times to review the 


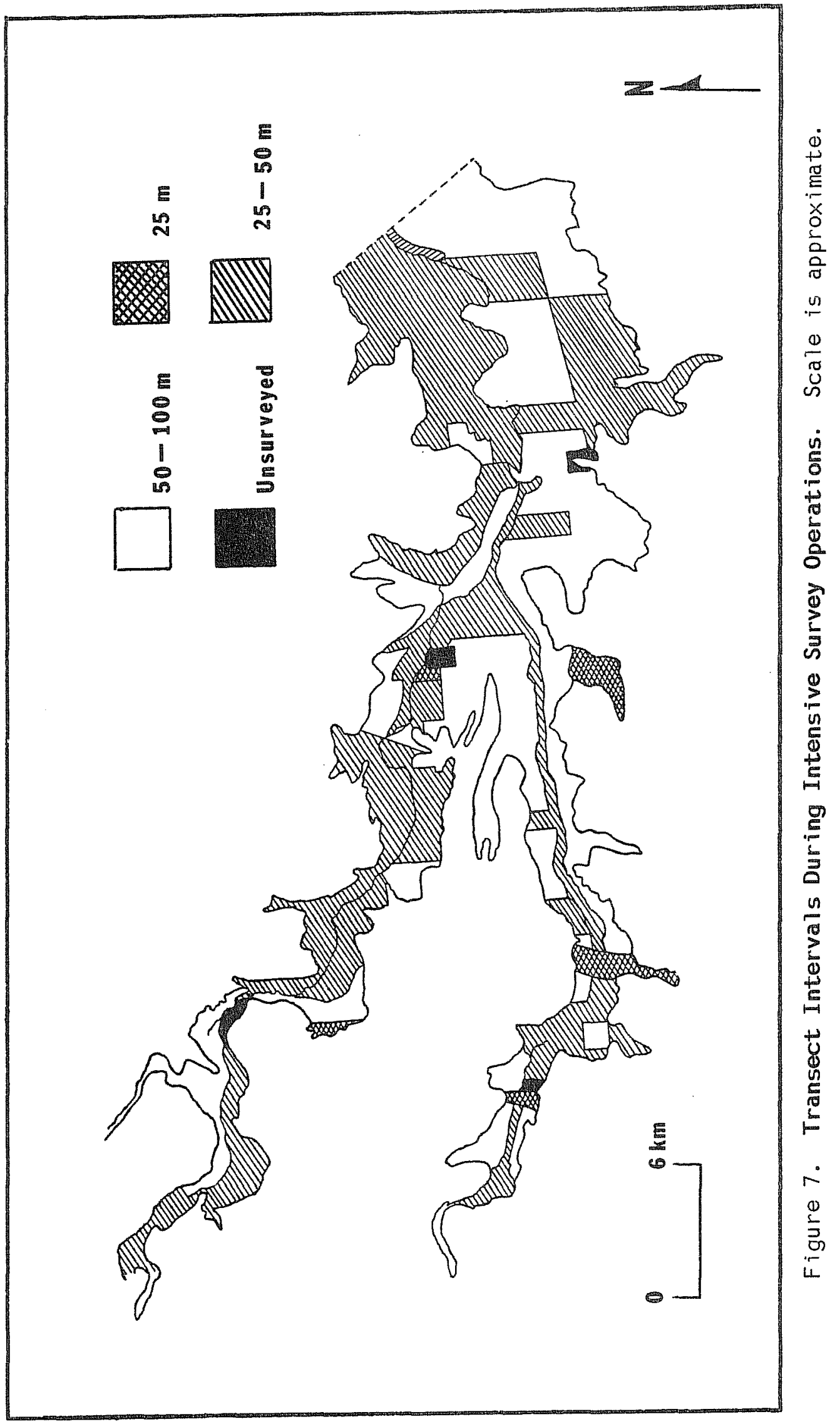


accuracy of the site description, dimensions, and location. Prior to field work, personnel were briefed on potential site types, locations, terrain, and survey conditions. Research methodology generally followed the guidelines presented by Hester, Heizer, and Graham's Field Methods in Archaeology (1975) and the Council of Texas Archeologists' performance standards (CTA 1981). Collected materials were limited to diagnostic or otherwise significant artifacts. A11 collected materials, field notes, photographs, and other site information is on file at the CAR 1aboratory (UTSA). Site information was recorded on standard site survey forms to match required data as needed by the Texas Archeological Research Laboratory, Balcones Research Center, Austin.

Testing and limited excavations at the 12 sites recommended for further work in 1981 to establish possible eligibility to the National Register of Historic Places were conducted through the use of mechanical and hand excavation techniques. Systematic grid sampling techniques were utilized when considered applicable to determine intrasite activity areas and material distributions. For each tested site, a selective testing procedure was established following a review of four specific elements: (1) an intensive survey of the site area; (2) consistent interval sampling through the use of a backhoe, when applicable; (3) excavations or tests in the form of $1-\mathrm{m}^{2}, 2$ $\mathrm{m}^{2}, 50-\mathrm{cm}^{2}$ shovel tests; (4) supplemental sampling in the form of soils chemistry, feature and matrix collections; and (5) a judgmental grid sampling technique employing $50-\mathrm{cm}^{2}$ test units over a metric sampling grid.

Past projects throughout the south Texas area have shown that backhoe trenching can be both effective and efficient. It is most applicable in large occupation zones where it is used to establish the vertical and horizontal extent of buried materials. When utilized, a series of approximately equidistant trenches was excavated, dependent upon site dimensions and available field time. As subsurface cultural concentrations were noted, a series of smaller interval trenches was excavated to determine the actual limits of concentrations and features.

Hand-excavated units were employed to further investigate trenching locations or in areas where mechanical testing was not possible. Trowels, shovels, and whisk brooms were utilized with arbitrary stratigraphic controls at $5-10 \mathrm{~cm}$ intervals. A11 materials were screened through $1 / 4$-inch or $1 / 8$-inch wire mesh. Consistent intervals of soil matrix and feature samples were collected when considered applicable. These samples were processed at the CAR-UTSA laboratory using ultrasonic or water flotation separation techniques. Judgmental grid sampling was used to define intrasite activity patterns by the collection of diagnostic subsurface materials. The $50-\mathrm{m}^{2} \mathrm{grids}$ were employed with 5-m intervals. Sampling was done both in assumed locations of buried deposits as well as control samples beyond suspected materials. The selection of a judgmental sampling technique was based on previous local as well as regional experience with random sampling methodology. Given the 1 imited site area, time, and funding constraints, as well as the predictability of a $20 \%+$ sample and the past sampling experiences of the project archaeologists, this technique was considered adequate if not superior to random sampling strategies. 
Laboratory methodology involved the processing of collected materials as well as their tabulations and a detailed analysis. Because of the scope of the project, the collection methods, the biased sample of material collection, and the surface context of much of the artifacts, no functional analyses were initiated at this phase of operations. Collected materials were identified as elements of a descriptive typological system. Whenever possible, common descriptive names of specific artifacts noted throughout the regional literature were associated with this typology. Curation of all materials is at the storage facilities of the CAR laboratory.

Analytical methodology, again, was a cumulative process that originated in the interpretation of background data and was flexibly adjusted by empirical information. Efforts were made to synthesize environmental as well as cultural data throughout project operations to more accurately assess the significance of prehistoric and historic site locations.

\section{FLUCTUATIONS IN METHODOLOGY RESEARCH, 1981-1984}

Several fluctuations of limited scope occurred in research methodology between the preliminary survey work of 1981 and the more extensive studies of 1984. These changes, which occurred during field, laboratory, and background studies, resulted from a cumulative assessment of ongoing work. Fluctuations in field methodology were made in response to: (1) changing field conditions and physiography; for example, the extent of ground cover directly affected survey transect intervals; (2) the initiation of a 1imited testing program at selected sites in 1984 (in addition to a continuation of archaeological surveys started in 1981); and (3) a growing (cumulative) recognition of site patterns and distributions. From a general perspective, field operations began in 1981 as a preliminary survey to locate and assess sites; by 1984 such investigations were made from the background of intersite distributions, patterns, and known chronological contexts of nearby sites.

A significant change in background research methodology occurred in 1984. Ongoing archival studies indicated an increasingly significant historical aspect to the study area (not recognized in detail in 1981 because of the preliminary nature of early work). As such, historical background research was intensified, and a reassessment of many historic sites identified earlier was initiated. The end result of this historical redirection was to discuss historic sites both individually and as an integral part of a historical overview to the study area and region.

Fluctuations in laboratory processing and analysis were negligible between 1981-1984 with the exception of an expanded scope of special studies in 1984. Variations in the most significant aspect of field methodology, transect intervals, have been discussed earlier in this section.

\section{SUPPLEMENTAL PROJECT OPERATIONS}

Survey work during 1981 primarily involved on-ground transects with personnel walking parallel compass courses for systematic coverage of all accessible areas. Because of time and manpower limitations, a 12-foot johnboat was used 
to travel down river from a point near the western margins of the reservoir. Localities typified by high, steep bluffs and almost inaccessible by overland routes were, in this manner, more easily investigated. Potential site locations along the river's edge were physically inspected during this segment of survey operations.

Following the identification of a number of archaeological sites, colonel Bill Bless and Colonel Ben Cheaney (United States Air Force) graciously offered their time and expertise as pilots of a small Cessna aircraft to view both actual and potential site locations. Low-level, slow-moving, aerial reconnaissance of selected areas has often significantly contributed to the interpretation of archaeological features. In this case, such a flight, particularly because of the low cost, was considered a valuable asset to the survey methodology. While it did not take the place of actual ground survey, the added overview supplemented and enlarged the perspective of surface investigations. In addition to performing transect flights over the entire area, previously recorded cultural sites were aerially photographed with infrared $f i l m$ as well as with Plus Pan-X and Ektachrome. It was hoped infrared photographs would reflect "hot spots" of concentrated activities at sites, such as the location of buried dumps adjacent to early historic sites or the intrasite distribution of features at prehistoric sites. Infrared photography unfortunately was not particularly successful during this time because of shortcomings in application.

During the course of the 1984 field work, a second attempt was made to utilize aerial photography as an aid in locating and/or assessing historic sites within the proposed reservoir area. Mr. Philip Hindes of Hindes Helicopters, Charlotte, Texas, graciously provided both his time and a Hughes $300 \mathrm{C}$ helicopter at no charge to the authors. Low altitude black and white and/or color photographs were taken of selected sites within the study area with very favorable results. Rectangular anomalies appearing in the photographs of the historic site 41 BX 274 were believed to be the locations of previously unidentified structures. Subsequent testing at the location confirmed the presence of one such structure (see 41 BX 274). We believe that other discernible anomalies appearing in photographs from the site represent additional features. Future investigations in the reservoir area should benefit from the use of aerial photography. 


\section{ENVIRONMENTAL SETTING}

\section{INTRODUCTION}

The understanding of the local physical environment is fundamental to any assessment of cultural resources. A background knowledge of the diversity and extent of the associated natural resources is particularly important to the study of prehistoric peoples who have intimately depended on these same resources in a hunting and gathering relationship for thousands of years. Given the complexity, diversity, and uniqueness of the environmental setting in and around the study area, it is critical to recognize the character of the natural resources and its influence on both aboriginal and historical occupations.

The study area is located approximately $20 \mathrm{~km}$ south of the Balcones Escarpment--the eastern extent of the Edwards P7ateau which abrupt7y borders the northern limits of the broad expanses of the Gulf Coastal Plain. The Medina River valley in southwestern Bexar County thus lies in a geological and ecological transition zone (Fig. 8,a,b). Riparian as well as upland natural resources are a mixture of flora and fauna from at least two biotic provinces.

Early descriptions of the region's natural setting are known from the geographic and geological records of Spanish explorers in the 16th and 17th centuries. The early accounts of such individuals as Pineda, who mapped the Gulf Coast in 1520, De León's expedition of 1687, Cabeza de Vaca's epic journey across the southwest, and Coronado's search for the seven cities of Cibola all reflect an awareness of and a practical interest in the region's geography and geology. Observations of these early explorers, such as Hernando de Soto's reference to oil. in southern Texas in 1543 (Sellards, Adkins, and Plummer 1958:15), illustrate the long-term significance of their discoveries.

The historic accounts of the Medina River are discussed in detail in the following sections. The section entitled Historical Overview, for example, presents descriptions of the river and its environs by such early travelers as Fray Espinosa, Celiz, and later, Berlandier. Other lesser known descriptions, such as Theodore Gentilz's Voyage a 1 a Laguna San Miguel in 1847 (in Kenda11 1974:111-117) also offers readers a glimpse of the wilderness between the Medina River and San Miguel Creek. Gentilz mentioned the presence of bears along the Atascosa River, and graphically described the dangers of the ravines along the Medina River which could and did throw horses and riders on occasion.

\section{GEOLOGY}

Geologic deposits in Bexar County are composed chiefly of sedimentary materials which accumulated along the Gulf Coast geosyncline during the Mesozoic and Cenozoic eras. The earliest formations are of the Cretaceous period with more recent Tertiary and Quaternary formations exposed toward the present coastline (see Fig. 9). 


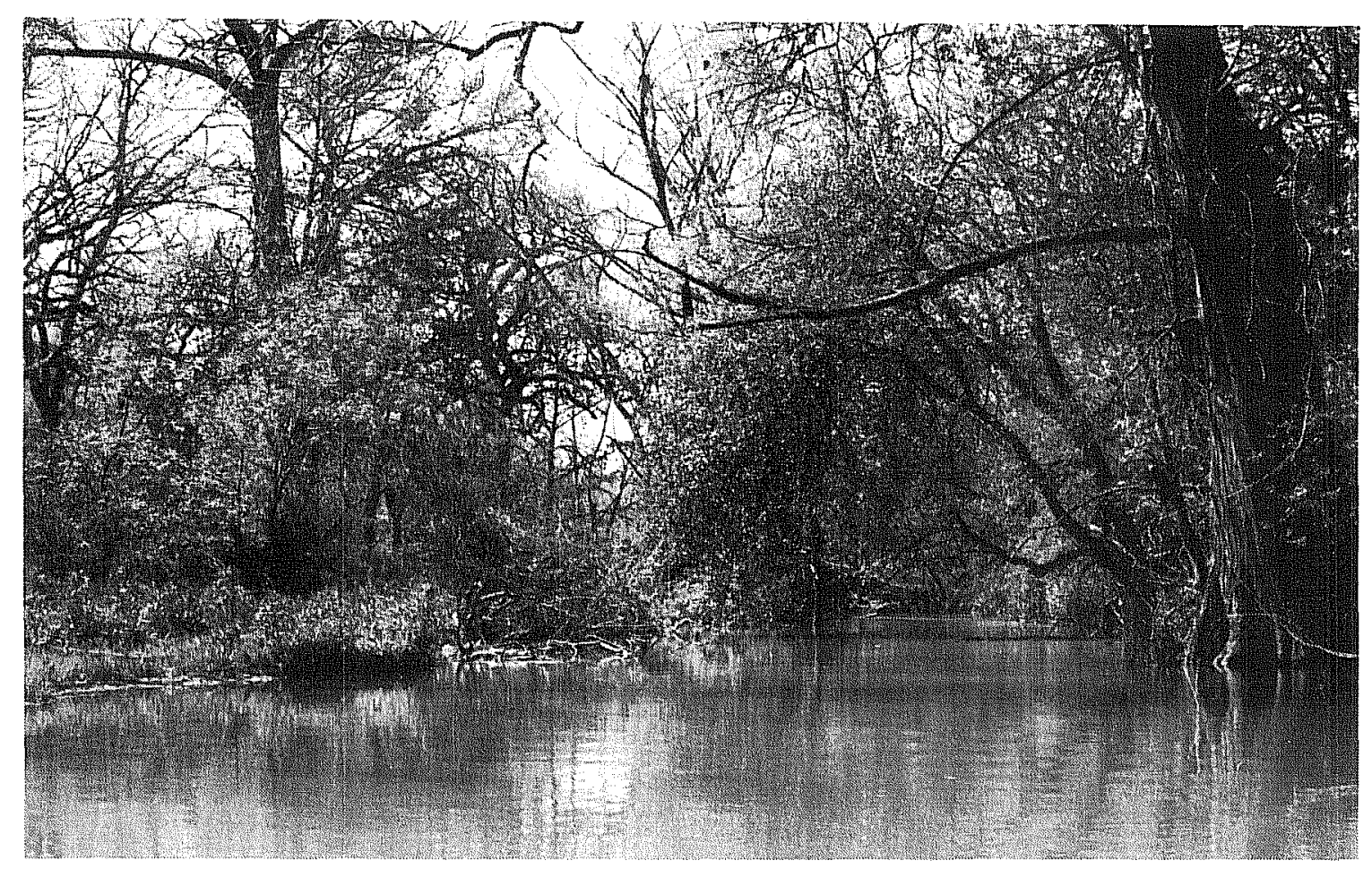

\section{a}

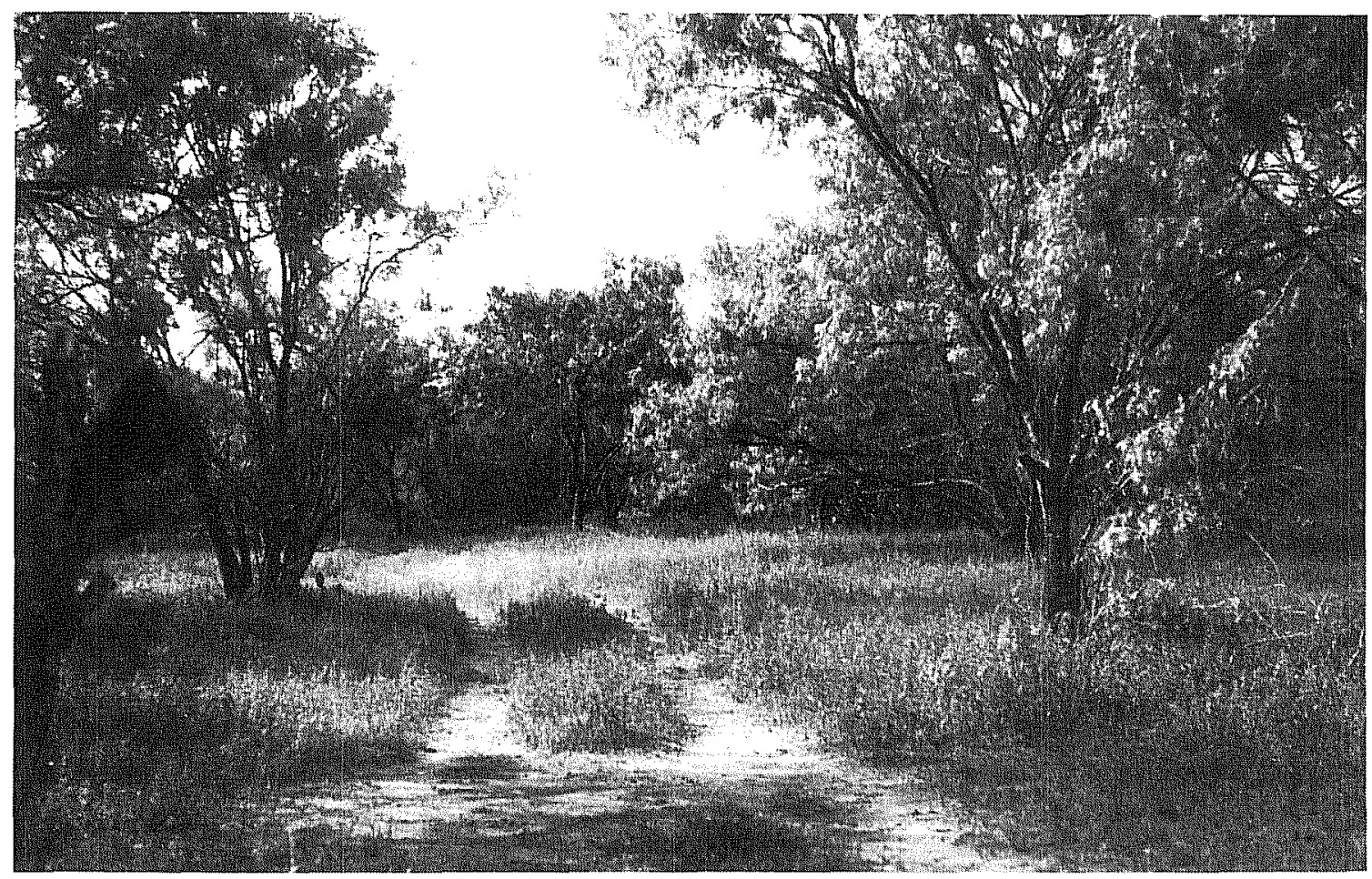

b

Figure 8. Environment in the Study Area. a, Medina River looking eastward; b, topography in vicinity of 41 BX 532. 


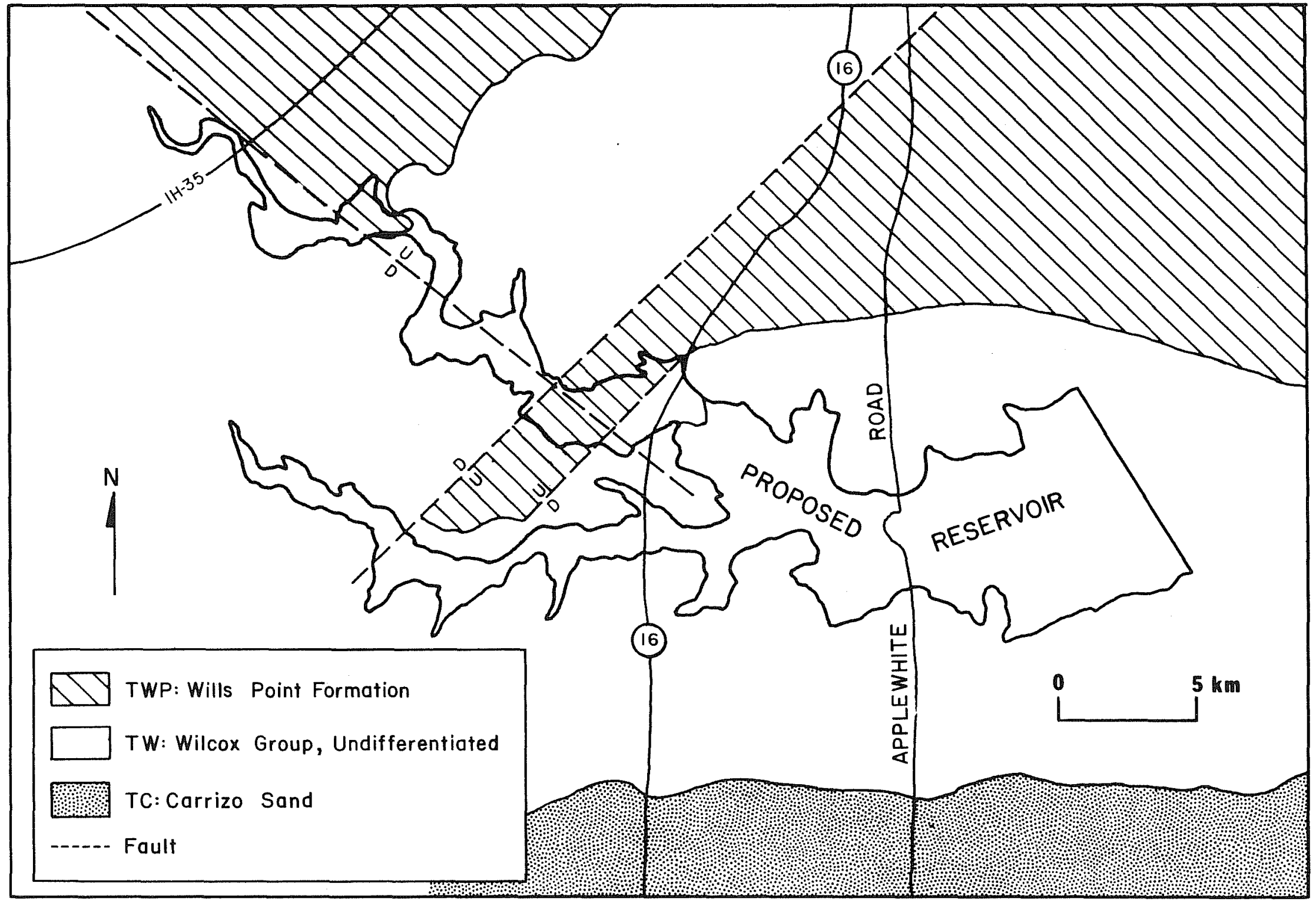

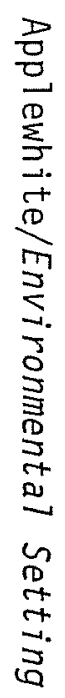

Figure 9. Geologic Map of the Study Area. Adapted from Sayre (1932-1933). 
Tertiary history of the area is thought to represent a series of fluctuations of the present coastline combined with sediment deposits from large fossil drainages. The causes behind these periods of sea oscillations are not clearly understood today; however, the changes have resulted in a complex interfingering of continental and marine facies in this area (Sellards, Adkins, and Plummer 1958:29).

Three principal geologic structures are present in or adjacent to the study area: (1) the Balcones Fault zone; (2) the Luling Fault zone; and (3) the Gulf Coast geosyncline. Both fault systems are within the Gulf Coast geosyncline. The geosyncline itself is characterized by the outcrop pattern of Tertiary formations (Austin et a1. 1975:181). Subsidence of the geosyncline may be indicated by the slope of pre-Cretaceous formations; in the Medina River-San Antonio River basin of Bexar County these formations are as much as 2500 feet below msl and more than 8000 feet below ms 1 in neighboring wilson County to the southeast.

The Balcones Fault zone is characterized by a series of semiparallel normal or gravity faults about 15 miles wide that extend from Hays county southwestward through Bexar County and then westward to Uvalde County. Displacement of single faults within the zone may vary as much as 700 feet and may be traced 50 miles. Total displacement of the fault zone varies from approximately 1500-1700 feet. The age of the faulting is not known but it is estimated between early Cretaceous and Pleistocene times (ibid.:185).

The Luling Fault zone extends from Caldwell County to southeastern Medina County and is generally located about 10 to 20 miles south of the Balcones Fault zone. In morphological make-up it is similar to the Balcones system but less wide. Several faults have been identified in the study area, and they are directly related to the alternating pattern of Eocene formations.

The proposed reservoir area is generally composed of two Eocene geologic formations: the Wills Point formation and an overlying undifferentiated Wilcox group. Faulting has caused an abrupt change in the horizontal bedding of these materials, and an upthrown block near the center of the study area has caused the lower Wills Point deposits to become exposed and flanked on the west and east by Wilcox deposits.

The Wills Point formation was first named following the identification of basal clays comprising the lowest or earliest Eocene deposits in the vicinity of Wills Point, Van Zandt County. First described by R. Penrose (1890), the Wills Point formation, as now defined, includes all the stratabelow the Wilcox group and above late Cretaceous Tehuacana 1 imestone or its equivalent (Sellards, Adkins, and Plummer 1958:555). Outcroppings of this formation are in the form of a broad, flat, featureless plain; and early geologists working in Mississippi termed the deposits "Flatwood." In Bexar County, the Wills Point is characterized by a narrow, continuous belt less than three miles wide. It extends northeastward and eventually widens to more than five miles. Total extent of the formation is estimated at 2700 square miles and is more well developed in northeastern Mexico. Thickness of the formation in Bexar County is about 250 feet but in Mexico thickens to over 3000 feet. The formation deposits of dark bluish clays are thought to represent deep offshore sediments which graduate into more shallow, silty materials or even 
sand in its upper limits. Economic resources of the Wills Point formation are its siliceous clays, used in the manufacture of bricks and tile; and its silty soils, suited to cotton, grains, and corn. Soils associated with Wills Point are Wilson clay loam and Crockett fine sandy loam; the latter is identified in the study area (see Soils).

The Wilcox group comprises a series of strata that includes all the deposits between the marine silty clays of the Midway group below and the marine, glauconite, fossiliferous sands of the Claiborne group above. The lower deposits of the Wilcox represent a transition from the marine mud and silts of the Wills Point deposits to coarser, littoral, deltaic, and non-marine deposits of the Wilcox (Sellards, Adkins, and Plummer 1958:573).

The strata of the Wilcox is composed of a heterogeneous series of sandy, ligitiferous 1 ittoral clays, cross-bedded river sands, lacustrine or lagoonal clays, and deltaic silts. Depths of deposits vary considerably, and its subdivisions in the locality of the study area are undifferentiated. Economic resources of the Wilcox group include clays for brick manufacture and stoneware and 7ignite deposits (ibid.:571-604).

\section{SOILS}

The study area is composed of four major soil associations: (1) HoustonHouston Black; (2) Lewisville-Houston Black; (3) Venus-Trinity-Frio; and (4) Hockley-Webb-Crockett series. Soils data are extracted from Taylor, Hailey, and Richmond (1966; Fig. 10).

The Houston-Houston B7ack soil series consists of dark grayish brown to black calcareous soils usually found in upland contexts. Characterized by a large amount of chert-bearing gravels, these soils are, because of their clay content, unusualiy plastic. Houston soils have a thinner, lighter colored surface and are generally more sloping than their Houston-Black counterparts. These soils have a very rapid run-off when saturated, and water erosion is a hazard.

Houston Black terrace soils are underlain by old alluvial sediments that include silt, gravels, and pebbles. This soil association occurs in upland areas between the Medina River and Leon Creek. It does not occur south of the Medina River.

Houston-Houston Black soils may have particular cultural resource relationships as their chert-bearing nodules found among these soils represent a significant raw lithic resource for the manufacture of stone tools in southwestern Bexar County. Lithic debitage from several sites (41 BX 559, 41 BX 568, and 41 BX 569) just north of Medio Creek indicate utilization of these materials. These upland soils represent the southern margins of this soil association across southern Texas. The lower Medina River valley acts as a natural boundary for this soil type in southwestern Bexar County. It is believed that local geologic faulting within the study area is not directly related to the absence of this soil type south of the drainage basin, but the hydrologic actions of the river drainage have sharply defined the margins of the soil type in this area. 


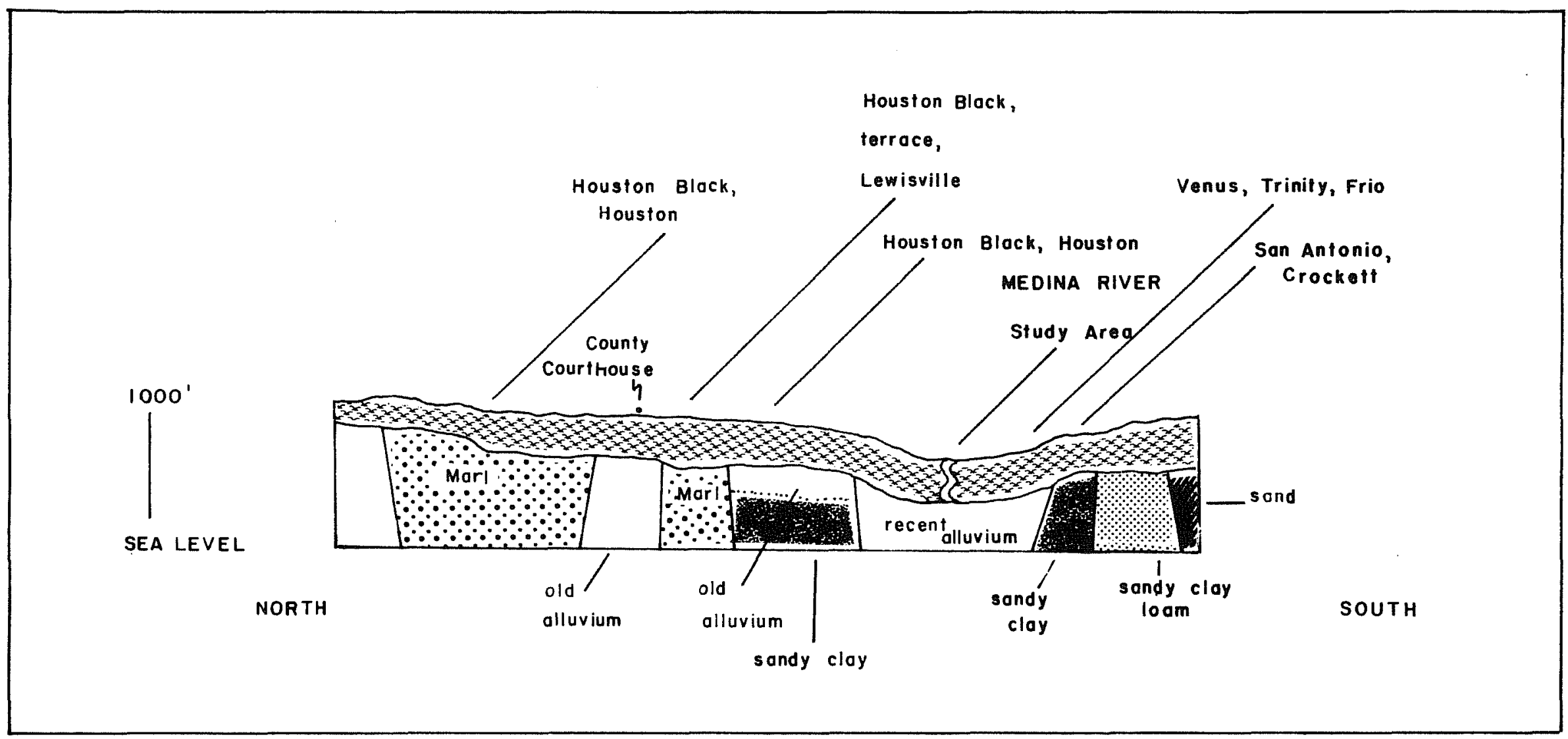

Figure 10. Soils in the Study Area. Adapted from Taylor, Hailey, and Richmond (1966). 
Lewisville soil is composed of moderately deep, dark brown, almost level alluvial soil. It is less clayey in the upper levels than Houston Black soil although underlying Lewisville material is of a reddish yellow, silty clay. The series has a weak blocky structure and contains large amounts of 1 ime. Below this may be deep beds of water-worn gravels. Lewisville-Houston Black soil occurs north of the Medina River in the northwest portion of the study area.

Venus-Frio-Trinity soils are deep, calcareous deposits found in bottomlands, lower terraces, or alluvial fans of major drainages such as the Medina River. The soils association is generally dark brown in color and changes to a light grayish brown in lower strata. Frio soil is stratified, occurs on lower terraces than the Venus series, and contains calcium carbonate. The soil types generally occur as long, irregularly shaped areas along the active floodplain of the Medina River.

Hockley-Webb-Crockett soils consist of deep loamy sands and sandy loams, sandy clay, and interbedded sandstone. These soils occur throughout the study area south of the Medina River. Hockley series are comprised of deep, light-colored sandy soils that generally appear on uplands. Coloration varies from pale brown to mottles of yellowish brown in the subsurface. Hockley soil is related to the crockett series but is sandier and less brown. crockett soil has a we11-defined accumulation of 1 ime. Webb soil is less sandy and more red in color than Hockley material.

The natural soil deposits of several prehistoric sites within the project area were identified when these sites could be broadly dated by diagnostic artifacts. Even though natural soil deposits can only reflect the broadest associations to cultural deposits, we felt such data may offer the reader and future researchers some basis of soil types and their chronological relationships with cultural deposits. A 1 ist of the site locations, soil types, and estimated chronological associations with cultural resources is provided as Table 1 .

\section{GEOMORPHOLOGY}

The geomorphological studies to date are the result of preliminary discussions with Dr. W. W. Hammond, assistant professor in the Division of Earth and Physical Sciences, UTSA; Vance Holliday, University of Wisconsin; a collection of background data, and an on-site inspection of the project area by geomorphologist, Glen Evans, Austin. Information from these sources has been integrated into the following discussion.

The geomorphology of the lower Medina River valley is complex, and the inferences presented are preliminary in nature. The information collected is directed toward a cultural resources perspective, specifically: (1) what influences recent geomorphological developments may have on the nature of cultural remains within the study area; and (2) given the natural geological and geomorphological setting, what effects may be identified on the future of such sites under impact from the proposed reservoir. A brief background to the geomorphology of the study area, inferences toward known (and postulated) 
TABLE 1. TERRACE SOILS AND RELATED CULTURAL DEPOSITS

\begin{tabular}{|c|c|c|c|}
\hline $\begin{array}{l}\text { Site } \\
\text { Number }\end{array}$ & $\begin{array}{l}\text { Estimated } \\
\text { Cultural Period }\end{array}$ & Soil Type*** & $\begin{array}{l}\text { General } \\
\text { Location }\end{array}$ \\
\hline $41 \mathrm{BX} 274$ & $\begin{array}{l}\text { Archaic (Early, } \\
\text { Middle, and Late) }\end{array}$ & $\begin{array}{l}\text { Undifferentiated } \\
\text { Venus clay loam (VcB) }\end{array}$ & $\begin{array}{l}\text { central study } \\
\text { area }\end{array}$ \\
\hline & Late Prehistoric & $\begin{array}{l}\text { transition of Venus } \\
\text { clay loam and Hockley } \\
\text { loamy fine soil }\end{array}$ & $\begin{array}{l}\text { central study } \\
\text { area }\end{array}$ \\
\hline $41 \mathrm{BX} 665$ & $\begin{array}{l}\text { Early-Late Archaic } \\
\text { (predominantly Late } \\
\text { Archaic) }\end{array}$ & $\begin{array}{l}\text { Webb soils, severely } \\
\text { eroded }(\text { WeC3)** }\end{array}$ & $\begin{array}{l}\text { south bank: } \\
\text { western study } \\
\text { area }\end{array}$ \\
\hline $41 \mathrm{BX} 460 *$ & Late Prehistoric & Venus clay loam ( $\mathrm{VcA}$ ) & $\begin{array}{l}\text { north bank, } \\
\text { northwest } \\
\text { section }\end{array}$ \\
\hline $\begin{array}{l}41 \text { BX } 653 \\
41 \text { BX } 656 \\
41 \text { BX } 658\end{array}$ & $\begin{array}{l}\text { Middle Archaic } \\
\text { Middle Archaic } \\
\text { Middle Archaic }\end{array}$ & $\begin{array}{l}\text { Venus clay loam ( } \mathrm{VcB}) \\
\text { Venus clay loam ( } \mathrm{VcB}) \\
\text { Venus clay loam ( } \mathrm{VcB})\end{array}$ & $\begin{array}{l}\text { north bank, } \\
\text { eastern } \\
\text { margins }\end{array}$ \\
\hline $\begin{array}{lll}41 & B X & 530 \\
41 & B X & 669\end{array}$ & $\begin{array}{l}\text { Late Prehistoric } \\
\text { Late Prehistoric }\end{array}$ & $\begin{array}{l}\text { Venus clay loam ( } V C A) \\
\text { Venus clay loam ( } V C A)\end{array}$ & $\begin{array}{l}\text { south bank, } \\
\text { eastern } \\
\text { margins }\end{array}$ \\
\hline $41 \mathrm{BX} 540^{*}$ & Early Archaic & Karnes loam $(\mathrm{KaB}) * *$ & $\begin{array}{l}\text { south bank, } \\
\text { eastern } \\
\text { margins }\end{array}$ \\
\hline $41 \mathrm{BX} 534^{*}$ & Early Archaic & Hockley loam (HkC2) & $\begin{array}{l}\text { south bank, } \\
\text { southeast } \\
\text { section }\end{array}$ \\
\hline
\end{tabular}

*Identified from 1981 studies. **Thought to be tentative association. ** Source: Taylor, Hailey, and Richmond (1966). 
site distributions, and recommendations for a comprehensive further study are discussed.

The Medina River drainage extends through the study area on a northwestsoutheast axis. It is bordered on its northern and southern flanks by rolling uplands which represent the remnants of fossil terraces of a much larger (wider) ancient river system. Modern terraces, frequently flooded, are located sinuously in the river floodplain. The Medina River valley within the study area is bounded on the north by blackland soils of an ancient alluvial plain. Approximately $6 \mathrm{~km}$ south, the river valley is bordered by an interstream divide of sand hills that separates the Medina River-San Antonio River basin from the Nueces River basin (Fisher 1985:Plate 1).

Two major tributaries, E7m and Medio Creeks, have their confluence points within the study area, and the confluence of Leon Creek is just east of the proposed reservoir. These confluence locations consist of unusually wide lowland areas associated with a large and varied collection of riparian biota. The most physiographically significant of these confluence points appears to be that of Elm Creek and the Medina River, as it may be the modern mergence of a much older river-tributary confluence, perhaps Leon Creek. This would in part explain the large, broad floodplain near the present confluence point and the intensity of prehistoric occupations in the area (see Paleoenvironment section).

Following an on-site inspection at this locale, geomorphologist Evans concluded a segment of an ancestral river channel once extended northward into the modern confluence area. The aggregation of terrace development and its extent are noticeable today as erosional gullies in this area which have exposed basal sediments of Eocene deposits. The more recent, overlying terrace materials, based on observations of deep erosional features, easily extend to more than $6 \mathrm{~m}$ below the modern surface at this location.

Former terraces and the direction and/or flow of old river channels can be identified for some portions of the study area, most easily in the southwest portion. In the western section of the proposed reservoir, modern channel shifts--excluding local oxbow formations--appear to have a northward trend. Former channels, identified from a series of aerial photographs, are much less sinuous and extend serialiy northward. This is contrasted to the eastern area where the modern channel has shifted southward and flows locally northeastward to its confluence with Leon Creek.

During his on-site inspection, geomorphologist Evans pointed out that the recognized abandoned river channels in the western portion of the reservoir (specifically $5 \mathrm{~km}$ both east and west of Somerset Road and its intersection with the river) offers the highest potential for deeply buried, as yet unidentified, prehistoric sites once located on former terraces. These abandoned channel locations are above the 550-foot (above msl) contour interval and are thus beyond reservoir impact. Evans' observations and the original identification of these abandoned channels are also recognized and substantiated by Fisher (1985:P1ate 1). 
Evans also noted that because of the extensive lateral movement of the river system and the frequent flooding episodes along the lowest, most recent terraces, the more recent natural deposits are not necessarily limited to those on the lowest terraces. The over-all flooding phenomena of this river system inundates midlevel terraces and creates a complex series of interbedded alluvial deposits of alternating ages. This is a significant aspect of stratigraphic interpretations at deeply buried archaeological sites within the study area.

The floodplain of the study area varies in width from less than $0.5 \mathrm{~km}$ in the western margins to over $2 \mathrm{~km}$ farther east. Variations in the width of the river channel itself are negligible in the same location; the expanding eastward-trending floodplain is thought to be the result of alluvial deposits from a series of ancient confluence points, contour elevation changes eastward, and the scouring effects of erosion along the sands and clays of the Wilcox formation.

The 1 imits of the modern floodplain, often bordered by high terraces at approximately the 550-foot contour, are characterized by unusually steep, sandy, barely negotiable, bluffs. In this respect, the physiography of the Medina River drainage is unique in the local area, as these high terraces physically $1 \mathrm{imit}$ accessibility to and from the floodplain. Historically, this aspect of the river precluded attempts at irrigating adjacent upland fields, and strictly 1 imited fords and crossing locations. Most of the modern highway crossings along the river in the study area may be traced to early fords utilized by travelers during Spanish colonial and Mexican Republic times. This is due more to practicality than to coincidence; intensive surveys conducted during this project along the river banks have shown there are few (to none) other passable localities available.

The southeast portion of the study area is comprised of a series of ephemeral (tertiary) drainage patterns that flow northward and downward toward the Medina River. Their junctures, identified by massive arroyo complexes along the river terraces, suggest extensive intermittent erosional sequences.

The variations of the Medina River drainage morphology in the study area are illustrated in Figure 11. Cross sections of the floodplain and adjacent uplands are derived from 7.5' USGS topographic maps. The profiles represent the western, central, and eastern cross sections of the proposed study area and indicate a complex pattern of distinctive, lateral channel movements along an ca. $12 \mathrm{~km}$ length. Recently identified prehistoric archaeological sites in the vicinity of the projected cross sections are also noted.

A preliminary correlation of Early Archaic period archaeological sites containing distinctive chronologically diagnostic materials and related contours in the western and eastern portions of the study area are presented in Figures 12 and 13 . These contour intervals are tentatively identified as portions of former terrace margins ca. 4500-3200 B.C. The postulation of such features has significant implications toward the identification of potential areas of deeply buried cultural deposits within the study area.

Geomorphologist Glen Evans (personal communication) identified several significant features of the study area that may be related to the post- 


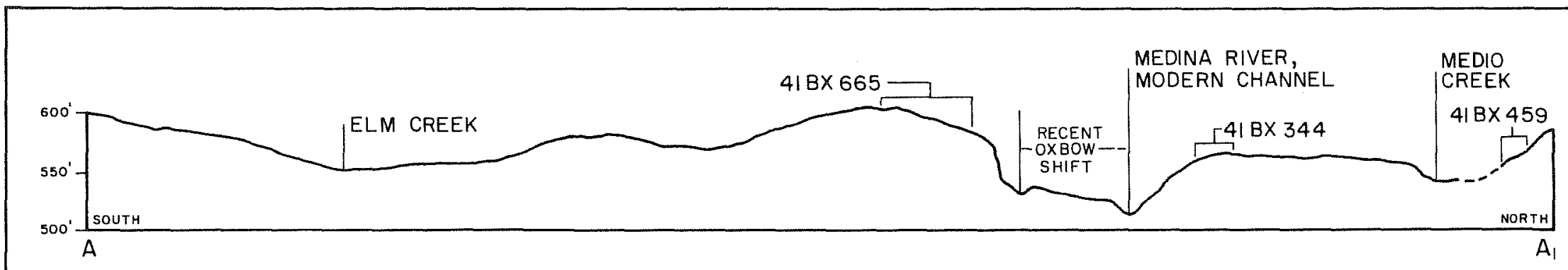

River valley cross section, vicinity of $41 \mathrm{BX} 665$ (western margins of study area).

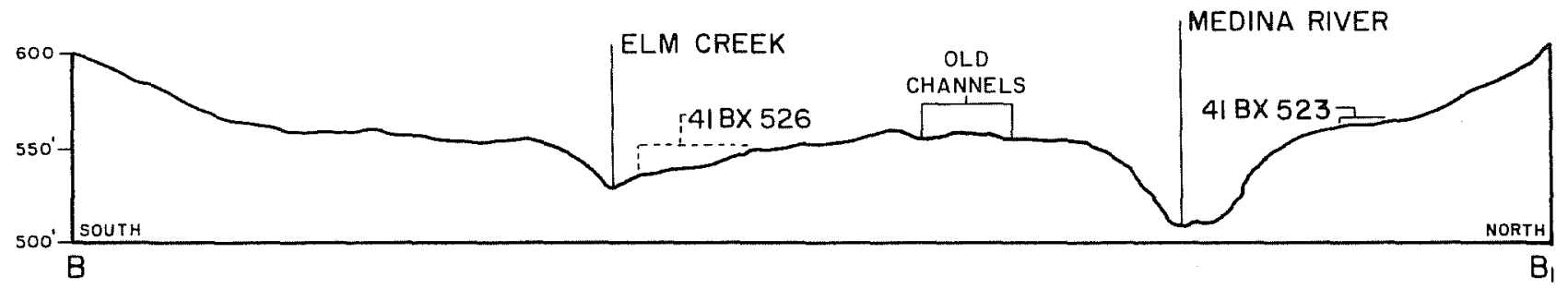

Vicinity of Highway 16 (central study area).

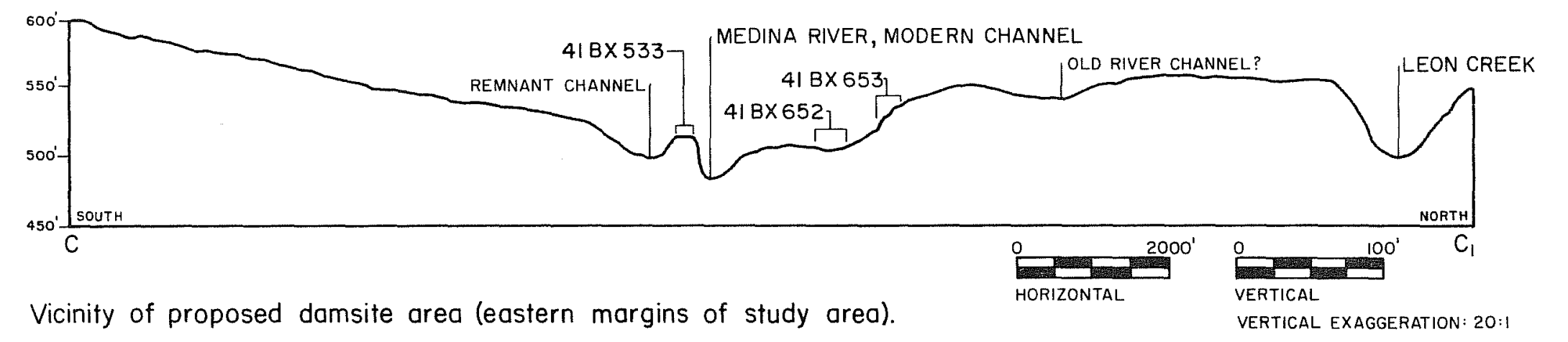

Figure 1l. Identified Geomorphological Changes (Post-Pleistocene) in the Study Area. 


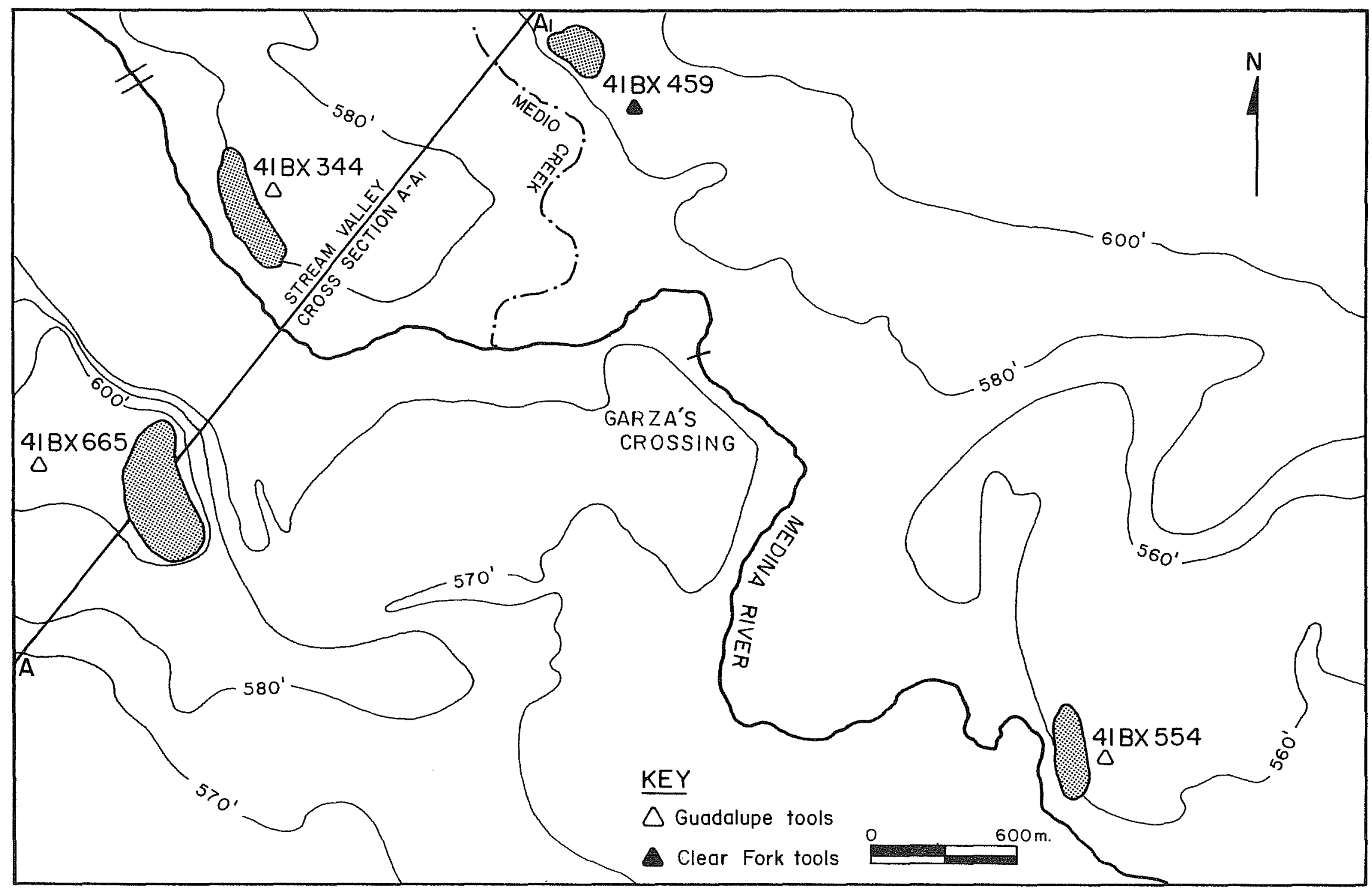

Figure 12. Postulated Terrace Rennants Associated with Early Archaic Occupation Sites in the Western Portion of the Study Area. Note $A-A_{1}$ refers to cross section shown in Figure 11. 
This page has been

redacted because it

contains restricted

information. 
This page has been

redacted because it

contains restricted

information. 
The results of background study and on-site geomorphological inspections have identified significant characteristics of the area's geological record that have affected the distribution, preservation, and extent of cultural remains within the study area. The authors recognize that, while the identification of these historical geologic characteristics are a preliminary step in considering the environmental relationship to cultural patterns, future work at individual sites will require detailed soils and geomorphological study also on an individual basis.

In summary, preliminary studies have identified: (1) the applicability and relevance of geomorphological studies for this portion of the lower Medina River valley; (2) the identification of features of the natural setting that have directly influenced the formation and preservation of cultural resources; (3) selective locations of the study area in which a reasonable potential exists for as yet unidentified cultural deposits; and (4) the identification of further work that would be most useful to assess individual site significance (during any possible future mitigation).

The geomorphological investigations of the proposed Applewhite Reservoir generally have followed the format presented in Collins and Holliday (1984). Two of the three objectives noted by Collins and Holliday (ibid.), the practicality and potential of such work, have been addressed by work to date. The third objective, including a plan for further work and recommendations for the utilization of established data, is presented in the Summary and Interpretations section of this report. Further geomorphological recommendations are thus discussed as an integral element of, and in the light of, site interpretations.

The long range goals of geomorphological research is not 1 imited to the identification of optimum locales for potentially significant buried cultural deposits. Instead, and as importantly, such research should contribute to a clearer understanding of past local as well as regional culturalenvironmental relationships. The information obtained from geomorphological interpretations at the proposed reservoir should, most significantly, offer substantial insights into reconstructions of the paleoenvironment.

\section{HYDROLOGY}

The Medina River originates at a series of small springs in northwestern Bandera County on the Edwards Plateau and flows southeast approximately 150 miles to its eventual confluence with the San Antonio River. The headwaters contain clear, shallow waters and 1 imestone bottoms. To the south of the Balcones Escarpment, much of the river water is lost to the recharge zone of the Edwards Aquifer, and the riverbed changes to gravel deposits, sandy 1oam, and heavy black loam.

The origins of the Medina River and its major tributaries are mainly stream flows that originate at discharge points along the Edwards Aquifer. Much of this base flow and part of the seasonal flood flows are lost by seepage as the drainage winds southeastward. To the south of the escarpment, most tributaries flow only intermittently. A substantial portion of the tributary that flows south of the Balcones Fault is related to effluent flow from urban 
areas (e.g., irrigation run-off or surface water run-off from suburban areas).

Measured on the Medina River near its confluence with the San Antonio River since 1954, the highest stream flows were recorded in 1973 with a flow rate of 28,300 cubic feet per second. In the same area, a minimum flow rate of 3.3 cubic feet per second was recorded in 1957 (Austin et a1. 1975:34, 44, 47).

\section{CLIMATE}

The climate of the general region is usually described as modified subtropical because of its cool (continental) winters and warm (marine) summers. Temperatures range from monthly averages (based on records from 1931-1960) of $52^{\circ} \mathrm{F}$ in January to $84^{\circ} \mathrm{F}$ in July. Relative humidity varies with season and time of day, usually ranging from $80 \%$ in the morning to $50 \%$ in the afternoon (Taylor, Hailey, and Richmond 1966; Table 2). Bexar County lies within a transition zone of three distinct climatological divisions; the Edwards Plateau, South-Central, and Upper Coast regions.

\section{TABLE 2. CLIMATE DATA SUMMARY FOR BEXAR COUNTY}

Rainfal1 Data

Recording Station:

Mean Annual Rainfa11:

Wettest Year:

Driest Year*:

Maximum 24-hour Rainfa11:

Temperature Data

Mean Annual Temperature:

Recorded Maximum:

Recorded Minimum:

Average Frost-Free Period (in days)**:
San Antonio

27.84 inches

52.28 inches, 1973

10.11 inches, 1917

21.0 inches, September, 1921

*Excludes data from 1984 drought.

**Number reflects Bexar County, not river basin frost-free period. 
The average growing season, between the times of ki1ling frost, averaged 289 days over a 51-year period (Austin et a1. 1975:167). Prevailing winds are southeasterly from the Gulf of Mexico during most of the year except in winter months. The highest wind recorded, $74 \mathrm{mph}$, occurred in 1942 during the inland movement of a tropical storm from the Gulf of Mexico. Precipitation averages 27.84 inches annually and is heaviest in May and September (Scurlock et al. 1976), but snowfall is rare. Rain usually takes the form of thunderstorms from April through September and drizzle during the winter months (Taylor, Hailey, and Richmond 1966). Thunderstorms are sometimes accompanied by hail and high winds and sometimes result in flash flooding.

Bexar County, perhaps because of its proximity to the elevations of the Balcones Escarpment, has the third highest maximum 24-hour recorded rainfall rates in a 17-county area related to the San Antonio River and Guadalupe River basin. These heavy rainfalls may be compared to Bexar County's rank of 16th in mean annual rainfall for the same area and time. Intensively heavy rainstorms may also partially account for the highest number of reported tornado sightings in the basin area between 1950-1973.

\section{BIOTA}

The study area, as part of a much larger region, is characterized by a diversity and integradation of biotic communities. The project area contains a mixture of two distinct biotic provinces reflected by peculiarities of vegetation, physiography, soils, and fauna according to Blair's (1950:102105) classification. The Balconian Biotic Province, centered around the Edwards Plateau, lies to the north while the Tamaulipan Biotic Province borders the project location to the south. Extensive moisture deficiencies occur just south of the study area; carbonates of $1 \mathrm{ime}$ are often deposited throughout subsurface soil levels as caliche, affecting the types and patterns of natural vegetation.

In southwestern Bexar County, the vegetation consists of a belt of post oak and brush communities just south of the Medina River surrounded by ta11 and short grasses. Thorny brush species include mimosa, acacia granjeno (Celtis pal1ida), mesquite (Prosopis juliflora), lignum vitae (Porliera angustiflora), tasajillo (Opuntia leptoalvis), prickly pear (0puntia 1indheimeri), Condalia, and Castela (BTair 1950:103). Post oak communities are characterized as a fairly open savanna of tall grasses with 1 arge, scattered post oak, black hickory, and blackjack oak trees.

Blackland prairies are associated with tall natural grasses found to the north of the study area, while even farther north is the flora of the Edwards Plateau. Vegetation associated with the south Texas plains to the south of the study area can be considered a rampant invasion of mesquite and other brush species over what was once a rolling plain of tall and short grasses.

Bottomlands in the project area contain a diversity of flora such as black willow, red ash, cypress, sycamore, and box elder along the waters' edge. A narrow soil area supports pecan, cedar, elm, hackberry, and cottonwood. 
Understory species are elderberry, greenbrier, and possumhaw (Austin et a1. 1975:402).

Blair (1950) suggests that the vertebrate fauna of the Tamaulipan Biotic Province includes some neotropical species, some of which have much in common with species which are Texan and Kansan related. He notes 61 species of mammals, 36 snake species, 19 types of lizards, three urodeles, two species of 1 and tortoise, and 1.9 anurans in the province (ibid.:103). The Balconian Biotic Province also contains a mixture of species from other provinces; species from the Chihuahan, Austroriparian, Tamaulipan, and the Kansan province are included.

Fauna indigenous to the area are somewhat different than the modern fauna due to extensive alterations to the landscape. While, for example, white-tailed deer are a prominent fauna regionally, their density is relatively low in most areas of the Medina River in southwestern Bexar County due to farming, ranching, and other land clearing or suburban activities. Fauna noted in the study area are white-tailed deer, javelina, turkey, bobwhite quail, mourning dove, armadil10, striped skunk, coyote, cottontail rabbit, jackrabbit, opossum, squirrel, gopher, fox, and raccoon.

Aquatic communities include a hellgramite (Corydalus), crayfish, grass shrimp, and other invertebrates. Fishes are represented by at least 12 species, including grizzard shad, four cyprinids, channel catfish, mosquito fish, sailfin molly, three sunfish, and the Rio Grande perch (Austin et al. 1975:404).

Birds considered rare or endangered that may be found locally are the brown pelican, the southern bald eagle, the arctic peregrine falcon, Attwater's prairie chicken, and the whooping crane. Additional endangered species are the fulvous tree duck, osprey, and the reddish egret.

\section{PALEOENVIRONMENT}

Little work has been done locally to identify the complex environmental changes that followed the termination of the Pleistocene epoch. While a vast body of data exists on aspects of Holocene developments generally, the study area's proximity to the Balcones Escarpment and its unique resources as well as Bexar County's character as an environmental transition zone complicate any broad regional perceptions of changing local cultural and/or environmental conditions.

Graham (1976), in his analysis of microfauna from Friesenhahn Cave in northern Bexar County, has postulated four climatological stages for the area from the end of the Pleistocene to modern times. This work is in part based upon microfauna sensitivity to subtle variations of their environment. Changes in the types, patterns, and densities of various microfauna may be compared to broad changes in climatic conditions. Table 3 is a summary of the paleoenvironmental and cultural data as it is known for the local area. First presented in Black and McGraw (1985:36), this chart is again presented in this report as its succinct data are directly applicable to a discussion of the current studies. 
TABLE 3. PALEOENVIRONMENTAL DATA COMPARED TO CULTURAL CHRONOLOGIES

Cultural Chronologies

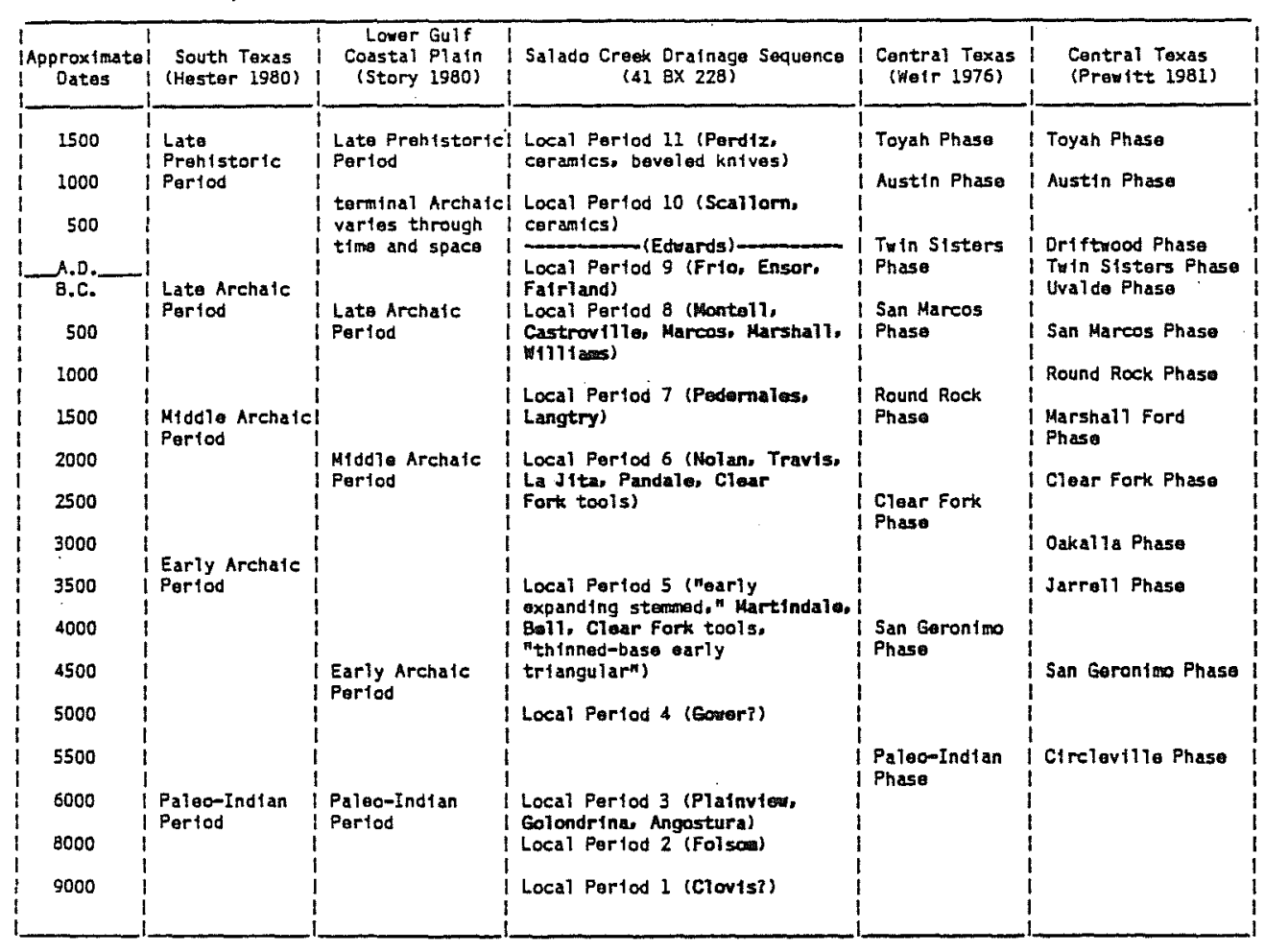

Paleoenvironmental Data

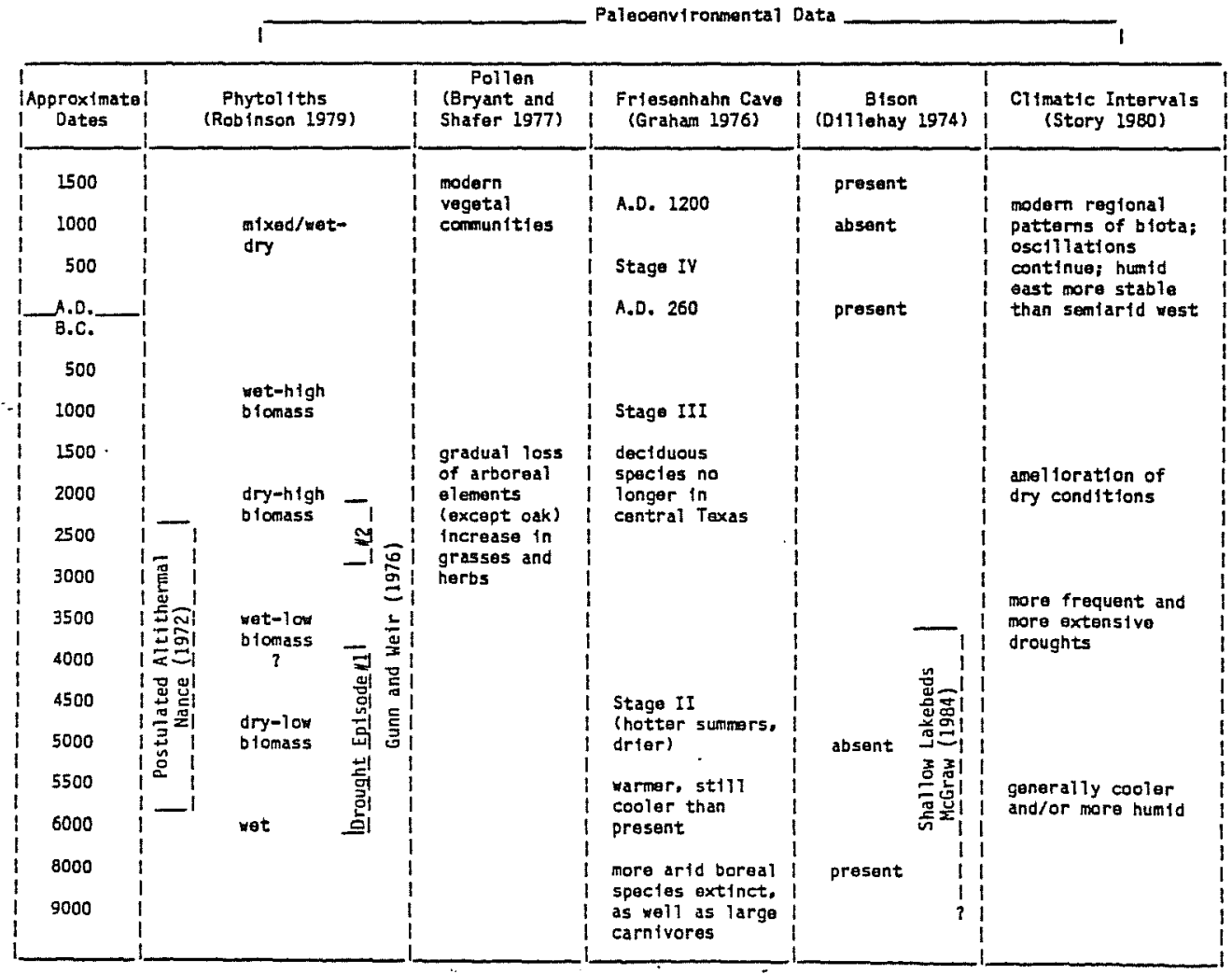

Source: Black and McGraw (1985:36). 
While only general climatological data are available for the period of 90006000 B.C., climatic conditions are thought to have been extremely violent regionally during the transitional Holocene epoch; presumably they are related to major shifts in continental weather patterns. Evidence for this may be seen locally in the margins of the Balcones Escarpment (approximately 20-25 km from the study area) along the Salado Creek drainage. Stream valleys in this location are underfed channels lying in broad and deep limestone valleys (floodplains). Researchers suggest that these stream valleys were formed during the late Pleistocene and/or early Holocene and were 1iterally gouged from the drainage courses by a series of high-energy, single event flooding sequences (Black and McGraw 1985). These floods were responsible for extensive deposits of gravels and cobbles, often in excess of 20-50 feet thick, which now underlie modern terraces. Although further data is needed to more clearly understand the causes and effects, the implications suggest a short period of climatic instability that created local weather patterns (tropical Gulf storms) of great intensity and short duration throughout the study area and region.

Given the proximity of the current project area to the Salado Creek drainage, the question arises as to the character of the Medina River valley at this time of changing environmental conditions. Certain geomorphological elements may be postulated; the river, unlike the Salado Creek drainage system, flows through a series of sand and clay deposits. High velocity water action in the form of extensive flooding would tend to flow in more linear (less sinuous) channel patterns across the flatter topography of southwest Bexar County. Extreme amounts of stream run-off upstream would cause secondary flooding over much of the projected former Pleistocene floodplain. Unlike the 1 imestone beds of the SaTado Creek drainage which were permanently cut by water action, the loose, friable soils along the Medina River drainage would have alternately eroded and been redeposited as flood and silt deposits along the margins of the river system. Given the meandering nature of the river course in more recent times, early terrace systems and redeposited materials may have alternately been destroyed or buried by a series of oscillating lateral channel movements.

The limits of the late Pleistocene floodplain cannot be accurately determined at this time, although contour patterns suggest it once existed at or near the 600-foot contour in the eastern half of the project area and as high as 650 feet in the western. Unfortunately, such a projection implies a substantial change in the direction and flow (to the south, southwest?) of this ancient river system. Alternatively, a major confluence may have existed west of the modern E7m Creek drainage that has 1 ong been obscured by more recent patterns of hydrology.

Lateral river channel movements have been identified in the western section of the study area south of Von Ormy Road (see Fig. 11). A major archaeological site, $41 \mathrm{BX} 665$, is situated on a former terrace just south of this locality, and at least three distinct channel movements northward, away from this site and terrace can be identified. Given the approximate ages of the chronologically diagnostic materials at the site (Early-Middle Archaic), these major channel shifts are projected to have occurred during a 2500-3000 year span. The extent of lateral movement in this area is estimated to be slightly over one kilometer to the present channel location; however, these 
estimates of time and distance do not consider assumed minor, as yet unidentified variations and/or oscillations.

Shifting confluence points have been identified in several sections of the study area; one major shift postulates the confluence of Leon Creek and the Medina River in the vicinity of the modern Elm Creek confluence. Topographic contours delineate a drainage pattern now characterized by an extensive arroyo complex in the direction of the now southeastward flowing Leon Creek. A major prehistoric occupation zone, $41 \mathrm{BX} 274$, now 1 ies along the eastern terrace of this locality with buried cultural deposits that are estimated at approximately 4500-4000 B.C. It is suspected that potentially older, more deeply buried deposits may underlie identified occupation zones. Such a fossil confluence of a primary tributary and/or extensive lateral channel movement could a7so account for the unusual1y wide floodplain in the vicinity of the Medina River and ETm Creek.

In summary, much more refined paleoenvironmental research is required for a clearer understanding of the river valley history. The observations presented here characterize significant aspects of the fossil river system and its physiographic effects on the pattern and distribution of prehistoric archaeological sites. It is hoped these observations will be incorporated into working hypotheses as more data become available to describe the environmental interrelationships of this ancient river system and its prehistoric peoples. 


\section{ARCHAEOLOGICAL BACKGROUND}

\section{INTRODUCTION}

The prehistory of the region is only broadly understood, and many significant questions still remain to be answered. For thousands of years, south-central and southern Texas were the home for hunting and gathering peoples that have left little behind except a few stone tools or the silent remains of ancient campfires as clues to their cultures, life styles, or origins.

The location of the proposed Applewhite Reservoir has been identified as the southern segment of a broad transition zone that separates the Gulf Coastal Plain from the abrupt elevations of the Edwards Plateau. As such, the project area is also thought to fall into a broad prehistoric cultural transition zone; aboriginal sites and artifacts throughout the county are known to contain a mixture of central and southern Texas related diagnostic projectile points and other cultural materials.

A brief discussion of the major prehistoric periods, the Paleo-Indian, the Archaic, and the Late Prehistoric, is presented. A summary of the chronological sequence as it is understood both locally and regionally is presented in Table 4. Historic Indian groups indigenous to the Medina River and San Antonio River confluence area are identified. The local archaeological record of Bexar County as well as problem areas of current research are also reviewed. For a more detailed discussion of the chronological sequence of prehistoric cultures and the regional archaeology, the reader is referred to Hester (1980) and Ha17, Black, and Graves (1982). Table 5 lists radiocarbon assays of the area, considered to be more applicable and accurate than interregionat correlations.

\section{PALE0-INDIAN PERIOD (ca. 9200-6000 B.C.)}

Evidences of Paleo-Indian activities in southern Texas exist throughout the area, but are relatively infrequent. The earliest radiocarbon date for southern Texas, collected from a prehistoric campfire at 41 GD 30 along Coleto Creek, is assayed at approximately 6000 B.C. (Table 5).

Although not well understood, there is a suggestion of two major cultural traditions in southern Texas 1 inked to the early Paleo-Indian period: a nonfluted Small Projectile Point Tradition across southern Texas and northeastern Mexico and a Plains-derived fluted point tradition related to contemporary patterns in the Great Plains and the Southwest. Both of these manifestations are thought to reflect regional adaptations to hunting and gathering subsistence patterns (Hester 1980:136). While Tittle is known of the cultural elements or the geographical extent of the Small Projectile Point Tradition, sites of the Plains-associated Paleo-Indian tradition have been found in varied but widely scattered, poorly preserved contexts across south-central and southern Texas.

Early sites related to this lithic tradition are characterized by Clovis (ca. 9200 B.C.) or Folsom (ca. 8800-8150 B.C.) projectile points. Both of these point types and their related peoples are associated with occupation and 
TABLE 4. LOCAL CHRONOLOGICAL CULTURAL SEQUENCE

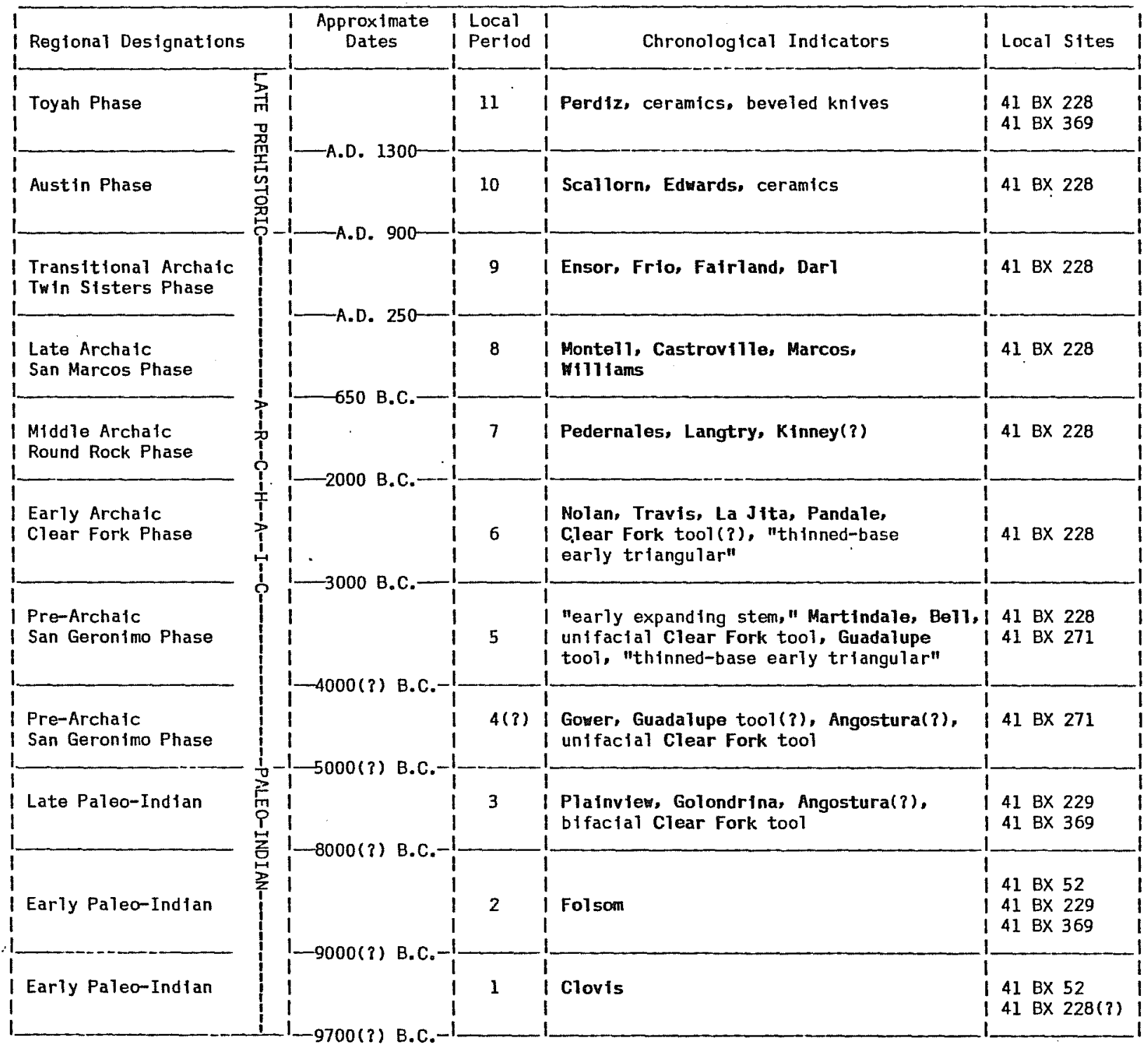

Source: Black and McGraw (1985:322). 
TABLE 5. REGIONAL RADIOCARBON ASSAYS

\begin{tabular}{|c|c|c|c|c|c|c|c|}
\hline $\begin{array}{l}\text { Local } \\
\text { Perjod }\end{array}$ & $\begin{array}{l}\text { Approximate Date } \\
\text { of Local Period: } \\
41 \mathrm{BX} 228\end{array}$ & Horizon Markers & Site & a Number & $\begin{array}{c}\text { Assay } \\
\text { Sample Number }\end{array}$ & Radfocarbon Date & Reference \\
\hline 11 & A.D. 1300 & $\begin{array}{l}\text { Perdiz, ceramics } \\
\text { Perdiz } \\
\text { Perdiz } \\
\text { Perdiz } \\
\text { Perdiz, ceramics } \\
\text { Perdiz, ceramics } \\
\text { untyped } \\
\text { Edwards } \\
\text { Perdiz } \\
\text { Perdiz, ceramics } \\
\text { Perdiz, ceramics } \\
\text { Perdiz, ceramics( })\end{array}$ & $\begin{array}{l}41 \\
41 \\
41 \\
41 \\
41 \\
41 \\
41 \\
41 \\
41 \\
41 \\
41 \\
41\end{array}$ & $\begin{array}{l}\text { BX } 36 \\
\text { LK } 201 \\
\text { LK } 201 \\
\text { BX } 36 \\
\text { JW } \\
\text { JW } \\
\text { MC } 222 \\
\text { BX } 2377 \\
\text { BX } 36 \\
\text { BX } 228 \\
\text { BX } 228 \\
\text { BX } 228\end{array}$ & $\begin{array}{l}T X-2815 \\
T X-4667 \\
T X-4668 \\
R L-817 \\
T X-4652 \\
T X-2207 \\
- \\
T X-2771 \\
\text { RL-816 } \\
T X-2811 \\
T X-3856 \\
T X-3855\end{array}$ & $\begin{array}{l}\text { A.D. } 1520-1610 \\
\text { A.D. } 1470-1500 \\
\text { A.D. } 1510-1590 \\
\text { A.D. } 1440 \\
\text { A.D. } 1430 \\
\text { A.D. } 1370 \\
\text { A.D. } 1290 \\
\text { A.D. } 1100 \\
\text { A.D. } 1090 \\
\text { A.D. } 1050 \\
\text { A.D. } 1020 \\
\text { A.D. } 1000\end{array}$ & $\begin{array}{l}\text { Gerstly, Kelly, and Assad 1978:253 } \\
\text { Highley } 1986 \\
\text { Highley } 1986 \\
\text { Gerstle, Kelly, and Assad 1978:253 } \\
\text { Black 1985 } \\
\text { Hester 1977. } \\
\text { Hall, Black, and Graves 1982:521 } \\
\text { Gerstle, Kelly, and Assad 1978:253 } \\
\text { Gerstle, Kelly, and Assad 1978:253 }\end{array}$ \\
\hline 10 & A.D. 900 & $\begin{array}{l}\text { Scallorn } \\
\text { Scallorn }\end{array}$ & & $\begin{array}{l}\text { BX } 228 \\
\text { BX } 228\end{array}$ & $\begin{array}{l}T X-3854 \\
T X-2812\end{array}$ & $\begin{array}{l}\text { A.D. } 980 \\
\text { A.D. } 910\end{array}$ & \\
\hline 9 & A.D. 250 & burlals & 41 & $B \times 1$ & TX-3993 & 100 B.C.-A.D. 260 & Lukowsk I n.d. \\
\hline 8 & 650 B.C. & $\begin{array}{l}\text { Fairland, Ensor(?) } \\
\text { Fairland, Ensor } \\
\text { Ensor, Frio, Castrovilio }\end{array}$ & $\begin{array}{l}41 \\
41 \\
41\end{array}$ & $\begin{array}{l}\text { LK } 67 \\
\text { LK } 67 \\
\text { BX } 1\end{array}$ & $\begin{array}{l}T X-3024 \\
T X-2911 \\
T X-3989\end{array}$ & $\begin{array}{l}370-210 \text { B.C. } \\
400 \text { B.C. } \\
400-130 \text { B.C. }\end{array}$ & $\begin{array}{l}\text { Brown ot a1. 1982:167 } \\
\text { Brown ot a1. 1982:167 } \\
\text { Lukowsk } 1 \text { n.d. }\end{array}$ \\
\hline 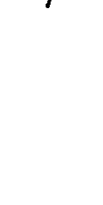 & 2000 B.C. & $\begin{array}{l}\text { Marcos(?) } \\
\text { Marcos(?) } \\
\text { Pedernales(?) } \\
\text { Zorra(?) } \\
\text { Travis, Nolan(?) } \\
\text { KInney }\end{array}$ & $\begin{array}{l}41 \\
41 \\
41 \\
41 \\
41 \\
41\end{array}$ & $\begin{array}{ll}\text { LK } & 67 \\
\text { LK } & 67 \\
\text { BX } & 228 \\
\text { LK } & 67 \\
\text { BX } & 1 \\
\text { BX } & 1\end{array}$ & $\begin{array}{l}T X-2909 \\
T X-2910 \\
T X-3852 \\
T X-3021 \\
7 X-2927 \\
T X-3992\end{array}$ & $\begin{array}{l}780 \text { B.C. } \\
730-660 \text { B.c. } \\
800 \text { B.C. } \\
1590-1520 \text { B.C. } \\
1950-1920 \text { B.C. } \\
2460-1690 \text { B.C. }\end{array}$ & $\begin{array}{l}\text { Brown ot al. 1982:167 } \\
\text { Brown ot al. 1982:167 } \\
\text { Brown ot al. 1982:167 } \\
\text { Assad 1979:21 } \\
\text { Lukowks } n \text {.d. }\end{array}$ \\
\hline 6 & 3000 B.C. & - & 41 & BX 228 & $T X-3853$ & 2920 B.C. & \\
\hline 5 & 4000 B.C. & $\begin{array}{l}\text { Guadalupe tools } \\
\text { Bell(?) }\end{array}$ & $\begin{array}{l}41 \\
41\end{array}$ & $\begin{array}{l}\text { BX } 228 \\
\text { BX } 271\end{array}$ & $\begin{array}{l}T X-3912 \\
7 x-3606\end{array}$ & $\begin{array}{l}3380 \text { B.C. } \\
3450-3390 \text { B.C. }\end{array}$ & Data on flle, CAR-UTSA \\
\hline 4 & 5000 B.C. & & & & & & \\
\hline 3 & $8000(?)$ B.C. & Plainview, Angostura & 41 & $B \times 229$ & & & \\
\hline 2 & g000(?) B.C. & Folsom & 41 & BX 52 & & & \\
\hline 1 & 9700(?) B.C. & Clovis & 41 & BX 52 & & & \\
\hline
\end{tabular}


subsistence patterns dependent upon mostly extinct faunal (and floral?) resources as well as the influences of a much cooler and wetter late Pleistocene climate. There are problems in determining and defining probable Paleo-Indian sites in the region. Such work cannot be systematically approached without a detailed understanding of paleoenvironmental influences and the geomorphological changes of the study area.

The Clovis complex is considered to be ancestral to the later Folsom. Clovis points have been found in indisputable association with mammoth bones in Arizona and in Roberts County, Texas. The typical Clovis point is leaf shaped with parallel to slightly convex sides and a concave base. Edges of the basal sides are ground, presumably to facilitate hafting. Clovis points range from 6 to $14 \mathrm{~cm}$ in length and are characterized by parallel flaking. A short, wide flute on one blade face is usually related to a more narrow flute on the reverse (Suhm and Jelks 1962:177; Turner and Hester 1985:80).

The Folsom complex, identified in many parts of North America, is associated with a lanceolate point with fluting that extends almost to the tip. Wide projecting points are usually found along the basal ends. The complex has never been accurately defined, and major variations of the diagnostic point type exist in Texas (Suhm and Jelks 1962:193).

Across the Southwest and Texas, a series of Late Paleo-Indian projectile point types overlies Clovis and Folsom materials. These types include Plainview (ca. 8200 B.C.), Golondrina (7000 B.C.), Scottsbluff (6500 B.C.), and Angostura (6500-6000 B.C.; Turner and Hester 1985:137-138). A collection of charred seeds and faunal remains from Baker Cave in Val Verde County indicates that a more modern climate was already changing the environment by ca. 7000 B.C. Hester (1981:119-128) suggests that this is an early indication of broad spectrum hunting and gathering patterns which developed into and are later reflected by regional Archaic cultures.

\section{ARCHAIC PERIOD}

Changing environmental conditions (Table 3) are thought to be responsible for the qualitative changes in subsistence patterns that developed regionally and characterize Archaic-style lifeways in Texas. As Holocene conditions changed toward more recent, modern environments, a complex series of hunting and gathering cultures developed and flourished from approximately 5000 B.C. to historic times (Hester 1980:149). Cultural transitions, like environmental transitions, are thought to occur relatively slowly; a cultural transition of hunting and gathering peoples, as reflected by changes in technologies and subsistence patterns, is postulated at the terminal Paleo-Indian-Early Archaic. This time period (ca. 6000-4000? B.C.) is poorly understood and somewhat controversial today (B1 ack and McGraw 1985; Hester 1980:146-149; Prewitt 1981). Some elements of this cultural transition can be delineated regionally by certain artifact types; for example, Guadalupe tools related to this general time, are spatially restricted in definable areas (Black and McGraw 1985). That changing environmental factors enormously influenced both qualitative and quantitative changes in environmentally sensitive huntergatherer cultural groups is an obvious precept. Not so obvious are the 
origins of change, specific regional adaptations of hunter-gatherers to these effects, and the traditions and diversities that have resulted.

Researchers have focused on models of climate change and more recently, estimates of both macro- and micro-movements of prehistoric groups across the Balcones Escarpment and the coastal plain. Gunn (1986) suggests that ethnohistorical evidence indicates movement patterns that are perpendicular to the Balcones Escarpment and across the soil zones of the coastal plain. He postulates that the climate history of central Texas and its margins has been dramatically unstable, and this significantly affected the character of prehistoric cultures and subsistence patterns. Gunn (1986) suggests that climatic variability was reflected by perpetual nomadism in both the historic and prehistoric past, and oscillations of the climate periodically infused the region with a complex pattern of intrusive populations.

The remains of Archaic occupation sites are scattered ubiquitously throughout south-central and southern Texas and reflect characteristics from both northern and southern areas. A wide variety of corner-notched projectile point types, bifacial and unifacial stone tools, features such as burned rock clusters of varying size, and occasionally single or multiple burials are associated with these sites.

Archaic occupation sites along the Edwards Plateau and farther northward include burned rock midden features composed of large accumulations of burned 1 imestone rock (see Weir 1976). North of the Medina River, in northern and central Bexar County, major occupation sites are situated on stream terraces and are usually associated with one or a series of spatially proximate, often buried, burned rock middens. An extensive distribution of chipped stone debitage and a variety of diagnostic projectile points indicate recurring occupations that span several thousand years. Major Late Prehistoric sites in contrast, are often physically discrete from these earlier sites. In southern Bexar County, and beyond the extensive outcroppings of 1 imestone formations of the northern area, Archaic period sites reflect some southern Texas site characteristics; while burned rock (and burned rock concentrations) are common in localities, they form much smaller clusters that are distinct from the massive midden accumulations common farther northward. Lithic materials originate from stream cobbles and upland gravel exposures rather than from the extensive exposures of ledge chert found along the escarpment. Occupations of southern Bexar County are often identified as extensive multicomponent, multiactivity zones $0.5 \mathrm{~km}$ or longer in length along modern or former stream terraces.

While Archaic materials are relatively abundant throughout the area, the considerable diversity of sites, assemblages, and a long time period has $1 \mathrm{imited}$ the understanding of Archaic $1 \mathrm{ifeways.} \mathrm{In} \mathrm{recent} \mathrm{years,} \mathrm{attempts}$ have been made to more clearly define aspects of this period (e.g., Weir 1976; Hester 1976; Prewitt 1981) but significant problems remain, particularly in the formulation and accuracy of such basic concepts as "phase" and "period." As a result of recent studies (e.g., B1ack and McGraw 1985; McGraw n.d.), the significance of subregional (or local) environmental niches that may have qualitatively affected Archaic cultural manifestations have become increasingly important (Story 1980). 


\section{LATE PREHISTORIC PERIOD}

Shortly after the turn of the millenium, approximately A.D. 700, technological innovations in the adaptive strategies of hunter-gatherer groups are recognized regionally. Arrow points become distinctive horizon markers of the Late Prehistoric period, and undecorated ceramics are dated to A.D. 1200. Excluding changes in technology and some aspects of social customs (i.e., burial practices), the overall subsistence pattern of a mobile, broad-based hunting-gathering tradition remained unchanged from earlier Archaic times (Hester 1981:119-128).

Along the Gulf coast, the use of ceramics apparently predates the technological innovations of the arrow point and/or bow and arrow. An early type of sandy paste ceramics is thought to have been manufactured along the central Texas coast ca. A.D. 100-500 (Fields, Freeman, and Kotter 1983:28). Aten (1979:436) suggests that arrow points were manufactured beginning about A.D. 600 .

By A.D. 1200, distinctive Late Prehistoric cultural patterns may be identified that are related to inland or 1 ittoral adaptations. The Rockport Complex (Corbin 1974) and the Brownsville Complex (MacNeish 1958) are associated with the natural resources concentrated along the southern Texas coast.

Inland adaptations were oriented toward the exploitation of grasslands and riparian zones along major drainage systems. Hester (1981:119-128) suggests that savanna subsistence patterns may be related to high or low resource density areas. Greater mobility of hunter-gatherer groups and a broader dispersal of occupation sites are postulated for low density resource localities. High density resource areas are thought to permit more stable occupations (less mobility), a seasonal exploitation strategy, and the reuse of established campsites. These theoretical concepts are directed primarily towards the indigenous natural resources; the introduction of migratory herd animals, for example, into a low density resource area could conceivably alter the locality into a high density resource area. Alternatively, the factor of cyclical, migratory animal species must be considered in terms of areal resource densities.

A certain amount of professional controversy exists in the similarities and differences of Late Prehistoric manifestations in central and southern Texas. While, for example, some arrow point types and other elements of Late Prehistoric assemblages are similar in both regions, important questions still remain on the influences and effects of areal resource distributions (or 1 ack of) and the distinctive character of 1ocal, nonregional, environments.

\section{HISTORIC PERIOD}

The Historic period is discussed in terms of the significant Indian groups known to have inhabited the area (Table 6). This discussion will hopefully aid in the location and interpretation of Protohistoric/Historic period Indian sites. Included will be a summary of known groups, general occupation 
patterns, the effect of these groups on the cultural development of the region and/or study area, and a discussion of potential site locations in the project location. Data to prepare this portion of the report were extracted primarily from Campbell and Campbel1 (1981), Sayles (1935), Tunnell and Newcomb (1969), Berlandier (1826-1834), and various other authors.

Perceptions of Tocal historic Indians have, in the past, centered around the Apache and Comanche, the most prominent of historic groups; however, these peoples were relatively late newcomers to the area. Indigenous groups with such curious names as Sulujam, Scipxames, Siguipam, Pampopa, Payaya, and Pastia have suffered in comparison from a lack of awareness and interest. These groups, and others $1 \mathrm{ike}$ them, however, have shaped and altered the early history of Spanish Texas. As part of the 1 abor force of missionized Indians, many of these local groups became a key element in the Spanish colonial effort to survive, colonize, and expand its influence upon an often adverse, if not hostile, environment.

\section{INDIGENOUS AND/OR INTRUSIVE PROTOHISTORIC-HISTORIC INDIAN GROUPS}

Indigenous Indian groups known from the 1 ocal area are related to at least five aboriginal linguistic stocks: (1) Coahuilteco, the most common; (2) Athapaskan (Apache); (3) Shoshonean (Comanche); (4) Tonkawan (central Texas groups); and (5) a Caddoan derivative related to Wichita groups (Sayles 1935).

Recent researchers such as Campbell and Campbel1 (1985:19-20) have pointed out the deficiencies of past studies that have too often lumped poorly described groups into the "Coahuiltecan" linguistic affiliation. Linguists such as Gursky (1964) have suggested an unrelated language, Quinigua, may have been contemporaneous with Coahuilteco, while others (e.g., Goddard 1979) conclude little or no relationship existed with such languages as Tonkawa, Coahuilteco, Karankawa, and others. Campbe11 and Campbe11 (1985:18) summarize linguistic studies to date as being characterized by diversity and reflecting a paucity of interpretable information.

Coahuiltecan groups, identified as locally inhabiting portions of the lower Medina River and/or upper San Antonio River basin include Pampopa, Payaya, Pastia, and Sulujam, the last also known as Chaadulames(?). Early accounts (01 ivares 1720, in Campbel1 and Campbel1 1981:53) indicate that at least one of these groups, the Pastia, were traditional enemies of another local Coahuiltecan band, the Payaya.

Campbell and Campbel1 (1985:46, 49) also conclude several poorly known groups, the Aguastaya and Mesquite (and perhaps others), may have 1 ived south of San Antonio during this period. Little, including language affiliation, is known of these groups at present.

Athapaskan peoples known in the area were loosely organized bands of Apache. Later, these peoples were inclusively identified as Lipan Apache.

Shoshonean groups appear late in the Historic period as enemies of the Coahuiltecans, Apache, Tonkawa, and possibly some Wichita, as well as the 
Spanish and Anglo-Europeans. Archival data (BAT Vol. 150:33-34) also identify the Taguayas as bitter enemies of the Comanche; their 20-year period of hostilities eventually caused the abandonment of outlying Spanish ranchos from 1765 to 1785 .

Little data exist concerning the Taguayas, although Sayles (1935:29) identifies Tauayas (sic[?]) as a tribe of the (Caddoan) Wichita group (confederacy?). Wichita tribes are known to have been in the San Antonio area ca. 1830; they are specifically mentioned by Berlandier (1826-1834) as hostile "Tawakonis." Sayles (1935:26-27) suggests these groups originally inhabited areas west and north of the Tonkawa in north-central Texas. It is interesting (unfortunately not substantive) to note that intrusive ceramic sherds, assumed to be Late Prehistoric and collected at 41 BX 459 (McGraw 1977), are thought to originate in the same general area of north-central

Texas. The ceramic fragments were identified as Boothe Brushed (Dee Ann Story, personal communication).

Tonkawan related peoples originating in the central Texas area consist of as yet unidentified groups contemporary with Coahuiltecans. Their general hunting-foraging areas are thought to have been generally north of the Medina River-San Antonio River basin (Sayles 1935:19).

\section{Pastia and Pampopa}

The Pastia and Pampopa groups inhabited portions of the lower Medina River drainage as early as 1709 (Espinosa 1930:4-5). They had cordial relations with neighboring Payaya prior to 1720 . Espinosa noted a Payaya encampment in southwestern Bexar County on the north bank of the Medina River where the river flows eastward before flowing southeastward again (vicinity of La Coste, perhaps along the Upper Presidio Road or Camino Pita, approximately 15 to $18 \mathrm{~km}$ west of the study area). Farther eastward, in excess of three leagues, approximately eight miles east of the western margins of the project area, a Pampopa settlement was identified. As individuals from the two camps were apparently mixed, friendly interactions are assumed. Espinosa also states (in Campbe11 and Campbe11 1981:46) that the Pampopa were camped at this location for at least 12 days in the spring.

Little else is known of these groups except the general territorial foraging range of the Pastia and/or Pampopa extended about 85 miles south of San Antonio toward the great bend of the Nueces River and perhaps farther (Campbe11 and Campbe11 1981:46-47). The range of the Pampopa is also illustrated by José Antonio de Alzate y Ramirez on a map entitled "Nuevo Mapa Geografica de 1 a America Septentrional," dated 1763 (Martin and Martin 1982:38, Map No. 3). Although this early map suffers from the inaccuracies of many maps of the period, Martin and Martin (ibid.) point out the artist, as royal geographer to the French Court, was noted for his practice of including only proven information and reliable sources. Alzate y Ramirez places the "Tierra de los Pampojas" across the interior of southern Texas from the Medina River to the Rio Grande. The area is bounded on the south, below the confluence of the Nueces and Frio Rivers, by the "Tierra de los Pajalantas (sic?) y otras Naciones, "including "los Carrizos" and "las 
Tortugas." The western 1 imits are not defined, although it appears to be we11 southeast of the upper Nueces River and the Frio River.

No observations of a ceramic tradition or plant cultivation have been noted in the Titerature for these groups. Some Pampopa 1ater entered Mission San José y San Miguel de Aguayo after 1720, but non-missionized groups were sti11 recorded in the surrounding area in 1727 (Campbel1 and Campbel1 1981). Campbel1 and Campbel1's (1985:50) research indicates that by this date approximate1y 500 Pampopa were inhabiting the lower Nueces River in Dimmit and La Salle Counties.

If Pampopa- and Pastia-related sites are situated in the present study area, the projections of Espinosa's diary would place the remains of at least one of these encampments along the western margins of the proposed reservoir, perhaps in the vicinity of the Medio Creek confluence. Early surveys here have identified several Late Prehistoric-Historic(?) sites defined by ceramic and arrow point fragments. Unfortunately, an extensive amount of natura erosion and modern alterations throughout much of this locality has limited the collection of potentially diagnostic materials as well as interpretations regarding occupations. Site $41 \mathrm{BX} 528$, based on the presence of a probable Guerrero point and Goliad ware sherds, may represent one of these historic Indian encampments.

Sulujam, Sigames, Siupam, and Chayopines(?)

The Sulujan, Sigames, Siupam, and the Chayopines have all been identified as inhabiting portions of the upper San Antonio River basin, the first three in the vicinity of the river's headwaters. In the spring of 1709, Espinosa $(1930: 5,13)$ noted approximately 500 individuals in this 10cale. It is assumed that this represented a gathering of bands rather than a semipermanent occupation (anything less than a temporary occupation would quickly deplete subsistence resources even in this favored natural setting). Given the short distance of this location from the Medina River, it is projected that the foraging range of these groups would have overlapped those of the Pampopa and Pastia. As no documentary evidence has yet uncovered supportive data, this report can only speculate that occupations did occur in or near the current study area, most likely near the confluence of the San Antonio River and the Medina River or in the vicinity of the Leon Creek and Medina River confluence. These locales offer more extensive riparian resources, such as pecans, for a hunter-gatherer subsistence.

Campbe11 and Campbe11's (1981:57-58) research indicates the Sulajam were identified as occupying portions of the San Antonio River south of San Antonio de Béjar in 1708. Their most recent study 1 ists two other groups, Aguastaya and Mesquite, who may have inhabited the San Antonio area. Unfortunately, little information is available on these latter groups.

\section{Payaya}

The Payaya were one of several groups identified as enemies of the Pastia in 1720 (Campbe11 and Campbe11 1981:53), although, as noted earlier, campsites 
with Pastia, Pampopa, and Payaya were observed in 1709. Payaya ranges are thought to have been situated to the west and northwest of these other groups, and such a territory could include portions of the Medina River valley as a shared boundary between the groups. It is possible that the eventual enmity that resulted between these groups was in part the result of territorial encroachments caused by the pressures of intrusive Apaches. The lack of current historical data precludes the identification of specific Payaya campsites in the current study area. General locations should be considered related to and perhaps located in the same areas as potential Pastia and Pampopa occupations and as yet unidentified historic Indian groups.

Campbel1 (1975) has discussed in some detail the ethnographic evidence currently available for the Payaya group. His research indicates the range of these Indians varied considerably through the early Historic period due to the displacements caused by both Spanish and Apache pressures.

The Payaya were first noted historical1y by Massanet (Campbe11 1975:5) in 1688-1689 as being in the vicinity of the Sierra de Sacatsol. Campbell (1975) believed this to be the southwestern margins of the Edwards Plateau, perhaps in the vicinity of the Anacacho Mountains of Kinney County. The Alarcon expedition of 1718 noted the Arroya de los Payayas approximately six leagues (15-16 miles) southwest(?) of the Medina River. This area was identified by Austin in 1828 as the western tributary of Rosalis Creek, itself a branch of the San Miguel Creek (Austin Papers 1828). Campbel1 (1975:8) suggests, and the authors of this report agree, that the Arroyo de los Payayas probably refers to modern San Francisco Pérez Creek, the western branch of Chacon Creek, in eastern Medina County. It is interesting to note that Austin's map identifies the "Camino Pita" through this area (Austin Papers 1828). Campbe11 (1975:6) uses an alternate interpretation of the background data to identify Massanet's 1690 location of six Indian groups along the Medina River. Bolton (1916:408) is cited as recognizing that the Medina River had been crossed twice by the Alonso de Leon-Massanet expedition on April 19 and 20, 1690. Campbell (1975) suggests a 1ikely locale for these crossings would have been where the river flows from west to east, near the present Medina County-Bexar County Iine.

While the authors agree with Campbel1's identification of the general location, a preliminary examination of available data does not indicate any known routes as crossing the Medina River more than once either in or adjacent to the current study area. After a review of Alonso de Leon's 1690 diary (Canedo 1968:137), the authors suggest an alternate interpretation that places the De Leon-Massanet route several leagues east and closer to the study area. Canedo's (ibid.) transcript indicates the expedition traveled north, arrived on the Rio Medina several miles above the (expected[?]) crossing ("arriba del paso") on Apri1 19, 1690, and stopped along the river's sloped banks. The following day, De Leon traveled two leagues east and arrived at the crossing (actually then crossing once, not twice). Alonso de León's diary of Apri1 19 and 20,1690, is transcripted by Canedo (1968:137) as: 
Miércoles, diez y nuevo del dicho, salimos del rumbo del norte, habiendo 17 egado al, rio Médina, arriba del paso, paramos en un bajio; habiendo andado siete leguas.

Jueves, viente del dicho, caminamos al rumbo del este $y$ a distancia de dos leguas 17 egamos al paso del río, donde paró el real, por ser necesario aliñar el paso de ét.

Within the context of known early routes within or adjacent to the study area and De Leon's diary references to 1andmarks, there are only two areas where he could have traveled eastward along the right bank of the Medina River (as it generally flows southeastward) for two leagues. One of these locations is in the vicinity of the San Antonio River confluence, well to the east of other identified early routes.

Williams (1979:114-115) believes this locale to be the vicinity of De Leon's road. In such a case, De Leon's identification of the Medina River is actual1y the present-day San Antonio River. Williams (ibid.) interprets the creek five leagues east of the river ("Arroyo de Leon") as actually being the Cibolo Creek and another creek six leagues farther east-northeast as Salty Creek in west-central Gonzales County.

Based on a preliminary estimate of early roads in the vicinity of the study area, the authors suggest an alternate route that is more in 1 ine with the later "Camino Pita" and Upper Presidio Road. The descriptions of these routes are derived from Berlandier (1826-1834:557-564).

Berlandier's account is quite specific in distances and general direction regarding day-to-day trave1. Berlandier's (1826-1834:561) party forded the Medina River at a crossing known as the Paso del Camino del Río Grande de Arriba or Tio Alberto. The location was ca. three leagues (ca. 8 miles) east of a little traveled road and crossing known as the Paso del Cañon and less than one league (two miles) west of Sauz Creek. From Berlandier's description of the Paso del Canon, it is reasonable to assume this locale is in the immediate vicinity of present-day Castrovi1le in Medina County. The Tio Alberto crossing, to the east, would be in the area of present-day La Coste. The Medina River flows eastward from Castroville to Macdona, in western Bexar County, a distance of over 10 miles (four leagues). As such, other fords may have been frequently utilized in this vicinity; such a crossing at Macdona, for example, would be less than two miles west of the study area.

This interpretation of the location of later roads in the 19th century is similar to Campbel1's (1975:6) assessment of De León's route in 1690, ". . along that section of the Medina River which flows from west to east near the present boundary between Medina and Bexar Counties. . . ."

The significance of these historical fords is illustrated by Massanet's account of six Indian groups living on the Medina River in this area: Tilpayai (Payaya), Cauya, Semoman, Saracuam, Pulacuam, and Anxau. A Payaya settlement and nearby Pampopa camp were also noted by Espinosa 19 years later in this locale (Campbe17 1975:9). He also observed Payaya ranging ca. three Teagues east (from this camp[?]). Such a location eastward from the Medina 
Applewhite/Archaeological Background

River crossings suggests direct relationships between these historic Indian groups mentioned in early diaries with the current study area.

\section{Apache}

The presence of Apache groups in the early 18th century directly affected routes of travel and exploration (or, more accurately, non-exploration) of areas just north of the study area along the margins of the Edwards Plateau. This area, commonly called the Hill Country, was first named the Lomeria Grande by early Spanish explorers (Weniger 1984:66). Considered to be the undisputed territory of hostile Apache groups, this area extended from the upper Brazos River, through the Colorado, San Antonio, Medina, and upper Nueces River basins. Weniger (ibid.) suggests that this area is physiographically more closely related to the northern margins of the Mexican Sierra Madre and not, as others have previously assumed, the southeastern extent of the Rocky Mountains.

European perceptions of those areas dominated by Apache groups in central and southern Texas are illustrated in Alzate's 1768 "Nuevo Mapa Geografico de la America Septentrional" (Martin and Martin 1982). Cox (1902:89), in discussing Spanish colonial boundaries of southeastern Texas, adds that early Spanish accounts identified a strip of territory ca. 200 leagues wide divided by the Rio Grande that formed a pouch, or bolsa, of 1 and. This area, extending in southern Texas almost to the mouth of the Rio Grande, was considered to be the favorite hunting ground of the Apaches and Lipan in the mid-18th century.

Apache activities in the local area resulted from a southern advance of these people across Texas from the Great Plains at the beginning of the 18th century. Originally seminomadic bison hunters with a strong secondary emphasis on incipient agriculture, the latter dwindled with the adoption of the horse. The pressures of warring Comanche and Wichita groups pushed Mescalero and Lipan Apache groups southeastward into the Spanish frontier, resulting in conflict with both Spaniards and the remnants of Coahuiltecan and Tonkawan bands (Tunne11 and Newcomb 1969:149-150).

The origin of the term Lipan is not known but it is noted in the historical literature of the early $1700 \mathrm{~s}$. The name may be related to a now unidentified local band chief (ibid.). The Lipan, of all the seminomadic groups that hunted or raided across southern Texas, were the only group that occupied campsites in the study area long enough for material evidences to accumulate (Campbe11 and Campbe11 1981:63).

The remnants of Lipan Apache campsites--rancherias--are scattered throughout southern Texas (ibid.), and favored locations include along the Nueces River in present-day La Salle, McMullen, Live Oak, and Nueces Counties. A major occupation site, described ca. 1784 and known to the Spaniards as "El Atascoso," was located approximately 12 leagues (31 miles) south of San Antonio and the Medina River in northern Atascosa County (Campbel1 and Campbe11 1981:63). It is interesting to note that Berlandier (1826-1834:283285) identifies a locality named Rancherias in 1828 about 13 leagues south of San Antonio near the Laredo Road (in present-day northern Atascosa County). 
He also noted the El Atascoso (River) as lying eight miles south. Whether El Atascoso and Rancheria are the same location is a speculative but interesting question; it seems unlikely that the name of a major Indian campsite and a river would be juxtaposed in the span of a generation along a we11-traveled route. Regardless, it is not probable that, as Campbel1 and Campbell (1981:63) speculate, the Apache rancheria of El Atascoso was located between San Antonio and La Bahìa. The early route from San Antonio to La Bahía and Goliad, described in some detail by Berlandier (1826-1834:369-372), would have passed well southeast of the Medina River confluence with the San Antonio River. Some other early literature sources and archival records identify "ET Atascoso" as the mission ranch of San José y San Miguel de Aguayo. This historical dichotomy should be noted, but further research is beyond the scope of this report.

Closer to San Antonio, and possibly in the study area, Lipan Apache camps have been documented along the Medina River from approximately 1760 (Ashford 1971). Projected site locations for these campsites are situated in the margins of the eastern study area in the vicinity of the projected location of the early Lower Presidio Road and the Leon Creek confluence. Oral history interviews with members of the Walsh family (formerly Pérez), whose property has passed through generations since Spanish colonial times, describe "an Apache[?] camp on the north bank of the river before its confluence with Leon Creek." Such a location would situate the campsite at or adjacent to the recently recorded site of $41 \mathrm{BX} 652$. On the opposite bank, approximately 0.6 $\mathrm{km}$ southeast of this recorded site, an unusual circular biface was collected along with several Late Prehistoric(?) ceramic sherds at 41 BX 669 . The biface was manufactured from Tecovas chert, or Quitaque jasper, from the southern high plains of the Texas Panhandle. The intrusive Quitaque material implies direct or indirect contact with this area. These possible historic Indian site locations are only considered speculations based upon fragmentary background data and unusual lithic materials associated with aboriginal ceramics.

\section{Comanche, Wichita Groups, and Tonkawa}

The Comanche, divided into a dozen or more loosely organized bands, originally inhabited areas north of the eastern Colorado plains and western Kansas (Tunnell and Newcomb 1969:152). Their ancestral struggle with the Plains Apache is presumed to have been a strong motivating factor in their southward advance across the Great Plains and into Texas. Comanches were heavily dependent upon bison hunting as a predominant food source but the lack of this faunal resource in any numbers $10 \mathrm{cally}$ suggests historical adaptations to such animals as white-tailed deer (and perhaps also pronghorn and wild horses) as these were abundant across the south Texas plains. Little can be said of the occupational patterns of the Comanche, wichita groups, and the Tonkawa as it is assumed all these peoples gravitated to the Tocal area more in search of warfare than natural resources. Past activity areas would most likely be in the form of very temporary campsites difficult to relate to particular groups.

The term Wichita is used here to identify a number of poorly described subtribes such as the Tawakonis, Waco, and Taguayas(?). These peoples, 
independent but often loosely allied with the Comanche by an economic exchange of kind (Tunne11 and Newcomb 1969:152), were responsible for most of the Indian depredations in the San Antonio area from the early 19th century to well after the Civil War.

Not related to Wichita or Comanche groups and existing as the remnants of indigenous central and southeastern inland bands, the Tonkawa are one of the most poorly described historic Indian groups. Tonkawa peoples had the misfortune of first accepting and then rejecting the cultural advances of the intrusive Spaniards. Although never becoming allies of the Comanches, they did have friendly relations with some Wichita.

\section{Occupation Patterns}

Occupation patterns of native Indian groups known from the lower Medina River-upper San Antonio River drainage can only be generally (vaguely) described, based on the existing body of information available. Except for the often incomplete references of early travelers (e.g., Terán, Massanet, Espinosa, Berlandier, and others) and the fragmentary background data from early mission records, little details remain as to the locations, interrelationships, and sociocultural elements of these various groups.

The bands inhabiting the area prior to the Spanish establishment of San Antonio in the early 18th century numbered approximately eleven (maybe more) identifiable groups: (1) the Sulujam, Sigames, and Siupam, in the vicinity of the headwaters of the San Antonio River; (2) the Pampopa and Pastia, along the lower Medina River and possibly within the study area; (3) the Payaya, located along the lower Medina River in approximately the same area as the Pastia; (4) the Chayopines, along the San Antonio River just east of its confluence with the Medina River; (5) the Lipan Apache, along the Medina River and southward; (6) the Comanche, who apparently camped wherever they wanted; and (7) at least two Wichita-related groups: the Tawakonis (Tahuacano) and Tauayas (Taguaya).

As the Pastia (and its related groups[?]; see Table 6) were enemies of the Payaya, it is assumed that--as Campbel1 and Campbe11 (1981:53) suggest-hostilities may have been caused by territorial disputes between adjacent populations. The original range of the Payaya is thought to have been west and/or northwest of the Pastia along the Medina River and toward the Nueces River. Territorial delineations of practically all of the known Indian groups are somewhat vague.

The estimates given for indigenous $10 \mathrm{cal}$ Indian groups do not include the Indians known to have occupied missions in San Antonio such as San Antonio de Valero and San José y San Miguel de Aguayo. For the most part, the origins of these mission Indians were located in the lower Nueces River or the lower San Antonio River-Guadalupe River drainages or eastward toward east Texas. A detailed discussion of known mission Indian groups in San Antonio is presented by Campbe11 and Campbe11 (1985).

The distribution of Protohistoric and early Historic occupations that centered around the Medina River-San Antonio River basin was considerably 
TABLE 6. INTRUSIVE AND INDIGENOUS INDIAN GROUPS IDENTIFIED ALONG THE MEDINA AND SAN ANTONIO RIVERS AND VICINITY

Vicinity of lower Medina River and/or upper San Antonio River, the lower Nueces River, and southeast:

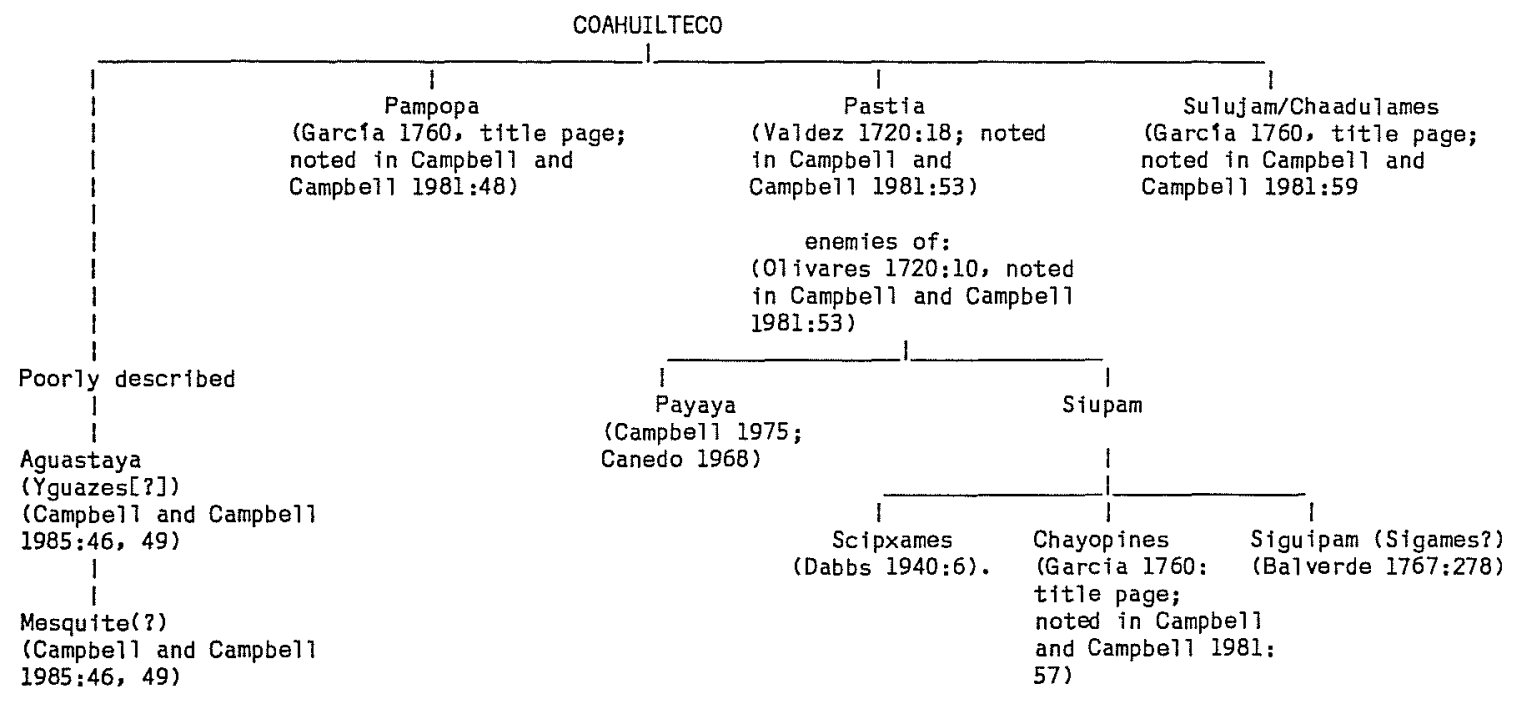

Vicinity of western Goliad County and surrounding area:

Pajalat Dialect

(Campbell and Campbel1

1981:55-56)

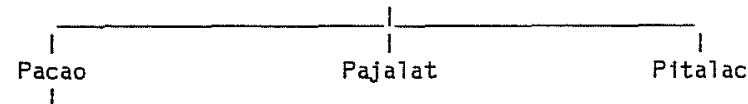

Arcahomo(?)

(Campbe11 and Campbeill

1981:55-56)

Throughout area:

ATHAPASKAN (ATHAPASCAN)

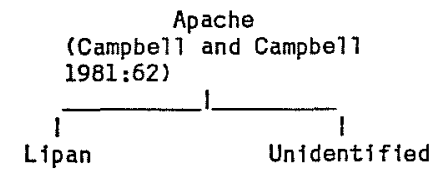

TONKAWAN

(Sayles 1935:33)

i

Unidentified Groups

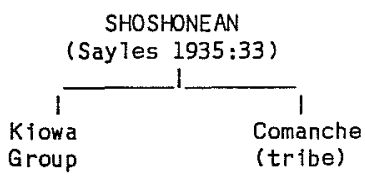

CADDOAN

(Sayles 1935:29)

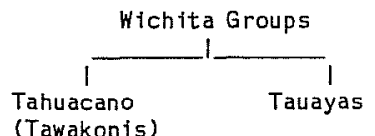

Tahuacano
(Tawakonis)

(Berland fer 1826-1834;

Sayles 1935:29)

Note: Ofvisfons are by postulated 11 nguistic associations. Table includes intrusive groups identified in local area, and does not inciude mission Indian groups transferred to area by the Spanish (see Campbel1 and Campbe71 1985). 
altered by the mid-18th century after the establishment of Missions San Antonio de Valero and San José y San Miguel de Aguayo (1718 and 1720, respective1y), combined with the added pressure of marauding Apaches from the northwest and the northward displacement of indigenous groups from extreme southern Texas and northeastern Mexico by Spanish activity. There is some indication that local groups not in missions at this time were slowly moving southeast (displaced?) along the San Antonio River (Campbe11 and Campbe11 1981:57). Certainly by the early 19th century, Apache camps along the Medina River were located in the same areas as earlier sites connected with other Ind $i$ an groups.

Indian hostilities seriously threatened the development of the Spanish presence in San Antonio for a number of years. Apache hostilities are noted in various accounts from the late 1600 s into the 1730 s.

The effects of a major smallpox epidemic on 1ocal Indian groups are not known, but it is assumed that mission Indian groups would have been the most seriously affected. Warring Comanche and Wichita groups eventually caused the abandonment of outlying ranchos from approximately 1765-1785. Another smal1pox and measles epidemic about 1777-1778 may have contributed to the decline of hostilities by approximately 1780 . Incipient rural development began again in the late 18th and early 19th centuries. However, a resurgence of Comanche attacks in 1814 (perhaps precipitated by the killing of a large number of the local male population during the Battle of the Medina in 1813) again forced the abandonment of areal ranchos. By 1830-1840, some Apache and Wichita groups had concluded a shaky peace with local Anglo and/or Spanish inhabitants, although Comanche depredations continued until after the Civil War. In summary, historic Indian hostilities affected the economic and cultural expansion of the study area specifically and the region generally.

In conclusion, the fragmentary details of historic Indian groups associated with the lower Medina River valley reflect a complex pattern of resource exploitation, conflict, and eventual decline. The record of such groups and their interaction with the slow but relentless expansion of Spanish colonial and later Anglo-Europeans are still poorly understood. In summary, given the present lack of available data, a more detailed outline of the types of aboriginal cultures, their territories, martial and subsistence patterns, etc., are far beyond the scope of work for this project.

\section{PREVIOUS ARCHAEOLOGICAL RESEARCH IN BEXAR COUNTY}

Because of a rich history, Bexar County would seem to have a number of unusually extensive and artifact-rich sites, but only in recent years has the archaeology been examined systematically and in detail. The earliest report of prehistoric investigations was written by Woolford in 1935 . His perceptive report was the first to describe distinctive site types with inferences as to their chronology. Orchard (1938) described archaeological sites in the $01 \mathrm{mos}$ Basin of central San Antonio and revised Woolford's earlier observations. Orchard and Campbe11 (1954) published a review of major sites and artifacts in the San Antonio area, including a description of Paleo-Indian materials collected prior to the construction of $01 \mathrm{mos}$ Dam in 
the 1920s. Over 100 burned rock clusters were noted, many associated with Plainview and Angostura projectile points.

In 1960, Schuetz (1960) reported a number of lithic workshop sites along the Martinez Creek drainage in southeast Bexar County, reflecting a somewhat early but temporary interest in noncentral, nonnorthern county areas. During the same period, Orchard and Campbel1 (1960) continued their descriptions of sites within the 01 mos Basin and near the headwaters of San Pedro Springs. Six years later, interest began developing around prehistoric localities in northern Bexar County, particularly the upper Salado Creek drainage (Schuetz 1966; Fox n.d.; Uecker ms.).

In 1972, W. B. Fawcett, Jr., published an overview of the county's prehistory following some earlier work (Fawcett 1972). A year later, C. D. Howard (1970) reported on Paleo-Indian materials in southern Bexar County. The same year, Dibble (1979), as part of the Texas Archeological Survey, conducted a preliminary survey of portions of the upper Salado Creek watershed. Continuing interest in northern Bexar County sites resulted in Scurlock and Hudson's (1973) publication of archaeological sites in the former Walker Ranch. This was complemented a year later by Hudson, Lynn, and Scurlock's (1974) report of further work in the same area.

The year 1974 marked a milestone in areal and regional research with the organization of the Southern Texas Archaeological Association and also the creation of the Center for Archaeological Research, The University of Texas at San Antonio. Since its inception, the Center has conducted over 300 projects in the region and has almost tripled the number of recorded sites 10cal1y.

In the San Antonio area, the Center has coordinated the extensive 201 Wastewater Treatment plant survey, published a detailed survey of over 28,000 acres as the Fort Sam Houston project (Gerstle, Kelly, and Assad 1978), and has been active in mitigating floodwater retarding locations for the Soil Conservation Service and the San Antonio River Authority (McGraw and Valdez 1978a, 1978b; Hester, assembler 1975). Historical archaeologists from the Center have investigated a number of Texas Archeological Landmarks for the City of San Antonio and related agencies, including the Alamo, the San Antonio missions, the 19th-century Guenther Mi11, the San Fernando Cathedral, the Spanish Governor's Palace, and many other historical locations.

Although much work has been concluded in the county, making it one of the best studied in the state, most of these past investigations have focused on central or northern areas in the county. Directly related to the current study area, Hester's (assembler 1975) preliminary data and McGraw's (1977) information on the Medio Creek drainage represent the only systematic investigations conducted in southwestern Bexar County.

Local prehistoric studies in recent years, following the accumulation of a substantial data base, have shifted to a synthesis of information and the formulation of preliminary concepts of subsistence and occupation patterns along the Ba7cones Escarpment and in surrounding areas (see Black and McGraw 1985). Current investigations in southwestern Bexar County may be used to compare and contrast data between these two distinctive ecotonal areas. 
Applewhite/Archaeological Background

\section{PREVIOUS ARCHAEOLOGICAL WORK IN THE STUDY AREA}

As noted, in 1975, Center personnel conducted a preliminary reconnaissance of parts of the proposed Applewhite Reservoir (Hester, assembler 1975). In 1977, A. J. McGraw of the Center staff conducted surveys along Medio Creek, a major tributary of the Medina River which enters the proposed reservoir basin at its northern end (McGraw 1977). McGraw's (1977) and McGraw and Van Note's (1981) preliminary research identified a total of 58 historic and prehistoric sites between 1977 and 1981. Sites relevant to the proposed Applewhite Reservoir area are presented as Appendix $V$ to this report, and McGraw and Van Note's (1981) report is incorporated into the present report. These three surveys provided the only archaeological research conducted in the study area up to 1984.

Prehistoric sites found to date in the reservoir area may be characterized by Late Prehistoric occupations (A.D. 950-1500) located near or adjacent to modern drainage channels. Archaic occupations (ca. 6000 B.C.-A.D. 500) are situated on secondary or higher terraces above and often removed from present drainage channels. Very little evidence of Paleo-Indian activities was discovered, and this may be caused by natural site destruction, deeply buried deposits not recognizable in surface contexts, or differences in Paleo-Indian subsistence patterns that resulted in site locations outside of the current survey areas.

Few Middle and Late Archaic (Local Periods 6[?], 7-9) diagnostic artifacts were recovered at prehistoric sites. A significant Late Prehistoric component (comparably similar to Local Period 11) was found at 41 BX 459 along Medio Creek. Unlike other areas in the county, most prehistoric lithic flintknapping sites were associated with occupational debris and not spatially discrete from occupation sites. Archaeological sites generally consisted of large occupation zones, in contrast to the more localized and smaller major occupation sites elsewhere. While specific concentrations of materials sometime occur in three zones, the zone limits are often difficult to distinguish. Given the survey area and its riparian context, relatively few diagnostic materials were recovered during the 1981 and 1984 investigations; this may be due to past informal relic collecting, or perhaps the rapid rate of soil deposition along terraces through time, resulting in intact, reasonably extensive, deeply buried occupational deposits. Archaeological data of the reservoir, when contrasted to the Salado Creek drainage synthesis, show distinctive changes in site locations, site sizes, and chronological diagnostics between the two areas. While it is believed that the development of a local prehistoric chronological sequence will greatly contribute to a more accurate appraisal of current and future research in the proposed reservoir, it must be noted that the Medina River itself, as an integral part of the resource system qualitatively and quantitatively affected the patterns of subsistence and occupation of hunters and gatherers who once exploited its resources.

\section{PROBLEM AREAS OF CURRENT RESEARCH}

The regional (and interregional) problem areas of current archaeological research also pertain to the project area in terms of theoretical and 
methodological considerations. A distinction between cultural resource management and more traditional academic work is not made at this point as the problems that affect one also plague or are found in the other. A description of project specific considerations is presented in the Research Design and Methodology section.

Regional studies, those of south-central and southern Texas have been, and in many respects still are, in a basic data-gathering stage. Physically, a vast amount of acreage, a long chronological span of prehistory, and a fragmentary archaeological record have combined to preclude or limit detailed analytical or theoretical constructs.

Current research focuses on three main problem areas: (1) the lack of detailed ethnohistoric or comparative ethnohistoric data coupled with fragmentary, widely scattered, and often confusing elements of the material culture(s); (2) a lack of information on the changing paleoenvironmental conditions with substantive evidence as to its effects on aboriginal populations; and (3) widespread differences in method and theory between various researchers.

While the archaeological resources of some areas are well documented--Bexar County, for example--the more common situation reflects counties or intercounty locations with very few recorded sites or lacking systematic or professional investigations. Archaeological resources throughout the region, while relatively abundant, are characterized by the paucity of cultural materials usually associated with the remains of hunter-gatherer campsites. They suffer too from modern relic collectors who, al though less in number than their suburban counterparts, share a common fanaticism of collection and site destruction.

Elements of the material culture, primarily lithics, have received widespread and detailed attention from researchers, but the vast majority are from differing typological perspectives. Very few examples of replicative studies can be noted generally, and (sometimes esoteric) 1ithic typologies sometime reflect the time and monetary efforts of the researcher rather than a considered potential for future comparative studies. Detailed site reports often reflect site-specific data, with little emphasis on a broader perspective of the widespread envirocultural context. Ethnohistoric data of indigenous historic groups are quite 1 imited, as well as cross-cultural ethnohistoric and/or ethnological analyses. Paleoenvironmental information through the region, as elsewhere, is limited, and comparisons with past cultural processes can be made only on the broadest levels.

Differences in theoretical and methodological approaches also affect the perspective of current researchers. Chronology is by far the single broadest point of dissension. An emphasis on defining the chronological record based primarily on the sequence of diagnostic projectile point types has both contributed to and detracted from the understanding of the archaeological record. Researchers in adjacent regions often find the same diagnostic type related to different cultural associations as well as time periods.

A final, and one of the most significant, areal problem that has surfaced in recent years has been the alarming and ever-increasing rate of site 
destruction through relic collecting activities. This is especially true of site locations near suburban areas or near modern developments. Site destruction, either by development, developers, or relic collectors, is the most severe and destructive of the current problems that face researchers today.

The problem areas mentioned are not limited to the region; in varying degrees, they exist for archaeological studies anywhere. Regionally, great strides have been taken in the last decade toward our understanding of archaeological resources beginning with a solid base of data collection. Studies of method and theory have guided the accumulation of much of this information (Hester 1981:493, footnote), and current research can not only synthesize this early data but can now employ "high resolution" analytical studies to complement field work (e.g., soil chemistry analyses, effective flotation techniques, computer analyses of artifactual materials, and interdisciplinary studies).

Given the positive and significant accomplishments of regional studies, the observed problem areas should be viewed as a measure of the advances to date and considerations for the future (see also Research Design and Methodology section for a discussion of research design elements that address aspects of these problem areas). 


\section{HISTORICAL OVERVIEW}

\section{INTRODUCTION}

The historical development of the local area is a complex one that originated with early Spanish interest in the region since the 16th century. As one of the oldest and historically significant cities of modern Texas, San Antonio's history reflects a number of personages who have influenced the development or changed the direction of the provincial government, politics, economics, and social structures. It reflects, too, the almost ever-present violence and harsh conditions that surrounded the frontier and its inhabitants.

The overview is divided into six major sections, each identifying a sociocultural or a sociopolitical period in the area's historical development: (1) Spanish exploration and settlement; (2) Mexican statehood; (3) Texas Republic; (4) early statehood and antebellum; (5) Civil War; and (6) postCivil War and industrialization. A brief summary of historical development identifying social, economic, and political elements of change is also included; a glossary for this section is provided as Appendix II to this report.

The historical overview presented in the following pages is purposefully detailed and, whenever possible, it relates historical events, developments, and personages to the local study area. A detailed discussion of the methodology and design of this overview is presented in the Research Design and Methodology section of this report.

\section{SPANISH EXPLORATION AND SETTLEMENT}

The Spanish presence in the area now known as Texas was initially established in 1519 when the Pineda expedition mapped the Gulf coast from Tampa Bay to Pánuco (Mallouf, Baskin, and Killen 1977:29). During the remaining 16th century, other Spanish explorers transversed the present state--including Alvar Núnez Cabeza de Vaca (Narváez expedition), Alonzo de Solis, Hernando de Soto, Luís Moscoso, and Francisco Vásquez de Coronado (Ashford 1971:10-31). In a 11, 20 Spanish expeditions are definitely known to have entered the present State of Texas or touched its coast prior to the incursion of La Sa11e in 1685 which led to an increased burst of Spanish activity (Ashford 1971:44).

In 1681, the Spanish government issued the Nueva Recopilicion de 1as Leyes de las Indias or the Law of the Indies, which was a voluminous work on the rules, regulations, laws, and the administration of the new territory claimed by Spain. These laws were followed for the next 140 years of Spanish rule.

Following the French and Spanish War, the Frenchman René Robert Cavelier, Sieur de La Salle, led an expedition to the Mississippi River which he explored. Subsequently losing his way, he passed the mouth of the Mississippi River and landed near Matagorda Bay, where he established the 111 -fated Fort Saint Louis. Spanish reaction to the French incursions 1 ed to the expeditions of Alonso de Leon between the years 1686 and 1690. Of particular interest to the study area was the expedition made in 1689 by De Leon when he 
reached a stream which he called the Medinal (Forrestal 1935:48, footnote \#37), probably named for the noted Spanish engineer and scholar, Pedro Medina (Arneson 1925:83-84). In 1690, De León, accompanied by Padre Damián Massanet, established Mission San Francisco de los Tejas, the first mission founded in east Texas (Ashford 1971:85). From this time, the premier goal of the Franciscan fathers was the christianization of the native Indian groups, and no entrada was complete without the dedicated padres. Secular interests sought to exploit the precious mineral resources and perceived the colonization of the outlying provinces as protection for the frontier from foreign intrusions.

During the year 1691, Domingo de Terán was appointed by the viceroy as the governor of the province, and an expedition was mounted to determine the presence or absence of the French and to establish eight new missions among the Indian tribes of east Texas (Ashford 1971:85). Terán was accompanied by the venerable Padre de Massanet, and some scholars believe the trail blazed by these early explorers became known as El Camino Real (Norve11 1945:33). (One branch of this road known as the Lower Presidio Road is located just south-southeast of the project area, ca. 1/8-1/4 mile, where it crosses the Medina River and is known today as Cassin Crossing.) Ashford (1971) reported that both men commented in their diaries upon the large numbers of buffalo which they found on the level plains near the Medina River. He further wrote that:

Massanet also noticed some deer, and Teran, who had served the king for 20 years in South America, compared the plain to that along the Rio de 7a Plata. . . From the Medina, Teran reports they marched five leagues [13 miles] over a fine country with broad plains, the most beautifu1 in New Spain (Ashford 1971:85).

On June 13, 1691, Padre Massanet called the area San Antonio de Padua in honor of St. Anthony of Padua (ibid.). He also suggested that the area would make a suitable location for a mission. De León reportedly left a smal1 garrison of men which was the beginning of the Presidio of San Antonio de Béjar (alternately, Béxar; Chabot 1937:9).

For over a decade (1702-1713) during the Eleven Years War of Spanish Succession, Spain and France were united as uneasy allies against most of the rest of Europe. While preoccupation with the problems at home led to a decrease in competition in the interior of the "New Philippines," some problems remained along the coastal area of the Gulf of Mexico.

The Diego Ramón entrada in 1707 , led by the military commander of the Presidio San Juan Bautista, was to curtail the activities of the various rebel1jous Indians, mainly those from Nuevo León (Campbe11 and Campbel1 1981:50). Accompanying the Ramón entrada was Padre Félix Espinosa, who, with Padre Antonio 07 ivares and Captain Pedro de Aguirre, reached the Medina River area in 1709, which 18 years earlier had been transversed by Terán and Massanet. Campbel1 and Campbe11 (1981:51) wrote about the entrada:

Espinosa's diary indicates that on April 12 the Spaniards visited a Pampopa encampment on the Medina River southwest of modern San Antonio. 
The narration continued:

We [Fathers Fé 1 ix Espinosa and Antonio de 01 ivares and Captain Pedro de Aguirre] continued our course towards the east through some ravines filled with holm oaks [live oaks], mesquites, and some white oaks, until we arrived at the Arroyo of Leon [Leon Creek] and we crossed it about a gunshot from where General Gregorio Salinas crossed it some years before (Ashford 1971:91).

By 1714, the Frenchman Louis Juchereau de St. Denis traveled over much of the province undetected by the Spanish and reached Mission San Juan Bautista and the Presidio del Rio Grande. The presence of St. Denis greatly alarmed the Spanish authorities, and again in 1716 an entrada led by Captain Domingo Ramon set out to establish presidios and missions in the province. The entrada led by Ramón was accompanied by Louis de St. Denis, Padres Félix Espinosa, Antonio Margil, and Hidalgo as well as 25 soldiers, six other priests and lay brothers, 14 mule drivers, eight women, one boy, two families, and five Indians. On May 13, the expedition reached the Medina River (on the upper Presidio Road adjacent to the study area on the west), and on July 2, 1716, they reached east Texas where they established five missions, reestablished one, and a presidio: San Francisco de los Neches, San Francisco de la Espada, Nuestra Señora de la Purisima Concepción, Nuestra Señora de Guadalupe, San José de los Nazonis, San Miguel de Linares, and Presidio de los Dolores (Norvel1 1945:38).

Padre Celiz, accompanying the Alarcon expedition, arrived in the area in 1718. A map accompanying the diary Celiz kept of the expedition shows them crossing the Medina River somewhere in the vicinity of present-day Garza's Crossing (within the study area, 41 BX 697) or Mann's Crossing (northwest of the study area). Celiz recorded the following:

On the 21st [Apri1] the camp left this pool [Los Charcos de 1a Pita] for the creek of Los Payayas which is about three leagues distant. ${ }^{2}$ [This creek was named for the Indians who camped there according to Celiz (Hoffman 1935:34-35, note 30).] All of this road is densely bordered by mesquites, oaks, and pecans. Halfway on this day's march, we were met by the father preacher Miguel Nunez. ...

22nd--rained--camp remained here.

On the 23rd it [the camp] left for Medina River which is about six leagues distant. The road is level without hills or ravines, but with many groves of trees. The way is bordered by different herbs and many different flowers. On the 24 th we crossed the Medina River with some difficulty because it had rained and the river was running. This river is densely shaded by poplars, elms, mulberries, savins [cypress] and hackberries (Hoffman 1935:47-48).

Further information of the Alarcon expedition on the Medina River was recorded in the Mesquia diary ${ }^{3}$ (Hoffman 1938): 
On the 23rd we went as far as the Medina River and we crossed it with some difficulty because it was somewhat flooded. There was no damage aside from the falling of a cargo of the fathers of Zacatecas, one tercio being of sugar and the other of salt. All of it would have been lost if help had not been given immediately. . .

During the same year, Father 0livares of the Mission San Francisco Solano (on the Rio Grande) left the mission with a few of the Xarames Indians and joined Alarcon (Ashford 1971:107). On May 1, 1718, the expedition founded the first mission, San Antonio de Valero on San Pedro Creek. The mission was named for St. Anthony and for the reigning viceroy of New Spain, Baltasar de Zúñiga, Marqués de Valero. On May 5, the presidio and the villa of San Antonio de Bejar was established and named in honor of the Duque de Béjar, a brother of the Marques de Valero, who had been killed fighting the Turks in Hungary. While the year 1718 marks the ceremonial forming of the city, no actual town, mission, or presidio was built until 1719 due to the lack of manpower and material.

From 1719 to 1720, the Spanish authorities attention turned abroad to Spain's war with the quadruple alliance of England, France, Austria, and the Netherlands (Ashford 1971:123). At home, this engagement resulted in the French chasing the Spaniards out of east Texas in the summer of 1719 (Ramsdel1 1959:16-17). Among those retreating to San Antonio de Béjar was Fray Antonio Margil de Jesús, president of the Texas missions, who belonged to the apostolic college of Nuestra Señora de Zacatecas (ibid.). From the years 1718 to 1721, the governor of Coahuila and Texas, Marques de San Miguel de Aguayo, led an expedition into the province accompanied by Father Juan de 1a Peña (Ashford 1971:125). The route followed by Aguayo was basically the same route taken by Alarcon in 1718 and either crossed the study area or was just north-northwest of the area. Peña, the expedition's diarist, recorded the following:

Thursday, 3. We journeyed east-northeast about three leagues, and the rest of the day traveled between north-northeast and northeast. . . We traveled on as far as the Medina River, a distance of nine leagues. The march was very difficult but we had to continue it, for we found no water along the way. . . . For about three leagues we traveled through woods in which we saw walnuts and oaks, and some vines that already were covered with clusters of grapes. . . . During the remainder of the day we passed through a flat country and found a great many deer. We saw around us, almost at the same time, as many as three or four hundred of these animals, and the mounted soldiers that covered the line of march, riding at full speed, captured two by driving them toward the droves of horses. They could have caught several had they not been afraid of throwing into disarray the line of march. Here also we found a great number of turkeys and quail. Nine leagues. Friday, 4. . We set out after High Mass and several Low Masses had been celebrated in commemoration of the feast of the day, our Lady of Sorrows, and entered the province of the Texas Indians, or Nuevas Filipinas, which is separated from the Province of Coahuila Nueva Estremadura by the Medina River. We traveled east-northeast 
about three leagues until we came to Leon Creek in which water can be found the greater part of the year, and in several esteros all year round. From here we advanced northeast along a beautiful plain until we came to San Antonio. On most of the route from the Medina River to Leon Creek we had crossed low hills and fertile valleys and had found a great quantity of flintstone. This kind of stone can be found at several places between the Rio Grande and San Antonio. That same day we reached San Antonio, which is six Teagues from the Medina River (Forrestal 1935b:13-15).

After arriving in San Antonio de Béjar, the expedition was joined by Frays Antonio Margí1 de Jesús and José Rodriguez, and two Tay brothers, Frays José Albadejo and Jose Pita (Forrestal 1935b:15). During this time, Fray Margí1 implored the Marques to allow him to establish a mission at San Antonio for the College of Zacatecas, the new mission to be called San José y San Miguel de Aguayo (Ashford 1971:125). In 1720, a second mission, with the above name, was established at San Antonio de Béjar. In eight months, the Marqués de Aguayo reestablished six missions, established two new presidios, and founded three new missions, placed 268 soldiers in the provinces, and left the Spanish power firmly established (Ashford 1971:132).

The development of the three separate Spanish communities in San Antonio de Béjar--presidio (military), villa (civilian), and mission (clerical)--led to small population increases and eventually to bitter rivalries and defined social classes. Hostile Indian raids by marauding Apaches also plagued the residents of San Antonio de Béjar at this time, making it very difficult for the settlers to grow crops and raise cattle.

In 1724-1728, Pedro de Rivera, traveling El Camino Real or Lower Presidio Road, made an inspection of the presidios in northern Nueva España and was accompanied by the engineer Francisco Alvarez y Barreiro, who produced a map showing the route of the expedition and approximate locations of Indian groups (Campbe11 and Campbe11 1981:51). In 1727, they inspected the Province of Texas, visited the four presidios, including San Antonio de Béjar and Nuestra Señora de Loreta (Go7iad), and covered 554 leagues, long enough to provide the two men with vivid descriptions of the country. Entering Texas, they crossed the Medina River which formed the boundary of the province from its mouth to the northern Hill Country of the Apaches and from the same said river to the Rio de San Andres de Caudachos (or the Red River; Murphy $1937: 134-137)$.

Southwest of the presidio of San Antonio de Béjar, Rivera found a Zacatecan brother ministering to the small pueblos (Mission San Jose) inhabited by the Mezquites, Payayas, and Aguastayas and a Queretaran Franciscan ministering at a small pueblo one-half league northeast of the presidio San Antonio de Valero (ibid.). Hoffman (1935) writes that "Rivera noted in 1727 that their [Payayas] most frequent home was on a creek bearing their tribal name, near the Medina River." Williams (1979:135) identified this creek as about six miles east of the waterhole known as Charco de la Pita (Francisco Creek/San Francisco Pérez Creek[?]) and along present-day Charcon (Chacon) Creek. It is believed Chacon Creek, perhaps known as Payaya Creek in the early 18th century, was al so known as Rosales Creek by the 1820 s (Austin 1828, map of 
the Camino Pita). This drainage is noted by Austin as approximately three leagues (ca. 7.8 miles) from the Medina River.

Campbel1 and Campbel1 (1981:62) provided an excellent assessment of the observations made by Rivera and Barreiro in 1727:

Some impression of maximum territorial range, along a north-south axis, may be obtained from recorded observations of Pampopa and Pastia encampments, which were distributed over an area extending from the Medina River southwest of San Antonio to the great southward bend of the Nueces River, a distance of approximately 85 miles. . . Very little information on subsistence has been recorded for these Indian groups. Rivera's observations are generalized and merely confirm the fact that all of the groups were hunters and gatherers. No reference is made to seasonal migration to prickly pear concentrations, and pecan harvesting is 1 inked indirectly with two groups encountered on the Medina River southwest of San Antonio.

At this time, three main roads transversed the province: El Camino Real (known as the Presidio del Rio Grande Road, the Lower Presidio Road4, or the old San Antonio Road--crossing at La Barranca, Paso de Travieso, Kerr's Crossing, and Cassin Crossing, respectively, and successively), the Presidio del Rio Grande Road or Upper Presidio Road, and the Bahia Road (Goliad Road; Fig. 14). This network tied together an area extending from Monclova, Mexico, to Mission San Juan Bautista in the Rio Grande, to San Antonio de Béjar and La Bahía (Goliad), and as far as Natchitoches, Louisiana, then a port of New Spain. That these routes were inland is no accident. In 1691, the King's Council had instructed the viceroy of Mexico to find a new 1 and route from Monclova to the eastern Indians, avoiding the indirect and circuitous route by way of the Gulf (Norvel1 1945:31). Later, Spanish incentives for inland networks were the threat of coastal Indians and other foreign coastal trade, which would eliminate the monopoly on Spanish goods supplied to the settlers.

From 1726 to 1730, there was relative quiet concerning Indian atrocities in the area and region, but by 1731 the Apache renewed their attacks (Ashford 1971:140). By 1729, as a result of recommendations made by Pedro de Rivera, a series of reforms was inaugurated which called for the suppression of the Presidio de Dolores and the reduction of the garrisons of the other three presidios in Texas (Chabot 1936:57). When the Presidio de Dolores in east Texas was withdrawn in 1729, the Queretarans requested that their three missions be moved to San Antonio de Béjar, and on 0ctober 29, 1729, the governor, the exguardian of the Queretaran College, and the president of the Texas missions (Isidro Felix Espinosa):

selected three places, two on the San Antonio river, and one on the Medina. . . where the missions were at first temporarily located, and where the Pacaos, Pajalots and Pitalacs agreed to settle, and submit to doctrine (ibid.).

Rivera, the ex-inspector, considered the location on the Medina River too exposed to the Apache so the viceroy in his final decree recommended that the 


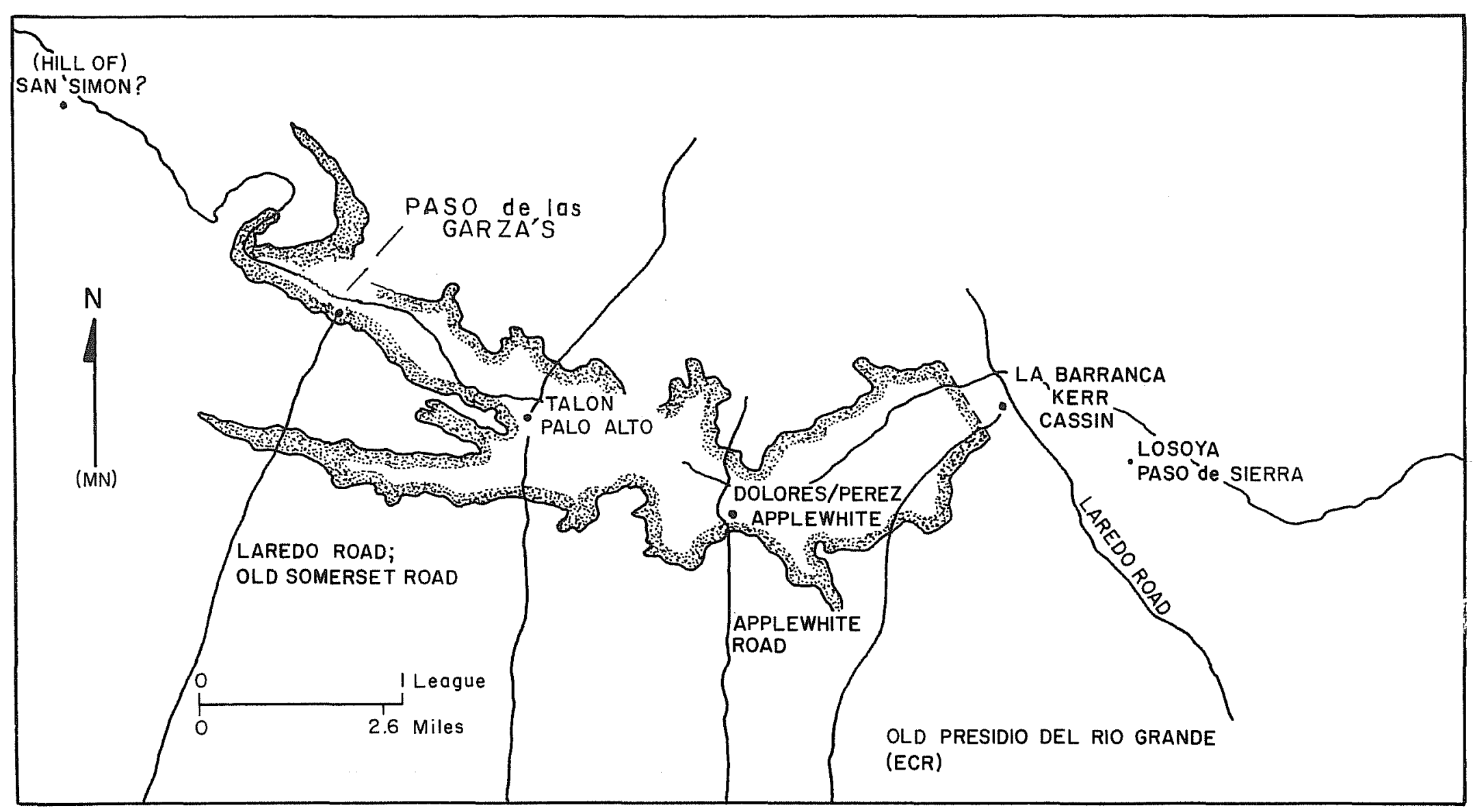

Figure 14. Early Routes in the Study Area. 
Captain of the Royal Presidio use his own judgement as to their location (Chabot 1936:58). The three missions transferred consisted of those founded in 1716 by Espinosa--San Francisco de los Neches which became San Francisco de la Espada, Nuestra Señora de Ta Purisima Concepción, and San José de los Nazonis which was renamed San Juan Capistrano. On January 12 , 1731, Captain Pérez proceeded to establish the said missions and place them in the possession of the Indian tribes under the guidance of the padres.

The year 1731 also marked the arrival of the Canary Island families to San Antonio de Béjar as had been proposed by Governor Aguayo to settle the province. Fifty-six Canary Islanders came straggling into San Antonio de Béjar--a town was laid out for them, and the Plaza began to be occupied. The first civil government in Texas was appointed to office by the captain of the presidio, and the settlers received the title of Hijos Dalgos or Hidalgos (Ramsde11 1959:21-23). Their settlement came to be called the Villa de San Fernando de Bexar and was to be the site of the capital of the province of Texas, although the governor was stationed in the east until 1773.

The arrival of the Canary Island families increased friction among the civilians, military, and clerical factions of the settlement, and early archive records abound with the controversies. Most of the controversies arose over the question of private 1 and versus mission 1 and tenure--a dispute that would culminate in the San Fernando Memorial of 1787 (BAT Vol. 150). In addition to the Canary Islanders, an even greater division was developing between the native-born Spaniards (peninsulars), criollos, mestizos, culebras, and indios. Interestingly, the Canary Islanders and their descendants, along with the military men and their descendants (such as Pérez, the Rodriguez, Ruiz, and Hernández) were to receive the first secular grants along the Medina River and/or Leon Creek in the study area. An archival search to date has not been able to definitely ascertain the early status of the lands included in the study area, but primary investigation lends support to the theory that the lands on the north and south banks of the Medina River between the Presidio del Rio Grande Road (modern-day Cassin Crossing) and present-day Von Ormy were unappropriated lands or "royal lands" at least until 1754 and possibly as late as 1780 when the Pérez family gained control of much of the area (TGLO Paschal vs. Pérez). on the south bank, the study area appears to be bounded by those 1 ands granted to Mission Espada in 1731 and Mission San José in 1766.

In 1736, Don Carlos Benites Franquis de Lugo, ad interim governor of Texas, succeeded in implementing a communication blockade between the missionaries in San Antonio de Béjar and the Rio Grande, along the Medina River:

Shortly after the removal of the mission guards, Chirino, a messenger bearing letters from the missionaries to the Rio Grande, was stopped by Alfarez Galvan and a group of soldiers stationed at the crossing of the Medina River (Castañeda 1938a:49-55).

The next year, 1737, Apache attacks increased in the area:

- . five Indian women and two boys from Mission San Francisco de la Espada went out to gather fruit on the Medina River. While there, they were suddenly attacked by a group of Apaches who killed 
the five women, horribly desecrated their bodies, slicing their abdomens with fiendish glee, and carried away the two boys (ibid.:48).

The Great Epidemic of smallpox and measles in 1739 resulted in great loss of lives among the settlers and the native Indian groups, and the population of the missions was severely reduced (Castañeda 1938a:67). Campaigns were somewhat diminished by this epidemic. According to Castañeda (ibid.), the Apache campaigns continued through at least the year 1762, when the Apache menace proved so dangerous that the fields could not be cultivated or the ranches maintained beyond the city limits. Ashford (1971) wrote that by 1759 the Comanche hostilities increased in the San Antonio area and that the Apaches were camped on the Medina River most of the time. Conflicting testimony offered by the San Fernando Memorial and supported by other documents in the Bexar Archives Translations (Bexar County Courthouse) stated that from 1749 to 1765 relative peace with the Apaches was achieved and that the residents were able to return to their ranches (BAT Vol. 150:33-34). The abandonment of the ranches occurred from 1765 to 1785 when the Comanches and Taguayas waged war--all the stock of the ranches was separated and dispersed - - and not until 1786 did the residents reestablish the ranchos and try to recollect the cattle (ibid.).

In 1746, José de Escandon, a lieutenant of the viceroy in the Seno Mexicano or Gulf Coast, was commissioned to conquer and settle the new provinces of Colonia del Nueva Santander which was more than 100 leagues from north to south and 60 or 80 leagues from east to west; the northern boundary of the province being the Medina and the San Antonio Rivers (Bolton 1962:292). Escandón's plan was to colonize the province with Spaniards and christianize Indians (ibid.). After exploring the country to and along the Rio Grande, he recommended the founding of 14 Spanish villas and a suitable number of missions with 12 of the villas to be established south of the Rio Grande and two north of that stream (Bolton 1962:273). Among the settlements established and proposed by Escandón were Reynosa, Camargo, Laredo, and Dolores, with the first three becoming permanent settlements (THC 1973:17). The founding of Laredo resulted in the opening of the Laredo Road (10cated east of the study area and crossing the Medina River at present-day Losoya), a new transportation network between San Antonio de Béjar and Laredo.

Escandón had recruited ranchers and frontiersmen from northern Mexico to form the basis of his colonies, and in 1748, "Nearly 4,000 persons gathered at Queretaro and marched northward, driving great herds of horses, cattle, burros, sheep and goats" (Myres 1969:15). Nuevo Santander developed as a center of stock-raising activity, and ranching gradually extended throughout the province. In addition to the large ranches operated by the missions of San Antonio de Béjar, private ranches owned by soldiers and settlers (particularly the Canary Islanders) also ran cattle and horses. "These ranches provided meat for the presidential garrisons and local markets, and tallow and hides for export" (ibid.).

Ranches, both civilian and mission, evinced little structure or organization, and "ranching" generally consisted of the occasional rounding-up of wild, unbranded stock which roamed the open range (Myres 1969:16). Round-ups were held when meat ran out or when it was decided that a shipment of hides and 
tallow was needed. The lack of organization was not entirely the fault of the ranchers as population was small, labor scarce, and no regular markets existed for the products, and Indian raids contributed to the unsettled conditions in the province (ibid.:17). Despite these problems, some ranchos in the San Antonio area did manage to:

support a small permanent work force, build habitations and other structures such as corrals, stockades, chutes, defenses, embankments, clearings, trails, roads, sheep-folds, water-holes and numerous other things necessary for breeding, propagating, raising. . the horses, cattle, sheep, goats, swine and all the other kinds of stock (BAT Vol. 150:59).

Spanish ranches in the study area were (Fig. 15) owned by José Antonio Péres (José Péres Casanova and also Pérez) and/or Juan Ygnacio Pérez (Pérez's Rancho or Stone Rancho; see 41 BX 274) Ca. 1754 or 1780 (TGLO Paschal vs. Pérez), Juan Manuel Ruiz ca. 1778 (Weddle and Thonoff 1976:154; see $41 \mathrm{BX} 344)$, and Francisco Ricardo Hernández. Spanish ranches adjacent to the study area were owned by José Angel Navarro (BAMR 25), Fernando Rodriquez (ibid.), and José Antonio de la Garza (BAMR 25).

The de Ta Garza ranch had been inherited by José Antonio (who secured Mexican title to the grant in 1824) from his father Leonardo de 1 a Garza, who had inherited the land from his father, Cristobal de 1 a Garza. The family had originally come to Texas with the Ramón expedition in 1716 (Weddle and Thonoff 1976:154).

The Navarro ranch had also been inherited (ibid.:152). José Angel Navarro appeared on a list of ranchers on the Medina River and/or Leon Creek in 1812 (BAMR Rol1 12). He received Mexican title to the 1 and on Leon Creek in 1838 (BCDR Book $\left.E_{2} A: 362\right) .5$

Fernando Rodriguez, son-in-law of Juan Ygnacio Pérez, owned the 1 and just north-northeast of the Pérez grant on the north bank of the Medina River. No title to the land can be located at the Texas General Land office, and nothing more is known about the ranch at this time.

Francisco Ricardo (Hernández) has been identified as having received a Spanish grant in the area. We know that he petitioned for 25,000,000 varas to the Mexican government on October 15, 1829 (BCDR Vol. E1:145). He received a Mexican grant for one league on December 3, 1833, at which time he claimed that he was a labrador, a native, and resident of Bexar and owned oxen and stock (TGLO Spanish Collection Vol. 31:34). Hernández sold the one league on the Medina River in 1836 to John Sutherland (DRT Juan Nepomenco Seguin Deed 1836).

These grants (see Fig. 15) along the Medina River correspond to those described by Myres and consisted of sitios which were of three types: the sitio de ganado mayor for large animals such as cattle, horses, burros, and mules; the sitio de ganado menor for small animals such as sheep, goats, and hogs; and sitios de criadero de ganado mayor for cattle breeding. A sitio de ganado mayor, frequently referred to as a league, consisted of 4428 acres. Livestock owners, such as Juan Ygnacio Pérez, generally applied for multiple 

sitios at one time, and in the case of Pérez, controlled four leagues south of the river and one league north of the river (BCDR Book 2A:67-71), almost the whole study area.

Spanish land grants in the area took in consideration the utilization of the land and the semiarid environment. Agricultural grants were divided into smaller units with access to irrigation, while pasture or dry land was al lotted in greater portions (Myres 1969:21). Although the 1ands situated adjacent to the Medina River would appear to have been a capable and dependable source of irrigation for crops, we know in fact that "although there is water in the Medina River, there is no convenient way of taking it out through a ditch because it is too deep... the situation of said land being such that it cannot be irrigated owing to its locality. . " (BCDR Book $\left.E_{2} A: 67-71\right)$.

During much of this time, events abroad were taking place which would result in a complete reorganization of the Province of Texas. The French and Indian War (or Seven Years War), 1754-1762, and the Treaty of Paris (1763), which ended the war, saw France and Spain ceding to England nearly all of their possessions east of the Mississippi River while Spain received the Louisiana Territory from France (Castañeda 1938b:204). Castañeda (ibid.) wrote about the events:

The cession of all Spanish and French territory east of the Mississippi to Great Britain in 1762 .. . brought grave fears to Spanish officials who foresaw the inevitable penetration of English goods into the Gulf Coast provinces of New Spain.

The struggling outpost of Los Adaes, the presidios of La Bahia on the Gulf coast and San Agustin on the Trinity had lost their purpose. In addition to the civil settlement at San Antonio de Bexar, there were settlers at San Sabá, Los Adaes, and La Bahía as well as private ranches scattered from Laredo to Los Adaes (Castañeda 1938b:44).

The removal of the French threat called for a reassessment of the situation in New Spain. In 1766, the Marqués de Rubi was commissioned to make an inspection of all the settlements from lower California to the Louisiana border. He was accompanied by Nicolás de la Fora, an engineer, who made a map of the areas visited which contained all the existing missions, presidios, and civil settlements (Ashford 1971:161). Examination and interpretation of the La Fora map (Castañeda 1938a:240) reveal that the expedition crossed the Medina River at either the Lower Presidio Road or the Laredo Road crossing located just east of the study area. Writing his report after the inspection, Rubi tried desperately to get the Spanish government to distinguish between the real and the perceived frontier of New Spain, because there was such a monumental difference between what was claimed and what the Spaniards actually held (Fehrenbach 1968:58).

In a series of reports the Marques made a number of proposals which would seek a radical change in Spanish Indian policy, with the "New Regulation of the Presidios" being implemented in 1772. Local1y, the change resulted in the strengthening of Bexar, and it becoming the new capital of the province; the establishment of the cibolo fort to guard and protect the ranches 
belonging to the citizens of San Antonio; and the arrival of the Adaesanos from east Texas, including the Rolen family whose descendants would later obtain a headright grant in the study area.

The year 1767 also saw the expulsion of the Jesuit order from a11 colonies of Spain (Castañeda 1938b:262-263). By 1769, the formal resignation of the temporal administration of the missions under the College of La Santa Cruz de Queretaro was offered but not until 1772 did the province of Guadalajara and the College of Zacatecas receive the six missions in Coahuila and Texas from the Queretarans, including Concepcion, San Juan Capistrano, San Francisco de la Espada, and San Antonio de Valero (Castañeda 1938b:259-263).

In 1777-1778, Father Agustin Morfi, chaplain of the Croix expedition, inspected the missions and presidios and later wrote a history of the province. In his Viaje de Indios y Diario del Nuevo Mexico, Morfi (n.d.) recorded the following:

Dec. 31,1777

From here [Gallinas creek] the soil changed and the vegetation. The sand ended, and with it the oaks, live-oaks, etc., and began a clayey soil, with large mesquite, prickly pear, of which we had seen no vestige in the forest left behind. The sand of the forest is in spots white, yellow, dark, and reddish, all equally fertile, because besides the trees the whole is covered with most beautiful grass. A little further along after the clearings, on the right of the road are seen some rock on which are painted some crosses to indicate the boundary of the lands of the mission of San Francisco de 1a Espada. At the edge of the forest is a group of thirty-one live oaks, so green, so straight that they are the shape of a beautiful maul. We went over a bald hill, rather long, where we saw wolf tracks. After going down from this the mesquite forest began again and continued to the river. Near the river we saw the ruins of a fence built to prevent the escape of the mission live stock. But the frequent visits of the Lipans who came to rob publicly, saved them the trouble of keeping up the fence. At 1:30 we arrived at the Medina River, the boundary line between the provinces of Coahuila and Texas. We crossed on dry land, although at intervals there are water holes and much water, abundance of fish and some alligator. The river bed is very deep, which makes it nearly impossible to get much use from the water. The banks are so steep, rough and slippery, that at times it is necessary to cli $\mathrm{mb}$ them on foot holding to a rope stretched from the top. We got over without this and stopped on the opposite bank, with the decision to pass the night there. The citizens who accompanied us and were behind, killed a bear which they ran up a tree. They brought us one of his paws and it did not appear to have been a very large one. We are and rested a little while. The Commanding General seeing the rain continuing, and the discomfort of spending the night in the tents, . . . and the mission of the Espada not being far, it was decided to go on to it. Anyhow it was necessary to carry the herd of horses there because there was no pasturage where we were, and no watering places in the river. 
In his History of Texas, 1673-1779, Morfi (1935) wrote the following about the area:

The Medina runs twenty-seven leagues from its source before it joins the San Antonio.... [It] forms the dividing line between the provinces of Coahuila and Texas.... Its bed is very deep as the result of the violent and frequent torrents that flow into it during the rainy season and the soft nature of the soil. In time of drought, the stream becomes intermittent, but there are always large pools or lakes where the traveler can provide himself with water and fish.

Morfi further described the ranches:

The ranches are of such little consideration and so miserable, that all the way to Santa Cruz and the Arroyo of the Civolo [sic] along the banks of the San Antonio river, that I would not mention them if I could disregard the one man who inhabits this very fertile region of this unfortunate province. The ranch called Chayopa [sic] contains only eight persons; Pataguilla, three; Cabras, 26; San Francisco, 17; Mora, 26; Las Mulas, 5; and in a11 they maintain 85 souls, who live in such dread and imminent risk of loss of 1 ife, even within their miserable huts, that not a single one of these ranches deserves the name of 'establishment'. . . . they [the ranchers] only aspire to independence... and they call themselves proprietors of extensive possessions from none of which they receive any benefit; this is their character, this is their passion; and in order to indulge it, they disregard all danger.

Lastly, al1 the souls which on our part populate such a rich and vast province are to be found in one villa, two presidios, one detachment, six ranchos, seven missions and dispersed Bucare1i... (Chabot 1932:67).

Morfi visited the area during the time that the majority of the citizens had abandoned their ranchos due to Indian raids; a much greater number of ranches had existed prior to 1765, so Morfi's history of these ranches at the time is very incomplete in regard to actual 1 and ownership. Morfi reported a population of 133 persons, representing 40 families, in 1778 (Chabot 1936:68). The 1783 census reported 96 persons, and in 1792, a total of 97 inhabitants were counted, including 32 Spaniards, 38 Indians, and 7 mulattoes, with 22 of these being farmers and/or ranchers, two builders, one artisan, two day laborers, and one religious person (ibid.). The decrease in population between the years 1778 and 1783 may be due to the severe smal7pox and measles epidemic in 1777 and 1778 which decimated the native populations and the residents of San Antonio de Béjar.

Teodoro de Croix, appointed commandant general of the province in 1778, made an attempt to correct the problems faced by the province--particularly those between missions and the secular landowners. He decreed that all wild cattle and horses were the property of the crown, and those taking or branding them 
must pay a tax for each one claimed. A 7 icense must first be obtained before exporting cattle, and the governor was empowered to grant 1 icenses. Also, round-up information would be required to be kept (Myres 1969:36-37). Domingo Cabe110, governor of Texas, issued a number of regulations concerning the rounding up, branding, and sale of stray cattle (ibid.:37).

These measures were intended to neutralize and balance the mission interests versus secular ranching interests, but rather the measures actually were a lethal blow to the missions, all of which were already in dire economic circumstances. The Bexar Archives contain a tremendous amount of information concerning the obtaining of 1 icenses and the round-up and branding of the wild stock; all of which clearly shows the dominance of the private ranches over the mission ranches (BAT Vol. 68). By 1778, the names of Jose Peres Casanova (José Antonio Peres or Pérez), Ygnacio Pérez, and Juan Manuel Ruíz, appear on the branding 1 ists and round-up 1 ists (BAT Vol. 68:63; Weddle and Thon off 1976:149).

The economy of the area was stimulated by the American Revolution in 1776 when great numbers of beeves were driven east to Louisiana to help feed the troops of Bernardo Gálvez, who had been commissioned by King Carlos III of Spain to fight the British along the Gulf coast. During the years 1779-1781, over 13,000 head of Texas cattle were rounded up on the ranches between San Antonio and La Bahía and escorted to Louisiana by soldiers from Béxar, La Bahia, and El Fuerte del Cíbolo (Weddle and Thonoff 1976:1-184).

By 1793, the decline of the status of the missions politically, economically, and religiously brought about the secularization of the missions. Mission lands were granted to the Indian converts, given to the former settlers of Los Adaes, or became the private property of individuals who had either already established powerful ranching dynasties or would as a result of the grants. By 1795, according to a census that year, 69 heads of San Antonio families made their living by ranching (Faulk 1964:261-263).

The opening of the 19th century saw the purchase of Louisiana from France by the United States and the formal establishment of the neutral ground between Louisiana and Texas which became a lawless no-man's 1 and. The Louisiana Purchase greatly increased American interest in Texas, and Spanish fear of the plans of the Americans was not wholly unfounded. Governor Antonio Cordero and Governor Simón de Herrera of Nueva Santander crossed the Sabine River and reoccupied the old Presidio of Los Adaes (Ashford 1971:193-194). Philip Nolan, with his force of about 20 men, entered Texas for the stated purpose of capturing wild horses, but the Spanish officials were suspicious of Nolan's intentions, and he was killed. Freebooters, privateers (such as Jean Lafitte) and filibusters abounded in Texas during the first two decades of the century. At San Antonio de Bexar, Zebulon Pike related that "2,000 souls resided in miserable mud-walled houses, covered with thatched grass roofs (Ashford 1971:197).

In 1810, growing discontent with Spanish rule in the provinces of New Spain culminated in a revolt led by Father Miguel Hidalgo in Mexico which was intended to transfer power from the native-born Spaniards (peninsulars) to the criollos. José Bernardo Gutiérrez de Lara, a Mexican adherent of Father Hidalgo, spread the revolution to the northern provinces. In San Antonio, 
Governor Manuel María de Salcedo called upon the citizens of Béxar to pledge their loyalty (Ashford 1971:202). On January 2, 1811, Juan Bautista de 1as Casas, the retired captain of the militia, overthrew the Loyalist government in San Antonio and proclaimed himself governor of the Free and Independent State of Texas. The Casas Rebellion resulted in the arrest and imprisonment of Governor Salcedo and Commandant Simon Herrera, the dissolution of the existing cabildo, the organization of a new council, and the sending of emissaries to carry the revolution to La Bahia and Nacogdoches (ibid.:202204).

In response to the Casas Rebellion, a group of Loyalists led by Francisco Ruiz, Ygnacio Pérez, and others recruited Father Juan Manuel Zambrano to overthrow the Casas government (DRT Bacarisse File). The participants stated that the countercoup was not an act against the Revolution but against the abuses of Casas. A new ruling junta was formed and included Ygnacio Pérez (Castañeda 1938b:34).

Emissaries were sent by the junta to Mexico, and here they met Lt. Colonel Ygnacio Elizondo, Governor Salcedo, and General Herrera, who were rallying supporters for the king. With Elizondo, Salcedo set a trap for the rebels and murdered Hidalgo, Allende, and Jimenez, three of the most important figures of the Revolution (Ashford 1971:204-205). Salcedo and Herrera returned to San Antonio and assumed their former command.

In 1812, Augustus Magee, a United States Army officer in Louisiana, joined with Bernardo Gutiérrez and formed the "Republican Army of the North." The Magee-Gutiérrez expedition marched west into Texas in 1812-1813 and captured Nacogdoches and La Bahía. Magee mysteriously died at La Bahía, and Colonel Samuel Kemper replaced Magee. The Republican army then moved toward San Antonio, encountering 1200 Loyalists under the command of General Simon Herrera, in the Battle of Rosillo Creek (southeast of San Antonio) where the Loyalist force was routed. The Republicans proceeded on into San Antonio, where Salcedo surrendered the town to them; Salcedo and Herrera were taken prisoner, and approximately 800 Loyalists joined the rebels. At this point, one of Gutiérrez' men, Capitán Delgado, and Gutiérrez entered into a plot to kill the captured governor and his officers. The Republicans escorted the Loyalists outside of Bexar, under pretext of sending them to New Orleans to be paroled, and Delgado proceeded to cut their throats. The murders were quickly discovered and so disgusted many of the American soldiers that they left and returned to the United States (Fehrenbach 1968:122-125). Delgado and Gutiérrez were both tried and found guilty of the murders, and Gutierrez was deposed of his position as commander-in-chief of the "Republican Army of the North" and as provisional governor of Texas. He was succeeded by General José Alvarez de Toledo.

Henry Perry, who had assumed Kemper's command, and Colonel Ignacio Elizondo met in a second battle at Alazan Creek where the Loyalists were soundly defeated (Ashford 1971:212). This battle was to have serious ramifications for the Republicans because it so infuriated Loyalist General Joaquin Arredondo that he himself led the last and final conflict with the Republican Army of the North at the Battle of the Medina on August 18, 1813. 
After assembling his troops in Laredo, Arredondo marched out and was joined by Colonel Ignacio Elizondo at the place called Cañada de Caballos. The two armies, consisting of infantry and cavalry, made a combined total of 1830 men with 635 infantry and 1195 cavalry. The march was continued from that point, and Arredondo reported that on August 16 he camped a league and a half this side of a place called Rancherias (possibly Rancherias Creek located in present-day Atascosa County or the Lipan Apache location known to the Spanish as Rancherias). On August 18, he directed his course:

toward the River Medina, proposing to change my course in order to cross it by a different road from the direct one as I remembered that this was a canon which would give an advantage to the enemy if they wished to form an ambush in the wooded space covering it . . . (Hatcher 1908:222).

Colonel Ignacio Elizondo and Ygnacio Pérez, with 180 cavalrymen, were then sent forward to scout out the enemy (Republicans):

but not to engage them in battle unless he thought himself strong enough to inflict an exemplary punishment upon them; and, if not, to keep up a slow fire while retreating to give me prompt information that I might make my plans. I informed him of the place at which I had arranged to cross the Medina River, and of the road, which was a shortcut [author's emphasis], so that he might follow it in his retreat until he joined me. ... At a short distance from the above-mentioned Medina River, Alferes Don Francisco Lopez was separated from the main party. He was seen by the enemy, and they instantly fired a volley at him. . . In view of this occurrence, Elizondo instantly ... commanded that the line be extended and that answer be made with a rapid and we11-directed fire (Hatcher 1908:223).

At this point the Republicans charged bravely, and Elizondo began his retreat. Arredondo sent 150 cavalrymen and two 1-1/2-pound cannons under Lt. Colonel Juan Manuel Zambrano up to Elizondo. The Republican army seeing Zambrano, believed it to be the entire Spanish army, therefore continuing the charge in a11 earnestness while Arrendondo, upon hearing of the hasty retreat of Elizondo, formed the line of battle. The battle waged for more than two hours with no decisive result by either side when General Toledo ordered Colonel Kemper and Colonel Miguel Menchaca to take the right and left flanks and the rear. Arredondo countered the move by sending out advance guards and a force to the rear meeting the fire of the enemy on all four sides. After four hours of fighting, the Loyalists decimated the Republicans, even pursuing those who had fled "putting to death as many as they [the cavalry] found on the way, penetrating as far as the Medina River" (ibid.:225). Arredondo reported that more than 600 bodies lay on the battlefield with another "100 prisoners who are now being shot" (Biesele, Hackett, and Webb 1939a:257).

Betran's narration of the battle provided information about the Republican forces that added to a more complete analysis. He related that the army under Toledo consisted of 800 Americans (infantry) under the command of 
Colonel Kemper and 7000 Mexicans (cavalry--including Indian compatriots) under the command of Colonel Menchaca.

On August 17, General Toledo marched out of Bexar to meet the enemy; upon reaching the Medina River, he bivouaced on the north bank in an advantageous position. In order to facilitate the cavalry, three fords were prepared at convenient distances, with the Americans under Kemper and Taylor placed on the right, the artillery in the center, and Menchaca, with the Mexicans on the 1eft. The next morning the enemy advanced within gunshot and opened fire, with the Republicans returning fire. Elizondo now began his retreat-Toledo ordered Colonel Menchaca to take "five of his companies, cross over the creek, Medina, and maneuver about the enemy so as to locate his stronghold" (Hunter 1925:12). The rest of the narrative of Betrán follows the events as reported by Arredondo.

Within and/or adjacent to the study area, the five crossings which would have been utilized by either the Republicans or the Loyalists were the following: the Laredo Road Crossing (present-day Losoya); the Pérez Road/Crossing (41 BX 682), just west ca. $50 \mathrm{~m}$ from present-day Applewhite Crossing; Talon Crossing (41 BX 680, just west of present-day Highway 16,; and Paso de 1 as Garza's Crossing (41 BX 697). We know that Arredondo was traveling the Laredo Road because his "men [were] observed on the Laredo Road about 50 miles from San Antonio" (Walker 1962:457-479).

Arredondo states that he informed Elizondo of the place at which he had arranged to cross the Medina River and of the road which was a shortcut--no doubt either the Presidio Road or Pérez's Road (1eading from Bexar to the ranch of Ygnacio Pérez). Henry Bullard, an aide-de-camp to General Toledo, related that the Americans had received rumors of Arredondo's plan to concentrate his forces at the junction of the road from San Antonio with the roads to Laredo and Paso del Norte (ibid.:474). This information supports the deduction that indeed it was one of the above two roads which were planned to be used by Arredondo.

The shortest route into Bexar would have been the Presidio Road or the Pérez Road; however, with Ygnacio Pérez owning the land on both sides of the Pérez Crossing (41 BX 682) as well as being a member of Arredondo's forces it is believed that Arredondo planned to use that crossing. The presence of the one ounce canister shot (41 BX 520) at the confluence of E7m Creek and the Medina River (Pérez Crossing [41 BX 682]) and archival research confirm that indeed the initial encounter of Elizondo's cavalry with Toledo's forces occurred on the Medina River with the main brunt of the battle being fought somewhere south-southeast of the study area. 6 Further evidence of the battle is a late 18th-early 19th-century stirrup found by a landowner in the vicinity of the postulated route of "Pérez's Road" due south of Pérez's Crossing (Applewhite Crossing) on the Medina River.

After the battle, the cavalry of Elizondo, along with Pérez, was ordered to pursue the escaping Republicans into San Antonio and as far as Nacogdoches (Bacarisse 1955). Arredondo, after entering Béxar, rounded up all the men, women, and children who were rebels or suspected rebels and proceeded to execute or imprison those who had not managed to escape. The count of persons executed or exiled was approximate1y 1000--one-third of the Texas 
Spanish population (Fehrenbach 1968:130). The property of the rebels was confiscated by Arredondo and generally ended up in the hands of loyal Spanish officers. One of the exiled rebels was Colonel Francisco Ruiz who escaped to a Comanche rancheria where he lived for several years and won reputation as an extraordinary man (Berlandier 1969:63). On a "List of Insurgents for the Month of March, 1814," signed by Jose Ygnacio Perez (the son of the lieutenant colonel) appears to be the name of Ruiz: "Tio Ruiz, su hijo y su familia de la Comsecion"--Uncle Ruiz, his son, and his family (BCA List of Insurgents). The name of Francisco Sosa, alias Rolen, al so appears on the list (ibid.). When a proclamation of amnesty was issued by Arredondo in October 1813, Francisco Ruiz, along with others, was excepted from this amnesty (Hatcher 1927:343). The divisiveness brought about by the battle is best reflected by Ygnacio Pérez, the Loyalist, and Francisco Ruiz, Republican--the two men were brothers-in-law and both at one time or another held extensive land holdings in the area.

Conditions after the purge of Arredondo were desolate everywhere. An almost total abandonment of San Antonio de Béxar was precipitated (either by death or exile), and a crushing blow was dealt to area stock raising. Pérez himself testified that his ranch was temporarily abandoned after the battle along with others (Castañeda 1950:121).

The Tetters written by Governor Antonio Martinez during the years following the battle illustrate the pitiful conditions around San Antonio de Bexar-food shortages (including beef and produce), iron and steel shortages, powder shortages, epidemics (smallpox), fires, etc. Only Ygnacio Pérez, according to Martinez, was we11-off (Taylor 1957:97).

In the waning years of Spanish domination, one last filibustering episode was to take place--Dr. James Long's Expedition. Long, entering Nacogdoches in 1819, declared Texas an independent republic. His forces were defeated by Lt. Colonel Ygnacio Pérez, and again in 1821, Long's forces were defeated at La Bahia by Perez (Ashford 1971:227-229). This episode resulted in much of the remaining farmlands around Béxar going to waste. Fehrenbach (1968) wrote that a "traveler crossing Spanish Texas faced risk of starvation and for some years even at Béxar food was scarce."

In 1820, when Moses Austin secured permission to bring in American colonists to Texas, Spanish power in the provinces was in the throes of death. Only the belief that American colonists might provide a buffer zone between the Spanish settlements and the Indians and prohibit future filibusters persuaded the Spanish authorities to even consider allowing American colonists into Texas.

In 1821, revolution broke out in Spain when Spanish 1iberals came briefly to power. Thus began a church-state struggle that eventually reached Mexico, where the idea of revolution had never really died (Fehrenbach 1968:153-154). In 1821, Mexico won her independence from Spain and, 1ocally, Americans began arriving in San Antonio de Béxar. 


\section{MEXICAN STATEHOOD}

In the period following Mexico's independence from Spain, conditions in the San Antonio de Béxar region gradually improved. Locally, the Tejano population began to expand farming and ranching operations during a lult in Comanche and Lipan Apache raids (Weber 1982:85). This 1 ul1 was a result of the peace treaties negotiated by Jose Francisco Ruiz between the Comanche and Lipan Apache and Emperor Agustîn de Iturbide in 1822 and between Waco and Tahuacana Indians and General Anastasio Bustamante in 1827 (McLean 1974:3335). Berlandier (1969:8) wrote about the Wacos and Tahuacanos:

These Indians visited the town [San Antonio de Béxar] to trade buffalo hides and bear grease for guns, ammunition and other goods manufactured by whites.

Families such as the Perez's, the Navarro's, the de 1a Garza's, the Rodriquez's, and the Hernandez's (see Fig. 15) continued and profited by the decrease in Indian hostilities and the forfeiture of state taxes, church taxes, and custom duties. Ruiz, notably absent, was living in exile in Natchitoches, Louisiana. It was there that Gaspar López, Commandant General of the Eastern Interior Provinces, offered him a full pardon in return for utilizing his influence with the Comanche and Lipan Apache (McLean 1974:33).

Land 1 aws, which had been formulated by the Spanish, remained in effect, al though the grants were made by Mexican states rather than the central government (Ashford 1971:241). Conditions established by the colonization law, such as establishing permanent landmarks, the utilization of the lands, and the payment of a nominal government tax within six years, were inserted in the decree and became a part of the title (ibid.).

During the years 1823-1824, en lightened immigration laws passed by the Mexican government allowed authorized empresarios to offer heads of families approximately 4605 acres per family to settle Texas (Fehrenbach 1968:146). The General Colonization Law of 1824 had four key provisions:

Public lands were remanded to the Mexican states for administration. State land codes must conform to the Constitution. No person could acquire more than 11 leagues $(48,708$ acres) for colonization. No foreigner was to be granted 1and; immigrants must become citizens (Fehrenbach 1968:146).

The Republic Constitution of 1824 made the former Spanish provinces into "sovereign" states; Coahuila and Texas were incorporated into one state, with its capital at Salti110. When its population grew to a sufficient number, Texas could then become its own state. Further immigration laws were passed by the state, and the year 1825 saw an explosion in empresarios and immigration into Texas, including San Antonio (ibid.:146-147).

The McMullen and McGloin empresario contract took in a part of the study area along the Medina River:

Leaving the ten litoral leagues along the coast of the Mexican Gulf as provided by the law of August 18, 1824, the grant sha11 begin at 
a point on the left bank of the Nueces, ten leagues from the coast, thence the line shall follow the said river to a point ten leagues from the presidio of Bahia del Espiritu Santo, thence a straight line shall be drawn to the mouth of the Medina where it enters the San Antonio, thence the 7 ine shall follow the right bank of the said river to its point of intersection with the 0ld Road between Bexar and Presidio del Rio Grande [Upper Presidio], thence along the said road to the Nueces, thence down the said river along the left bank to the point of departure (Castañeda 1971:315).

Fehrenbach (1968:150) wrote that "only eighty-four titles were issued, and the colony did not succeed, but the Irish settlers grimly stuck." The town of the colonists was San Patricio, and many of the descendants of the original settlers 1 ive in this area today; however, none of the colonists' titles were to 1 and on the Medina River, although the official grant encompassed this area.

One of the effects of the increased immigration into the region was the opening of new roads which often followed or paralleled the old original Spanish caminos. These networks would later form the basis of early communities in the area as well as be the main avenue of trade.

The two factors mentioned, separate statehood versus joint statehood and the explosion of Anglo immigrants into the study area with their growing political power, would culminate in the 1830 s with the population of Bexar split over the issue of separate statehood versus a joint Coahuila and Texas.

Changing social, political, and economic developments during this time led men Tike Ygnacio Pérez, Francisco Ricardo Hernandez, José Angél Navarro, and José Antonio de la Garza, to apply for and obtain legitimate titles to their property from the State of Coahuila and Texas. Some of these men would be able to retain their holdings while others (such as Francisco Hernandez) would eventually sell out to Anglo-American speculators in the closing months of the Mexican conflict (DRT Juan Nepomenco Seguin Deed 1836).

Local government under the State of Coahuila and Texas consisted of a municipality controlled by the principal major town and often divided into distritos, with an ayuntamiento, the alcalde, the regidores, the sindico, and the alguacil (Fehrenbach 1968:144; also see Appendix II, this report). offices were generally held and controlled by a complex maze of interrelated family connections. Political events in San Antonio de Béxar during the 1830s, however, often found members of the same family on opposing sides of the Liberal versus Conservative cause (e.g., Pérez and Ruíz).

Slavery, which had been legalized in Texas in 1828 , contributed to the increasingly complex sociocultural-political climate of San Antonio de Bexar as well as other areas of the state. The question of slavery was to be politically controversial for the four decades between 1820-1860.

In 1828-1929, General Mier y Terán was commissioned to determine the boundary between Mexico and the United States in the Sabine River-Red River region while the Comision de Limites' duties were defined much more explicitly concerning observations on the social, political, and economic realities of 
Texas. Accompanying the expedition was the French scientist-naturalist Jean Louis Berlandier who kept a diary and detailed notes on the expedition. Ewers, in writing his introduction to Berlandier's (1969) The Indians of Texas in 1830, wrote:

On February 20, the explorers left Laredo bound for the old capital of the Province of Texas, San Fernando de Bexar. They traveled the 01d Bexar Road, long used by soldiers and rumbling supply carts from distant Mexico City. . . it required ten days of hard travel over a rough road and through desolate and uninhabited country. . . In 1828, San Antonio had a population less than 1,500 .

In Berlandier's (1826-1834) Journey to Mexico the following was related about the area:

February 28. Very early in the morning we started off to reach the Medina River... about four leagues from Rancheria in the midst of the forest of oaks of which we have spoken, we arrived at the field of the battle of Medina 7 ... On the other side of the forest we transversed is the Medina River, on the northern bank of which we established our camp amid a lovely prairie... The Medina is very pretty: its banks are covered with a dense shrubbery and its waters are crystalline. Some leagues farther to the east this river joins the San Antonio River.... Often the Medina resembles an arroyo and can be crossed dry-shod. At other times, when it has rained for a long time in the west, the flood crests are so considerable that no one would dare to cross it.

General Mier y Terán wrote a most disturbing report to the government after his expedition which identified problems in Mexican Texas:

... the Mexican presence "disappeared" beyond San Antonio. The ratio of Mexicans to Norteamericanos was 1 to 10, and Mexicans were becoming the very lowest class. The foreign immigrants had their own schools (the Mexicans had none), and their older children were sent back to the United States to be educated (Fehrenbach 1968:164).

Mier y Terán made several recommendations which reflected both the Mexican fear and helplessness concerning the state:

The government should send ethnic Mexican colonists to Texas; encourage Swiss and Germans to colonize; encourage trade between Texas and the Gulf coast of Mexico; garrison more troops in Texas, using convict conscriptees who after their term of service might be forced to settle in the province (ibid.:165).

Terán's proposals were presented to the Mexican Congress which resulted in the Decree of April 6, 1830. Changes in Mexican policy which would eventually result in increasing discontent, violence, and resistance to the political structure included the introduction of Mexican convicts in Texas, the prohibition of further colonization of Texas by Anglo-American settlers, 
the prohibited importation of slaves, the introduction of non-Englishspeaking settlers, collected customs and supervised trade, centralization of the government, and the dispatch of spies to the region (Fehrenbach 1968:148165).

Political events in Mexico during the years of 1828 and 1831 left the Constitution of 1824 hanging in shreds (ibid.:169). Military rule was imposed by garrisons; Texas was placed under the command of Don Manuel Mier y Terán with Colonel Don José de los Piedras at Nacogdoches, Captain Juan Bradburn at Anáhuac, and Colonel Don Domingo de Ugartechea at Velasco. Men were stationed at La Bahia (now renamed Goliad), and the standing troops at Béxar were increased (Fehrenbach 1968:170). A series of engagements now followed which served as a prelude for the following fight.

In the years 1832 through 1835, conventions assembled at San Felipe adopted resolutions and framed a proposed state constitution. Sixteen Anglo-Texas districts responded. At Béxar, the ayuntamiento, although wholly Mexican, supported the movement for separate statehood (Fehrenbach 1968:182). Again, the ensuing conflict would divide families--this time, Jose Ygnacio Pérez and his uncle José Francisco Ruiz. After a last great surge of immigration in 1833 and 1834, when Anglo-American immigration was resumed by the Mexican government, conditions further deteriorated in the province.

In 1 ate 1835, word was received that General Martin Perfecto de Cós had crossed the Rio Grande bound for San Antonio. An ensuing call for arms for all able-bodied men was issued by Stephen F. Austin. In San Antonio, Captain Juan Seguin formed a group of volunteers; among them was Blas Herrera (see 41 BX 670). Engagements now ensued at Gonzales and Goliad. Cós arrived in San Antonio on October 9 with 800 soldiers and took over the city. The Texan army camped outside of town (Fehrenbach 1968:195).

On November 28, an engagement known as the Grass Fight took place (possibly in the study area) between the Mexicans and the Texans. William A. Taylor, a member of the Texas army, related the following about the battle:

Some days previously to this fight, it was rumored in camp that there was a quantity of silver coming in from Mexico, on packmules, to General Cos, to pay off his soldiers with. Our spies kept a good lookout in that direction, in order to give the news as soon as the convoy should be discovered coming, so that we might intercept the treasure before it should get inside of San Antonio. On the morning of the 28th, the day of the skirmish, Colonel Bowie was out in the direction of the Medina [ca. 10-12 miles from Bexar] with a company, and discovered some mules coming with packs, and, supposing they were the expected mule-train with silver, he at once sent a runner for additional troops. The camp was then above town, at the old mill on the San Antonio river. Colonel Burleson immediately started, with the required reinforcements, to join Colonel Bowie; but before we could meet Bowie, the latter, fearing the train would escape, made the attack with the few troops he had. About the time of Burleson's arrival, Bowie had fallen back to a ditch or ravine near by [sic] as a better position; and as soon as Burleson came up, they made a united attack on the Mexicans, who 
fell back to another ravine, but were soon followed and soon routed, when they fled. And thus ended the celebrated Grass Fight. The Mexicans left their packs as they fled, but upon examination they were found to contain nothing but grass, which they had gone out the night before and cut for their horses in the fort, and they were now bringing it in. This circumstance was, of course, quite a disappointment, and hence this little skirmish was called 'The Grass Fight.' We lost one man (missing) and had two wounded in the fight. The Mexican loss is not known. If they had any killed or wounded, they took them away (Day 1967:534).

The success of the Texan army at the "Grass Fight" did not improve the morale of the soldiers who had grown tired and weary of the siege--they had little artillery, no regular food supply, and insufficient clothing (Fehrenbach 1968:196). By December, most of the Texas militia had returned home; the whole army, including Americans, was approximately 300-500 men (ibid.:197).

A consultation was held by the officers in which it was agreed to abandon the siege; however, when a captured Mexican officer related that Cós' army could be easily taken, Ben Milam assembled the troops, along with Blas Herrera and Juan Seguin's company, and stormed Béxar on December 5. Cós was defeated and signed a surrender--he was allowed to march out of town toward Monclova (Fehrenbach 1968:198).

Two engagements followed the surrender of Cós at San Antonio: the Matamoros Expedition which was led by Dr. James Grant and Colonel Frank Johnson and the Goliad Massacre under Colonel James W. Fannin, Jr.

Meanwhile, General Santa Anna, now president of Mexico, was enraged that his brother-in-1aw Cos had surrendered San Antonio, and made plans to squelch once and for all the rebellious Texans. He arrived in Saltillo and formulated his plans for attack. He reached Laredo in mid-February 1836-here he was seen by Blas Herrera, who had been sent as a scout to the Rio Grande by Juan Seguin and subsequently warned Travis of Santa Anna's approach (Williams 1933:10-11; see 41 BX 670). He continued his march at an alarming rate. José Enrique de 1 a Peña, a member of the Mexican army, recorded the following in his diary:

... between five and six in the afternoon we crossed the Medina River, a little stream whose banks were rich with pecan trees. This was the place where General Arredondo had fought against the colonists who had rebelled during the Spanish regime. Here we spent the night, having received orders from the commander in chief that we could rest and arrive in Bejar the next day. This day we traveled between twenty-eight and thirty miles, and that night a captain of the grenadiers from Aldama died of a pain, no help being available for him. On the 3 rd of March between eight and nine in the morning, after the troops had put on their dress uniforms, we marched toward Bejar entering between four and five in the afternoon within sight of the enemy, who observed us from inside their fortifications (Perry 1975:36-37). 
Juan Nepomuceno Almonte, also a member of the Mexican forces, wrote the following in his journal:

Feb.--Sunday 21st--At 7:30 A.M. left Arroyo Hondo--weather cloudy-slight showers--not cold--wind south east. To Francisco Perez 4 leagues, (a stream of water very distant, but not on the road) To Arroyo de 1 Chacon, good water, 3 leagues. To the river Medina 2 leagues; all good road, but broken by large hills. At quarter before 2 o'clock the President arrived. The day completely overcast; the whole division at $50^{\prime} c l o c k$, when it commenced raining heavily--all wet but baggage dry, at $120^{\prime}$ clock at night it cleared some.

Monday, 22nd--Commenced cloudy, but cleared at $100^{\prime} c 7$ ock. The troops cleared their arms and dryed [sic] their clothes; no desertions whatever or sickness. We passed the day at Medina to rest the troops. Two men from the Ranchos near Bexar arrived, one menchaca [Menchaca] and another; killed a beef; various other persons came in, reviewed the troops. Sr. Ramirez y Sermer [Sesma], marched to cut off he retreat of the enemy with _dragoons It was believed the enemy discovered our movements.

Tuesday, 23--At 7:30 A. M. the army was put in march--To the Potranca 1 1/2 1eagues--To the Creek of Leon or De1 Medio, $31 / 2$ 1eagues--To Bexar 3 leagues, in all 8 1eagues (Asbury 1944).

Walter Lord (1961) wrote that Santa Anna reached the banks of the Medina River at 1:45 P.M. on February 21. Here they joined General Sesma's troops, who had arrived the previous night, and received a delegation from San Antonio, who brought word that the Alamo men would be attending a fandango that night and could easily be taken. A plan was initiated to capture the men but a blinding storm from the north hit. Lord (1961) further wrote:

The pretty green Medina, so easy to ford a few hours ago was now a deep, foaming torrent. One glance convinced them it just couldn't be crossed.

Archival-historical research and ethnological investigation of the route that General Santa Anna's army took on his march to Bexar yielded two potential camps-crossings on the Medina River within the study area: Tálon Crossing (or Palo Alto Road) in the vicinity of modern-day Highway 16 and the Laredo Road (01d Somerset Road at Paso de las Garza's Crossing, also known as Santa Anna's Trail). It is interesting to note that $A 1$ monte reached the Medina River on February 21, 1836, and rode into Béxar on February 23, while Peña did not reach the Medina River until March 2 and did not enter Béxar until March 3, three days before the battle. Lord (1961) reported that Santa Anna reached the Medina River on February 21, where he joined General Sesma's troops. The evidence is clear: multiple camps were established on the Medina River, and it is more than probable that more than one crossing was utilized by the Mexican army--this would account for the somewhat conflicting archival and ethnological research results. The latter two crossings are both in the study area. 8 
From the Medina River, Santa Anna's army marched into Béxar and Taid siege to the Alamo which was under the command of Travis. For a brief time Travis and Bowie shared the command, and at one time Bowie became so dissentious that Travis and his command moved to the Medina River and camped (possibly in the study area; Dobie 1957).

Francisco Antonio Ruiz, alcalde pro tem, was held under house arrest by Santa Anna (Santos 1966:10). On March 5, Santa Anna ordered Don Ramón Músquiz (political chief), Don Refugio de la Garza (curate), and others to assemble at a temporary fortification erected at Potrero Street to attend to the wounded once the storming of the Alamo commenced.

While the siege of the Alamo was taking place, elected representatives from the colonies were assembled at Washington-on-the Brazos. Here on March 2, 1836, the Texas Declaration of Independence was signed. José Francisco Ruiz and Juan Antonio Navarro, representatives from Bexar, were the two native Texans to sign the declaration (Santos 1966:9). Escorting Ruíz and Jose Antonio Navarro to the Convention, on the orders of Colonel Travis, were Blas Herrera, Francisco Gómez, Eusabio Garión, and Antonio Coe (Coc?; BCA Ruíz Files, Pension claim).

The Texas Constitution, which was adopted on March 16, included these points:

. . Texas was a unitary, not a federal Republic;. . . the President served three years and could not succeed himself, ... nor lead an army in the field; no clergyman, of any faith, might hold an office; and each family head in Texas was entitled to a league and one labor of 1 and. Slavery was legalized, but slaverunning was equated with piracy. . (Fehrenbach 1968:222-223).

On Apri1 21, 1836, Santa Anna's forces were defeated by the Texans at the Battle of San Jacinto. With the victory came a new era in Texas history.

\section{TEXAS REPUBLIC}

The Republic of Texas in 1836 was a frontier community with approximately 40,000 persons, most of whom were subsistence farmers. There was no money economy, nor any money. Industries did not exist, roads were mere trails, and organized schools were nonexistent (Fehrenbach 1968:247-248). Government was loosely organized with the old Mexican system of municipalities, ayuntamientos, alcaldes, regidores and alguacils being replaced with counties, city councils, mayors, aldermen, sheriffs, and justices of the peace.

Locally, the population remained predominantly Mexican; however, a new sociocultural element was quickly injected into the area. The fledgling Republic had no money but it did have a wealth of 1 and--land which it offered to settlers and soldiers in the form of certificates (headrights), bounty grants, donation grants, pre-emption grants, and script (Table 7). While many of these grants were made to Mexican citizens, most of them ended up in the hands of Anglo-Americans, sometimes by grant but most often by purchase from Mexicans who were unfamiliar with the new laws and their rights. 0ften 
TABLE 7. IDENTIFIED HEADRIGHTS, BOUNTY, AND DONATION GRANTS FOR PROPERTIES WITHIN THE PROPOSED RESERVOIR AREA

\begin{tabular}{|c|c|c|c|}
\hline $\begin{array}{l}\text { Survey } \\
\text { Number }\end{array}$ & $\begin{array}{l}\text { Headright, Bounty, } \\
\text { or Donation Grant }\end{array}$ & Date & Assignee \\
\hline 35 & $\begin{array}{l}\text { Bernardino Ruiz } \\
\text { I league, I labor }\end{array}$ & March $6,1838 * *$ & None \\
\hline 36 & $\begin{array}{l}\text { Bruno Martinez } \\
1 / 3 \text { Teague }\end{array}$ & June $19,1837^{* *}$ & $\begin{array}{l}\text { John W. Smith } \\
\text { John R. Cunningham }\end{array}$ \\
\hline 37 & $\begin{array}{l}\text { Henry Peace } \\
\text { I league, I labor }\end{array}$ & August 4,1838 & None \\
\hline 39 & $\begin{array}{l}\text { Christopher A. Yoacum } \\
1 / 3 \text { league }\end{array}$ & Ju7y $4,1838 *$ & None \\
\hline 40 & $\begin{array}{l}\text { Jose Maria Sais } \\
\text { l/3 Teague }\end{array}$ & April 23, 1837* & $\begin{array}{l}\text { William H. Steele } \\
\text { Ludovic Colquhoun }\end{array}$ \\
\hline 45 & Joseph Jordan & Cancelled & None \\
\hline 46 & $\begin{array}{l}\text { Cruz Landin } \\
\text { I league, I Tabor }\end{array}$ & August $10,1838 *$ & Luciano Navarro \\
\hline 48 & $\begin{array}{l}\text { Francisco Rolen } \\
\text { I league, I labor }\end{array}$ & September $1,1837^{* *}$ & $\begin{array}{l}\text { Enoch Jones } \\
\text { John W. Smith }\end{array}$ \\
\hline 49 & $\begin{array}{l}\text { Rufino Rodriquez } \\
\text { I league, I labor }\end{array}$ & November $3,1837^{* *}$ & Samuel McCullough \\
\hline 50 & $\begin{array}{l}\text { Nicholas Mosby Dawson } \\
\text { I/3 Teague }\end{array}$ & $\mathrm{J}$ anuary $30,1838 * *$ & None \\
\hline 1174 & Frank Tin A. Paschal & $\begin{array}{l}\text { patent date } \\
\text { January } 27,1841\end{array}$ & \\
\hline
\end{tabular}

* indicates date survey was completed

* indicates date when headright was issued 
these grants overlapped the old Spanish and Mexican grants which had been held by families for years--such was the case in the study area. Out of the 17 grants in the area up to this time--including Spanish, Mexican, and Republic--only four remained in Mexican hands, and many of the original holdings were greatly reduced (1egal battles over the deposition of these lands would tie up the courts until the 1850s).

Anglo-Americans owning 1 and in the area included Nicholas Dawson, Franklin Paschal, Hiram Thompson, Enoch Jones, Henry Peace, John Smith, John Sutherland, and Stephen Jett (Fig. 16). Samuel McCullough (McCullock), a free Negro, and the man whom Congress recognized as "among the first to shed his blood in the war of independence" was also in the study area (Schoen 1936:27). Mexican families retaining or acquiring land at this time included Ygnacio Pérez (41 BX 274), Luciano Navarro, Bernardino Ruiz, and Francisco Antonio Ruiz (41 BX 344). Bl as Herrera lived on the land of $F$. A. Ruiz, his brother-in-1aw (41 BX 670). For more information on biographical data and land grant information concerning Luciano Navarro, John W. Smith, Henry Peace, Bernardino Ruíz, and Franklin Paschal, see Appendix III.

In the 1830s, Ygnacio Pérez, Mexican Loyalist, owned and/or controlled 17,712 acres in the study area on which he ran horses, 342 head of cattle, and 250 head of sheep (Walsh n.d.). Other members of the family owned and/or controlled another ca. 4000 acres (ibid.). The Navarro brothers, Jose Angel and Luciano, also owned and/or controlled ca. 8856 acres along the Medina River and Leon Creek in or adjacent to the study area where they had ranching operations (BCA Surveyor's Field Notes Vol. Al:12).

On November 23, 1836, President Houston, with an eye on supply for the Texas army, ordered General Houston to send 100 to 200 men "to drive all the stock from the Nueces, Aransas, Medina, and San Antonio Rivers except cattle of any citizen friendly to the cause (Barton 1959). This order, no doubt, had tremendous ramifications for those ranchers on the Medina River (such as the Pérez family) for we know that in December 1836, Ygnacio Pérez left Béxar for the Rio Grande where he remained until 1847 (TGLO Paschal vs. Pérez). Sociocultural as well as political factors also precipitated the move as Pérez testified that "he left fearing he would be killed... and that he would return as soon as he could do so with safety for himself and his family" (TGLO Paul vs. Pérez:339).

Indian problems continued to plague the residents of Béxar, and a new policy of war against the Indians was advocated. Militia companies, regular army forces, and local bands called "ranging companies" were employed in campaigns against the Comanche Indians in the region and the San Antonio area (Fehrenbach 1968:258). Lieutenant Nicholas Dawson of the Texas Rangers (see $41 \mathrm{BX} 520$ ) participated in a number of engagements with the Comanches (Webb 1952:45-46). Pierce (1969) wrote about the ranger camps (possibly located in the study area) of John C. (Jack) Hays:

From base camps on Leon Creek and the Medina River, the rangers went on patrols, several of which were for the purpose of determining whether rumors of an impending Mexican invasion had any foundation in fact. The Comanches were sought out repeatedly by the rangers who thus kept them at a safe distance from the town. 


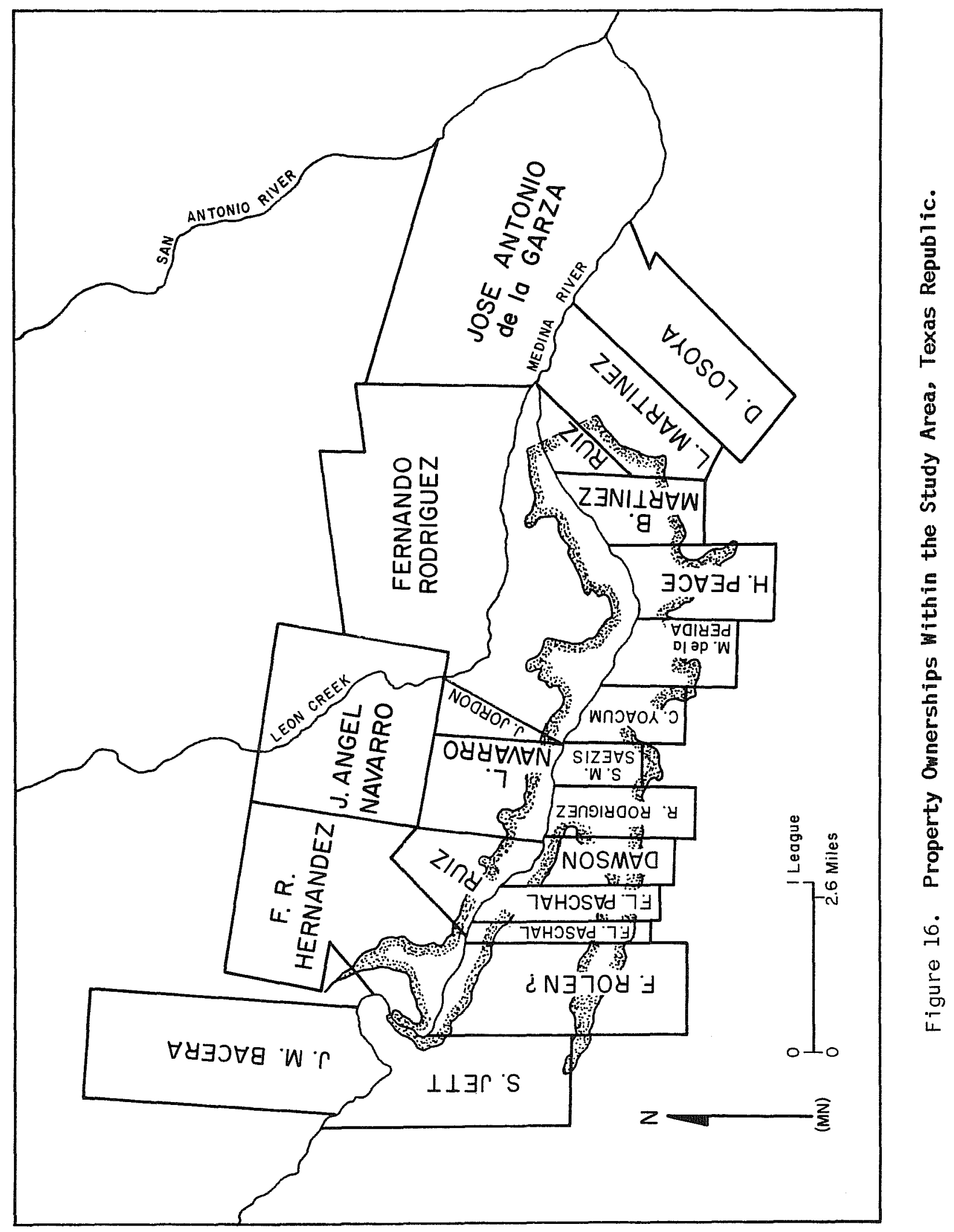


Considerable trade, with resultant transportation networks, was established during the Republic between the Mexican border points and San Antonio. Beans, leather, piloncillo, shoes, and saddles were exchanged in San Antonio for calico, tobacco, American hardware, and other commodities (Biesele, Hackett, and Webb 1939b:98). This trade gave rise to freebooting on the part of the Tawless element, who began to operate in the "no-man's land" between the Nueces River and the Rio Grande.

This element was combated by Texas spy companies and 1ater the Ranger force under the command of such officers as Captain "Deaf" Smith and Captain Jack Hays; at this time they scouted as far south as the Rio Grande. During the early spring of 1837:

'Deaf' Smith, with a spy company of twenty men left his camp on the Medina [possibly located in the study area] near San Antonio with the intention of raising the $f l$ ag of independence on the spire of the church at Laredo. On the 16th of March he arrived at the old Ygnacio ranch. . . the following day.. . he was attacked by a superior force of Mexican cavalry. . . The engagement lasted about forty five minutes, when the Mexicans retreated. . . . Two of the Texans were wounded. . . 'Deaf' Smith and his company returned to San Antonio without entering Laredo (ibid.).

Immigration of large numbers of Southerners (most of whom brought their slaves) into Texas, which had begun in the 1820 s and enormously accelerated prior to and during the Republic, magnified an already complex sociocultural problem. While slavery and slave trading with the United States gained legal sanction under the laws of the Republic, foreign trade was illega1; however, African slave trade continued illegally (Sibley 1968:132-143). Politically, the question of slavery was an influencing factor in the debate over annexation from 1836 to 1845 . Other immigrants from revolution-plagued European countries (particularly Germany) also began to arrive in San Antonio in the 1840s. These pioneer families were the first to settle in the post-SpanishMexican settlement of San Antonio prior to the Civil War.

Events in Mexico and Texas in the years 1837-1839 resulted in increased hostilities between the two entities. The new hard line of Bustamante and Lamar's advocated pressure against the Mexicans contributed to a series of forthcoming engagements.

In 1841, Sam Houston was again elected president. He proceeded to reduce the army to a few companies of Rangers, and the Texas Navy was sold (Fehrenbach 1968:261). In the meantime, Santa Anna, again elected president of Mexico, formulated plans for the reoccupation of Texas. In 1842, he dispatched a force of men under Vásquez across the Rio Grande and easily captured San Antonio, Refugio, and Goliad. Sam Houston proceeded to move the government from Austin to Houston but was prevented from removing the archives in what has come to be called the Archive War. The Mexicans under Vasquez retired back to Mexico but the Texas militia grouped at San Antonio (ibid.)

Santa Anna, again in September 1842, sent General Adrian Woll with 1300 Mexicans into San Antonio. Joseph Eve, Charge d'Affairs to Texas, wrote the following about Woll's Invasion: 
You wi11 have heard before this reaches you that the Mexicans are again in Texas. San Antonio was taken on the 11th of September by 1,300 Mexicans commanded by Gen. Wo11. The District court was in session at the place the Judge and lawyers were made prisoners in the city of Mexico if rumour be true. Among the prisoners Wm. E. Jones the most eloquent man that I have ever heard speak in Texas very popular and a very fine fellow, three other members of Congress are among the prisoners (Nance 1940:504).

Again the Mexicans only remained for several days, then retreated with their prisoners. Two fights ensured between the Texas militia and Wo11: the Battle of the Salado and Dawson's Massacre (see 41 BX 520). Eve (Nance 1940) reported the following about the engagements:

Colo. [sic] Caldwe11, who was one of the San Tafe [sic] prisoners and had recently reached home, upon hearing that San Antonio was in possession of the enemy, marched 200 Texian volunteers when [sic] and reached within four miles of that place, when he was attacked on the 18th of September by 1,100 Mexicans in a thick wood he fought them from $110^{\prime} \mathrm{clock} A$. M. until one hours sun in the evening when the Mexicans retreated. Caldwell reports ten of his command wounded none killed and about one hundred Mexicans killed and about 200 wounded [Battle of the Salado].

On the same day a company of 59 volunteers from Fayette county in attempting to join Caldwell were attacked by the Mexican cavalry, and fought until 33 were killed as reported by a Mexican prisoner and the Colone] taken. But Colo. [sic] Moore has since marched to the ground with 150 men and reports that he found the bodies of 48 Texans most savagely mangled and lacerated [Dawson's Massacre-Nicholas Dawson].

Houston was now pressed to do something to allay public opinion; however, he had no intention of making war (Fehrenbach 1968:261). He called upon General Alexander Somervel1 and his Army of the Southwest. Somerve11's men assembled on the Medina River and Leon Creek at three camps. Camp Leon--the headquarters of Somerve11's Southwestern Army from November 13 through about November 19 when the army was moved to Camp Cook (located on Leon Creek at the crossing of the road to Presidio del Rio Grande); Camp Cook--headquarters camp and rendezvous point located near the Medina River crossing of the road to Presidio del Rio Grande, some 13 miles southwest of San Antonio; Camp Howard-headquarters camp and final assembly point (on the Medina River perhaps a mile of two downstream from Camp Cook; Pierce 1969:36, 77, 92).

A letter (Chabot 1940:158-159) written by Israel Worsham to his father, Jeremiah Worsham, on November 22 from Camp Leon described the situation on the Medina River:

Dear Father,

.. there are about six hundred men at Madena [sic] and two pieces of artillery twelve yoke of oxen were pressed to carry them today. Tomorrow we will join them. And the next day we are 
ordered to march to the Riogrande [sic] there will be no longer delay.

\author{
farewe 11
}

\title{
Israe1 Worsham
}

This army marched to Laredo and captured it on December 8, with Somerve1 1 marching along the river as a show of demonstration (Fehrenbach 1968:262). At this point the army was ordered back to Gonzales; approximately 300 men refused to go and elected a new colonel, Fisher. They crossed the border and engaged the enemy--the episode being known as the Mier Expedition.

On June 14, 1843, Houston and Santa Anna negotiated (with Britain as mediator) a truce which went into effect in early 1844. The question of annexation rose again, and by 1845, under a subcurrent of manifest destiny, the United States shifted its position to a favorable attitude on the annexation of Texas. The Mexican government, now under General Herrera, made one last desperate attempt to save Texas for Mexico but it came too 1ate. The Texas Congress met at Washington-on-the-Brazos, writing a state constitution which was approved along with annexation (Fehrenbach 1968:265-266).

In 1845, Mexican troops crossed the Rio Grande into the disputed territory between the Nueces River and the Rio Grande. President James K. Polk declared the intrusion a direct act of aggression and ordered General Zachary Taylor to reconnoiter the regions to the lower Rio Grande (Mallouf, Baskin, and Killen 1977:44). Taylor with his men left San Antonio in July 1845 and arrived in Corpus Christi the same month where 3554 of his men congregated at the Nueces River (Norvell 1945:134). Archival research and analys is of the route of General Taylor place him on the old Corpus Christi Road which crossed the Medina River in the vicinity of present-day Losoya, roughly paralleling Highway 281 which is just east of the study area.

On December 29, 1845, President Polk signed the treaty of annexation. Texas officially became a part of the Union on February 19, 1846.

\section{EARLY STATEHOOD AND ANTEBELLUM}

The Mexican War ended on February 8, 1848, when the Treaty of Guadalupe Hidalgo was signed, formally establishing the southern boundary of Texas and the United States at the Rio Grande. Mexican trade, which had been established during the Republic and which had virtually ceased to exist during the war was resumed (Roemer 1935:131). Dr. Ferdinand Roemer (1935), traveling through the area in 1848, observed a caravan of the traders (carretas) and related that they provided the city (San Antonio) with smuggled goods which could be bought cheaper from them due to the high import duties on legally imported articles.

In the study area, at the crossings of these trade routes with the Medina River, the first smal1 "communities" were established. These communities were more often than not at the centers of family groupings, such as at Paso de las Garza's where the Ruìz, Herrera, Guzmán, and de la Garza families as 
well as others had settled. Mexican traders traveling through the area found it a desirable place and, by 1850, a smal1 group from Mexico established themselves throughout the area.

Other trade economy revolved around supplying the army garrisons (established in 1846 when Texas entered the Union) along the border and the Comanche and on west to California (Fehrenbach 1968:320). San Antonio became a center for the stage lines traveling the region with at least three routes passing through and/or adjacent to the study area.

In 1847, Ygnacio Pérez returned to Texas from Mexico. Here he found that the land which he claimed and paid taxes on had been granted to those individuals who possessed headrights, bounty, and donation rights, or had purchased the land from the above. Thus began the long series of court battles over the right of possession which was not settled until 1851, at which time Pérez was able to retain one league on the north bank of the Medina River but lost four leagues on the south bank (TGLO Paschal and others vs. Pérez; Paul vs. Pérez).

Immigration from the United States increased dramatically in the late 1840 s to the early 1850s. San Antonio as well as other areas of south-central Texas became an enclave for these refugees, particularly the Germans. Unique cultural patterns were to accompany each of these groups into Texas.

The 1850 United States Census (BCA) for the Medina River reflected the changing ethnic patterns. [Author's note: The census includes that part of the Medina River in Bexar County at the time and is inclusive of the study area.] A total population of 336 persons was on the Medina River, representing 74 families. A breakdown of the population shows that there were 227 Texans (including native-born Mexicans and Anglos), 62 Mexicans (Mexico), 36 from the States (representing New York, Mississippi, Massachusetts, Georgia, Virginia, Illinois, Tennessee, Pennsylvania, Louisiana, Vermont, South Carolina, and North Carolina), and 11 individuals from foreign countries (five from Germany, one from Ireland, four from France, and one from Scotland). Familiar names to the area included those descendants of the earliest Spanish and Mexican settlers as well as those individuals receiving Republic grants--names such as Francisco A. Ruiz and family, Blas Herrera and family, Ygnacio Pérez and family, Stephen Jett, and Hernandez. While the population of San Antonio in 1850 was predominantly German (but the culture was basically Ang7o-Mexican; Fehrenbach 1968:285), the Medina River area remained predominantly Mexican.

Indians continued to be a problem for the settlers. Roemer (1935), after meeting Colonel Jack Hays in San Antonio, wrote about the Rangers, whose job it was to protect the settlers:

The company of so-called rangers which he [Hays] commands, is composed of about sixty young men, mostly sons of the western colonists, who entered as volunteers and who were formerly paid by the Republic of Texas but since its annexation are now paid by the United States. 
Each must furnish his own horse and weapons. The latter consist of a rifle and pistols. Many also carry the Colt's revolving pistol which enjoys quite a popularity in Texas. The duties of the rangers consist chiefly in making frequent excursions along the borders, so as to keep the Indians in check. Upon news of an Indian raid, or other acts of violence, they are to go in pursuit of the enemy immediately and to mete out punishment. To accomplish their purpose, they live in tents throughout the year, changing the location of the camp from time to time. ...

Victor Bracht, a7so in Texas in 1848, described the Indians as being coarse, savage, faithless, deceitful, cowardly, and cruel; he further commented that their character had not been elevated by their contact with the whites (Bracht 1848:73).

From 1852 to 1861, the greatest numbers of Anglo-American immigrants were to enter the study area--not as absentee landowners, but as homeowning residents ultimately responsible for significant culture change in the area. Men such as Theodore Heermann (see 41 BX 520), and Stephen, John, and Jesse Applewhite (see $41 \mathrm{BX} 666,41 \mathrm{BX} 669$, and $41 \mathrm{BX} 538$ ), whose economic base came from a "semi-plantation" tradition utilizing slaves brought with them to Texas, and Enoch Jones (see $41 \mathrm{BX} 664$ ), a member of the elite mercantile class mostly from the northern states, basically dominated the city of San Antonio in the 1850s. Other names which appeared in the area were Stanfield, Avant, Mudd, Macdona, Quesenbury (Quesenberry), Dever, Desmuke, and Miller, among others.

The Pérez family suffered a great loss during this time when José Ygnacio Pérez died in 1852 (Chabot 1937:179). The ranch, which by this time was known as the "Rancho de Ta Purisima Concepción," was left to the heirs of Jose Ygnacio Pérez and continued to be operated by them. One family in particular, Maria Josefa Pérez Linn and her husband Jacob Linn, would be responsible for the continuity of the ranch (see 41 BX 549).

Francisco A. Ruiz, Blas Herrera, and their families continued to ranch much the same way as their predecessors had for the past three quarters of a century--open rangeland with horses, cattle, and mules--and subsistence farming on the side.

Portions of the land of Luciano Navarro were sold to Miguel Calvo in 1847 (BCDR V01. $D_{2}: 372$ ) and subsequently to George F. Howard, Indian agent, in 1850 (BCDR Vol. 12:103). An interesting fact concerning the ranch was reported by Colonel J. K. F. Mansfield on an inspection tour of Texas military establishments in 1856:

The Camels. Brevet Maj. Henry C. Wayne was in San Antonio in charge of a drove of camels of 34 in number. ... Major Wayne has in his employ nine citizens who are engaged in the charge of these animals. . . These camels are kept on a Ranch of Mr. Howard on the Medina about 12 miles out of San Antonio at the rate of 30 dolls [sic] per month (Biesile, Hackett, and Webb 1938:141). 
By the 1850s, five cultural classes existed on the Medina River or influenced the area by their association: the small subsistence farmers which included both Mexicans and Anglos; the Mexican ranchers who were continuing age-old ranching techniques; the Southern, Anglo-Protestant "semi-plantation" contingent with their slaves; the merchant class (including the Mexican cartmen and Anglo wagoners); and the European immigrants (mainly Irish and German).

A developing socioeconomic and sociopolitical Anglo influence slowly eroded the Mexican power base, established in the area at this time. In many cases, however, there was a great amount of intermarriage between the social classes. Within the study area, located peripheral to San Antonio, this developing influence would only marginally affect the residents at this time and would not really culminate until the 1860 s and 1870 s.

Frederick Law 01msted (1857), who traveled the state in 1854-1855, described the condition of the Mexican population, most of whom had been relegated to second-class citizenship:

The Mexicans appear to have almost no other business than that of carting goods. Almost the entire transportation of the country is carried on by them, with oxen and two-wheeled carts. Some of them have small shops for the supply of their own countrymen, and some live upon the produce of farms and cattle-ranches owned in the neighborhood. Their livelihood is, for the most part, exceedingly meagre, made up chiefly of corn and beans...

The Mexicans were treated for a while after annexation like a conquered people. Ignorant of their rights, and of the new language, they allowed themselves to be imposed upon by the newcomers, who seized their lands and property without shadow of claim, and drove hundreds of them homeless across the Rio Grande. They now, as they get gradually better informed, come straggling back, and often their claims give rise to litigation, usually settled by a compromise. . . Americans, in speaking of them, constantly distinguish themselves as 'white folks'.

From several counties, they have been driven out altogether. . . . Even at San Antonio, there had been talk of such a razzia. A Mexican, caught in an attempt to steal a horse, had been hung by a lynching party on the spot [on the Medina], for an example. His friends happened to be numerous and were much excited, threatening violence in return. Under pretext of subduing an intended riot, the sheriff issued a call for an armed posse of 500 men, with the idea of dispersing and driving from the neighborhood a large part of the Mexican population. But the Germans, who include among them the great majority of young men suitable for such duty, did not volunteer as had been expected, and the scheme was abandoned. . . . One of them, who lived on the Medina in the vicinity of the place of the occurrence [author's emphasis], told us he had no complaint to make of the Mexicans; they never stole his property, or troubled him in any way. 
Construction techniques for homes in the area also reflected the influx of the Anglos. Along with the plastered stone/adobe and adobe palisados of the Spanish and Mexican population, the vernacular architecture of the Anglo settlers as well as the academic architecture such as the Enoch Jones home (41 BX 664) were added. Stone, the most abundant resource in the area, was the most widely used construction material by all groups up to this time. Window glass and sawn lumber were both scarce and expensive and not widely utilized.

European goods were available to those who could afford them, as well as articles manufactured in the North, but the trade was limited to the tiny affluent mercantile class which placed heavy mark-ups on the items (Fehrenbach 1968:321). Money took three forms: depreciated bank notes from the United States, promissory notes, and Spanish/Mexican silver pesos with very little cash economy (ibid.:321).

Incipient industry in San Antonio during the late 1850 s and early 1860 s consisted of soap making, milling, and brewing. San Antonio, with a population of 8235 persons, was witnessing accelerating changes, such as stores, restaurants, and saloons, with many of these being operated by the German settlers.

During the $1850 \mathrm{~s}$, an undercurrent of political crisis was brewing in Texas which was indicative of a more dangerous situation in the United States. Locally, the Know-Nothing party gained control of city government when their candidates captured every official position. The party would disintegrate as fast as it appeared, however. The secret vigilante organization known as the Knights of the Golden Circle, which had sprung up statewide, with their goals of making the South safe for slavery and the conquering of Mexico, reflected the chaotic status of the city and the state as a whole.

As far as the South was concerned, conditions rapidly deteriorated when on November 8, 1860, Abraham Lincoin was elected president. The southern states, led by South Carolina, rapidly seceded from the Union. The Texas Secession Convention, which assembled in Austin in January 1861, voted to secede from the Union, and on March 2, 1861, the state overwhelmingly voted for the ordinance. On Apri1 12, 1861, Fort Sumter in South Carolina was fired on by Confederate forces and thus the War Between the States had begun.

\section{CIVIL WAR}

In the early months of 1861, thirty-two state militia units, under old Rangers such as John S. (Rip) Ford and Ben and Henry McCullough, were created by the state legislature. On the Medina River, Captain Theodore Heermann (1861) formed the Medina Guards, 30th Brigade, Texas Militia. The ethnic composition of the unit is in contradistinction to statements made by Fehrenbach (1968), who wrote that the Mexican minority south of San Antonio was politically inert, regarded the war as an Anglo affair, and chose not to participate. The militia unit under Heermann consisted of 64 men of whom 35 were Anglo and 29 were Mexican; however, an examination of the officers reveals that only one out of thirteen was Mexican, reflecting the sociopolitical status of the Anglos over the Mexicans. Captain Heermann reported, 
October 1861, that the men had been drilling as 1 ight infantry at their muster grounds on the Medina River but offered themselves as cavalry (ibid.). Throughout the war the unit remained in the San Antonio area, principally on the Balcones Escarpment, holding back the Comanche who had become increasingly bold and dangerous during this time.

An economic revolution in Texas in the 1860 s was precipitated by two factors. The ranches/ranchers, most of whom had lost their cowboys to the war effort, were decimated by both this loss and the corresponding Indian threat. For cotton farmers (such as the Applewhite family), the blockade of the Texas coast by Union forces eliminated their coastal trade network. Some cotton continued to be grown, but it was imported only with great difficulty-subsistence crops such as corn frequently replaced the cotton in many areas. With the elimination of the coastal trade, the Rio Grande virtually became the "back door of the Confederacy" (Mallouf, Baskin, and Killen 1977:47). In San Antonio, merchants carrying wagonloads of cotton to the Rio Grande helped to supply the war-torn South with a much-needed source of revenue (ibid.). These same merchants frequently returned with other goods which were in short supply in San Antonio, including some luxury items which commanded large sums of money (Fehrenbach 1968:360).

Transportation routes adjacent to and through the study area and also communities were further developed by Rio Grande trade and the establishment of the military courier service by the Confederates from Brownsville northward to other parts of the state. The mounted couriers rode the trail taken by General Zachary Taylor in 1846, stopping at designated way stations to change horses (Mallouf, Baskin, and Killen 1977:47). The study area witnessed the reutilization of some old roads such as the Perez Road as well as the establishment of new interconnecting links to the road network (BCA Commissioners Court Minutes Vol. 2a:348-349).

The small communities, such as the ones at Paso de las Garza's and "Rio de Medina" (Castro n.d.), benefited and developed further as the result of the increased transportation. Communities also profited when, in 1862, San Antonio became the Confederate Army headquarters. Soldiers, stationed at camps in the area, were frequent visitors to homes such as the Enoch Jones homesite (41 BX 664; DRT Enoch Jones Files).

In 1862, the Confederate Conscription Law was passed; resistance was so substantial that martial law was declared. In San Antonio, a number of Unionists, mainly ethnic Germans, was driven out of town and their property confiscated. Many of the predominantly German communities, such as New Braunfels and Fredericksburg, were occupied by troops; one group of Germans was massacred on the Nueces River while trying to flee to Mexico.

Conditions along the Mexican border had also deteriorated when Mexico became embroiled in its own civil war. Events worsened when the Federal Army Corps under Major General Dana seized Brownsville and the Rio Grande Valley (Fehrenbach 1968:377). Colonel John S. (Rip) Ford was called in to undertake a campaign on the Rio Grande, and in San Antonio between December 22, 1863, and March 17, 1864, he assembled his "Cavalry of the West." They rode into the valley and in a series of battles almost completely routed the Union forces. On May 12, 1865, the Battle of Palmito Hill was fought and won by 
the Confederates--over a month after the Civil War had ended at Appomatox (ibid.:390).

\section{POST CIVIL WAR--INDUSTRIALIZATION}

The years following the Civil War, when Union soldiers occupied the state and carpetbaggers flourished, were no less than tragic. Economically, politically, and socially, the state was devastated. In the following years, the State (by a collective effort of individuals) would have to try to put back together what had been pulled apart.

Locally, the soldiers returned home to find the area still suffering from an extended drought in 1863. Falling cotton and land prices made planting acres valueless except for subsistence farming, and this was negated by the drought. Many of the farms and ranches (or portions) were sold at this time, and survey maps of the study area become increasingly more complex. A severe cholera epidemic in 1869, following a river flood, devastated the San Antonio population, calling attention to the need for a sanitary water system. Those who owned property on the Medina River, such as the Jacob Linn family, left the city and fled to the countryside (Patricia Walsh, personal communication; see 41 BX 274 and 41 BX 549).

Economically, there were three viable factors. One was the tremendous number of "longhorns" running wild; second was the fact that many of the Blacks who had been freed chose to stay; and, third, San Antonio was becoming a developing center for wool (Ramsdell 1959:46). From the first factor, enterprising men would form the nucleus of the second great cattle industry when round-ups were conducted, and drives were held to the northern markets and to the coastal hide and tallow factories. The great cattle trails would criss-cross the state, with a portion of the Dodge Trail passing through and/or adjacent to the study area on the east (DRT Maps Files Oversized Folio Collection). The great cattle drives would continue until the late $1870 \mathrm{~s}$, when the invention and introduction of barbed wire would be the cause and stimulus for a reorganization of ranching. The second economic factor was a form of tenantry (sharecropping) replacing slavery--thereby continuing the existence of some of the larger farms and/or ranches. This system of farming would include not only blacks, but Anglos and Mexicans as we11, and would subsequently evolve into full-fledged tenant farming which lasted until the $1930 \mathrm{~s}$ and 1940s. Families such as the Applewhites and the Perez-Linn-Walshs, would successfully utilize this method (see 41 BX 538, 41 BX 661, and 41 BX 549).

Community development was spurred by the establishment of churches in the study area. The Santisima Trinidad Church at Paso de las Garza's (41 BX 667) was constructed on 1 and donated by Blas Herrera in 1866-1867 (BCA B1as Herrera File) to serve the Catholic population of the area, which was predominantly Mexican and Irish. The Oak Island Methodist Church (41 BX 521) was organized, ca. 1867, by the Reverend John Wesley DeVilbiss, circuit rider, for the Anglo-Protestant population of the area. The 1 and was donated by the Applewhite family. 
Another cultural development in the study area was the opening of the 0ak Island school; classes were held in the church. Official provisions for schools had been instituted in 1854 , but not until 1868 did the state constitution call for a centralized state public school system. Most rural areas had "field schools"--a school which families had established by providing a building and hiring a teacher (Fehrenbach 1968:303).

During the $1870 \mathrm{~s}$, further road development took place in the study area. Somerset Road (01d Somerset Road) was opened along the route of the Laredo Road (BCA Commissioners Court Minutes Vol. 3A) crossing at Garza's Crossing (41 BX 697) where Blas Herrera, Jr., had reestablished a ferry (ibid.:560; see $41 \mathrm{BX} 671$ and 41 BX 673).

Postal service was established in 1879 , serving ca. 180 persons, in the vicinity of present-day Von Ormy. This service was discontinued in 1880 and reestablished in 1886 (Castro n.d.).

Indians continued to be a problem for the citizens, attacking mule trains and raiding the ranches and settlements. The Indian problem was finally subdued when the Texas Rangers were reinstated by the 14th Legislature during the administration of Richard Coke.

The 1870 s and 1880 s were a time of tremendous growth and change in San Antonio--and a time of opportunity as well. Many of these changes would have a direct effect on the cultural elements of the city. Rippling waves of change would reach the study area but the effects would be somewhat diminished. Some of the developments in San Antonio between 1869-1883 included small private industries; hospitals; a safe, clean water supply; telephones; electricity; a mail carrier system; and the arrival of the Galveston, Harrisburg, and San Antonio Railroad. Fox (1983:285) wrote that: "By the late nineteenth century, the cotton and cattle kingdoms of Texas were made tributary to American industrialized society."

With the arrival of the International and Great Northern and San Antonio Railroad in the study area in the early to mid $1880 \mathrm{~s}$, the small "communities," such as Paso de 7 as Garza's and "Rio de Medina," shifted toward the railroad location; such was the case generally across all the state. Where the railroad went, communities flourished; where it bypassed the towns, they withered. The new settlement that grew up around the railroad came to be named Von Ormy after an east European, Count Von Ormy, who had purchased the Enoch Jones complex in 1885, estab7ishing a "royal court" at the home (DRT Enoch Jones File; 41 BX 664). Count Von Ormy did not stay long, but he so impressed the citizens that they named their community after him.

With the arrival of the railroad also came new methods of construction. Sawn lumber and glass became readily available to the vast majority of the inhabitants, and wood frame housing (such as board and batten, beveled siding, and weatherboard) replaced stone as the most commonly utilized construction material. Architectural styles represented academic (Victorian, including Gothic Revival) and vernacular. 
Settlement patterns shifted away from the river, reflecting the utilization of secondary sources of water. Few late 19th-century and early 20th-century structures are within the boundaries of the study area due to this shift.

Industries in the area in the 19th century consisted of small operations such as cotton gins, gravel pits, and a brick factory (most of which were located outside the immediate study area). Early 20th-century operations centered around the discovery of $0 i 1$ and gas.

Subsistence remained very much tied to the land. Farms managed to survive despite droughts and were supported by 19th-century inventions of windmi11s and mechanized equipment.

A final "20th-century immigration" into the area resulted in new Mexican settlement, with a resultant shift in social and political power to the predominantly Mexican-American population.

Modern development in the area has been affected by $0 i 1$ and gas exploration and the construction of modern super-highways such as Interstate 35, Loop 1604, and Highway 16. Agriculture-related enterprises remain, while a large proportion of the population works in San Antonio and the industrial and/or medical fields. Many of the residents are direct descendants of the early Spanish, Mexican, European, and Anglo-American settlers.

\section{HISTORICAL SUMMARY}

Spanish interests in the region developed from three general interests north of the Rio Grande: (1) the protection of Spanish colonial frontiers; (2) precious mineral explorations; and (3) Christianization of native Indian groups. Throughout this early period, Spanish efforts at settlement and expansion were threatened by the inherent shortcomings of governmental corruption and restrictive regulations. An emphasis on non-coastal tradetransportation networks to avoid foreign smugglers and freebooters did 1ittle to spur regional economic developments.

By the mid-18th century, major political reforms contributed to an increase in economic growth as well as a development of regionalism. Combined with an overextension of Franciscan friars across frontier Texas and the emergence of local, competitive private ranches, the church influence in the late $1700 \mathrm{~s}$ began a gradual decline that was never overcome in the following decades. Smallpox and measles during this same period contributed to an abrupt decline of native Indian groups. Pressures from intrusive Apaches and 1 ater Comanches apparently forced nonmissionized indigenous Indian groups southeastward from the lower Medina River valley by the beginning of the 19 th century. The early 1800s saw enlightened immigration laws and a brief influx of non-Mexican ethnic groups. Although peace treaties were concluded with the Apache and other groups in 1823, Comanche depredations continued to plague settlers for the next two decades. By 1830, increasingly complex political problems eventually split local inhabitants over government issues. This in a large part centered around the issues of separate statehood for Texas versus the joint Coahuila-Texas concept. Changing ethnic patterns were also developing as Anglos continued to increase locally; Mexican ethnic, 
social, economic, and political influences began a gradual, long-term decline. By 1836, after a series of increasingly violent confrontations, hostilities climaxed at the Battle of the Alamo and at San Jacinto. Indirectly related to these political events was the subsequent acquisition of former Mexican lands locally by newly arrived Anglos.

The Texas Republic was characterized by a population with a poor, rural economic base. Most Anglos were subsistence farmers, and little currency was available. The Republic's government was loosely organized, and this in no small part contributed to continuing political confrontations with Mexico and the inability to control hostile Indian groups. A distinct U. S. southern cultural influence gradually emerged both locally and regionally and achieved a small florescence by the mid-19th century. An initial movement toward Texas Independence by European powers and Mexico contributed to a reversal of U.S. attitudes toward Texas annexation, and the Republic became a state in December 1845.

Accelerating cultural changes, the development of incipient industries, and expanding trade networks characterized Antebellum Texas. By the middle of the 19th century, the final shift of the local ethnic hierarchical structure occurred as Mexicans were often relegated to a second-class citizen status. An economy of kind still dominated trade, and business was 1 imited to a smal1, affluent, mostly Anglo class.

The Civil War precipitated a short-term economic revolution in Texas, both regionally and locally as the Rio Grande (and the trade network associated with it) became a "backdoor" for trade with the Confederacy.

Post-Civil War years were marked by Reconstruction efforts and severe economic and governmental instability. By 1875, following some revival of stabilization, trade networks and a developing cattle industry contributed to positive economic aspects of the late 19th century. Unfortunately, failing cotton prices and land values, and an eventual decline of the cattle industry later created serious problems for the lower classes and precipitated a gradual economic shift by the early 20th century. The development and expansion of incipient industries and the impact of $0 i 1$ and gas explorations have ushered the regional and local area into modern times. 


\section{INVENTORY OF RESOURCES}

\section{INTRODUCTION}

Descriptions of sites identified during the 1984 work follow the revised site survey format recently designed by the Texas Historical Commission (see Appendix IV). The format is more detailed and lengthier than earlier report formats. The 1981 survey data have been incorporated into this descriptive style format for continuity and site comparisons. Descriptions of sites identified during the 1977 Medio Creek survey (McGraw 1977) are presented in Appendix V. These site descriptions do not follow the revised site survey format. The recommendations for the Medio creek sites are included in Table 13 along with the 1981 and 1984 sites.

Descriptions of recorded sites were divided into two main divisions, prehistoric and historic. Prehistoric sites may reflect a wide range of temporal and functional types. While a site's chronological association cannot always be discerned by an intensive survey, site function(s) is more easily identifiable by the types, frequencies, and patterns of scattered remains.

Historic sites were determined by relatively substantial manifestations. Post-1930 structures (or structures less than 50 years old) which would not generally be eligible for the National Register of Historic Places nor contribute to interpretations of the area's history were not recorded or assigned site numbers.

Designations of historic sites followed the criteria established by the Texas Historical Commission's Cultural Resource Information System (THC 1981). A historic site is "composed of any evidence of man's occupation or activity on or beneath the ground surface dating from the time of European contact up to fifty years ago." Historic architectural sites include the "location of a building, or group of buildings (generally at least 50 years old), possessing integrity of design, setting, materials, or workmanship and which is significant in American history, architecture, or culture. The site may be associated with important historical persons or events, or the buildings may be representative of a particular architectural style, period, or construction method." A historic engineering site is identified as "the location of individual structures, systems, or technological networks which are significant in the history of American industry, engineering, or technology."

The definition of a site, a basic premise in archaeological investigations, becomes, at times, an often difficult concept during archaeological surveys. In the most general and academic terms, a site is described as any location that reflects evidences of past human activities. Regionally, this means the remains of chipped stone debitage, burned rock (and burned rock features), burials, historic structures, or even the occurrence of musket balls. A problem that often surfaces throughout survey work (fortunately not in the current studies) has been the minimum artifactual evidence that constitutes an archaeological site. Interpretations at such a point become more judgmental and qualitative than a simple reliance on quantitative counts of artifactual fragments. Multicomponent sites, as described in this report, 
are those sites which contain the remains of both prehistoric Indian cultures as well as historical cultural remains.

Inferences of site significance made on the basis of a representative surface collection must be considered as preliminary as they may be far from accurate; however, the addition of archival research and oral history interviews may refine these inferences, and general conclusions should be considered reliable.

Site function as well as functional components of historic sites were determined by combining several lines of evidence: archaeological, architectural, archival/historical research, and oral history information. The use of functional components was believed to be a valuable determinant in assessing the significance of historic sites in the proposed reservoir area. Functional components utilized are presented in Figure 6.

Architectural evaluations followed the criteria for historic sites in use by the Texas Historical Commission's Texas Heritage Conservation Plan Computerization Program Manual (Mallouf et a1. 1981:61-72). This review was conducted in part to ascertain sites potential eligibility to the National Register of Historic Places.

Historic architectural sites were analyzed as to function; often structures exhibited multiple functions; when this occurred, the primary usage was determined. Over half of the architectural sites identified in the proposed reservoir area are still in use. The remaining structures are either abandoned and/or in varying stages of ruin.

Relevant data recorded concerning the structures were (1) present use; (2) owner; (3) original use; (4) original owner; (5) physical condition; (6) architectural style; (7) exterior construction materia7; (8) floor plan; (9) roof type; (10) door and window treatments; (11) porch styles (if present); (12) wall treatments; (13) ornamentation; (14) interior features, such as ceilings, walls, floors, window and door features, fireplaces, and stairways; (15) levels of alterations; and (16) other areas of significance to the site, including agriculture, architecture, commerce, exploration and settlement, industry, military, religion, and transportation.

A photographic record was made at each identified structure. Special photographs were made of distinctive details, such as foundations or piers and sills, hardware, etc. Scaled architectural floor plans and sketches were al so made for those sites recorded during the 1981 survey and which are recommended for further work (testing/archival) during present studies. A final mitigation plan will include recommendations for detailed mapping and photographing of these sites according to the Texas Catalog, Historic American Buildings Survey (Goeldner 1974) criteria, with assessments by a qualified architectural historian (for those sites found to meet the criteria for National Register nomination).

The historic architectural sites reflect a broad range of styles, socioeconomic levels, and temporal associations. Standing buildings can provide information on (1) sequence of building types and styles, (2) socioeconomic status, and (3) ethnic affiliations as evidenced by construction methods and 
materials. Architectural styles represented by this survey are Greek Revival, Spanish Colonial Revival, 19th-Century Industrial, and vernacular (pioneer Anglo, pioneer European, ethnic Mexican), and mid-late 19th century church styles.

Construction materials and methods represented reflect the utilization of abundant stone resources in the local area, the ethnicity of the population, and a developing transportation network. Materials and method of construction are brick, adobe palisado, field stone, stuccoed stone, cut/dressed stone, and wood frame (including board and batten and beveled siding). The absence of $10 \mathrm{~g}$ construction in the area of the proposed reservoir is notable, considering the abundant natural wood resources found locally. Either these structures have not survived or, more importantly, this may represent the ethnic affiliations of the earliest inhabitants.

Site descriptions are presented in the following format:

Permanent site number: trinomial designation as per TARL.

Type of site: historic or prehistoric; identified by chronological association and function(s), if possible. Site types are (1) occupation sites which reflect the remains of former campsite activities, such as burned rock clusters and lithic reduction processes in a discrete, definable area; (2) occupation zones, distinguished from the former by a much larger physical activity area as well as multifunctional, multicomponent materials; and (3) specific activity sites, such as lithic workshop sites or Tithic quarry locations, identified by a relatively small site area and a lack of occupational debris, such as burned rock or other features; (4) multicomponent sites, as described in this report, contain both prehistoric and historic cultural remains.

Location: in terms of generally definable landmarks (highways, water sources, etc.) in the area.

Elevation: given as feet above mean sea level (ms1).

Topographic context: topographical designations (e.g., uplands, terrace, etc.).

Water source: 1ocation to major river or minor tributaries and secondary sources of water (e.g., well, cistern) at historic sites.

Vegetation and soil: the vegetation noted at time of survey along with the so $i 1$ association.

Site condition: estimates on site integrity, rates of erosion, extent of site damage.

Artifactual materials present: actual artifacts observed and/or collected.

Site discussion: year the site was first recorded and comments on revisit (if applicable). Includes postulated temporal associations, collected/ observed artifactual materials, architectural evaluations (if applicable), 
genealogical information of original occupants as well as subsequent occupants, and additions/renovations of structures.

Site significance: as evidenced by the artifactual materials or structural remains and how they are related to the study area, region, and state. Can answer or provide information toward National Register of Historic Places criteria.

Management recommendations: Does meet or does not meet requirements for potential eligibility to the National Register of Historic Places. Recommendations for site management include avoidance, preservation, and mitigation. In some cases, recommendations are made for further work in order to determine a site's potential eligibility to the National Register of Historic Places.

As per the Guidelines for the Content of Cultural Resource Management Report (Bruseth and Thurmond 1981:7), prepared with the Council of Texas Archeologists approval, no specific location maps or data identifying individual sites will be presented. These data have been made available to involved agencies and parties and are on file at the center laboratory.

\section{SITE 41 BX 273 (Munk Home)}

Type of site: Historic.

Location: Approximately $200 \mathrm{~m}$ south of Elm Creek on the south side of an unnamed road.

Elevation: ca. 540-550 feet above ms 1 .

Topographic context: Along the margins of the E1m Creek drainage near its confluence with the Medina River.

Water source: E1m Creek is ca. $200 \mathrm{~m}$ from the site; we11/cistern(?).

Site condition: Occupied.

Artifactual material present: The site is occupied; no artifactual material has accumulated on the surface around the structure. Buried accumulations are postulated adjacent to the site but have not been located.

Site discussion: This site was first identified in 1975 (Hester assembler, 1975:22). The site was surveyed by personnel from the CAR-UTSA during the 1981 studies for the proposed reservoir. During the 1981 field work, the prehistoric 1ithic scatter, identified by Hester (assembler, 1975:22) as being near the Munk home, was noted as spatially discrete from the historic occupation site. On the basis of the surface extent and distribution of lithic debris, the prehistoric site location was assigned a separate trinomial designation, 41 BX 525. A more detailed records search was recommended in 1981 if the structure was to be impacted by the proposed reservoir. Further testing then would be based upon the results of the background archival data. Records research in 1984 revealed that members of 
the Munk family purchased 1 and in the study area during the period of 1882 1884 (BCDR Book 32:242, 326; Vo1. 19:402). They were engaged in farming, particularly vegetables (Mary Walsh, personal communication). Several members of the family are buried in the 0ak Island Cemetery nearby.

The historic occupation is evidenced by a modified stone home with fireplace, constructed during the late 1800s. Outbuildings are a barn and an aboveground cistern, appearing to date to the early to mid-1900s.

Site significance: The site is representative of those established in the late 19 th century by small farmers in the study area. The use of stone in the construction of the house indicates a construction date prior to the arrival of the railroad (ca. 1883), when lumber became both readily available and economical.

Management recommendations: In the opinion of the authors, this site is potentially eligible for the National Register of Historic Places based on its potential to yield information important in history. Limited testing is recommended to determine the extent and significance of cultural deposits and their temporal associations along with architectual documentation of the structure(s) and mapping of the site. Further archival research to clarify the Munk family's importance to the development of the study area is also recommended, particularly as the location may reveal a distinctive sociocultural historical development within the area. The site is within the maximum flood pool level of the proposed reservoir.

SITE 41 BX_274 (Stone Rancho, Pérez's Rancho, Rancho de 1a Purísima Concepcion)

Type of site: Multicomponent.

Location: Situated southwest of the intersection of Applewhite Road and Watson Road.

Elevation: Prehistoric component, ca. 500-540/550 feet above ms1; historic component, ca. 540-570 feet above ms 1 .

Topographic context: The prehistoric component is located on the margins of a large riparian zone which constitutes the floodplain confluence of El $\mathrm{m}$ Creek and the Medina River. The historic component is located on upland margins adjacent to steep terrace bluffs along the Elm Creek-Medina River confluence. The locality offers one of the widest and longest overlooks southward beyond the river within the study area. The prehistoric occupation zone extends westward for ca. $1.5 \mathrm{~km}$. The historic component overlies margins of the prehistoric materials, and the original historic occupation complex may have extended into the floodplain.

Water source: Medina River-Elm Creek confluence is ca. $200 \mathrm{~m}$ from the site; well or cistern within historic component.

Vegetation and soil: Several distinctive floral contexts were noted across the extensive occupation zone: riparian along the floodplain margins, 
upland, and modified (through land clearing or farming). Large oak, cottonwood, and pecan trees dominate the margins of the floodplain, and thorny brush and mesquite cover the upland areas. Adjacent to and east of the site, 1 and has been cleared for farming and pasture. The soil is a fine-grained aeolian deposit overlying a more clayey, compacted subsoil.

Site condition: The prehistoric component contains deeply buried undisturbed deposits of at least $3 \mathrm{~m}$ in depth. The historic component is ca. $70 \%$ disturbed by farming and ranching activities.

Artifactual materials present: The prehistoric component consists of Early Archaic through Late Prehistoric cultural materials. Diagnostics are Early Triangular bifaces, Guadalupe and Clear Fork tools; Marsha11, Perdiz, Be11, and Martindale projectile points; Late Prehistoric ceramic sherds; and a corner-tanged perforator. Historic cultural materials collected consist of hard paste earthenwares (sponge/spatterware, banded slip/mocha, hand-painted, jasper ware, feather-edged/she11 edged, transferware, Gaudy Dutch, ye11ow ware, luster, ironstone, and undecorated), soft paste earthenwares (Mexican lead-glazed, tin-enameled majolica, and unglazed), porcelain, stoneware, metal, glass, shell, chipped stone, and bone.

Site discussion: The prehistoric component was first identified in 1975 by Hester (assembler 1975). Lithic debris, ground stone fragments, and a biface basal fragment characterized the site. No on-site inspections were conducted during the 1981 survey due to the inaccessibility of the site. In 1984, the site was one of those recommended by the RFP for limited testing during the inception of that study.

The historic component was first identified in 1984 by interviews with the landowner and an on-site inspection; archival research confirmed the location of late Spanish colonial occupations in the area. The historic component (originally designated separately as 41 BX 663) is the Ygnacio Pérez Spanish colonial homesite.

Preliminary survey information suggested the historic site was adjacent to but spatially and chronologically separate from the prehistoric occupation zone. Background archival research, concurrent with field work, indicated the possibility of a much larger historic complex (rather than a single structure, as previously thought) that extended over earlier prehistoric deposits. This was verified by several shovel tests placed eastward toward the historic component away from the known distribution of surface materials from the prehistoric occupation zone and was further substantiated by subsurface sampling of the historic component, after a decision was made to redefine the historic and prehistoric site areas. This decision was based not only on the subsurface distributions of materials but by the presence of Goliad ware collected at the historic component. 0ften associated with historic Indian groups, the ceramics are thought to represent activities which spatially and chronologically overlap the major site components. The redefined occupation zone extends ca. $1.5 \mathrm{~km}$ northwest to southeast and a minimum of $250 \mathrm{~m}$ east.

Historic Component: The Spanish colonial rancho complex (ca. $100 \mathrm{~m}^{2}$, possibly larger) consists of a stone dwelling, buried remains of a postulated 
jacal structure, and also may contain the buried remains of other outbuildings as well as corrals and other rancho features. Additionally, background research suggests that at least portions of the rancho may have been fortified against hostile Indian attacks. Aerial photographs taken of the site revealed two rectangular anomalies located in the southeast margins of the site. One of the anomalies was confirmed to contain significant artifactual materials. The other may be indicative of site features.

The Pérez (Péres) family was one of the most influential families of Spanish Texas-politically, socially, and economically. The patriarch of the family, Juan Ygnacio Pérez, was an officer in the Spanish Army, father-in-1aw to Governor Antonio Cordero, and ad interim governor from 1815 to 1817 . The son of Domingo and María Concepción (de Carvajal), Pérez was born on February 8, 1756 (BCA San Fernando Church Records). Grandparents of Juan Ygnacio Pérez were Joseph Antonio Péres, and Paula (Granado), daughter of Juan and María Robaina de Bethencourt, both Canary Islanders who arrived in San Antonio in 1731 (Chabot 1937:178).

Juan Ygnacio Pérez married Clemencia Hernández (granddaughter of Andres Hernández) in 1781 (ibid.:179). From this union, eight children were born: (1) María Leocadia, born December 8, 1784, died December 18, 1784; (2) José Ygnacio, born September 25, 1786, married Maria Josefa Cortinas May 30, 1812; (3) María Gertrudis, born January 2, 1790, first marriage to Antonio Cordero, governor and second marriage to José Cassiano; (4) Pedro José Antonio de 1 a Concepción, born March 23, 1794, died March 1794; (6) Concepción, born September 2, 1795; (7) Maria Antonia (born or adopted), married Jacinto Jimenez 1812; (8) María Josefa (adopted?), died December 2, 1815. A ninth child, José Antonio de la Concepción, was rescued from the Comanches at the age of five and adopted by Pérez.

In 1804, Juan Ygnacio Pérez bought the Commandencia of the Presidio (Spanish Governor's Palace) from Joseph Menchaca for the sum of 800 pesos (BCA Land Grants and Sales No. 511:1-4). In 1813, as a Spanish Cavalry captain, he participated in the Battle of the Medina under the leadership of General Joaquin de Arredondo. He was one of the soldiers, who, along with Elizondo, pursued the escaping Republicans to Nacogdoches (Bacarisse 1955).

In 1819, Juan Ygnacio Pérez was responsible for the scattering of Dr. James Long's forces at Nacogdoches (Faulk 1964:139). Pérez was acting governor of the Texas Province from ca. 1815 to March 1817 (BCA Pérez Files).

Juan Ygnacio Pérez died in 1823, and was buried 0ctober 7 , in the Purísima Concepcion Chapel, the parish church of the city (Chabot 1937:179). Clemencia (Hernández) Pérez died in 1825 at the age of 60 years and was buried near Ygnacio (BCA Pérez Files).

José Ygnacio Pérez, the son of Juan Ygnacio and Clemencia (Hernández) Pérez, was born on September 25, 1786 (ibid.). He married María Josefa Cortinas, daughter of Jose and Gertrudis de Ta Zerda Cortinas in 1808 or 1812 . To this union, eight children were born: (1) José Antonio de Jesús Ylario, born November 8, 1812, married Malina Pérez; (2) María de la Trinidad Ygnacia de la Concepción, born April 19, 1815 (single); (3) José Antonio de Tas Nieves Fernando, born August 7, 1819, died August 19, 1819; (4) José Fernando 
Serbu10 de Jesús Trinidad de 1a Concepción, born December 29, 1820; (5) María Josefa de Jesús Anastacia Toribia, born August 16, 1824, married Jacob Linn; (6) José Ygnacia, born November 7, 1828, married Concepción de la Zerda; (7) Maria de la Concepción Clemencia, born January 29, 1834 (single; BCA Pérez Files). At least one other son, Ygnacio Pérez, Jr., was al so born (Chabot 1937:179; BCCH Wi11s and Probates \#923, Concepción Pérez Wi11).

On October 26, 1852, Ygnacio Pérez died. He was buried in the chapel at the Pérez Ranch on June 2, 1861 (Chabot 1937:179).

The Spanish land grant to the Pérez family occurred possibly as early as 1754 or 1780 (TGLO Paschal vs. Pérez). We know that Joseph Antonio Péres (José Antonio Péres or José Péres Casanova), grandfather of Juan Ygnacio Pérez, branded "two calves and two anejas" between January 1778, and Apri1 1778 (BAT Vo1. 68:63). In 1778, Juan Ygnacio Pérez was one of 26 ranchers, who signed a petition to the council of the Presidio de Béjar asking for round-up and branding privileges in the vicinity of Cleto Creek (Weddle and Thonoff 1976:149). He also appears on a 1ist of ranchers in the Béjar area in 1778 (Thonoff 1981:17). In 1795, the ayuntamiento submitted the names of 35 men and 10 widows legitimately engaged in the business of raising cattle; (Juan) Ygnacio Pérez was included on this 1ist (BAMR 25:586-590). In 1806, under oath, Andres Benito Courbiere related "that Ygnacio Perez was the owner of several houses. . one hacienda with a farm near this villa, and a considerable number of head of stock..." (BAT Vol. 19:60).

In 1808, Perez was issued a title for four sitios of 1 and on the west (south) bank of the Medina River by Colonel Antonio Cordero, military and political governor of the Province of Coahuila and ad interim governor of Texas (TGLO Vo1. 43:119-121; Fig. 17) and one sitio on the east (north) bank by Nemesio Salcedo (TGLO Vol. 49:100). In his application for the grant, Pérez stated that he was the possessor of cattle, sheep, etc. Cordero adjudicated the said lands to Pérez and commissioned the Regidor, Manuel Barrera to survey and designate the 1 ands for Pérez. In 1812, Juan Ygnacio Pérez and José Ygnacio Pérez appear on a 1 ist of ranchers on the Medina River-Leon Creek (BAMR 51:381).

Juan Ygnacio Pérez's wi11, made in 1820, recorded the following:

I declare that I have a ranch of four leagues, for 1 arge stock on the other side of the Medina River and another league on this side -. on this league there is a stone house and wooden corrals. . . On these pasture lands there is some 1 arge stock both branded and unbranded, which I consider part of my property. . I declare that I have 23 mules with harness of knotted rope and 15 mules with trace chains and a11 the horses and muTes marked with my brand after my son Jose Ygnacio has taken those he chooses as his since he acquired them by his own personal labor and industry, and not having a brand he used mine... I al so have farming equipment, oxen and other movable goods... (Walsh n.d.).

A division and partition of the property in 1839(?) resulted in Jose Ygnacio Pérez acquiring three leagues on the south bank of the Medina River 


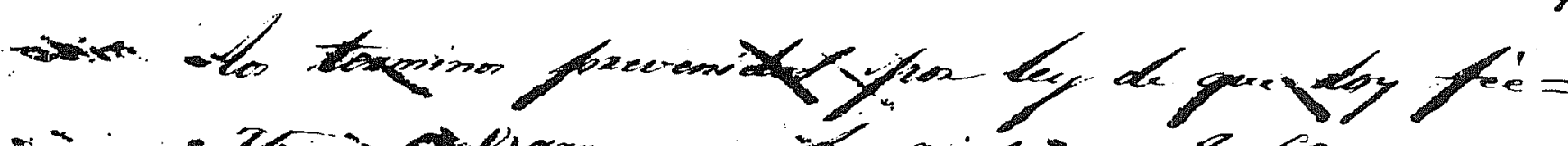

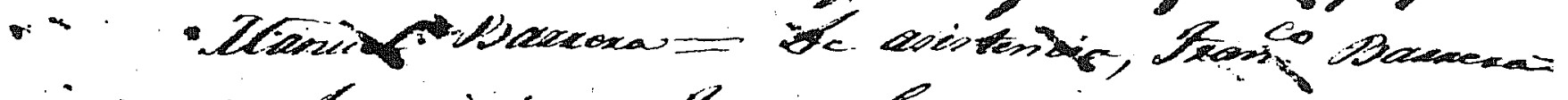

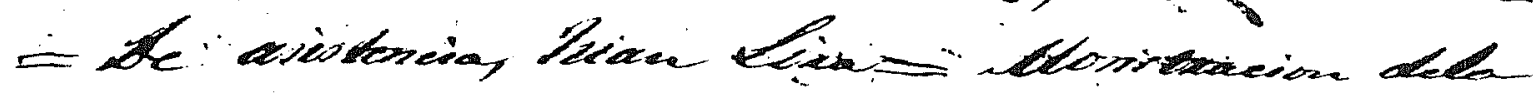

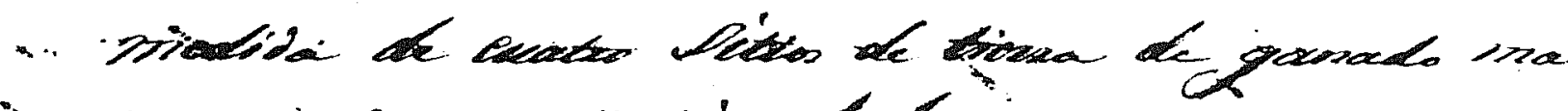

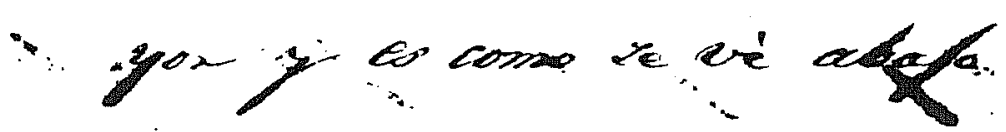
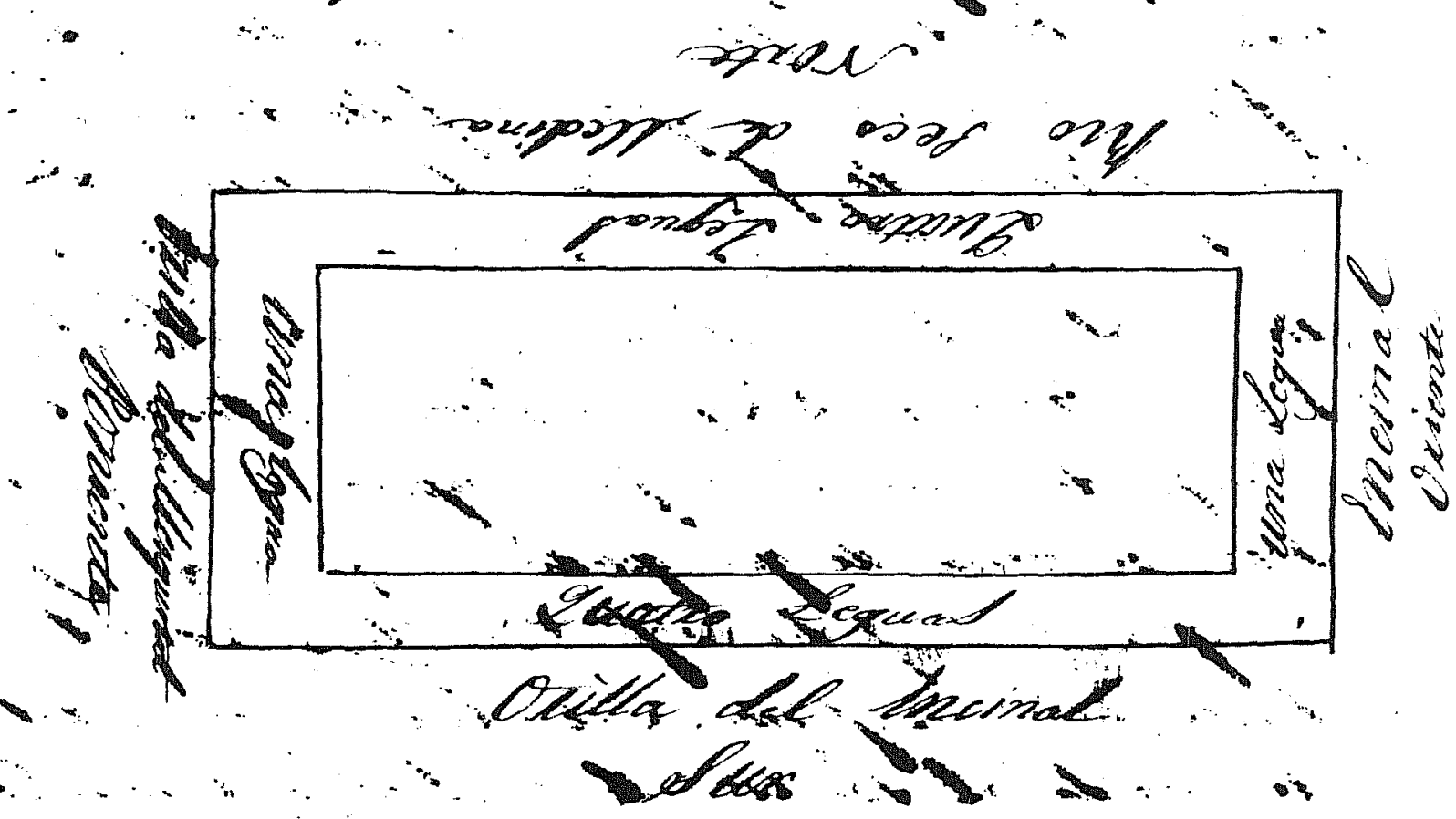

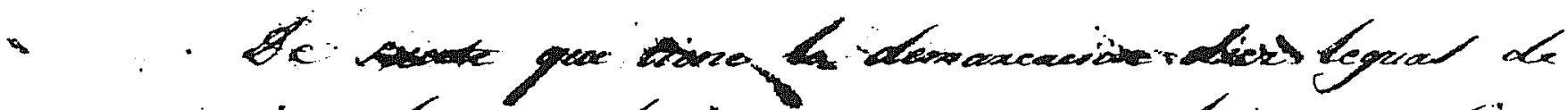

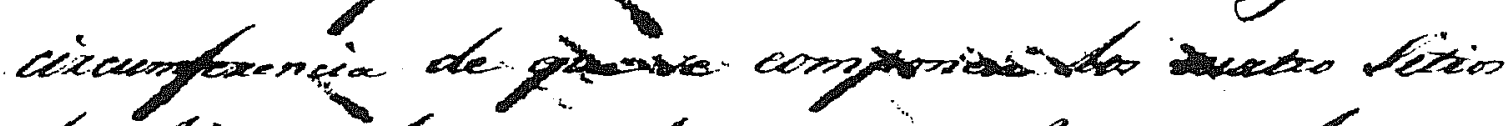

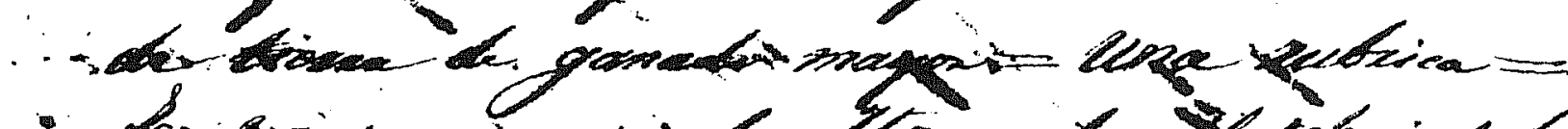

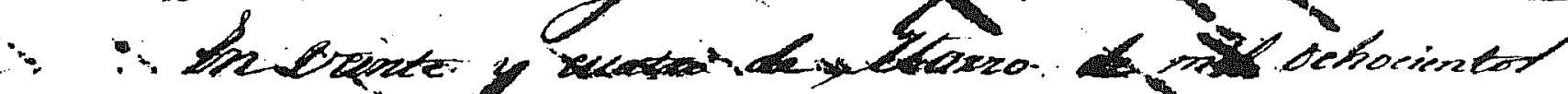

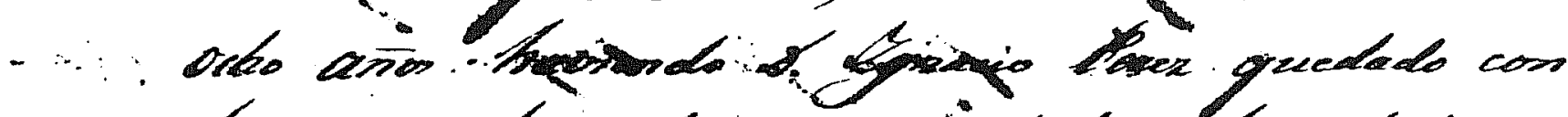

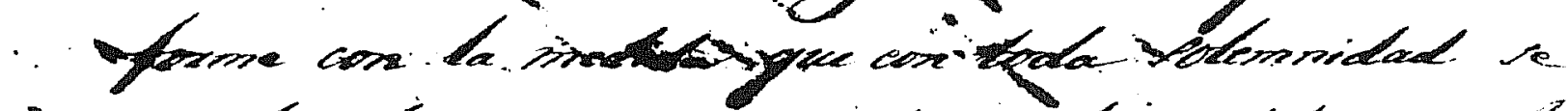

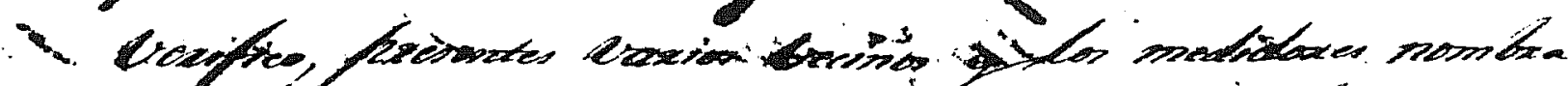

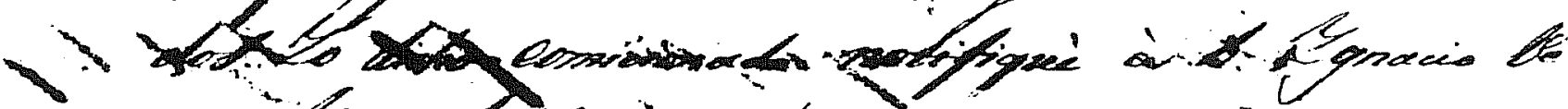

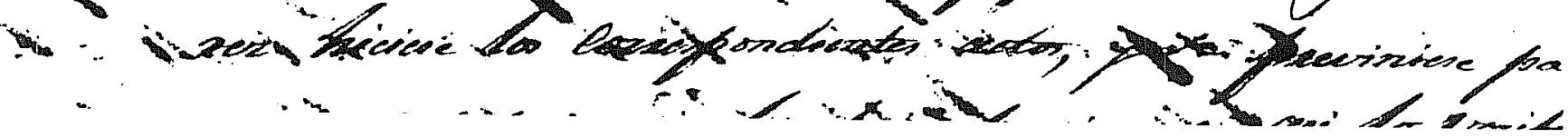

Figure 17. Surveyor's Map I 1 lustrating Ignacio Pérez's Claim of Four Leagues Along the Southern Banks of the Medina River. 
(two Teagues to him and one league he bought from Concepción Pérez for \$30) and one Teague to Gertrudis Pérez (whose first husband was Antonio Cordero, Spanish governor, and second husband was José Cassiano; BCDR Book B2:32).

José Ygnacio Pérez inherited, held possession, and lived on the Pérez Ranch, a "stone rancho," from at least the year 1800 until 1836. The land was cultivated, and he owned a large stock of cattle, horses, sheep, etc., that he pastured on the ranch (TGLO Paul vs. Pérez).

In 1834, Ygnacio Pérez petitioned the governor of the State of Coahuila and Texas for a legalized copy of the title of the Pérez Ranch, stating that, in the lapse of years, the testimonio of the corresponding title had been lost and that the original should exist in the archives of the former Province of Coahuila. The search was instituted, and the copy, certified as true and legal, was made (TGLO Paschal vs. Pérez).

In December 1836, Pérez, with his family, left Texas for the Rio Grande, fearing that if he remained in Texas he would be killed. [Author's note: Apparently there was a bounty on Ygnacio Pérez offered by a party of volunteers under Smith and Cook.] Pérez remained in Mexico until the year 1847 when he returned to Texas. According to testimony offered by Pérez, his stock continued to reside on the ranch, and taxes were paid by an agent of Perez. Other witnesses offered testimony that the ranch was not occupied by any agent, and in fact "the roof of the stone house was in a dilapidated condition and no signs of cultivation" were present (ibid.).

The will of Jose Ygnacio Pérez, made in 1849, stated the following:

I declare to own one sitio of land on the left margin of the Medina River, where I have a rock house [casa de piedra] some shacks [jacales] and some corrals [corrales] that I inherited from my late parents. . . Said sitio is my desire to donate it to my three daughters, Maria Trinidad, Maria Josefa, and Maria Concepcion. . . I I declare to own two sitios of 1 and on the right margin of 1and on the right margin of the Medina River... Said lands are in litigation on a law suit, and $I$ believe that said 7 ands will be given to me... I declare to own 380 head of cattle ... [and] 350 head of minor animals [cabesas de ganada menor] (BCA Probate Records Vol. D, red:169-177).

The lawsuit mentioned by Pérez reached the Texas Supreme Court in 1851. It was a direct result of the changing legal systems after the establishment of the Republic. Pérez was to lose the two leagues on the south bank of the river and retain the property on the north bank. (For a further discussion of the ranch see 41 BX 549.)

Testing of the historic component was directed toward three objectives: (1) a determination of the exact location of former structures;

(2) substantiation of chronological site age and span of occupations; and

(3) a reassessment of site potential based on collected materials as we11 as archival research. 
A problem encountered during intensive survey of the site area was a broadly scattered collection of limestone rocks which once composed the main occupation structure. The rock scatter precluded clear estimates of potential foundation locations as well as judgments on other possible site features (walls, outbuildings, corrals, etc.).

Given the objectives, limited site area, and manpower available, five specific methodologies were initiated:

1. An intensive resurvey of the site area and an interim analysis of collected diagnostic materials.

2. A systematic grid sampling strategy employing a 50-m ${ }^{2}$ grid and $50-\mathrm{cm}^{2}$ shovel tests utilizing a judgmental sampling technique.

3. Systematic sampling along the $50 \mathrm{~m}^{2}$ with an elevation interval of $2 \mathrm{~cm}$ to identify possible localized, manmade, contour anomalies.

4. A small-scale contour map of the $50 \mathrm{~m}^{2}$ with an elevation interval of $2 \mathrm{~cm}$ to identify possible localized, manmade, contour anomalies.

5. Phosphate $\left(\mathrm{PO}_{3}\right)$ soils chemistry sampling along the outlined grid zone to identify locations of increased $\mathrm{PO}_{3}$ distributions.

Al1 work was completed except the phosphate sampling, which was postponed due to time limitations. Phosphate sampling was considered applicable to the scope of operations but not critical to later site interpretations.

A summary of collected artifacts along with specific provenience from grid sampling is provided in the section entitled Material Culture, and general artifact concentrations are illustrated superimposed upon a sma11-scale contour map in Figure 18. Sampling units were $50-\mathrm{cm}^{2}$ shovel tests and screened through 1/4-inch wire mesh. Units were generally excavated to an average depth of $30 \mathrm{~cm}$; a historic cultural zone consisting of compacted soil, a slight color change, and a lense of cultural debris was invariably noted between $12-24 \mathrm{~cm}$ below the ground surface. Given the average dimensions of known Spanish colonial and Mexican Statehood period structures in the area, a 30-foot square was projected on the contour map to postulate areas of former structures. These are noted in Figure 18 as areas A, B, C, and $D$. Area $D$ is the location of a rectangular anomaly noted on a review of aerial photographs of the site.

A rectangular outline ca. $4 \times 5 \mathrm{~m}$ in the southeast margins of the site was noticed. A subsequent $1-\times 2-\mathrm{m}$ unit in this area excavated to $25 \mathrm{~cm}$ below the surface recovered an extensive amount of historical debris, including several items of 19th century(?) jewelry. It is believed this feature is the ephemeral remains of a small, dirt-floored structure (jacal) that at one time served as an occupation. Due to the limited amount of testing, little else is known of this feature at this time.

Limited testing at the historic component of 41 BX 274, and substantiated by archival research, indicates significant cultural deposits and extensive features exist in this location. Diagnostic materials indicate multiple 




Figure 18. Smal1-Scale Contour Map and Overlying Sampling Grid at 41 BX 274, Historic Component. Areas A-D represent possible buried structural remains. Cross-hatched areas represent concentrations of historic materials collected from subsurface sampling. Dashed lines indicate main site area. 
occupations from the early 19 th century (and perhaps earlier) to the mid $1800 \mathrm{~s}$. The presence of Goliad ware also suggests a historic period Indian component as part of or in the immediate vicinity of the historic component.

The unique variety of collected ceramics and metal from this site indicates that while this location was the site of a frontier ranch complex, the former inhabitants had both access to and the monetary resources necessary to obtain nonutilitarian, status-oriented material goods. At a time when these items were (both regionally and locally) a rarity (e.g., hand-painted porcelains), their occurrence at this site suggests that the former occupants had a social and economic position far above their contemporaries. Background archival research has confirmed that not only was Pérez prominent in the politics of the period but he was also one of the wealthiest and most successful of the Spanish ranchers in the region.

Prehistoric Component: The entire vicinity of the Elm Creek-Medina River confluence was extensively resurveyed during the 1984 field work to more clearly define the site area and to determine the scope of 1 imited testing operations that were to follow. Following initial survey, it was determined that the confluence location is related to an extensive prehistoric activity zone that extends from the vicinity of Applewhite Road and the river crossing upstream ca. $1.5 \mathrm{~km}$.

Following intensive survey and limited testing operations, we believe 41 BX 274 to be an extensive multiperiod occupation zone with specific concentrations of intensive activity areas as reflected by the discovery of deeply buried, intact features with chronologically diagnostic artifacts. Given the distribution and depths of materials, we project an intact, buried activity area in the northern site area in excess of $75-100 \mathrm{~m}^{2}$. This activity component, as identified by diagnostic materials noted in situ, dates to ca. 3500-3000 B.C. The varying depths of other noted features (burned rock clusters) in this area suggest the possibility of earlier deposits.

Given the extensive and intensive cultural deposits known to exist at this location, we estimate this location to be one of the largest occupation zones in the project area with an archaeological potential that can be measured in importance from a regional perspective. Since much of the materials are located on the margins of or in the maximum flood pool of the proposed reservoir, we anticipate severe site damage across much of this occupation zone.

A previously identified site, the prehistoric occupation zone has been extensively redefined following a series of intensive surveys as well as hand and mechanical excavation units. Well over a kilometer in length (see 41 BX 274), the site contains Early Archaic through possible historic Indian materials as identified by surface collections of diagnostic artifacts.

Limited testing, following intensive surveys to define the zone area, intrasite material concentrations, etc., took the form of five hand-excavated test groups in different locations. Systematic shovel testing and backhoe trenching were also employed (Fig. 19). 
This page has been

redacted because it

contains restricted

information. 
Test Group 1 consisted of two hand-excavated units; Unit A was a $2-m^{2}$ unit on the east side of a ranch road that bisected a concentration of 1 ithic debris and burned rock. Unit B, $1 \times 2 \mathrm{~m}$, was located just west of the road and ca. $5 \mathrm{~m}$ west of Unit $A$. Located in the approximate center of the occupation zone, the locality was first identified by an apparent deflated concentration of fire-reddened 7ithic debris and a scattering of burned rock. Test Group 1 was excavated to determine the extent of subsurface cultural materials and the possibility of a buried feature in this location. Unit A was excavated to a depth of 99.27 (60 cm below the ground surface) and Unit B to 99.47 (40 cm below the ground surface). The soil in both test units consisted of a poorly stratified fine-grained silty material, noncompacted to a depth of ca. $20 \mathrm{~cm}$. Soil compactness is noticeable at this depth as well as small caliche nodules scattered throughout subsequent levels. No stratigraphy was noted to a depth of $60 \mathrm{~cm}$. On1y $141 \mathrm{ithic}$ flakes and chips were found in Unit $A$ to this same depth, and all materials were in a widely scattered horizontal and vertical context in this unit. The same paucity of cultural materials was noted in Unit B. No features or diagnostic materials were collected at this test group location, and hand-excavations were suspended when backhoe trenching was allowed to test the site area. Subsequently, three backhoe trenches (Backhoe Trench series 1) were excavated adjacent to the handexcavated units. Each trench was ca. $4 \times 2 \mathrm{~m}$ and 3-4 m deep. Homogeneity of subsoil was noted to the floor of these trenches, and no features or cultural materials were noted during monitoring of the trenching. The 1ocation apparently represents an area containing a surface scatter of cultural materials extensively deflated by erosion.

Test Group 2 was situated in the northern margins of the occupation zone following intensive survey which identified a large burned rock cluster eroding from an arroyo wall ca. $3 \mathrm{~m}$ below the surface. A $1-x$ 4-m unit was excavated to eventually expose this feature (Feature 1; Fig. 20). The length of this linear burned rock cluster was slightly over $4 \mathrm{~m}$, with an irregular width varying between $50-100 \mathrm{~cm}$. The top of the feature was measured at 97.65 and the bottom at 97.40 (ca. thickness of $16 \mathrm{~cm}$ ). A smal1 burned rock cluster was also exposed ca. $1 \mathrm{~m}$ north of the main burned rock cluster at an elevation of 98.51. This burned rock cluster is thought to represent a later, presumably unrelated activity (Feature 2). Two chronologically distinct lithic tools were recovered in situ from the large burned rock cluster: an Early Triangular biface and a Guadalupe tool fragment. Both these artifacts have been dated to ca. 3380 B.C. locally. A third small burned rock cluster was uncovered ca. $4 \mathrm{~m}$ east of Feature 1 on the opposite side of the eroding arroyo complex. Partially eroded by a gully, the remains of a burned rock cluster ca. $2.5 \times 1 \mathrm{~m}$ were exposed to an elevation of 97.03 (vertically lower than the Early Archaic component of Feature 1). The following is a list of the lithic materials recovered from each of the three features from this test group. 




a

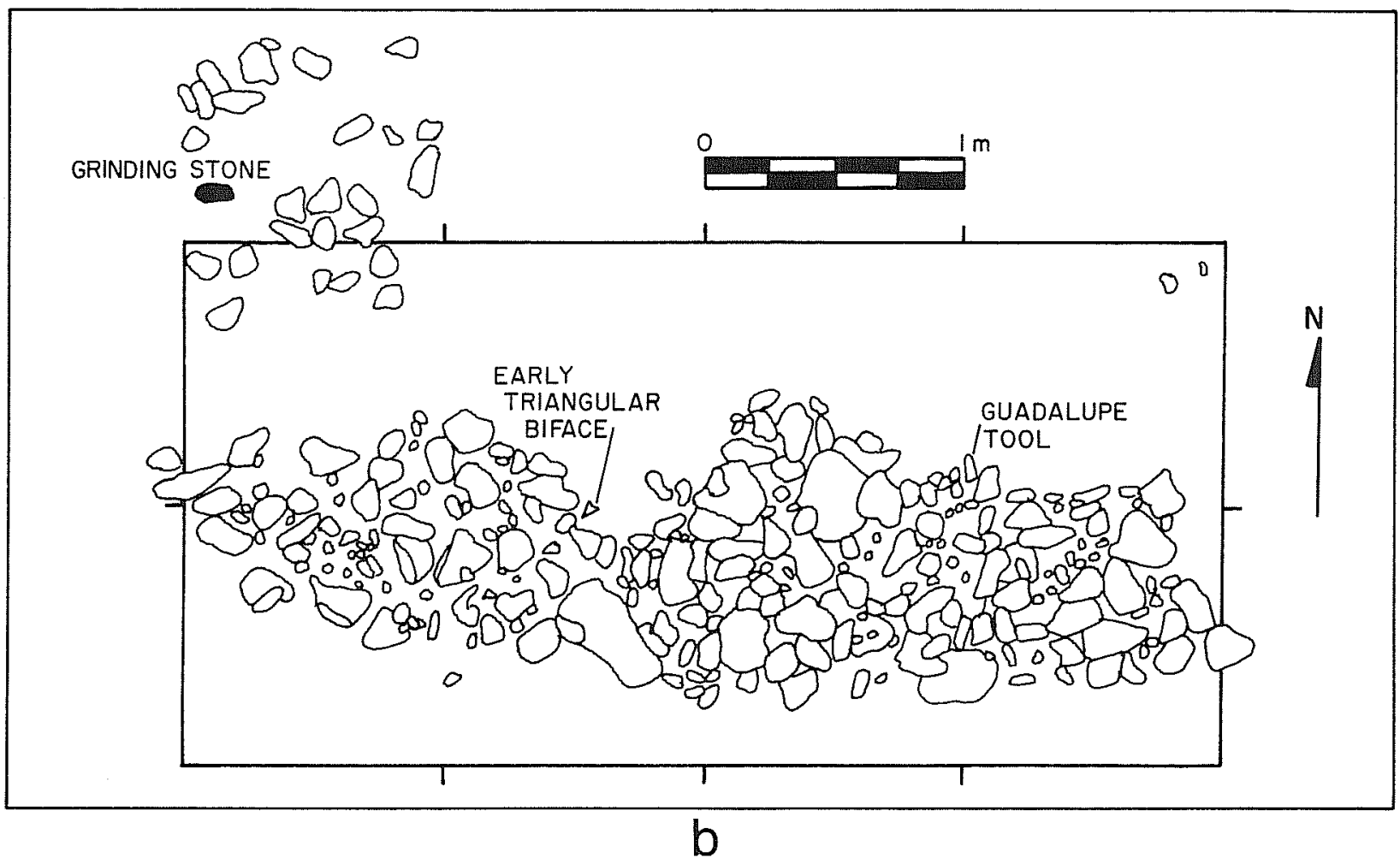

Figure 20. Feature 1 at 41 BX 274. a, burned rock cluster exposed at 41 BX 274; b, horizontal map of burned rock feature. 
Feature 1 (burned rock cluster, ca. 1 x $4 \mathrm{~m}$ in length, 97.64-97.40)

Type $\quad$ Count

Corticate chip fragments $\quad 31$

Decorticate chip fragments 62

Primary flakes 5

Secondary flakes $\quad 19$

Tertiary flakes

Single faceted platform $\quad 17$

Multifaceted platform 39

Utilized debitage 1

Core fragments 8

Guada7upe tool 1

Early triangular biface 1

Feature 2 (burned rock cluster, ca. $1 \mathrm{~m}^{2}, 98.60-98.51$ )

Type $\quad \underline{\text { Count }}$

Corticate chip fragments 3

Decorticate chip fragments $\quad 10$

Tertiary flakes

Single faceted platform 4

Core fragment

Ground stone cobble
3

4

1

Feature 3 (burned rock cluster, ca. $2.5 \times 1 \mathrm{~m}, 97.03-96.91$ )

Type count

$\begin{array}{lr}\text { Corticate chips } & 7 \\ \text { Decorticate chips } & 47 \\ \text { Primary flakes } & 1 \\ \text { Secondary flakes } & 6 \\ \text { Tertiary flakes } & \\ \text { Single faceted platform } & 5 \\ \text { Multifaceted platform } & 14 \\ \text { Core fragments } & 2\end{array}$

Test Group 3 consisted of a systematic series of $50-\mathrm{cm}^{2}$ shove 1 tests along the central and southern site zone locations. A71 units were excavated to a minimum depth of 50-60 cm and were spaced at consistent intervals (allowing for the variabilities of topography and brush) at ca. 50-m intervals. Given the large site dimensions, it was thought that the deep but relatively slow and costly efforts of mechanical trenching could be favorably complemented by quickly dug shallow test units. These shovel tests would be directed toward an identification of any shallow cultural deposits that might be concealed by relatively recent aeolian sand deposits. The systematic sampling would also contribute to a broader interpretive base for discussing site significance. While in design, this would appear to work quite well, the practical result 
of these efforts only confirmed what was becoming apparent through backhoe trenching; while an extensive scatter of lithic materials existed on the surface of this occupation zone, prehistoric features and material concentrations existed in discrete intrasite activity areas. Only scattered lithic debris were noted through the shovel testing, and no features were discovered. The contribution of Test Group 3 to site interpretations was primarily an objective form of systematic sampling that determined the 7 ack of significant cultural materials in various site areas.

Test Group 4 consisted of a series of $1-m^{2}$ units opened into a horizontal excavation to most effectively cover an activity area first identified by an extensive concentration of eroding burned rock. Two Guadalupe tools were also collected during investigations within $5 \mathrm{~m}$ of the burned rock concentrations. Total horizontal area of Test Group 4 is illustrated in Figure 19. On1y an estimated 25-30\% of the burned rock concentration-feature has been uncovered. As the actual size of the feature became apparent, excavations and 1 imited testing continued only long enough to determine the physical extent and chronological associations of the materials.

Total estimated area of the burned rock concentration and related activity area of this feature (Feature 4) are over $50 \mathrm{~m}^{2}$. Testing suggests this is a chronologically discrete feature, perhaps related to Feature 1 at Test Group 2. The natural stratigraphy of this area is unusually complex and suffers from the effects of modern erosion. Given the complexity of the natural as well as cultural stratigraphy and the 1 imited feature area uncovered, investigations suggest Early Archaic cultural deposits 1 ie upon an ancient terrace remnant long since buried by modern aeolian materials. Since both Feature 4 at Test Group 4 and Feature 1 at Test Group 2, ca. 10 m north, are known to be of the same cultural age, it is assumed occupational activities took place on the slopes and base of a small knoll at the edge of a fossil floodplain. Activities are known to extend to at least $8 \mathrm{~m}$ east as per the remains of a small burned rock cluster exposed in a backhoe trench in this area at a depth of $98.51-98.41$.

The Early Archaic burned rock cluster and related cultural materials are thought to extend across the locality at a depth of ca.98.60-97.90. A modern erosion channel has apparently bisected the early cultural deposits. The most significant diagnostic materials recovered from this feature are Guadalupe tools associated with Martindale and Bell projectile points. In two instances, a projectile point was associated with a Guadalupe tool in the same (and adjacent) unit and at the same elevation. Provenience of 7 ithic materials is listed in Table 8.

Test Group 5 was a single excavation unit $\left(1 \mathrm{~m}^{2}\right)$ excavated ca. $25 \mathrm{~m}$ southeast of Test Group 4. Intensive survey of the site area discovered a rodent burrow characterized by 1 ithic debris scattered throughout the backdirt. Two smal1, unidentified dart points were extracted from the disturbed area. Additionally, a small grooved cobble was also later found. This artifact is similar to Turner and Hester's (1985:258) description of Waco "Sinkers" that commonly occur in central Texas. Although the test unit was excavated to a depth of $40 \mathrm{~cm}$ below the surface, only a disturbed scatter of lithic debris was collected. No features were noted. 
TABLE 8. PROVENIENCE OF COLLECTED MATERIALS FROM FEATURE 4, TEST GROUP 4, 41 BX 274

\begin{tabular}{|c|c|c|c|c|c|c|c|c|c|}
\hline \multirow[b]{2}{*}{ Unit $\left(1 \mathrm{~m}^{2}\right)$} & \multicolumn{2}{|c|}{ Chips } & \multirow[b]{2}{*}{$\begin{array}{c}\text { Core } \\
\text { Fragments }\end{array}$} & \multicolumn{4}{|c|}{ Flakes } & \multirow[b]{2}{*}{ Tools } & \multirow[b]{2}{*}{$\begin{array}{l}\text { Projectile } \\
\text { Points }\end{array}$} \\
\hline & Corticate & Decorticate & & Primary & Secondary & $\begin{array}{l}\text { Tingle } \\
\text { Sint } \\
\text { Faceted } \\
\text { Platform }\end{array}$ & $\begin{array}{l}\text { Pary- } \\
\text { Multi- } \\
\text { Faceted } \\
\text { Platform }\end{array}$ & & \\
\hline E1000 N1001 & 15 & 15 & 10 & 1 & 8 & 14 & 10 & $\begin{array}{l}\text { (1) Distally } \\
\text { Beveled Biface } \\
(98.37)\end{array}$ & $\begin{array}{l}1 \text { (Unidenti- } \\
\text { fied) } \\
(98.47)\end{array}$ \\
\hline E997 N1000 & 1 & 6 & & & & 1 & 1 & & \\
\hline E997 N999 & 19 & 17 & & 2 & 3 & 13 & 7 & & \\
\hline E998 N999 & 3 & 12 & 1 & & 2 & 2 & 7 & $\begin{array}{l}\text { I (Guada lupe) } \\
\text { (98.47) }\end{array}$ & $\begin{array}{l}1 \text { (Be11) } \\
(98.47)\end{array}$ \\
\hline E999N999 & 2 & 12 & & & 2 & 5 & 7 & $\begin{array}{l}1 \text { (Guadalupe) } \\
(98.57)\end{array}$ & $\begin{array}{l}1 \text { (Martindale) } \\
(98.57)\end{array}$ \\
\hline $\begin{array}{l}\text { El000 N999 } \\
\text { E999 N998 }\end{array}$ & $\begin{array}{l}4 \\
2\end{array}$ & 5 & 1 & 2 & $\frac{1}{2}$ & $\begin{array}{l}3 \\
2\end{array}$ & $\begin{array}{l}1 \\
1\end{array}$ & & \\
\hline E998 N998 & 8 & 13 & & & 1 & 8 & 4 & $\begin{array}{l}2 \text { (Guadalupe) } \\
(97.97-98.05)\end{array}$ & \\
\hline E999 N998 & 5 & 16 & 2 & & 6 & & 12 & $\begin{array}{l}\text { 1 (Unifacial } \\
\text { Distally } \\
\text { Beveled Tool; } \\
98.20 \text { ) }\end{array}$ & \\
\hline E1000 N998 & & 2 & & & & 2 & & & \\
\hline
\end{tabular}


Mechanical trenching consisted of four separate groups of trenches (Fig. 21). Individual trenches in these groups were ca. $4 \times 1.5 \mathrm{~m}$ and varied in depth from 1-3 m. Trenching was utilized to determine the extent and depth of suspected subsurface deposits. The general location of trenches is illustrated in Figure 19.

Backhoe trench series 1 was a group of three trenches excavated adjacent to the hand-excavated Test Group 1. Similar subsoil and (a lack of) cultural materials were found in each trench; from the surface to ca. $22 \mathrm{~cm}$ the soil consisted of a loose, fine-grained sand. Three small chert flakes were noted at $10 \mathrm{~cm}$, three burned sandstone fragments at $14 \mathrm{~cm}$.

A distinct soil change was noted at $25 \mathrm{~cm}$; the soil became more compact and clayey. No cultural materials were noted. Caliche inclusions $(1-1.5 \mathrm{~cm}$ in diameter) were observed in wall profiles at $40-45 \mathrm{~cm}$. By $53 \mathrm{~cm}$, the soil became very compact with an increase in caliche nodules. A slight color change was noted with ephemeral calcareous lenses. At 2.5-3 m, the soil had become so compacted that excavation efforts were terminated. Wall profiles were basically homogeneous, and no features or cultural levels were noted.

Backhoe trench series 2 consisted of five trenches along the southeast margins of the occupation zone. While some lithic debris was observed scattered along the surface, only one trench revealed any indication of possible prehistoric activity (two fragments of mussel shell and four smal1 pebbles[?]). Limestone bedrock or a large outcropping was found in three of the trenches at $1.5 \mathrm{~m}$ below the surface. A compacted caliche was struck in the last two trenches at 1.4-1.8 $\mathrm{m}$, and further testing by the backhoe proved infeasible. No features or natural stratigraphy was noted in the area except for a 700 se topsoil layer. Below $30 \mathrm{~cm}$, a soil transition was noted with more compacted clayey soil and caliche intrusions.

Trench series 3 consisted of two $2 \times 1.5 \mathrm{~m}$ excavations dug to $1.6 \mathrm{~m}$. Bedrock was uncovered at this depth. Both trenches were excavated in an area of high surface concentrations of 1 ithic debris and burned rock. Unconsolidated, sandy materials were noted to $90 \mathrm{~cm}$; below this, the soil became compacted and clayey. Small pebbles were noted at $55 \mathrm{~cm}$. No cultural materials were observed below the surface in either trench.

Backhoe Trench series 4 was excavated in the northern margins of the occupation zone in the vicinity of hand-excavated Test Groups 2 and 4. Fifteen individual trenches were excavated in three general locations: (1) three trenches in the up 1 and margins adjacent to Test Groups 2 and 4; (2) four trenches just west of this former area and along the floodpla in margins; and (3) five trenches farther west along the modern banks of the Medina River (Fig. 19).

As the significance of Features 1 and 4 was recognized in this area, efforts were made to describe the intrasite relationships. Particular interest was placed on the floodplain as a former resource (exploitation) area or as the location of a multifunctional occupation area related to the activities of Feature 1 and 4 . Only one of the five trenches revealed any cultural materials: a small burned rock cluster ca. $75 \mathrm{~cm}$ in diameter was uncovered at a depth of $1.94 \mathrm{~m}$ below the surface. No diagnostic artifacts were 
associated with this feature, and adjacent backhoe trenches showed no evidence of related features or other cultural materials. Feature matrix was removed from this burned rock cluster, and all soil was processed by flotation to extract possible bone and seed remains. Preliminary inspection of these materials indicated burned bird bone fragments (waterfowl?) were the most common type of the recovered bone. Very little charcoal was observed, although some small fragments were collected, and a variety of small snails was recovered for further analysis.

No cultural materials were excavated in trenching of several small knolls along the banks of the modern river channel to the west of the site. Extensive gravel beds were encountered at varying depths of $90-150 \mathrm{~cm}$ below the surface.

Only one of the three upland-excavated trenches adjacent to Test Groups 2 and 4 had a cultural feature; this trench was 1ocated ca. 6 m northeast of Test Group 4, and a small burned rock cluster ca. $1 \mathrm{~m}^{2}$ was uncovered at a depth of 98.51-98.48 (or about $1 \mathrm{~m}$ below the ground surface). A small distally beveled bifacial tool (Clear Fork) was collected in situ from this feature. Its horizontal relationships and diagnostic tool type suggest a contemporaneous or perhaps slightly earlier date than the Early Archaic cultural features exposed in Test Groups 2 and 4.

Site significance: The historic component of the site is one in a series of occupations and/or land ownership by members of the Pérez-Linn-Walsh families in this area of the Medina River valley for at least 185 years, with ownership possibly as early as 1754-1780. The original family member in the area, José Antonio Péres (Pérez), was from the Canary Islands and arrived in San Antonio de Béjar in 1731. The family was one of the most influential and wealthiest in Spanish Texas. Additionally, the rancho complex itself is a reflection of changing Spanish colonial economic patterns of the late 18th century; its existence and success illustrate the decline of mission ranch influences, the growth of privately owned ranching, and a subsidence of Indian hostilities which had contained the expansion of Spanish influence in Texas for almost a century.

The authors consider the prehistoric component to be eligible for nomination to the National Register of Historic Places because of the depth, extent, and possible significance of intact deposits. The site represents the remains of activities during a poorly understood period. The presence of undisturbed features dating from the transitional Late Paleo-Indian through more recent times indicates further investigations should offer substantial contributions to the archaeological record.

Management recommendations: In the opinion of the authors, this site is eligible for listing on the National Register of Historic Places based on: (1) the association with events that have made a significant contribution to the broad patterns of our history; (2) the association with the 1 ives of persons significant in our past; and (3) the potential to yield information important in prehistory or history. We recommend that a determination of eligibility to the National Register of Historic Places should be sought from the Keeper. 


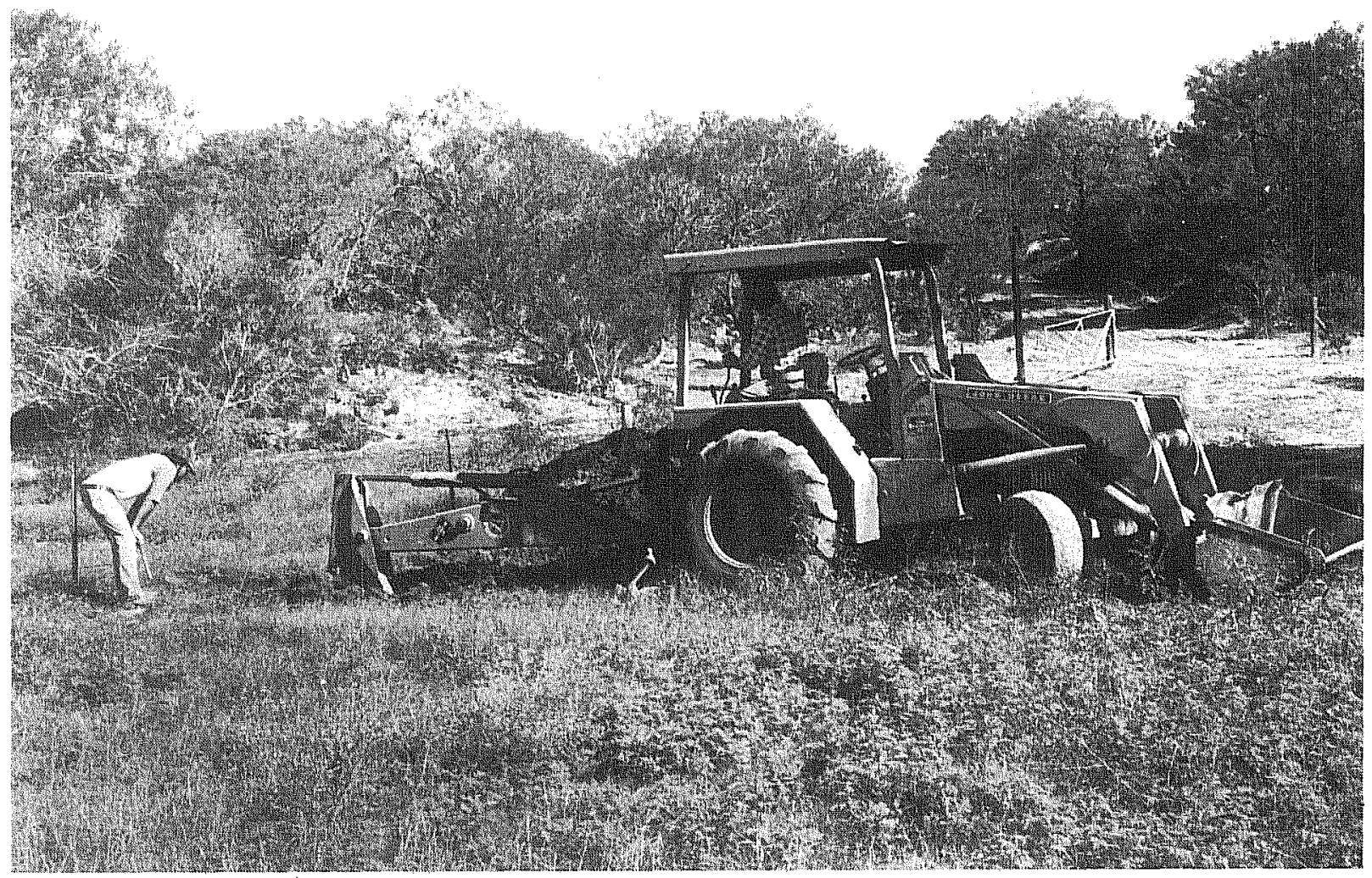

Figure 21. Backhoe Trenching in Progress at 41 BX 274.

The prehistoric component is located within the conservation flood pool Tevel of the proposed reservoir. Portions of the historic component are located in the maximum flood pool level with the most obvious remains located adjacent to this leve1. Additionally, a review of proposed reservoir data indicated that the site is in the vicinity of the projected future location of a lake pump station with potentially destructive impacts. Vandalism has already occurred at this site, and increased accessibility will only lead to further attempts. Avoidance of this cultural resources zone is strongly recommended; if not possible, mitigation is suggested to partially offset the destructive impacts of the proposed reservoir. 


\section{SITE 41 BX 277 (Pérez Cemetery and Chape1)}

Type of site: Historic.

Location: This site is ca. $1.2 \mathrm{~km}$ south of Watson Road and ca. $700 \mathrm{~m}$ west of Applewhite Road.

Elevation: ca. 570 feet above msl.

Topographic context: The site is located on a marginal upland context adjacent to a former terrace of the Medina River and a projected fossil confluence of Leon Creek.

Water source: Not applicable to a cemetery site.

Vegetation and soil: The site area has been cleared; short grasses surround site complex. The soil is a fine-grained, sandy material overlying more compacted clayey soil.

Site condition: The chapel is restored. The area surrounding the complex has been cleared by modern farming; however, it appears that the site itself has changed little and remains intact.

Artifactual material present: Not applicable.

Site discussion: This cemetery was first identified in 1981 from records research, and no on-site inspection was conducted here due to difficulties in access. In 1984, permission was obtained to conduct an on-site survey of the property. The site consists of a reconstructed stone and plaster chapel (not roofed) and an adjacent cemetery. The reconstructed chape1 (with two of the original ornate iron gates) sits on the foundations and/or ruins of the original chapel which may have existed at this location in the early 1800s, when the landowners, Colonel Juan Ignacio and José Ignacio Pérez, were residing at the nearby rancho (41 BX 274). An estimated 55 to 60 burials are located directly west of the chapel within a fenced area; most are poorly marked. Research revealed that beneath the floor of the present chapel lies the bodies of seven members of the Perez-Linn family. These burials are of the following people:

Jose Ignacio Pérez (the colonel's son), the first person buried in the cemetery, born September 24, 1786, died October 26, 1852.

Maria Josefa Cortinas Pérez, the wife of José Ignacio Pérez, born 1786(?), died Saturday, June 1, 1861, at 2 p.m.

Jacob Linn, the son-in-1aw of José Ignacio and Josefa Pérez, born November 30, 1825, in Bavaria, died December 8, 1878.

María Josefa de Jesús de Anastacia Toribia Pérez Linn, the wife of Jacob Linn, born Apri1 26, 1824, died December 23, 1889.

Ignacio del Refugio, the son of José Ignacio and Josefa, born(?), died(?). 
Ignacio Martin Pérez, the son of José Ignacio and Josefa Pérez, born(?), died(?).

Maria Trinidad Pérez, the daughter of José Ignacio and Josefa Pérez (Casamira de 1 a Concepción Linn Walsh always referred to her aunt as "Mama Trinidadcita"), born December 14, 1855, buried July 1, (?).

Total area of the chapel and cemetery complex is ca. $61 \times 66.5 \mathrm{~m}$. The chape 1 and cemetery are directly related to but spatially discrete from the former ranch at 41 BX 274.

Site significance: The chapel and cemetery are an important component of the Perez rancho site (41 BX 274); the graves of members of one of the most influential families in the study area are located here. Additionally, the site is part of the continuous occupation in this area along the Medina River valley by the Pérez-Linn-Walsh family for over 150 years.

Management recommendations: In the opinion of the authors, this site is eligible for listing on the National Register of Historic Places based on the cemetery's primary significance being derived from the graves of persons of transcendent importance, age, and association with historic events. We recommend that a determination of eligibility should be sought from the Keeper.

Although the site is above the maximum flood pool level of the proposed reservoir, it is estimated that the site is located in proximity of the southern margins of a projected diversion canal from the proposed reservoir to the Leon Creek drainage. It should be noted that the site has been vandalized in the past, and proximity to such reservoir margins would greatly increase accessibility to the site. Preservation of this site must be considered a priority if the proposed reservoir is to be constructed.

\section{SITE 41 BX 343}

Type of site: Small prehistoric lithic reduction site, possibly some light occupational activities as well.

Location: Along the upland margins and slopes of an eroded terrace remnant on the south side of Medio Creek, approximately $0.5 \mathrm{~km}$ southeast of Interstate Highway 35 and its intersection with Medio Creek.

Elevation: 550 feet to 570 feet above ms 1 .

Topographic context: The site is located along the highest terrace of the modern creek channel and extends westward (ca. $150 \mathrm{~m}$ ) to a flat upland area. Probably related to past 1 and clearing, deep erosional gullies (0.5-2 $\mathrm{m}$ deep) dissect the site's eastern slope. 
Water source: Medio Creek is less than $50 \mathrm{~m}$ from the northeastern site margins.

Vegetation and soil: Tarrant associated, rolling soil; dark grayish brown calcareous clay loam with some natural occurrence of small chert cobbles and pebbles. The site area and its environs have been cleared of natural vegetation by extensive modern 1 and alterations. Short grasses dominate the location currently used as a pasture area, and some thorny brush and mesquite were observed in the northwest margins of the site in deep erosional gullies and along the eastern slopes toward the drainage.

Site condition: Severely damaged by past land clearing, plowing, and natural erosion.

Artifactual materials present: A light scatter of lithic debris in the form of small core fragments; secondary and tertiary flakes; and corticate and decorticate chips was observed across the site area (ca. $200 \times 150 \mathrm{~m}$ ). It was estimated surface distribution density of these materials did not exceed more than two debris fragments per $20 \mathrm{~m}^{2}$. Several fire-reddened chips and less than a dozen small burned and/or fragmented limestone cobbles were also noted in a disturbed context, suggesting at least some temporary form of occupational activities.

Site discussion: The site was first identified in 1981. Subsequent intensive surveys (the site was revisited on two separate occasions) employed transect intervals of ca. $25-35 \mathrm{~m}$ along simple east-west azimuths. A $50-\mathrm{cm}^{2}$ shovel test excavated to a depth of $30 \mathrm{~cm}$ in the estimated center of the site area did not recover any prehistoric materials or features, although a modern pull-ring tab was noted at $27 \mathrm{~cm}$. 0bviously, this indicates serious subsurface disturbance to a depth of at least $30 \mathrm{~cm}$, possibly the extent of a deep plow zone. Severe erosional gullies disect the northern and eastern site margins and slopes, with individual erosional exposures varying in depth from $0.5 \mathrm{~m}$ to almost $2 \mathrm{~m}$. No diagnostic artifacts, material concentrations, or features were noted on the surface or in numerous erosional exposures. One small medial biface fragment of 1 ight brown chert was collected from the southeast portion of the site, representing the only worked chipped stone material from this location.

Examination of the area directly across the creek channel (east) indicated severely modified terraces due to land grading and bulldozing. Several burned rock fragments were observed in this area, but no identifiable materials were noted. It is possible that at one time prehistoric materials ranged to Medio Creek in this locality, but the degree of modern alterations has seriously impacted the integrity of cultural deposits.

Site significance: Site 41 BX 343 is thought to represent the remains of a small 1ithic workshop area, as evidenced by the types of 1ithic debitage present. Given the natural occurrence of chert cobbles and pebbles in the stony soils at this location, the site may have also functioned as a lithic procurement area similar to $41 \mathrm{BX} 569$, ca. $1.5 \mathrm{~km}$ to the east. Unfortunately, the extensive surface disturbances caused by land clearing, plowing, 
and erosion have seriously affected the potential of this site to contribute to a clearer understanding of prehistoric lithic procurement patterns and distributions in the lower Medina River valley. It should be recognized that potential, as yet unidentified, buried deposits may qualitatively affect site significance.

Management recommendations: The site is located in the maximum flood pool level of the proposed reservoir and is one of the more severely disturbed locales identified in the project area. On the basis of investigations to date and the lack of chronologically diagnostic or culturally significant materials, site 41 BX 343 does not meet the criteria for National Register nomination. It should be noted, however, that the subsurface examination of cultural deposits was limited to a small test unit and inspection of erosional cuts. If stratigraphically earlier deposits are located at this site in excess of, for example, $2 \mathrm{~m}$ in depth, these would not have been identified by work to date.

The site lacks the material indicators usually associated with known buried sites of the study area: variation of patina on surface scattered lithic debris, evidences of buried materials such as lithic debris, bone, and shel1 fragments from erosional walls or washes, burned or fire-fractured rock associated with intact buried features which may have been revealed during episodes of land clearing or deep-plowing, and spatial association with other nearby known occupation sites/zones.

\section{SITE 41 BX 344 (Francisco Antonio Ruíz Site)}

Type of site: Multicomponent.

Location: Parallel to and adjacent to entrance road of former Prosise Ranch complex, from gate to end of property.

Elevation: ca. 560-580 feet above msl.

Topographic context: The site is located along an upper terrace of the Medina River.

Water source: Medina River is ca. $150 \mathrm{~m}$ from site; we11.

Vegetation and soil: Short grasses and mesquite trees were noted.

Site condition: Some areas are extensively disturbed by the modern ranch complex. Erosion along the terrace wall is moderate to heavy.

Artifactual materials present: In 1981, the archaeological evidence consisted of a light surface scatter of lithic debris. A proximal fragment of a Guadalupe tool was found at ca. $220 \mathrm{~cm}$ in situ. Charcoal flecks were aTso observed. In 1984, a revisit to the site revealed that historic materials were also present. Artifactual materials observed but not 
collected were hard paste earthenwares (hand-painted, ca. 1820-1850; flow blue ceramics, ca. 1820-1850; pearlwares, ca. 1820-1850; banded slipware, ca. 1820-1850; yellow ware; transferware, ca. 1820-1850; Blue Willow); stoneware, ca. mid to late 1800 s; porcelain, including hand-painted; ironstone, ca. 1ate 19th-early 20th century; glass (pressed bottle fragments and milk glass); and metal (brass powder compact, cut nails, etc.).

Site discussion: The site was identified in 1981. The dimension of the site, based on the scatter of artifactual materials, is ca. $200 \times 400 \mathrm{~m}$, linear in shape. The prehistoric component is multifunctional. Buried deposits were observed in a bulldozer cut in the southeast portion of the site. A profile of this cut indicated that the site may have included a minimum of three buried cultural levels: (1) a surface to $15 \mathrm{~cm}$ cultural zone; (2) at $180 \mathrm{~cm}$; and (3) at ca. 300-325 cm below the surface. A proximal fragment of a Guadalupe tool was found in situ in the wall at ca. $220 \mathrm{~cm}$. Five meters east and at a depth of $301 \mathrm{~cm}$, a lithic debris concentration was collected from a small pocket in the profile. Charcoal flecks were also observed throughout the length of the $15-\mathrm{m}$ profile. The site is unusual in two respects: (1) the extensive depth of deposits, particularly below a possible artifact associated with the Early Archaic; and (2) the bul1dozer cuts revealed that intact, deeply buried cultural components exist.

The occurrence of deeply buried prehistoric archaeological deposits has been recognized at other Tocales within the study area. Site 41 BX 274 , for example, reflects Early Archaic associated features and materials, including Guadalupe tools buried 2-3 $\mathrm{m}$ below the surface.

Because of extensive modern alterations to the surface area of $41 \mathrm{BX} 344$, only a disturbed, light scatter of 1 ithic debris may be observed. Observations at the bulldozer cut indicate that traces of intact subsurface deposits exist at this site, and a reasonable possibility exists for further, more concentrated buried materials in the immediate area. Although the site is located above the maximum flood pool level, it should be considered significant because the identification of buried deposits over $3 \mathrm{~m}$ in depth indicates a probability that some buried site deposits may be more directly affected by reservoir impacts (along the steep terrace margins).

Archival research conducted in 1984 suggested that the site should contain a historic component. The area is a part of a Spanish land grant which has been identified by Weddle and Thonoff $(1976: 154)$ as inherited by Juan Manual Ruiz, patriarch of the Ruiz-Navarro-Herrera families. Copies of family papers located at the Bexar Archives say that the land was granted to the Ruiz family in 1774 (BCA Ruiz Files). (The original Spanish grant has not been located by the authors.) From January 1778, to Apri] 1778, Juan Manuel Ruiz branded "two calves and two anejas" (BAT Vol. 68:63). Chabot (1937:199) wrote that in 1822, when José Francisco Ruiz returned to Texas from the United States, he gave "attention to his large ranch holdings west and southwest of San Antonio."

The first conclusive record found, by the authors, is dated 1838, when Francisco Antonio Ruíz, son of Juan Manuel Ruíz, was granted a tract of 1 and on the Medina River (BCDR Vol. A1). In 1849, Ruiz registered his brand "on the Medina for horses, mules and cattle" (BCA Records of Marks and Brands). 
In 1850, Francisco Antonio Ruiz, age 39, his wife Concepción, age 41, and two sons were living on the Medina River (BCA 1850 Census Records). The 1 and was resurveyed for Ruiz in 1855 (BCA Surveyors Field Notes, Vol. F1). In 1883, the Francisco Antonio Ruíz survey was subdivided by Maria Antonia Ruíz de Herrera, sister of Ruiz and wife of Blas Herrera. Of eight children, each child received approximately 128 acres of 1 and. The site is on the property inherited by Francisco Herrera and Benito Herrera (BCDR Vo1. 32:437, 612). For a further discussion of this survey, see 41 BX 667, 41 BX 670, 41 BX 671, 41 BX 672, 41 BX 673, 41 BX 674, and 41 BX 697.

During a revisit to the site in 1984, the historic component was confirmed. The site contains one stuccoed frame home (ca. Tate 1800s; Figs. 23; 24,a), one plastered stone or stuccoed frame home (extensively remodeled, ca. late 1800 s; Figs. $22 ; 24, b)$, numerous cinder block homes of recent origins, several sheds and/or barns of recent origins, and numerous other farming and/or ranching-related objects. The structures sit directly along the edge of an eroding terrace ca. $150 \mathrm{~m}$ north of the Medina River. This entire terrace for ca. $400 \mathrm{~m}$ contains extensive deposits of historic cultural materials (glass, ceramics, and metal). A scatter of stones and cut nails probably indicates the remains of an early structure. Artifacts observed eroding from the terrace indicate an occupational sequence from ca. 1820-1840 to the present. The artifactual assemblage is remarkably like that of the Ygnacio Pérez site (41 BX 274) and contains some materials (e.g., porcelain sherds) that indicate a we11-to-do economic status.

Ruiz Family: Juan Manuel Ruỉz was born in Queretaro in 1726 (or 1737). He married Manuela de la Peña, born 1745, in Saltillo. To this union, 12 children were born: (1) Maria Gertrudis Josefa, born November 22, 1766, married Angel Navarro; (2) Ana Petra, born July 23, 1769, died August 2, 1769; (3) Ana Petra, baptized September 11, 1770, died September 11, 1770; (4) Maria Antonia, born 0ctober 24, 1771, first marriage to Francisco Calvi110 and second marriage to Marcos de Ybarbo, August 21, 1788; (5) José Antonio, born March 9, 1774, died March 13, 1774; (6) José Antonio Pablo Longino, born March 13, 1775, died February 13, 1812 (single); (7) Maria Ygnacia, born September 26, 1779, died 0ctober 8, 1779; (8) José Antonio Francisco Victoriano, born August 31, 1789, married Josepha Hernández, March 8,1804 , died January 20, 1840; (9) José Francisco, born January 29, 1783; (10) María Gertrudis, born November 21, 1786; (11) José Francisco, born March 8, 1789; and (12) Juan Francisco, twin of José Francisco (BCA Ruiz Files).

Juan Manuel Ruiz died on July 30, 1797, and was buried in San Antonio (Chabot 1937:198). His wi11, dated 1797, left "one roofless rock house located at the corner of Real and Flores Streets in the Villa of San Fernando, also one axe, two slightly used hoes, and one painting on linen of St. Anthony de Padua" (BCA Ruíz Files).

José Francisco Ruiz, the son of Juan Manuel Ruíz and Manuela (de 1a Peña) Ruiz was born on August 31, 1780, in San Fernando de Béxar (Chabot 1937:198). He was sent to Spain in his youth to acquire his education and upon his return joined his father in a business enterprise (Chabot 1937:199). On January 20, 1803, Ruiz was appointed school teacher by the order of the Cabildo (Santos 1966:5). He married María Josepha Hernandez, the granddaughter of Andres Hernandez, on March 7, 1804. The marriage was performed 


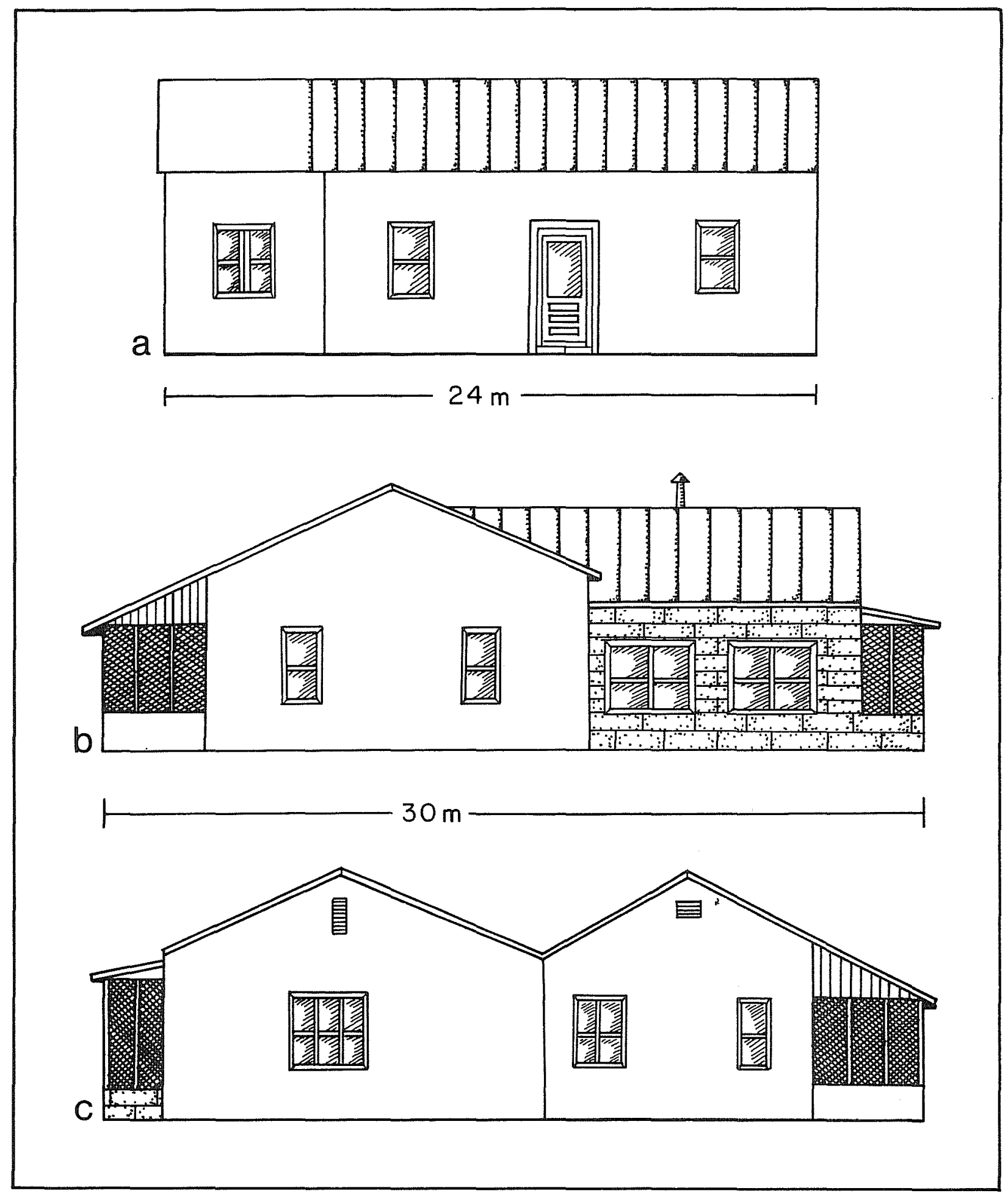

Figure 22. P1astered Stone Structure at 41 BX 344. a, front; b, view toward west; $c$, view toward east. 

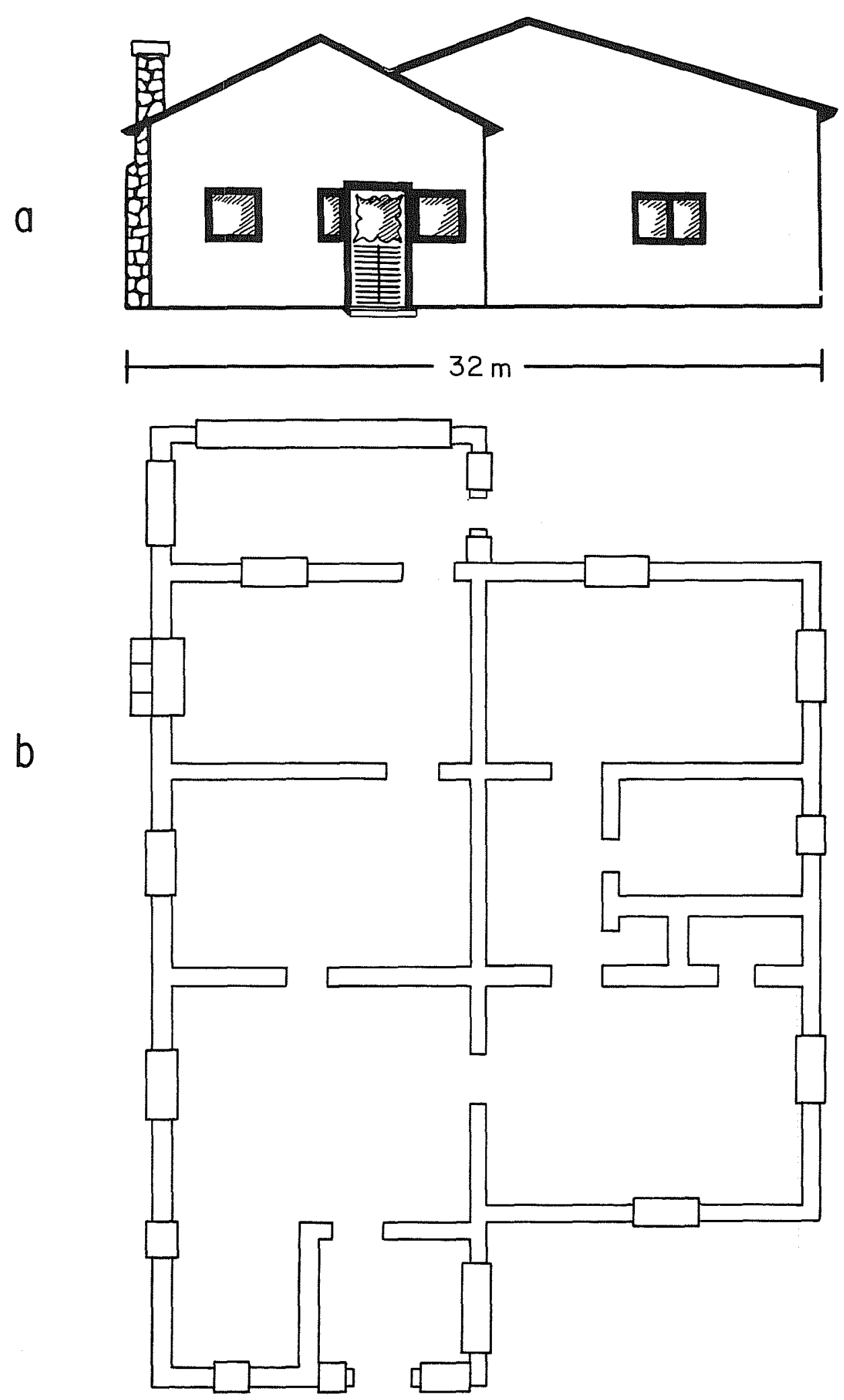

Figure 23. Stuccoed Frame Structure at 41 BX 344 . a, front; b, plan. 


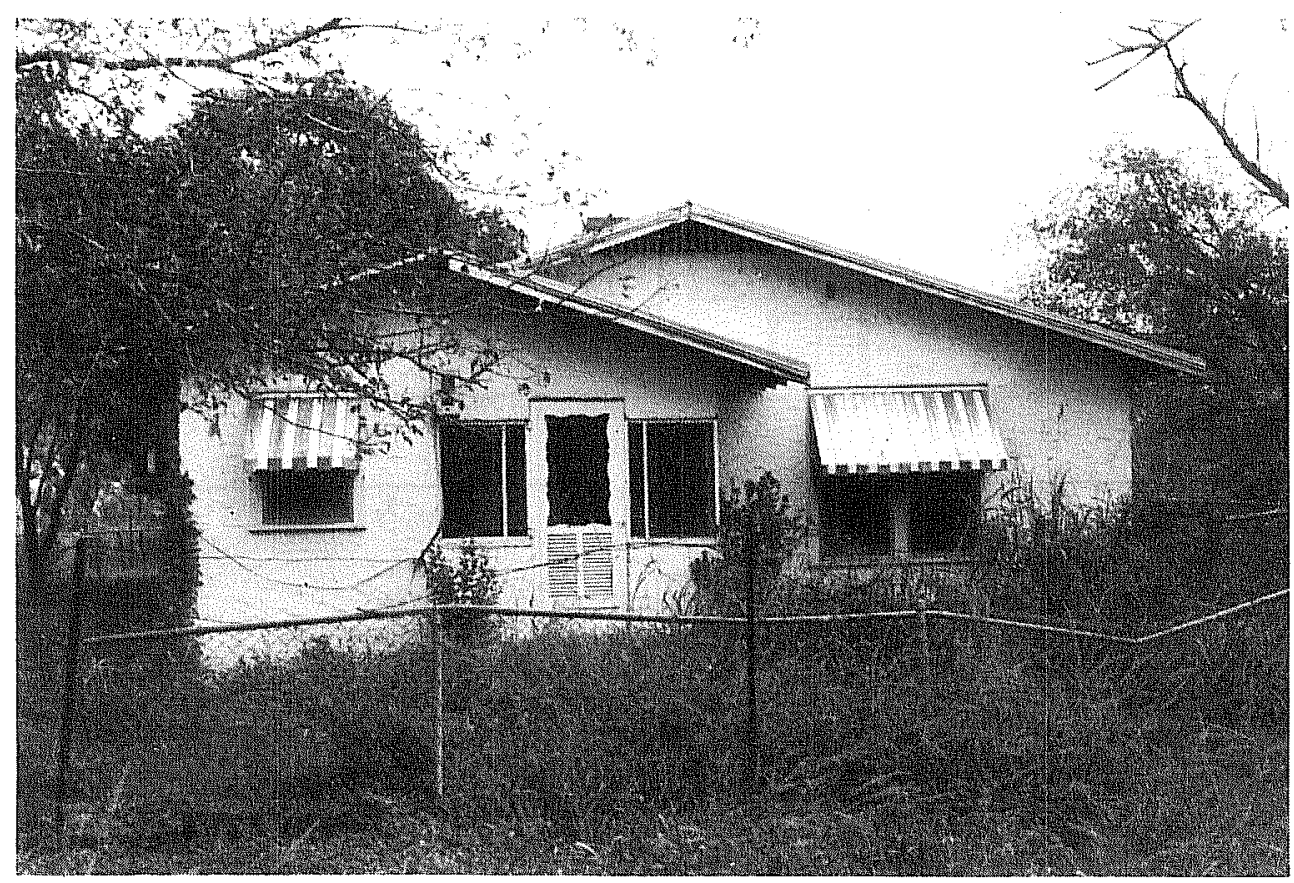

a

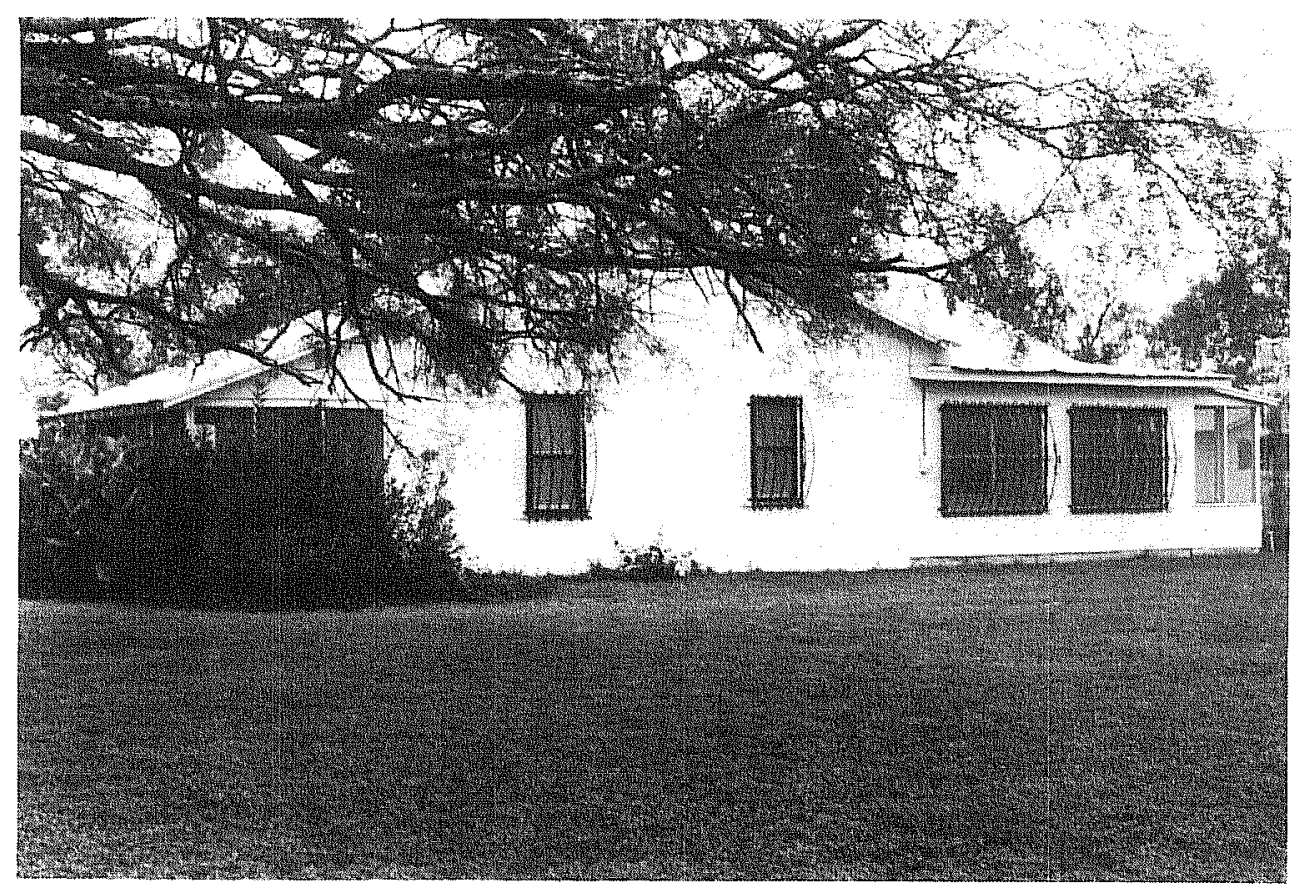

b

Figure 24. Views of Two Structures at 41 BX 344. a, stuccoed frame house; b. plastered stone house. 
by Rev. José McDelgadille and witnessed by Juan Ygnacio Pérez and Clemencia (Hernandez) Pérez, sister of Josefa (BCA Ruiz Files). This marriage made Juan Ygnacio Pérez and José Francisco Ruiz brothers-in-1aw.

Three children were born to this union: Maria Lugarda de Jesús, born June 15, 1804; Maria Antonia Paula de 1a Concepción, born June 14, 1809; and Francisco Antonio, born 1804 or 1811 (BCA Ruíz Files, see F. A. Ruíz). In 1811, Ruiz, along with others, was responsible for inducing Juan Manuel Zambrano to Tead a counterrevolution against Casas (Santos 1966:6-7).

In 1813, Ruiz fought under General Toledo at the Battle of the Medina where Royalist General Joaquin de Arredondo's forces soundly defeated the insurgents (ibid.). Jose Francisco and his family were forced to flee from Texas to the United States, along with other leading families, to escape the wrath of Arredondo. John C. Ewers, in his introduction to Berlandier's (1969:11-12) The Indians of Texas in 1830 wrote, "Ruiz found refuge among the Comanche and lived among them and their allies for eight years."

In the fall of 1821, Ruiz was living in Natchitoches, Louisiana. After Mexico gained her independence from Spain, Gaspar Lopez, Commandant General of the Eastern Interior Provinces, offered him a full pardon in return for utilizing his influence with the Comanche and Lipan Apache as a Commissioner of Mexico. Ruiz accepted the offer, and in March 1822, he convinced Pitsinampa, a Comanche chief, to hold a council of their principal chiefs, captains, and elders. It was attended by 5000 persons, and on the advice of Ruiz, they resolved by unanimous vote to send a delegation to Mexico City to make a peace treaty with Emperor Augustin de Iturbide--Ruiz acted as interpreter for the meeting. On December 14, 1822, the treaty was affirmed, and on January 19, 1823, Ruiz signed the treaty at the request of Chief Gounique, Comanche representative (McLean 1974:33).

By 1826, Ruiz was serving with the Mexican Army in Texas. He requested the command of a post and was sent to Nacogdoches to he $1 p$ quell the Fredonian Rebel1ion and, in 1827, he became commandant of the detachment at Nacogdoches. Ruiz accompanied a delegation of Waco and Tahuacano Indians from Nacogdoches to San Antonio in 1827, where General Anastasio Bustamante concluded a treaty with them as well as with the Comanches (ibid.:35).

From 1832 to 1836, Francisco Ruiz 7 ived at Ygnacio Pérez's "Stone Rancho" (TGLO Paul vs. Pérez). In 1836, Ruiz was elected as a representative to the Convention at Washington-on-the-Brazos, where on March 2, 1836, he signed the Declaration of Independence--one of only two native Texans to do so. He served as the first senator from Bexar to the First Congress of the Republic of Texas (Santos 1966:9). On January 20, 1840, José Francisco Ruiz died and was buried in San Fernando Cemetery (BCA Ruiz File).

Francisco Antonio Ruíz was born in 1804 (or 1811), the son of Jose Francisco Ruizz and Josepha (Hernández) Ruiz (BCA Ruíz Fịes).9 Francisco Antonio married Concepcion Soto, and to this union four children were born: (1) Francisco Antonio, born 1840, lived in El Paso; (2) Alejandro Modesto, born 1841; (3) Eugenio, who married Carlota Garcia; and (4) Francisco, who Tived in El Paso (Chabot 1937:200). 
In 1836, Francisco Antonio Ruiz was a member of the City Council and alcalde pro-tem due to the absence of the first and second alcaldes and most of the council (BCA Ruiz Files). He remained in San Antonio when the Mexican Army under General Santa Anna approached and was subsequently held under house arrest until the fall of the Alamo on March 6, 1836 (Santos 1966:10). On March 5, 1836, Santa Anna ordered Ruiz, Don Ramon Musquiz (political chief), Don Refugio de la Garza (curate), and others to assemble at a temporary fortification erected at Potrero Street to attend to the wounded once the storming of the Alamo commenced. Ruiz wrote the following about the events:

As soon as the storming commenced we crossed the bridge on Commerce street with this object in view, and about 100 yards from the same, a party of Mexican dragoons fired upon us and compelled us to fall back on the river and place we occupied before. Half an hour had elapsed when Santa Anna sent one of his aide-de-camps with an order for us to come before him. He directed me to call on some of the neighbors to come up with carts to carry the dead to the Cemetery, and also to accompany him, as he was desirous to have Col. Travis, Bowie, and crockett shown to him.

On the north battery of the fortress lay the lifeless body of Col. crockett. Col. Bowie was found dead in his bed, in one of the rooms of the north side.

Santa Anna, after a11 the Mexicans were taken out, ordered wood to be brought to burn the bodies of the Texians. He sent a company of dragoons with me to bring wood and dry branches from the neighboring forest. About 3:00 in the afternoon they commenced laying the wood and dry branches upon which a pile of dead bodies was placed; more wood was piled on them, and another pile brought and in this manner they were arranged in layers. Kindling wood was distributed throughout the pile and about $50^{\prime}$ clock in the evening it was lighted.

The dead Mexicans of Santa Anna were taken to the grave-yard but not having sufficient room for them, I ordered some of them to be thrown in the river, which was done on the same day (Behrends 1859:80-81).

On December 27, 1836, José Francisco Ruiz wrote a letter from Columbia to his son-in-7aw Blas Herrera and asked Blas to tell Francisco to send some cattle as soon as possible and a saddle (Santos 1966:15-16). These cattle, no doubt, were to be sent from the ranch. The 1840 census of the Republic of Texas lists Francisco Ruiz, attorney, as owning 794 acres of 1 and under survey but without a completed title from the Texas General Land office, five town lots, and administrator of an estate with 8856 acres and one town 7 ot (White 1966:16).

From 1837 to 1841, Francisco Antonio served as City Alderman. He became very opposed to annexation with the United States and argued that only those who had fought in the Revolution should decide the issue. According to accounts, Ruiz, around 1845, chose to leave Béxar to live among the Indians on the frontier (Santos 1966:11). He returned to the area by at least 1849, and 
died on October 18, 1876. He was buried at the Ruiz-Herrera Cemetery on the Medina River (see 41 BX 543; ibid.).

Site significance: The site represents one of a series of ownership and/or occupations in this area of the Medina River valley by members of the RuizHerrera family for over 150 years and possibly as early as 1774. The family was one of the most influential in this region during the Spanish, Mexican, and Republic periods. Work to date has established an occupation sequence from at least as early as 1820-1840 through the present; as such, the site offers a unique opportunity to document transitional culture changes in the study area. Additionally, the extensive depth of identified prehistoric deposits suggests a possibility of further, as yet unidentified materials dating to the Early Archaic period and possibly earlier.

Management recommendations: In the opinion of the authors, this site is eligible for listing on the National Register of Historic Places based on: (1) the association with events that have made a significant contribution to the broad patterns of our history; (2) the association with the lives of persons significant in our past; and (3) the potential to yield information important in history. We recommend that a determination of eligibility should be sought from the Keeper.

The site is located above the maximum flood pool level of the proposed reservoir. At this time, it appears that severe secondary impacts wi11 occur at this site. Easy access to the site may increase the likelihood of vandalism by "pot-hunters"; if this happens, a historic archaeological site which offers a rare opportunity to contribute to the areal and regional record may be lost.

The locations of all ancillary facilities connected to the proposed reservoir have not been released by Freese and Nichols, Environmental Consulting Firm; when these locations are selected and/or disclosed, avoidance of this site should be considered a priority. If the site is to be affected in any way (or cannot be avoided) then mitigative measures must be undertaken. Limited testing is recommended for the newly identified historic component to better assess the temporal associations at the site and to locate any subsurface structural remains. Archival research in the Texas General Land Office, Bexar Archives, as we 11 as the early mission records, might help to locate the original grant issued to the Ruiz family. Primary source documents (e.g., wills and probates, city tax rolls, deed records) would provide further documentation of the site.

\section{SITE 41 BX 346A}

Type of site: Prehistoric occupation underlies an abandoned modern house and two small outbuildings.

Location: Approximately 150-200 m east of Palo Alto Road on the north bank and upper terraces along the Medina River.

Elevation: 500 to 530 feet above mst. 
Topographic context: Along the upper terrace margins of the Medina River, $200 \mathrm{~m}$ from the modern crossing of the drainage.

Water source: Medina River is ca. $150 \mathrm{~m}$ south of the site.

Vegetation and soil: Portions of the site have been cleared in the past, but most of the area was overgrown with prickly pear cactus and high grasses. Some mesquite trees are scattered throughout the area. The soil is a Venus clay loam, a limey, sometimes silty material, darkish brown to gray in color.

Site condition: Extensive land clearing in the fall of 1985 has severely damaged or destroyed surface evidences of prehistoric occupations.

Artifactual materials present: Burned and fire-fractured limestone cobbles, two crudely worked medial biface fragments, and a moderate to relatively dense surface scatter of Tithic debris were observed when the site was first recorded in 1981. No features or concentrations of burned rock (clusters) were noted.

Site discussion: During the 1981 investigations, it was not determined whether the prehistoric surface materials represented the results of site deflation or whether they were a surface indication of 1arger, intact subsurface deposits possibly extending westward across Highway 16. Extensive and systematic testing in excess of 2-3 $\mathrm{m}$ in depth would have been required to clarify site potential, and this was beyond the scope of the 1981 study. The site was recommended for further work in the form of mechanical and hand testing to determine the actual horizontal dimensions (estimated at $200 \times 300 \mathrm{~m}$ ) as we11 as the vertical extent of deposits.

The area was revisited both in the spring and fall of 1985 . Intensive survey suggested this site may have been related to a potential unrecorded site location just to the west of $41 \mathrm{BX} 346 \mathrm{~A}$ but separated from it by the extensive highway/bridge/road cuts of the Palo Alto crossing of the Medina River.

In October 1985, it was observed that extensive bu11dozer clearing of the terraces and marginal uplands severely damaged a11 of the site area of $41 \mathrm{BX} 346 \mathrm{~A}$. Clearing efforts disturbed $1.5-3 \mathrm{~m}$ of the upper soil of the site area, and subsequent erosion generated by autumn rains have progressively increased site disturbance.

Site significance: Based on the cumulative data of 1981 and 1984 investigations at both $41 \mathrm{BX} 346 \mathrm{~A}$ and $41 \mathrm{BX} 346 \mathrm{~B}$, we believe that $41 \mathrm{BX} 346 \mathrm{~A}$ was once the eastern margins of a large occupation zone now physically separated by the modern 1 and alterations of the Highway 16 and bridge construction. This relationship was not recognized in 1981 as property access into areas west of Highway 16 was quite 1 imited.

Cumulative information based upon the physical evidences at such sites as $41 \mathrm{BX} 344$ and 41 BX 274 has indicated the possibility of deeply buried cultural deposits (in excess of $2-3 \mathrm{~m}$ in depth) along the terraces of the Medina River in the study area. It should be recognized that while severe and extensive damage has occurred as a result of recent 1 and clearing, the 
possibility still remains for intact, deeply buried stratified cultural deposits to exist in portions of the site area. This possibility is strengthened somewhat by a consideration of the extensive combined activity area of $41 \mathrm{BX} 326 \mathrm{~A}-41 \mathrm{BX} 346 \mathrm{~B}$ along the terrace margins (more than $1 \mathrm{~km}$ in length).

Management recommendations: Given the extensive activity size of the 41 BX 346A-41 BX 346B site complex, an accurate estimate of its cultural potential cannot be determined on the basis of work to date. Mechanical and hand excavations are required to assess the possibility and significance of subsurface cultural deposits for a more accurate determination of potential eligibility to the National Register of Historic Places.

\section{SITE 41 BX 346B}

Type of site: In 1981, investigations at 41 BX $346 \mathrm{~A}$ revealed a possible continuation of cultural deposits westward across Highway 16 right-of-way. Subsequent access into areas west and adjacent to 41 BX $346 \mathrm{~A}$ did, in fact, identify an extensive prehistoric occupation site.

Location: The site was originally defined as within and around a large, eroded gully on the north bank of the Medina River, ca. $600 \mathrm{~m}$ west of $41 \mathrm{BX} 346 \mathrm{~A}$. The site is located just west of the Palo Alto crossing of the Medina River.

Elevation: 500 to 550 feet above msl.

Topographic context: Along the upper terrace of the modern river channel. The site extends north, away from the river, ca. $250 \mathrm{~m}$.

Water source: The Medina River is ca. 50-75 m south.

Vegetation and soil: Thorny brush predominates the vegetation across the site area. Portions of the site, particularly toward the river bluff, have been cleared in the past. However, the area is overgrown with thorny brush and medium to tall grasses. The soil is dark brown clayey Venus loam along the terrace margins that eventually deteriorates into an extensive erosional gully complex ca. $175 \mathrm{~m}$ north of the southern site margins.

Site condition: Approximately $50 \%$ of $41 \mathrm{BX} 346 \mathrm{~B}$ is dissected by an extensive erosional/arroyo complex with some gullies in excess of $3 \mathrm{~m}$ in depth. This area is extremely disturbed by natural erosion. Other portions of the site, especially toward the southern margins, are much less affected. The recovery of several projectile points, other lithic tools, and several small eroded burned rock clusters suggests a potential for further, as yet undisturbed, buried deposits.

Artifactual materials present: Preliminary inspection revealed only a disturbed light scatter of lithic debris and a few mussel shel1 fragments along the arroyo complex in the northern portion of the site area. Examination of wall profiles of the deep gully cuts showed no exposures of intact or 
otherwise significant materials. Site 41 BX $346 \mathrm{~B}$ was extensively reassessed during intensive survey along the terrace margins adjacent to the river.

Intensive survey into these locations indicated that an exposure of 1ithic debris, burned rock, and mussel shell extended northward, away from the terrace margins at least $250 \mathrm{~m}$ and encompasses the extensively eroded locality first identified. Several small burned rock clusters (ca. $1 \mathrm{~m}$ in diameter) were noted eroding from the terrace edge. Inspection of the high terrace vertical profile adjacent to the drainage revealed mussel shel1, occasional burned rock fragments, and chert debris exposed along the wall to at least $2 \mathrm{~m}$ below the surface. Nine biface fragments were collected from this site; four represent medial or reworked distal fragments of dart points; unfortunately, the fragmentation and reworking precludes specific type identification.

Site discussion: Site dimensions of 41 BX $346 \mathrm{~B}$ are ca. $300 \times 250 \mathrm{~m}$. Additionally, given the large site area, it is the authors opinion that modern construction of Highway 16 and bridge complex directly east of $41 \mathrm{BX} 347$ destroyed additional deposits that would have linked the site with $41 \mathrm{BX} 346 \mathrm{~A}$ (just east of the highway). The artifact collection, primarily bifacial fragments, suggests Middle to Late Archaic activities at this location, but this is based only upon the general character and form of the materials as the identification of specific type forms is somewhat Timited by fragmentation and reworking.

Site significance: The reassessed potential of 41 BX $346 \mathrm{~A}-41$ BX $346 \mathrm{~B}$ indicates it is one of the larger prehistoric sites in the study area and has both the surface indications and the subsurface potential for stratigraphic, buried cultural deposits and features. The site represents an example of a chronologically extensive prehistoric occupation of aboriginal hunters and gatherers in this area of the lower Medina River valley. The occurrence of such deposits, not definable without extensive limited testing in the form of systematic mechanical and hand excavations, could provide both new insights into the broad pattern of the local and regional prehistory as well as significant information on such poorly understood time periods as the Early Archaic of south-central Texas.

Management recommendations: Based on the redefined site characteristics of $41 \mathrm{BX} 346 \mathrm{~B}$, potentially significant cultural deposits are thought to exist in the southern portion of the site area. While the original locality of the extensive gully complex is extremely disturbed, the southern portion reflects a distinct concentration of 1ithic surface scatter, burned rock, and eroding features. We recommend both mechanical and hand testing of this site location to determine its potential eligibility to the National Register of Historic Places if adverse impacts should occur in this area.

\section{SITE 41 BX 347}

Type of site: Prehistoric terrace occupation site.

Location: On and adjacent to a modern, abandoned ranch complex, ca. $0.5 \mathrm{~km}$ east of Highway 16 and north of the Medina River. 
Elevation: 530 to 540 feet above msl.

Topographic context: The site is located along the upper terraces and terrace margins of the modern channel of the Medina River. In the opinion of the authors, the deserted ranch complex is modern in age, and the occupation structure and outbuildings are estimated to have been constructed 20-30 years ago.

Water source: The Medina River is ca. $200 \mathrm{~m}$ south.

Vegetation and soil: Medium to tall grasses cover the site area, which has been cleared and leveled in the past. The modern alterations and activities in the immediate area, which include land clearing, leveling, deep-plowing, bulldozing, and construction, have severely altered natural site conditions. The soil is a dark brown Venus clay loam with underlying yellowish clays and caliche exposed in erosional gullies along the site margins.

Site condition: Extensively disturbed across the entire site area (ca. $200 \times 300 \mathrm{~m}$ ) by modern alterations and/or constructions, with severe erosion noted along the terrace slopes.

Artifactual materials present: A light to moderate collection (ca. $200 \mathrm{x}$ $300 \mathrm{~m}$ ) of 7 ithic debris was observed on the surface and along the eroded slopes when this site was first visited in 1981. Several fragments of firefractured rock were also noted in a disturbed context in the gullies. No diagnostic materials or features were noted and/or collected.

Site discussion: The light to moderate lithic scatter observed across the site area indicates at least some disturbance of prehistoric materials, while the extent of modern alterations suggests these disturbances may be extensive in nature. The burned rock fragments noted along erosional exposures reflect some aboriginal occupation activities, but no evidences of features or material concentrations were noted. Since no significant diagnostic artifacts were collected and no extensive subsurface testing was conducted, the spatial and temporal associations with nearby sites $41 \mathrm{BX} 346$ and $41 \mathrm{BX} 348$ are unclear. Two $50-\mathrm{cm}^{2}$ shovel tests at both ends of the site excavated to a depth of $35 \mathrm{~cm}$ did not recover any fragments of 1 ithic debris or distinctive soil stratigraphy. Given the physical context of the site location and the known occurrence of deeply buried stratified cultural materials nearby, it is possible such deposits may underlie the surface at 41 BX 437. It would, however, be difficult to determine the location and extent of such potential deposits without mechanical testing. Additionally, such an expenditure of time and manpower could more productively be employed at nearby sites 41 BX 346 and 41 BX 348, where both diagnostic artifacts and eroding elements of burned rock features have been observed.

Site significance: This site area represents one of several localities in the study area in which prehistoric remains have been disturbed and possibly destroyed by modern constructions and alterations. While deeply buried features and deposits may still exist in portions of the site area, the uncovering of these materials would require the destruction of all modern structures (an abandoned barn, several small outbuildings) to facilitate subsurface examination. Given the extent of site surface disturbance and the 
lack of any observed features or diagnostic materials, we believe that monitoring of the location, should it be impacted in the future, would be adequate to assess the possibility of buried features or cultural deposits. We believe that in the most cost-effective and pragmatic sense, any efforts at actual subsurface testing to determine the extent and significance of buried materials should be directed toward nearby sites $41 \mathrm{BX} 346$ and 41 BX 348.

Management recommendations: The authors have reviewed this site both in the context of local archaeology and in the larger perspective of the regional archaeological record. The lack of cultural features or diagnostic materials observed somewhat offset the potential for deeply buried prehistoric deposits. In the opinion of the authors, such potential for buried deposits should be tested in the area but would be more productively conducted at nearby sites 41 BX 346 and 41 BX 348. Based on the 1 imited amount of data available from survey, shovel testing, and the extent of modern disturbance, we suggest: (1) extensive subsurface testing at sites $41 \mathrm{BX} 346$ and 41 BX 348, with particular emphasis on possible intersite and/or depositional relationships to $41 \mathrm{BX} 347$, and (2) systematic monitoring of $41 \mathrm{BX} 347$, should it be impacted, to identify any exposures of cultural deposits. Should subsurface testing at the nearby sites 41 BX 346 and 41 BX 348 prove productive and significant, the subsurface potential of 41 BX 347 could and should be reviewed and reassessed for further work.

\section{SITE 41 BX 348}

Type of site: Prehistoric; light to moderate lithic scatter; possible temporary occupation.

Location: The site is located along the western edge of an extensive arroyo complex adjacent to the Medina River, ca. 600 m east of 41 BX 347 , and the north terrace margins adjacent to the modern river channel.

Elevation: 520 feet to 540 feet above ms 1 .

Topographic context: Situated along the edge of a 1 arge arroyo adjacent to the Medina River channel.

Water source: Intermittent water in arroyo; Medina River is ca. 150-200 m south of the arroyo.

Vegetation and soil: Severe erosion has stripped upper soil zones to expose deep deposits of tan-colored clay and caliche. Practically no portion of the site area except the extreme margins reflects any topsoil. Mesquite trees and some thorny brush were observed along the site margins; short grasses cover the remainder of the locality. The lack of vegetation such as oak or mesquite trees is presumably related to lack of soil.

Site condition: Severely eroded and disturbed.

Artifactual material present: Chert debitage in the form of corticate and decorticate chips, a small burned core fragment, several secondary and 
tertiary flakes, and four scattered fragments of burned rock were observed. No features or diagnostic artifacts were collected, and density of surface scatter was estimated at two to three artifacts per $20 \mathrm{~m}^{2}$ over the $150 \times 100 \mathrm{~m}$ site area. An occasional mussel shell fragment was noted.

Site discussion: Cultural deposits are both deflated and extensively disturbed by soil erosion. Deep gullies, often in excess of $3 \mathrm{~m}$ in depth, are common throughout the site area. Inspection of the numerous walt profiles created by erosion did not identify any intact cultural deposits, materials, or features.

Site significance: The locality is thought to have once represented a light to moderate prehistoric activity area, although relationship to specific time periods is impossible without a collection of chronologically diagnostic materials. An estimated $90 \%$ or more of the site area has been severely damaged or destroyed by erosional impacts.

Management recommendations: In the opinion of the authors, the site remains are not worthy of consideration for potential nomination to the National Register of Historic Places, and no further work is recommended based upon the information available to date. Should further, future adverse impacts occur, we do recommend monitoring at the site location to identify the exposure of possible, as yet unidentified, site deposits.

\section{SITE 41 BX 350}

Type of site: Light to moderate prehistoric Tithic scatter; possible temporary occupation.

Location: Along the western edges of an extensive arroyo complex north and adjacent to the Medina River, ca $1.4 \mathrm{~km}$ west of Applewhite Road.

Elevation: 540 feet above ms 1 .

Topographic context: The site is located along an extensive erosional feature north of the modern river channel. Deep gul1ies have dissected the former terrace margins in this locality.

Water source: The Medina River is ca. $250 \mathrm{~m}$ south.

Vegetation and soil: The extreme site margins are bordered by a partially cleared pasture. The majority of the (uncleared) site area is overgrown with dense thorny brush. The soil is a Venus clayey loam or eroded elements of this soil association.

Site condition: Eroded and disturbed.

Artifactual materials present: Chert flakes and chips, a few reddened by fire, are scattered across the surface (ca. $100 \mathrm{~m}^{2}$ ). Artifact surface density is estimated at one to two fragments of debitage per $15 \mathrm{~m}^{2}$. Several smal1 burned rock fragments were noted in both cleared and uncleared site 
areas, but no features or diagnostic materials were observed during the 1981 intensive survey. Inspection of the extensive vertical profiles exposed by erosion did not reveal buried cultural materials (gullies were eroded to depths of 1.5-2.5 m). During a revisit and reinspection of the site area in 1984, one small undecorated ceramic sherd ca. $1.4 \mathrm{~cm}$ in diameter (similar to the Late Prehistoric Leon Plain variety) was collected from a colluvial slope wash. No other materials or features were noted.

Site discussion: The site area has been severely damaged by natural erosion as well as past land clearing efforts. The location is thought to represent a sma11, temporary lithic workshop and occupation area utilized during the Late Prehistoric and possibly earlier, but the disturbance and deflation of surface exposed materials preclude further interpretations.

Site significance: The small fragment of Leon Plain indicates at least some temporary activity occurring at this location during the Late Prehistoric period. Unfortunately, site disturbances, both natural and manmade, have compromised the potential for significant contributions to the local and regional archaeological record.

Management recommendations: It is the opinion of the authors that the lack of features and diagnostic materials combined with extensive erosional processes indicate the site is not of National Register potential. The possibility of buried cultural deposits, common throughout portions of the study area, is thought to be limited due to the severity of past erosion and 1 imited discernible site area. As in the case of 41 BX 348, we recommend site monitoring should the location be further impacted by future construction activities.

\section{$\underline{\text { SITE } 41 \text { BX } 515}$}

Type of site: A prehistoric Tithic scatter is evident and also a possible occupation site, but the surface has been extensively modified, so interpretations of site function are difficult. Site dimensions are ca. $150 \mathrm{~m}^{2}$, possibly larger.

Location: The site is Tocated ca. $100 \mathrm{~m}$ west of Somerset Road and ca. $100 \mathrm{~m}$ south of the Medina River.

Elevation: 550 feet to 560 feet above ms 1 .

Topographic context: The site is located along the terrace margins adjacent to the modern floodplain of the Medina River.

Water source: The Medina River is ca. $100 \mathrm{~m}$ north.

Vegetation and soil: The site is covered by short to medium grasses. Large oak and pecan trees are common throughout the area. The northern portion of the site consists of dark gray alluvium as part of the modern river bottom; soil on the upper terrace slopes in the southeast section of the site is composed of eroded, clayey, medium gray Venus loam. 
Site condition: The surface of 41 BX 515 has been extensively, if not severely, disturbed by poor land clearing efforts to remove dense underbrush and create a parklike environment. The subsurface extent of disturbance is not known, but is estimated at a minimum of $30-40 \mathrm{~cm}$. Intact subsurface cultural deposits may exist in unidentified areas of the site below this level.

Artifactual materials present: Evidence of past activities is a light distribution of lithic debris scattered across the area; exposures of debitage are more common along the terrace slopes in the southern site area. Several burned rock and mussel shell fragments were also noted in the southern site area. No features or diagnostic materials were observed.

Site discussion: Extensive modern alterations to the area and the lack of chronologically diagnostic materials preclude definitive assessments of site function or periods of occupation. The site's proximity to the Medio Creek confluence does indicate a spatial relationship to a series of Late Prehistoric and/or Historic occupation sites: $41 \mathrm{BX} 459,41 \mathrm{BX} 461$, and $41 \mathrm{BX} 463$. Additionally, the site is located in the immediate area of a historical crossing (Garza's Crossing) which may date to Spanish colonial times.

Site significance: Dense brush and deep alluvial deposits preclude assessments of the site's potential significance. In the opinion of the authors, further work is necessary to identify, describe, and assess the character and importance of this site location.

Management recommendations: We recommend both systematic mechanical and hand testing at site 41 BX 515 to determine potential eligibility for nomination to the National Register of Historic Places. This site is located in the maximum flood pool level of the proposed reservoir area.

\section{SITE 41 BX 516}

Type of site: Prehistoric occupation site.

Location: Approximately 150-200 m west of Somerset Road, just north of its intersection with the Medina River. The site is located north of the modern channel of the river.

Elevation: 560 feet to 570 feet above $\mathrm{ms} 1$.

Topographic context: Along and extending away from the upper terraces north of the modern Medina River channel.

Water source: The Medina River is ca. 150-200 m south.

Vegetation and soil: Natural soil in this area has been completely disturbed, and bulldozing has resulted in clayey, tan-colored subsoil superimposed over the remnants of natural depositions (as observed from vertical wall profiles along the river terrace edges). Natural vegetation has been completely stripped from the area, and small thorny brush and tall.grasses now cover the area. 
Site condition: Severely damaged by land clearing, leveling, commercial dumping, as well as by natural erosion.

Artifactual materials present: A light scatter of lithic debris in the form of chert flakes and decorticate chips was observed across the site area (ca. $350 \times 100 \mathrm{~m})$. Several burned or fire-fractured cobbles were also noted along the eroding slopes at the southern site margins and scattered across the site area. No features or diagnostic artifacts were observed or collected.

Site discussion: First identified in 1981, the area was revisited in 1984. Preliminary estimates suggested a temporary prehistoric occupation site extensively damaged by modern alterations. The site's location near a historic ford was noted along with some speculation that it was used in the prehistoric(?) past as well. Lithic material at the site was believed to be a surface manifestation.

Orat interviews with the 1 andowner in 1984 indicated not only the identified site area but adjacent localities had been used as a city dump ca. 25-30 years ago because of the natural deep erosional gullies. The estimated vertical site disturbance was to $7 \mathrm{~m}$. The site was remembered as the natural arroyo complex that was used as the exit and entrance to a river fording area prior to the modern bridge crossing. Additionally, the location, which had been in the family since the early 19th century, was remembered as having an unusual number of "arrowheads" on the surface.

Site significance: Pragmatically, given the extreme nature of disturbance and site destruction at 41 BX 516, little can be said regarding its past significance. Given its proximity to one of the earlier historic crossings on the Medina River (Garza's Crossing, $41 \mathrm{BX} 697$ ), it is possible that the same location was used by Historic period Indians and earlier Indian groups as we11. Unfortunately, the lack of site integrity and extent of disturbance preclude further interpretations.

Management recommendations: The 1981 recommendations suggested that because of the extreme nature of site disturbance, no further work was necessary in this area. In the opinion of the authors, and following a 1984 reassessment of the locality, we still concur with these earlier recommendations. We do suggest monitoring of the terrace margins of $41 \mathrm{BX} 516$ if reservoir impacts should occur to identify the exposures of any potential, as yet, unrecognized buried deposits which may have escaped earlier destructive impacts.

\section{SITE 41 BX 517}

Type of site: Light prehistoric lithic scatter. No cultural materials other than chert chips and worked cobbles observed.

Location: Just south of Fischer Road, ca. 250 m west of its intersection with Somerset Road.

Elevation: 620 feet above ms 1 . 
Topographic context: The site is located in a flat upland area. Once a cleared farming area, the site is now overgrown with dense thorny brush.

Water source: Medina River is ca. $1.5 \mathrm{~km}$ to the south.

Vegetation and soil: The site is densely overgrown with mesquite, prickly pear cactus, whitebrush, and other thorny brush. Surveying at one point was reduced to $10-\mathrm{m}$ intervals and crawling on hands and knees through openings of the thorny brush. The soil is Houston Black clay, a dark colored, almost level soil composed of outwash plains of ancient alluvium. The soil grades from dark grayish brown sandy to clayey loam on the surface to a paler clayey brown material by ca. $100 \mathrm{~cm}$. Calcareous chert cobbles are known to occur naturally as a layer of gravel and cobbles near the base of the old alluvial deposits.

Site condition: Disturbed by past land clearing and deep plowing to a depth of at least $40-50 \mathrm{~cm}$.

Artifactual materials present: A light scatter of lithic debris in the form of secondary and tertiary flakes, corticate and decorticate chips, and several cobble core fragments was observed over the site area, ca. $150 \times 200 \mathrm{~m}$. Artifact density of surface materials was ca. one chert fragment per $20 \mathrm{~m}^{2}$. No diagnostic materials, burned rock, or features were noted.

Site discussion: Given the modern alterations to the site's surface, the surface materials must be viewed as disturbed and in a secondary depositional context. A $50-\mathrm{cm}^{2}$ shovel test in the middle of the site area excavated to a depth of $30 \mathrm{~cm}$ recovered one small core fragment and a single decorticate chip, but these were sti1l within a deep plow zone. It is possible that some deeper, intact cultural deposits may exist in this locality, but extensive efforts would be necessary to uncover such materials (i.e., machine stripping of upper disturbed soi1). The site is thought to represent the remains of a single activity prehistoric lithic workshop and possible quarry site because of the natural occurrence of chert gravels and cobbles and the range of observed Tithic debris.

Site significance: This small site appears to be one of the very few examples of a single activity prehistoric site in the study area utilizing an upland lithic resource area. The identification of this natural source of chert materials is significant to the interpretation of $10 \mathrm{cal}$ prehistoric sites, both locally and elsewhere along the Medina River-San Antonio River drainages.

Management recommendations: In the opinion of the authors, this site is potentially eligible for listing on the National Register of Historic Places. The elevation of the site should preclude any adverse impacts of potential reservoir construction, and avoidance of the area is considered to be the simplest recommendation. 


\section{SITE 41 BX 518}

Type of site: Moderate to possibly extensive prehistoric occupation site.

Location: The area surrounds a modern ranch complex just east of Somerset Road about $100 \mathrm{~m}$ north of its intersection with Elm Creek.

Elevation: 550 feet to 570 feet above $\mathrm{ms}$.

Topographic context: The site extends along the terrace slopes on the north bank of Elm Creek, a major tributary of the Medina River.

Water source: E7m Creek is ca. 50-75 m south.

Vegetation and soil: Two soil types are intermixed at this locality (Taylor, Hailey, and Richmond 1966:77, 84): Crockett fine sandy loam, a dark colored sandy loam, and Webb fine sandy loam, a reddish brown sandy clay underlain by a yellowish red sandy clay. Depths of both soil types generally range to ca. $80 \mathrm{~cm}$. The entire site area has been cleared of natural vegetation, and portions are used as corrals, pasture, occupation, or farming locales.

Site condition: Partially disturbed by modern farming (root plowing, land clearing, etc.), the upper soil zones to a depth of at least $60 \mathrm{~cm}$ may be affected. Possible intact subsurface deposits may still exist.

Artifactual materials present: A moderate scatter of fire-reddened, burned rock and lithic debris covers the $250 \times 200 \mathrm{~m}$ area. Lithic materials consist primarily of decorticate chips and secondary and tertiary flakes, with an occasional small core fragment noted. Surface artifact density is estimated at ca. three to four 1 ithic fragments per $15 \mathrm{~m}^{2}$. The surface scatter represents a disturbed artifact context. No diagnostic materials or features were observed along the slopes.

Site discussion: Examination of the modern channel cut of Elm Creek along its banks at 41 BX 518 indicates zones of alluvial and terrestrial soi deposits in excess of $5 \mathrm{~m}$. It is possible that cultural deposits not affected by modern surface alterations may lie within these deeply buried zones in portions of the site area; however, the identification and assessment of such site materials would not be feasible without systematic hand and mechanical testing to determine the potential depth of deposits and extent of site area.

Site significance: This prehistoric archaeological site represents a relatively large occupation area along a major tributary in the lower Medina River valley. An identification of the extent of cultural materials and their chronological context would contribute to the interpretation of both diachronic and synchronic prehistoric activity patterns of the local archaeological record.

Management recommendations: In the opinion of the authors, further work in the form of mechanical and limited hand testing is necessary to determine this site's potential for contributing information important to the understanding of local and regional prehistory. 


\section{SITE 41 BX 519}

Type of site: Historic.

Location: Situated on the edge of an upper terrace south of the Medina River and ca. $2 \mathrm{~km}$ east of Highway 16 .

Elevation: ca. 510 feet above msl.

Topographic context: Along the margins of the modern floodplain.

Water source: Medina River; we11.

Vegetation and soil: Dense brush covers northern portion of site area. A cleared field of high grasses is located to the south. The soil is a clayey a) Tuvium.

Artifactual material present: No artifacts were observed in 1981 due to a dense overgrowth of thorny brush and high weeds. In 1981, trash deposits were suspected to exist in the vicinity. During a revisit to the site in 1984, dump and/or refuse areas containing recent materials were noted northwest of the site in extensive arroyos. Earlier dumps may be deeply buried under the modern accumulations.

Site condition: Abandoned and/or deteriorated.

Site discussion: First recorded in 1981, the investigations recorded an abandoned one-story wood-framed house encompassing ca. 800 square feet and a two-story wood-framed house. Estimated age of construction was late 19th century or early 20th century based on construction techniques and materials (e.g., 6 over 6 glass panes). As recommended by the Corps of Engineers in their RFP, the site was revisited in 1984 to conduct limited testing and/or further archival research. A thorough archival search (including deed records at the Bexar County Courthouse and Surveyor's Field Notes) on the property was conducted in 1984, at which time it was not possible to definitively establish ownership of the buildings. The structures are built on property owned ca. 1903 by Albert Picard and may possibly be associated with him (David Picard, personal communication). According to descendants of Alfred Picard and present owners of the property, the single story structure was moved onto the property from a prior location.

The single story structure with frame siding (No. 117 siding) is built in a "shotgun" style (Fig. 25,a). This vernacular style of architecture of oneroom width, end to end alignment, and front and back doors in the narrow gab7e ends, usually accompanied a "boom," such as the oil boom in the study area in the early 1900s. The two-story structure has 6 -inch beveled siding (No. 105 siding) on a poured concrete foundation (Fig. 25,b). Doors are four panel construction with 4 over 4 wooden framed windows. Access to the second floor of this structure was from the outside by means of stairs (no longer existing). Turned posts are located on the south side of the structure and support part of the second story. 


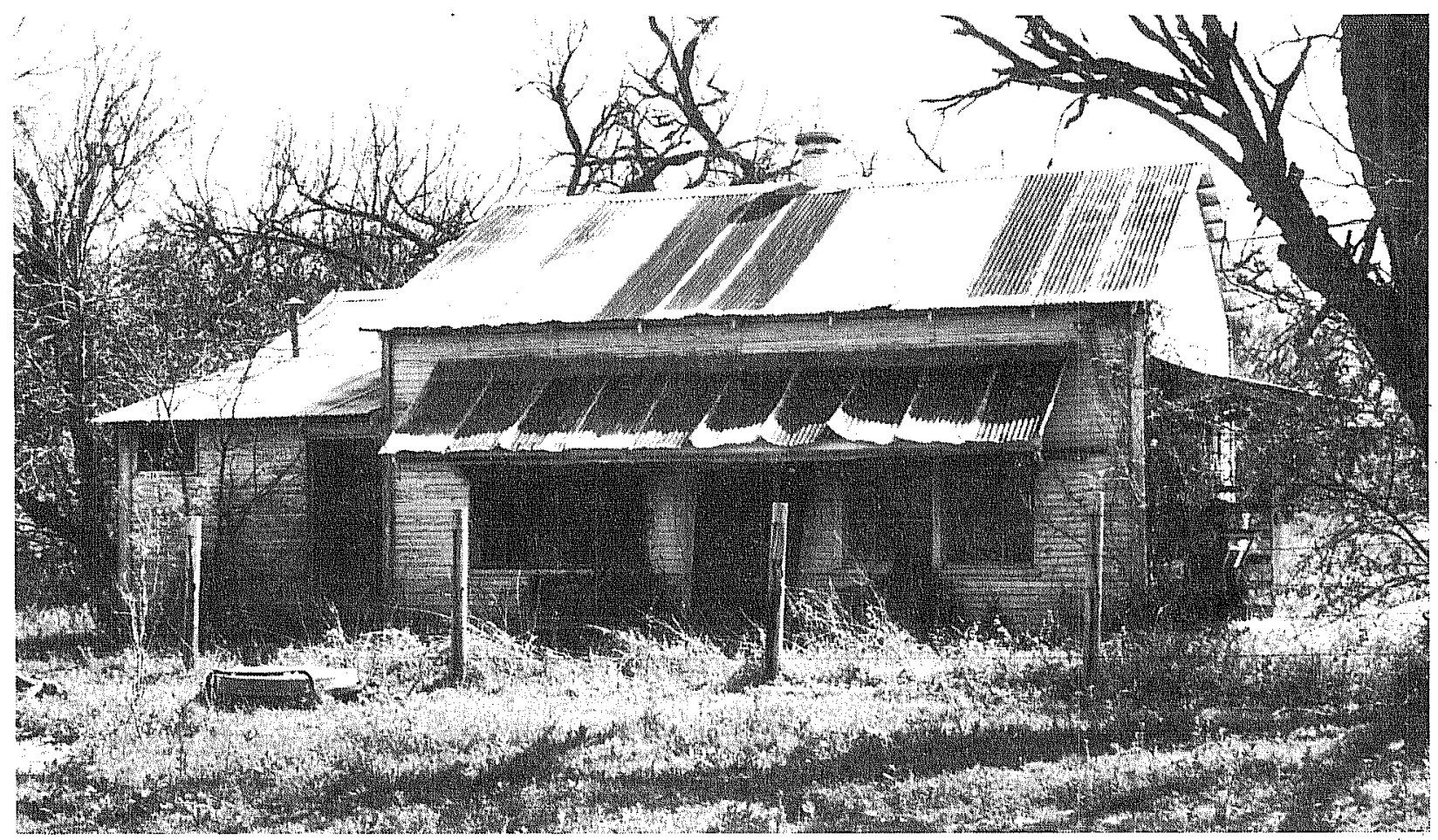

a

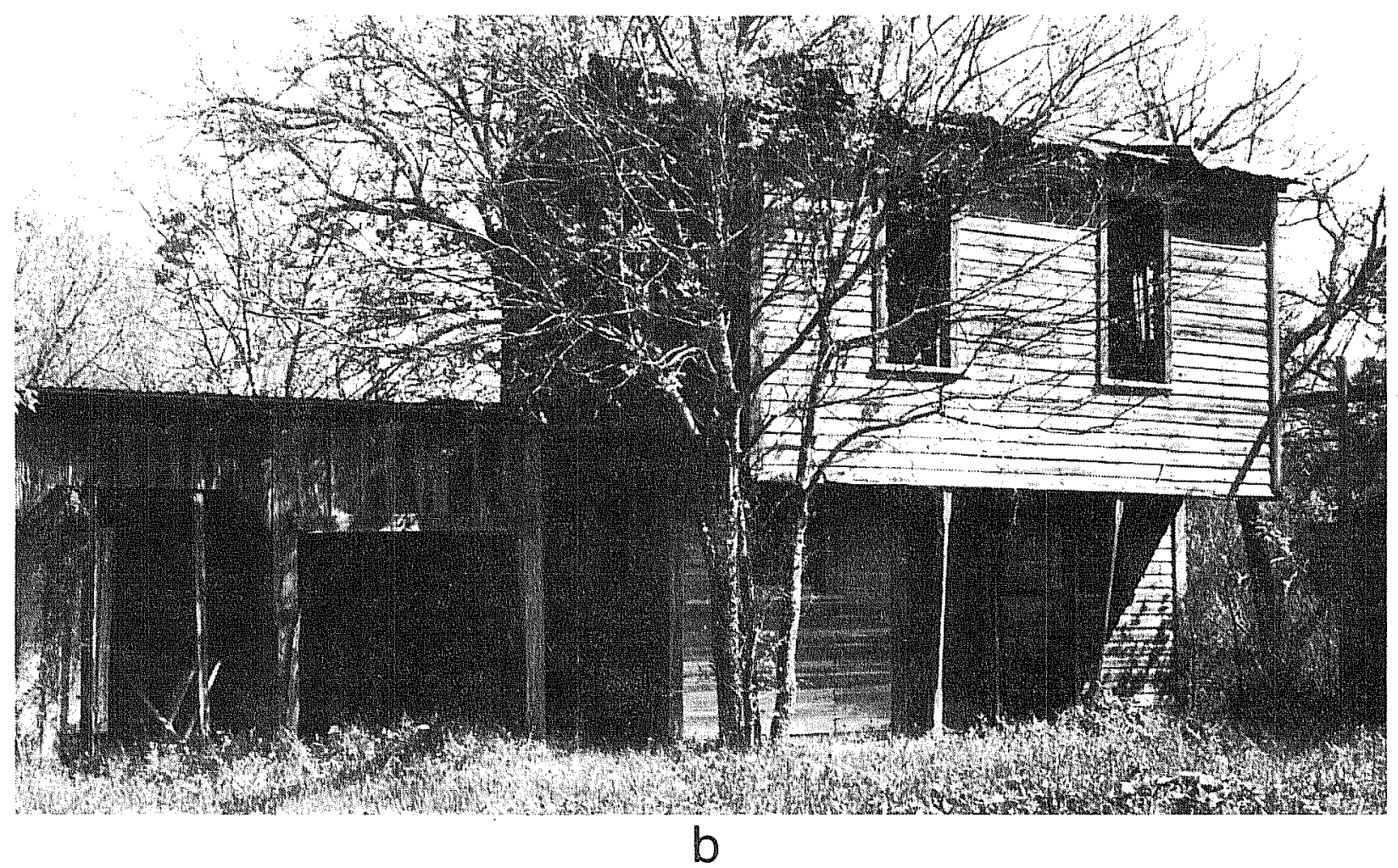

Figure 25. Views at $41 \mathrm{BX} 519$. a, single story frame structure; b, twostory frame structure. 
Outbuildings consist of three sheds of frame construction as well as an encased well. Electricity has been added to the site.

Site significance: The "shotgun" structure is representative of the vernacular architecture constructed in the 1 ate 19 th/early 20 th centuries. The value of this structure as it pertains to the information which may be yielded to the history of the study area rests upon the time that it was moved onto the property. The two-story structure of undetermined primary use with its associated outbuildings has a better potential to yield information important to the history of the area. In particular, the buildings may be associated with the early pecan harvesting industry in the lower Medina River valley.

Management recommendations: In the opinion of the authors, this site is potentially eligible for listing on the National Register of Historic Places based on the potential to yield information important to the history of the area. The site is located within the conservation pool level of the proposed reservoir. Further archival research is necessary to determine the builders of the historic structures at 41 BX 519. Limited testing would revea 1 occupational sequences and temporal associations of inhabitants and clarify this site's importance in the study area.

SITE 41 BX 520 (Battle of the Medina, estimated initial encounter)

Type of site: Historic.

Location: South bank of Elm Creek, County B1ock 4191, Parcel 6A.

Elevation: ca. 530-540 feet above msl.

Topographic context: Within the immediate vicinity of the Elm Creek confluence. The site is located along the upper terrace slopes along the south bank of Elm Creek.

Water source: Elm Creek and Medina River.

Vegetation and soil: Soil is a clayey alluvium. Portions of the site are covered by short grasses and bounded by mesquite brush.

Site condition: Partially cleared.

Artifactual material present: One .99 ounce canister shot was recoverd. In 1981 , the landowner also reported finding at least three other "musket balls" at the site.

Site discussion: Surveyed in 1981, this site was recommended by the Corps of Engineers in their 1984 RFP for further work in the form of limited testing. The artifact collected from the site was originally identified in 1981 as a one-ounce musket bal1 commonly used in the early to mid 19th century. A preliminary literature search revealed that after the Battle of the Medina in 1813, General Joaquin Arredondo captured 80 English guns of one-ounce bal1 size and 400 rounds of ammunition. During the 1981 study, it was believed 
that skirmishes related to the battle may have occurred around the crossings of the Medina River and nearby Elm Creek, but the authors felt that the presence of one artifact could not substantiate this hypothesis. In 1984, intensive resurvey of this area in lieu of limited testing (as the site had been critically altered by land clearing since 1981) did not uncover any other historic materials. However, in 1984, the original artifact was more correctly identified by a military historian as a .99 ounce canister shot from a light field piece (cannon) of the late 18 th to early 19 th century (Samuel Nesmith, personal communication). The inconsistency first came to light during a comparison with musket balls excavated from an artillery emplacement used during the Battle of the Alamo in 1836 (Labadie 1986). While slightly larger, the artifact from 41 BX 520 weighed noticeably less than other lead one-ounce balls. Subsequent research suggests a lead-alloy bal1 commonly used as canister shot in four to six-pounder field pieces of this time period.

As an additional note, in February 1986, a late 18th-century or early 19thcentury military saddle stirrup (Fig. 26) was found by a local landowner ca. two miles south of 41 BX 520 near the present-day Applewhite Road. Identified by $S$. Nesmith (UTSA consultant, military history), the artifact is the second distinctly military, early 19th-century item to be found in this area. While this isolated find is of limited interpretive value, it should be noted the loss of a stirrup, even today, is not a casual incident for horseback riders.

Extensive archival research and detailed analysis in 1984 of primary documents and secondary sources (see Historical Overview section) confirmed the fact that the initial encounter of the Battle of the Medina was indeed on the banks of the Medina River in the vicinity of 41 BX 520 .

Site significance: Site 41 BX 520 fits the criteria used to evaluate sites for listing on the National Register of Historic Places based on its association with an event that has made a significant contribution to the broad patterns of the area's history and has yielded or may be likely to yield information important to the area's history (see Historical Overview section).

Management recommendations: In the opinion of the authors, this site is eligible for listing on the National Register of Historic Places based on the criteria previously cited. We recommend that a determination of eligibility should be sought from the Keeper. Portions of the site are within the conservation pool level of the proposed reservoir, and the remaining portion is within the maximum flood pool level of the proposed reservoir. Careful monitoring of this site is essential.

SITE 41 BX 521 (0ak Island Church and Cemetery)

Type of site: Historic.

Location: Approximately $0.5 \mathrm{~km}$ southeast of the intersection of Loop 1604 with Jett Road. 


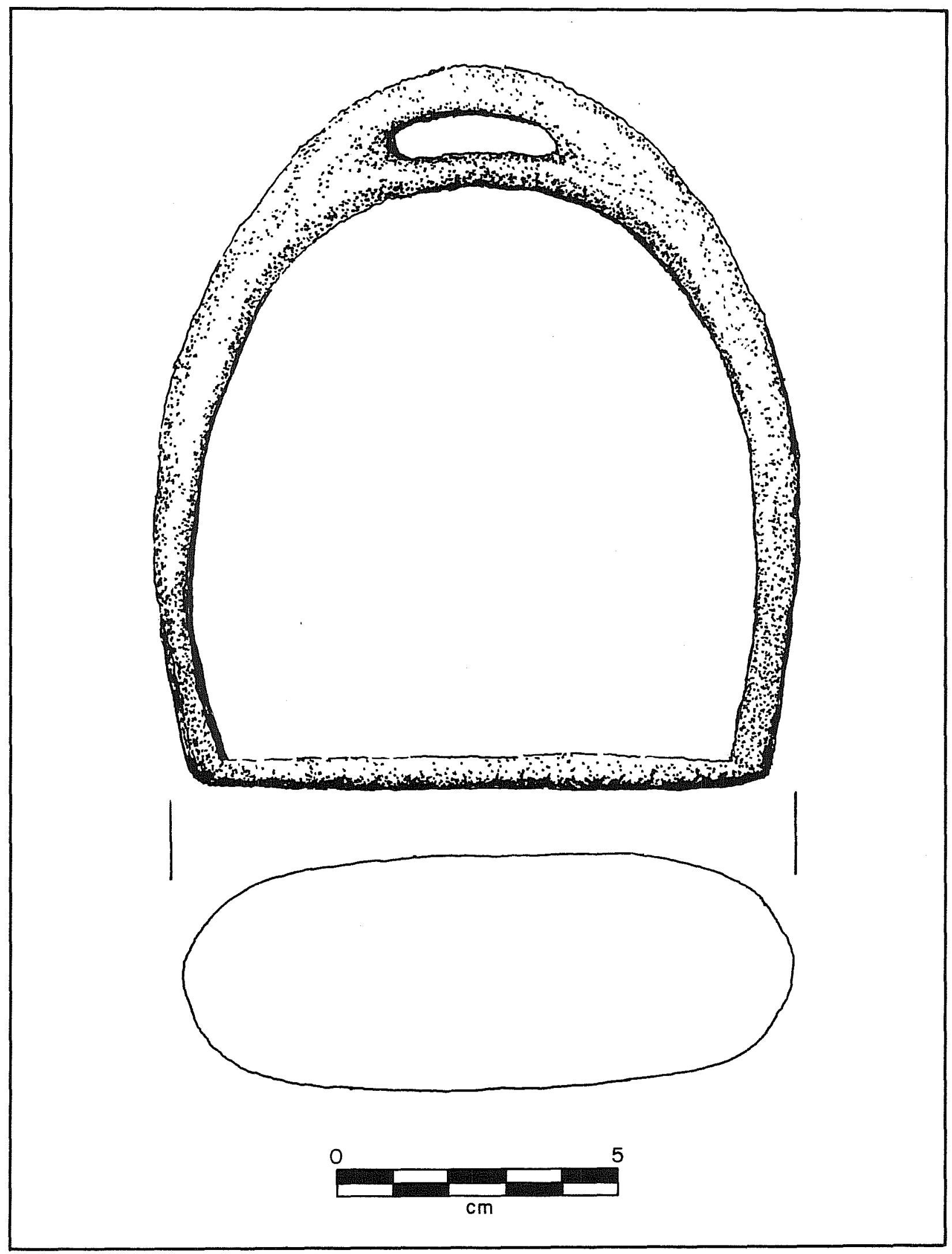

Figure 26. Early Historical Military Stirrup from 41 BX 520. 
Elevation: ca. 550-570 feet above ms 1 .

Topographic context: Along the upland margins of the Medina River floodplain.

Water source: We11.

Vegetation and soil: The site area is cleared and has only short grasses currently. The soit is tan-colored, sandy.

Site condition: Maintained and not in use.

Artifactual material present: Not applicable.

Site discussion: The 0ak Island Cemetery was first surveyed in 1981, at which time it was found to be one of the older cemeteries in the area. No primary impact was expected at this location, and no further work was recommended at this site unless it was to be impacted by some aspect of the proposed reservoir construction. Revisited in 1984, the cemetery was found to include the graves of many of the early Anglo-Protestant families who settled along the Medina River, including the grave of Reverend John Wesley DeVilbiss. The site also includes the Oak Island Methodist Church which was organized around 1867 or 1868 by Reverend John Wesley DeVilbiss, circuit rider who came to the Republic of Texas in 1842 to minister on the Hispanic borders in the Southwest. The vernacular church structure was built in 1872 of indigenous reddish fieldstone and holds some of the furniture made by DeVilbiss and his son (Fig. 27). Stone lintels are over all doors and windows. A State Historical Survey Committee marker was placed on the church in 1967. The church also was designated a Methodist Landmark by the Southwest Texas Conference, on June 6-9, 1966, and bears a United Methodist Historical Site $\mathrm{pl}$ aque. Located just west of the church structure was the wood-framed Oak Island School which has been torn down.

In 1984, scaled floor plans were drawn, and photographic views of the church were recorded. A 1ist of burials was al so obtained. Reevaluation of the elevation of the site revealed that indeed portions of the cemetery may be under the maximum flood pool level of the proposed reservoir. Some of the graves in the lower northeast corner of the cemetery may be exposed to severe erosion from water action.

Site significance: Although most cemeteries and properties used for religious purposes are not eligible for the National Register, those (such as 0ak Isiand) that meet the criteria of architectural significance or historical importance and, in the case of cemeteries, derive their significance from graves of persons of transcendent importance (such as the Reverend John Wesley DeVilbiss) do qualify. The church and cemetery both reflect the changing cultural patterns (such as the influx of Anglo-Protestants) that emerged in the study area just prior to and after the Civil War period.

Management Recommendations: In the opinion of the authors, this site is eligible for listing on the National Register of Historic Places based on: (1) the association with events that have made a significant contribution to the broad patterns of our history; (2) its association with the lives of 


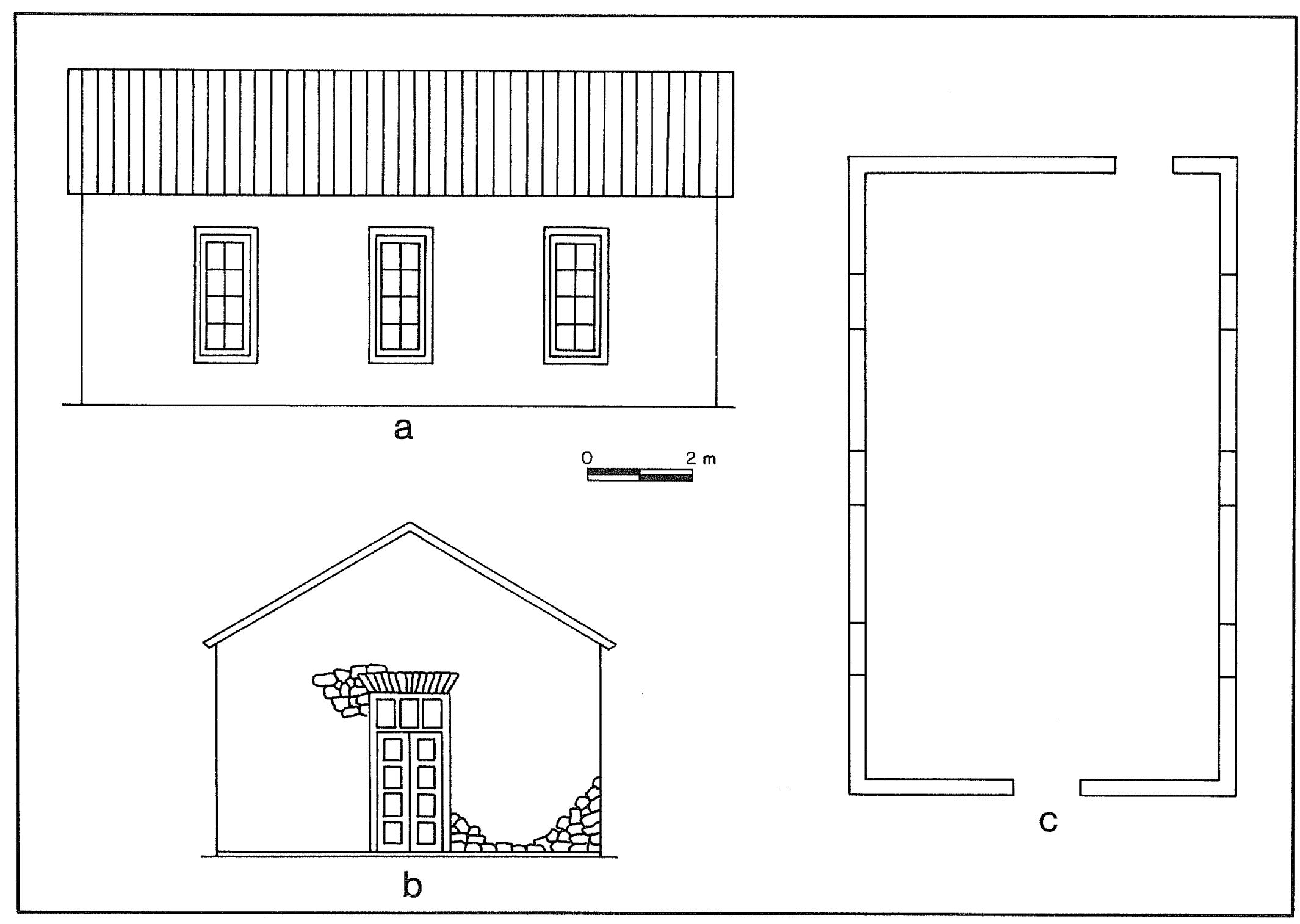

Figure 27. Views of the Oak Island Church, 41 BX 521. a, side view; b, front view; c, plan view. 
persons significant in our past; (3) the embodiment of the distinctive characteristics of a type, period, or method of construction; and (4) the yielding of information important in history. We recommend that a determination of eligibility should be sought from the Keeper. Mitigation at this site should include plans for the protection of the extreme northern part of the cemetery (e.g., a protective wall). Preservation of this site is of utmost importance if the proposed reservoir is constructed.

\section{$\underline{\text { SITE } 41 \text { BX } 522}$}

Type of site: Small prehistoric 1ithic scatter, possibly temporary occupation.

Location: East of Somerset Road, about $2 \mathrm{~km}$ south of its intersection with Elm Creek.

Elevation: 590 feet above msl.

Topographic context: Along the northern slopes of a small hill overlooking the Elm Creek drainage.

Water source: Elm Creek is ca. 400-500 m to the north.

Vegetation and soil: Once cleared in the past, the area is now overgrown with mesquite and other thorny brush. The soil is Duval loamy fine sand, a wind-eroded sandy upland soil, reddish brown in color.

Site condition: At least partially eroded and disturbed by past land clearing.

Artifactual materials present: Several decorticate chips and tertiary flakes (less than 20 were observed over the $100-150 \mathrm{~m}^{2}$ area) were observed scattered across the site. No diagnostic artifacts, features, or material concentrations were noted. An occasional fire-fractured burned rock fragment was observed.

Site discussion: The site appears to represent a small, temporary prehistoric lithic workshop associated with an occasional camping activity. The overlook to Elm Creek may be significant, although the lack of diagnostic materials precludes accurate interpretations of site function and interrelationships. Given the general soil depths of Duval sand in the area (Taylor, Hailey, and Richmond 1966:15; subsurface material deposits are sometimes in excess of $3 \mathrm{~m}$ ), a possibility exists for as yet unrecognized, deeply buried cultural deposits. Past land clearing and plowing, however, have not brought any material evidence of such deposits to the surface.

Site significance: The lack of diagnostic materials and the infrequent surface distribution of 1ithic debris suggest only a small, temporary prehistoric lithic workshop and temporary occupation site. While deeper deposits may exist, such materials are not thought to be under impact from potential reservoir construction in the vicinity. It should be noted that the site elevation should be well beyond any direct impacts. 
Management recommendations: In the opinion of the authors, avoidance of the site is recommended during any future construction activities; given the limited site area, current data, and artifactual content, no other work is necessary at this time.

\section{SITE 41 BX 523}

Type of site: Historic.

Location: Approximately $1 \mathrm{~km}$ east of Somerset Road along the south bank of Elm Creek.

Elevation: ca. 560 feet above msl.

Topographic context: Along the upper terrace of the Elm Creek tributary. Water source: Elm Creek is ca. $50 \mathrm{~m}$ from site.

Vegetation and soi1: Dense brush covers the entire site area. The soil is a clayey, dark gray alluvium.

Site condition: Destroyed.

Artifactual material present: In 1981, bricks, ceramics, glass, and unidentifiable metal fragments from the mid 20 th century were reported. The site was not revisited in 1984.

Site discussion: In 1981, the survey crew reported that the site may have been the location of a historic structure, but there was no architectural evidence (such as foundation stones, etc.) on which to base a definitive statement. No intact features were noted, and extensive gut7y erosion has severely disturbed the area.

Site significance: Due to the highly disturbed nature of the site, resulting from plowing, erosion, and the late chronological association of artifacts, the site does not appear to be significant to interpretations of the study area.

Management recommendations: At the present time, given the amount of destruction and previous investigation, this site does not appear to merit National Register status.

\section{SITE 41 BX 524}

Type of site: Mutticomponent historic and prehistoric.

Location: The site is located approximately $350 \mathrm{~m}$ south of ETm Creek and ca. $100 \mathrm{~m}$ west of paved road.

Elevation: ca. 550-570 feet above ms 7 for the prehistoric component and 534 feet above ms 1 for the historic structure. 
Topographic context: Along the upland margins and slopes of the Elm Creek drainage.

Water source: Elm Creek is ca. $400 \mathrm{~m}$ south of the site. A well is expected to be in the vicinity.

Vegetation and soil: Most of the site area has been cleared; tall grasses cover the area, and mesquite brush borders the property beyond the fence line.

Site condition: In 1981, the prehistoric site was partially eroded, and much of the area was cleared for farming. In 1984, the historic structure was occupied, but portions of the house were somewhat deteriorated. The grounds surrounding the structure were kept as a yard.

Artifactual material present: In 1981, eroding sandstone fragments, which appeared to be hearth components, were noted. No historic artifacts were collected.

Site discussion: In 1981, an occupied wood frame two-story structure was located on a high hill above Elm Creek. An extensive prehistoric site indicating multifunctional activities extended from the hill to Elm Creek. Sandstone fragments were eroding from the surface and indicated the possibility of buried components. The 1981 survey suggested that further work in the form of mechanical and hand testing would be necessary to more accurately determine the significance of the prehistoric site due to its extensiveness and the potential for subsurface deposits.

Revisited in 1984, the historic structure was still occupied, although the condition of the home was somewhat deteriorated. At this time, it was noted that the two-story wooden frame structure (ca. early 20th century) had a twostory porch on the east (front) side supported by large wooden columns (this area is badly in need of renovation and/or repair). Wooden sash double hung windows with 4 over 4 glass panes were noted. The remains of a stone fence were seen along the eastern side of the site. Later additions have been made to the west side of the structure. No outbuildings are currently standing at the site.

In 1984, the prehistoric component consisted of a small to moderate scatter of lithic debris and burned rock extending from the hilltop northward toward the drainage, ca. $400 \mathrm{~m}$. The width of the surface scattered materials was estimated at ca. $300 \mathrm{~m}$. Several core fragments were noted, but the majority of debitage consisted of corticate and decorticate chips and flakes. Several small burned rock clusters ca. $1 \mathrm{~m}$ in diameter were exposed in shallow erosional washes along the lower northern slope. No diagnostic materials were observed or collected. Several completely patinated tertiary flakes were noted in the western site margins. The unusual area of this prehistoric site, surrounding a prominent overlook, and the possibility of as yet uneroded buried features indicates that further work in the form of handexcavated test units is warranted. Such investigations would more accurately describe the significance and extent of prehistoric deposits in this area. 
Site significance: The historic structure at this site is an outstanding example of those built in the industrial period in the area. The size and details of original construction reflect financial stability of the owner and/or builder.

Management recommendations: In the opinion of the authors, this site is potentially eligible for listing on the National Register of Historic Places. The historic component lies well above the maximum flood pool level of the proposed reservoir, and no primary impact is expected. The prehistoric component partially lies within the maximum flood pool level. Limited testing is recommended to accurately determine this site's eligibility to the National Register of Historic Places. Further archival research is necessary to determine the owner and/or builder of the historic structure and their importance to the history of the study area.

\section{SITE 41 BX 525}

Type of Site: Prehistoric occupation site.

Location: Approximately $250 \mathrm{~m}$ south of Elm Creek near its confluence with the Medina River.

Elevation: 550 feet above msl.

Topographic context: The site is 10 cated on a small knoll adjacent to the modern channel of Elm Creek, a major tributary of the lower Medina River. The locality is ca. $0.7 \mathrm{~km}$ from the river-creek confluence.

Water source: Elm Creek is ca. $300 \mathrm{~m}$ to the north of the site.

Vegetation and soil: The site area, under cultivation, has been cleared of natural vegetation. The soils in the site area are Lewisville dark-colored silty clay, brownish gray Karnes calcareous loam, and Venus brown 7 imey loam. This mixture of soil types in the local area represents old alluvium depositions adjacent to an older terrace remnant deposit (Karnes 1oam).

Site condition: Cultural deposits appear to be disturbed to at least $50 \mathrm{~cm}$ below ground surface due to land clearing and cultivation. Intact subsurface deposits may exist below this level, given the extent of cultural materials identified on the surface as well as the extent of cultural deposits on terrace remnants in nearby areas, such as 41 BX 274.

Artifactual materials present: A moderate to large surface distribution of Tithic debris and burned rock is scattered across the site area, ca. $200 \mathrm{~m}^{2}$. Sma11 mussel shell fragments were also observed. No diagnostic artifacts or features were noted. The vertical extent of deposits is unknown; the location was not shovel tested during survey as the area was under cultivation.

Site discussion: The site is located near 41 BX 273, a historic occupation structure, but is spatially discrete and separated from it. Site 41 BX 525 reflects the remains of a prehistoric occupation site of currently unknown 
age situated along a former terrace near the present confluence of Elm Creek and the Medina River. The mixture of soil types surrounding the site area indicates a complex pattern of stream-terrace development that cannot be identified in the present scope of work.

Site significance: Site 41 BX 525 is situated near the confluence of a major tributary and the modern river channel. Such locations in other portions of the study area, for example Medio Creek and the Medina River or along the north bank of Elm Creek and the Medina River, often indicate a concentration of intensively occupied prehistoric archaeological sites. Site potential lies in the extent of its, as yet unidentified, buried cultural deposits. It is the authors' opinion that such deposits are both probable and potentially significant, based upon the extent and intensity of surface materials and the site's physiographic context.

Management recommendations: Further work is needed to identify and assess the extent and significance of possible buried deposits at this site before determination of National Register eligibility can be made. The site is located in the maximum flood pool level of the proposed Applewhite Reservoir. We recommend 1 imited testing in the form of mechanical as well as hand testing to determine the prehistoric significance of this site.

\section{SITE 41 BX 526}

Type of site: Prehistoric occupation site.

Location: North of Elm Creek, ca. $1 \mathrm{~km}$ south of Noyes Road.

Elevation: 550 feet above msl.

Topographic context: The site extends along a modern terrace of Elm Creek, a major tributary of the lower Medina River.

Water source: Elm Creek is 50 to $150 \mathrm{~m}$ distant.

Vegetation and soil: Natural vegetation has been removed by former 1 and clearing and cultivation. The soil is a dark grayish brown Venus clay loam. Karnes clay loam, a light brownish gray eroded soil, is exposed in the northern portions of the site (along the upper slopes).

Site condition: Partially damaged by land clearing and plowing. Site may include intact subsurface cultural deposits.

Artifactual materials present: A small to moderate scatter of burned rock and lithic debris was noted throughout the site area, ca. 400-500 m parallel to the modern stream channel. The extensive length of the site area may indicate the remains of a prehistoric occupation zone rather than a single site area. Concentrations of 1 ithic debris were observed in the eastern portion of the site area. An Early Archaic associated Guadalupe tool was collected from the surface along the southern margins of the site. No other diagnostic materials or features were noted. 
Site discussion: Site 41 BX 526 represents the largest prehistoric activity area identified along EIm Creek in the study area. Examination of rodent burrows along the stream terrace revealed 7 ithic debris in the backdirt, suggesting some potential for subsurface cultural deposits; two $50-\mathrm{cm}^{2}$ shove 1 tests excavated to a depth of $30 \mathrm{~cm}$ did not uncover such deposits, but it is quite possible that cultural materials may lie buried well below such shallow depths.

Site significance: The recovery of a Guadalupe tool indicates at least some Early Archaic activities at 41 BX 526. The extent and distribution of burned rock across the site area suggest that it may be related to early occupation and resource exploitations of the Elm Creek drainage. The horizontal extent of the site area also suggests a multiple occupation sequence probably encompassing an extensive time period.

Management recommendations: Given the extensive site area and the presence of a diagnostic tool related to a poorly understood period of the regional archaeological record, we believe 41 BX 526 is of potential National Register quality. We recommend a systematic program of limited testing to more accurately define the extent and significance of prehistoric cultural deposits at this location and determine the site's eligibility for nomination to the National Register of Historic Places. The site is located in the maximum flood pool level of the proposed Applewhite Reservoir.

\section{$\underline{\text { SITE } 41 \text { BX } 527}$}

Type of site: Historic.

Location: Approximately $1 \mathrm{~km}$ northwest of the intersection of Noyes Road and Highway 16.

Elevation: $550-560$ feet above ms .

Topographic context: On a high terrace remnant, ca. 250-300 m south of the Medina River.

Water source: Medina River is ca. $275 \mathrm{~m}$ from site; well associated with barn structure; cistern associated with uncompleted three-story structure.

Vegetation and soi7: The site area has been cleared in the past and is covered by ta11 grasses.

Site condition: Two of the structures are still in use and a third is abandoned.

Artifactual material present: In 1981, no artifacts were collected. In 1984 , surface collected artifacts consisted of three sherds of hard paste earthenware, three sherds of 7 ate 19th/early 20 th-century ironstone, one sherd of undecorated porcelain, two stoneware sherds of 1ate 19th/early 20thcentury origins, one miscellaneous sherd, one metal object related to farming/ranching equipment, and 11 sherds of glass of late 19th/early 20th-century origins (see Material Culture section). 
Site discussion: In 1981, the site was described as having three separate structures: (1) a partially collapsed store building with two floors characterized by oval windows on the south and north sides (Figs. 28,a,b; $29, a, b)$; (2) a two-story barn, presumably related to the first building (Figs. $30, a, b ; 31, a, b)$; and (3) a slightly more recent wood frame structure (not illustrated). The stone buildings were presumed to have been constructed during the 1ate 19th/early 20th-century and the wood-frame house from the early to mid-20th century.

A 1 arge proportion of the collapsed stone building and the multiple rooms suggests a non-private residence such as a hotel or hospital. Local residents reported that the building was an uncompleted sanitorium of late 19 th-century origins.

Although recommended by the authors of the 1981 report for further work in the form of archival research and hand testing, the site was not included specifically in the RFP issued by the Corps in 1984. During a 1984 field visit by Daphne Derven, Corps of Engineers archaeologist, and Paul White, Texas Historical Commission, however, both suggested that the two structures should be further documented by archival research and architectural documentation.

The 1984 archival research was aimed at determining early owners of the property. It was hoped that through this research the builder(s) of the structures would be revealed. Deed research revealed that the property was headrighted to Nicholas Mosby Dawson (Daws), who emigrated to Texas as a single man prior to the Declaration of Independence. He received a headright of one-third league of 7 and by virtue of Certificate No. 89 issued by the Board of Land Commissioners, Bexar County (BCA Headrights:98). The headright on the Medina River was surveyed by Wi17iam Lindsey on August 12, 1838, said survey containing five labors of arable and three and one-third labors of pastureland (BCA Surveyor's Field Notes, Book Al:54).

Dawson served in the Texas forces from January 29, 1836, to May 10, 1837, participating in the Battle of San Jacinto. For his services, he received Bounty Warrant 1912 for 1280 acres and Donation Certificate 779 for 540 acres (a) 1 patented to his heirs in counties other than Bexar; Miller 1967:217,756). The 1840 Census of the Republic of Texas, Bexar County, 1ists Dawson as owning 1476 acres of 1 and under survey based on a grant but without a final title confirmed by the Texas General Land Office (White 1966).

In 1840, Dawson (as a 1 ieutenant in the Texas Rangers) participated in the routing of the Comanches on the Colorado River under Colonel Moore. Dawson, Captain Thomas J. Rabb, and Lieutenant Owen led the attack and were responsible for killing many of the Comanche warriors (Webb 1952:45-46).

In 1842, when General Woll attempted to recapture San Antonio, Dawson came from La Grange with 53 men and attempted to join Caldwel1's forces on the Salado River. He was cut off and surrounded by the Mexicans, who kept out of rifle range, turning their artillery on the Texans. Dawson raised a white flag as a sign of surrender, but the men were fired upon, only 15 escaped. Many were killed after surrendering. Dawson was killed along with his men; this encounter is known as Dawson's Massacre (ibid.:73-74). 


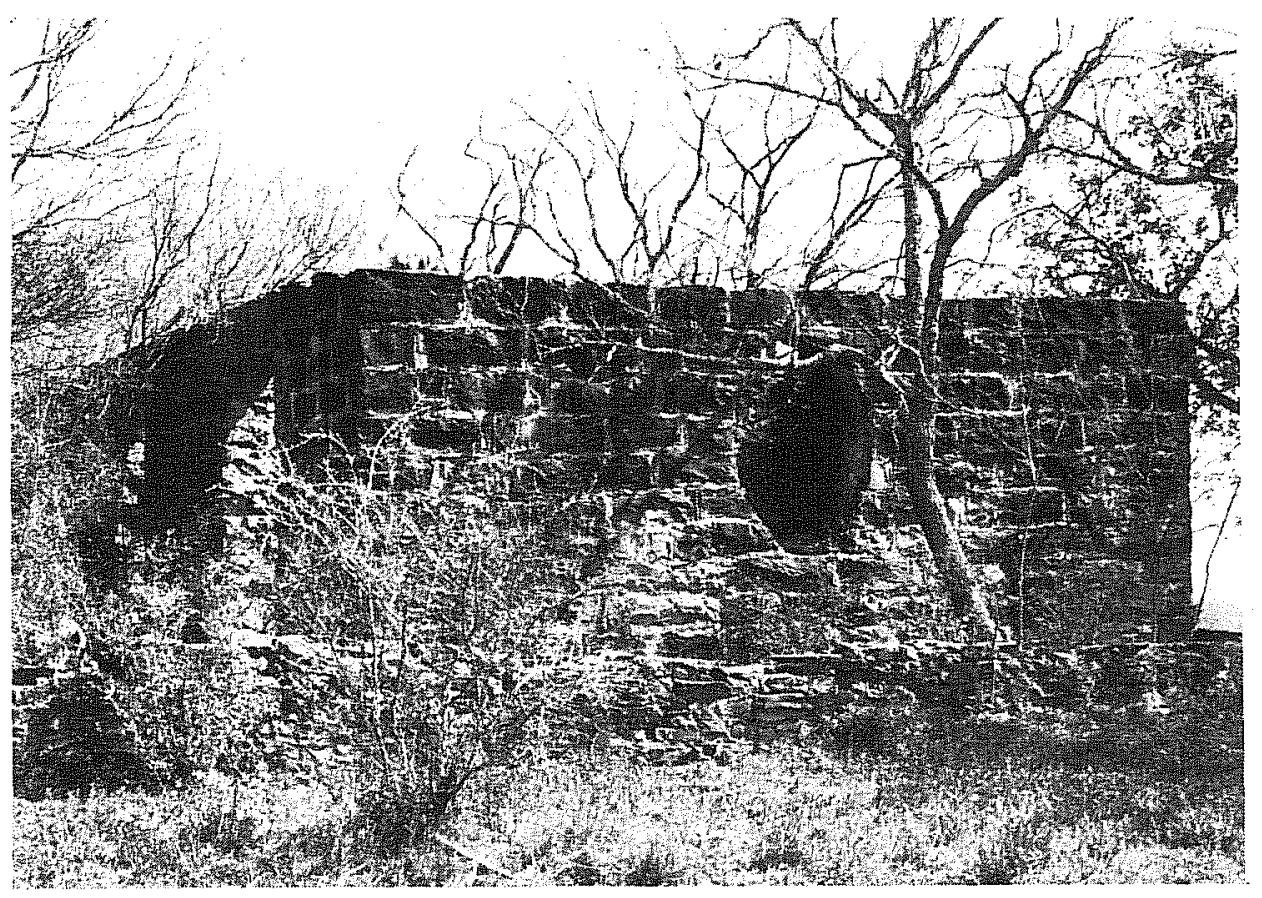

a

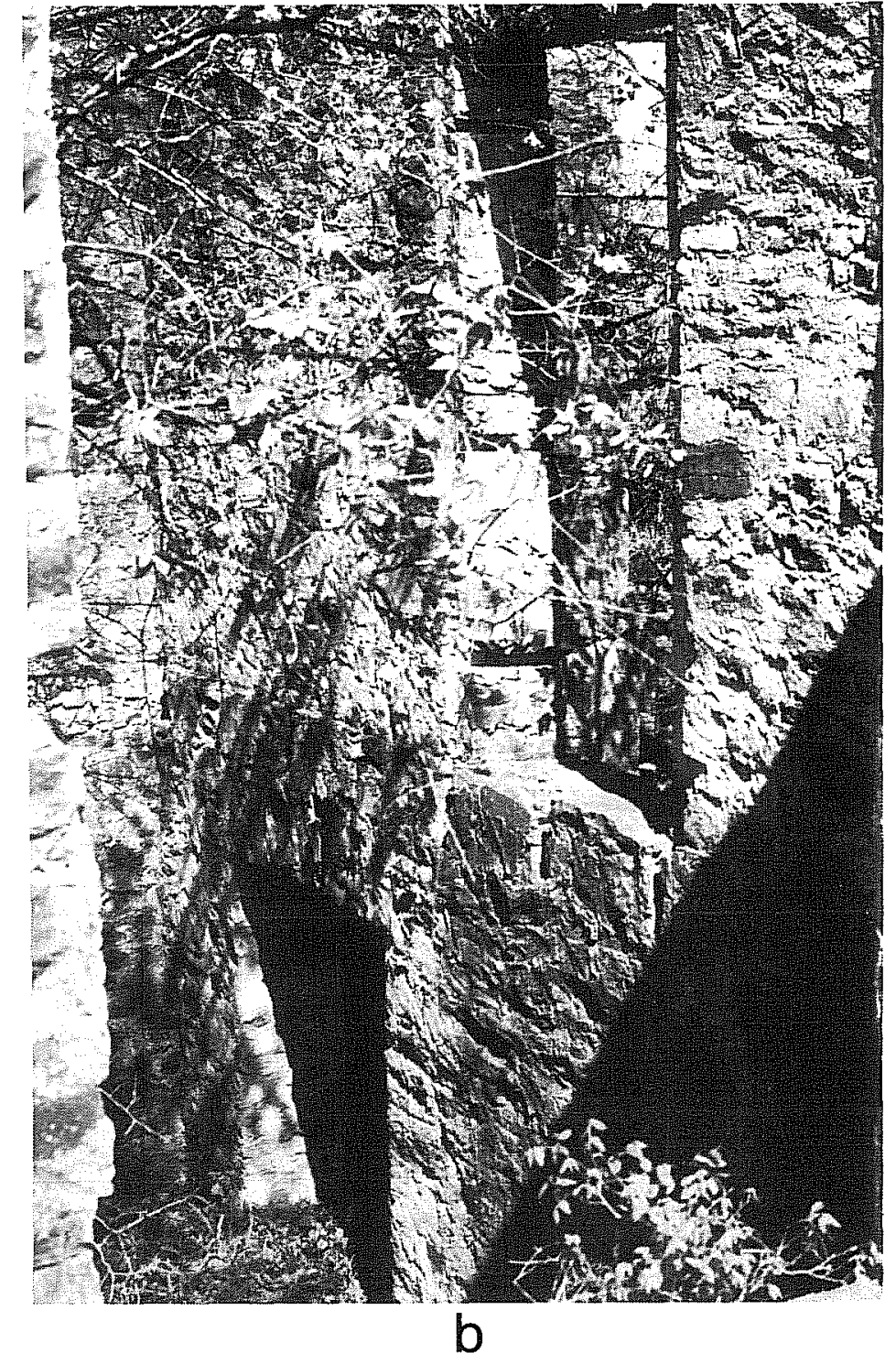

Figure 28. Historic Structure at 41 BX 527. a, looking north; b, interior of structure, note 1 ower level.

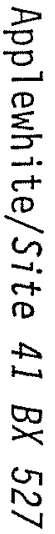


On November 6, 1855, George Dawson, father and sole heir of N. M. Dawson, sold 738 acres to Theodore Heermann of San Antonio for $\$ 6500$ (BCDR Vol. N1:635). Heermann, a physician, had come to Texas from Louisiana about 1850 (Barnes 1910:241). The amount of the sale equates to approximately $\$ 8.80$ an acre, an amount that tends to substantiate the hypothesis that a building was present when Heermann bought the acreage. Heermann also bought 876 acres out of the Rufeno Rodriquez survey (BCDR Vol. 193:54).

In the early 1860s, Captain Heermann (1861) formed the Medina Guards, 30 th Brigade, Texas Militia. In Blanco County and other counties north of San Antonio, the Comanche threat was so acute that frontier 1 ife was tenuous. When Rip Ford's company was galvanized into action during the Civil War, Heermann's company was left on the Balcones Escarpment (Fehrenbach 1968:377), where his company killed two renegades on the Blanco River (Ford 1963:348).

In 1870, Heermann married a local woman, Felipa Flores, and to this union two sons were born: (1) Felix, born November 15, 1870, and (2) Alfred, born February 19, 1873 (BCCH Wills and Probates 2286). Both Felix and Alfred were born at Heermann's residence on the Medina River (possibly the stone structure at 41 BX 527). Barnes (1910) wrote that Theodore Heermann "built a partially finished house, the ruins of which are near the Leon, and which are said to be haunted."

In 1883, Theodore Heermann was 1isted with a taxable income of $\$ 30,290$ (DRT Steves Scrapbook). Heermann does not appear in any of the city directories as a practicing physician--perhaps he worked in the Medina River area and would therefore not necessarily appear in the directories, but whatever occupation he followed he was quite successful as evidence by his income.

Heermann's wi11, made on February 23, 1895, 1eft his estate to his two sons Felix and Alfred in equal shares. Heermann died on April 6, 1896.

Research to date has not definitely established the builder or builders of the historic structures at $41 \mathrm{BX} 527$. The site was revisited a minimum of three times for the purpose of producing scaled floor plans and architectural renderings of the two stone structures. An extensive photographic record was initiated. The barn structure presented no problems with scaled drawings; however, the uncompleted three-story structure was extremely difficult to execute. It was therefore decided in the interest of time and finances to obtain a photographic record at this time and recommend architectural documentation for this structure at a later date. The barn stone structure possibly had three stages of modification, evidenced by changes in mortar, stone size, and lintel treatment (Derven and White, personal communication). These variations may also be explained as having been produced by one or more artisans working over a period of time on the building (e.g., much the way a modern bricklayer wi11 lay a course of brick one day, and then a second course a second day, etc., which frequently produces variations in mortar and construction material).

A close visual inspection of the structure revealed a keystone with the date of 1886 carved into it. This date corresponds to the time when Theodore Heermann was living on the property. The present owner's son also reported that when his father acquired the property a set of wooden pens was attached 


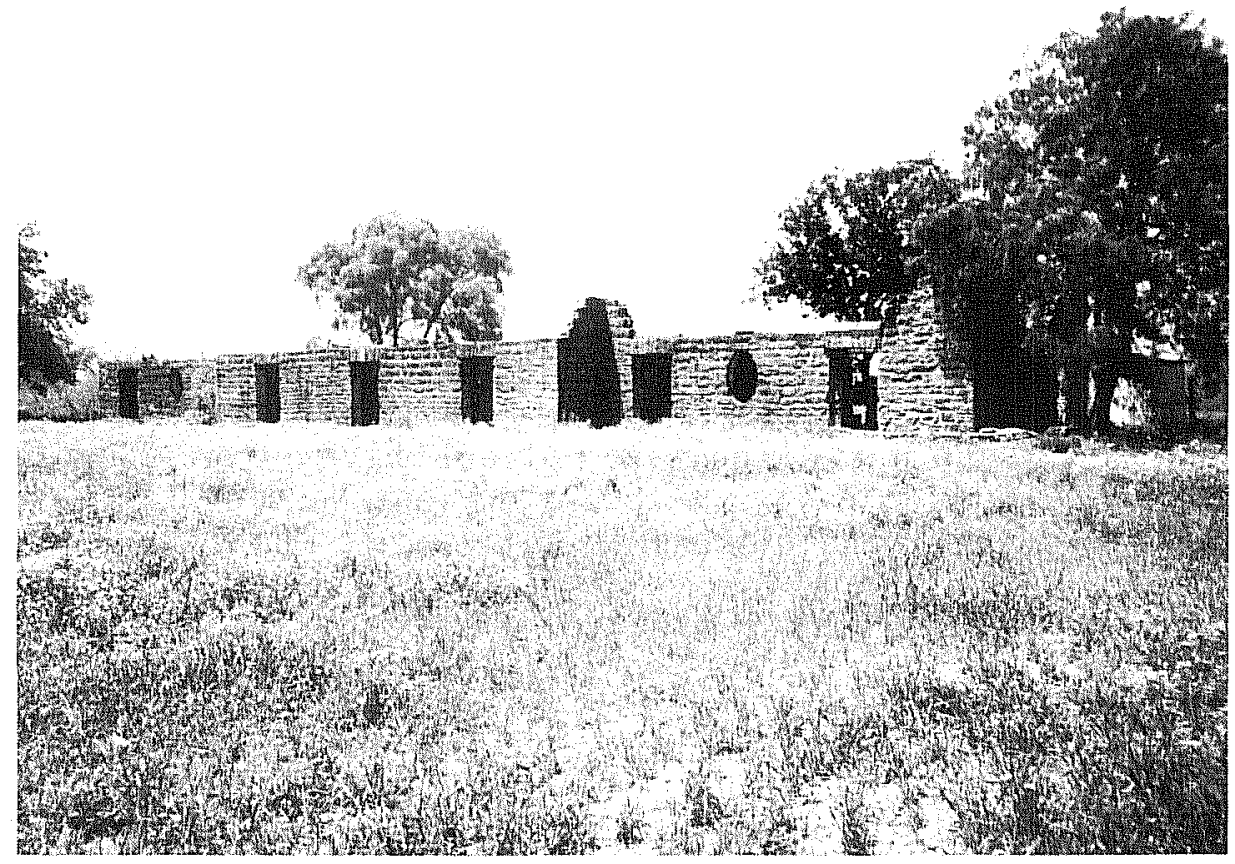

a

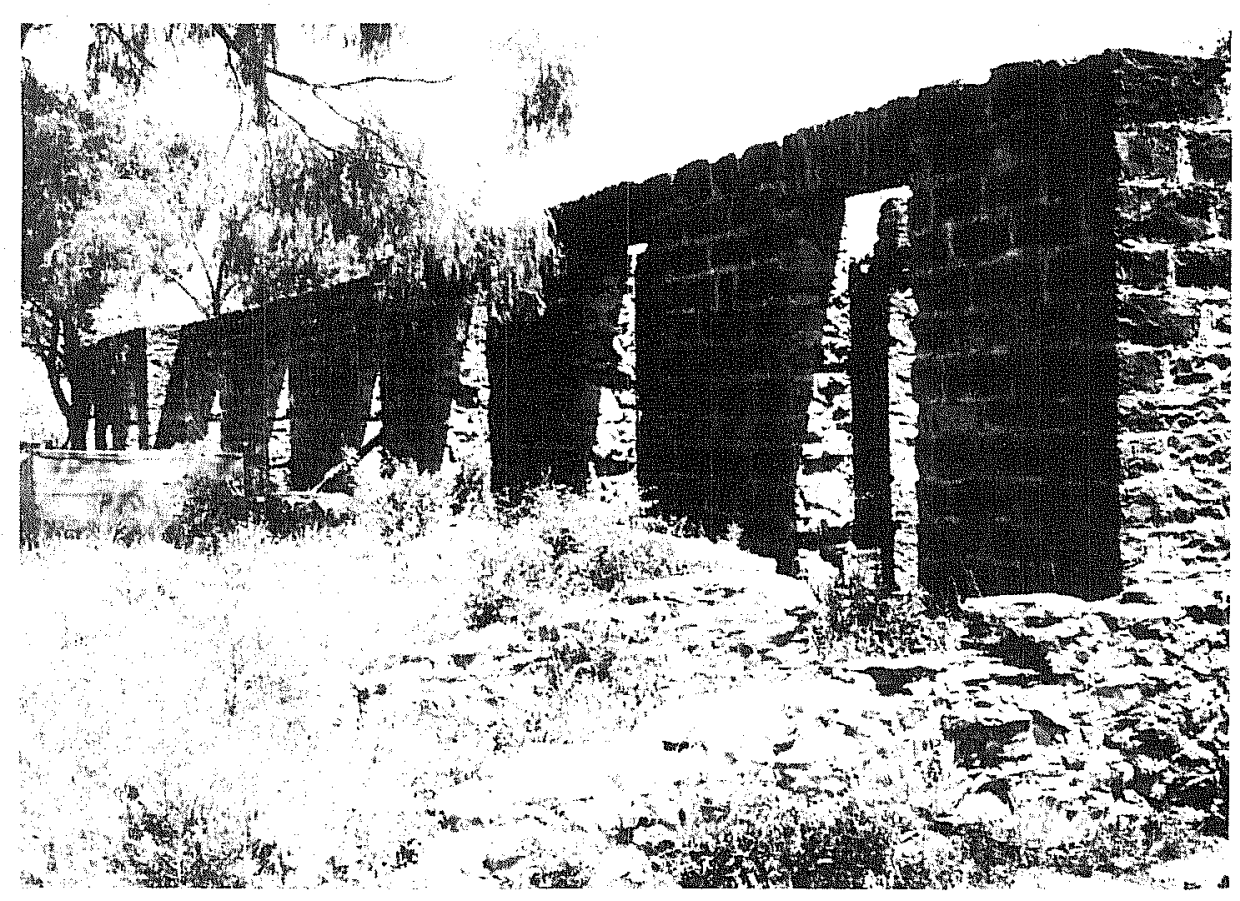

b

Figure 29. Exterior Views of Historic Structure at 41 BX 527. a, looking west; b, stone wall, looking north. 
on the west side of the structure along with a well which was filled in. The structure is very reminiscent of those built by German farmers in the Hill Country that served as a combination barn and home. The large openings on each end would provide a wagon drive through (necessary in wet weather to protect wooden wagon wheels), and the upstairs loft would provide sleeping space and hay storage.

A careful field inspection of the three-story stone building revealed that the structure had never been completed. The structure is of cut and dressed stone. An initial "H" was found carved into a lintel over the main entrance on the west side of the building (date not positive--may be recent) and an unusual good-7uck hex sign over a second-story entrance on the east side. A large stone-1ined underground cistern is adjacent to the structure.

The small frame structure is typical of the board and batten structures constructed around the turn-of-the-century. No other work was done on this structure since it is currently occupied by ranch hands. A board and batten privy is also present adjacent to the frame structure which is also in use.

Additionally, during the course of the field inspections a section of a stone-lined roadway (see Fig. 44) was located ca. $80 \mathrm{~m}$ west-southwest of the structures. This stone-lined section appears to have been placed in a "mudhole" which during wet weather would have become boggy, thereby hindering travel. A quarry (gravel and/or stone?) of undetermined age is located just south of the structures.

Site significance: The two stone buildings at 41 BX 527 are extremely impressive in terms of architectural significance and the probable association with early historic personalities residing in the study area. The site has the potential to reveal information important in the history of the study area (e.g., it offers a unique opportunity to examine early stone cutting and laying techniques.)

Management recommendation: In the opinion of the authors, this site is eligible for listing on the National Register of Historic Places based on: (1) the embodiment of the distinctive characteristics of a type, period, and method of construction; and (2) the potential to yield information important in the history of the area. The authors recommend that a determination of eligibility should be sought from the Keeper. Architectural documentation based on the Texas Catalog. Historic American Buildings Survey (Goeldner 1974) criteria for the three-story stone structure is recommended, along with further archival research to ascertain the builder(s) of the structures and their original use. Limited testing in the vicinity of the filled in well to establish temporal associations is al so recommended. This site, al though sitting on a high terrace, is situated within the maximum flood pool level of the proposed reservoir. Should the reservoir level reach and/or exceed this maximum flood pool level, the site will become an island. It is further believed that erosion caused by the conservation pool level will severely affect the site. Preservation of this site should be a high priority. 


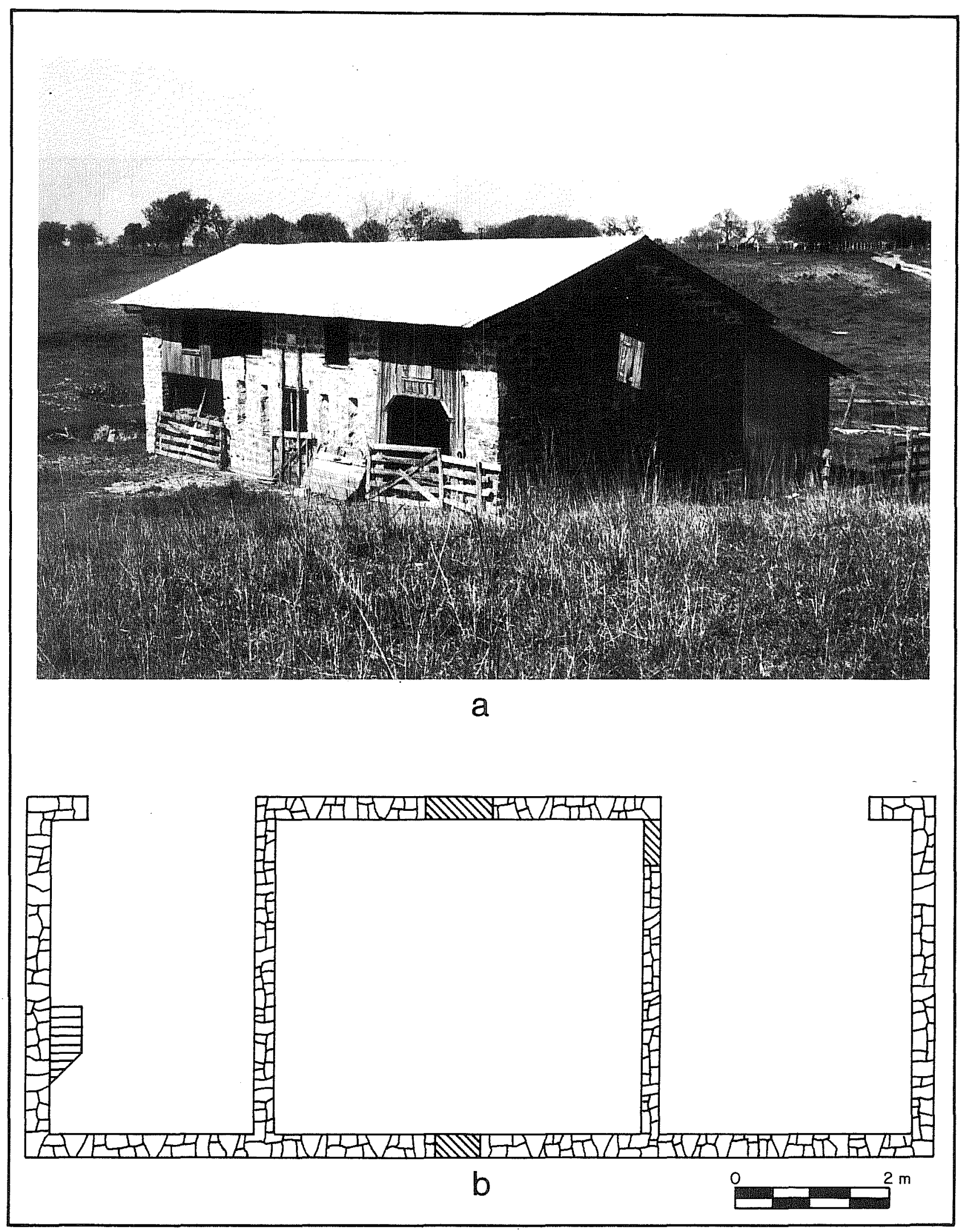

Figure 30. Views of Barn Structure at 41 BX 527. a, front view; b, floor plan. 
Applewhite/Site 41 BX 527

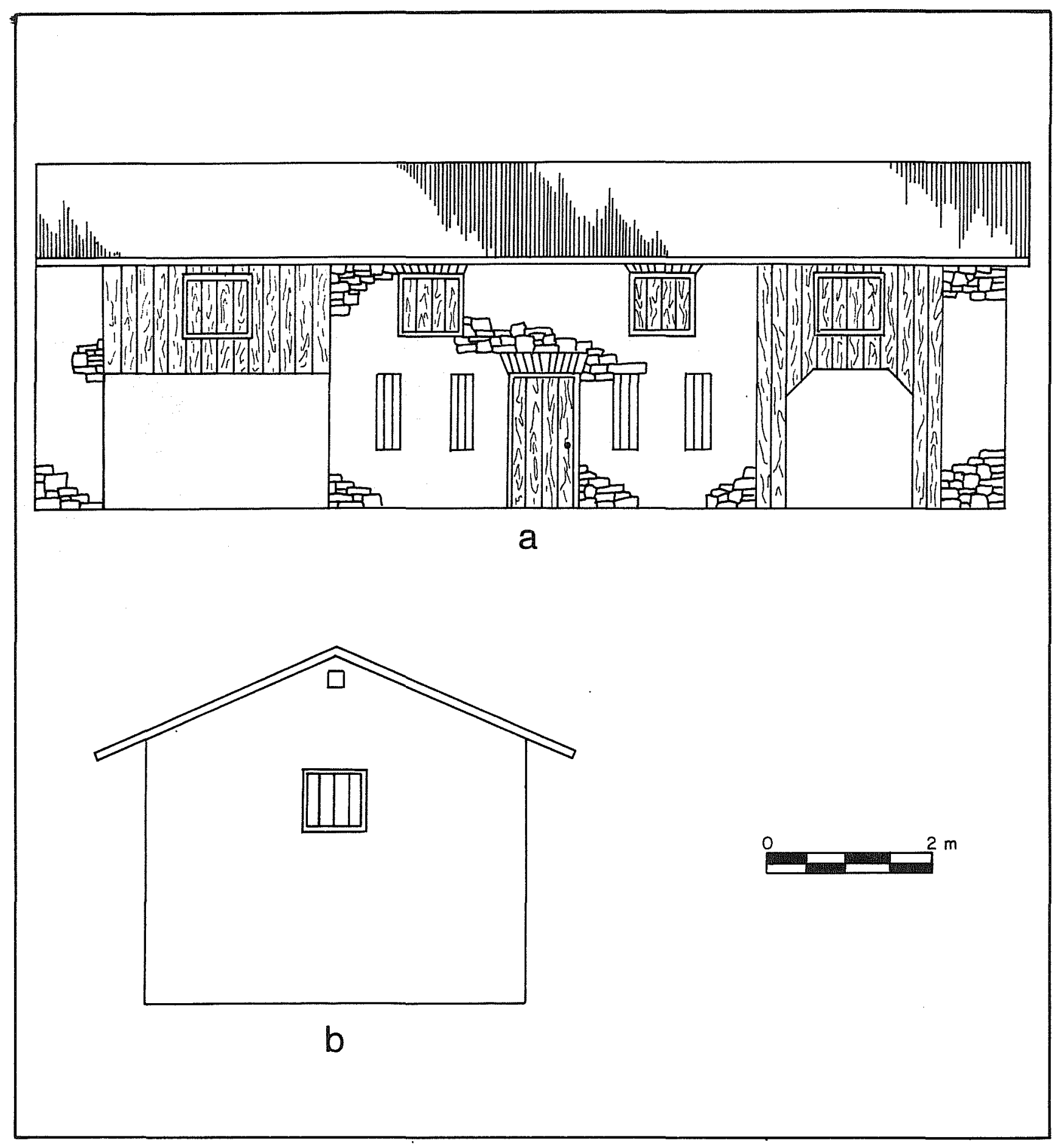

Figure 31. Scaled Drawings of Barn Structure at 41 BX 527. a, front view, toward west; b, side view, toward south. 


\section{$\underline{\text { SITE } 41 \text { BX } 528}$}

Type of site: Extensive prehistoric occupation zone.

Location: Along the upper terrace margins on the south bank of the Medina River, ca. $1 \mathrm{~km}$ north of Noyes Road and $1.5 \mathrm{~km}$ west of Highway 16.

Elevation: 550 feet to 560 feet above msl.

Topographic context: The site follows the terrace margins above the floodplain of the Medina River.

Water source: The present channel of the Medina River is ca. $0.5 \mathrm{~km}$ north.

Vegetation and soil: The site location has been extensively modified by 1 and clearing, cultivation, and most recently, as a pasture. Natural vegetation has been removed from a11 areas except the steep slopes adjacent to the river floodplain. The soil is a dark grayish brown Venus clay loam.

Site condition: Approximately $75 \%$ or more of the site area has been extensively damaged or altered by natural erosional processes or by recent alterations such as land clearing. Some areas of the terrace margins, while showing some surface disturbance, have intact subsurface cultural deposits ca. $25 \mathrm{~cm}$ below the surface. Or, as yet unidentified subsurface deposits may exist across the extensive site area.

Artifactual materials present: A small scatter of lithic debris and burned or fire-fractured rock litters the area. No features were noted, although a small dart point similar to Refugio was noted at this site in 1981, along with a small undecorated ceramic fragment $\mathrm{ca} .2 \mathrm{~cm}$ in diameter. The site was revisited on several occasions, and during subsequent surveys in the eastern terrace edges a large (ca. $6 \mathrm{~cm}$ in diameter) undecorated rim sherd fragment was recovered. Also noted were exposures of mussel shel1 fragments and burned rock eroding along the steep terrace slopes.

A visit in 1984 revealed recent 1 and clearing along the eastern portion of the site. Bulldozing had exposed ca. $25 \mathrm{~m}^{2}$ to a depth of $30 \mathrm{~cm}$; a large scatter of mussel shell fragments, burned rock, lithic debris, and prehistoric and historic Indian ceramic sherds was observed at that time. Three sma11 exposures of mussel she11 concentrations ca. $40 \mathrm{~cm}$ in diameter were identified, and 23 fragments of small undecorated sherds were collected.

A fragment of a probable Guerrero point was also collected in 1984 . The small proximal fragment has been burned and somewhat shattered but is very similiar to those found at mission sites, historic Indian sites, and historic ranchos. Fine parallel flaking is present. Also collected were a large thin biface, which has been referred to in the literature as a "knife," and a Scallorn arrow point.

Site discussion: Site 41 BX 528 represents the remains of an extensive prehistoric and/or possible historic Indian occupation zone. We believe a zone is a more accurate description of this location taking into account the extensive activity area, lack of concentrated materials (with the exception 
of the eastern site margins), and potential for both multicomponent and multifunctional prehistoric and/or historic Indian elements. The presence of a probable Guerrero point at this site is extremely important and may well represent an occupation at this site by historic Indian groups such as those mentioned by the early chroniclers (e.g., Pastia, Payaya, and Pampopa) or later intrusive groups such as the Apache. Although much of the surface area has been severely damaged and/or disturbed, portions of 41 BX 528 may stil1 contain intact subsurface deposits, as exemplified by the feature exposures uncovered by land clearing in 1984.

Site significance: Site 41 BX 528 represents one of the larger prehistoric and/or possible historic Indian activity locations in the study area. The presence of identified intact subsurface deposits and features related to the Late Prehistoric and/or Historic periods suggests that further significant buried materials may exist at this location, and the identification and assessment of these deposits will offer a significant contribution to the local and regional archaeological record.

Management recommendations: In the opinion of the authors, this site is potentially eligible for the National Register of Historic Places based on the information that may be yielded to the area's prehistory. The site is located in the maximum flood pool level of the proposed Applewhite Reservoir. Limited testing utilizing mechanical and hand testing is recommended to determine the size and extent of as yet unidentified cultural components. Such testing would also offer more accurate insights into the intrasite activity distributions of this extensive occupation zone.

\section{SITE 41 BX 529 (A1fred Heermann Burial)}

Type of site: Historic.

Location: Approximately $1 \mathrm{~km}$ northwest of the intersection of Noyes Road and Highway 16.

Elevation: ca. 530 feet above ms1.

Topographic context: Located at the base of a terrace remnant along an old channel of the Medina River.

Water source: Not applicable.

Vegetation and soil: The cemetery is surround by several 1 arge oak and hackberry trees. These trees are surrounded by cleared fields of tall grasses.

Site condition: Abandoned.

Artifactual material present: Not applicable.

Site discussion: In 1981, the survey team recorded the presence of two graves with headstones at this location. One of the headstones was reported to be that of A. Heermann, with a date of 1873-1903. Recommended in the 1984 
RFP issued by the Corps of Engineers for further limited testing and archival research, the site was revisited a minimum of two times. Archival research revealed that Alfred Heermann (see 41 BX 527 discussion), son of Theodore Heermann, had acquired a portion of this property from his father's estate (BCCH Wills and Probates 2286). On August 24, 1898, the Heermann sons equally divided the properties (BCDR Vo1. 193:54). On November 25, 1909 (1903?), Alfred Heermann met a tragic death at the age of 36 from a gunshot wound to the upper left lung (BCCH Vital Statistics Book 2:109).

A reinspection of the grave at 41 BX 529 confirmed the fact that one of the graves was indeed that of Alfred Heermann. The second grave is still unknown. Both graves are enclosed in an ornate fence such as commoniy used in cemeteries of that time period. The possibility of other graves in this vicinity is very high. In 1984, after field work in the reservoir area had been completed, the son of the landowner reported encountering a burial while remodeling one of the ranch houses located just east of these burials. Unfortunately, the Center for Archaeological Research was not notified in time to examine the burial.

Site significance: The graves are those of members of an early prominent family in the study area.

Management recommendations: In the opinion of the authors, this site is eligible for listing on the National Register of Historic Places based on the association with the lives of persons significant to the past. We recommend that a determination of eligibility should be sought from the Keeper. Mitigation should include testing of the larger area now suspected to contain burials. Relocation of the two burials will be necessary if the reservoir is to be constructed. This site is within the conservation pool level of the proposed reservoir.

\section{SITE 41 BX 530}

Type of site: Extensive prehistoric occupation site.

Location: On upland margins, ca. $50 \mathrm{~m}$ south of an arroyo complex adjacent to the Medina River.

Elevation: 530 feet to 540 feet above msl.

Topographic context: Along the upper terraces and upland margins adjacent to the Medina River floodplain.

Water source: The Medina River is ca. $100 \mathrm{~m}$ to the north.

Vegetation and soi1: Portions of the site have been extensively damaged by natural erosion as well as past efforts at land clearing. Much of the site area is currently overgrown with mesquite and other thorny brush. Soil, extensively eroded along the slopes, is a dark grayish brown Venus clay loam.

Site condition: The distribution of surface materials across most of the site area reflects both natural erosional and manmade disturbances. 
Observations in 1981 indicated that much of the surface material was exposed during weathering processes, and buried deposits might exist in the area.

Artifactual materials present: A small to moderate scatter of 1 ithic debris and burned or fire-reddened rock fragments was distributed across the site area. Two small undecorated prehistoric ceramic sherds were collected at the site. No other diagnostic materials or features were noted.

Site discussion: Following the original recommendations for further work in 1981, 41 BX 530 was revisited, tested, and reassessed in 1984. The 1981 recommendations suggested further work in the form of mechanical and hand testing be utilized to determine the nature of prehistoric activities at the site and the probability of buried components.

Work in 1984 involved intensive resurveys and hand testing, as the landowner was adverse to mechanical testing in this area. The assessments of 41 BX 530 and nearby $41 \mathrm{BX} 531$ suggest that these two sites may actually be an extensive occupation zone rather than discrete site areas. Following intensive surveys into previously inaccessible areas and the results of limited testing at both 41 BX 530 and nearby 41 BX 531, we believe that both these sites can be more accurately described as the locations of specific material concentrations in a large prehistoric occupation zone. The boundaries of this zone encompass both the former site areas of 41 BX 530 and $41 \mathrm{BX} 531$. Results of testing, interpretations, and site recommendations for 41 BX 530 are similar to those presented for 41 BX 531.

In 1981, two prehistoric sites, 41 BX 530 and 41 BX 531, were identified as intensive activity areas and recommended for further work to determine site significance and potential. The sites were separated by a tract of inaccessible property ca. 300-400 m in length. In 1984, intensive surveys into this previously inaccessible area revealed cultural deposits that not only link 41 BX 530 and 41 BX 531 into an occupation zone but also identify the new $7 y$ surveyed location (described as 41 BX 669) as the most concentrated locality of cultural materials of this zone.

Investigations in the $41 \mathrm{BX} 530$ and 41 BX 531 areas, the east and west margins of the occupation zones, consisted of intensive surveys to redefine site boundaries and hand excavations in the form of $50-\mathrm{cm}^{2}$ shovel tests and one $1 \mathrm{~m}^{2}$. Mechanical testing, considered a valuable aid to increase the efficiency of testing and accuracy of evaluations, was not utilized because of the 1 andowner's reluctance to have heavy machinery travel across 10cal ranch roads.

Intensive surveys of $41 \mathrm{BX} 530$ indicated that the site area, with cultural materials primarily exposed along the slopes of an extensive arroyo complex, had been seriously eroded and deflated. No features were exposed in the numerous erosional cuts along the slopes. A $1-\mathrm{m}^{2}$ test unit was excavated in the northern section of the site to a depth of $75 \mathrm{~cm}$ below the surface. The excavation unit revealed homogeneous, fine-grained, unstratified soils to a depth of $18 \mathrm{~cm}$. At this level, materials became more compact and clayey with a slight color change. Several small caliche intrusions were noted between 40-70 cm. No features were discovered, and recovered materials consisted of two corticate chips, one chert core fragment, seven decorticate chips, three 
burned rocks, one secondary flake, and four tertiary flakes at $0-10 \mathrm{~cm}$; two decorticate chips and one tertiary flake at 10-20 cm; three decorticate chips and two tertiary flakes at $20-30 \mathrm{~cm} ; 30-40 \mathrm{~cm}$ was sterile; two decorticate chips at 40-50 cm; one tertiary flake at 50-60 cm; and $60-75 \mathrm{~cm}$ was sterile. Hand testing and intensive surveys suggest (1) 41 BX 530 and 41 BX 531 are the margins of an extensive prehistoric activity zone ca. $0.5 \mathrm{~km}$ in length and over $200 \mathrm{~m}$ wide; (2) if stratified cultural deposits exist, they may be in the form of deeply buried features similar to those found at nearby $41 \mathrm{BX} 274$; and (3) only further testing employing a systematic strategy of mechanical and extensive hand testing can accurately evaluate this area (see a1 so 41 BX 669).

In summary, (1) 41 BX 530 and 41 BX 531 have been marginally tested and require further work; (2) $41 \mathrm{BX} 669$ is an integral cultural and physical aspect of this occupation zone (hence with similar recommendations); and (3) a cumulative collection of information to date (including background archival research) suggests the possibility of an additional, significant historic Indian component in this locality. All this is somewhat complicated by the occurrence of a newly identified historic component at 41 BX 669 . Thus, site interpretations, assessments, and recommendations must consider $41 \mathrm{BX} 530,41 \mathrm{BX} 531$, and $41 \mathrm{BX} 669$ as integral7y related cultural resource elements of an extensive multicomponent, multiperiod occupation zone (Fig. 32).

Site significance: Site 41 BX 530, as the western margins of an extensive prehistoric occupation zone along the Medina River, represents an integral component of a potentially long-term prehistoric occupation in the study area. In the opinion of the authors, while we recognize the limited artifacts recovered to date at this site, we also consider it to be part of a much larger occupation zone as identified in the 1984 studies.

Management recommendations: In the opinion of the authors, this site is potentially eligible for listing on the National Register of Historic Places based on the information that may be yielded to the area. The site is within the conservation pool level of the proposed Applewhite Reservoir area. As noted, an accurate determination of both 41 BX 530 and the encompassing occupation zone cannot be concluded without more extensive, further testing employing both mechanical and hand testing to uncover potentially deeply buried deposits.

\section{SITE 41 BX 531}

Type of site: Prehistoric occupation.

Location: Along a high terrace south of the Medina River, ca. $300 \mathrm{~m}$ northwest of Neal Road.

Elevation: 500 feet to 520 feet above ms 1 .

Topographic context: Along the upper terrace and upland margins adjacent to the Medina River floodplain. 
This page has been

redacted because it

contains restricted

information. 
Applewhite/Site 41 BX 531

Water source: The Medina River is 50-75 m north.

Vegetation and soil: The site is affected by natural erosional processes. The area has been partially cleared, but because of dense brush cover in some areas, the actual site dimensions may be larger than surface indications (a minimum of $100 \mathrm{~m}^{2}$ ). The soil is a dark grayish brown Venus clay loam bordered by Karnes clay loam with deep erosional gullies along the steep slopes.

Site condition: Natural erosion has extensively affected site integrity along the floodplain/terrace margins, and past land clearing has disturbed surface exposed materials to an estimated depth of at least $30 \mathrm{~cm}$. Possible deeply buried deposits may exist below the disturbed zone.

Artifactual materials present: A small scatter of 1 ithic debris in the form of decorticate chips, secondary and tertiary flakes, and several core fragments was observed across the site. Small burned chert cobbles and firefractured 1 imestone rock fragments were also noted, but no concentrations were identified. No diagnostic artifacts or features were located or collected during site inspections.

Site discussion: Assessments in 1981 suggested the possibility of buried subsurface deposits because of the extensive soil depths exposed in erosional cuts along the terrace margins and the surface disturbed scatter of burned rock and 1 ithic debris. It was suggested that the site may have been, because of spatial proximity, related to the prehistoric site 41 BX 539 , although the surface boundaries of 41 BX 531, unlike other portions of the site, seemed quite distinct. Additionally, it was also suggested that the site may have been related to 41 BX 530 to the southwest or an extension of that site. Unfortunately, access was not available to confirm this speculation. Further work was recommended in 1981 to determine the horizontal extent of 41 BX 531 as well as the likelihood of subsurface components.

The site was revisited in 1984 for further work and subsequently reassessed following intensive surveys and limited hand testing (as the landowner was adverse to mechanical testing). Access into previously unsurveyed areas to the west of $41 \mathrm{BX} 531$ also contributed to site reappraisal.

Site 41 BX 531 was investigated by a series of five $50-\mathrm{cm}^{2}$ shovel tests spaced at approximately $30-\mathrm{m}$ intervals parallel to the modern terrace. A11 test units were excavated to an average depth of $50 \mathrm{~cm}$, and the soil was screened through 1/4-inch wire mesh. Although an extensive surface scatter was observed across the site area, the systematic shovel testing revealed little in the form of subsurface deposits. Only two test units recovered any lithic debris (with a total count of only nine flakes and chips). As noted in the site discussion of 41 BX 530, 41 BX 531 has been identified as the eastern margins of a prehistoric occupation zone that includes 41 BX 530 to the west and the recently identified 41 BX 669 (see also descriptions of 41 BX 530 and 41 BX 669). Site interpretations, assessments, and recommendations must consider $41 \mathrm{BX} 530,41 \mathrm{BX} 531$, and $41 \mathrm{BX} 669$ as integrally related elements of an extensive multicomponent, multiperiod prehistoric occupation zone. 
The limited amount of subsurface testing to date precludes an accurate interpretation on the potential of buried deposits at the site, although present interpretations suggest the main concentration of materials lies ca. $150 \mathrm{~m}$ or more west, in the area of $41 \mathrm{BX} 669$.

Site significance: Site $41 \mathrm{BX} 531$ and its relationship to the defined occupation zone encompassing adjacent 41 BX 530 and 41 BX 669 represent a potentially significant archaeological resource area because of the unique recovered artifacts from $41 \mathrm{BX} 669$, the surface extent of cultural materials, and the potential for, as yet, unrecognized buried deposits.

Management recommendations: In the opinion of the authors, this site is potentially eligible for listing on the National Register of Historic Places. The site is located in the conservation pool level of the proposed Applewhite Reservoir. Investigations to date have only tested a small portion of the subsurface at $41 \mathrm{BX} 531$, and mechanical testing (not available previous7y) is needed to define the buried aspects of the site area as well as a more accurate appraisal of the relationship of $41 \mathrm{BX} 530,41 \mathrm{BX} 531$, and 41 BX 669.

\section{$\underline{\text { SITE } 41 \text { BX } 532}$}

Type of site: Prehistoric lithic scatter; possible occupations.

Location: In a flat upland area about $1 \mathrm{~km}$ south of the present channel of the Medina River. This site spans Neal Road east of Applewhite Road.

Elevation: 530 feet above msl.

Topographic context: Although the site is situated in an upland context some distance from a water source, both topographic and aerial soil maps indicate an ancient river channel and a filled-in tributary drainage in the immediate area of 41 BX 532.

Water source: The present channel of the Medina River is ca. $1 \mathrm{~km}$ north. Estimated fossil river channel was $300 \mathrm{~m}$ or less from site area. Estimated fossil tributary was $100 \mathrm{~m}$ or less from site area.

Vegetation and soil: Natural vegetation has been replaced by cultivated crops, and the site location has been both cleared and deep plowed. The soil in the area is related to Hockley loamy fine sand, a sandy soil that is pale brown.

Site condition: The surface area has been severely disturbed by modern 1 and clearing and cultivation, with disturbances extending to at least $30 \mathrm{~cm}$, the estimated depth of a deep plow zone. Intact cultural deposits may lie buried below this depth (see Site discussion).

Artifactual materials present: A small 1ithic scatter was observed across the site area. Several small fire-reddened decorticate chips were observed also; this suggests some activities other than lithic reduction may have 
taken place at the site. A projectile point, a Late Archaic Marcos point, was found within the plow furrows of the site in 1981.

Site discussion: Due to the extensive and intensive amount of modern disturbance, the area was not recommended for further work in 1981. The site was selected, however, by the U.S. Army Corps of Engineers, Fort Worth District, for 1 imited testing in 1984. Unfortunately, 1 imited testing of this area proved unfeasible at this time as it was under extensive cultivation. The site was, however, revisited and also reassessed on the basis of cumulative data over the three-year period, particularly from the perspectives of intersite distribution patterns, geomorphology, and the known occurrence of buried sites in the study area.

The fine-grained sandy soil of the site represents the upper zones of an eroded Hockley loamy fine sand exposed ca. $600 \mathrm{~m}$ west at 41 BX 534, a prehistoric occupation site containing Early Archaic Bulverde projectile points (see $41 \mathrm{BX}$ 534). Given the relative proximity of these sites and the related soil types, earlier deposits than the Late Archaic Marcos-associated materials may exist below the surface at 41 BX 532 . Mechanical and hand excavations at sites such as 41 BX 274 in the study area have shown such deposits may exist $3 \mathrm{~m}$ or more below the surface in this area.

Additionally, and as important, present interpretations of prehistoric site distributions compiled during 1984 studies indicate an unusual pattern of prehistoric sites in the southeastern portion of the study area. These sites are characterized by relatively extensive lithic scatters and occupation sites well over a kilometer from the present river channel. Situated in modern upland contexts, sites such as 41 BX 534, 41 BX 532, 41 BX 541, $41 \mathrm{BX} 535$, and 41 BX 536 are now thought to represent the remains of sites not only associated with former channels of the Medina River, but also fossil tributaries and/or drainage patterns having their source well south of the river valley. Diagnostic artifacts from several of these sites indicate Early Archaic activities, and it is believed that this occupational site pattern is distinct and related to, but qualitatively separate from, later resource exploitations along the Medina River valley riparian zone.

Site significance: Site 41 BX 532, following extensive reassessments of site function and physiographic context, is thought to represent the remains of prehistoric activities related to a former terrace and/or river channel of the Medina River. Additionally, its location is thought to be related to a tributary water course that once ran perpendicular to the ancient river channel just west of the site area. As such, it represents one of a series of sites that may indicate distinct patterns of resource exploitations through changing environmenal conditions. In the opinion of the authors, while the upper levels of the site have been disturbed, a good possibility exists for deeply buried, intact cultural deposits.

Management recommendations: Limited testing operations are recommended to determine the extent and significance of cultural deposits at this site. Such further work that would necessitate both mechanical and hand testing could add significant data not only to changing patterns of prehistoric activities in the study area, but also contribute to an understanding of the same phenomenon from a regional perspective. In the opinion of the authors, 
such work would be necessary to determine the potential eligibility of this site for nomination to the National Register of Historic Places. The site is within the conservation pool level of the proposed Applewhite Reservoir.

\section{SITE 41 BX 533}

Type of site: Prehistoric occupation.

Location: Surrounding an arroyo complex adjacent to the Medina River. The site is ca. 500 m west of Neal Road.

Elevation: 500 feet above msl.

Topographic context: The site is located along a high terrace just south of the modern floodplain. It extends southward and borders a large arroyo complex which enters the river floodplain just east of the site location. A very small lithic scatter was observed on the southern edges of this erosional gully.

Water source: The Medina River is ca. 80-100 m from the site.

Vegetation and soil: Thorny brush and mesquite covered all the site area in 1981, along with high grasses. The soil is eroded Venus associated clayey loam. The site was revisited in 1984 and found to be destroyed by extensive land clearing that has resulted in severe natural erosion.

Site condition: Bulldozing, land clearing, and subsequent natural erosion have destroyed an estimated $95 \%$ or more of the site area.

Artifactual materials present: Lithic debris and fire-reddened rock fragments were observed scattered over a ca. 200- x 400-m area in 1981. Several sandstone hearths were identified eroding along the slopes, $c a .75 \mathrm{~cm}$ below the surface. An Early Triangular biface (Early Archaic) was collected from an erosional gully in close association with a small burned rock cluster, ca. $1 \mathrm{~m}$ in length. Mussel shell fragments were also observed within numerous small erosional gullies along the slopes of the occupation area.

Site discussion: The Early Archaic diagnostic collected at this site along with potential intact surface deposits indicate that significant cultural deposits might lie below the surface. Recommendations in 1981 suggested further work to more clearly define the horizontal and vertical extent of the site. Revisits to the site area in 1984 found that 1 and clearing and severe erosion following the loss of topsoil and vegetation cover had resulted in disastrous slope erosion. Recent gully erosions along the entire site length were often more than 2-3 m deep. The site area was carefully reinspected for indications of exposed or still intact subsurface deposits. Unfortunately, surface indications of the former site were almost nonexistent except for a disturbed small scatter of lithic debris along the steep lower slopes of the southern site area.

Site significance: The present value of the former site area 1 ies in the identification of chronologically diagnostic materials in 1981 and its 
physiographic location on an eroding terrace remnant. The identification of an Early Archaic(?) cultural level ca. $1 \mathrm{~m}$ below the surface is a useful indicator of chronology should other similar physiographic features and cultural deposits be identified in further studies.

Management recommendations: Because of the extensive and severe manmade and natural damage to 41 BX 533, no further work is recommended at this location. If further work to test the occupation zone of $41 \mathrm{BX} 530,41 \mathrm{BX} 531$, and 41 BX 669 occurs, we recommend this site also be considered for the potential subsurface deposits and intersite distribution patterns. The site is located within the conservation pool level of the proposed Applewhite Reservoir.

\section{SITE 41 BX 534}

Type of site: Prehistoric occupation.

Location: Approximately $100 \mathrm{~m}$ north of Neal Road and about $300 \mathrm{~m}$ east of Applewhite Road. A small scatter of burned rock extends ca. $50 \mathrm{~m}$ south of Neal Road.

Elevation: 540 feet to 550 feet above ms1.

Topographic context: The site is located on the slopes of a small knoll overlooking a tertiary, intermittent drainage along the Medina River. A review of topographic and aerial maps indicates the location was once adjacent to an old channel of the Medina River.

Water source: The Medina River is ca. $800 \mathrm{~m}$ north of the site.

Vegetation and soil: The eastern slopes of the site have been cleared and are cultivated. The western portion of the site is covered by dense thorny brush, and several extensive erosional gullies dissect the area. In 1984, bulldozing in portions of the western site area has additionally damaged the surface of the prehistoric occupation. The soil is Hockley eroded and loamy fine sand, pale brown, and mottled.

Site condition: The surface area of ca. $65 \%$ of this site area has been altered by natural erosion or modern land clearing and/or cultivation. Eroding burned rock and lithic materials suggest portions of the subsurface sti11 contain intact subsurface deposits.

Artifactual materials present: A moderate scatter of 1 ithic debris and firereddened burned rock fragments 1 itters the site area (ca. $300 \times 400 \mathrm{~m}$ ). First identified in 1981, no features or diagnostic materials were observed, although the distal portion of an unidentified projectile point was collected. Revisited on two occasions in 1984, a small, eroding burned rock cluster (ca. $1 \mathrm{~m}$ in diameter) in the western portion of the site was identified. Three Bulverde projectile points were surface collected from within a $5-\mathrm{m}^{2}$ area around this eroding feature.

Site discussion: Recommendations in 1981 suggested that because of the extensive site area and the indications of prehistoric occupations, testing 
in the form of mechanical and hand excavations be conducted to more accurately identify the multifunctional character of past activities at the site as well as chronological associations. In 1984, following interpretations of site distributions and intersite relationships in the area, 41 BX 534 was identified as a potential location for an Early to Middle Archaic occupation site associated with a former river channel-terrace complex. Additionally, its location near a northward-running ephemeral tributary today indicates the prehistoric site location may have once been situated along a former confluence point. The collection of chronologically diagnostic Early Archaic Bulverde points at this location supports the time sequence postulated for site distributions and intersite relationships in this portion of the study area (see also site description of $41 \mathrm{BX} 532$ ).

Site significance: Site 41 BX 534 represents the remains of an extensive prehistoric occupation site thought to have been occupied during the Early to Middle Archaic period(s) and possibly earlier. While portions of the site's surface have been moderately to extensively disturbed by natural and manmade alterations, the observation of eroding features and diagnostic materials indicates that intact cultural deposits still exist in subsurface contexts. The depth, extent, and significance of these deposits can only be measured by systematic limited testing. Although the site was recommended for further work in 1981, no testing has yet been initiated in this area.

Management recommendation: In the opinion of the authors, site 41 BX 534 is potentially eligible for nomination to the National Register of Historic Places. It represents an occupational location of a poorly understood regional Early Archaic cultural episode associated with recognized geomorphological changes in the local study area. The site is located in the maximum flood pool level of the proposed Applewhite Reservoir. Should the site area be impacted by future modifications, we recommend an initiation of work as suggested in 1981.

\section{SITE 41 BX 535}

Type of site: Prehistoric occupation site.

Location: About $500 \mathrm{~m}$ south of Neal Road and $1.3 \mathrm{~km}$ east of Applewhite Road.

Elevation: 550 feet to 590 feet above $\mathrm{ms} 1$.

Topographic context: Upland.

Water source: The nearest modern source of water is the Medina River ca. $1 \mathrm{~km}$ north of the site.

Vegetation and soil: Moderately to extremely dense thorny brush covers practically all of the site area. Deep erosional cuts along the eastern site margins dissect the eastern slopes. Eroded Hockley sandy, loamy soil is associated with the southern, upper slopes of the site area; down slope and northward, Crockett fine sandy loam covers the site area. Crockett soils have a sandier, thicker, and lighter colored surface layer than Hockley soils 
and have a sandier, more permeable subsurface layer (Taylor, Hailey, and Richmond 1966:13).

Site condition: Natural slope erosion has affected the surface of the site. Examination of erosional cuts along the slopes indicates in situ lithic debris exposed in gully walls $5-15 \mathrm{~cm}$ below the present surface.

Artifactual materials present: Two projectile points and one basal point fragment were collected from the site area (ca. $300 \times 500 \mathrm{~m}$ ). Two of the small dart points are identified as Transitional Archaic Ensor projectile points, and the other is an extensively patinated corner-notched dart point with an alternately beveled blade, similar to a variant of the Early Expanding Stem (Black and McGraw 1985:121). A small to moderate scatter of lithic debris and burned rock was also observed across the site area. Split cobbles and utilized cores and fragments were also noted. The occurrence of primary reduction materials such as cores, fragments, and primary flakes at 41 BX 535 suggests a local source material, such as an upland outcropping of Uvalde gravels along nearby hilltops or slopes.

Site discussion: Site 41 BX 535 represents an unusually extensive prehistoric occupation site situated in an upland context. The presence of both Early and Transitional Archaic dart points indicates a long period of occupational activities at this site area. Interpretations of site distributions and patterns within this portion of the study area suggest that the site may be related to a water source that was once much closer to 41 BX 535 than the modern channel of the Medina River. The closest possibility for such a source of water is two small dry tributary runoff channels adjacent to the lower slopes at distances of ca. $300 \mathrm{~m}$ from the site's margins. The origins for the water source of these ephemeral drainages are not identified; certainly former upland springs or seeps are a possibility, given the area's location over the Carrizo-Wilcox geologic formations, a noted subsurface aquifer for the region.

Site significance: The extent, or even the probability of such water sources in relation to prehistoric sites in this portion of the study area are not clearly understood currently. Certainly, however, the occurrence of such water sources would have influenced the distribution of prehistoric occupation and subsistence patterns in the local area and would be in contrast to the more easily recognized exploitations of the adjacent riparian zones in the river valley.

Management recommendations: The elevations of 41 BX 535 are at the maximum projected extent of the flood pool in the proposed reservoir area. Thus, the main areas of the site are presumed to be beyond primary future impacts. In the opinion of the authors, however, two significant elements indicate that at least some further work should be conducted at this site location: (1) the identification of possible water sources that may have qualitatively affected prehistoric site patterns in the local area, and (2) the extensive area of the site, while extensively and intensively surveyed, has not been explored in a subsurface context. Site 41 BX 535 represents an example of an unusual prehistoric occupation pattern of the local area, and information to date cannot accurately assess the potential of this site without further work 
in the form of mechanical and hand testing to determine the extent and cultural associations of its material components.

\section{SITE 41 BX 536}

Type of site: Prehistoric occupation site.

Location: on a ridge complex southeast of a small tertiary drainage about $200 \mathrm{~m}$ north of Loop 1604 and $300 \mathrm{~m}$ east of Applewhite Road.

Elevation: 560 feet to 600 feet above ms 1 .

Topographic context: Upland.

Water source: Approximately $2 \mathrm{~km}$ from the modern channel of the Medina River. The site is located ca. $40 \mathrm{~m}$ from a small (dry) tertiary stream channel.

Vegetation and soil: Portions of the site area have been partially cleared to accommodate a modern (ca. 1950s), sma11, but abandoned homesite; however, low grasses and thorny brush still cover the majority of the site area. The soil is eroded Hockley sandy loam, light brown in color.

Soil condition: The site area has been partially disturbed by grazing and other ranching activities such as land clearing. Natural erosion has also created numerous small gullies along slopes.

Artifactual materials present: A small scatter of lithic debris and an occasional burned rock are distributed across the site area (ca. $500 \mathrm{~m}^{2}$ ). The medial portion of an unidentified projectile point type was collected, but no other diagnostic artifacts or features were noted.

Site discussion: First identified in 1981, the site was revisited and resurveyed in 1984. Preliminary interpretations suggested a prehistoric occupation site in a similar physiographic context as 41 BX 535, that is, an extensive occupation site in an upland area. Although in comparison with $41 \mathrm{BX} 535$, site 41 BX 536 does not reflect the same intensity of surfacescattered 1ithic debris.

Site significance: Site 41 BX 536 lies adjacent to but beyond the maximum projected elevations of flood pool impacts of the proposed reservoir area. Site significance, as in the case of $41 \mathrm{BX} 535$, lies in the recognition of a prehistoric occupation area associated with nonriverine exploitation patterns of natural resources.

Management recommendations: In the opinion of the authors, while further work in the form of subsurface testing is necessary to more accurately describe the character and content of this site, such work cannot be recommended in the context of the site's location beyond the maximum flood pool elevations of the proposed reservoir. The recognition of the character of this site as part of changing patterns of prehistoric exploitation along and within the lower Medina River valley should be considered, however, in 
future assessments and interpretations of intersite patterns and distributions of prehistoric occupations in the study area.

\section{SITE 41 BX 537}

Type of site: Prehistoric scatter of 1ithic debris; possible temporary occupation.

Location: Along the upper terrace and just south of an extensive arroyo complex, south of the Medina River and about $300 \mathrm{~m}$ north of Neal Road. The southern site margins are situated adjacent to the historic site 41 BX 538, and it is possible that prehistoric activities once occurred in this nearby area. However, past modern activities at 41 BX 538 have obliterated all surface traces of such prehistoric activities.

Elevation: 510 feet above msl.

Topographic context: The site is located along an extensive erosional complex adjacent (just south of) to the modern channel of the river. Reviews of topographic and aerial maps indicate that this arroyo complex is the extremely eroded remains of a former river channel south of, but parallel to, the modern channel.

Water source: The Medina River is ca. 75-100 m north.

Vegetation and soil: Most of the site area lies in a cultivated, flat field, and natural vegetation has been removed by land clearing. The soil is Venus associated grayish brown clayey loam.

Site condition: The surface of 41 BX 537 has been extensively disturbed by deep plowing to a depth of at least $30 \mathrm{~cm}$. Intact subsurface cultural deposits may exist below this depth, but this is not indicated by surface evidence.

Artifactual materials present: 0nly a disturbed, small scatter of 1 ithic debris was noted across the site area (ca. $200 \times 300 \mathrm{~m}$ ). Only two small fragments of burned rock were observed over this same area. A $50-\mathrm{cm}^{2}$ shove 1 test in the approximate center of the site area was excavated to a depth of $40 \mathrm{~cm}$; no cultural materials were recovered.

Site discussion: Preliminary observations in 1981 suggested the activity area of the site may have been related to the more intensively occupied prehistoric sites east of $41 \mathrm{BX} 537$, and that this site might actually form the western margin of such an activity zone. Additional7y, 41 BX 537 is spatially proximate to 41 BX 533 but physically separated from it by an extensive arroyo complex. In either case, 41 BX 537 is considered to be the marginal remains of a more extensive prehistoric activity area. While subsurface cultural deposits may exist in this area, the lack of any surface indicators of an intensive lithic scatter and only a few burned rock suggest future testing for such deposits could be conducted more productively at nearby sites, e.g., sites 41 BX 530, 41 BX 531, and 41 BX 669 located to the east of 41 BX 537. 
Site significance: Site 41 BX 537 is spatially proximate to other prehistoric sites recognized as having significant cultural deposits. While the site does not appear to contain potential for further work, it should be considered in any assessment of intersite relationships developed from future testing at such nearby sites as 41 BX 530, 41 BX 531, or 41 BX 669.

Management recommendations: On the basis of the limited information to date, 41 BX 537 does not represent the remains of a potential National Register quality site. The site is located in the conservation pool level of the proposed reservoir area. We recommend periodic site monitoring. Additiona $17 y$, we recommend 41 BX 537 be considered (or reconsidered) along with future data derived from testing at nearby sites.

\section{SITE 41 BX 538 (Applewhite/Watson Home)}

Type of site: Historic.

Location: Approximately 30-50 m north of Neal Road.

Elevation: ca. 510 feet above msl.

Topographic context: Along the upper terrace margins of the Medina River floodplain just west of the river's confluence with Leon Creek.

Water source: The Medina River is ca. $100 \mathrm{~m}$ from the site.

Vegetation and soil: Portions of the site area have been cleared and are under cultivation. Approximately $40 \%$ of the site area is covered by dense thorny brush. Soil is a clayey, medium brown alluvium.

Site condition: Maintained and occupied.

Artifactual material present: Few artifacts were observed at this site, and nothing was surface collected. The continuous occupation at this site has kept most of the material cleared from around the structures. Early dumps must be located in the vicinity and may be deeply buried north of the house toward the river in extensive arroyos.

Site discussion: The site was first recorded in 1981. Two structures, a large two-story wood frame building (Figs. 33,a,b) ca. 24 by $30 \mathrm{~m}$ and a smaller cut stone/adobe building (Fig. 34 ,a-d) ca. 8 by 5 m were recorded. Both structures were believed to be of late 19th-century construction, al though the wood frame structure was considered to be of somewhat later origins. The larger wood frame house was postulated to be a stagecoach stop reported to be in the vicinity. The smaller structure was believed to be a smokehouse.

Site 41 BX 538 was recommended by the Corps of Engineers in their 1984 RFP for limited testing. In 1984, following those recommendations submitted to Freese and Nichols, Inc., detailed records and archival research were initiated on the site. Because of current occupations at this site, limited testing was not conducted. The site was revisited a minimum of four times in 


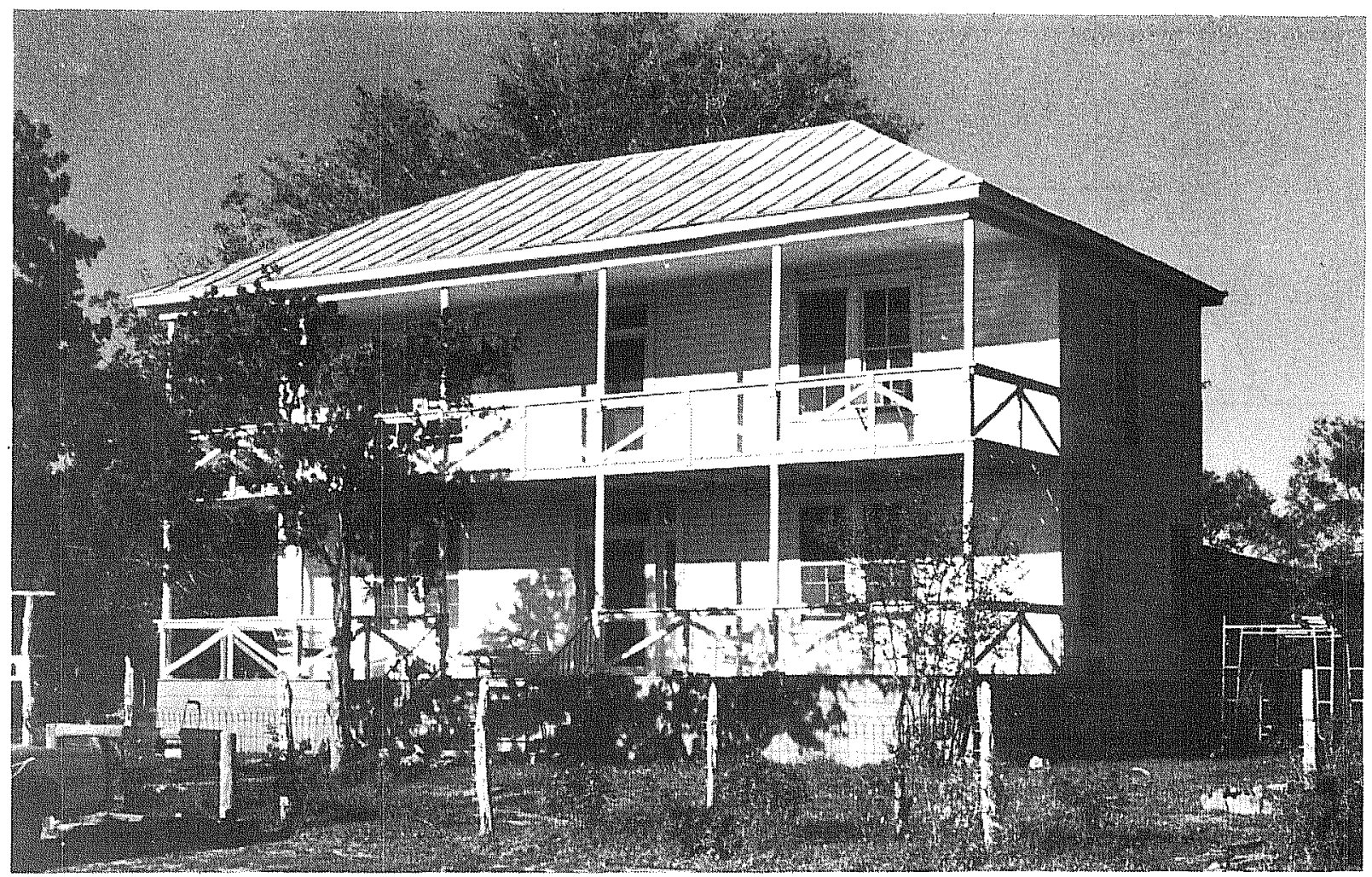

a

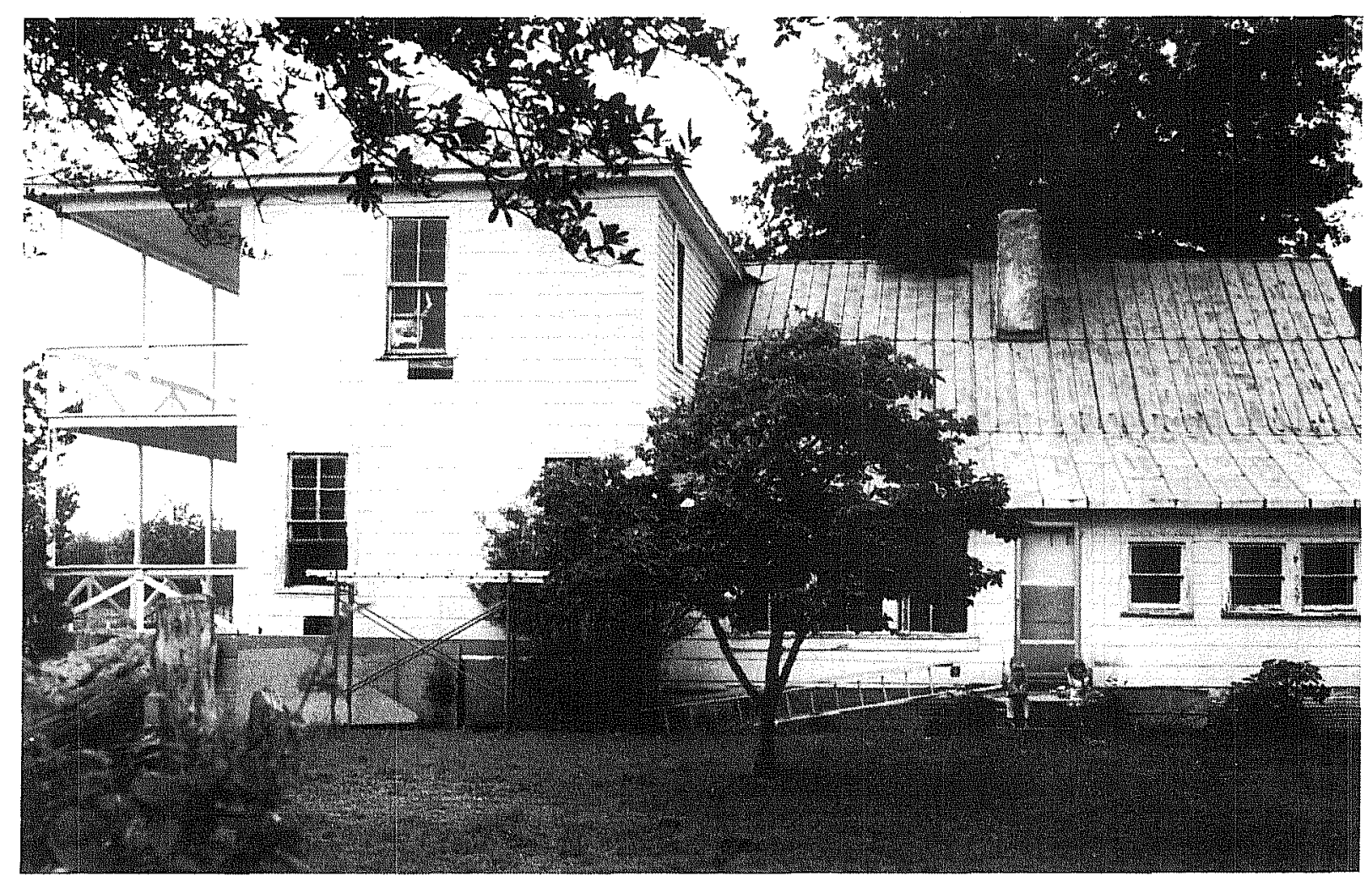

b

Figure 33. Structures at 41 BX 538. a, front ob 1 ique view of historic Applewhite home; b, side view showing original one-story structure and later two-story addition. 


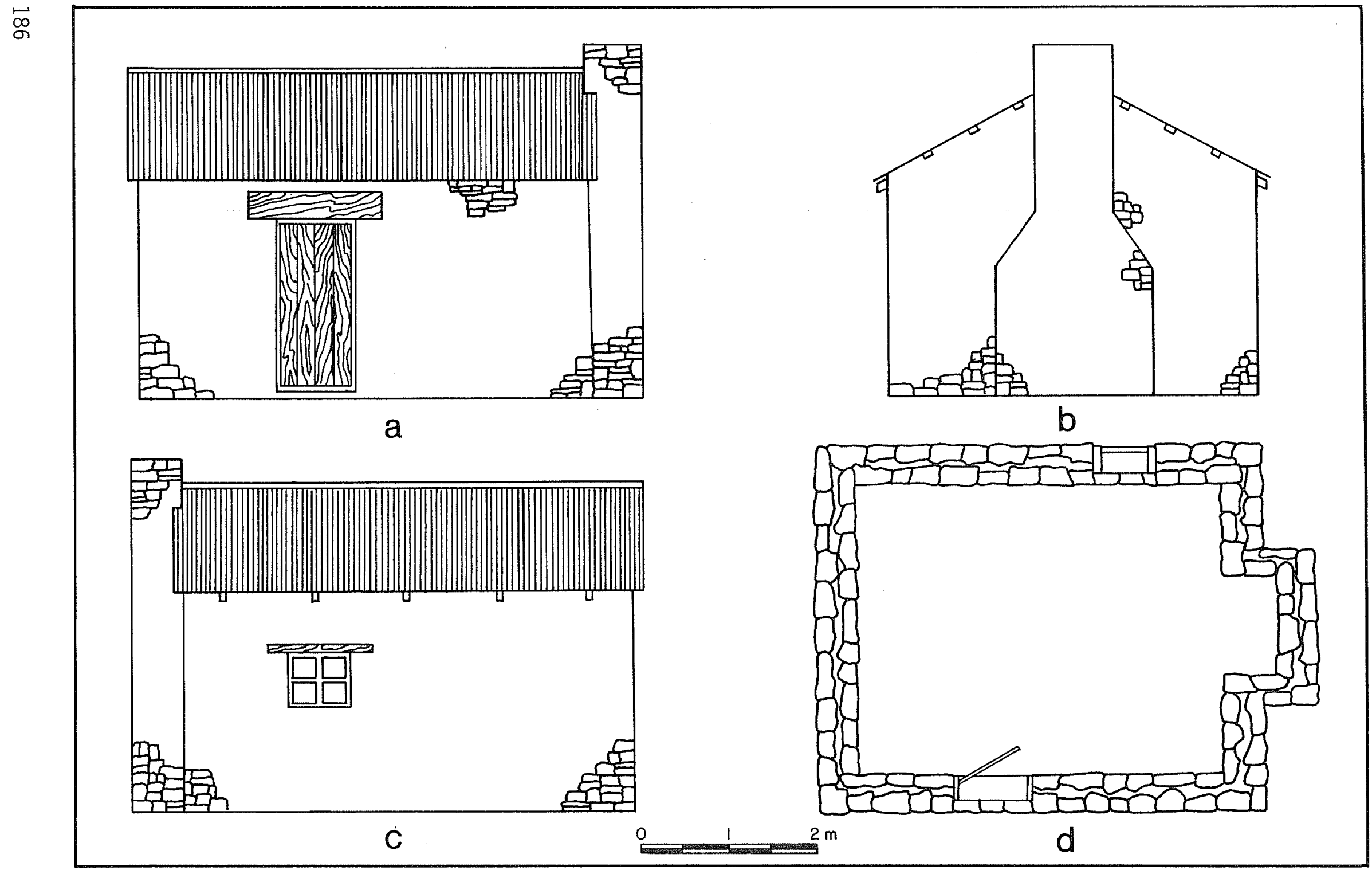

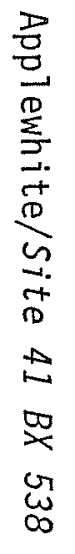

Figure 34. Plan Views of Small Cut Stone/Adobe Building at 41 BX 538. a, front view; b, side view; c, rear view; d, floor plan. 
order to provide architectural documentation (such as scaled floor plans and views) and a photographic record of the structures. A careful examination of the property at this time revealed an original one-story stone home with basement which formed the core of the large two-story wood frame structure. The stone structure remains completely intact within the frame additions. The smaller stone structure with fireplace was also noted as being originally plastered and may have functioned as a kitchen rather than a smokehouse or as slave quarters. The wood-frame two-story addition of 6 -inch beveled siding consists of a double porch with columns (replaced), a five bay front, single door with sidelights on the first floor and a single door on the second floor, four over four wooden frame windows, and a standing seam roof. This addition is approximately three feet off the ground supported by 1 arge pillars under the foundation. This phase of modification to the original stone house is attributed to John Watson, early farmer and rancher in the area (Louise Jones, personal communication). (John Watson [1818-1898] is buried in the 0ak Island Cemetery.) Other buildings consist of a wooden frame well house, a wooden frame barn with corrugated tin siding, a wooden frame tack shop(?), a concrete cistern, a wooden shed garage, a wooden frame hay shed, a deteriorated wooden frame shed of unknown use, and a partial set of mesquite pens which are still being used.

Archival research as well as extensive oral history interviews provided information about the Applewhite family, early owners of the site. The origin of the Applewhite family was in England. At least 10 generations of the Applewhite family have been on American sojl since 1665, when Henry Applewhite arrived in Jamestown, Virginia. Early family members were politically influential as revealed by their involvement in the House of Burgesses and the American Revolution (Mullens n.d.).

Stephen, John, and Jesse Applewhite, the sons of Thomas and Rachal (Mixon) Applewhite, came to Texas ca. 1853. Stephen was married to Eliza Thompson of Mississippi. As early as 1853, John and Jesse Applewhite were purchasing property in the study area- -643 acres from L. Thompson and Hiram Thompson for the sum of $\$ 1929$, being a part of the original headright of Christopher Yoacum (first husband of Louisiana J. Thompson). In 1854, Stephen Applewhite purchased one-third of a league of land from John R. Cunningham, assignee of the Bruno Martinez headright (BCDR Vol. L2:231-232).

Thomas Carroll Applewhite, born July 27, 1840, to Stephen and Eliza Applewhite, came with his father to Texas in 1853. He served in the 30 th Brigade, Texas Militia 1861, reenlisting in 1862 in Captain Duncan's Company C, Colonel Haupt's regiment of Texas Cavalry, CSA, as a private. Reenlisting again in 1864, he served for six months in Captain J. F. Davis' Company E, lst Regiment, 2nd Brigade, Texas State Troopers. He married Josephine Cindere11a Desmukes, daughter of Dr. A. W. Desmukes, in 1871, in San Antonio. From this union nine children were born: (1) Andrew A., (2) Jesse Carro11, (3) Samuel P., (4) Sidney Wallace, (5) John A., (6) Fannie E., (7) Josephine, (8) Minnie, and (9) Frank (Mrs. Joe Mullens, personal communication).

The Applewhite family brought their black slaves with them to Texas and continued to buy and sell slaves once established in Texas (Mrs. Joe Mullens, personal communication). This information has been substantiated by records in the Bexar County Courthouse (BCCH Wills and Probates). Historic 
structures 41 BX 538 and 41 BX 666 (original structures prior to subsequent modifications) and $41 \mathrm{BX} 669$ are three of the original homes built by the Applewhite family ca. 1850-1870.

On February 10, 1872, Stephen and Eliza Applewhite conveyed to their son, Thomas Carroll Applewhite, a part of the extensive Applewhite holdings (BCDR Vol. W:473). A ranch was established there by Thomas Carroll Applewhite. The following brands were registered to the Applewhite family:

AU Jesse Applewhite, registered December 22, 1873

A. Thomas Carrol1 Applewhite, registered Apri1 20, 1874

$\theta$ Stephen Applewhite, registered August 21, 1875

(BCA Records of Marks and Brands).

Site significance: of primary importance, this site is one of the few within the proposed reservoir which can yield information about the rural affluent Southern Anglo slave-holding population in the study area. In addition, the transformations of the Civil War/post-Civil War period (when the economic base shifted from cotton to cattle) can be documented at this site. Further, the architecture of the main two structures based on method of construction and distinctive style reflects the cultural setting of this time period and social class.

Management recommendations: In the opinion of the authors, this site is eligible for listing on the National Register of Historic Places based on the following criteria: (1) the association with events that have made significant contributions to the broad patterns of our history; (2) the association with the lives of persons significant in our past; (3) the embodiment of distinctive characteristics of a type, period, and method of construction; and (4) the potential to yield information important in our history. We recommend that a determination of eligibility should be sought from the Keeper. Architectural documentation of the two-story stone/wood frame structure based on the criteria of the Texas Catalog, Historic American Buildings Survey (Goeldner 1974) is recommended as well as site mapping. The latter would identify the relationships of all site components (including estimates of destroyed structures). Limited testing (when possible) would be necessary to establish temporal associations postulated by archival research and oral history interviews. The site is located within the conservation flood poot level of the proposed reservoir.

\section{SITE 41 BX 539}

Type of site: Small, prehistoric occupation.

Location: On a slight rise along the upland margins of a former river terrace just north of Neal Road and ca. $300 \mathrm{~m}$ south of the modern channel of the Medina River.

Elevation: 530 feet above msl. 
Topographic context: Along the upland margins of a former terrace of the Medina River.

Water source: The Medina River is ca. 300-350 m north.

Vegetation and soil: Natural vegetation has been cleared from the site area, and only short grasses cover the location. Dense thorny brush borders the western edges of the site. The soil is eroded dark-colored Venus clayey 10am.

Site condition: Severely damaged by 1 and clearing and subsequent natural erosion. Less disturbed portions of the site may lie below the surface ca. 150-175 m west.

Artifactual materials present: The site, as first identified in 1981, consisted of a moderate to intensive concentration of lithic debris and burned rock exposed in an ca. $100-\mathrm{m}^{2}$ area. No features, such as burned rock clusters, were identified. One chronologically undiagnostic distal biface fragment and a subovate, thick bifacial tool were surface collected from the site.

Site discussion: Because of the proximity to 41 BX 537 and 41 BX 531, preliminary interpretations of site interrelationships suggested that the activity area of site 41 BX 539 may have been related to occupational episodes at these other sites. Recommendations in 1981 indicated that mechanical and hand testing be conducted to more accurately determine the importance and actual extent of this unusually small, intense occupation area.

In 1984, surveys of previous7y inaccessible areas west and adjacent to 41 BX 539 determined that this site is the eastern margins of an early prehistoric terrace occupation parallel to, but distinct from, sites 41 BX 530, 41 BX 531, and 41 BX 669. A scatter of 1ithic debris and burned rock was found to extend over $150 \mathrm{~m}$ from the originally defined site area, and the western areas of the site appear much less disturbed by both 7 and clearing and erosion than the eastern margins. A distribution of burned rock, thick and thin biface fragments, and utilized and/or retouched lithic debris litters the western portion of the site.

According to the 1981 recommendations, 41 BX 539 was investigated through limited testing in 1984; unfortunately, the landowner was adverse to the use of mechanical testing, and only hand testing in the form of two $50-\mathrm{cm}^{2}$ shovel tests and a $1-\mathrm{m}^{2}$ unit was initiated. A7l materials were screened through $1 / 4$-inch wire mesh.

Shove 1 Test 1 was excavated to a depth of $50 \mathrm{~cm}$ in the eastern portion of the site area (the originally defined site location in 1981). Only nine smal1 fragments of chert debitage in the form of decorticate chips and small tertiary flakes were collected; two small fragments of burned rock were also noted. No identifiable soil stratigraphy was noted in the unit profile, and inspection of the test wall of the unit suggested extensive site deflation as the collected materials were all recovered within $12 \mathrm{~cm}$ of the surface. The soil matrix, a reddish brown clayey, compacted material is similar in 
composition to subsurface soil exposed in natural erosional gullies in the immediate area that underlie darker, less compacted topsoil.

Shovel Test 2 was excavated ca. 150 m west of Shovel Test 1 to a depth of $40 \mathrm{~cm}$. A dark grayish brown surface soil was noted to a depth of $\mathrm{ca} .32 \mathrm{~cm}$ with a graduation to a lighter gray, more compacted clayey soil. Results of Shovel Test 2 are as follows:

Depth

Decorticate

Chips
Secondary

Flakes
Tertiary

Flakes
Burned Rock

Fragments
$0-10 \mathrm{~cm}$

$10-20 \mathrm{~cm}$

$20-30 \mathrm{~cm}$

$30-40 \mathrm{~cm}$
7

4

3
3

1

No features or diagnostic materials were collected or observed from the test unit.

A $1-\mathrm{m}^{2}$ test unit was excavated ca. $75 \mathrm{~m}$ west of the eastern site margins to a depth of $40 \mathrm{~cm}$. Soil stratigraphy was similar to that found in Shovel Test 2, with a soil transition noted at ca. $31-34 \mathrm{~cm}$. Materials collected in the form of lithic debris appeared concentrated on or near the surface with some indications of more deeply buried deposits. Recovered materials from the test unit are as follows:

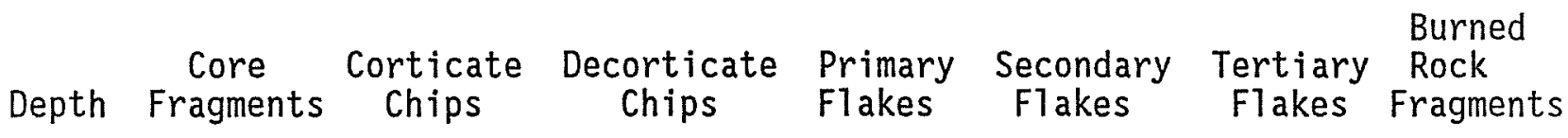

\begin{tabular}{llllllll}
\hline $0-10 \mathrm{~cm}$ & 1 & 1 & 3 & & 2 & 1 & 5 \\
$10-20 \mathrm{~cm}$ & & & 7 & 1 & 3 & & 3 \\
$20-30 \mathrm{~cm}$ & 1 & & 2 & & 2 & & 1 \\
$30-40 \mathrm{~cm}$ & & 1 & 3 & & 1 & 1 & 2
\end{tabular}

Several mussel shell fragments were noted at a depth of 7 and $18 \mathrm{~cm}$ below the surface.

Site reassessments following hand testing. in the form of two $50-\mathrm{cm}^{2}$ shove tests and a $1-\mathrm{m}^{2}$ test unit, surveys into previously inaccessible areas, and cumulative data interpretations revealed the site area as identified in 1981 as extensively damaged by erosion and deflation, but the main location of concentrated surface materials (ca. $150 \mathrm{~m}$ west) appears much less disturbed. Extensive scatters of burned rock, thick and thin bifaces, and utilized and/or retouched lithic debris litter the main site area. The site area, originally estimated at ca. $100 \mathrm{~m}^{2}$ is revised to ca. $150-175 \times 100 \mathrm{~m}$, with the long axis of the site paralleling the former terrace margins. The location of the site on a former river terrace (thought to have been at ca. 530-foot contour) suggests a long period of prehistoric activities, and subsurface deposits may be significantly older than those of nearby sites. 
Site significance: In relation to other nearby sites, 41 BX 539 is located noticeably farther south from the modern river channel, as well as being slightly higher in elevation. The extensive distribution of chipped stone and burned rock on the surface combined with evidence of subsurface materials suggests that this site may contain significant, as yet unidentified, buried deposits potentially older than other sites in this portion of the study area.

Management recommendations: We recognize the $1 \mathrm{imitations}$ of the testing conducted to date at the site and recommend a much more detailed and systematic program of testing to include mechanical trenching to determine the potential eligibility of site 41 BX 539 to the National Register of Historic Places. The site is located in the conservation pool level of the proposed reservoir.

\section{SITE 41 BX 540}

Type of site: Prehistoric occupation. Total estimated area of site including potential subsurface deposits is ca. $250 \mathrm{~m}^{2}$.

Location: Surrounding a small knoll on Neal Road, about $1 \mathrm{~km}$ south of the Medina River. In the immediate area of the proposed damsite of Applewhite Reservoir.

Elevation: 530 to 550 feet above ms 7 .

Topographic context: The site is located along a former terrace remnant of the Medina River. The old channel is projected to have flowed parallel to its modern course, but ca. $500 \mathrm{~m}$ south along the lower slopes of the terrace remnant.

Water source: The modern channel of the Medina River is ca. $1 \mathrm{~km}$ north of the site location.

Vegetation and soil: Land clearing and cultivation have cleared the site of natural vegetation; the soil is Karnes series light brown calcareous loam. A subsurface layer, ca. $1 \mathrm{~m}$ below the surface, is distinctly more reddish and clayey.

Site condition: The site's surface, to a depth of ca. $30 \mathrm{~cm}$, has been disturbed by cultivation, particularly deep plowing. Intact cultural deposits are known to exist at least $1 \mathrm{~m}$ below the surface.

Artifactual materials present: A small to moderate scatter of 1 ithic debris was noted across the area when the site was first identified in 1981. A subtriangular uniface (Clear Fork tool?) and a proximal projectile point fragment (Refugio) were collected at this time. Additionally, burned rock fragments were noted eroding from the road cut area which bisects the site. When the site was revisited in the fall of 1984, an Early Archaic Bell projectile point was collected from an in situ context along this road cut. 
Site discussion: The presence of prehistoric occupation debris and diagnostic 1 ithic materials prompted 1981 investigators to recommend further work in the form of mechanical and hand testing to determine the extent and potential of subsurface cultural deposits. The site was selected during 1984 studies for further work, and the area was revisited and reassessed. Unfortunately, the landowner was adverse to mechanical testing, and only a 1 imited amount of subsurface examination through hand excavations was conducted.

Following an intensive resurvey of the site area, and prior to testing, a sma11, almost completely eroded feature of burned rock was noted in the northern profile of the road cut. Further examination of this disturbed area recovered an extensively reworked Early Archaic Bell projectile point ca. $125 \mathrm{~cm}$ below the surface. Two $50-\mathrm{cm}^{2}$ shovel tests and one $1-\mathrm{m}^{2}$ unit were excavated in this area. Additionally, a small profile cut was made into the road cut itself to expose and extract the Early Archaic Bell point. A total of only seven decorticate chips and tertiary flakes was found in the two 50$\mathrm{cm}^{2}$ shovel tests excavated to depths of $60 \mathrm{~cm}$. The same paucity of materials was noted in the $1-\mathrm{m}^{2}$ unit; several flakes were noted to ca. $38 \mathrm{~cm}$; a sterile zone was identified between $43-70 \mathrm{~cm}$, and a single unidentifiable biface distal fragment was recovered at $70 \mathrm{~cm}$. No other materials were recovered, and the unit was terminated at $75 \mathrm{~cm}$.

Soil exposures along the adjacent road cut, ca. $20 \mathrm{~m}$ from the $1-\mathrm{m}^{2}$ unit, indicated a distinct soil transition that occurs ca. $1 \mathrm{~m}$ below the surface. An uncompacted, fine-grained sand overlies a more compacted, clayey, and distinctly red-colored subsoil. The Bell projectile point was extracted $21 \mathrm{~cm}$ below this soil transition within the upper level of the compacted red clayey material.

Site significance: To date, we do not feel that the site area has been adequately tested (due to the limited examination of subsurface deposits by hand testing) and, thus, a definitive assessment of site significance cannot be made at this time. We do believe that the material evidence from this site indicates further investigations are warranted to identify other probable, intact Early Archaic features. The recovery of a diagnostic Early Archaic projectile point from an in situ context below over a meter of soil deposits suggests that cultural materials from this site may be deeply buried.

Management recommendations: In the opinion of the authors, this site is potentially eligible for listing on the National Register of Historic Places based on the information that may be yielded to the area's prehistory. The site is located within the conservation pool level of the proposed reservoir. A systematic and extensive program of testing, particularly mechanical techniques (i.e., backhoe), is recommended to most effectively and adequately test this prehistoric site.

\section{SITE 41 BX 541}

Type of site: Prehistoric light occupation, ca. $100 \times 300 \mathrm{~m}$. 
Location: Along a slight ridge about $100 \mathrm{~m}$ east of Applewhite Road and ca. $700 \mathrm{~m}$ south of Neal Road.

Elevation: 550 to 570 feet above ms 7 .

Topographic context: Upland.

Water source: The nearest modern water source is the Medina River, ca. $7 \mathrm{~km}$ north of the site. The local drainage pattern suggests a past water source somewhat closer to the site area, either in the form of an intermittent tributary (ca. $100 \mathrm{~m}$ east) or a lateral, southward river movement (ca. $1 \mathrm{~km}$ north of the site).

Vegetation and soil: The site area is overgrown with thorny brush, mesquite trees, tall grasses, and prickly pear cactus. The location has been cleared in the past, but not in recent years. The soil is Hockley loamy fine sand, severely eroded by wind and water. Weathering has exposed sandy clay loam along the slopes of the site.

Site condition: The site area appears extensively disturbed by both natural erosion and modern ranching activities. A thin "sheet" of lithic debris was exposed along a sandy clay loam contact with upper, shallow soil deposits suggesting site deflation of cultural materials.

Artifactual materials present: A light lithic scatter composed of decorticate chips and flakes, a few fire-reddened or burned, and an occasional fire-cracked rock litter the site area. No diagnostics artifacts or features were observed.

Site discussion: The lack of chronologically diagnostic materials precludes interpretations of occupation or activity periods at the site. Site integrity has been further compromised by both natural erosion and efforts at 1 and clearing. In addition to intensive surveys over the site area, two 50$\mathrm{cm}^{2}$ shovel tests were excavated to depths of $30 \mathrm{~cm}$ in the northeast and southwest portions of the site. No artifacts were recovered from either test unit.

The site was revisited in December 1984, but no significant artifacts were observed, and previous site assessments were not changed.

Site significance: Based on intersite distribution patterns in this area of the proposed reservoir, $41 \mathrm{BX} 541$ is thought to represent the remains of a temporary occupation site adjacent to an ephemeral, or intermittent, small tributary that flowed northward toward the Medina River. The infrequency of lithic remains and the lack of chronologically diagnostic artifacts preclude further interpretations of site function.

Management recommendations: Based on the estimated extent of site disturbance and lack of significant cultural materials, no further work is recommended in this area. These assessments are made on current information available and should future information (such as interpretations of intersite distributions or geomorphological studies) contribute further data to site significance, these recommendations should be reassessed. 


\section{SITE 41 BX 542 (Hernández Cemetery)}

Type of site: Historic cemetery.

Location: Approximately $1.5 \mathrm{~km}$ north of the Medina River and $\mathrm{ca} .1 \mathrm{~km}$ southwest of the intersection of Watson Road and Howard Road.

Elevation: ca. 580 feet above msl.

Topographic context: Flat, upland area, partially cleared.

Water source: Not applicable; the nearest natural water source is the Medina River, ca. $1.5 \mathrm{~km}$ south of the site.

Vegetation and soil: The cemetery is located among a small grove of oak trees within a cleared field. The soil is a dark gray clayey material with some small chert cobbles and pebbles.

Site condition: Currently abandoned.

Artifactual materials present: Grave markers of stone and wood are in the cemetery, and a wrought-iron fence surrounds the cemetery.

Site discussion: The site, ca. $30 \mathrm{~m}^{2}$, was first identified in 1981. Approximately six graves were estimated to be located here, and other unmarked, unidentified burials may also exist. Recommendations of the 1981 survey included further archival research to assess the historical significance of the Hernández family and of the deceased family members buried in the cemetery. In 1984, archival research revealed the names of six individuals buried at the cemetery:

Serah H. Grabb(?), daughter of G. W. Grabb, born December 1, 1888, died August 9, 1891.

Rafalita H. Rodriquez, born August 17, 1883, died May 24, 1910.

Paulita H. Rodriquez (Maria Paula Elena Hernández), born August 27, 1836, died December 22, 1919.

Carlota Hernández, born (?), died May 14, 1899.

Simon Rojo Rodriquez, born 1833, died Apri1 5, 1905.

José de Jesús Hernández.

José de Jesús Hernández (no. 6 on the 1ist) was a direct descendant of Francisco Hernández, patriarch of the Hernández family and original owner of the extensive Spanish colonial rancho known as San Bartolo (located on the lower San Antonio River; Chabot 1937:37). Jesús married Carlota Pérez Casanova. She died on May 4, 1899, and is buried in the cemetery near her husband. From the union of José de Jesús and Carlota Casanova Hernández, 10 children were born: (1) Maria Paula Elena, born 1832 or 1836, and married Simón Rojo Rodriquez. Simon died on Apri1 5, 1905, and is buried in the Hernández Cemetery. "Paulita" died December 22, 1919, and is buried next to 
her husband; (2) Pedro Pasqua1, born 1833; (3) Mariana, born 1841 ; (4) Joseph, born 1843; (5) Serapio Inocento, born 1847; (6) Locaria Concepción; and (7) Guadalupe Manuela, twins, born 1848; (8) Angel; (9) Francisco; and (10) Jesús.

Site significance: This is one of the early cemeteries in the area that contains the graves of some of the early settlers.

Management recommendation: In the opinion of the authors, this site is potentially eligible for listing on the National Register of Historic Places. The cemetery 1 ies well above the maximum flood pool level of the proposed reservoir; however, should increased accessibility to the area and/or possible construction activities occur in the vicinity, further archival research will be necessary to clarify the Hernandez's family role in the development of the study area. If the site is to be affected, then stabilization and/or protection is warranted. If this is not possible, then relocation of the graves may be necessary.

\section{SITE 41 BX 543 (Ruîz-Herrera Cemetery)}

Type of site: Historic cemetery.

Location: On a high bluff on the north bank of the Medina River ca. $500 \mathrm{~m}$ from the end of Quesenberry Road.

Elevation: ca. 570 feet above ms T.

Topographic context: On the upper margins of the Medina River valley.

Water source: The Medina River is ca. $500 \mathrm{~m}$ from the site.

Vegetation and soil: The site has been cleared. Several large mesquite and hackberry trees are scattered within the cemetery. Soil is a clayey a) Tuvium.

Site condition: Still in use. The southern edges of this cemetery are located directly adjacent to steeply eroding bluffs on the margins of the Medina River.

Artifactual material present: Not applicable.

Site discussion: This cemetery was first identified in 1981. In 1984, a revisit to the cemetery revealed the presence of a State Historical Survey Committee marker. The cemetery was started in the 1840 s and contains the burials of Francisco Antonio Ruiz, early San Antonio alcalde, and Blas Herrera, messenger to Travis at the Alamo (see Historical Overview section). Numerous graves of other prominent early Mexican settlers in the area are located here.

Site significance: This cemetery is an extremely important site in the study area as it contains the graves of several historical figures of outstanding importance. 
Management recommendations: In the opinion of the authors, this site is eligible for listing on the National Register of Historic Places. A cemetery will qualify if, as in the case of the Ruiz-Herrera Cemetery, the primary significance is derived from the graves of persons of transcendent importance and from age. We recommend that a determination of eligibility should be sought from the Keeper.

Located at ca. 570 feet above msl, the cemetery appears at present to be experiencing severe erosional problems along the southern margins. Further erosion along the face of the bluff will precipitate slumping of a portion of the cemetery. If the proposed reservoir is constructed, some type of stabilization/preservation must be afforded this site.

\section{SITE 41 BX 544}

Type of site: Prehistoric occupation of ca. $100 \times 200 \mathrm{~m}$.

Location: At the confluence of the Medina River and Elm Creek, $1 \mathrm{~km}$ west of Applewhite Road and adjacent to the south banks of both Elm Creek and the Medina River.

\section{Elevation: 530 feet above msl.}

Topographic context: Along the margins of the upper terrace above Elm Creek and the Medina River, adjacent to the modern confluence of the Medina River and the creek.

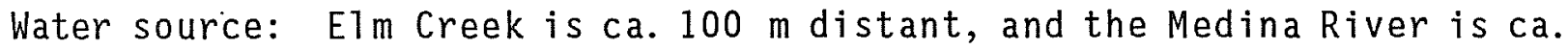
$100 \mathrm{~m}$ distant.

Vegetation and soil: The site area has been completely cleared; the western portion is a cultivated field; the eastern section is dominated by a (occupied) farm complex. Severe erosion characterizes the steep slopes leading toward the drainage. The soil is identified as Venus clay loam, dark grayish brown in color.

Site condition: The surface area of the site has been severely disturbed, and no intact cultural deposits were found or are believed to exist in this location. Land clearing has disturbed soil depths to $30-40 \mathrm{~cm}$ or more.

Artifactual materials present: At site 41 BX 544, first identified by a brief inspection during 1975 (Hester, assembler 1975:22), researchers noted a few chert flakes scattered on the surface. Twenty-six flakes, two possible ground stone fragments, and the basal fragment of an unidentified triangular biface were found. In 1984, a light to moderate lithic scatter of decorticate chips and flakes and burned rock was still observable along the eroded slopes of the site. An occasional flake or burned rock fragment was noted across the surface of the disturbed area. No diagnostic materials or features were noted or observed.

Site discussion: The site was initially identified in 1975 (Hester, assembler 1975) and was revisited in 1981. Access problems precluded an on- 
ground investigation during 1981 but after consideration of the site's proximity to a major confluence of $E 7 \mathrm{~m}$ Creek and the Medina River, further work was recommended that included intensive survey and limited testing.

Entrance into the site location was obtained in 1ate 1984, and intensive surveys were conducted on two subsequent visits. Investigations found the area to reflect almost total surface site destruction caused by modern alterations and natural erosion. No portions of the site's surface were identified as having potentially intact or relatively undisturbed cultural deposits. No subsurface testing was conducted in 1984 as the landowner was adverse to such work.

Site significance: The site location is thought to have had potential prehistoric significance because of its proximity to a major river/stream confluence. The site is spatially proximate to the 41 BX 274 occupation zone and may be related to both the intensive and extensive aboriginal interests in this local area. While no surface areas are intact, nearby sites (41 BX 274) indicate deeply buried cultural deposits. If 41 BX 544 should possess these same characteristics, it is possible that the site may still contain significant, as yet unidentified, cultural materials.

Management recommendations: Based on the almost total surface site destruction, preliminary recommendations suggested that no further work was necessary at this location. Recently collected data from nearby sites that reflect intact, buried cultural deposits in excess of $2 \mathrm{~m}$ below the surface indicate that a modification of the original recommendation is necessary. We urge that limited testing be conducted at 41 BX 544 in the form of both mechanical and hand excavations. Limited testing is considered necessary to determine the significance and extent of possible buried deposits and to determine the site's potential eligibility to the National Register of Historic Places.

\section{SITE 41 BX 545}

Type of site: Prehistoric temporary occupation site, ca. $300 \times 150 \mathrm{~m}$.

Location: On the southern upper terrace of the Medina River, about $1.2 \mathrm{~km}$ north of Neal Road.

Elevation: 530 feet above ms 1 .

Topographic context: Along and adjacent to the modern channel of the Medina River.

Water source: The Medina River is $\mathrm{ca} .100 \mathrm{~m}$ north of the site location.

Vegetation and soil: The area has been partially cleared of natural vegetation and is currently cultivated in the southern margins. The soil is clayey Venus loam, dark grayish brown in color. The northern site margins are steeply eroded. Dense thorny brush covers uncleared segments. 
Site condition: Moderately to severely disturbed by natural erosion in the northern margins. Extensively disturbed by land clearing and deep plowing in the southern half of the site.

Artifactual materials present: A light scatter of decorticate chips and flakes and an occasional fire-reddened cobble was observed across the site. No diagnostic materials or cultural features were observed.

Site discussion: First identified in 1981, the paucity of cultural materials and the disturbed nature of the location led investigators to recommend no further work in this area. Site 41 BX 545 was reassessed in 1984 following the addition of information from nearby sites located in previously inaccessible areas. A major consideration for sites such as 41 BX 545, arising from this cumulative data base, is the potential for significant, deeply buried deposits not easily discernible from intensive survey or shallow shovel tests.

Site significance: A review of sites in this portion of the study area indicates that a series of Early Archaic sites with associated diagnostic materials are situated along or adjacent to an ca. 540 -foot contour above msl. Since Early Archaic materials have been excavated in deeply buried contexts in the study area (see $41 \mathrm{BX} 274$ ), other prehistoric site locations from this period are thought to have a high potential for deeply buried cultural deposits. On the basis of interpretive evidence to date, 41 BX 545 is not thought to contain such early deposits. Located adjacent to the modern channel of the Medina River, the site is not associated with the projected contour elevation of other significant Early Archaic sites. A careful examination of the extensively eroding northern slopes exposing a series of profiles caused by natural erosion (in excess of $20 \mathrm{~m}$ in length and 4-6 $\mathrm{m}$ in depth) also did not identify any evidence of deeply buried cultural deposits.

If the site does contain buried deposits, we suggest that these materials will be more shallow and less old than Early Archaic materials. As such, these deposits, estimated to be within $1 \mathrm{~m}$ of the surface, have been at least partially damaged by deep plowing (estimated at $\mathrm{ca} .40 \mathrm{~cm}$ ). Inspection of the site area, however, shows little evidence of significant deposits exposed in a disturbed context in plow furrows.

Management recommendations: The 1981 recommendations, based on the natural damage and modern alterations to the site area and the lack of significant cultural materials, did not recommend further work at this location. Further consideration of the site, based upon preliminary 1984 intersite distributions and patterns, indicates some potential for limited subsurface deposits, identifiable only by extensive hand testing or shallow mechanical trenching. In the opinion of the authors, while such work would be necessary to more accurately describe the nature and potential of (estimated) Late Archaic-Late Prehistoric deposits, such work would be more cost effective and productive at other nearby sites (e.g., 41 BX 669) that have demonstrated National Register potential. 
Applewhite/Site 41 BX 546

\section{SITE 41 BX 546}

Type of site: Prehistoric temporary occupation, ca. $200 \mathrm{~m}^{2}$.

Location: Along the southern terrace of the Medina River, ca. $500 \mathrm{~m}$ west of 41 BX 545.

Elevation: 530 feet above ms 1 .

Topographic context: Situated adjacent to the modern upper terrace of the Medina River channel.

Water source: The Medina River is ca. $100 \mathrm{~m}$ north of the site location.

Vegetation and soil: Approximately half of the site is covered by thorny brush and mesquite trees; the southern upland margins have been cleared and are under cultivation. The soil is a dark grayish brown Venus clayey loam.

Site condition: The southern portion of the site has been extensively damaged by 7 and clearing and cultivation. The northern margins of the site, along the steep slopes, have been severely affected by natural erosion.

Artifactual materials present: Lithic debris in the form of several core fragments, corticate and decorticate flakes, and chips are scattered across the site. Several burned rocks and small mussel shell fragments were also noted. No diagnostic artifacts were collected, and no cultural features were observed.

Site discussion: This site, in physiographic character and material composition, appears similar to nearby 41 BX 545. Some subsurface deposits may exist in this location, but the paucity of surface materials and the lack of chronologically diagnostic artifacts suggest that the subsurface investigation of other nearby sites could offer more valuable contributions to the understanding of such locations and their associated temporal span.

Site significance: This site location is thought to represent a temporary occupation activity campsite of undefined temporal association. The similarity to nearby site $41 \mathrm{BX} 545$ suggests Late Archaic to possible Late Prehistoric associated occupations, although the remains of such activities are both light and moderately to severely disturbed by both natural erosion and modern impacts.

Management recommendations: No further work was recommended at 41 BX 546 following the 1981 studies, based on the extensive erosion, limited site area, and the lack of chronologically diagnostic materials. Reassessments of site significance in 1984, following a cumulative and more extensive data base suggest that, as in the case of nearby 41 BX 545 , some moderately shallow subsurface deposits may exist in this area. It is believed, however, that such cultural deposits of estimated Late Archaic-Late Prehistoric sites could be much more effectively and productively investigated at other nearby locations that reflect more intensive (and extensive) occupational activities. 


\section{SITE 41 BX 547}

Type of site: Prehistoric temporary occupation, ca. $150 \mathrm{~m}^{2}$.

Location: Site 41 BX 547 is located about $75 \mathrm{~m}$ south of Leon Creek and $500 \mathrm{~m}$ east of Highway 16.

Elevation: 560 feet above msl. .

Topographic context: The site is located along the modern upper terrace just south of the Leon Creek channel.

Water source: Leon Creek is ca. 75-100 m north of the site location.

Vegetation and soi1: The northern portion of the site is covered in mesquite trees, dense thorny brush, and tall grasses. The southern portion of the site has been cleared and is cultivated. The soil is a clayey dark grayish brown Venus clay loam.

Site condition: The slopes along the northern margins are extensively eroded. The southern portion of the site is altered by past land clearing and cultivation.

Artifactual materials present: Lithic debris in the form of decorticate and corticate chips and flakes (some fire-reddened) and several burned rocks are scattered across the site area. No features or diagnostic materials were observed. The density of the surface distribution was quite light and estimated at three or four fragments of 1 ithic debris per $25 \mathrm{~m}^{2}$.

Site discussion: The site area is located on a terrace remnant with the modern channel of Leon Creek to the north and an old, buried parallel channel just to the south (Taylor, Hailey, and Richmond 1966:sheet 78). The site area appears to be located in a narrow strip (ca. $150 \mathrm{~m}$ wide) between these two natural features. The infrequency of cultural materials exposed on the surface and the lack of diagnostic materials preclude identification of temporal context. Several other archaeological sites (e.g., 41 BX 274, 41 BX 653) with a similar identified soil type, Venus clay loam (VeB), in the study area are associated with former stream channels. As such, these sites represent earlier prehistoric activity areas when compared to sites adjacent to modern drainage channels. Sites such as 41 BX 547 are estimated to be associated with the Early and/or Middle Archaic period rather than the Late Prehistoric. Such observations are, of course, tentatively based on limited site and sediment data.

Site significance: The identification of a possible correlation between soil types and archaeological sites of particular prehistoric periods could be a useful local as well as regional contribution to further studies. However, in the opinion of the authors, such work could be pursued more effectively and productively at other less disturbed and more extensive archaeological sites in the study area, e.g., 41 BX 274 and 41 BX 653.

Management recommendations: Based on the limited surface extent, lack of diagnostic materials, and infrequent lithic debris, no further work is 
recommended at this time at 41 BX 547 . While some subsurface deposits may exist at this location (and determination of potential eligibility to the National Register cannot be made without identifying such deposits), the site's elevation beyond the maximum flood pool level indicates that the location will avoid proposed reservoir impacts. Should the site area be affected by construction activities or other future damage, we recommend mechanical and hand testing to determine the extent and significance of subsurface cultural deposits.

\section{$\underline{\text { SITE } 41 \text { BX } 548}$}

Type of site: Prehistoric temporary occupation site, ca. $150 \mathrm{~m}^{2}$.

Location: About $275 \mathrm{~m}$ south of Leon Creek, $1 \mathrm{~km}$ east of Highway 16.

Elevation: 550 feet above ms 7 .

Topographic context: Modern uplands. The site may have been located adjacent to a former channel of Leon Creek, parallel to the modern stream course, but ca. $300 \mathrm{~m}$ south (Taylor, Hailey, and Richmond 1966:sheet 78).

Water source: The modern channel of Leon Creek is ca. 275-300 m north of the site location.

Vegetation and soil: The area has been cleared and root plowed, and is used alternately as pasture or for cultivation. The soil is a light brownish gray, calcareous Karnes loam grading from silty to clayey composition.

Site condition: The surface area of the site is severely disturbed by deep plowing to a depth of at least $30 \mathrm{~cm}$. Subsurface cultural deposits may exist at this location, but the area was not tested since it was under cultivation during the period of intensive survey.

Artifactual materials present: A light scatter of lithic debris was observed along plow furrows. Fire-fractured rock and small mussel shell fragments were also observed. Artifact density over the severely disturbed surface was estimated at three to four fragments of lithic debris per $20-25 \mathrm{~m}^{2}$.

Site discussion: Interpretations of this site are 1 imited because of the displacement of surface materials and lack of diagnostic artifacts. As noted, the site appears to be situated near a former channel of Leon Creek and as such may represent one of the relatively earlier prehistoric sites along the Leon Creek drainage (the site was apparently established prior to a stream shift into the creek's modern channel).

Site significance: The potential National Register status of this site is indeterminate based on the Timited amount of information to date and the lack of subsurface testing.

Management recommendations: Avoidance of this site area during any proposed reservoir construction activities is recommended, e.g., the proposed Leon creek diversion canal. If avoidance is infeasible, we recommend limited 
mechanical and hand testing to determine the nature and extent of potential buried deposits as well as the site's potential eligibility for National Register status. The site is located within the maximum flood pool level of the proposed reservoir.

SITE 41 BX 549 (Linn Ranch Home Headquarters)

Type of site: Historic occupation.

Location: On the south bank of Leon Creek ca. $700 \mathrm{~m}$ east of Highway 16.

Elevation: ca. 550 feet above msl.

Topographic context: Located on a steep bluff along the margins of the Leon Creek channel.

Water source: Leon Creek is ca. 100-150 m north of the site. A well and pump are located adjacent to the ranch house.

Vegetation and soil: Because the site is abandoned, the occupation area of ca. $100 \mathrm{~m}^{2}$ is densely overgrown with high grasses and mesquite trees. The soil is a fine-grained silty material, medium brown in color.

Site condition: Abandoned and partially collapsed.

Artifactual material present: No artifacts were collected in 1981. In 1984, three sherds of transferware, seven sherds of ironstone (1ate 19th century), four miscellaneous fragments of hard paste earthenwares (ceramic insulator, ceramic dog figurine, and two doll legs), and one metal button were surface collected.

Site discussion: The site was first surveyed in 1981. An abandoned chape (Fig. 35,a,b) was identified adjacent to a wood-frame one-story building. A preliminary records search indicated a series of structures which presumably existed at this location at the turn of the century. Recommendations for 1981 suggested further archival research and limited testing, as the site was located in the immediate area of a diversion channel associated with the proposed reservoir.

A7though the Request for Proposal for 1984 studies issued by the Corps of Engineers did not include the site for further work, the Proposal submitted by the CAR-UTSA for 1984 work again reinstated the need for additional work at this site. In 1984, an extensive archival search was initiated on the property as well as a series of oral history interviews with landowners and descendants of the past occupants.

The house and church structures were identified as belonging to Jacob Linn and Maria Josefa Pérez Linn (a descendant of Colonel Juan Ygnacio Pérez, ad interim governor of Texas, ca. 1815-1817, and an early Spanish 1and grant holder in the study area. Jacob, the son of Daniel and Elizabeth (Gohnok) Linn, was born on November 30, 1825, in Egsweiler, Bavaria. At the age of eight, Jacob, along with his mother, father, and sister, came from Bavaria to 

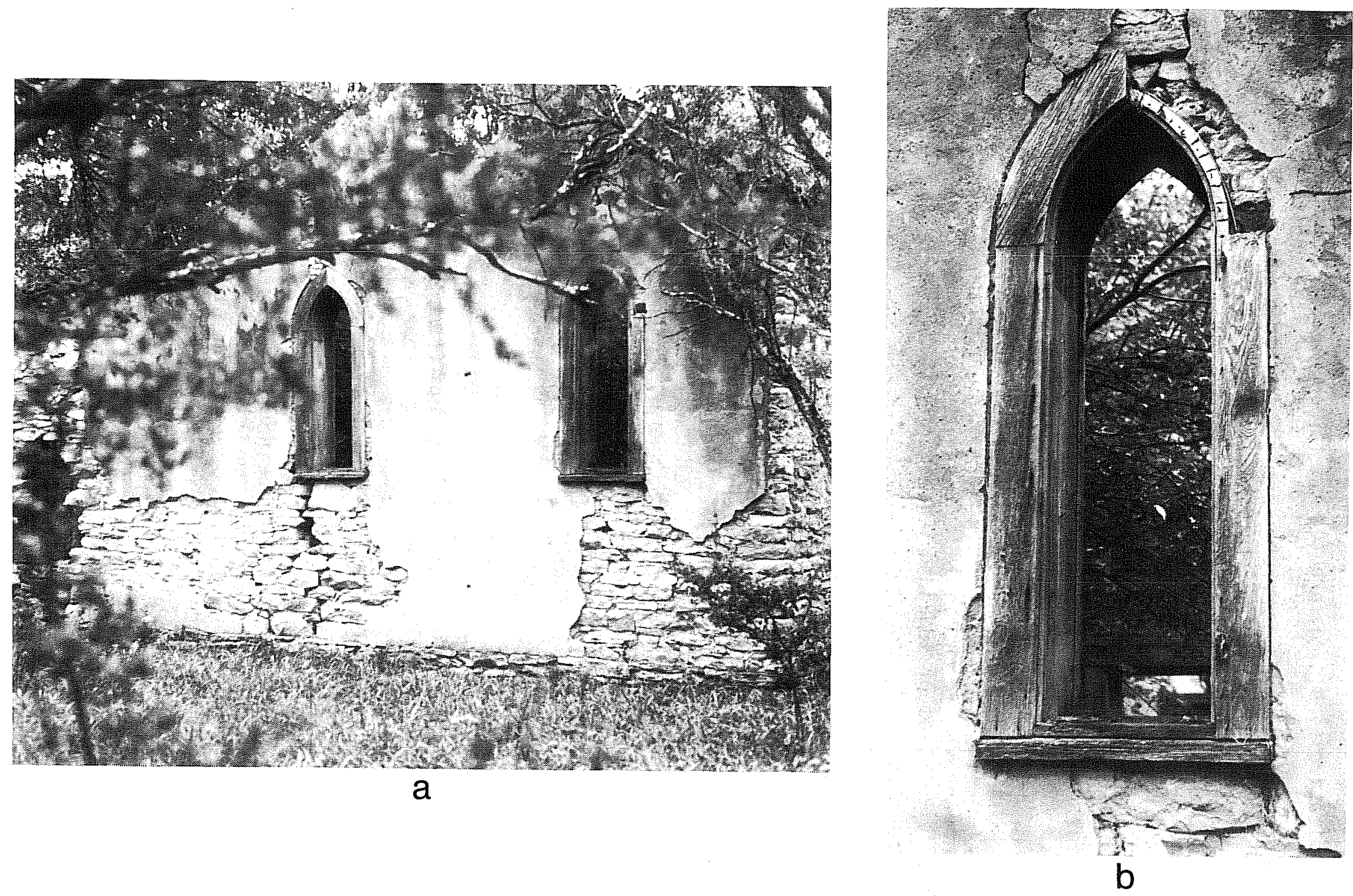

Figure 35. Chape 1 at 41 BX 549, Linn Ranch Home Headquarters. a, side view of sma 11 chapel structure; 
Texas. Elizabeth Linn died enroute; his father, Daniel, died as the voyagers reached Port Lavaca, and his sister died shortly after their arrival in San Antonio. Jacob, the only surviving member, was adopted by Father Francisco Maynes of San Fernando Church, and received an education in both English and Spanish. After the death of Father Maynes, Jacob, then a young man, apprenticed in the gun-making business, eventually establishing his own shop. It was written about the shop:

[In] possession of one of the most completely equipped shops then known in the new world, Jacob Linn, gifted with the genius of an artist, the guns and arms there, created by him, were the most finished and perfect specimens of the gunmakers art. Here he catered to the rich and the poor. Here were to be found arms, plain and untrimmed, but here also, were others display--with a rising scale of value, most elaborately designed and beautifully with gold and silver all worthy of the most fastidious dons of the land (Chabot 1937:180).

In 1855-1856, Jacob Linn married Maria Josefa Pérez (ibid.). María Josefa, the daughter of José Ygnacio Pérez and Josefa Cortinas Pérez, was born on August 16, 1824 (BCA Pérez Files). She was the granddaughter of Colonel Ygnacio Perez. As a young girl, Maria Josefa lived in the Spanish Governor's Palace while attending school, and on the Pérez Ranch during the other times. After their marriage, the Linns continued to reside in San Antonio for a time, but after the death of her parents (Ygnacio in 1852 and Josefa Cortinas in 1861) Maria Josefa inherited a part of the ranch, including the old Pérez ranch house, and the family moved there. Their headquarters were subsequently established on Leon Creek where Linn entered into the stock and ranching business (historic site 41 BX 549).

Three children were born to the Linns: (1) María Trinidad, born December 14, 1855; (2) Jacobo, born 1856 or 1857 and died September 22, 1859 (BCA El Carmen Church Records); and (3) Casimira de Ta Concepción, born March 4, 1868 (Chabot 1937:180-181).

The Linns were devout Catholics, but the nearest community church was four miles away, so an altar was "set up" in one of the rooms of the house which was known as the church; a priest came once a month and said mass for the assembled family, servants, and workmen. One room in the house was set aside as a guest room for the priest (Home Life of Early Ranches of Southwest Texas ms.).

The Linns were fairly self-sufficient--corn (used for feed and cash crop), cotton, cane (for syrup), wheat, pumpkins, peppers, tomatoes, goats, cows, sheep, and hogs were raised or grown on the ranch. Nothing was wasted, and all was utilized. Deer and wild turkeys were also plentiful. Linn also bred horses for personal use and for sale (ibid.).

The later years of Jacob Linn's 1 ife were devoted to wood carving doll furniture, tables, etc., for family members. The cross for the graves of Ygnacio Pérez and Concepción Pérez were carved by Linn (J. Lea], Bexar County archivist, personal communication). The fireplace mantel in the old Linn home on Leon Creek is believed to also have been carved by Linn. Jacob Linn 
died on December 8, 1878, at the Leon Creek home and was buried in the chape1 on the Walsh Ranch (41 BX 277). María Josefa died on December 23, 1889, and is buried in the church next to her husband (BCA Pérez Files).

María Isabel de la Trinidad, the first child of Jacob and Josefa Linn, married Santiago Herrera, son of Manuel Herrera and Maria Rivera at the Leon Creek home on May 20, 1883. One son, Jacob, was born to Trinidad on January 3, 1884; he was adopted by Josefa and Jacob Linn and took the Linn name. Jacob married Evelyn Elise Heermann. He died on May 3, 1911. Trinidad died July 1, 1891, and was buried at the Purisima Concepción Chapel (Chabot 1937:180-181).

The third child of the Linns, Casimira de 1 a Concepcion, married Frank T. Walsh (born on April 19, 1860, in San Antonio), on November 5, 1891. Frank's parents were Patrick and Johanna Sweeney Walsh, who came to Texas from Ireland. Frank was associated with his father in the contracting and construction of railroads in Texas and Mexico. Concepción and Frank had seven children: Mary, Anita, Lottie, Bessie, Frank T., Harry, J., and Edward (ibid.).

Concepcion Linn Walsh inherited the estate of her aunt, Trinidad Pérez, which included 1390 acres of Tand on the Leon Creek and the Medina River, one house, and one lot on the west side of Military Plaza (Spanish Governor's Palace), and one house and lot on the west side of San Pedro Creek (BCCH Wills and Probates 923), and also 2600 acres from the Linn estate (BCDR Vol. P2:159-160). Concepcion and Frank Walsh continued to own the Spanish Governor's Palace until 1929, when they sold it to the City of San Antonio for $\$ 55,000$. The heirs of Concepción and Frank Walsh continue to reside on the 7 and inherited by them from their parents.

Archival research also revealed the probable presence of at least two graves within the chapel complex: Paula Pérez and María Isabel de la Trinidad Pérez (Chabot 1937:180). At least one marriage took place here, that of Maria Isabel de la Trinidad to Santiago Herrera (ibid.).

This site was revisited at least twice in 1984 . The partially collapsed late 19th-century vernacular stone chapel structure with Gothic Revival features was originally plastered. The wood frame stucco home is enclosed on the south and east side by a wrap-around porch supported by square wooden posts. The roof is of standing seam tin. Outbuildings are suspected to be in the area but were not located in field surveys.

Site significance: The history of the site over the past 185 years by members and/or descendants of the prominent Pérez family along the Medina River valley in the study area may be documented. The site further offers the opportunity to document a prosperous upper-class farming/ranching complex of the post-Civil War period, thereby yielding information important to the history of the area.

Site recommendations: In the opinion of the authors, this site is eligible for 1 isting on the National Register of Historic Places based on: (1) the association with events that have made a significant contribution to the broad patterns of our history; (2) the association with the lives of persons 
significant in our past; (3) the embodiment of the distinctive characteristics of a type, period, or method of construction; and (4) the potential to yield information important in history. We recommend that a determination of eligibility should be sought from the Keeper.

Preservation of this site should be considered a priority when the location of the proposed diversion canal from Leon Creek is determined. If preservation is not possible, then mitigative measures will be necessary (including relocation of suspected burials). The site is located in the maximum flood pool level of the proposed reservoir.

\section{SITE 41 BX 550}

Type of site: Prehistoric temporary occupation, ca. $200 \mathrm{~m}^{2}$.

Location: On an upper terrace of $E 1 \mathrm{~m}$ Creek, on the north bank, ca. $1.75 \mathrm{~km}$ east of Highway 16.

Elevation: 540 feet above ms 1 .

Topographic context: Along the upper terrace adjacent to the modern creek channe1. Approximately $400 \mathrm{~m}$ west of the creek/river confluence.

Water source: Elm Creek is $75 \mathrm{~m}$ south.

Vegetation and soil: The site is located on the eastern margins of a cultivated field and extends into dense brush. The field has been cleared and root plowed. The eastern portion of the site is covered by a variety of climax vegetation, including mesquite, oak, pecan, hackberry, and other deciduous species. Tall grasses are scattered throughout. The soil is a dark grayish brown calcareous Venus clay loam.

Site condition: The site is moderately to severely eroded along the southern portion which steeply slopes toward the Elm Creek drainage. Surface evidence of the site appears to be concentrated in this area as only a small amount of lithic debitage or burned rock was noted in a graded dirt road that forms the northern margins of the site.

Artifactual materials present: A light scatter of lithic debris, small burned rock fragments, and an occasional mussel shell fragment was observed. No features or diagnostic artifacts were collected or observed.

Site discussion: Reviews of aerial photographs and topographic maps suggest that this location has been the area of several lateral river channel shifts that have progressed northward to the river's current drainage. The effect of this hydrological pattern on subsurface cultural deposits is not identifiable on the basis of available information. The two most likely possibilities, given the fact that the remains of prehistoric activities are deposited here, are that these materials have been scoured or displaced by shifting stream movement or they have become deeply buried. 
Site significance: The location of the site near a major drainage confluence suggests a strong potential for significant cultural deposits in a subsurface context; the elevation of the site closely parallels the contours of 41 BX 274, an extensive occupation zone situated along the eastern margins of this same confluence. Cultural deposits at 41 BX 274 have been found to extend more than $3 \mathrm{~m}$ below the surface.

Management recommendations: Preliminary recommendations in 1981 suggested that no further work was necessary at this location based upon the lack of significant surface deposits and diagnostic artifacts. The recent 1984 identification of deeply buried cultural deposits in this vicinity (at 41 BX 274), only suspected in 1981, has required a reassessment of 41 BX 550 recommendations.

As such, while the authors recognize the paucity of surface cultural materials and their often disturbed erosional context at this site, we also believe a strong potential exists for deeply buried materials which cannot be identified or assessed without excavations in excess of 2-3 m. Most effectively, this could be accomplished by mechanical trenching and subsequent hand testing. Given the nature of stratified, deeply buried sites in the vicinity, we believe such work to be necessary to more accurately assess the potential of such sites as 41 BX 550 for nomination to the National Register of Historic P1aces.

\section{SITE 41 BX 552}

Type of site: Prehistoric occupation, ca. $300 \mathrm{~m}^{2}$.

Location: The site is located about $600 \mathrm{~m}$ north of Loop 1604 and $800 \mathrm{~m}$ south of EIm Creek.

Elevation: 550 to 570 feet above ms7.

Topographic context: Uplands. The site is located along the margins of an extensive ridge complex overlooking the floodplain of Elm Creek to the north.

Water source: Elm Creek is ca. $350 \mathrm{~m}$ north of the site location.

Vegetation and soil: Most of the site area has been cleared of natural vegetation. The northeastern margins still contain dense thorny brush and prickly pear cactus. The soil is reddish brown eroded Webb sandy loam which grades into a clayey loam at less than $25 \mathrm{~cm}$.

Site condition: Large portions of the site have been severely damaged or destroyed by modern alterations and natural erosion. The margins of a cleared, cultivated field, a farm (ranch complex), several suburban homes, and an access road compose the site area. While most of the area has been cleared, dense thorny brush and prickly pear cactus still cover the northeastern site margins. Erosion has created moderate to extensive site deflation in this latter area. Less than 15-20\% of the original site area may still contain intact cultural deposits. 
Artifactual materials present: A moderate scatter of chipped stone was observed across the site area. Deflation in the northern edges reflects a more (disturbed) intensive scatter. Fire-fractured rocks in erosional gul1 ies indicate relatively recent eroded burned rock clusters. A Middle Archaic (2650-2050 B.C.; Turner and Hester 1985:153) Travis projectile point was surface collected from the eastern portion of this site. No other diagnostic materials or features were noted.

Site discussion: Site $41 \mathrm{BX} 552$ represents the remains of a prehistoric occupation site associated with Middle Archaic activities; cultural deposits may be multicomponent, but extensive hand testing would be required to identify such elements. Sections of the site appear to contain some soil depth; a $50-\mathrm{cm}^{2}$ shovel test excavated to a depth of $25 \mathrm{~cm}$ in the northeastern portion of the site resulted in the recovery of two small decorticate chips and a single tertiary flake at a depth of $18-21 \mathrm{~cm}$.

Site significance: The site represents prehistoric occupation activities associated with a definable period of prehistory and, additionally, indicates an area where the resources of a tertiary stream drainage were exploited rather than the riparian zone of the river valley. The suggestion of some soil depth across the extensively damaged site surface may also indicate a potential for significant buried cultural features.

Management recommendations: Systematic limited testing in the form of hand excavated units $50 \mathrm{~cm}^{2}, 1 \mathrm{~m}^{2}$, and $2 \mathrm{~m}^{2}$ is recommended to determine the possibility and significance of buried cultural deposits. Such work would more accurately describe the character of the site and its potential for nomination to the National Register of Historic Places. The site is located in the maximum flood pool level of the proposed reservoir.

SITE 41 BX 553 (Hernández Home)

Type of site: Historic occupation.

Location: Located at the intersection of Howard Road and Watson Road.

Elevation: ca. 620 feet above msl.

Topographic context: The site is situated within a densely overgrown acre of mesquite trees and thorny brush in a flat, upland pasture.

Water source: Cased well.

Vegetation and soil: Originally cleared during occupations, now overgrown with thorny brush and tall grasses.

Site condition: Ruins.

Artifactual material present: None collected.

Site discussion: The site was first recorded in 1981 from a preliminary records search and identification from a nearby roadway. No on-site survey 
was conducted due to inaccessibility. The 1981 report recommended a literature search and possible hand testing to determine the structure's historical significance. Revisited in 1984, the structure was observed to be in complete ruins. An encased well was noted ca. $20 \mathrm{~m}$ from the former structure. Archival research as well as oral history interviews revealed that the structure was the former home of Jesus Hernandez, descendant of Francisco Hernandez (owner of the Spanish colonial rancho known as San Bartolo located on the San Antonio River). The structure dates to the 1 ate 19th century (Camille Boyer, Hernández descendant, personal communication).

Site significance: The structure was originally thought to represent the occupational remains of a Hernández family Spanish/Mexican 1 and grant identified from a preliminary records search. Further archival information indicated that the earlier Hernández land grant and the Hernández occupation at 41 BX 553 are two apparently unrelated families of the same name. Further, the occupational activities at 41 BX 553 date to a much later episode of settlement (ca. the late 19th century). The site is associated with the nearby cemetery site of $41 \mathrm{BX} 542$.

Management recommendations: The former occupational activities at the site represent a distinctive and significant element of late 19th-century sociocultural historical developments of the study area. In the opinion of the authors, this site is potentially eligible for listing on the National Register of Historic Places based on the potential to yield information important to the history of the area. We recommend that the site be stabilized and/or protected if it is to be affected by the reservoir. The site is adjacent to the maximum flood pool level of the proposed reservoir.

\section{SITE 41 BX 554}

Type of site: Prehistoric occupation site, ca. $300 \mathrm{~m}^{2}$.

Location: The site is adjacent to a large arroyo complex just north of the Medina River, about $1.5 \mathrm{~km}$ south of Watson Road.

Elevation: 550 to 570 feet above msl.

Topographic context: The site is adjacent to a steep, extensive erosional complex just north of the modern channel of the Medina River.

Water source: The Medina River is ca. 150-200 m south of the site.

Vegetation and soil: Dense brush, including mesquite trees, thorny brush, and cactus, covers the western portion of the site. The eastern section has been cleared, root plowed, and is cultivated. The soil is a grayish brown clayey Venus series loam bordered by brown, silty, Lewisville alluvial deposits.

Site condition: Extensive slope erosion was observed along the western and southern margins; much of the surface has been altered by land clearing. The probability of moderate to deeply buried subsurface cultural deposits, 
however, is considered high because of their occurrence at other physiographically similar sites in the study area (e.g., 41 BX 274).

Artifactual materials present: The site is characterized by a moderate to intensive scatter of lithic debris, fire-reddened cobbles, and fire-fractured limestone. The distribution of several of these burned rock accumulations across the site area suggests the eroded, scattered remnants of small, disturbed burned rock clusters. Mussel she11 fragments were also observed. An Early Archaic Guadalupe tool was surface collected from the site area. No other chronologically diagnostic artifacts or features were observed.

Site discussion: Preliminary assessments in 1981 suggested that 41 BX 554 was either a large area of prehistoric activity or possibly a multifunctional, multicomponent occupation zone. The site, following examination of the extensive profiles exposed in erosional gullies, was thought to contain intact, possibly significant features. Mussel shell fragments and lithic debris were observed along the erosional arroyo walls to a depth of at least $150 \mathrm{~cm}$.

Site significance: Reevaluations of 41 BX 554 based on interpretations of prehistoric site characteristics in the study area does not change the original evaluation of site significance. These characteristics establish the potential for Early Archaic associated sites to have deeply buried significant stratified cultural deposits along this portion of the river vai1ey.

Management recommendations: The authors recommend further systematic testing, utilizing both mechanical and hand excavations, to establish a much clearer picture of site function, components, and extent of cultural deposits. Given the poorly understood regional cultural developments associated with the Early Archaic and the study area's potential for deeply buried, stratified deposits, we believe that further investigations of 41 BX 554 may offer valuable contributions to the local and regional archaeological record, and this work would offer an evaluation of the potential eligibility of the site to be nominated to the National Register of Historic Places. The site is located in the maximum flood pool level of the proposed reservoir.

\section{SITE 41 BX 568}

Type of site: Prehistoric temporary occupation site.

Location: The site is located on a high bluff above the Medina River on the north bank, ca. $0.9 \mathrm{~km}$ west of Garza's Crossing (the intersection of Somerset Road and the Medina River).

Elevation: 560 to 570 feet above msl.

Topographic context: The locality is on a high terrace just west of the confluence of Medio Creek and the Medina River. Situated on the western margins of the Medio Creek floodplain, the site is also just northeast of a 1 arge, former oxbow of the Medina River. 
Water source: The Medina River is $75-150 \mathrm{~m}$ from the site.

Vegetation and soil: The soil is Venus clay loam, dark grayish brown in color. Small calcareous concretions (less than $0.5 \mathrm{~cm}$ in diameter) were observed occurring naturally in the soil at this location. The area has been partially cleared of natural vegetation, and the western half of the site area is situated in a plowed field. The eastern portion of site $41 \mathrm{BX} 568$ is covered by a moderate to dense growth of mesquite and smaller thorny brush.

Site condition: The site is extensively disturbed by modern 1 and clearing, plowing, and natural erosion along site margins and slopes. No surface areas of the site remain undisturbed, and only deeply buried cultural deposits, if they exist, would remain intact at this location.

Artifactual materials present: 0nly decorticate chips and secondary and tertiary flakes were observed in cleared areas. No chronologically diagnostic lithic materials, mussel she11, or bone fragments were noted during the 1981 survey. Artifact distribution density across the surface of the site area (ca. $250 \times 100 \mathrm{~m}$ ) was estimated at ca. 1-2 fragments of 1 ithic debitage per $25 \mathrm{~m}^{2}$. An occasional burned, fire-fractured 1 imestone cobble was also observed, but no features or burned rock concentrations were. identified.

Site discussion: First recorded and intensively surveyed in 1981, the site area was revisited in the fall of 1984 and reassessed. Particular emphasis was placed on the rate of identifiable erosion and in the context of an expanded data base, i.e., the recognition of 41 BX 568 as adjacent to or integrally related to the intensive prehistoric occupations along the Medio Creek-Medina River confluence. Survey transects were worked in 50- to 75-m intervals in cleared, open areas and narrowed to ca. 25-m intervals in dense brush along the eastern site margins. This change in survey methodology was undertaken to accommodate the poorer surface visibility in brush-covered areas and, conversely, to take advantage of greater ground visibility in portions of the site previously cleared. Since the southern margins of the site extended to the high banks along the river, the erosional exposures along this ca. $250-\mathrm{m}$ area were inspected for evidences of features and relative abundance and depth of prehistoric materials exposed in a subsurface context. Several small mussel shell fragments as well as six chips and flakes were observed along the length of the exposure; unfortunately, in an eroded, disturbed context. As these materials were already eroding down slope, the original subsurface depth of deposits was not identifiable, although the infrequent observation of materials and 1 ack of features suggested only a light distribution of subsurface cultural deposits in this area.

In November 1984, the site was revisited but little change was made regarding assessment of site condition or material distributions. No diagnostic artifacts or features were observed, although a reinspection of eroding slopes identified several small burned rock fragments in the southeastern edge of the site area. A mussel shell valve and a fire-reddened decorticate chip were also noted in an apparently undisturbed context (ca. $1.68 \mathrm{~m}$ below the surface) exposed along the wall of an erosional gully ca. $20 \mathrm{~cm}$ east of the burned rock. 
Site significance: The observed artifactual content of the site has been relatively minimal, and practically all of the surface area is extensively disturbed. Reevaluations of the site in 1984 did not substantially change original interpretations of extensive site disturbance and a paucity of prehistoric evidences. However, given the expanded data base available in 1984 (that is, the identification, limited testing, and interpretation of a much larger collection of sites in the study area), the significance of site $41 \mathrm{BX} 568$ is in its relationship to nearby sites in one of the most intensively occupied prehistoric activity locales in the study area, the confluence of Medio Creek and the Medina River.

Management recommendations: Preliminary assessment in 1981 of this site recommended no further work due to extensive surface damage and 1 ack of significant materials, but cumulative evidence since 1981 and particularly during recent limited testing operations in 1984 have verified the potential of deeply buried cultural deposits well in excess of several meters in depth throughout the study area. Although surface areas of site $41 \mathrm{BX} 568$ have been severely disturbed, considering the proximity to the Medio Creek confluence area, deeply buried deposits may exist in a relatively undisturbed context here. Regardless, an accurate measurement of site significance and potential cannot be assessed without limited testing (in excess of 2-3 $\mathrm{m}$ ), most efficiently in the form of mechanical trenching, and preferably in conjunction with similar work at other selected archaeological sites identified in the Medio Creek-Medina River confluence area. Such data would offer a significant contribution to an understanding of aboriginal occupation patterns along the lower Medina River valley as well as in an environmental transition zone between the Gulf Coastal Plain and the Edwards Plateau, and would help to describe the character of the site and its potential for nomination to the National Register of Historic Places.

Site 41 BX 568 is located adjacent to but not in the estimated maximum flood pool elevation of the proposed reservoir. As such, the projected severity of impacts (especially increased erosion) regardless of extent, would be considered a secondary impact.

\section{SITE 41 BX 569}

Type of site: Prehistoric, small (temporary) occupation and quarry/workshop area.

Location: Approximately $1.35 \mathrm{~km}$ northeast of the confluence of Medio Creek and the Medina River, and $1 \mathrm{~km}$ south of Fischer Road.

Elevation: 580 to 610 feet above ms 1 .

Topographic context: Generally flat uplands with slight slope to south and the Medina River drainage.

Water source: The Medio Creek is ca. $500 \mathrm{~m}$ to the southwest of the site.

Vegetation and soil: Medium to tall grasses cover the site area most of the year. The site is located within a large, cleared field, occasionally 
cultivated. Taylor, Hailey, and Richmond (1966: Sheet No. 77) indicate the site location generally consists of Lewisville series dark-colored, clayey soil bordered by clayey Willacy loam. Both types are related to old alluvial outwash plains or terraces in the south-central portion of the county. Surface inspection of the location indicates the occurrence of calcareous gravels and cobbles currently exposed and noted in nearby bulldozer excavations to depths of $2 \mathrm{~m}$ below the surface at $41 \mathrm{BX} 368$, ca. $250 \mathrm{~m}$ to the southwest. These cobbles are often larger than $12 \mathrm{~cm}$ in diameter and contain a medium- to fine-grained chert beneath their calcareous cortex.

Site condition: Moderately to severely disturbed by land clearing and a long period of plowing and cultivation.

Artifactual materials present: A light scatter of 1ithic debris, including core fragments; primary, secondary, and tertiary flakes; and corticate and decorticate chips was observed. An occasional fire-fractured or reddened cobble was also noted. No features or material concentrations were observed, and no diagnostic materials or finished lithic forms were noted across the site area $(200 \times 300 \mathrm{~m})$.

Site discussion: First recorded in 1981, the site was intensively surveyed along north-south transects at $75-$ to $100-\mathrm{m}$ intervals. Ground visibility was quite good, and recent plowing furrows exposed some cultural materials (disturbed but subsurface). Additional7y, directly west of 41 BX 569, ca. 20-30 m, bul7dozer stripping of topsoil exposed ca. 40 acres to a depth of 2$3 \mathrm{~m}$ below the original ground level. This operation was continuously monitored over a period of several months in the event that a western subsurface extent of 41 BX 569 continued into this area, to identify and assess any buried materials uncovered, and to determine the frequency, extent, and distribution of the chert gravels/cobbles found in the local soil association. Within the area bulldozed for topsoil, calcareous and chert cobbles were distributed from the surface to a depth of 2.5-3.5 $\mathrm{m}$ with cobbles becoming slightly larger and noticeably more calcareous as depth increased. Several tested cobbles and one core fragment were uncovered in the backdirt of this bulldozed acreage, but no other cultural materials were noted. The exposures of chert cobbles are apparently related to a series of deep beds of water-rounded 1 imestone gravels sometimes found underlying Lewisville soils at depths of 1-2 m (Taylor, Hailey, and Richmond 1966:25).

The site was revisited in 1984, and no changes were made regarding site significance or site interpretations. Surface artifact density, in the form of Tithic debris, was estimated at 2-3 fragments of debris per $25 \mathrm{~m}^{2}$.

Site significance: In general terms, the significance of 41 BX 569 lies in the recognition of site function as a lithic resource procurement area and lithic workshop. The site is in an upland (or marginal) location exploited for chert cobbles. Considering prehistoric lithic procurement patterns and sources of raw materials in the study area, it is distinct from other available locales such as riverbed gravels or gravel/cobbles exposed in thin beds or eroding hilltops, such as Uvalde gravels.

In specific terms, the significance of site 41 BX 569 is its proximity to a series of intensively occupied prehistoric sites along the Medio Creek-Medina 
River confluence. Given the site function and spatial proximity to these other sites, probable intersite activity relationships (for the exploitation of local lithic raw materials) can be assumed.

Management recommendations: The significance of site $41 \mathrm{BX} 569$ is not within the integrity or extent of cultural deposits, but in the recognition of site function and intersite relationships to a nearby extensive prehistoric activity area. Taking into account the disturbances caused by land clearing and cultivation, the identification of depth and extent of gravel/cobble deposits from the adjacent 40-acre tract, and the fact that the site is well beyond the estimated impacts of the maximum flood pool of the proposed reservoir, no further work is recommended at this site at this time. Should any construction or other activities occur in the future at this location, we recommend monitoring of this site for possible unidentified buried features or deposits below the deep plow zone (disturbed) and to the base of the gravel deposits (ca. $2 \mathrm{~m}$ ).

While 41 BX 569 is not considered to be of potential National Register quality as an individual site, it is believed to have once been an integral ancillary activity area having specific functional relationships to the prehistoric sites in the Medio Creek-Medina River confluence area. This area is considered to reflect a significant aspect of aboriginal exploitation and occupations of the lower Medina River valley.

\section{SITE 41 BX 652}

Type of site: Multicomponent.

Location: The site is situated on the north bank of the Medina River along a former terrace in the northeastern margins of the proposed reservoir area.

Elevation: $\quad 510-530$ feet above ms 1 .

Topographic context: The modern river channel is now well south of this location through the creation of an oxbow, and the site location is now situated on upland margins.

Water source: Medina River; at one time, the site was located within $50 \mathrm{~m}$ of the channel; after recent channel movement, distance to water is estimated at $400 \mathrm{~m}$.

Vegetation and soil: Thorny brush, mesquite trees, and tall grasses cover the surface of the site. Aeolian sands overlie silty, clayey alluvial soil deposits.

Artifactual materials present: The site was identified from the presence of small cobble and/or core fragments and other lithic debris, including secondary and tertiary flakes and decorticate chips. A Langtry projectile point and an untyped small corner-notched dart point with unsymmetric lateral blade edges (Edgewood) were collected. During intensive resurveys, three additional bifaces were collected: (1) a large triangular biface that may have functioned as a knife; (2) a burned lanceolate fragment with a reworked 
distal end; and (3) the proximal portion of an expanding stem deeply cornernotched untyped dart point. Several irregular chert blades were also observed as well as fire-reddened debitage. A small sherd of undecorated soft paste ware thought to be Leon Plain was also collected. Two historical items were recovered at the site, a small badly corroded button and a Spanish olive jar fragment (see Material Culture section).

Site discussion: The site was first identified in 1984 as a large scatter of burned rock, lithic debris, and several diagnostic artifacts. A small burned rock cluster was noted eroding from an erosional cut ca. $25 \mathrm{~cm}$ below the surface. No diagnostic materials were observed with this feature. Given the site dimensions (ca. $400 \times 100 \mathrm{~m}$ ) based on the 1 ithic scatter and the range of projectile point types as well as the occurrence of historic and prehistoric materials, we believe this site to be an extensive multicomponent, multiactivity location. A long period of occupations is postulated, and the observation of intact features in erosional cuts suggests further, perhaps more substantial deposits 1 ie buried nearby. Background research data also suggest this general location may have been the area of a historic Indian campsite. The presence of artifactual material suggests a possible early historic association between the Spanish and the Indian populations in the area.

Site condition: The site area appears to have been cleared at one time, but thorny brush and mesquite trees have recovered the vicinity. Site margins are extensively eroded, but other areas seem to have extensive soil depth.

Site significance: Site significance cannot be accurately determined without subsurface testing in the form of mechanical and hand excavations.

Management recommendations: In the opinion of the authors, this site is potentially eligible for listing on the National Register of Historic Places based on the information that may be yielded to the prehistory and history of the area. The site lies within the conservation pool level of the proposed reservoir. Site significance cannot be accurately determined without further investigation in the form of limited testing to determine the extent and potential of cultural materials.

\section{$\underline{\text { SITE } 41 \text { BX } 653}$}

Type of site: Extensive prehistoric occupation area.

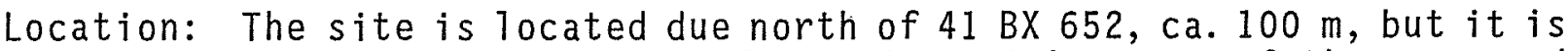
spatially discrete. The site is located ca. $1 \mathrm{~km}$ west of the proposed damsite on a former terrace of the Medina River.

Elevation: 540 feet above ms 1 .

Topographic context: Site 41 BX 653 appears to be situated on an earlier, slightly higher former terrace of the river channel. The modern river channel has shifted south over $0.5 \mathrm{~km}$ (also see $41 \mathrm{BX} 652$ ). 
Water source: Distance to the Medina River is estimated at $500 \mathrm{~m}$. During site occupations, the ancient channel may we11 have been within $100 \mathrm{~m}$.

Vegetation and soil: Vegetation consists of upland thorny brush, mesquite trees, and tall grasses. As at 41 BX 652, aeolian sands overlie silty, clayey alluvium. The site is situated in almost flat uplands with very little slope and is associated with a former river terrace related to a 540 to 550 -foot contour interval within the area.

Site condition: Some minor erosion was noted along ranch roads which bisect the site. Most of the site materials appear buried. The present landowner relates that this area has never, to his knowledge, been cleared (the mesquite trees are used as a natural windbreak for cattle during winters).

Artifactual materials present: An extensive scatter of 1ithic debris, including secondary and tertiary flakes and decorticate chips, some fire reddened, was noted. A Late Archaic Monte11 projectile point fragment was collected in this area.

Site discussion: Several eroded, small burned rock clusters ca. $1 \mathrm{~m}$ in diameter were observed, but no diagnostic materials were collected from these locations. Much of the area is covered by aeolian sand, and cultural materials are thought to be generally buried within or below upper, shallow soil zones. This sand also complicates estimates of total site area, al though several intensive surveys suggest a surface material scatter ca. 500 $x 300 \mathrm{~m}$. Interestingly, the extent of surface scatter follows the shape of the 540-foot contour as identified from topographic maps. The higher elevation of this site implies an earlier occupational sequence than 41 BX 652 to the south. Site occupations are thought to be Early Archaic through Late Archaic, although this is speculative without subsurface testing.

Site significance: No firm assessments of site potential can be made without some form of subsurface testing; if cultural materials are buried, the significance of these possible deposits may be of potential National Register status.

Management recommendations: The observations of eroding features, the extensive site area, and the potential of buried, significant deposits suggest that an accurate assessment of this area cannot be made without subsurface testing to determine the extent and potential of this site. The site is located in the maximum flood pool level of the proposed reservoir.

\section{SITE 41 BX 654}

Type of site: Prehistoric lithic workshop, possibly temporary occupation.

Location: Cultural materials were noted along a ranch road north of the Medina River ca. $200 \mathrm{~m}$ west of the eastern margins of the proposed damsite location.

Elevation: $530-540$ feet above msl. 
Topographic context: Site occupies presumed location of former terrace of old river channel, now well within upland margins.

Water source: Current distance to the Medina River is ca. $200 \mathrm{~m}$ from the site.

Vegetation and soi1: The site is covered by upland flora; thorny brush, tall grasses, some oak, persimmon, and mesquite trees were noted. Aeolian sands overlie silty, clayey, alluvial deposits.

Site condition: The location evidences extensive erosion caused by naturat processes; much of the cultural material on the surface appears in deflated areas.

Artifactual materials present: A light scatter of lithic debris was observed across a $100 \times 200 \mathrm{~m}$ area. These included corticate and decorticate chips and secondary and tertiary flakes. No finished or expended tools or diagnostic lithic materials were noted. Only a small amount of burned rock fragments was observed. No features were identified from erosional cuts.

Site discussion: This location is thought to represent a temporary lithic reduction center proximate to more extensive activity areas farther to the east. The presence of an occasional burned rock fragment may indicate temporary camping activities as well.

Site significance: The potential significance of this site to local and regional archaeological studies is severely compromised by the impact and extent of natural erosional processes across the site; some erosional gullies that disect the site are $75 \mathrm{~cm}$ in depth with displaced 1 ithics exposed in these washes.

Management recommendations: No further work is recommended at this location due to the paucity of observed materials combined with the severity of natural erosional processes across the site area. The location of this site is important as it is situated on a similar elevation contour as nearby extensive occupation sites.

\section{$\underline{\text { SITE } 41 \text { BX } 655}$}

Type of site: Prehistoric 7ithic processing and occupation site (multifunctional; suspected multicomponent from the extent and intensity of debris scatter).

Location: Situated within and adjacent to a sendero cut for utility power lines along the proposed damsite location ca. $400 \mathrm{~m}$ north of present river channel.

Elevation: $530-540$ feet above msl.

Topographic context: Like nearby $41 \mathrm{BX} 654$, this site is located near a 540 foot contour which may represent an early terrace along the north bank of the Medina River. A wide, distinctive gully runs parallel to the river course 
today, ca. $200 \mathrm{~m}$ south of the site; this may be the remnants of a fossil channel related to this contour elevation.

Water source: The distance to the present channel of the Medina River is estimated at $400 \mathrm{~m}$; distance to the former channel is thought to be less than $200 \mathrm{~m}$.

Vegetation and soil: Upland flora; thorny brush, tall grasses, mesquite, some oak, and persimmon trees were noted. The soil is an aeolian deposit overlying a compacted, clayey alluvium.

Site condition: Approximately $70 \%$ of the site remains intact.

Artifactual materials present: An extensive scatter of burned limestone rock fragments was observed along the sendero cut. Comparatively little burned rock was noted beyond the clearing of the sendero, although a moderate scatter of Tithic debris (decorticate chips and flakes) was found in an area ca. $100 \times 250 \mathrm{~m}$.

Site discussion: The distribution of materials suggests that much of the site area may be buried by recent aeolian deposits. No intact features were noted in the narrow exposures of the sendero, and no diagnostic 1ithic materials were collected here. However, the extensive scatter of burned rock associated with a moderate to heavy distribution of secondary to tertiary lithic reduction materials suggests possible multicomponent activity at this site.

Site significance: Given its proximity to the proposed damsite location and elevation as well as the potential for significant buried cultural deposits, this site is recommended for further work in the form of limited testing to determine the vertical and horizontal depths of estimated deposits, and to more clearly assess their potential to the regional archaeological record.

Management recommendations: Further investigations in the form of subsurface testing are recommended to determine if the site and materials may be of potential National Register quality. Intensive surveys cannot identify the potential of suspected buried cultural deposits at this point. This site, like site 41 BX 654, is located along an elevation contour associated with a former river channel terrace. Nearby site locations along this same contour suggest that extensive activities once occurred in a linear fashion at this elevation.

\section{SITE 41 BX 656}

Type of site: Prehistoric occupation (multifunctional), possibly multicomponent.

Location: The site is located along a distinctive upland contour ca. $1.5 \mathrm{~km}$ east of Applewhite Road and north of the Medina River.

Elevation: $530-540$ feet above msl. 
Topographic context: Like several other nearby sites, $41 \mathrm{BX} 656$ is thought to be situated on a former river terrace. Now situated in uplands, the site encompasses the highest points of contour relief.

Water source: The distance to the modern channel of the Medina River is ca. $200 \mathrm{~m}$. Distance to water source during site occupations is thought to be less than $100 \mathrm{~m}$.

Vegetation and soil: Upland flora; thorny brush, tall grasses, mesquite, and some oak were noted. The soil is an aeolian deposit overlying fine-grained, clayey alluvium.

Site condition: It is estimated that $60-70 \%$ of the site remains intact following the impacts of modern erosion. Because of the associations with extensive prehistoric neighboring sites along the same natural contour, this site may represent portions of a very large occupation zone that can only be defined by subsurface testing. While no diagnostic materials were collected, we believe this is due in a large part to overlying sand which may contain buried cultural deposits.

Artifactual materials present: An extensive scatter of 1ithic debris was noted across the site, including fire-reddened and burned secondary and tertiary flakes and corticate and decorticate chips. Two small burned rock clusters, ca. $75 \mathrm{~cm}$ in diameter, were observed eroding from erosional slopes, but no diagnostic materials were collected throughout the site area (ca. 100 $x 200 \mathrm{~m})$. An extensive scatter of burned rock was noted across the site, and much of the cultural material was exposed in erosional cuts, suggesting that other materials may remain intact below the surface in other site areas.

Site discussion: Site $41 \mathrm{BX} 656$ is one of several sites in the eastern portion of the study area located on or near a 530 to 540 -foot (above ms 1) contour. It is postulated these sites may be broadly related chronologically because of their proximity and topographic similarity. Unfortunately, the 1 ack of diagnostic artifacts to date at 41 BX 656 precludes more substantive interpretations.

Site significance: The occurrence of eroding cultural materials and features as well as postulations of intersite relationships suggests that potential cultural deposits at site 41 BX 656 may offer significant contributions to the local and regional archaeological record.

Management recommendations: Further work in the form of limited testing is recommended to determine the extent and significance of buried deposits and a determination of their potential eligibility to the National Register of Historic Places. The site is located within the conservation pool level of the proposed reservoir.

\section{SITE 41 BX 657}

Type of site: Prehistoric lithic workshop site, possibly temporary occupation site. 
Location: The site is located along high bluffs on the north banks of the Medina River, ca. $500 \mathrm{~m}$ east of Applewhite Road.

Elevation: ca. 530 feet above ms 1 .

Topographic context: The site is located on the margins of a steep bluff ca. 20-25 m above the floodplain. The locality may have been cleared at one time but now dense brush chokes the surface.

Water source: The distance to modern channel of the Medina River is less than $100 \mathrm{~m}$.

Vegetation and soi1: Dense thorny brush, whitebrush, and oak, persimmon, and mesquite trees were noted.

Site condition: The site is thought to be seriously impacted by erosion and former land clearing.

Artifactual materials present: A very light scatter of lithic debris, including a core fragment, several secondary and tertiary flakes, and an occasional decorticate or corticate chip, was observed.

Site discussion: Total site area is estimated at $50 \times 100 \mathrm{~m}$ and possibly slightly larger, given the extent of aeolian sand deposits. No features or diagnostic materials were collected, although an occasional burned rock fragment was observed, suggesting temporary occupation. Slope erosion was noted as being quite severe along steep bluff margins.

Site significance: The site is severely eroded.

Management recommendations: No further work is recommended at this location given the limited site area and lack of cultural materials. Based on the lack of diagnostic artifacts and the severe erosion, this site does not appear to meet National Register of Historic Places criteria.

\section{SITE 41 BX 658}

Type of site: Prehistoric temporary occupation site.

Location: The site is exposed along the erosional cuts of a ranch road ca. 1 $\mathrm{km}$ east of Applewhite Road and north of the Medina River.

Elevation: 540 feet above msl.

Topographic context: Located in modern uplands, the site is situated on what is thought to be a former terrace remnant.

Water source: The modern channel of the Medina River is ca. $200 \mathrm{~m}$ south of the site. 
Vegetation and soil: Upland flora; thorny brush, whitebrush, tall grasses, mesquite, and occasionally oak trees were noted. The soil is a fine-grained sandy, aeolian deposit overlying more compacted, clayey alluvial materials.

Site condition: Seriously impacted by local erosion.

Artifactual materials present: A 1ight scatter of 1 ithic debitage (chert flakes, decorticate chips) is distributed over the site area (ca. $100 \mathrm{~m}^{2}$ ). No features or diagnostic artifacts were collected. Several small burned rocks were noted widely scattered over the site area.

Site discussion: See artifactual materials present.

Site significance: Given the limited site area, extent of damage through natural erosional processes, and the lack of diagnostic materials, this site does not appear to be able to yield information important to the prehistory of the area.

Management recommendations: Given the limited site area, lack of features, diagnostic or otherwise significant materials, and effects of erosion, the site does not appear to meet National Register of Historic Places criteria. The location may be used to formulate prehistoric occupation patterns based in part on related landforms.

\section{SITE 41 BX 659}

Type of site: Prehistoric temporary occupation site.

Location: The site is located on the edges of a large ravine/arroyo complex north of the Medina River and ca. $1 \mathrm{~km}$ east of Applewhite Road.

Elevation: $500-520$ feet above ms 1 .

Topographic context: Situated on the edges of an extensive arroyo complex adjacent to the modern floodplain of the Medina River, the original site area has been altered by long-term erosional processes. Deep ravines dissect the area.

Water source: The distance to the Medina River is ca. $75 \mathrm{~m}$ south of the site.

Vegetation and soil: Erosion has stripped the topsoil from the area and affected vegetation growth; flora consists of some thorny brush, mesquite, whitebrush, and tall grasses. The soil is a fine-grained aeolian deposit interfingered with underlying compacted silty, clayey materials.

Site condition: The location appears extensively damaged by long-term natural erosional processes. The original site area may have been larger but this has long been destroyed by erosion. 
Site discussion: This site has been extensively damaged by natural erosion, and less than an estimated $15 \%$ of the site area appears relatively undisturbed.

Site significance: Little inference can be made regarding the former site function or significance because of the severely eroded condition.

Management recommendations: No further work is recommended at this location due to the extensive amount of erosional damage, the limited site area, and the 1 ack of observed diagnostic materials or features. The authors do not believe this site is of potential National Register quality.

\section{SITE 41 BX 660}

Type of site: Historic; a light to moderate scatter of early 20th-century glass, ceramics, and corroded metal in an area of ca. $75 \mathrm{~m}^{2}$ was noted.

Location: The site is located ca. $0.8 \mathrm{~km}$ east of Applewhite Road and north of the Medina River.

Elevation: 570 feet above msl.

Topographic context: The site is located on slightly sloping uplands that have long been cleared for pasture acreage. It is thought the original site location was partially determined by its proximity to these cleared fields and/or pastures.

Water source: A boggy area ca. $20 \mathrm{~m}$ west of the cultural scatter suggests an old we11, possibly a cistern buried by modern topsoil.

Vegetation and soil: The site and the large adjacent areas have been completely cleared of any vegetation. The soil has been disturbed by former plowing. The soil type is a clayey, subangular, blocky material.

Site condition: No structural remains, outlines, or intact historical features were noted. Continuous plowing has practically obliterated the site.

Artifactual materials present: A 1ight to moderate scatter of sma11, unidentifiable glass fragments, rusted metal, and several wire nails was observed. A11 materials suggest disturbance in the past, perhaps by the plowing of the site area.

Site discussion: Current landowners indicate this was the location of a small wooden tenant shack occupied in the 1920 s-1930s, perhaps slightly earlier. It is significant to note that, while very little remains of the occupation(s), oral interviews with the current landowners indicate one of the tenant families who once occupied this former structure was named Hammer. One of the individuals of this family, Frank Hammer, later gained notability as the Texas Ranger who (abruptly) ended the careers of the notorious Bonnie and Clyde. 
Site significance: The site was the location of a tenant farmer occupation but has been almost completely destroyed.

Management recommendations: Survey estimates of this site suggest that $80 \%$ or more of the site area has been destroyed or extensively damaged by 1 and clearing, farming, and natural erosion. The site is located above the maximum flood pool elevation of the proposed reservoir. Based on the amount of destruction at the site and work performed to date, the site does not appear to be eligible for the National Register of Historic Places.

\section{SITE 41 BX 661 (Tenant House)}

Type of Site: Historic structure and prehistoric temporary occupation site.

Location: The site is east of Applewhite Road and north of the Medina River.

Elevation: ca. 530-540 feet above msl.

Topographic context: The location is situated along a modern terrace of the Medina River. The general location, because of the natural slope and past efforts at land clearing, shows moderate to extensive damage through modern erosion.

Water source: The distance to the Medina River is ca. 250-300 m south of the site. Given the historic occupation, a well or cistern is thought to be located in close proximity to the existing structure, but no evidences of such a well were noted during intensive surveys.

Vegetation and soil: Riparian flora observed in area; oak, pecan, and cottonwood trees and tall grasses were noted. The soil context is quite eroded, exposing clayey materials.

Site condition: The prehistoric component has been displaced by erosion. The historic component consists of an abandoned structure (deteriorated) and dumps half buried along nearby arroyo slopes as well as adjacent to the structure on the south. The ground area (with cultural deposits) immediately surrounding the structure appears to be intact.

Artifactual materials present: The prehistoric component consists of a moderate scatter of 1 ithic debris in the form of secondary and tertiary flakes, decorticate chips, and burned rock. No features or diagnostic materials were collected. The site dimensions for the prehistoric materials are estimated at ca. $100 \mathrm{~m}^{2}$. The historic materials observed but not collected consisted of two sherds of stoneware, two sherds of pressed glass, one fragment of graniteware (ca. 1930s), numerous sherds of undecorated ironstone (ca. 1920-1930s), numerous sherds of glass, and numerous fragments of unidentifiable rusted metal and iron.

Site discussion: The prehistoric component is estimated to be the remains of a light temporary occupation possibly associated with nearby 41 BX 274 to the west. The historic component consists of an abandoned wooden structure in deteriorated condition (Fig. 36). Large trash dumps were noted half-buried 


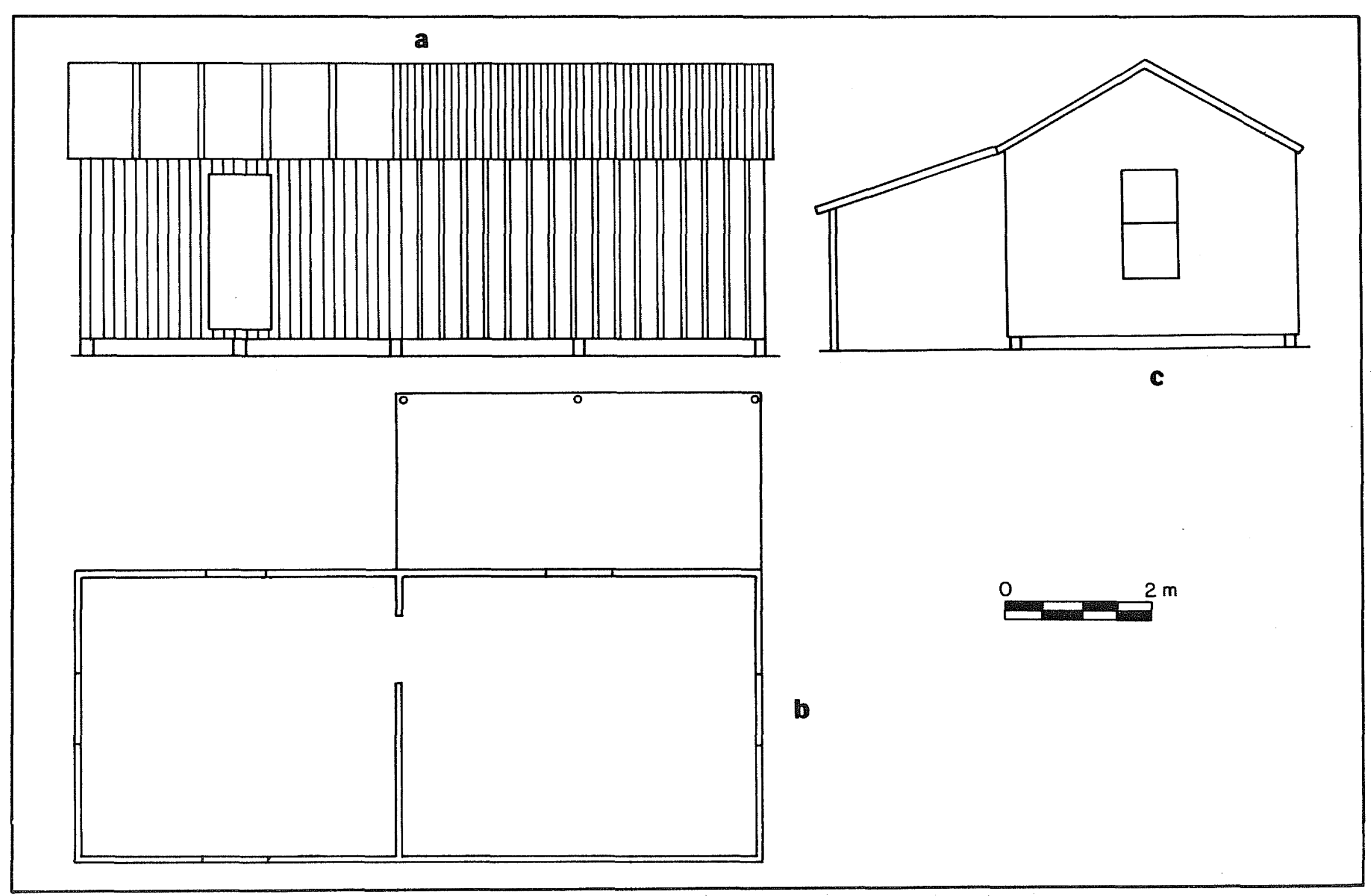

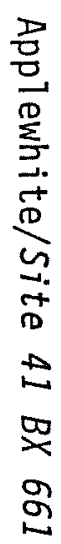

Figure 36. Plan Views of 41 BX 661. Ear1y 20th-Century Tenant Occupation. a, front view, looking east; b, side view, looking south; $c$, floor plan. 
along nearby arroyo slopes. The one-story frame house consists of two rooms with the southern room added at a later date. The wood frame appears to be flooring material rather than exterior frame siding. The tin roof (on the original structure) appears to have a primary use for something other than roofing material. The interior of the structure has been 1 ined and relined with old newspapers (only fragments remain).

Discussions with current landowners indicate that the structure was a tenant occupation, ca. 1920-1930s. An analysis of the artifactual material suggests an earlier occupation date of ca. 1880-1930s. The artifactual material present at this site is not indicative of the postulated socioeconomic level of tenant farmers (e.g., pressed glass, ornate brass pul1s, etc.); however, the structure itself does reflect this level. Perhaps the refuse reflects dumping by persons other than the original occupants.

In 1984, a scaled floor plan of the structure was made. Oral history interviews with the current landowners were conducted.

Site significance: This site possibly represents one of the few tenantrelated occupations within the conservation pool level of the reservoir. As such, it offers a unique opportunity to document the cultural patterns of one very important aspect of the history of the study area.

Management recommendations: In the opinion of the authors, this site is potentially eligible for listing on the National Register of Historic Places based on the information that may be yielded about the history of the area and the association with events that have made a significant contribution to the broad patterns of our history. Further archival research is recommended to determine the interrelationships of this economic feature to the historic development of the study area and to identify, if possible, the span of occupations as well as individuals involved. Limited testing is also recommended to clarify the temporal associations of the site as evidenced by surface scatter and economic status of the occupants.

The prehistoric materials are extensively scattered, and the site area is damaged by erosion; no further work is recommended regarding the prehistoric aspects of this site.

\section{SITE 41 BX 662 (Domestic Brick Kiln)}

Type of site: Historic brick kiln.

Location: Approximately $0.5 \mathrm{~km}$ east of Applewhite Road on the north terrace of the Medina River.

Elevation: ca. 530 feet above msi.

Topographic context: The site is located on the margins of an eroding terrace complex adjacent to the floodplain of the Medina River. The clayey, compacted subsoil exposed by erosion is presumed to have been the source of raw material for the kiln. 
Water source: The Medina River is ca. $200 \mathrm{~m}$ south.

Vegetation and soil: Densely overgrown with thorny brush and mesquite trees.

Site condition: The upper exposed surface is disturbed by natural erosion. Intact portions of the kiln exist below the surface.

Artifactual materials present: Brick fragments.

Site discussion: The site is the remains of a brick kiln (Fig. 37). The bricks from this kiln were used locally to manufacture portions of the walls for 41 BX 681, a Walsh family residence built ca. 1920. Little remains of the kiln today.

Site significance: The site represents one of the few identified "semiindustrial" sites in the study area. Additionally, it represents a locally significant specialized historical feature significant to the social and economic development of the local area.

Management recommendations: In the opinion of the authors, the site is potentially eligible to be listed on the National Register of Historic Places based on the potential to yield information important in history. Mapping of the site is recommended. The site is located in the conservation pool level of the proposed reservoir.

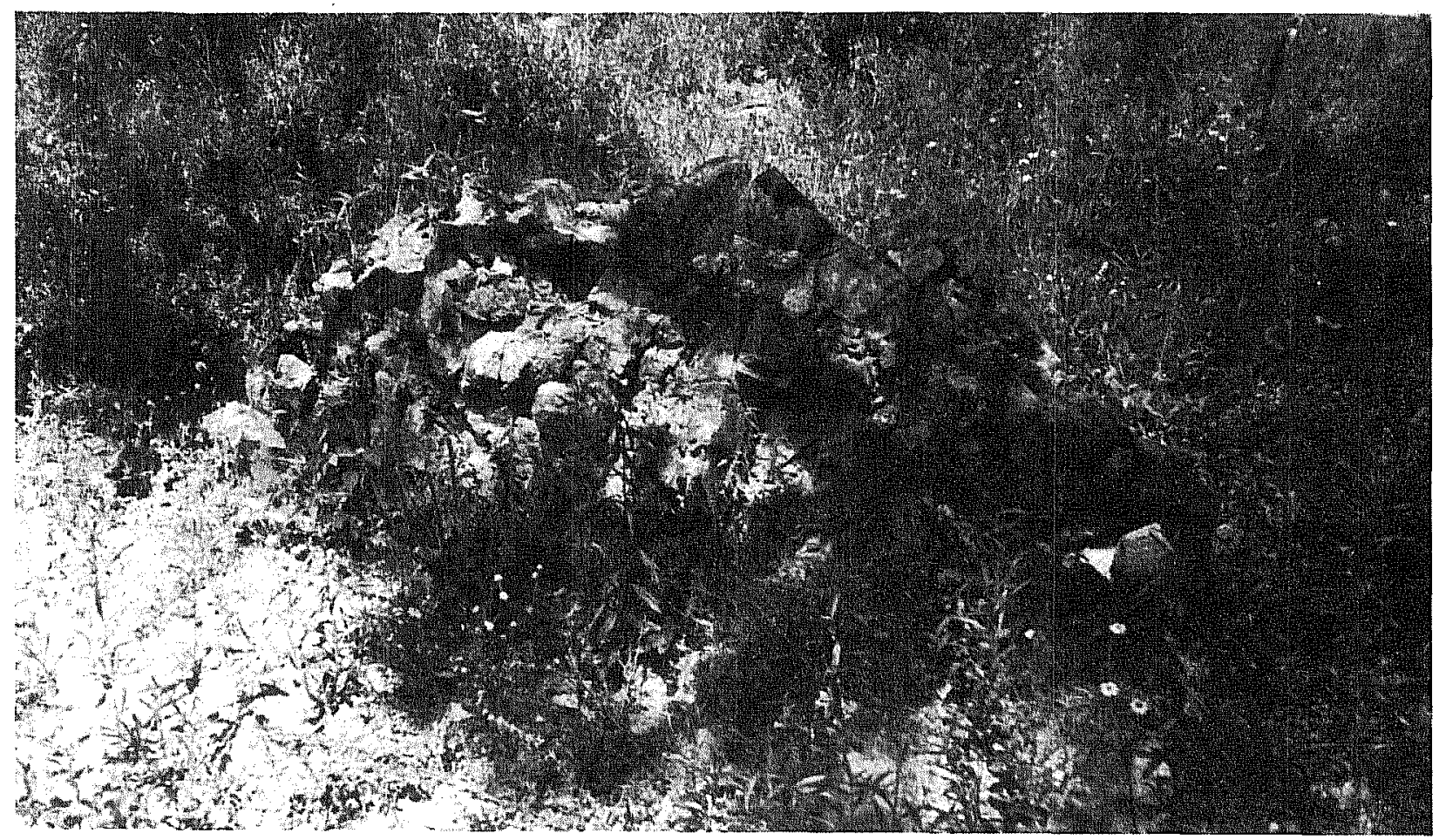

Figure 37. Brick Kiln Remains at 41 BX 662. 


\section{SITE 41 BX 664 (Enoch Jones Complex)}

Type of site: Multicomponent. Historic dwelling and outbuildings complex. A prehistoric occupation site underlies the historic component.

Location: The site is located north of Von Ormy Road and south of the Medina River in the western margins of the project area.

Elevation: ca. 580-610 feet above msl.

Topographic context: The site is situated on the edge of a prominent bluff that overlooks a former oxbow of the Medina River; the large floodplain below the site is now known as Live Oak Slough. Extensive erosion occurs along the entire length of the bluff margins. Elevations beyond the face of the bluff drop to below 520 feet above ms 1 .

Water source: Cistern/we11. In 1858, the Medina River was ca. $50 \mathrm{~m}$ behind the site. By the 1930s, a rechannelization of the river moved the channel to ca. $300 \mathrm{~m}$ north.

Vegetation and soil: The historic occupation site has been cleared of natural vegetation. Thorny brush and mesquite trees are scattered through the complex area, and oak and elm trees and other riparian flora were noted along the bluff margins. The soil is somewhat eroded and/or disturbed by modern alterations. The soil consists of aeolian deposits overlying compacted clayey materials, except in scattered locations where the upper deposits have been eroded.

Site condition: The prehistoric component is $90 \%$ destroyed by extensive modern alterations and erosion. The historic component is in varying levels of ruins. The main historic architectural site is currently occupied.

Artifactual material present: The historic artifacts observed, but not collected, from the southern edge of the site consisted of undecorated ironstone sherds (ca. 1ate 19th century), glass sherds (1ate 19th century), and unidentifiable metal fragments. Shovel tests located 4 to $6 \mathrm{~m}$ from the door openings at the barn did not reveal any artifactual material.

Site discussion: The site was identified in 1981, but was not given a site number as it was located in an inaccessible area. The historic structure (Fig. 38,a) was recorded as the Von ormy house and was recommended for archival documentation, intensive survey, mapping and recording. The site was believed to be potentially eligible for listing on the National Register of Historic Places.

Access to the site was obtained in 1984. Extensive archival research had preceded an on-site investigation. The site is a farm/ranch complex with standing structural components that consist of a stone residence with basement, a single-story plastered stone "barn" with loft, a stone smokehouse (in ruins), a wooden frame house ca. 1930s-1940s construction, two stonelined cisterns, and a set of wooden pens. Archival research and survey indicate that a stone blacksmith shop was located ca. $30 \mathrm{~m}$ south of the "barn" structure; a stone wall ca. 10 feet high and two to three feet thick 

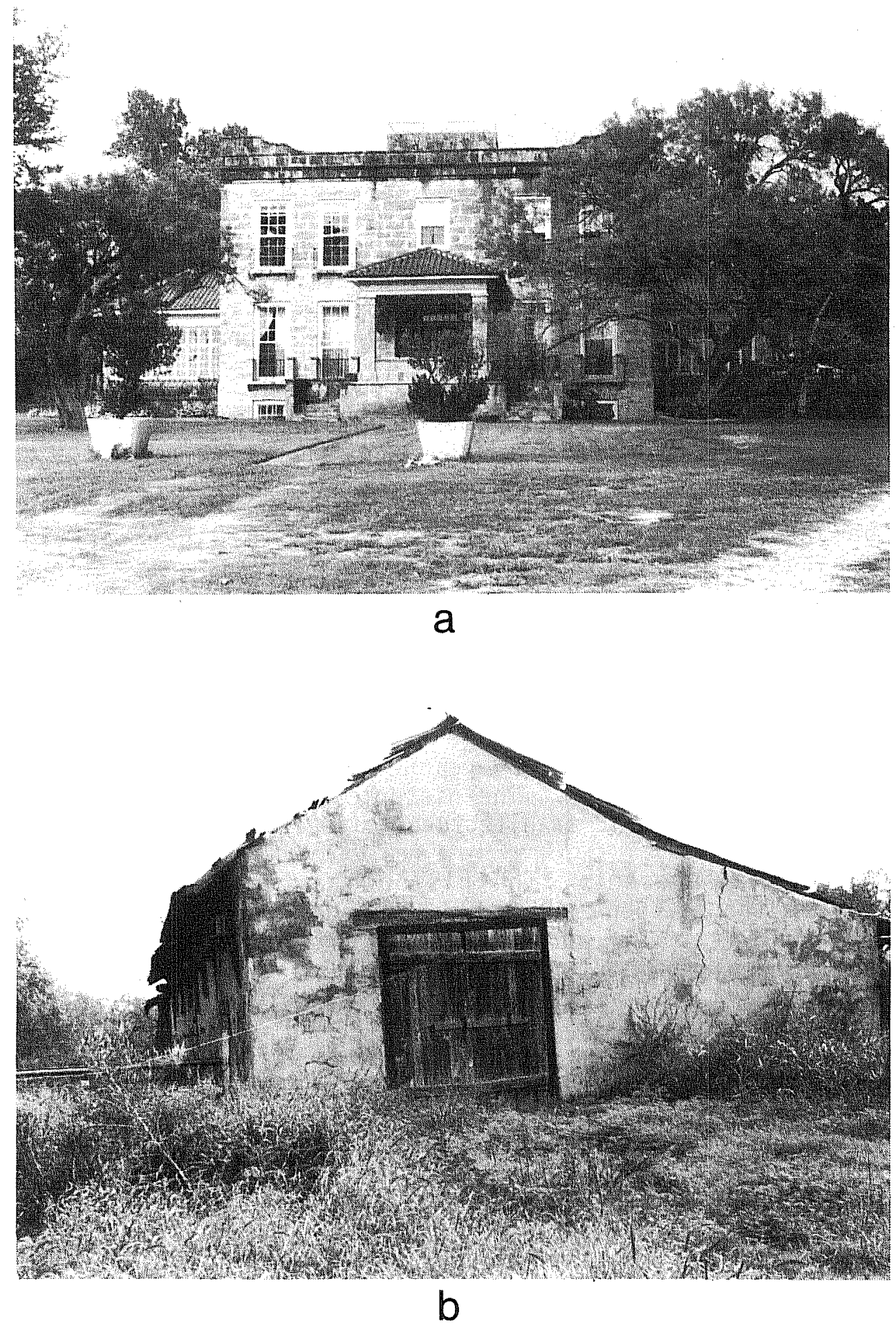

Figure 38. Structures at 41 BX 664. a, Enoch Jones residence, front view looking north; b, barn structure, side view looking east. 
once enclosed the south side of the "barn" structure (extending 100 feet [33 m] away from the structure). Archival research also revealed that just north of the "barn" were hog and sheep pens (not located during the survey).

The home, built ca. 1858 by Enoch Jones, was reportediy constructed from undressed stone quarried on site (the basement was where the stone was quarried). The original architecture of the home appears to be Greek Revival with Victorian touches. The handsome proportions of the home included large stone columns, a symmetrical facade with side-lighted centered door with transom, nine light sash windows, and a wide double gallery porch with stickwork trim.

The first floor consisted of four large rooms, two on each side of the hall, which ran the entire length of the house. The rooms were approximately 16 feet high and 24 feet wide. They were connected on each side of the hall by high, paneled arched sliding doors. The front rooms were used by the Jones family as parlors with the other two rooms utilized as bedrooms. Fireplaces were located in all rooms, 14 in all.

A circular staircase of hand-turned walnut led upstairs where the same scheme of rooms was carried out as below. The walls were of plaster. On the roof was a large storage tank that supplied water (pumped from the Medina River by means of a hydraulic ram) for a complete system of indoor plumbing (including a shower bath--possibly one of the earliest in the state).

The kitchen, store rooms, and servant's (slaves) rooms were located in the basement. Some alterations to the structure have occurred. The original four stone columns and the double gallery were removed and replaced with a sma17 central porch. Two wing additions have been added on the east and west sides of the structure. Inner walls were knocked out to make larger rooms, and the fireplaces were refaced with tile. Additional bathrooms as well as a first floor kitchen have been added. These alterations and additions have not destroyed the integrity of the structure. The engineering details of the house are extremely interesting; Enoch Jones was an engineer of national prominence.

The smokehouse ("Pig Rooster") is located just northwest of the main house. An early photo (ca. 1931) shows the structure in fairly good condition. The construction techniques of the smokehouse appear to be very similar to the home and are of the same undressed quarried stone. The smokehouse is now in ruins, and portions have been bulldozed.

The blacksmith shop was already in ruins in 1931. Construction techniques and materials appear to be like the other two structures.

The plastered stone "barn" structure is ca. $100 \mathrm{~m}$ to the east of the house (Figs. 38,b; 39). The structure is ca. $60 \times 24 \mathrm{~m}$. Two fireplaces are located within the structure. Archival research and oral history interviews revealed that slaves were quartered here when Jones owned the property. In 1948, Charles Ramsde11, San Antonio historian, wrote that: 


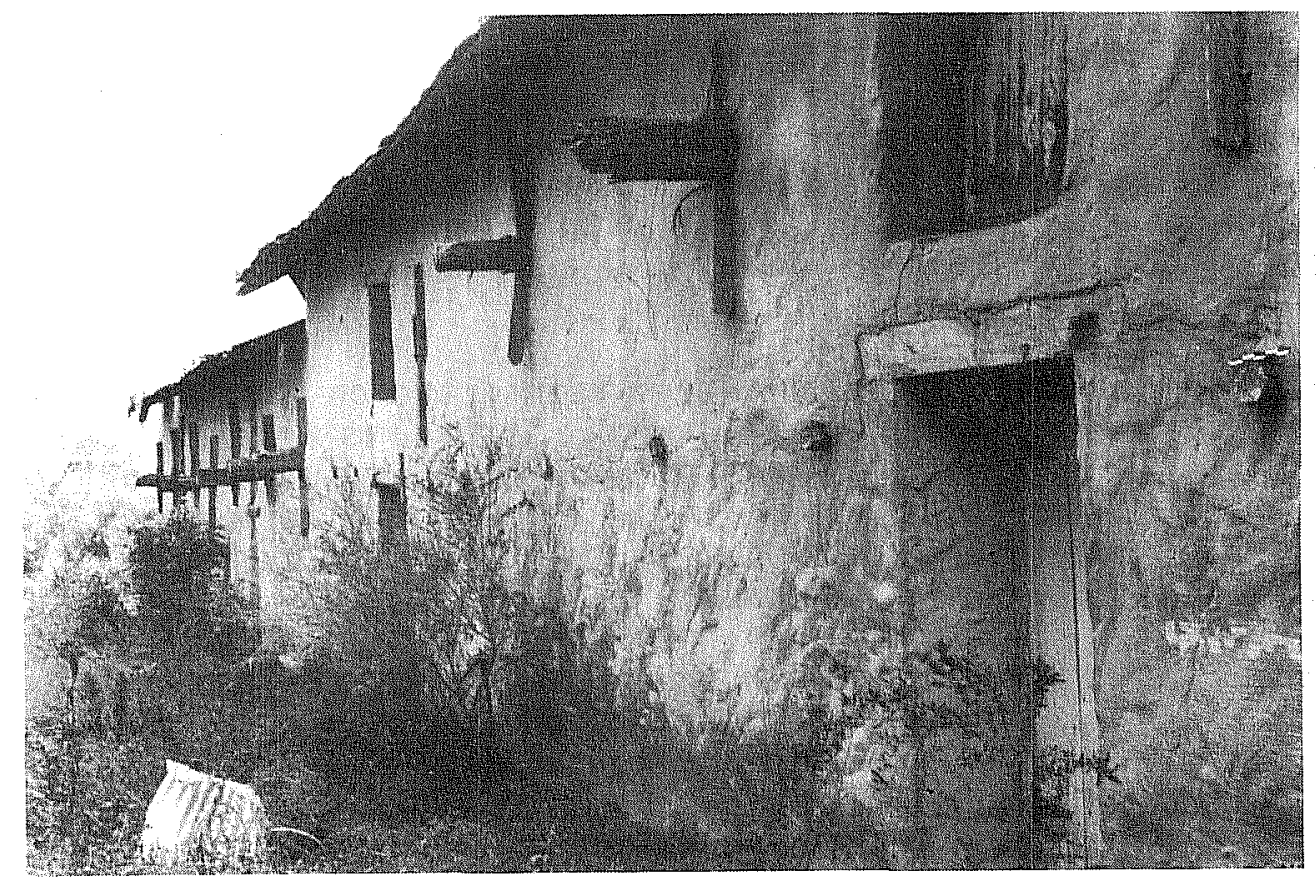

Figure 39. Barn Structure at $41 \mathrm{BX} 664$. View towards the east.

the barn which still stands in pretty much its original shape is as impressive as the house. It is a beautiful stone building about 150' long, following the contour of a ridge, and it has of all things, two fireplaces. One of them was used to warm the young lambs. Enoch Jones was one of the first ranchmen in Texas to import fine Merino sheep. .. Another feature of the barn was water running through the troughs (Ramsdel1 1948).

Speculation currently is that the barn structure may predate the other structures at the site, given the distinctive differences in architectural styles, construction techniques, and materials. Construction is of plastered stone and adobe, quite distinct from the careful stonework of the main structure and the smokehouse. In fact, the stonework and materials are very reminiscent of portions of the south wall constructed at Mission Espada in the 1780s. Long wooden beams run the full width of the structure and terminate on the exterior in an extremely unique bracing system (these appear to have been replaced). Other beam fragments are occasionally found in the walls of the structure. Sections of these beams were used for an experimental dendrochronological study by Dr. Joel Gunn, associate professor of anthropology at UTSA (see Appendix VII). 
Archival research revealed that this property was a part of the extensive Spanish land grant to the Pérez family ca. 1754-1780 (TGLO Vol. 43:119-123). José Ygnacio Pérez continued to claim this grant until 1851, at which time litigation over the property reached the Texas Supreme Court (TGLO Paschal vs. Pérez and Paul vs. Pérez:340). The case was decided against Pérez, and he lost the four leagues on the south bank of the river (see $41 \mathrm{BX} 274$ ). In 1849, José Ygnacio Pérez specified in his will that "500 varas in frontage by the river" [on the south bank] be given to Francisco Antonio Ruiz for services he had rendered to Ygnacio Pérez. According to Pérez's will, "these lands have some buildings on them" (BCA Probate Records Vol. D, red:169-177). It is not clear whether Pérez specifically meant that the structures were located on the 500 varas or on other parts of the four-league grant. Further archival research revealed that Francisco Antonio Ruiz paid taxes on this property (the land where the barn is; Bexar County Tax Assessor-Collector's Records, County B Tock 4300, Parcel 1). It is interesting to note that the 500 varas lie directly across the Medina River from the Ruiz property on the north bank (see 41 BX 344 ).

Enoch Jones: Enoch Jones, born at Worcester, Ohio, in 1802, was the son of Thomas G. and Susana (Jones) Jones. Principally self-educated, he entered the grocery store business under Mr. Alexander. As a young man, Jones secured the contract to construct the locks on the western division of the Pennsylvania Canal. Previous to this, he constructed the dam at Johnstown, one of the first large reservoir dams ever constructed in this country. After his engineering work on the Erie Canal, he moved to Detroit, Michigan, where he started a store in the city and engaged in lumber manufacturing (Chabot 1937:318).

Sometime around 1835, Jones emigrated to Texas and settled on the Brazos River where, in partnership with John Smith, he acquired tremendous holdings in cheap land (DRT Enoch Jones File).

On September 1, 1837, Jones, in partnership with John Smith, bought the headright of Francisco Rolen for one Teague and one labor of 1 and for the sum of $\$ 800$ (BCDR V01. B1:65-67). According to the deed purchase, Jones and Smith were to select such location as they deemed best. On August 12, 1838, William Lindsey surveyed the said league and labor for Jones and Smith on the south bank of the Medina River, the survey being No. 48 in Section 2. The survey contained 12 labors of arable land and 14 labors of pastureland (BCA Surveyor's Field Notes, Book Al:26).

In 1838, Enoch Jones married Miss 01 ive Ann Selkirk, the niece of John Vassar--founder of Vassar College. To this union, five children were born, only two of whom lived to maturity: 01 ive Ann and Flora Kate (Crimmins 1931).

In 1838 or 1839 , Mr. Jones returned to St. Louis, leaving John Smith, his partner, to conduct their business in Texas. In St. Louis, Jones entered the general merchandise and 7 umber trade. A year or so 7 ater, he expanded and opened a 1 ike establishment in Detroit (ibid.). When Smith died ca. 1845, Jones closed out the business in St. Louis and returned to Texas with his family. They 1 anded at Galveston on February 11, 1846, sailed to Port Lavaca, and then came to San Antonio (Chabot 1937:318). He immediately 
opened a general merchandise store on Main Plaza next to the Cathedral, renting the store and living in the same building (Crimmins 1931). At this time, Jones owned approximately 18,635 acres of land in the area.

In 1845, with his business expanded, he built a three-story building on the corner of Main Plaza and Market Street, giving the ground in the back of the store to the city for the erection of a market house (ibid.). Mr. Jones' partner in this business was Joseph Ulrich (Chabot 1937:318).

Jones advocated the issuance of script by the Republic of Texas and led the movement in buying large quantities. When the State was admitted to the Union the United States redeemed the script and paid Jones full value (Crimmins 1931).

In 1847, 01 ive Ann Selkirk Jones died and was buried in San Antonio (ibid.). In 1852, Jones married Charlotte Tompkins of San Antonio who, with her sister, had established a school in a small adobe home just north of the Cathedra1. In 1853, Mrs. Jones gave birth to twin girls--the first American twins born in San Antonio. Shortly thereafter, the Jones family moved into a home on South Flores Street.

On November 19, 1851, Jones (by partition deed) acquired the eastern half of the original Francisco Rolen headright, with the Smith estate acquiring the western half (BCDR Vol. Fl:73).

On May 12, 1858, Jones wrote his last will and testament in preparation for a trip to New York City. In the will, Jones wrote the following about the 1 and holdings on the Medina River:

First I wish my wife to have in full and absolute property all the household and kitchen furnishings of every description of which I may die possessed, the slaves at present in her name and also the full and entire use and control and enjoyment of my farm on the Medina river, and of the proceeds thereto during her natural life. And for the purpose of improving said farm by the immediate erection of a dwelling house and houses and such other improvements as may be deemed necessary. I hereby appropriate and set apart all of the lumber on the lot in San Antonio whereon I now reside so much as may be and in constructing the stone buildings and the proceeds of the balance of the lumber on said lot together with the further sum of five thousand to be paid by J. UTrich and Co. I hereby direct to be applied in the erection of such buildings and improvements. . . Fourthly I give to my wife one half of all the stock of sheep, goats, ? cattle and horses of which I may die possessed... (BCA Will No. 686:27).

In 1863, Jones died, and no further work was done on the home. His family continued to live on the property, and Mrs. Jones' sister, Mary Elizabeth Newton, and family, came to 1 ive with her. Samuel Newton, the husband of Mary Elizabeth, was the first Protestant minister to permanently settle and 
reside in San Antonio (Chabot 1937:159). During the Civil War, soldiers and officers stationed at present Von Ormy were frequent visitors to the home (Crimmins 1931). Subsequent owners of the property included Norbert Von Ormy; the Charpas; and T. B. Baker, president of the Baker Hotels in Texas (ibid.).

Norbert Von Ormay (Count Von Ormy): Very 1ittle factual information has been compiled on the man known as Count Von Ormy. According to early newspaper reports, an east European, Count Von Ormy, was a visitor to the Enoch Jones home in the 1860s or 1870s. He subsequently purchased the Jones home and/or farm on June 24, 1885, from the heirs of Enoch Jones for the sum of $\$ 19,000$ (BCDR Vo 1. 42:174-175). The Count then brought his wife, family, and about 20 servants to Texas the following year and established a "royal court" at the home (Crimmins 1931). Unfortunately, the Countess returned to Prussia(?) after a year (Webb 1952 Vo1. 2:846).

What happened at the "Von Ormy Castle," as the Jones home had now come to be called, is not quite clear. According to local stories, a stranger appeared at the Von Ormy home and for several days, both the Count and the stranger were secluded in the home. Not long after this, the Count sold the place (Crimmins 1931). Deed research reveals that on February 17, 1887, a supposed deed was executed by F. G. Seglict for Oscar Schmidt and Emme Schmidt to Count Von Ormy for a consideration of $\$ 40,000$, thus conveying his title to the Von Ormy home (BCDR Vol. 130:483). The 1and then passed from Schmidt to Charles S. Noyes on assumption of a note for $\$ 6000$ (BCDR Vo1. 59:142) on May 7, 1888. In July 1894, Count Von Ormy, through his attorney, $W . C$. Belcher, filed claim to recover the tract of 1 and he previously owned. Von Ormy claimed that Schmidt fraudulently obtained the land by pretending to give Von Ormy other property in Germany as a consideration but that the said property did not belong to Schmidt (BCDR Vol. 430:483).

In any case, the citizens of the small town located near the Von Ormy home were so impressed with the count that they named the small community after him--Von Ormy.

Site significance: The site is one of the most impressive historical architectural sites in the San Antonio area for the period of its construction. The historic complex represents an elite socioeconomic antebellum farm and ranch cultural development in the region. As a merchant and prominent entrepreneur, Enoch Jones was one of the few persons in the region who possessed extreme wealth and had access to material goods not available to most citizens (as such it would be interesting to compare and contrast the site with other antebellum farm and ranch complexes).

Management recommendations: In the opinion of the authors, this site is eligible for 1 isting on the National Register of Historic Places based on: (1) the association with events that have made a significant contribution to the broad patterns of our history; (2) the association with the lives of persons significant in our past; (3) the embodiment of the distinctive characteristics of a type, period, or method of construction and that possess high artistic values; and (4) the potential to yield information important in history. We recommend that a determination of eligibility should be sought from the Keeper. The site lies above the maximum flood pool level of the 
proposed reservoir. On-site inspections indicate that the main occupation structure is located within $15 \mathrm{~m}$ of the eroding margins of the proposed flood pool leve1, and the "barn" structure is located within $5 \mathrm{~m}$ of this proposed level. Severe erosion is already occurring here, and the added impacts of a potential erosional water source will cause immediate and destructive secondary impact to this complex (Glen Evans, personal communication). The authors further believe that increased accessibility from the north would possibly lead to vandalism of the site. Preservation of this site is a priority if the proposed reservoir is to be constructed.

Architectural evaluations (including scaled drawings based on the Texas Catalog, Historic American Building Survey [Goeldner 1974] criteria) are recommended as well as mapping of the site. Further archival research should be conducted on the "barn" structure (e.g., the Ruiz and Pérez holdings). It may be possible that blueprints of the structures are in existence (e.g., in family collections or archives such as at the University of Texas at Austin), and this should be investigated. A photographic record of the structures was begun in 1984; we recommend a more extensive record of al1 details. Archival research in 1984 led to the discovery of two early newspaper reports which contained pictures of four of the structures ca. 1930s-1940s. Attempts to locate the original pictures or negatives were unproductive; however, the authors feel that they may exist in unindexed portions of the San Antonio Express collections. Every attempt should be made to locate these pictures (if they still exist). Limited testing should be carried out in the area of the blacksmith shop in order to determine the presence and extent of subsurface foundations. Testing of early dumps would help to clarify socioeconomic status of the inhabitants and provide a comparative study to other antebellum sites in the study area.

\section{SITE 41 BX 665}

Type of site: Extensive prehistoric occupation zone. Early to Late Archaic occupations are known to have existed here; the possibility exists of earlier buried deposits.

Location: The site extends primarily along and above the 600 -foot contour ridgeline south of Von Ormy Road in the western portion of the study area. The margins of the site may have extended to the historic site $41 \mathrm{BX} 664$, but these marginal areas are extremely eroded and whatever prehistoric activity was located here is destroyed.

Elevations: $570-600$ feet above msl.

Topographic context: The site is located on a former terrace of the river.

Water source: During site occupations, the river channel is thought to have been within $100 \mathrm{~m}$ of the site; since then, the river channel has shifted northward in a series of lateral movements.

Vegetation and soil: The site is partially cleared (that which exists in a plowed field), although a portion of the site is overgrown with a dense 
growth of mesquite trees and thorny brush. In this latter area, erosion has seriously affected site integrity.

Site condition: Approximately $50 \%$ of the site area is seriously affected by natural erosion. The remainder of the site area may have a potential to contain intact deposits below the (disturbed) plow zone.

Artifactual materials present: The site can be described as a former prehistoric terrace occupation spanning a considerable time period. Although no features were observed, an extensive scatter of lithic debris was noted. Diagnostic lithic tools and projectile points collected include Langtry,

Pedernales, Marsha11, Bulverde, and Edwards(?) projectile points as well as Guadalupe and Clear Fork tools. As noted, portions of the site are extensively eroded; it is estimated that 1 ess than $50 \%$ of the site remains intact over ca. $400 \mathrm{~m}^{2}$.

Site discussion: Site 41 BX 665 represents an extensive prehistoric occupation locale associated with a long period of activities (Early Archaic to Late Prehistoric). The site location and physiographic context should be of significant interpretive value in postulations of site patterns and distributions within the study area.

Site significance: Site 41 BX 665 is located well beyond the elevations to be impacted by the proposed reservoir. As noted, the potential of the site is derived from an identification of its chronological associations and interpretations toward intersite patterns within the proposed reservoir.

Management recommendations: In the opinion of the authors, this site is potentially eligible to be listed on the National Register of Historic P1aces. No further work is recommended at this time as the site location is presumed to be well beyond the maximum flood pool impacted areas of the proposed reservoir. This site represents one of the largest prehistoric occupation zones within or adjacent to the project area. Its cultural resources indicate a span of occupations of over 5000 years, and an understanding of this site is important to any interpretations of the areal prehistory.

\section{SITE 41 BX 666 (Applewhite/Mullens Home and Farm)}

Type of site: The historic component is the Applewhite home and farm complex, and a prehistoric component underlies the historic.

Location: South of Neal Road in the eastern margins of the proposed reservoir and south of the Medina River, ca. $2 \mathrm{~km}$ west of the proposed damsite.

Elevation: $540-550$ feet above msl.

Topographic context: The site apparently was situated on an old alluvial floodplain. A historical seep spring is known to have existed in the locality. 
Water source: A spring is located ca. $25 \mathrm{~m}$ northeast of the historic site area. A well or cistern is thought to be located in the vicinity of the historic component but is as yet unidentified.

Vegetation and soil: Practically all of the site area has been cleared; vegetation consists of short grasses and an occasional mesquite tree along the site margins. The soil is a sandy, fine-grained material.

Site condition: Historic structure is occupied. Prehistoric component is disturbed by modern farming.

Artifactual materials present: A variety of prehistoric artifacts was observed in the landowner's possession; a11 were collected in the immediate site area and include Angostura, Pedernales, Langtry, Perdiz, and Scallorn projectile points and Clear Fork tools. The Angostura was reportedly collected ca. three feet below the surface while excavating a stock tank in the center of the site area several years ago. Historic artifacts collected by the owners include a copper/brass bell and fragments of glass resembling window pane glass.

Site discussion: The site was identified in 1984. The site consists of both a historic house structure (Fig. 40,a,b) and an extensive prehistoric activity area. The prehistoric component, ca. $300 \mathrm{~m}^{2}$, is not clearly defined and may extend southward into neighboring properties. Prehistoric activity areas in ca. $40 \%$ or more of the site area have been disturbed by modern farming (plowing); deeper deposits may remain intact below the plow zone.

The historic component is a single-story stone and adobe home built ca. 1870s by the Applewhite family, an influential Anglo-American family that attempted to develop a southern farming-plantation complex in the study area (see 41 BX 538 for a further discussion of the fami1y). The historic structure (of tannish fieldstone) was original1y two 16 -foot rooms joined by a "dogrun" between the two sections. Fireplaces are located in both gable ends on the west and east sides of the house. One 9-over-9 window is located on the northeast side with a second window located on the west side. Renovations to the home by Mr. and Mrs. Ike Mullens, present owners, and Applewhite descendants, included enclosing the "dog-run" with frame, adding a porch on the north side, an enclosed porch on the south side of the structure across the full length of the house, and a frame addition on the southwest corner of the house. Electricity has been added to the home.

Located approximately 50 feet from the west side of the house are portions of an old wagon road which has severely eroded. Archival research revealed that portions of the old El Camino Real (the 01d Presidio de Rio Grande Road or Lower Presidio Road) formed the southeast boundary of the grant upon which the house sits and runs due west of the structure (BCA Surveyor's Field Notes, Book A1:25; A5:442).

The 1 and on which the historic structure sits was headrighted to Bruno Martinez in 1837 (BCA Headrights, No. 36) and originally surveyed for John W. Smith, attorney and assignee of Martinez on August 2, 1838 (BCA Surveyor's Field Notes, Book A5:442). Archival research revealed that a second assignee, John R. Cunningham, received the same property on May 4, 1938 (BCDR 


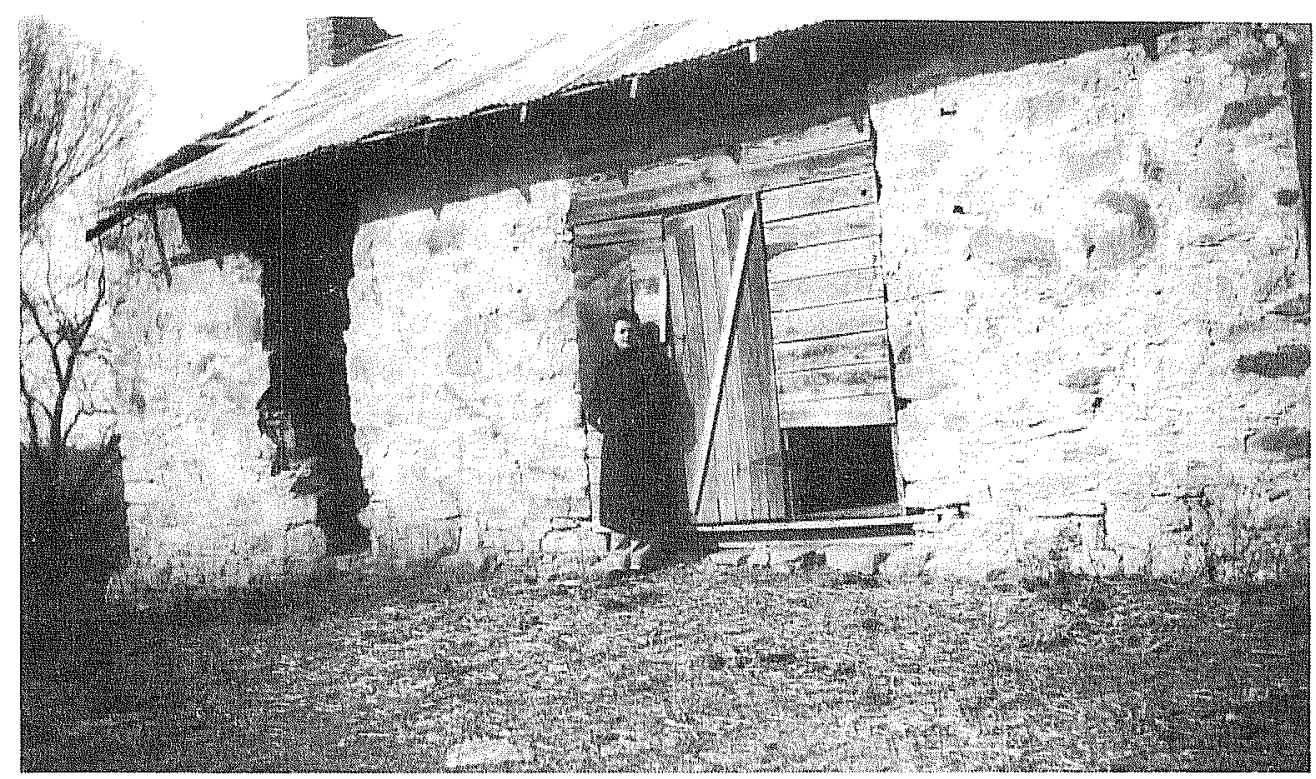

a

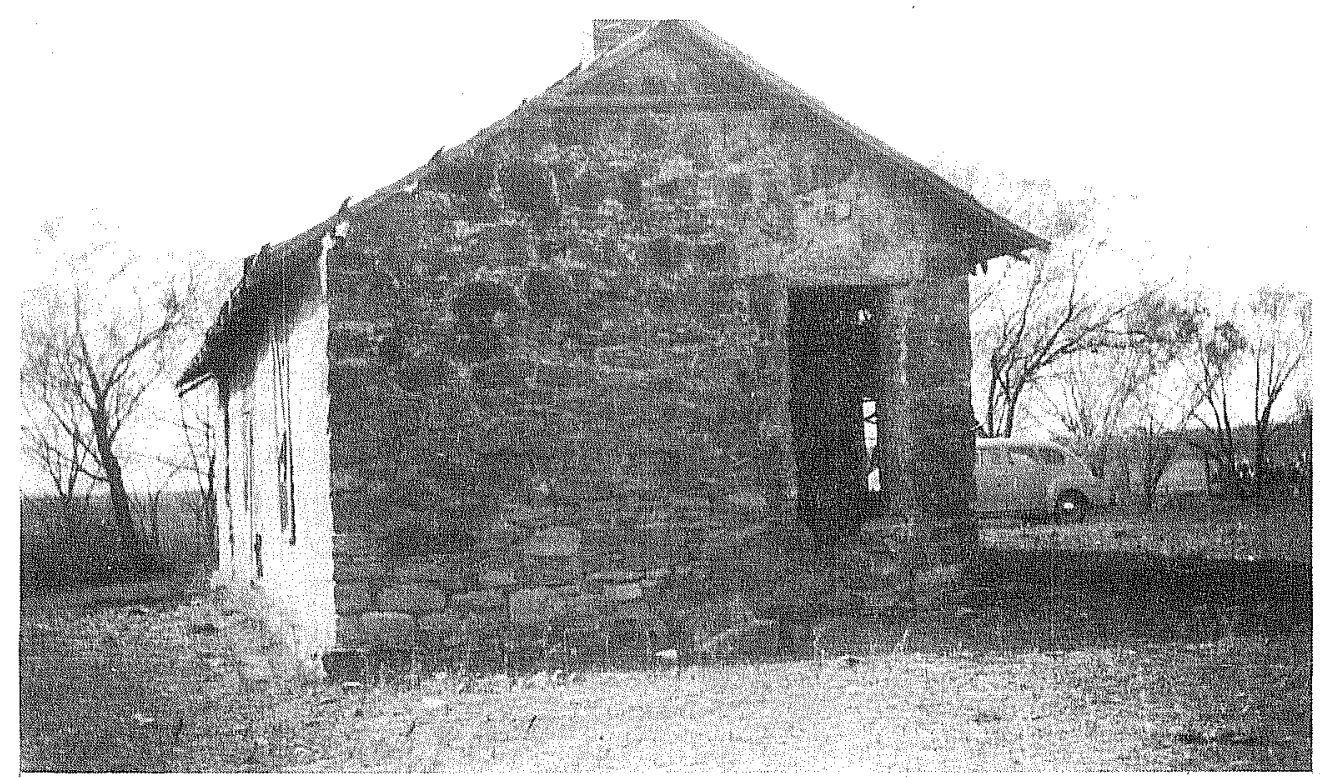

b

Figure 40. Views of Historic Structure at 41 BX 666. a, rear view, looking north; b, side view, looking west. Photographs courtesy of landowners, ca. 1953-1954, prior to renovation. 
Book L2:231). Cunningham patented the property on September 22, 1852 (ibid.). Stephen Applewhite and Harrison(?) Presnall bought the $1 / 3$ league from Cunningham's heirs for $\$ 321$ on February 4, 1854 (BCDR Book L2:232). Deed research revealed that Stephen and Eliza Applewhite bequeathed the property to their son Thomas Carroll Applewhite on February 10, 1872 (BCDR Book W1:473). The present owners of the property are Mr. and Mrs. Ike Mullens. Mrs. Mullens is the granddaughter of Thomas Carroll Applewhite.

Outbuildings, at present, consist of a modern garage, one garage with \#117 siding (slightly older than the other structures), a shed, and two modern trailer houses. Several years ago, the Mullens, while doing some work north of the historic structure, uncovered foundations of a second structure at ca. $16-35 \mathrm{~cm}$ under the present ground level. Large stones which appeared to be laid with an adobe mortar and glass sherds which resembled window panes were encountered. Postulated function of this structure is a kitchen. Estimated site area for the historic component is ca. $200 \mathrm{~m}^{2}$.

Oral history interviews with Mr. and Mrs. Mullens revealed that antebellum slave labor and later tenant farmers had several small homes located in the southern margins of the site area. These have not been documented as they are located in currently inaccessible property.

Site significance: This site is one of three built in the study area by the Applewhite family. The historic structure is extremely representative of early vernacular architecture in the region ca. 1850-1870. It is somewhat unique in that most "dog-trots" were of $10 \mathrm{~g}$ construction or $10 \mathrm{~g}$ and stone construction as opposed to stone. The structure is further interesting in that the style is so radically different from the two other Applewhite homes in the study area (sites 41 BX 538 and 41 BX 669). The historic component offers an opportunity to study and document the antebellum slave holding population in the study area. The prehistoric component offers the opportunity to yield information which can be important to the prehistory of the area, in particular, the Late Paleo-Indian period.

Management recommendations: In the opinion of the authors, this site is eligible for listing on the National Register of Historic Places based on four criteria: (1) the association with events that have made a significant contribution to the broad patterns of our history; (2) the association with the lives of persons significant in our past; (3) the embodiment of the distinctive characteristics of a type, period, or method of construction; and, (4) the ability to yield information important to the prehistory and/or history of the area. We recommend that a determination of eligibility should be sought from the Keeper. State Archeological Landmark status is also proposed.

This site is located within the maximum flood pool level of the proposed reservoir. Given the extensive site area of both historic and prehistoric components and the significance of materials and historic structures relevant to the cultural development of the study area, further archival research is recommended for the historic component along with limited testing to determine the extent of the original complex. Architectural evaluation by a qualified architectural historian is recommended. Limited testing is also recommended for the prehistoric component to determine the extent and 
significance of subsurface deposits which appear to be deeply buried and to determine the potential eligibility to the National Register of Historic Places. Relocation of the historic structure may be warranted. $\frac{\text { SITE } 41 \text { BX } 667 \text { (Santisima Trinidad Church and Cemetery at Paso de las Garza's }}{\text { Crossing) }}$

Type of Site: Historic church and cemetery.

Location: The site is located along the northern terrace of the Medina River ca. 300 m east of the Paso de 1a Garza's Crossing. The cemetery is located on the slopes of the terrace below the former location of the Santisima Trinidad Catholic Church (ca. 1867-1920).

Elevation: ca. 550-570 feet above msl.

Topographic context: The site is located on an eroding former terrace. A11 graves appear to be situated on the slope. A local informant reports that some graves have already eroded due to natural erosional processes combined with cyclical flooding sequences of the river.

Water source: Not applicable. The former church location may have included a we11 or cistern feature but no evidence of this remains.

Vegetation and soil: The cemetery site is densely overgrown with tall grasses, thorny brush, and mesquite trees. The soil is quite eroded on the slopes and consists of a mixture of loose, sandy material and compacted, clayey subsoil.

Site condition: The location of the church structure is destroyed. The area has been used as a landfill by the city of San Antonio up until the last five or six years. The cemetery is abandoned and subject to erosion from water action on the steep bluff.

Artifactual materials present: None at church location; cemetery contains some tombstones and fences.

Site discussion: The cemetery was first surveyed in 1984 by a field team from the CAR-UTSA. The church location was identified by a combination of archival research and oral history interviews (as well as an on-site inspection with a former member of the church). Previous work and research in 1977 by John Leal, Bexar County archivist, produced a translated copy of the original sacramental records of the former Santisima Trinidad Church.

The site contains both the location of the church and the cemetery, which was original1y located behind the one-story wood frame Santisima Trinidad Church in use from approximately 1867 to 1920 . Oral history interviews with Adolph Herrera, direct descendant of B1 as Herrera, who donated the 1 and for the church and cemetery, revealed the possibility that an earlier church was constructed of stone and was a two-story structure (see 41 BX 674). Many of the tombstones from the cemetery are sti11 present, al though the majority have been destroyed by weathering or vandalism. In 1977, ca. 17 tombstones 
were legible enough to be recorded by John Leal. There appear to be at least 38 more graves, mostly unmarked, in the cemetery. The earliest recorded date was 1872; however, the burials probably date to ca. 1867. A 1ist of known burials is presented in Table 9. Local informants report that some burials may be as early as 1840 , but this has not yet been documented. Total site area for the cemetery is estimated at ca. $100 \mathrm{~m}^{2}$.

Site significance: The church was the earliest to minister to the predominantly Catholic population in the study area. The cemetery contains the graves of many of the early settlers in the area and was significant to the historical development of the region.

Management recommendations: In the opinion of the authors, this site is eligible for Tisting on the National Register of Historic Places. We recommend that a determination of eligibility should be sought from the Keeper. Portions of the site lie within the maximum flood pool level of the proposed reservoir. Recommended National Register of Historic Places eligibility is based on: (1) the association with events that have made a significant contribution to the broad patterns of our history; (2) the association with the lives of persons significant in our past; and (3) the ability to yield information important to the history of the area. Limited testing would define the limits of the burials. Relocation of the graves will be necessary if the proposed reservoir is constructed. Archival research in the Catholic Archives would be worthwhile to help further assess the church structure and its role in the study area.

\section{SITE 41 BX 668}

Type of site: Prehistoric occupation site.

Location: The site is located on the south bank of Elm Creek, ca. $1 \mathrm{~km}$ north of Loop 1604.

Elevation: 550-560 feet above msl.

Topographic context: The site encompasses a small knoll above the south bank of Elm Creek. The entire area has been cleared for farming; its present use is for grazing.

Water source: Elm Creek is ca. $300 \mathrm{~m}$ to the north of the site.

Vegetation and soil: Short grasses. The soil is a silty, clayey sand.

Site condition: The locale has been severely damaged by past land clearing and long-time cultivation. Natural erosion, in part accelerated by plowing, has caused extensive deflation on the (hil1) slopes of site 41 BX 668 . No area of the site is thought to contain intact cultural deposits.

Artifactual materials present: A light to moderate scatter of 1ithic debris and burned rock was noted on the upper portions of the knoll, ca. $200 x$ $300 \mathrm{~m}$. No features or diagnostic materials were collected, and the material distribution was thought to be deflated across the site area. 
TABLE 9. LIST OF DATA RECORDED FROM TOMBSTONES AT 41 BX 667*

Reyes, Paula H., born _ 15, 1886, died December 12, 1926, by family.

Reyes, Maria Juana, born Ju1y 12, 1873, died September 2, 1892.

Falon, Pablo, dates unreadable.

Juares children, Ciria Cay and Vincente, born 1922 and died 1926.

Gusman, Eduviges, died January 20, 1924, at the age of 28 years, stone from family.

Kenny, Ellen, born August 20, 1882, died November 17, 1883, stone from parents.

Lombrana, Concepcion, died Ju1y 20, 1925, at the age of 75 years.

Lombrana, Ursula Coe, died Apri1 13, 1906, age 57 years.

Gusman, Eugenio, born January 23, 1894, died October 23, 1918, stone from his wife.

Gusman, Margarita Castillas de, born October 15, 1865, died Ju1y 9, 1924, stone from her husband, Cecilio Gusman and children.

Leon, Antonio de, born November 9, 1918, died Ju1y 5, 1924.

Herrera, Mary a G., born January 5, 1890, died August 19, 1918.

Gusman, Juan, born June 25, died July 2, 1900, age 12 years, 8 days.

Garcia, Juan Antonio, died August, 1901, age(?), stone from wife and daughter.

Arraus, Antonio, born May 23, 1886, died June 3, 1913, stone from his mother.

Scanlan, Marget F., born(?), died June 4, 1886, age 54 years.

Scanlan, R. F., born January 13, 1868, died 1872 .

*Data recorded by John Lea], Bexar County archivist, March 1977. 
Site discussion: Site $41 \mathrm{BX} 668$ is believed to represent an area of 1 ight to moderately intensive prehistoric activities that included occupation and lithic reduction processes. Unfortunately, the lack of identifiable, chronologically diagnostic materials and extent of erosional impacts have caused deflation and have seriously affected site significance.

Site significance: At this date, the site's potential contributions to the local or regional archaeological record are considered to be marginal, given the extent of site disturbance and lack of identifiable, significant cultural materials.

Management recommendations: No further work is recommended at this site due to the extensive effects of 1 and clearing and erosion. The site does not meet the eligibility requirements to be listed on the National Register of Historic Places.

\section{$\underline{\text { SITE } 41 \text { BX } 669}$}

Type of site: Multicomponent.

Location: The site is located along the upper river terrace, south of the Medina River, ca. $1 \mathrm{~km}$ west of the proposed damsite.

Elevation: 500 to 530 feet above msl.

Topographic context: The site extends along the southern margins of the modern river channel. A major arroyo complex is located just west of the site.

Water source: The Medina River is $150 \mathrm{~m}$ maximum distance from the site and a minimum of $50 \mathrm{~m}$.

Vegetation and soil: Vegetation consists of thorny brush, tall grasses, and often dense mesquite trees. The soil is an aeolian deposit overlying silty, clayey, compacted materials.

Site condition: The main historic structure is in ruins and overgrown with thorny brush and mesquite trees. Approximately $70 \%$ of the total site area is estimated to be intact (historic and prehistoric).

Artifactual materials present: The prehistoric site component consists of an intensive terrace occupation that includes a scatter of lithic debris and eroding burned rock clusters, varying in size between 1-2 $\mathrm{m}^{2}$. Late Prehistoric alternately beveled bifaces, Perdiz arrow points/preforms, a circular stone biface manufactured from Tecovas jasper, and a Leon Plain ceramic sherd were collected at this site. Late Archaic Fairland and Montell projectile points as well as an exhausted(?) Clear Fork tool were also collected on Tater intensive resurveys. One button inscribed "orange colour," which dates to ca. 1820 s to 1840 s (see Material Culture), was surface collected. 
Site discussion: The site was first identified in 1984. The site area (ca. $200 \times 120 \mathrm{~m}$ ) may be related to the prehistoric sites $41 \mathrm{BX} 530$ to the west and 41 BX 531 to the east. If so, 41 BX 669 would then be considered the most intensive activity area of this occupation zone. Since much of the cultural material appears buried, such observations are considered preliminary. Intrusive Tecovas, or Quitaque, jasper from the Texas Panhandle suggests significant interpretive potential, and the possibility exists that this location may contain a historic Indian site component.

The historic site component consists of the stone ruins (ca. 20 feet $\times 40$ feet; Fig. 41,a,b) of one of three Applewhite family homes built in the study area during antebel1um Texas. A large stone-1ined underground cistern is located at the southeast corner of this structure. Visible outbuildings consist of a plastered stone corn crib. The main structure and cistern are densely overgrown with thorny brush and mesquite trees. Architectural scale drawings and mapping of the site were prohibited at the time of the original survey. A revisit to the site several weeks later revealed that portions of the stone walls were being knocked down (perhaps to salvage the stone). On the initial visit, the complex was photographed in detail. Extensive archival research was conducted on the Applewhite family (see 41 BX 666 and 41 BX 538). Oral history interviews were held with the present landowner to recall aspects of the site. An early painting of the main structure (abandoned and already deteriorating) revealed approximately $40 \%$ deterioration in ten years.

Site significance: Temporal associations for the prehistoric component include Late Archaic through Late Prehistoric, as suggested by surface collected diagnostic artifacts. Early occupations may underlie known deposits. Given the nature and extent of prehistoric diagnostic materials, a strong potential exists for the recovery of features significant to the regional archaeology.

The historic component represents an antebellum occupation by members of the Applewhite family, cotton farmers utilizing slave labor. The site offers an opportunity to examine more in depth this "semiplantation" contingent in the study area (e.g., socioeconomic status as revealed by material culture, architectural assemblages of southern immigrants to the study area, and 1 anduse patterns).

Management recommendations: The site lies with in the conservation pool level of the proposed reservoir. In the opinion of the authors, the historic component is eligible for listing on the National Register of Historic Places based on the potential to yield information important to the history of the area, the association with persons significant in our past, and the embodiment of the distinctive characteristics of type, period, and construction techniques. We recommend that a determination of eligibility should be sought from the Keeper.

In the opinion of the authors, the prehistoric component is potentially eligible for 1 isting on the National Register of Historic Places. Further work in the form of limited testing is recommended to clarify the potential for nomination to the National Register of Historic Places. Additional archival research on the Applewhite family would be useful (e.g., wills and 


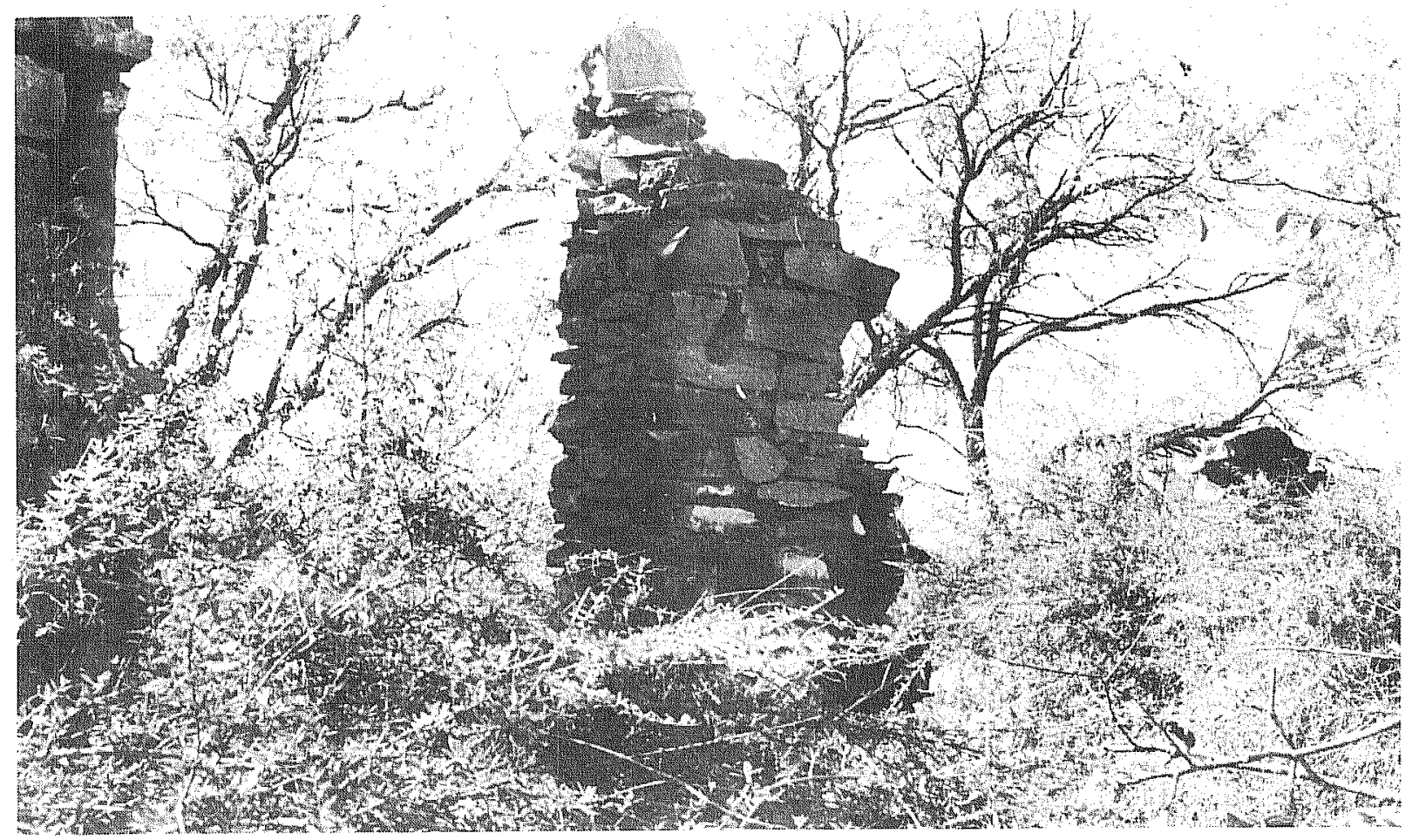

a

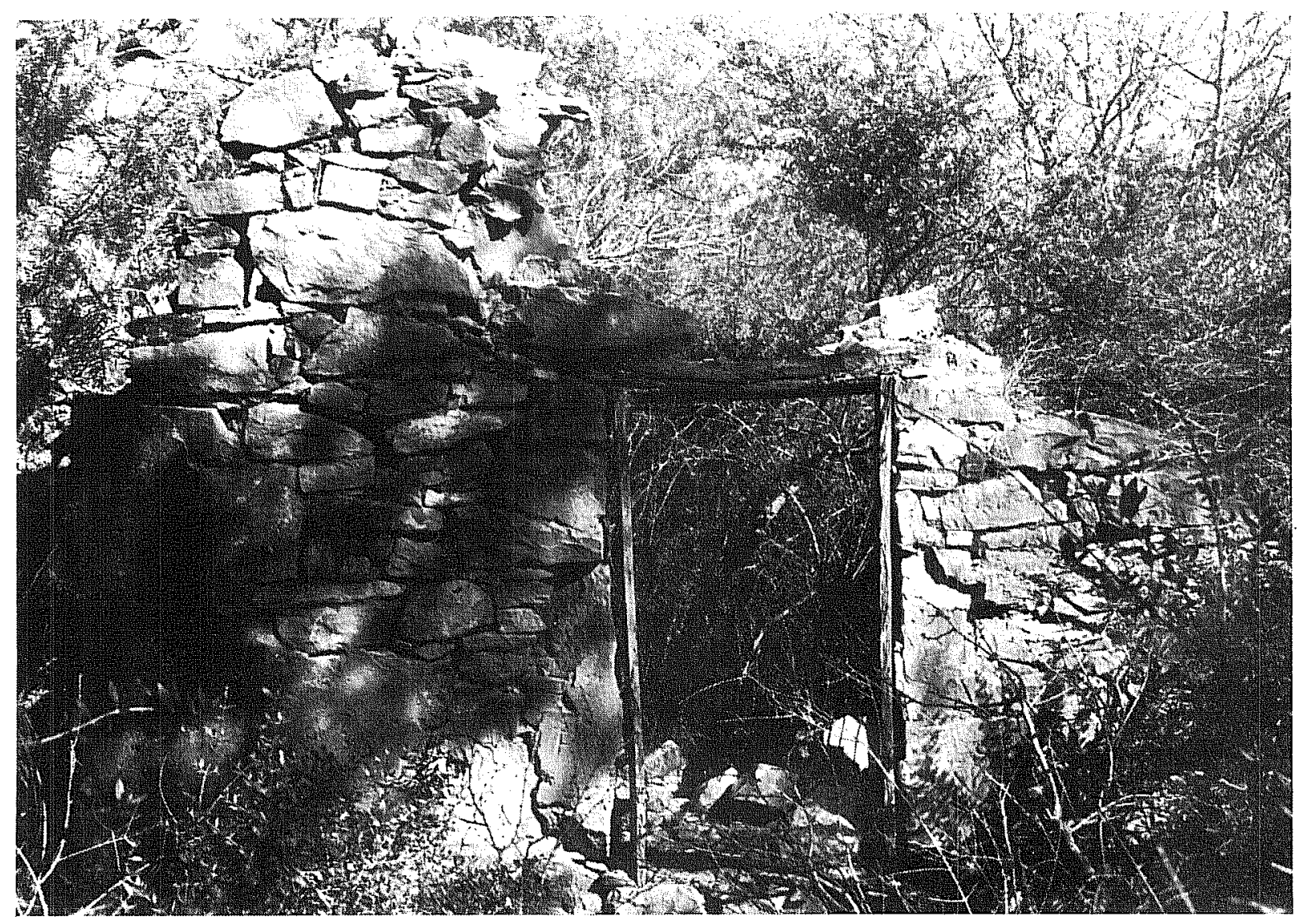

b

Figure 41. Stone Ruins at 41 BX 669. a, south wall remnant; b, wal1 with door. 
probates, further deed work). Scaled floor plans (if possible) and mapping are also recommended for the historic structures and component. If this site is confirmed to be of National Register status, mitigation by major excavation would be recommended.

SITE 41 BX 670 (B1as Herrera and María Josefa Ruìz Home)

Type of site: Historic ranch complex (ca. early to late 1800s).

Location: The site is situated north of the Medina River and south of the junction of Quesenberry Road and Somerset Road. The site is north of the Ruíz-Herrera Cemetery.

Elevation: 540 to 550 feet above ms 1 .

Topographic context: The site is located on the extreme margins of an extensively eroded steep terrace above the floodplain.

Water source: The Medina River is ca. 100-150 m from the site. A possible well or cistern may be in the immediate site area but remains undiscovered to date.

Vegetation and soi1: Mesquite trees, thorny brush, and cactus were noted. The soil is severely eroded along terrace margins.

Site condition: Approximately $80 \%$ of the site has been affected by 1 and clearing techniques (including bulldozing) and moderate to severe erosion along the terrace walls. None of the original structures are standing.

Artifactual material present: Artifacts observed but not collected included soft paste earthenware (one sherd ca. early 1800s), glass sherds, hard paste earthenwares, 19th-century ironstones, stoneware, rusted metal, and one dime dated 1967. Also noted were recent trash deposits on the eroding terrace.

Site discussion: The site was identified in 1984 from archival research and an oral history interview (in addition to an on-site inspection) with Mr. Adolph Herrera, descendant of Blas Herrera. The site consists of the historic farm and ranch complex occupied by Blas Herrera ca. 1840-1870 (and possibly much earlier). Structural features at the site are the foundation remains of a stone and adobe home, which has been seriously damaged by terrace erosion and bulldozing. A wooden frame house (ca. late 19th or early 20 th century) constructed of shiplap is to the north of the foundational remains of the stone and adobe home. Outbuildings consist of two wooden frame sheds and a set of corrals appearing to date to the same occupational sequence as the frame house. Artifactual materials suggest that the site has been occupied in recent years, although it is currently abandoned. Approximately $100 \times 150 \mathrm{~m}$ in size, a significant portion of the ranch complex may exist below the ground.

B1 as Herrera was born on February 2, 1802, to Benito Herrera from Punta de Lampasas and Jacoba Herrera de las Fuentes from San Fernando de Béxar (BCA Ruíz Files). He married Maria Antonia Ruíz, born 1809, the daughter of José Francisco Ruíz and Josepha (Hernández) Ruíz (Chabot 1937:199). 
When hostilities broke out in 1835, Juan Seguin formed a company of volunteers--among those who joined was Blas Maria Herrera (BCA Ruiz Files). He participated in the Siege of Bexar and took an active part in the Storming of Bexar (BCA Ruiz Files, Pension Claim). Blas was sent by Seguin to scout any Mexican troop movements along the Mexican border; about the middle of February 1836, he returned and reported that a large force of Mexicans was crossing the Rio Grande and marching toward the interior. Seguin immediately reported this to Colonel Travis and vouched for the integrity of his messenger (Williams 1933:387).

At this time, Blas received orders from Colonel Travis to escort and protect his father-in-law, Colonel José Francisco Ruiz, and José Antonio Navarro, to the convention at Washington-on-the-Brazos. Also sent for the same purpose were Francisco Gomez, Eusobio Garion(?), and Antonio (Coc?) Coe (BCA Ruiz Files, Pension Claim).

In a letter written to Blas by Jose Francisco Ruiz, his father-in-1aw from Columbia, on December 27, 1836, Ruíz warned:

Even though it might mean leaving your family, I would like for you to come if the Mexican troops should approach and you feel endangered. Anyway, you could be of no service to your family if you were killed or taken prisoner. If for any reason you should remain, then by no means should you take arms against the Texans. Give the same advice to your friends for only God could possibly return the territory of Texas to the Mexican government. Texas has the arms and money for her defense and shall remain forever free. . (Santos 1966:15).

According to the sworn testimony of Antonio Menchaca:

General Felix Houston [in late 1836] sent the order to destroy the City of San Antonio and to remove the families to the East of the Brazos River. Col. John K. Seguin then in command at that place selected Blas Herrera as bearer of the dispatch for General San Houston asking him the revocation of the order so disastrous for the citizens of that place. General Sam Houston having granted the request, Blas Herrera who in the middle of so many dangers threatening him had faithfully and happily fulfilled his mission was detained by General Felix Houston at camp Preston near LaVaca whereupon he was several times entrusted with delicate missions for different places and finally specially charged to attent on Col. Ruiz then Senator who had fallen dangerously sick (BCA Blas Herrera File).

A headright of one league and one labor of 1 and were granted to Herrera on December 6, 1837 (BCA Headrights, No. 455). On September 18, 1837, Herrera sold the headright to Juan Seguin for the sum of $\$ 800$ (BCDR Vo1. D1:113). Blas and Maria Antonia Herrera 1 ived on the land granted to her brother, Francisco A. Ruiz (see 41 BX 344). In 1849, Blas registered his brand "on the Medina" (BCA Records of Marks and Brands, Book A). 
María Antonia and BTas had nine children: (1) Jacoba, married Miguel de la Garza in 1850 (41 BX 673); (2) Francisco, married Luisa Ramirez (41 BX 344); (3) Benito, married Narcisa Calderón (41 BX 344); (4) Antonia, married Josiah Cass; (5) Blas, Jr., married Sabina Salinas (41 BX 671); (6) Juan José, died in San Antonio; (7) Manue1, married Refugia Tijerina; (8) José Maria, married Josefa Pérez; sister of Rumaldo (41 BX 672); and (9) Josefa, married Fernando Sandoval (Chabot 1937:199-200).

B1 as Herrera donated the 1 and on which the Santisima Trinidad Church was built (site 41 BX 667). He served as a Justice of the Peace of Bexar County, and was elected road reviewer (BCA Ruiz Files). On July 9, 1879, Blas Herrera died at the age of 77 years. Father Julio Sayet signed the church records book (BCA Santisima Trinidad Church Burial Records, 1867-1905). He was buried at the Ruiz-Herrera Cemetery on the Medina River (site 41 BX 543). The property (128 acres) on which the home was located was deeded to ManueT Herrera, son of Blas and Maria Antonia Ruíz de Herrera on December 1, 1883 (BCDR V01. 32:612). The property remains in the possession of the RuizHerrera descendants.

Site significance: This site represents one of a series of occupations in this area of the Medina River valley by members of the Ruiz-Herrera family for possibly over 200 years. Research has definitely established occupation at site 41 BX 670 by Blas Herrera and his family since at least 1849 . The farm and ranch complex represents a distinctive socioeconomic component in the study area.

Management recommendations: In the opinion of the authors, this site is eligible for listing on the National Register of Historic Places based on: (1) the association with the 1 ives of persons significant in our past, and

(2) the potential to yield information important to the history of the area. We recommend that a determination of eligibility should be sought from the Keeper. The site lies within the maximum flood pool level of the proposed reservoir. Limited testing is recommended to establish temporal associations as defined by archival research, oral history interviews, and preliminary artifactual analysis. Further archival research on Blas Herrera and his family is recommended (e.g., primary sources such as wills and probates, and further deed records searches). Preliminary archival research reveals that a Spanish grant was made to the Ruiz family as early as 1774 in this area (see $41 \mathrm{BX} 344)$. Further searches of primary documents in the Texas General Land Office and the Bexar Archives are recommended. If warranted, mitigation of the site may include major excavation.

SITE 41 BX 671 (B1as Herrera, Jr., and Sabina Salinas Home)

Type of site: Historic.

Location: The site is located ca. 75 m northeast of the juncture of the Medina River and Somerset Road.

Elevation: 540 to 550 feet above msl. 
Topographic context: The site is located on the margins of an extensive arroyo complex north of the Medina River and just east of Garza's Crossing. The uplands extend northward from the site.

Water source: The Medina River is ca. $75 \mathrm{~m}$ south of the site. A cistern or we11 is thought to possibly exist, as yet undetected, in the vicinity.

Vegetation and soi7: Mesquite trees, huisache, and prickly pear dominate the vegetation in areas that have not been extensively cleared for farming. The soil is a moderately compacted clayey, fine-grained material.

Site condition: The site is extensively damaged by modern 7 and clearing. This site is located adjacent to the area used as a 1 andfill by the city of San Antonio (see 41 BX 667).

Artifactual material present: None observed.

Site discussion: This site was first identified in 1984 by a combination of archival research and oral history interviews (in addition to an on-site inspection) with Mr. Adolph Herrera. The site is extensively disturbed, and is only indicated by a few scattered stones lying on the surface. The home was apparently situated just east of the old original Somerset Road (Laredo Road) that served the early settlers in the area of Garza's Crossing (41 BX 697). Blas Herrera, Jr., and his family are some of the earliest settlers in the western portion of the study area. He served in the 30 th Brigade Medina Guards during the Civil War and reestablished a ferry at Garza's Crossing in 1875 (BCA Commissioner's Court Minutes Vol. 3A:560-561). The property (129 acres) of Blas Herrera, Jr., was deeded to him on December 1, 1883, by Maria Antonia Ruíz de Herrera as part of a subdivision of the Francisco Antonio Ruiz survey (BCDR Vo1. 32:612; for a further discussion of the Herrera and Ruiz families, see 41 BX 670 and 41 BX 344; a7so see 41 BX 697 for a discussion of Garza's Crossing).

An early painting of the home done by Damaso Hernández in 1952 shows the structure in relatively good condition. The structure appears to be a single story home with a shed porch supported by posts. The architectural 1 ines of the structure are very reminiscent of the ethnic Mexican vernacular architecture seen in the study area (see 41 BX 672).

Site significance: The site is one of a series of early occupations in the study area that formed the basis of the earliest community developments around the crossings of the Medina River.

Management recommendations: In the opinion of the authors, the site is potentially eligible to be placed on the National Register of Historic Places based on: (1) the association with events that have made a significant contribution to the broad patterns of our history; (2) the association with the lives of persons significant in our past; and (3) the potential to yield information important to the history of the area. The site lies within the maximum flood pool level of the proposed reservoir. Limited testing is recommended to determine if any structural features remain buried beneath the ground as well as any associated artifacts. Further archival research would contribute to a more precise assessment of the significance of the site and 
family to the area's history. If warranted, major excavation is recommended if the proposed reservoir is constructed.

SITE 41 BX 672 (BTas Herrera/José María Home)

Type of site: Multicomponent prehistoric and historic occupation site.

Location: The site is located a short distance west of Garza's Crossing and north of the Medina River in the western portion of the study area.

Elevation: ca. 550 to 570 feet above msl.

Topographic context: The site is located on the margins of a high bluff overlooking the floodplain and modern channel of the Medina River. An extensive arroyo complex was once located adjacent to and just west of the site area but this has been filled by modern land alterations.

Water source: The Medina River is ca. $100 \mathrm{~m}$ south of the site. The historic component includes a filled well (cistern?) behind the structural features.

Vegetation and soil: The site has been cleared by many years of occupation as well as land clearing and landfilling along the site margins. Vegetation consists of short grasses.

Site condition: The prehistoric component is largely destroyed by bulldozing and landfilling. The historic component is maintained by the present owner.

Artifactual materials present: Rotting lumber, scrap metal.

Site discussion: The site was first identified in 1984 . The site consists of two one-story homes built ca. 1840 by Blas Herrera on land originally granted to Francisco Antonio Ruiz in 1838 and possibly to the Ruiz family as early as 1774. A third home of wood frame (board and batten) is also located here and a wood frame barn structure. An earlier barn was located just northeast of the present barn according to the present landowner and Herrera descendant. The two homes are representative of the early ethnic Mexican vernacular architecture known as adobe palisado or chamacuero, an elaboration of the simple jacal in use in the 18th and early 19th centuries in San Antonio. Adolph Herrera (personal communication) described the method of construction:

Long cedar poles were cut and then placed vertically in the ground where windows or doors were to be located--subsequent poles were placed every 2 to 2-1/2 feet. Cypress from the river banks was then cut for shingles and small cypress strips were placed horizontally between the cedar poles, using pegs or square nails. Stones, broken into small chunks, were then placed in between the poles/strips using adobe. The adobe was then pressed/thrown in to fill any chunks remaining--the whole wall was then smoothed with the adobe. Plaster made from $1 \mathrm{ime}$, sand (fron the river), cactus 
(prickley pear; cut and stripped), salt, and water, was then applied to the walls, with the final stage being that of whitewashing.

Of the two adobe palisado structures, the northernmost one is in the best condition. The structure located to the south has been extensively altered (a large pavilion has been added onto one side). The second structure has had minor alterations but these do not severely affect the integrity of the structure (Figs. 42). The two homes reportedly were partially constructed with scrap wood obtained from the Alamo (ca. 1836-1837) or during the U.S. Army reconstruction period (1846-1849). The interior floor plan consists of two rooms, each with a fireplace along the west wall (Adolph Herrera, personal communication). A filled well lies to the east of the two structures and is marked by a depression on the ground surface. This property (128 acres) was deeded to José María Herrera, son of Blas Herrera and María Antonia Ruiz de Herrera on December 1, 1883. The deed from Maria Antonio Ruiz Herrera was part of a subdivision of the Francisco Antonio Ruiz survey (BCDR Vol. 32:612). The property is currently owned by Mr. Adolph Herrera, a great grandson of Blas Herrera.

The site area is ca. $100 \mathrm{~m}^{2}$; the original rancho complex with postulated outbuildings could easily extend to $200 \mathrm{~m}^{2}$ or more. Extensive archival research, oral history interviews, and a scaled floor plan were conducted on the property in 1984.

Large wooden gates, $4 \times 8$ feet each, were also observed at this site. The origins of these badly weathered gates (Fig. 43) are not known, although interviews with the landowner suggest a local San Antonio mission. The workmanship, technique, and style of the gates are representative of the Spanish colonial period. The massive construction and size of these gates preclude their use as anything except within a large exterior entranceway (perhaps a main gate).

The extent of current background research could not accurately determine specific origins of these gates; it is possible that such documentation exists, either in the personal records of the descendants or in architectural records of the San Antonio missions themselves, if they still exist. It is an interesting speculation that the gates are from the same source as the remainder of the scrap wood and that they were in actual use in the early 19th century at San Antonio de Valero and perhaps at the Battle of the Alamo in 1836. In January 1986, Kevin Young, curator and historian at Presidio La Bahia at Goliad, Texas, in personal communication with the authors, postulated that a major construction episode of Spanish colonial fortifications along the Texas frontier apparently took place during the early 19th century following an increase in militarism and Indian hostilities. Young suggested that the walls of Mission San Antonio de Valero may have been strengthened at this time along with extensive constructions on the south wall of La Bahia, possibly by the same engineers duirng this short time. It is interesting to note the reconstructed main entranceway at Presidio La Bahia is of a similar design and size as the artifacts at 41 BX 672 . The individual entrance gates of La Bahia, when compared to those of the study area, have dimensions that vary by less than $15 \mathrm{~cm}$. 


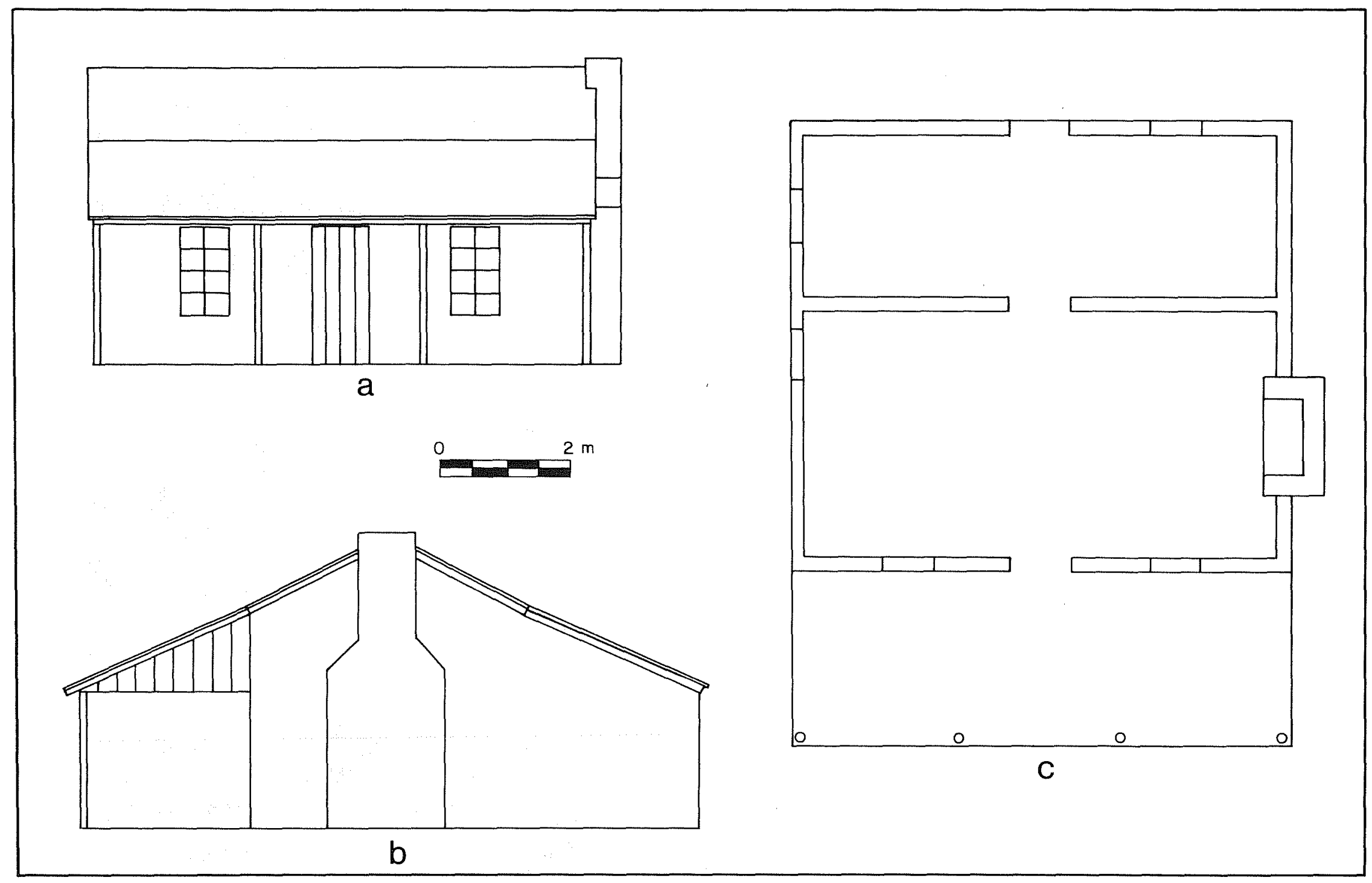
complex; b, side plan; $c$, floor plan of structure. 
Site significance: The site is one in a series of occupations in this area of the Medina River valley over the 1 ast 140 years and possibly as $10 n g$ as 200 years ago by members of the Ruiz-Herrera family. The homes are situated adjacent to Garza's Crossing and are a part of the original settlement that developed around the crossing. The one historic structure is an extremely fine example of the ethnic vernacular architecture of the area and/or region in the late 18th or early 19 th century and as such offers a unique opportunity to study construction techniques of this type of structure.

Management recommendations: In the opinion of the authors, this site is eligible for 1 isting on the National Register of Historic Places based on: (1) the association with events that have made a significant contribution to the broad patterns of our history; (2) the association with the lives of persons significant in our past; (3) the embodiment of the distinctive characteristics of a type, period, or method of construction; and (4) the potential to yield information important to the history of the area. We recommend that a determination of eligibility should be sought from the Keeper. Limited testing is recommended (particularly in the well area) in order to help clarify postulated occupational sequences as well as structural and/or site limits. Further archival research on the Ruiz-Herrera family would contribute to interpretations of the history of the study area. Archival research might also be able to authenticate the Spanish colonial

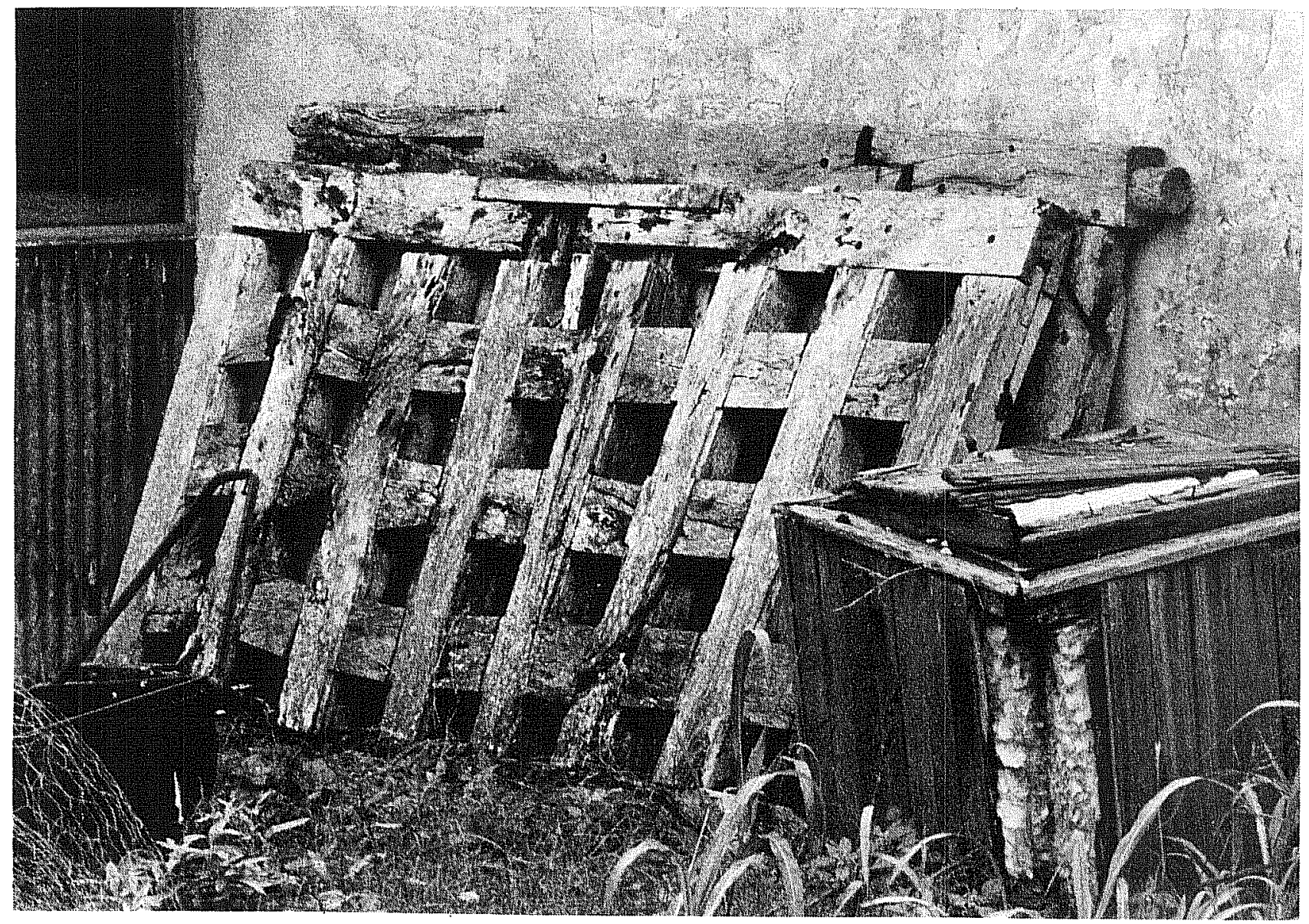

Figure 43. View of Large Wooden Gates at 41 BX 672. 
gates and should be undertaken. Mapping and architectural evaluation by a qualified architectural historian are recommended. The main portion of the site lies above the maximum flood pool level of the proposed reservoir. However, it is the belief of the authors that severe secondary impacts in the form of erosion with subsequent slumping along the extensive arroyos located directly behind the area will greatly affect this site. Preservation of the site should be considered a priority if the proposed reservoir is to be constructed.

SITE 41 BX 673 (Miguel de la Garza Home)

Type of site: Historic occupation.

Location: The site is located north of the Medina River and east of Garza's crossing in the western portion of the study area.

Elevation: 540 to 550 feet above ms 1 .

Topographic context: The site is located on the eroded margins of a terrace complex adjacent to the north bank of the Medina River.

Water source: The Medina River is ca. $75 \mathrm{~m}$ south of the site. A well or cistern may be located in the site area, however, no evidence of this was found during intensive surveys.

Vegetation and soil: Mesquite trees, huisache, whitebrush, and prickly pear dominate the flora. The soil is eroded along arroyo slopes.

Site condition: The site is extensively damaged by erosion and landfilling activities.

Artifactual materials present: Recent trash deposits. Older deposits may underlie the recent dumping.

Site discussion: The site was first identified in 1984 from a combination of archival research and oral history interviews. The site is reported to be the home of Miguel de 1 a Garza and Jacoba Herrera de 1a Garza, daughter and son-in-1aw of Blas Herrera. Miguel and Jacoba married in 1850 (BCA Marriage Certificate \#486), and the structure would probably date at least this early. The land on which the site is located was again part of the extensive grant to Francisco Antonio Ruiz in 1838. Preliminary research reveals that the 1 and may be a part of the extensive Spanish grant in this area to the Ruiz family ca. 1774 (see 41 BX 344). The site is 1ocated just northeast of the area known as Garza's Crossing (41 BX 697). Miguel de la Garza established a ferry at this location at an unknown date; by 1875 he had already abandoned the ferry (BCA Commissioner's Court Minutes Vo1. 3A:560; see 41 BX 671 and $41 \mathrm{BX} 697$ for a further discussion). The property was deeded to Jacoba Herrera de 1a Garza in 1883 by Maria Antonia Ruiz Herrera during a subdivision of the Francisco Antonio Ruiz survey (BCDR Vol. 32:612).

Site significance: The site is one of a series of sites located adjacent to Garza's Crossing which formed the basis of the first small communities 
located in the western margins of the study area. The 1 and has been in the possession of the Ruiz-Herrera families since at least 1838 and possibly as early as 1774 .

Management recommendations: In the opinion of the authors, the site is potentially eligible to be listed on the National Register of Historic Places based on: (1) the association with events that have made a significant contribution to the broad patterns of our history; (2) the association with the lives of persons significant in our past; and (3) the potential to yield information important in history. Limited testing is recommended to determine the presence and/or absence of subsurface remains and to establish temporal associations (if possible). Further archival research on the de la Garza family as well as the Ruiz-Herrera families would help to clarify their significance in the study area. Primary documents research would be extremely beneficial. The site lies within the maximum flood pool level of the proposed reservoir.

\section{SITE 41 BX 674}

Type of site: Historic.

Location: The site is Tocated adjacent to 41 BX 667 , north of the Medina River, and ca. $300 \mathrm{~m}$ east of the modern Somerset Road.

Elevation: 550 to 560 feet above ms l.

Topographic context: The site is situated on the marginal uplands adjacent to a steep and eroded terrace remnant of the Medina River.

Water source: The Medina River is ca. $100 \mathrm{~m}$ south. A well or cistern is projected for the site area but has either been destroyed or buried by modern alterations.

Vegetation and soil: Natural vegetation has been cleared in the area, and only tall grasses remain over the site area. Natural soil cover has been disturbed or removed (or eroded) by land clearing.

Site condition: Extensively altered and damaged by mechanical brush clearing. The site is directly adjacent to the area used by the city of San Antonio as a landfill.

Artifactual materials present: None observed.

Site discussion: The site was identified in 1984 by the combination of archival research and oral history interviews. A scatter of 1 imestone rocks in a roughly rectangular pattern indicates the remains of this site; possible foundations may exist below the surface. An oral history interview with Mr. Adolph Herrera, descendant of the Ruiz-Herrera families, revealed the possibility that the site may represent the original Santisima Trinidad Church at Paso de las Garza's Crossing, ca. 1867 (see 41 BX 667). Archival research confirms the location of a structure at this site in 1883 but suggests that it might be a store (BCDR Vol. 32:612). Mr. Herrera recalls that the 
structure was of stone and was a two-story structure; it was already in ruins ca. $1920 \mathrm{~s}$. The site area is ca. $50 \times 75 \mathrm{~m}$. If portions of the site remain intact, they are in a subsurface context. No shovel testing was performed at the site.

Site significance: The site is one in a series of sites in this immediate area (Paso de las Garza's Crossing) that formed the basis of the earliest community development in the western portion of the study area.

Management recommendations: In the opinion of the authors, the site is potentially eligible for the National Register of Historic Places based on: (1) the association with events that have made a significant contribution to the broad patterns of our history, and (2) the potential ability to yield information important in history. Limited testing is recommended to determine the possibility and extent of buried foundations. Further archival research is needed to clearly assess the primary use of the structure (records at the Catholic Archives may contain information about the Santisima Trinidad Church). Other oral history interviews with descendants and 1ocal informants would be considered beneficial in helping to assess the site's relationship to the area cultural development. The site lies within the maximum flood pool level of the proposed reservoir.

\section{SITE 41 BX 675 (Thompson Burial)}

Type of site: Historic cemetery.

Location: The site is located ca. $1 \mathrm{~km}$ east of Highway 16 and south of the Medina River.

Elevation: ca. 550 to 570 feet above msl.

Topographic context: The site is located in upland margins adjacent to high terraces on the south bank of the Medina River.

Water source: Not applicable.

Vegetation and soil: Unknown.

Site condition: Unknown.

Artifactual materials present: Unknown.

Site discussion: The site consists of a small cemetery of at least two burials. An 8-x 12-foot spiked metal fence surrounds one of these burials, and the long axis of the fence is east to west. A stone tombstone 30 inches high, 14 inches wide, and semicircular at the top marks one gravesite. A footstone was also noted. The tombstone is inscribed: In Memory of, Louisiana J., Wife of H.L. Thompson, Born Sept. 25, 1818, died Jan. 27, 1863. Little other data is available at this time, particularly on the possibility of additional burials. Oral history interviews revealed that a Yoacum child and Stanfield child are also buried here (Anna Mae Gosch, personal communication). As noted, an on-site inspection of the cemetery and 
surrounding area is strongly recommended when access can be obtained into this property area.

Site significance: Not known at this time.

Management recommendations: No on-site inspections of this site were conducted as the current 1 andowner does not reside in the area and has not responded to attempts at contact. A11 information was obtained from local informants, and this data should be considered preliminary as discrepancies may exist, particularly in specific location. Given the nature of the site, historical burials, we strongly recommend that further on-site assessments occur as access is obtained.

\section{SITE 41 BX 676 (Cholera Burials)}

Type of site: Historic burial site.

Location: The site is located ca. $0.5 \mathrm{~km}$ east of Applewhite Road and north of the Medina River on the edges of a large pasture.

Elevation: 540 to 550 feet above mst.

Topographic context: The site is located in a large open area; marginal uplands border the site.

Water source: Not applicable.

Vegetation and soil: The entire site area has been cleared and, except for the specific site area, ca. $30 \mathrm{~m}^{2}$ or less, is composed of pastureland.

Site condition: cleared field.

Artifactual materials present: None

Site discussion: Little is known of this site other than the information derived from oral interviews with the present landowners. Several burials are known to exist in this area (exact number unknown). The burials are of people who died as a result of a cholera epidemic that swept the San Antonio area in the early 1900s. They are of either "ranch hands" or tenant farmers who were in the area at that time. Should further work continue on the development of the proposed reservoir, it is critical that this site area and its burials be mitigated.

Site significance: Unknown at this time.

Management recommendations: Further background research is needed on this location to determine the identity of individuals related to this site and to determine the potential eligibility status for listing on the National Register of Historic Places. Additionally, should the proposed reservoir become a reality, limited testing will be necessary to determine the exact number and location of burials. Proper state and county officials should be notified of these burials to determine a safe and responsible course of 
action. The site is located in the maximum flood pool level of the proposed reservoir.

\section{SITE 41 BX 680 (Ta7ón/Palo A7to Crossing)}

Type of site: Historic river crossing; component of early road network.

Location: The site is located ca. $1.5 \mathrm{~km}$ west of Highway 16.

Elevation: ca. 520 to 540 feet above msl.

Topographic context: Historic river crossing in the vicinity of Highway 16; location reflects a shallow, gravel riverbed area.

Water source: Not applicable

Vegetation and soil: Not applicable.

Site condition: Abandoned. The site was identified in 1984.

Artifactual materials present: None.

Site discussion: As noted in the Geomorphology section, historical fords are often located in the vicinity of modern crossings of the Medina River. Talon Crossing was first identified from a review of the original field survey notes of the $4 \times 1$ league grant of 1 and belonging to Ignacio Pérez on the south banks of the river in the early 1800s. (His heirs subsequently lost title to this property in the early 1850s.) Several specific survey reference points were identified, and Talón Crossing was identified as being ca. two leagues west of Pérez's eastern boundary. Today this location of Talón Crossing would be situated in the vicinity of modern Highway 16.

Intensive surveys in this area have identified an old roadbed and crossing in the vicinity of sites 41 BX 527, 41 BX 528, and 41 BX 529. While it was known that a crossing existed in this locality, it was presumed the crossing was of a much later period, ca. 1ate 19th-and/or early 20th-century origins. The Pérez survey records, written much earlier, indicate the crossing in this vicinity was in use and known as early as or earlier than late Spanish colonial times. The crossing is generally associated with a road identified as the Agua Negra Road (pre-1850) and later the Palo Alto Road (pre-1900).

A limestone-1ined roadbed (Fig. 44) was uncovered leading to the postulated crossing during reassessments of previously identified sites (41 BX 529). The estimated age of the roadbed is speculative, but it would compare to adjacent historical structures known to have been constructed during the 1800 s and perhaps related to the road network.

Site significance: The crossing is one of two in the study area which can be dated to the Spanish colonial period; as such its location offers a contribution to the study of the Spanish colonial period on a regional basis. At these crossings, often the first small communities developed in the study area. 


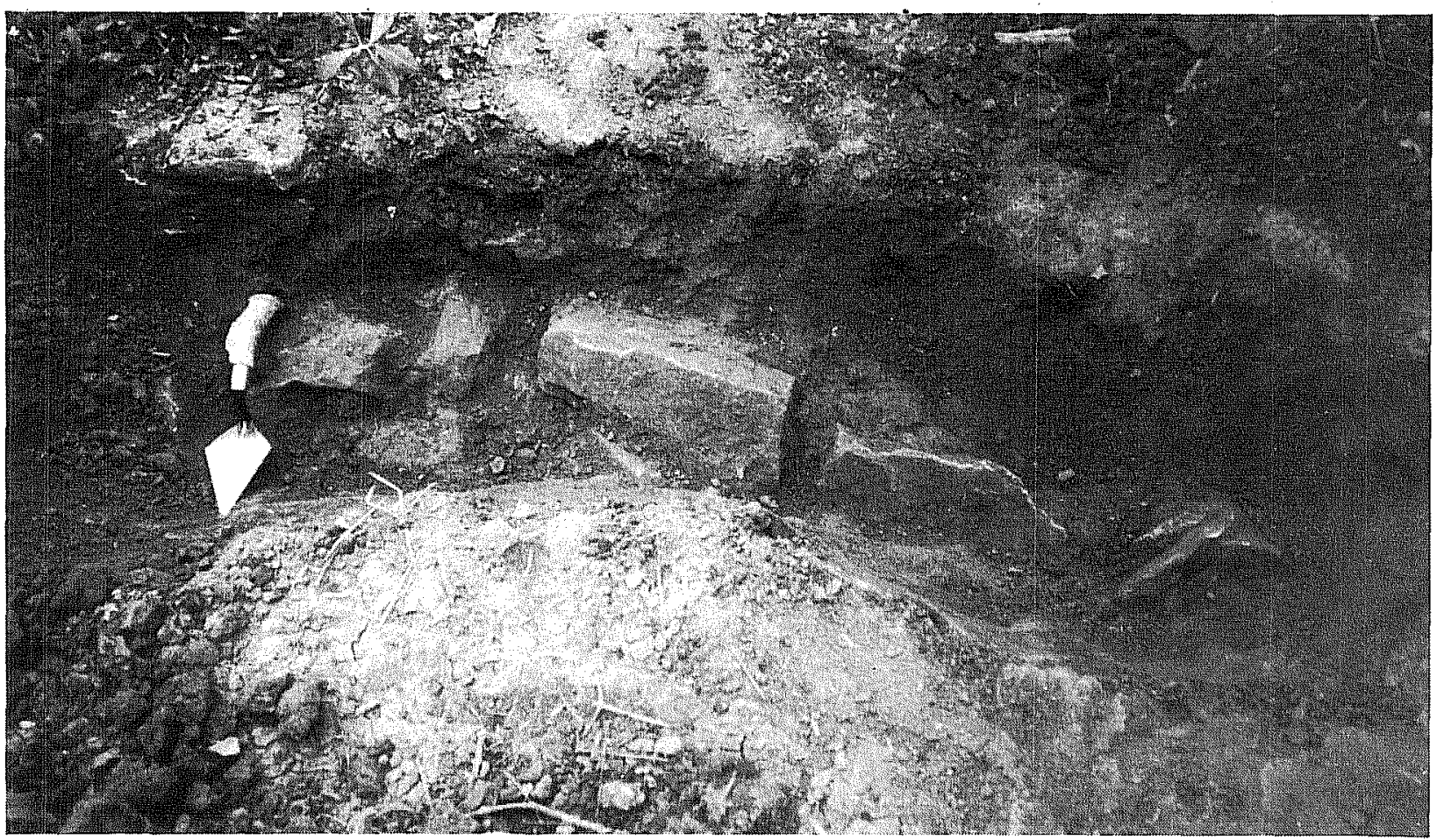

Figure 44. Evidence of Stone-Lined Roadway Leading to Ta1on Crossing, $41 \mathrm{BX} 680$.

Management recommendations: In the opinion of the authors, this site is eligible for listing on the National Register of Historic Places based on: (1) the potential to yield information important in our history; and (2) the association with events that have made a significant contribution to the broad patterns of our history. We recommend that a determination of eligibility to the National Register of Historic Places should be sought from the Keeper. The site is located in the conservation pool level of the proposed reservoir. Monitoring of this locality should be considered essential if the proposed reservoir is to be constructed.

\section{SITE 41 BX 681}

Type of site: Historic occupation complex.

Location: The site is situated in the uplands equidistant between Leon Creek and the Medina River, just east of Applewhite Road.

Elevation: ca. 560-570 feet above ms 1 .

Topographic context: The site is located in an upland context.

Water source: Cistern. 
Vegetation and soil: The entire site complex has been cleared of natural vegetation, and short grasses cover the site.

Site condition: Occupied.

Artifactual materials observed: None

Site discussion: The site was identified in 1984. The site consists of a ranch complex, including a stone dwelling and wooden frame outbuildings constructed in the early 20 th century. Still occupied, the structures represent a progression of changing occupations by members of the same family since the late 18th to early 19th century. The house is constructed partially of bricks manufactured at site 41 BX 662 and is composed of two floors. Additions through the years have somewhat modified the building but the basic design remains intact. A chapel is located inside the house which contains privately owned artifacts that date to the Spanish colonial period.

Site significance: The site is one in a series of occupations in the eastern portion of the study area by the Pérez-Linn-Walsh family over the last 185 years. The 7 and has been in the family's possession since 1754 or ca. 1780 (see $41 \mathrm{BX} 274$ ). The locale is significant to an understanding of the local cultural development of one of the most historically prominent families in the area.

Management recommendations: In the opinion of the authors, the site is potentially eligible to be listed on the National Register of Historic Places based on: (1) the association with events that have made a significant contribution to the broad patterns of our history; (2) the embodiment of the distinctive characteristics of a type, period, or method of construction; and (3) the potential to yield information important in our history. We recommend that a determination of eligibility to the National Register of Historic Places should be sought from the Keeper. The site is located above the maximum flood pool level of the proposed reservoir.

Architectural documentation and mapping of the site are recommended (blueprints of the home may exist and be in the possession of family members). Further research on the later members of the Linn-Walsh family would help to clarify the site's significance. Oral history interviews with the present occupants (if possible) would help to contribute to a better understanding of the historical features.

SITE 41 BX 682 (Dolores/Pérez/Applewhite Crossing)

Type of site: Historic crossing.

Location: The vicinity of the crossing is ca. $50 \mathrm{~m}$ to the east and to the west of the present Applewhite Road where it crosses the Medina River.

Elevation: 490 feet above ms 1 . 
Topographic context: Historic ford of Medina River that dates to Spanish colonial period. The river is unusually shallow and covered by gravel bars in this area, thus affording a (relatively) east crossing.

Topographic context: River bottom; grave1s.

Water source: Not applicable.

Vegetation and soil: Riparian vegetation along banks; gravel bars in river channel.

Site condition: In use.

Artifactual materials present: At present, a concrete bridge spans the river at this point.

Site discussion: The site was identified in 1984. This location represents one of the crossings of the Medina River in use since at least the late 18th century. Its location to the nearby Perez rancho (41 BX 274) makes it the most easy access to any locale south of the river in this vicinity. An early crossing in this vicinity was speculated since the recording of the historic site of the Spanish colonial Pérez rancho, but it was not until an intensive review of archival records and family historical documents that the crossing was verified. To the Spanish, the crossing was known as Dolores Crossing; subsequent names of Pérez and Applewhite came from the early landowners in the area. The crossing is one of the locations believed to have been fortified by rebels prior to and during the Battle of the Medina in 1813 and probably was the crossing mentioned by Arredondo stating his intentions to cross the Medina River and circumvent the main body of enemy rebels (see also 41 BX 520).

Site significance: The crossing is one of two in the study area which can be dated to Spanish colonial times. Few Spanish landmarks have been positively identified; as such, this research should contribute to future studies on the Spanish colonial period in the region.

Management recommendations: In the opinion of the authors, this site is eligible for listing on the National Register of Historic Places based on: (1) the potential to yield information important to our history; and (2) the association with events that have made a significant contribution to the broad patterns of our history. We recommend that a determination of eligibility to the National Register of Historic Places should be sought from the Keeper. The site is located in the conservation pool level of the proposed reservoir. Monitoring of this site should be considered a priority if the proposed reservoir is to be constructed.

\section{SITE 41 BX 697 (Paso de 1as Garza's Crossing)}

Type of site: Historic river crossing.

Location: The site is at the juncture of the Medina River and Somerset Road. 
Elevation: 510 feet above msl.

Topographic context: The river crossing location reflects a shallow gravel riverbed area.

Water source: Not applicable.

Vegetation and soil: Riparian river flora.

Site condition: Maintained and in use.

Artifactual materials present: Somerset Medina Bridge, Bexar County, erected 1914.

Site discussion: The site was identified in 1984 as one of three early river crossings in the study area. The Spanish referred to the areas as Los Encinos (TGLO Vo1. 43:119-121; BCDR Book E2A:67-71). José Miguel de la Garza (after whom the crossing was possibly named) operated a ferry at this site in the mid 1800s (BCA Commissioner's Court Minutes Vol. 3A:560). He abandoned the ferry operation ca. 1870-1875, and in 1875 Blas Herrera, Jr., was granted permission to reestablish the ferry (ibid.). Rates (BCA Commissioner's Court Minutes Vol. 3A:560) were established as follows:

For each loaded wagon, with one pair of animals $\quad .75$

For each empty wagon, with one pair of animals $\quad .50$

For each empty wagon, with additional animal belonging thereof $\quad .10$

For each loaded Mexican cart with two pair of animals or less $\quad .50$

For each empty Mexican cart with two pair of animals or less $\quad .50$

For each empty Mexican cart, additional animal thereto belonging .10

For each single horse and buggy, or two horses and buggy, carriage, ambulance or other convayance (sic)

For each additional animal thereto belonging

For each horse, mule, or jack-ass with rider

For each foot passenger

For a11 horses, mules, asses, cattle, hogs, or sheep driven or led the roud (sic), each per head

The ferry was located at the point where the public road to somerset lold Somerset Road or Laredo Road) crossed the river (just east ca. $50 \mathrm{~m}$ from the present bridge).

Paso de las Garza's was the point around which the first small settlement developed in the western portion of the study area. This settlement consisted mainly of family groupings such as the Ruiz-Herrera family, the de la Garza and the Guzman families.

The crossing is one of the sites postulated as having been utilized by the forces of General Santa Anna in 1836 on their way into San Antonio. Temporary camps were established at these crossings.

Site significance: The site is one of three early crossings in the study area. The historical development of the western portion of the study area 
was greatly influenced by this crossing. The site represents one of the historic engineering sites.

Management recommendations: It is the opinion of the authors that this site is eligible for listing on the National Register of Historic Places based on: (1) the association with events that have made a significant contribution to the broad patterns of our history; and (2) the potential to yield information important in our history. We recommend that a determination of eligibility to the National Register of Historic Places should be sought from the Keeper. The site is within the conservation pool level of the proposed reservoir. Monitoring of this site should be considered a priority if the proposed reservoir is constructed. 


\section{MATERIAL CULTURE}

Artifacts collected during the cultural resources study of the proposed Applewhite Reservoir are divided into two main groups, prehistoric and historic materials, and further distinguished on the basis of provenience: surface survey or excavated contexts. The description of these cultural materials constitutes only a preliminary analysis, and certain artifact categories, particularly projectile points, may be further redefined.

\section{HISTORIC MATERIALS (939 specimens)}

Historic artifacts collected throughout the survey area were primarily ceramics and metal. The artifacts are categorized by type and include both the surface and limited testing collections.

Ceramics are divided into categories according to the physical properties of the sherds: hard paste earthenwares, soft paste earthenwares, porcelain, and stoneware. The hard and soft paste earthenwares were differentiated by the hardness of the material; between 2-6 on the Moh's scale, respectively. A miscellaneous ceramic category is for those items considered somewhat of a novelty, e.g., clay marbles. Subdivisions of these main categories of ceramics are based on a descriptive assessment of individual characteristics, including the presence or absence of decoration, type, utilitarian aspects of the vessel, presence or absence of glaze, and type.

Hard paste earthenwares are divided into the following groups: sponged/ spatterware, flow blue, banded slip/mocha, hand-painted, jasper ware, feather edged/she11 edged, transfer-printed ware, undecorated, lusterware, ironstone, and a unidentified category. The undecorated category, no doubt, contains a number of sherds that probably belong to one of the other categories, but they have no distinguishing traits.

The soft paste earthenwares are divided into the following groups: Mexican lead-glazed, tin-enameled majolica, and unglazed. The Mexican lead-glazed ceramics are divided into decorated, undecorated, and sandy paste utilitarian wares. Unglazed soft paste ware is divided into wheel thrown and handmade, including bone-tempered Goliad (historic Indian) ware.

The stoneware category comprises variants such as Albany glaze/slip, Bristol glaze, salt glaze, and $10 c a l$ manufactures. No further attempt was made to provide an analysis of the variants at this time.

Metal artifacts are made from copper, iron, brass, silver, lead, gold, and other alloys. Known functional categories for the metal artifacts represent military-related items, personal adornment items (jewelry), farming/ranching items, and household artifacts.

Analysis of the glass fragments is by color, since practically no complete specimens were recovered during field work. The extremely small size of the individual fragments do not indicate form. Colors identified are clear, green, aqua, amber, and purple. Green fragments predominated the collection. 
Faunal materials (bone) collected from 41 BX 274 limited testing operations were weighed by unit and then separated into articulated and nonarticulated groups to facilitate further analysis (see Table 29 for weight and provenience and Appendix VI for a complete discussion of the bone recovered).

Chipped stone was noted at historic sites; the large number of chips and flakes is presumed to represent an as yet unidentified historical 1ithic reduction process in early Spanish colonial sites. Similar materials are recorded at other historic sites, such as Rancho de las Cabras (Ivey 1983:4761), the Spanish Governor's Palace (Fox 1977:16), and the Alamo P1aza (Fox, Bass, and Hester 1975). The provenience of collected historic lithic materials is presented in Table 10.

A brief description of the varieties of hard and soft paste earthenwares, porcelain, stoneware, glass, metal, and miscellaneous categories follows. For a more detailed description of certain types of ceramics, the reader is referred to Davis and Corbin (1967), Scurlock et a1. (1976), and Corbin, Alex, and Kalina (1980). Specimen frequencies and provenience for historic materials are presented in Table 10.

\section{CERAMICS}

Soft Paste Earthenwares (33 specimens)

Unglazed (11 sherds; Fig. 45,a,b,g,h)

Provenience: 41 BX 274, 41 BX 652 (Table 10).

Unglazed soft paste earthenwares are divided into three groups: (1) wheelthrown; (2) hand-formed, including bone-tempered Goliad or Indian ware; and (3) unidentified or miscellaneous. Wheel-thrown soft paste earthenwares recovered from the study area include two fragments of a Spanish olive jar surface collected from 41 BX 652 (Fig. 45,a) and one sherd surface collected from 41 BX 274 (Fig. 45,b) which may also be from a Spanish olive jar or may be of local manufacture. Specimen $A$ (the two sherds have been glued together) is a pale yellowish white to cream color and may have a thin yellow slip, although the surface is badly weathered. Sherd thickness is $10 \mathrm{~mm}$. Specimen B is a light buff to tan color.

Goggin (1970) identified three main styles of olive jars: Early (1500-1580), Middle (1580-1800), and Late (post 1800). Great variation in form, paste, thickness, and surface treatment exists within each of the styles. Paste color of the Early and Middle styles is generally reddish brown to terra cotta red with some well-fired Early style examples ranging to a pale lemon yellow (Goggin 1970:9, 12). Two color ranges are found in the Late style, a pale yellowish white to light gray and a terra cotta to brick red but grading to a pale or light buff (ibid.:18). Occasional sherds of an extremely thick yellow-glazed ware come from vessels about a meter and a half high. No range of dates has been determined for these vessels, although Goggin (1970:30) believes they are a Late style. 
All forms were thrown on a potters wheel with various methods used for joining. While widely represented in Mexico, the ol ive jar is relatively scarce in Texas, New Mexico, and Arizona, where mission sites yield only a few sherds (ibid.:17). Wheel-thrown ceramics of 10cal manufacture recovered from Spanish colonial sites are generally evenly fired, probably in a primitive kiln and tend to be pinkish tan to tan in color with a sandy paste (Ivey 1983:31).

The major function of these vessels was to transport liquids, generally olive oil, olives in brine, and wine. It was not uncommon for the jars to be re-utilized to carry water after they had served their primary purpose (Goggin 1970:6).

Bone-tempered wares are relatively plentiful on early Spanish sites in southern Texas (Jones and Fox 1983:38), and are almost indistinguishable from Late Prehistoric Leon Plain ceramics. Goliad ware varies considerably in thickness, hardness, color, and surface finish (decorated or undecorated). The curvature and thickness of sherds recovered from 41 BX 274 suggest a single, original vessel shape probably in the form of a small 011 a (Fig. 45,g). One fragment of this ware recovered from $41 \mathrm{BX} 274$ is characterized by burnishing. Decorations on Goliad ware and/or sealing with asphaltum has been reported in coastal areas as well as Missions San Juan, San Antonio de Valero, and San José (Scurlock et a1. 1976:193).

Other sherds in this category were either too deteriorated or too burned to make an adequate evaluation on origin, form, or function.

Mexican Lead Glazed (16 sherds; Fig. 45,c,d,e,f,j)

Provenience: 41 BX 274, 1imited testing (Table 10).

Mexican lead-glazed ceramics are distinguished from earlier Indian ceramics by the absence of bone temper, the presence of lead glaze, and finer manufacturing techniques; they usually represent utilitarian wares. Three varieties of this ware were collected from the study area: (1) decorated; (2) undecorated; and (3) sandy paste utilitarian. Decorated Mexican leadglazed specimens consist of white, green, orange, dark brown, or cream handpainted designs (Fig. 45,c). Other decorated wares with a thin red paste are hand painted with black lines as decorations (Fig. 45,d). Three sherds, distinctive by their orange, white, and green decorations, were collected from 41 BX 274 (Fig. $45, j$ ). Undecorated sherds with a red paste are distinguished by differences in rim shapes, quality, and presence or absence of glaze on the surfaces (interior/exterior).

Sandy paste utilitarian wares (Fig. 45,e,f) are distinguished by their comparative thickness, sandy paste, and a yellow or green glaze. They appear to be the second most common type of pottery used at Spanish colonial sites (Ivey and Fox 1981:34). Mexican lead-glazed wares historically were probably manufactured in the pottery centers of Mexico, and now comprise a large portion of the ceramic collections from mid-18th-century Spanish sites in 
Figure 45. Soft Paste Earthenwares.

a, Spanish olive jar fragment (41 BX 652);

b, soft paste wheel-thrown pottery fragment (4l BX 274);

c, Mexican lead-glazed, decorated (4I BX 274);

d, Mexican lead-glazed, red paste (41 BX 274);

e,f, Mexican lead-glazed, util itarian ware (41 BX 274);

$\mathrm{g}, \mathrm{h}, \mathrm{Gol}$ iad ware (4I BX 274);

i, majolica (41 BX 274);

j. Mexican lead-glazed, decorated ware (41 BX 274). 


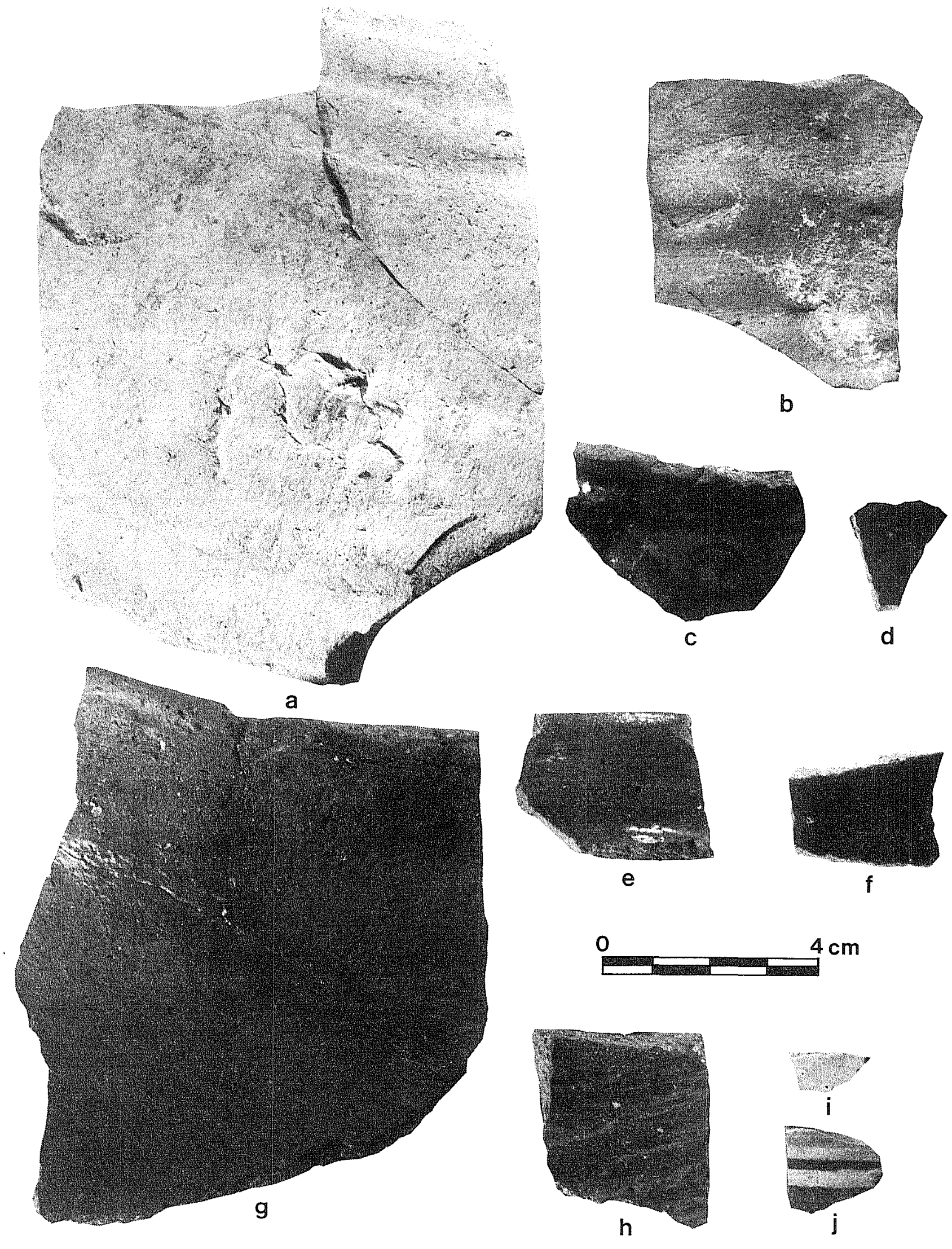


TABLE 10. PROVENIENCE OF COLLECTED HISTORIC MATERIALS

\section{$418 \times 274$}

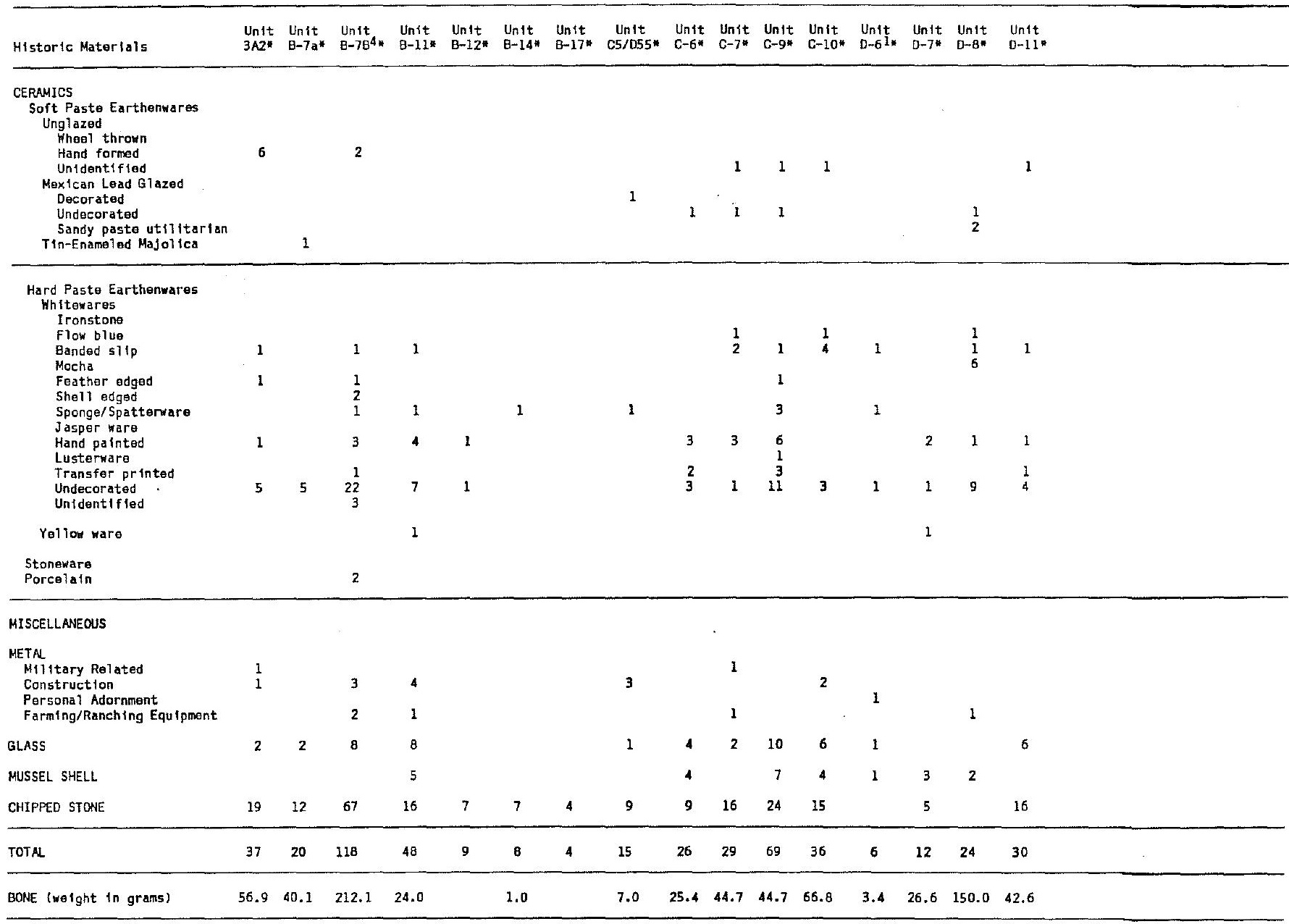




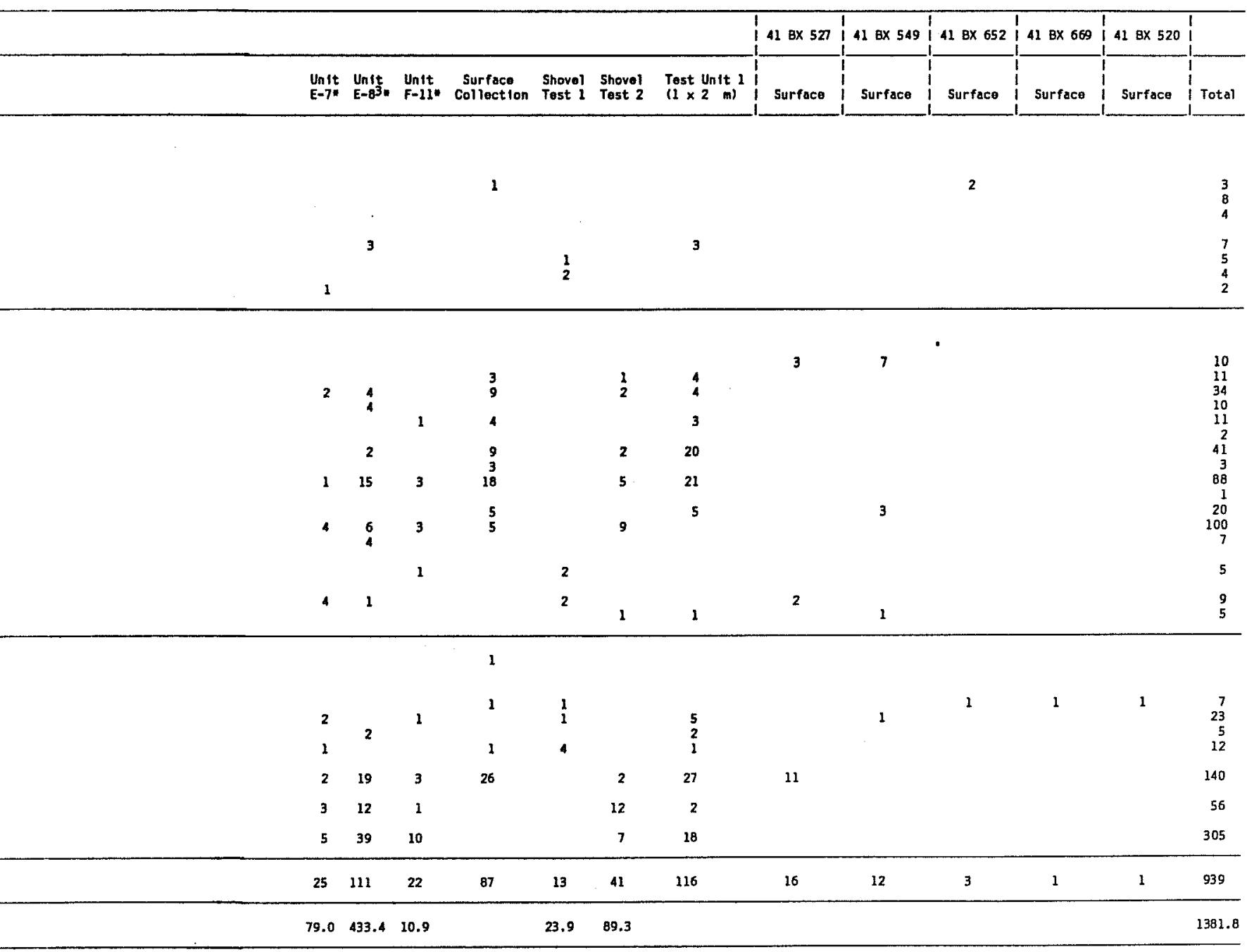


Texas (Jones and Fox 1983:38). Mexican lead-glazed wares have been manufactured from the 18th century until the present day.

Tin-Enameled Majolica ( 2 sherds; Fig. 45,i)

Provenience: 41 BX 274 (Table 10).

Tin-glazed majolicas are found in Italy, Spain, and Portugal, and are known as faience in France, Belgium, Sweden, Germany, Hungary, and Denmark, and delft in England and Holland (Barber 1908:9). Found throughout western Europe in the 18th century, the ceramics differ stylistically, but the common characteristics are a soft earthenware paste and an opaque, white-colored glaze. Most wares found in southern Texas sites were made in Puebla, Guanajuato, or Mexico City. The earliest dates of manufacture are in the 14 th century, and by the 17 th century its popularity had increased both in the variety of styles and centers of manufacture (Lister and Lister 1982).

Majolica has been recovered from archaeological sites in the San Antonio area, including Missions Espada and San Juan (Scurlock et a1. 1976:196), Rancho de las Cabras (Ivey and Fox 1981; Jones and Fox 1983; Ivey 1983), the Al amo (Fox, Bass, and Hester 1975), and the Alderete property (Fox, Valdez, and Bobbitt 1978). Six varieties are known from this area: (1) Huejotzingo (1770-1800); (2) San Elizario, popular in northern Mexico in the 1ate 18th century (Gerald 1968:46) and in Texas after 1760 (Ivey and Fox 1981:35); (3) Monterey; (4) Guanajuato, a red paste with a cream-colored glaze (Fig. 45,i); (5) Puebla, blue on white; and (6) San Augustine, blue on white (Scurlock et a1. 1976:196).

Hard Paste Earthenwares (343 sherds)

\section{Whitewares}

Ironstone (10 sherds; Fig. 46,b)

Provenience: 41 BX 527 and 41 BX 549, surface (Table 10).

Ironstone is a glossy whiteware characterized by a fine white paste. Sti11 manufactured, the pottery originated in England in the early 1800s. It was not widely imported in large quantities until after 1851 (Walker 1971:123). Ironstones are common in historic sites that date post $1860 \mathrm{~s}$ and have been found locally at sites such as Hot Wells (Fox and Highley 1985:28-32). One illustrated sherd (Fig. 46,b) has a makers mark: Viking, pat'd Dec. 20, 1908.

Flow Blue or Flown Blue (11 sherds; Fig. 46,c,d)

Provenience: 41 BX 274 (Table 10).

Flow blue ceramics are distinguished by a decorative technique in which the (glaze) firing is done in a chlorinated atmosphere, causing the enamel to 
flow slightly. The design results in a slightly blurred but still distinct effect. Vessels are printed in the same manner as transfer printing (Davis and Corbin 1967:19). First manufactured in England, ca. 1825, the ware became popular in the mid-Victorian era. The two illustrated specimens (Fig. 46,c,d) are rim sherds probably from plates. A delicate tulip design with dots forms the border.

Banded S7ip, Including Mocha Ware (44 sherds; Fig. 46,e,f; Fig. 47,b,c)

Provenience: 41 BX 274 (Table 10).

Banded slipware is characterized by a slip painted and banded technique (Fig. 46,e,f). A utilitarian ware, it seems to have been most popular from the early to mid-19th century in Texas, although it was manufactured in England as early as 1787 (Robacker and Robacker 1978:24). This ware is most usually green, brown, gray, blue, and white, with black used in the designs and banding. Varied colors and stamped rim patterns reflect a variety of designs. One variety known as mocha or "Tobacco spit ware" was initially produced in England in 1789 and gained wide popularity by 1836. This ware was produced by the use of a diffusing agent, tobacco soaked in urine and turpentine, which caused the slip to run (ibid.). Pattern names for the banded slip wares include the following: rope twist or earthworm, (Fig. 47,b), checker, cat's eye, daisy forming a diamond, twig, seaweed (Fig. 47,c), leaf, zigzag, arrow, scro11, cross, dash, dot, dot-and-stripe, and stripes and waves (Robacker and Robacker 1978). This ware was manufactured as late as 1903 (Davis and Corbin 1967:25).

Edged Ware, Including Shell Edged and Feather Edged (13 sherds; Fig. 46,g,h)

Provenience: 41 BX 274 (Table 10).

Edged ware, first manufactured in England in the 1ate 18th century, is characterized by a hand-painted molded rim. The paint on this type of vessel is a monochrome, usually blue, green, or red. The feather-edged design is claimed to have been produced by Wedgewood as early as 1774 . The type was most popular in the United States between 1790 and 1830 or 1840 (Noel Hume 1963:299). Sherds of this type are fairly common in historic sites dating earlier than 1850 (Davis and Corbin 1967:25). Locally, edged wares have been found at Mission San Juan Capistrano (Schuetz 1969:16), Mission San José (Schuetz 1970:21,24), Mission Espada (Scurlock et a1. 1976:199), the Alamo (Eaton 1980:30), and at other sites in the San Antonio area. Three sherds from the study area are a red monochrome, nine sherds are a green monochrome, and one sherd is a blue monochrome. The sherds are predominantly rims from plates. 
Figure 46. Hard Paste Earthenwares.

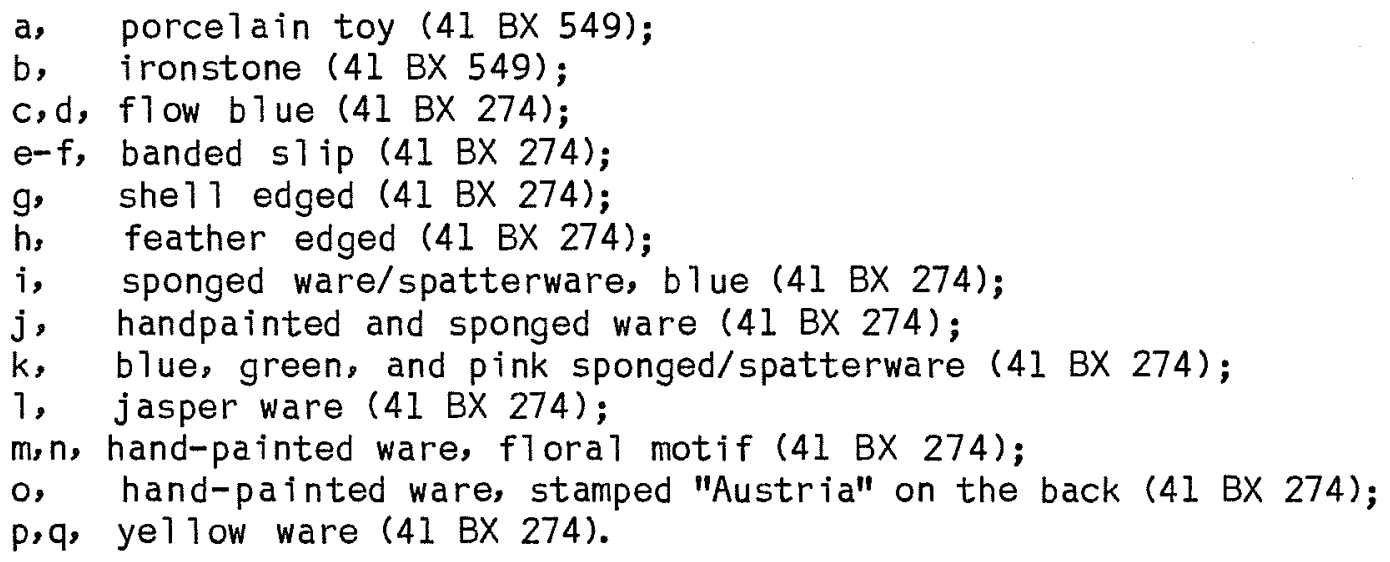




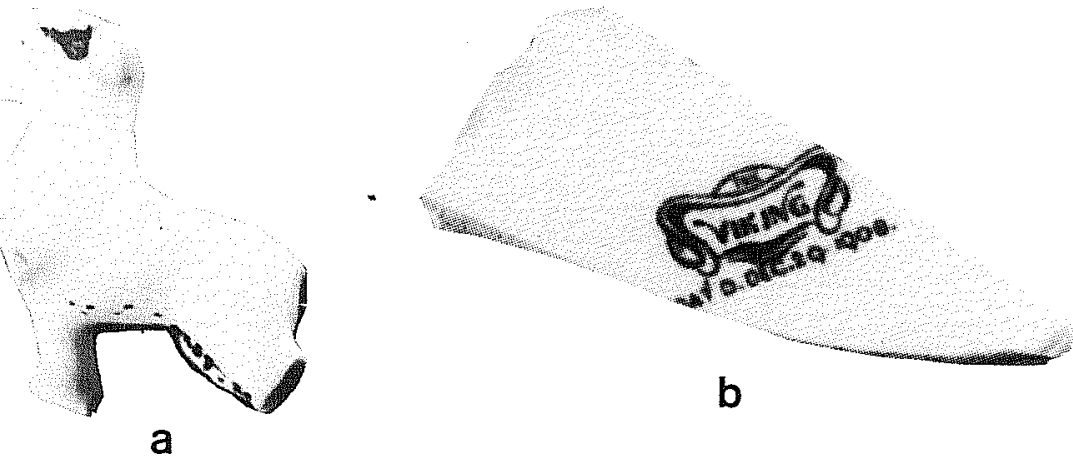

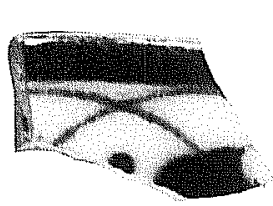

d

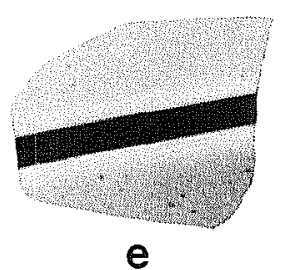

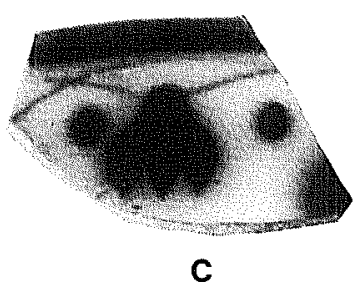

nominy)

g

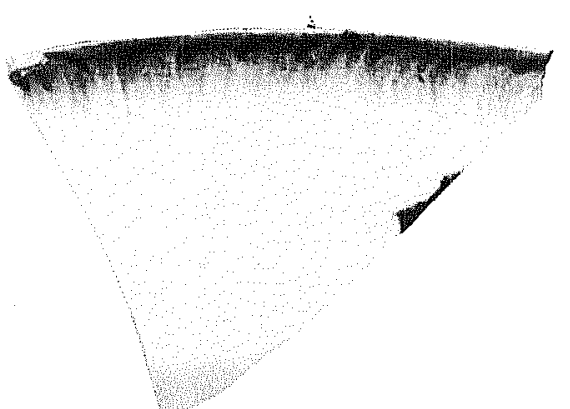

h

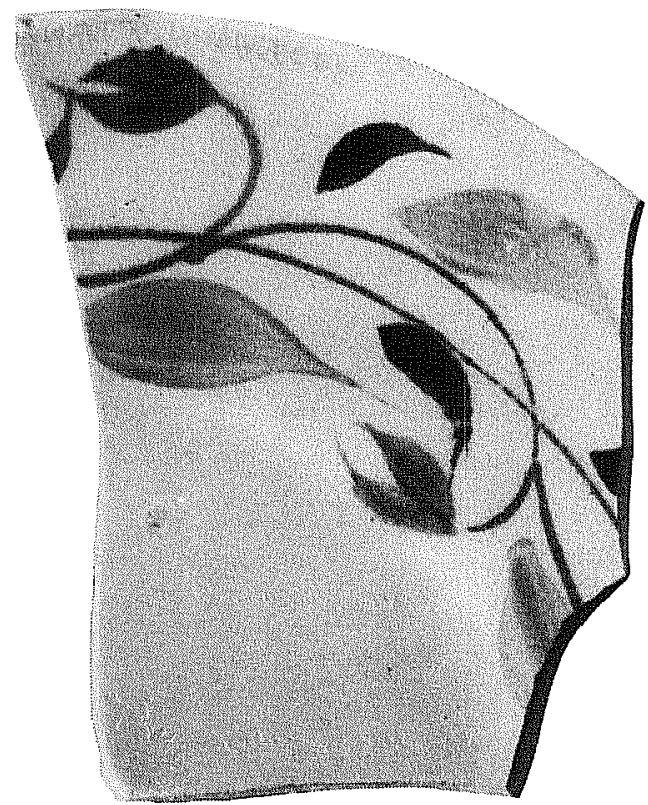

m
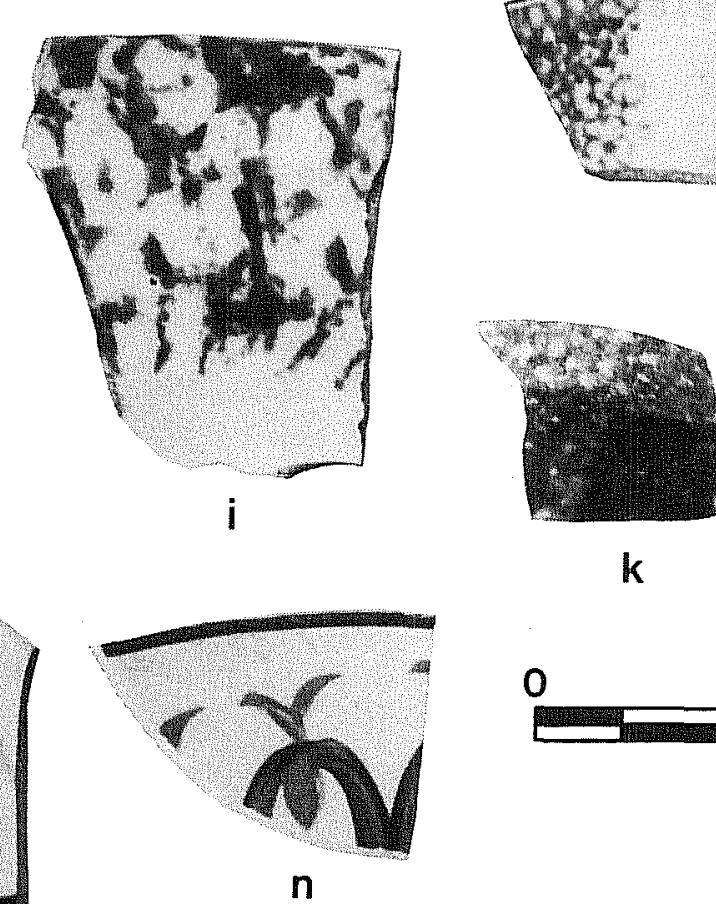

k
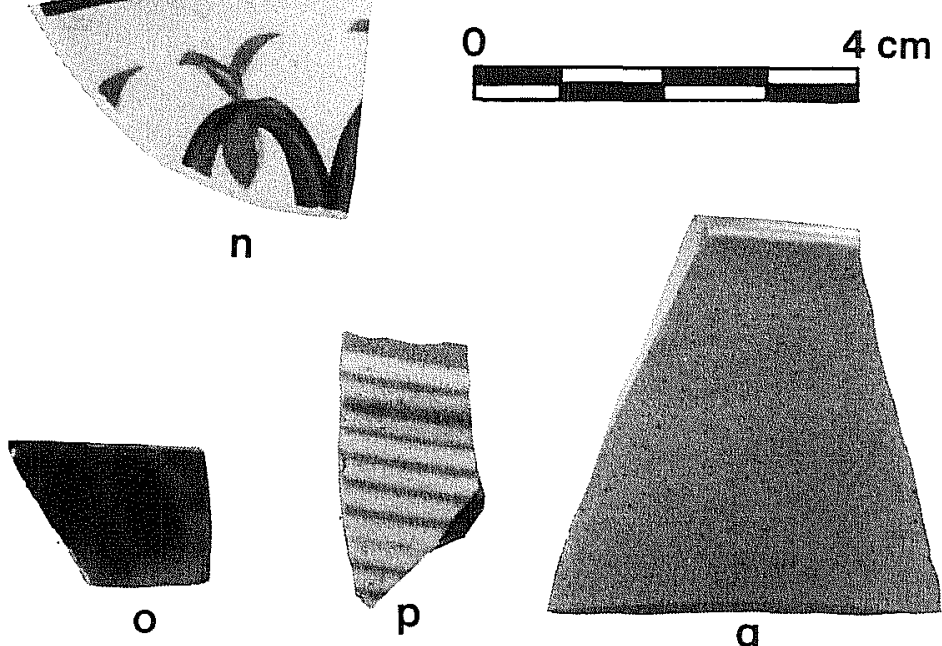

0
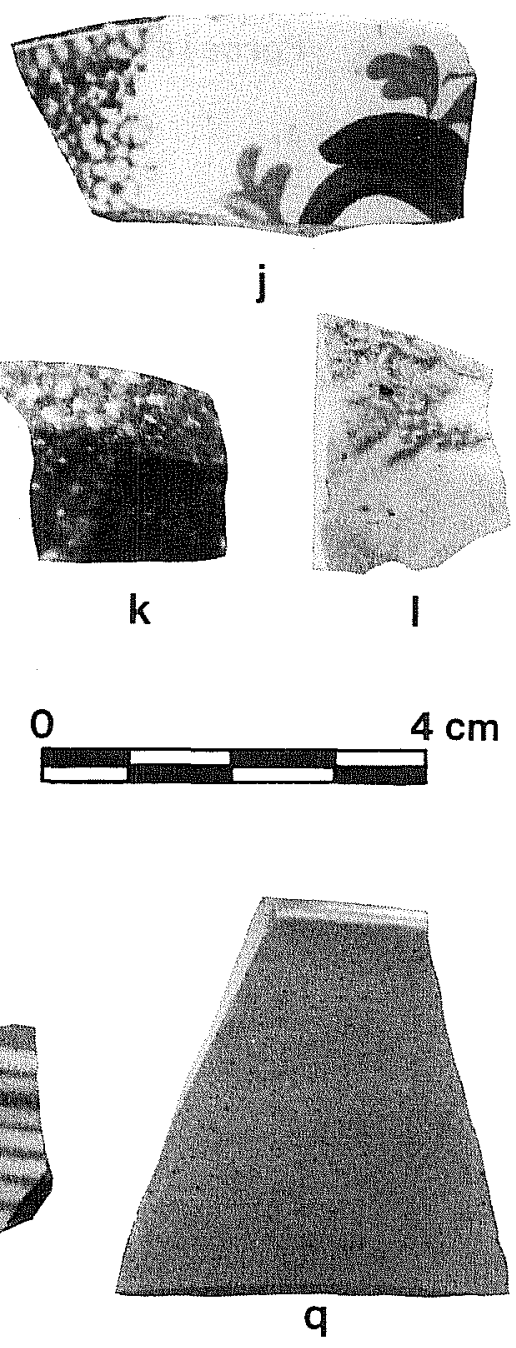
Figure 47. Hard Paste Earthenwares, Stoneware, Porcelain, and $\mathrm{Cl}$ ay Marble Collected at 41 BX 274.

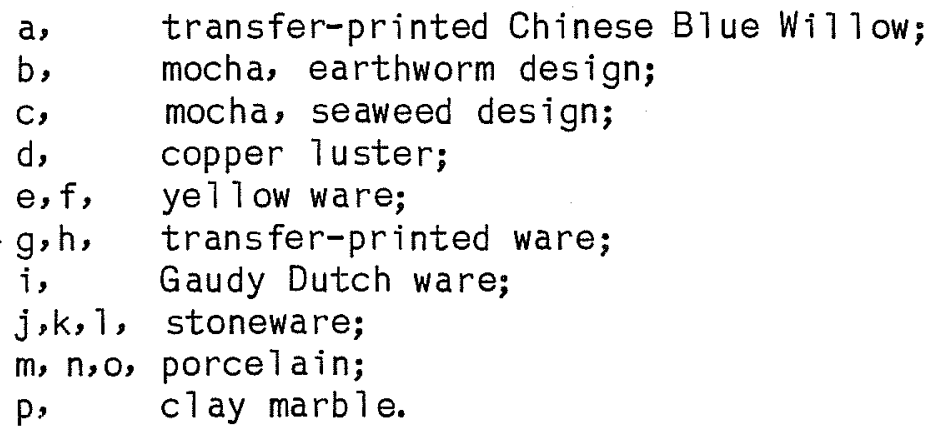




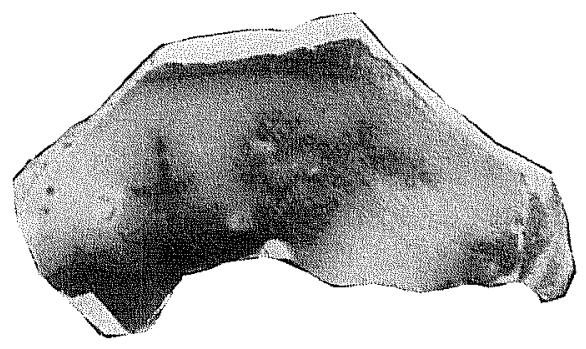

a

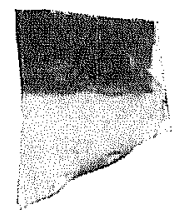

e

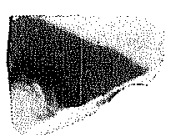

f

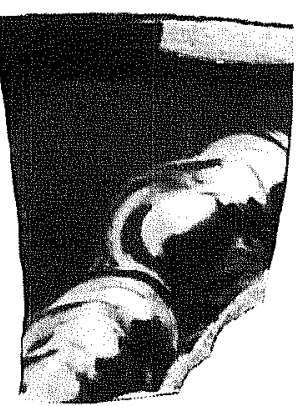

b

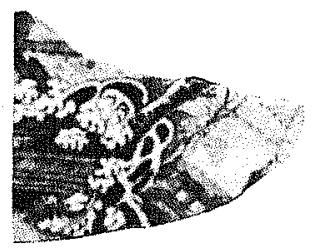

g

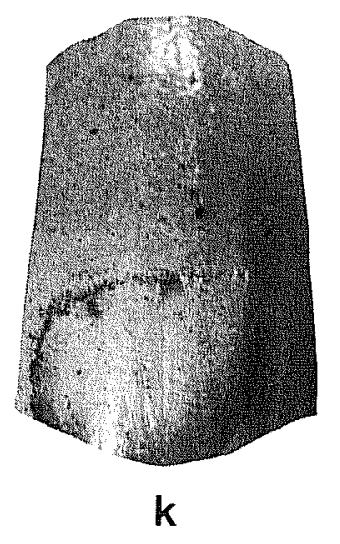

k
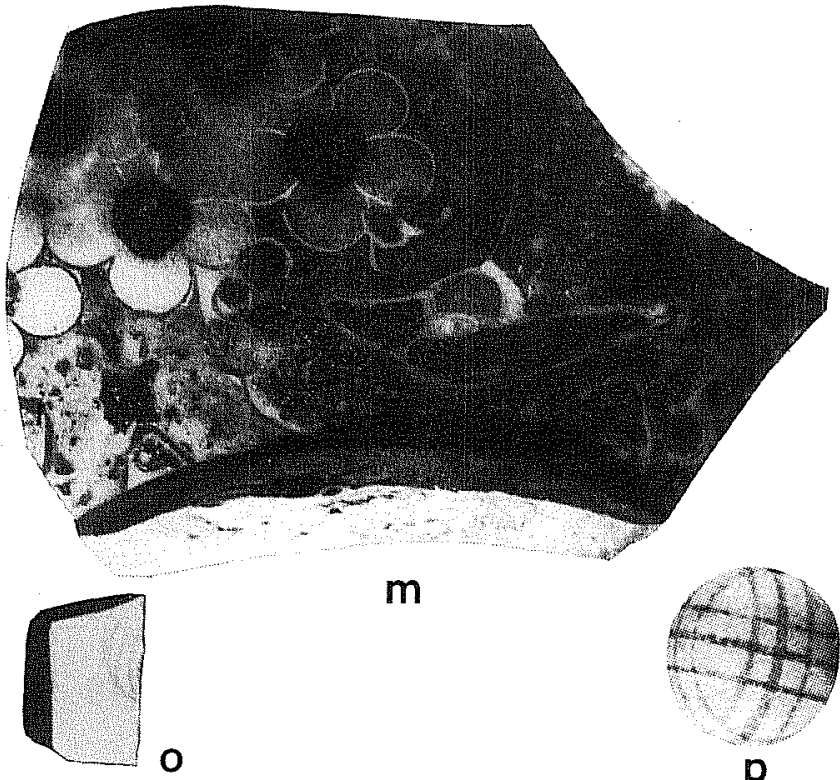
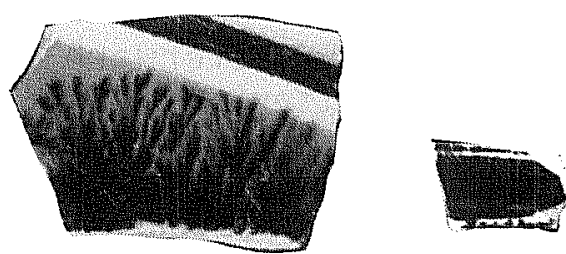

C

d
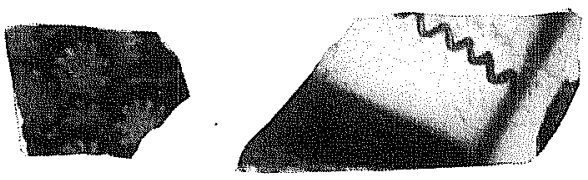

h

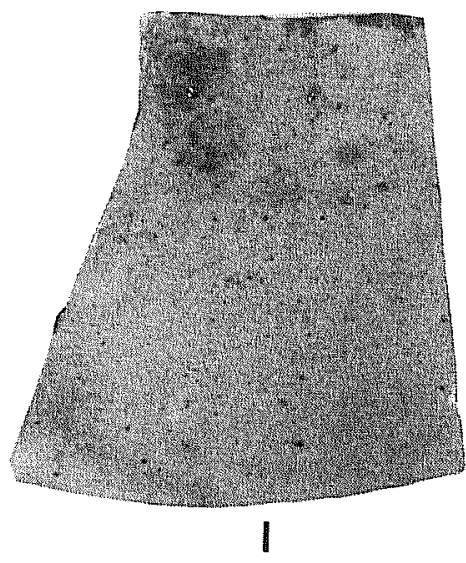

m

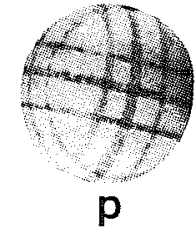


Sponged/Spatterware ( 41 sherds; Fig. $46, i, j, k$ )

Provenience: 41 BX 274 (Table 10).

Sponged or "spatterware" is a distinctive decorative pattern produced by a sponging/spattering technique often in combination with hand-painted floral designs. The actual process of creating the sponged/spatterware design is not known at this time (Robacker and Robacker 1978:34). Most probably the technique consisted of using a tapped "maulstick," a wooden paddlelike implement that originally served as a hand prop (ibid.:34). The potter would cover the areas of the dish not to be covered by the paint. The painter then took his/her brush containing a supply of paint and then tapped it on the maulstick thus creating a sprinkle effect (Robacker and Robacker 1978:35). There is also the possibility that a sponge--the use of which can result in a variety of effects--may have been used. Although this ware was made as early as 1790 in England (Greaser and Greaser n.d.:5), it reached a peak of popularity about 1830-1840 and continued in use until mid-19th century (Robacker and Robacker 1978:32). Seven basic colors were used in the production of spatterware: red, yellow, green, purple, blue, pink, and brown sometimes with black. Colors were often used in combination as well; approximately 85 patterns of spatterware have been identified (ibid.). Sponged/spatterware colors represented by the sherds in the study collection consist of the following single colors and color combinations: blue (Fig. 46,i); green; pink; purple; pink and green; handpainted and sponged (Fig. 46,j); blue, green, and pink (Fig. 46,k); and yellow and green. Forms represented appear to be plates, bowls, cups, and pitchers.

Jasper Ware ( 3 sherds; Fig. 46,1)

Provenience: 41 BX 274 (Table 10).

Jasper ware has been produced by the Wedgewood potteries since at least as early as 1774 (Godden 1975:174) and continues in production today. These ceramics have a basalt body of varying colors: white, black, green, pink, blue, salmon, $1 \mathrm{ilac}$, and yellow. Relief motifs of varying colors can be undercut, sharpened-up, or applied (ibid.). It is very difficult or impossible to accurately date these wares, particularly when dealing with incomplete vessels. Although the Wedgewood potteries were the primary manufacturers of jasper wares, many imitators also produced the wares (firms such as the Adams firm and several other Staffordshire potteries; Godden 1975). The three sherds from 41 BX 274 are of a white basalt body with a light blue relief. The relief motif is a heavy floral design similar to one used by the Wedgewood potteries as well as the Staffordshire potteries. The three sherds appear to represent one vessel.

Hand-painted Ware, Including Gaudy Dutch ( 88 sherds; Figs. 46, m, n, 0; 47,i)

Provenience: 41 BX 274 and 41 BX 549 (Table 10).

Hand-painted earthenwares consist of an extensive variety of wares over a long temporal span. The whitewares group dates to ca. 1780 when English 
potters manufactured crude, hand-painted floral motif earthenware. Blue banding was common on these wares, especially around the foot of the vessels, handles, and bowl rims. Hand-painted wares are generally polychrome in green, purple, blue, red, and brown with floral motifs. Black and gold banding with linear designs have been noted also (Scurlock et a1. 1976:198). Specimens from the study area predominantly consisted of brightly painted floral designs; most of these sherds appear to represent plates, saucers, and cups. Two specimens (Fig. $46, \mathrm{~m}, \mathrm{n}$ ) have a delicate floral motif and are rim sherds from plates. One sherd (Fig. 46,0) is stamped "Austria" on the back. One additional sherd (Fig. 47,i) is what is commonly known as "Gaudy Dutch." These wares were produced by potteries such as Staffordshire and were in favor from ca. 1800 to 1850 (Wedgewood and Ormsbee 1947:160). Colors used in this ware include cobalt blue, apple green, rust red, and clear pink. Platters, plates, handleless cups, saucers with cup plates, bowls, sugar bowls, cream pitchers, teapots, coffeepots, and the $1 \mathrm{ike}$ were produced (ibid.:161). One sherd from the study area appears to be from a sma11 bow 1 or a cup.

Lusterware (or Lustre wares; 1 sherd; Fig. 47,d)

Provenience: 41 BX 274 (Table 10).

Luster decoration is formed by applying thin metallic films to ceramics. The two most common effects are silver luster or copper luster. Lusterware has been produced in England since the 19th century, and the process is still in use today (Godden 1975:214). The Staffordshire potteries, the Sunderland potteries, the Wedgewood potteries, as well as others, produced lusterware (ibid.). Various processes were used to produce luster such as a "resist" process and stencilling. The one specimen from 41 BX 274 (Fig. 47,d) is a rim sherd in copper luster.

\section{Transfer (Printed) Ware (20 sherds; Fig. 47,a,g,h)}

Provenience: $41 \mathrm{BX} 274$ and $41 \mathrm{BX} 549$ (Table 10).

A form of white, hard paste earthenware, transfer-printed ware reflects a decorative technique of transferring a design from a copper plate to a ceramic surface before ghost or glaze firing. Two types of methods were used in this process, both invented in the mid-18th century in England (Coysh 1970:7-8). The process was also known as "black printing," as b7ack was the earliest and easiest color to work with (Davis and Corbin 1967:16).

Blue was the most popular design color between 1818 and 1829, and "blue Staffordshire" and "old blue" have become general names of transfer-printed earthenwares. Oriental designs were most popular (e.g., Blue Willow design; introduced in 1780; see Fig. 47, a), but other motifs include floral and geometric borders. 0ther colors were introduced in 1829, including red, lighter blue, green, purple, gray, and brown (ibid.). With numerous colors available, potters began producing polychromatic vessels (Walker 1971:114). 
Transfer-printed wares were being imported into the United States by the mid $1780 \mathrm{~s}$ and reached their peak of popularity between 1790 and 1850 (Walker 1971:116). These wares were popular at San Antonio missions near the study area where large numbers have been recovered (Scurlock et a1. 1976:198). Several temporal styles are present in these collections. The Blue Willow sherd (Fig. 47,a) appears to be the bottom of a small bow1. Characteristic of the true Blue Willow pattern is the pagoda and the willow tree. The standard willow pattern which was being used by makers in the $1830 \mathrm{~s}$ has a pagoda, a three-arch bridge, two birds in the sky, and a prominent willow tree (Coysh 1970:14). Figure 47,g is a monochromatic purple on a white background. Figure 47 , h is a monochromatic cobalt blue floral design on a white background, and probably dates 1820-1850s.

Undecorated (100 sherds; not illustrated)

Provenience: $41 \mathrm{BX} 274$, limited testing (Table 10).

Davis and Corbin (1967:26-27) note an increase in imported plain wares into the United States from England after 1860. They speculate that many of the undecorated sherds from historic sites reflect this influx. Some of the undecorated sherds collected from the study area undoubtedly represent portions of decorated vessels. On basal sherd was impressed with the back stamp of "Davenport" over an anchor. This mark dates between 1830 and 1850 (Fox 1986:122, 124-125).

Unidentified ( 7 sherds; not illustrated)

Provenience: $41 \mathrm{BX} 274$.

Seven sherds could only be identified to paste composition. They were a11 too burned to make any further assessment.

Yellow Ware ( 5 sherds; Figs. $46, p, q ; 47, e, f$ )

Provenience: 41 BX 274 (Table 10).

Yellow ware was originally manufactured in England in the latter half of the 1820 s and was produced in mass in New Jersey, Pennsylvania, Ohio, Vermont, New York, and Maryland by the 1840s and 1850s (Leibowitz 1985:9). The peak of production for yellow ware was in the 1860s and 1870s after which time it lost favor; it was produced as late as 1930 (ibid.).

The yellow ware produced in England had a yellow paste with various yellow glazes applied to the yellow-bodied piece. Yellow ware made in the United States did not have a yellow glaze but a clear alkaline glaze (Leibowitz 1985:9). Fired at $2200^{\circ} \mathrm{F}$, it was extremely nonporous and durable, and quickly gained favor with both potters and homeowners. It was a common household/kitchen item. Items produced in yellow ware were numerous: jars, pitchers, spittoons, chamberpots, teapots, tureens, mugs, cups, custards, sauce dishes, rice dishes, bowls, cake pans, pie plates, butter crocks, jelly 
molds, candlesticks, soap dishes, bottles, snuff jars, toilette items, and nappies (ibid.:19).

By the 1840s, decorated yellow ware was being produced, and early designs consisted of a thin slip band applied with a slip quill that the decorator would blow through as the vessel was turned on a wheel. Mocha decorations were also applied to yellow ware. Pressed or moulded yellow ware, introduced in the $1860 \mathrm{~s}$, allowed for vertical and horizontal lines, floral decorations, and other scenes to be produced (Leibowitz 1985:12-13). One sherd from the study area (Fig. 46,p) is a rim sherd with multiple white horizontal bands around the 1ip. The sherd is probably from a bowl and dates ca. 1840-1850s. Two sherds (Fig. 46,q) are American made--they have a clear alkal ine glaze applied over the yellow paste. Two of the sherds (Fig. 47,e,f) are from one vessel and have a blue band around the lip section. These sherds, which probably predate the other yellow ware sherds, are from ca. early 1800 s.

Stoneware (9 sherds; Fig. 47,j-1)

Provenience: 41 BX 527 surface; 41 BX 274 (Table 10).

Stoneware, varying widely in paste and glaze colors, is impermeable and dense but not translucent. The ware may be glazed or unglazed, although the former is most common (Deetz 1977:47). Stoneware is commonly found in late 19thand early 20th-century sites in the 10cal area. Stonewares from the study area are represented by two sherds which appear to be an Albany slip with salt glaze, three sherds with a Bristol glaze, and four sherds of probable local manufacture. Figure $47, \mathrm{j}$ appears to be the bottom section of a mediumsized crock or churn. Figure $47, \mathrm{k}$ is a handle section from a cup, and Figure 47,1 is of undetermined function.

Porcelain ( 3 sherds; Fig 47,m,n,0; 1 button, not 117 ustrated; 1 figurine, Fig. 46,a)

Provenience: 41 BX 274 and 41 BX 549 (Table 10).

Porcelain differs from earthenware by its greater hardness and the fine, impermeable paste. Porcelain sherds are both decorated and undecorated and reflect distinctive styles of decoration. These include hand-painted polychromes, decalcomania, or transfer (Scurlock et a1. 1976:203). Three major groups of porcelain have been produced in England: hard, soft, and bone china, the last actually being a special form of soft porcelain manufactured from oxen bone ash (Davis and Corbin 1976:29). Three fragments of Chinese (trade) porcelain were collected from $41 \mathrm{BX} 274$. Two of the sherds are an extremely thin-walled glazed porcelain with remnants of the original red hand-painted design present. The design on these sherds is remarkably similar to complete specimens which date to the $\mathrm{Ch}^{\prime}$ ien Lung period (1736-1795) of Chinese porcela in production (Hobson 1976:Plate 125). Forms represented by the two sherds are probably cups or bow7s. The third specimen from 41 BX 274 is a thick-walled porcelain with a complex floral design which is hand painted. The sherd has been extensively burned, and therefore, no adequate assessment can be made of the original paint colors. This imported 
ceramic, probably first arriving in the New World by way of the Manila Galleon (Eaton 1980:31), appears 10cally at 41 BX 274 in the 1ate 18th or early 19th century, and perhaps earlier elsewhere. Chinese porcelain similar to specimens shown in Figure $47, \mathrm{~m}$ and 0 have also been identified locally at Mission San Antonio de Valero (ibid.) as well as at Rancho de las Cabras (Ivey 1983:16-17). The presence of these sherds at 41 BX 274 is probably indicative of the social/political/economic status of the Pérez family, and they may have been family heirlooms. One small porcelain button was also collected from $41 \mathrm{BX} 274$. A small porcelain figurine of a dog was surface collected from 41 BX 549 (Fig. 46,a). This figurine probably belonged to one of the Linn children and is similar to other whimsical items produced in the Tate 19th century.

MISCELLANEOUS (1 marb7e; Figs. $47, p ; 49, c$ )

A small clay marble was surface collected from 41 BX 274. The artifact is decorated with a pair of intersecting triple lines across the marble.

\section{METAL ARTIFACTS (47 items)}

The following is a 1 ist of the metal items recovered during this project; provenience is noted (Table 10).

lead/alloy bal1

lead bal1

cut nails

cartridge casing

percussion cap

iron handle

metal tab
Surface collected from 41 BX 520 . Identified as grape or canister shot (S. Nesmith, personal communication), 9 oz.

Surface collected from 41 BX 274, .41 caliber (Fig. 48, b).

Twenty-three fragments and whole cut nails were recovered from limited testing at $41 \mathrm{BX} 274$. They are moderately to extremely corroded, and $2-3 \mathrm{~cm}$ in individual length (Fig. 48,C,d). Cut nails were manufactured as early as 1790 and continued in production through the 19th century when wire nails were introduced (Nelson 1968).

Recovered from limited testing at 41 BX 274 . Henry rimfire 1 arge caliber she11 casing, $1 \mathrm{~cm}$ in diameter (Fig. 48,e).

Recovered from 1 imited testing at $41 \mathrm{BX} 274,6 \mathrm{~mm}$ in diameter (Fig. 48,f).

Recovered from 1 imited testing at 41 BX $274,9.3 \times$ $5.7 \mathrm{~cm}$ (Fig. 48,g),

Recovered from $41 \mathrm{BX} 274,1.9 \mathrm{~cm} \times 1.2 \mathrm{~cm}$, copper (handle?; Fig. 48,h). 
sma11 lead fragment

brass(?) handle

button, metal

button, metal

button

metal tab

ring, silver(?)

jeweTry (ear rings or sma11 pendant)

pewter tab

iron kettle fragment

pocket knife

ox shoe fragment

button, metal
Recovered from 1 imited testing at $41 \mathrm{BX} 274,4.5 \mathrm{~g}$ (Fig. $48, i$ ).

Recovered from limited testing at $41 \mathrm{BX} 274$. Length is $4.5 \mathrm{~cm}$, width is $1.7 \mathrm{~cm}$, thickness is $0.38 \mathrm{~cm}$. Stamped: V.R. SECURE below crest of crown (Fig. 48,j; 49,a).

Recovered from 41 BX 652. Stamped "W. W. PLATED." Possible early 19th-century military button (S. Nesmith, personal communication), $1.5 \mathrm{~cm}$ in diameter (Fig. $48, k$ ).

Recovered from limited testing at 41 BX 274. Stamped "TREBLE GILT WARRANTED," $1.7 \mathrm{~cm}$ in diameter (Fig. 48,1).

Recovered from limited testing at $41 \mathrm{BX} 274,1.7 \mathrm{~cm}$ in diameter, 4-hole (Fig. 48, m).

Recovered from limited testing at $41 \mathrm{BX} 274,1.5 \mathrm{~cm}$ in diameter (Fig. 48,n).

Recovered from 1imited testing at 41 BX 274. Extensively tarnished and corroded ( $F$ ig. 48,0; see also Fig. 49,b for stamped ring designs).

Recovered from 1 imited testing at 41 BX 274 , brass(?; Fig. 48, p, q; Fig. 49,d, d').

Recovered from 1 imited testing at 41 BX 274 (Fig. 48,r).

Recovered from 1 imited testing at 41 BX 274 (Fig. 48, s).

Recovered from limited testing at 41 BX 274 (Fig. 48,t; Fig. 49,e).

Recovered from 1 imited testing at 41 BX 274 (Fig. 48,u).

Recovered from 41 BX 669. Stamped "ORANGE COLOUR." Possible early 19th-century military button, $1.8 \mathrm{~cm}$ in diameter (S. Nesmith, personal communication; Fig. $48, v)$.

GLASS (140 specimens; not i17ustrated)

Small glass fragments were collected primarily from 1 imited testing at $41 \mathrm{BX} 274$, with some surface collected at $41 \mathrm{BX} 527.01$ ive green (wine bottle?) fragments predominate the collection at 41 BX 274, but clear, amber, 
Figure 48. Metal Artifacts.

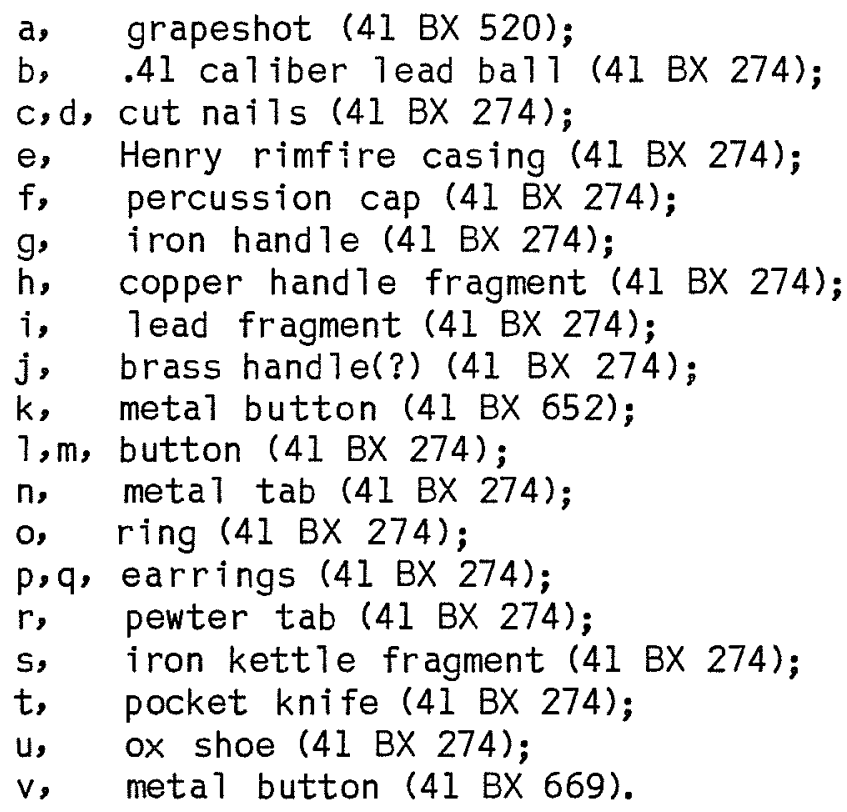


Applewhite/Material Culture
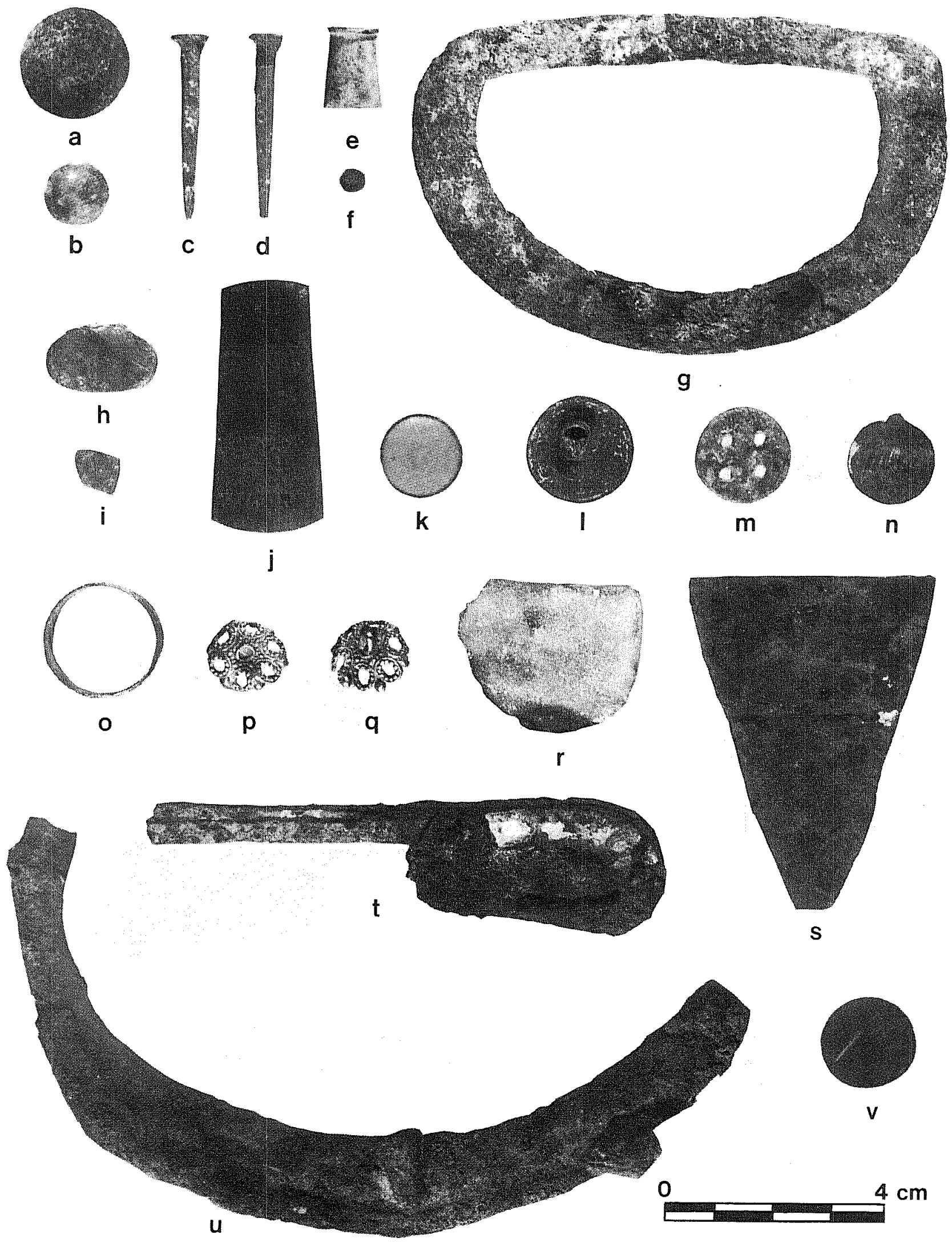

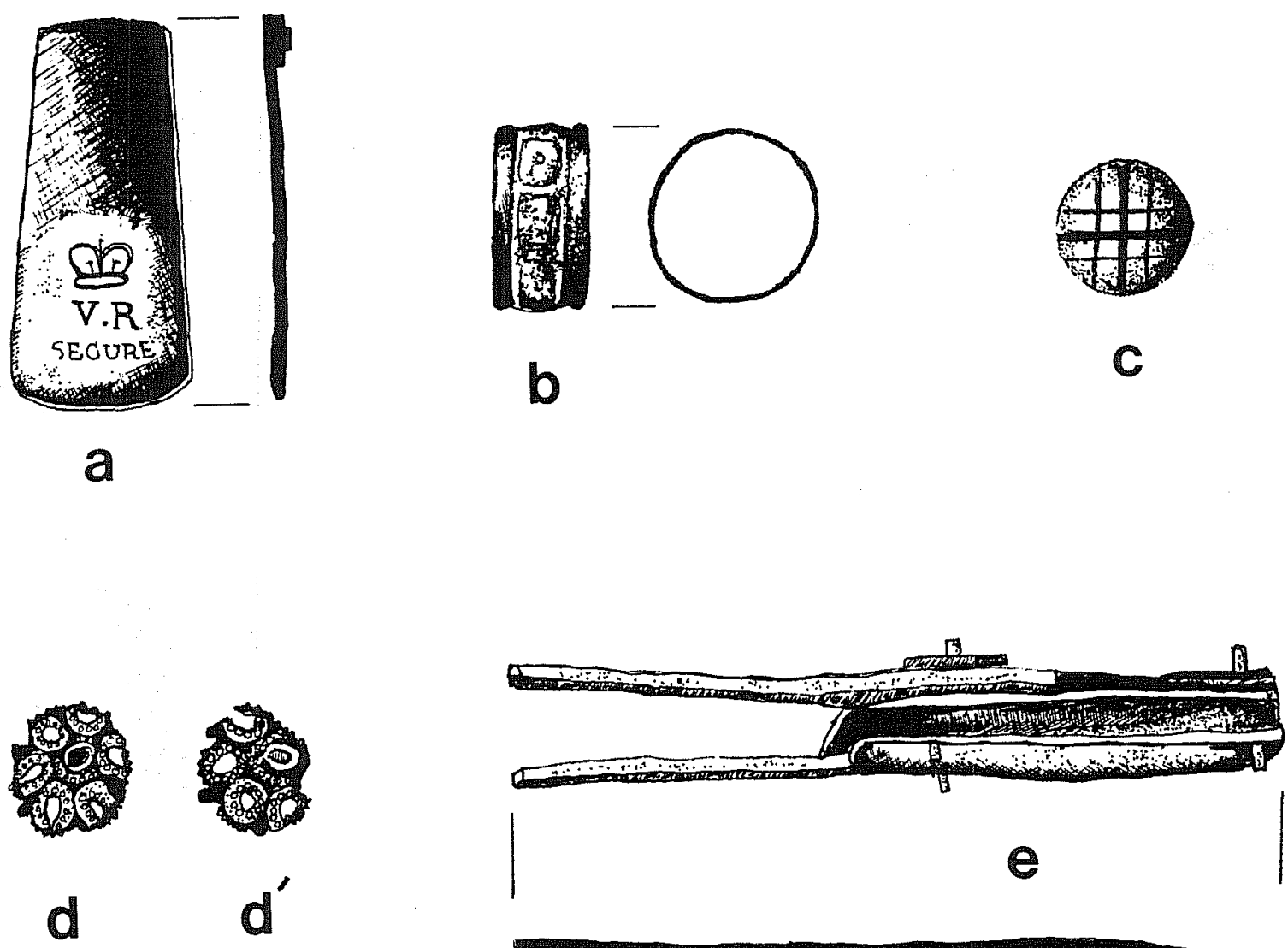

d
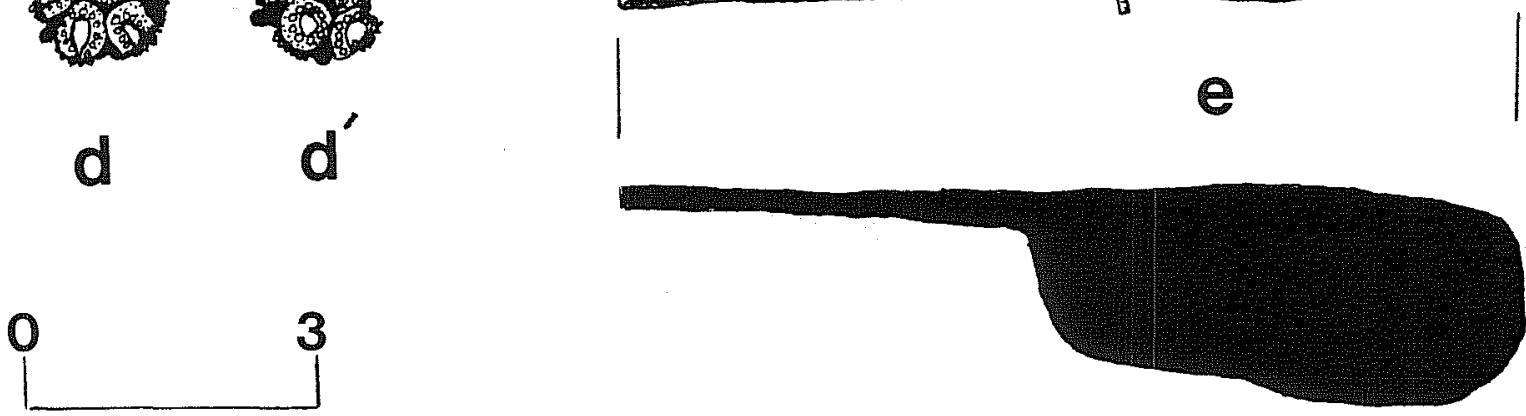

$\mathrm{cm}$

Figure 49. Details of Selected Artifacts from Limited Testing at 41 BX 274. a, brass(?) handle; b, silver(?) ring; c, clay marble; d,d', jewelry; e, pocket knife. 
Applewhite/Material Culture

brown, and light blue fragments are also represented. See Table 10 for provenience and frequency.

SHELL (56 fragments; not i11ustrated)

Mussel she11 fragments were collected during limited testing at 41 BX 274. See Table 10 for specific provenience.

CHIPPED STONE (305 fragments; not i11ustrated)

Chipped stone was recovered from historical context at 41 BX 274 . This debitage consisted of primarily decorticate chips, several secondary flakes, and tertiary flakes. As noted by Ivey and Fox (1981:37) and Ivey (1983), the occurrence of chert flakes and fragments reinforces the idea that the use of stone tools continued throughout the 18th century in the San Antonio River valley. At 41 BX 274, this utilization of chipped stone may reflect a continuance of this technology into the early to mid-19th century by historic Indian occupations in the vicinity of a Spanish ranch. The occurrence of historic Indian Goliad ware at 41 BX 274 also lends support to this conjecture. One smal1 possible gunflint was also recovered during limited testing at $41 \mathrm{BX} 274$. See Table 10 for frequencies and provenience.

\section{PREHISTORIC MATERIALS}

A variety of chipped stone tools, prehistoric ceramics, projectile points, and point fragments were collected from the investigated areas. The majority were from surface collections (unless noted otherwise) and represent chronologically distinct forms. Artifacts were separated and categorized by a descriptive typological system and then compared to photographs, drawings, and text by Turner and Hester (1985) and Suhm and Jelks (1962). Artifact classes will be defined preceding individual descriptions, and the reader is referred to Crabtree (1972), Gerstle, Kelly, and Assad (1978), Hester (1980), Joukowsky (1980), Bl ack and McGraw (1985), and Turner and Hester (1985) for further discussions on stone tools, chipping techniques, and southern Texas tool technologies.

Sorting projectile points and other lithic artifacts into prehistoric cultural types has long been a significant problem of Texas archaeology. Past and most present researchers still concentrate on defining these artifacts by morphology. Unfortunately, lack of data or methodology limits the temporal and geographic implications of this work.

In 1985, Black and McGraw postulated a local chronological sequence for the upper Salado Creek drainage of northern Bexar County and attempted to standardize the associated lithic artifacts into a consistent format. When possible, previously described type names were used as well as references to other postulated or accepted type descriptions. Emphasis was placed on artifacts which did not fit previously defined types, revision of contradictory descriptions, and "problem" or poorly defined types. The resulting 
classifications were based on a description of morphological traits by group and form.

Typological categories identified by Black and McGraw's (1985) work are utilized for the identification of materials recovered from the current study area. Not a11 artifact categories 1 isted in Black and McGraw's (1985) typology are used in current identifications. Table 11 presents the morphological groups and forms recognized in this current study. Abbreviations used for artifact measurements are: L, length; W, width; and T, thickness. A11 are measured in centimeters. Table 12 presents the provenience for all collected prehistoric materials. Materials collected from surface surveys and excavated contexts are described by material type, site, and provenience.

\section{THICK BIFACES (TK; 9 specimens)}

Thick bifaces, percussion flaked with a maximum thickness of $\mathrm{ca} .1 .5 \mathrm{~cm}$ or more, are generally thought to represent an early stage 1 ithic reduction, such as rough shaping or general thinning of the raw material. Marginal trimming is absent from most specimens, and they often retain small areas of cortex. Some of these forms may have functioned as tools, but the identification and interpretations of such utilization cannot be made without extensive microwear pattern studies (B1ack and McGraw 1985:75).

\section{TK1. Group 1 - Subdiscoidal (2 specimens; Fig. 50,n,p)}

Specimen 1 is rounded in appearance and is flaked by soft hammer and pressure. This tool is manufactured from Tecovas (or Quitaque) jasper, a material indigenous to north Texas. The reader is referred to the site discussion of 41 BX 669 for a detailed interpretation of the significance of this artifact in the study area.

\section{L: $4.94 \mathrm{~cm}$ in diameter; T: $1.4 \mathrm{~cm}$.}

Provenience: $41 \mathrm{BX} 669$, surface.

Specimen 2 is manufactured from a medium brown, fine-grained chert. The artifact's edges, where thinned, are translucent. The thickest edge on the specimen is steeply beveled on the dorsal face, and this is contrasted to the opposite (dorsal) end which has a much more acute working edge. The artifact is only marginally bifacially worked.

L: $4.70 \mathrm{~cm} ; W: 4.15 \mathrm{~cm} ; \mathrm{T}: 1.57 \mathrm{~cm}$.

Provenience: 41 BX 669, surface. 
TABLE 11. PREHISTORIC ARTIFACTS, MORPHOLOGICAL GROUPS AND FORMS

Thick Bifaces (TK)

TK1. Group 1 - Subdiscoidal

TK2. Group 2 - Elliptical

TK2:1. Form 1 - Narrow

TK4. Group 4 - Elongate

TK4:1. Form 1 - Sma 11

TK11. Group 11 - Rounded Fragment

TK14. Group 14 - Pointed Fragments

Thin Bifaces (TN)

TNI. Group 1 - Lanceolate

TN1:1. Form I - Percussion Flaked

TN1:2. Form 2 - Pressure Flaked

TN2. Group 2 - Narrow

TN2:2. Form 2 - Thin, Leaf Shaped

TN3. Group 3 - Leaf to Ovate

TN3:2. Form 2 - Medium

TN8. Group 8 - Stemmed

TN8:2. Form 2 - Miscellaneous Contracting Stem

TN16. Group 16 - Misce11 aneous Fragments

TN16:1. Form 1 - Distal Fragments

TN16:3. Form 3 - Miscel1 aneous Fragments

Arrow Points (A)

Al. Group 1 - Contracting Stem Arrow Points, Perdiz

Ala. Group la - Contracting Stem Arrow Points, Perdiz, Possible Preform

A2. Group 2 - Expanding Stem Arrow Points

A2:2. Form 2 - Scallorn

A3. Group 3 - Miscellaneous Arrow Point Fragments

A3:1. Form 1 - Distal Fragment

$A 3: 2$. Form 2 - Basal Fragments

Dart Points (D)

D1. Group 1 - Side and Corner-Notched TrianguTar

DI:1. Form 1 - Frio

$D 1: 2$. Form 2 - Ensor

Dl:10. Form 10 - Edgewood

D2. Group 2 - Broad Triangular with Expanding Stem

D2:1. Form 1 - Monte11

D2:3. Form 3 - Marsha11

D2:5. Form 5 - Marcos

D3. Group 3 - Miscellaneous Sternmed

D3:1. Form 1 - Pedernales

$\mathrm{D} 3: 2$. Form 2 - Langtry

D3:4. Form 4 - Bulverde

D3:11. Form II - Be11

D3:12. Form 12 - Miscellaneous Stemmed (Proxima1)

D4. Group 4 - Early Expanding Stem

D4:3. Form 3 - Martindale 
TABLE 11. (continued)

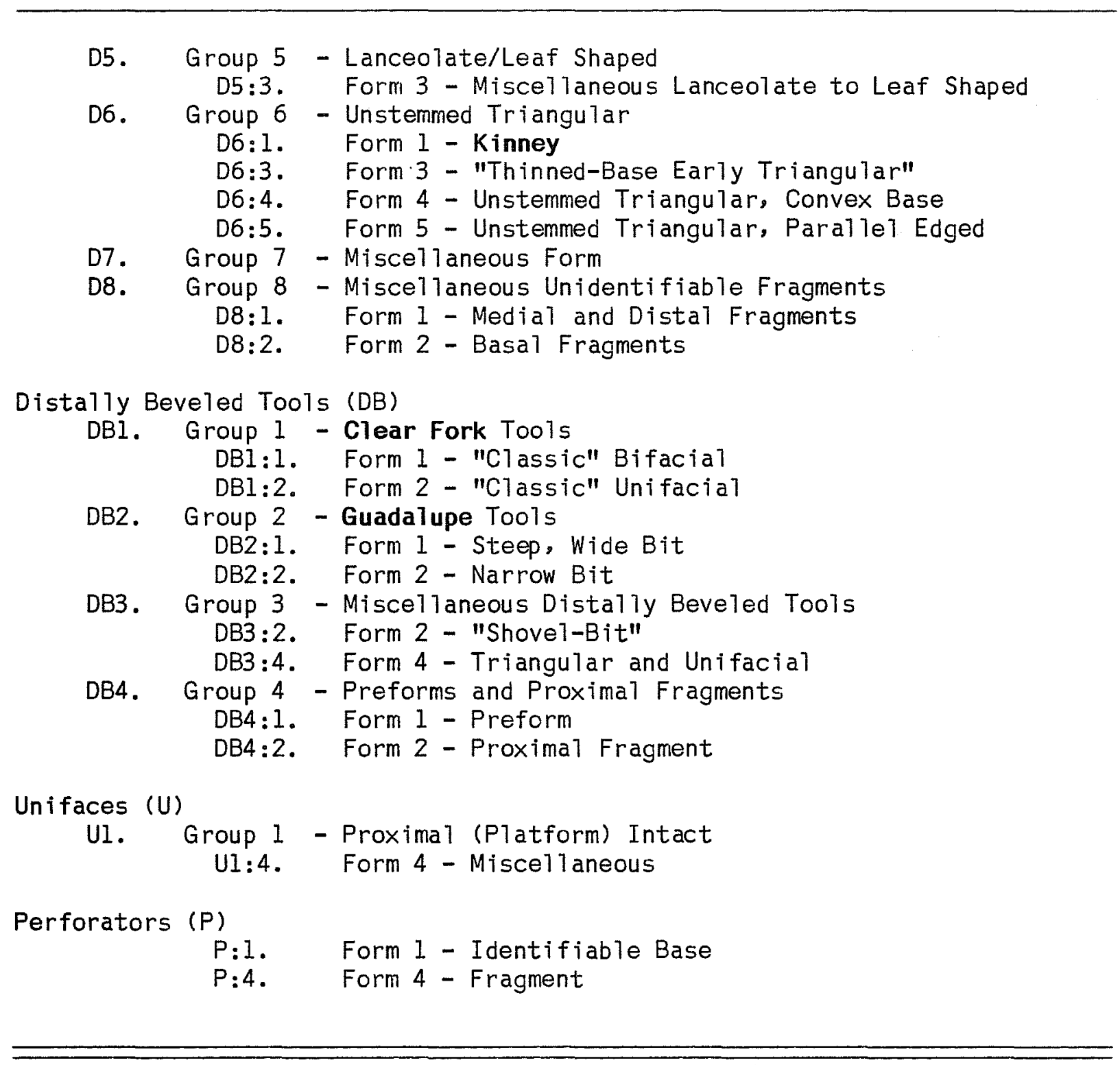


TABLE 12. PROVENIENCE OF COLLECTED PREHISTORIC MATERIALS

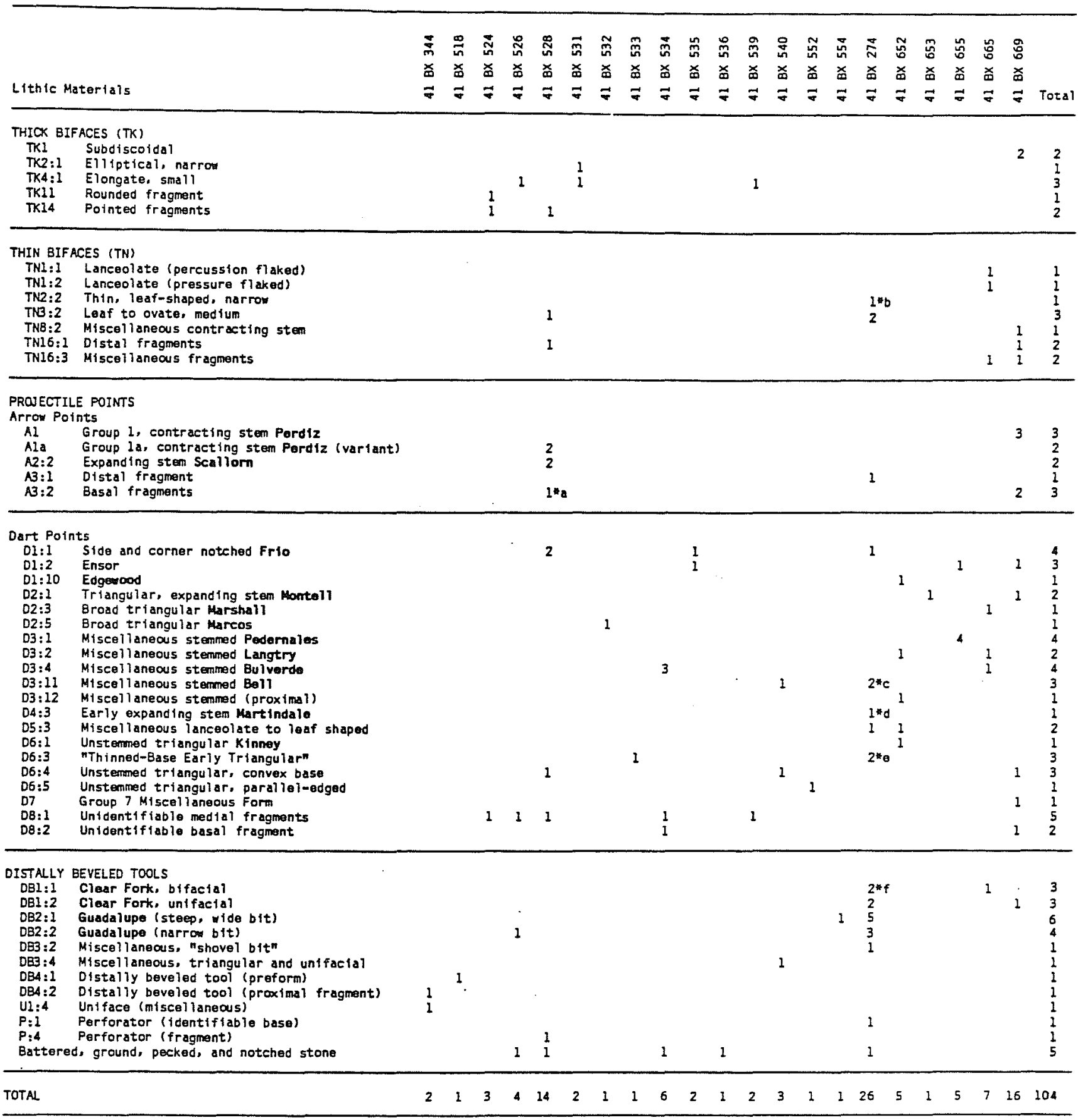

Note: Ut1lized/modffled chipped stone and spectal collection of ithic debris at 41 Bx 344 are discussed separately in text.

*a Guerrero(?)

to E1000 N1001

* E998 N999 (1). Surface (1)

* E999 N999

"Q Feature 1 (1), Surface (1)

"f Surface (1), Backhoe Trench (I) 
Figure 50. Collected Lithic Materials from 41 BX 669.

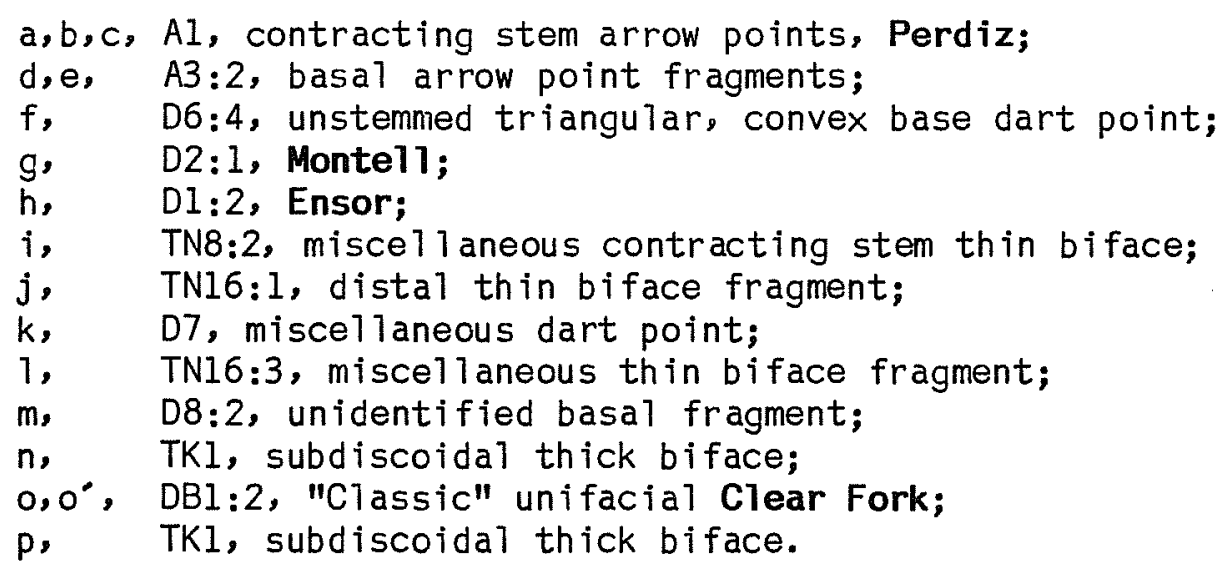




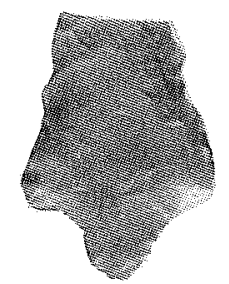

a

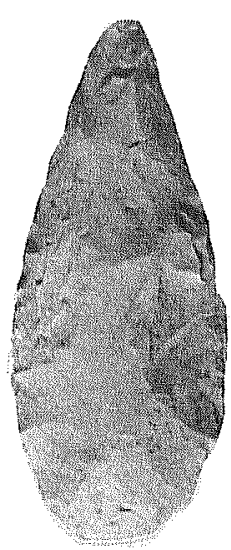

f

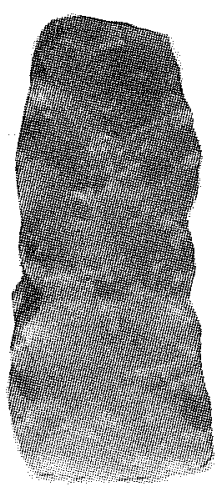

k

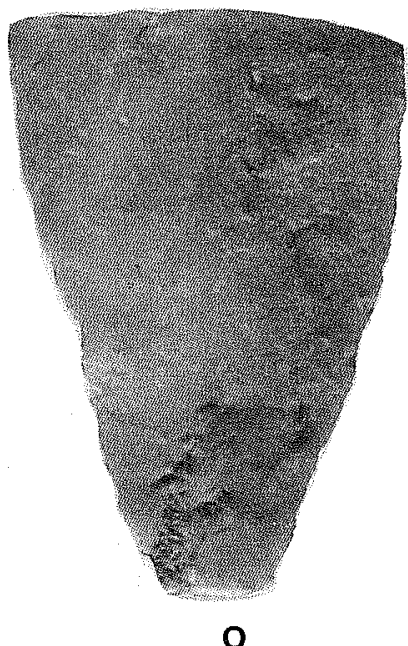

O

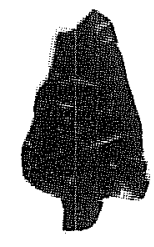

b

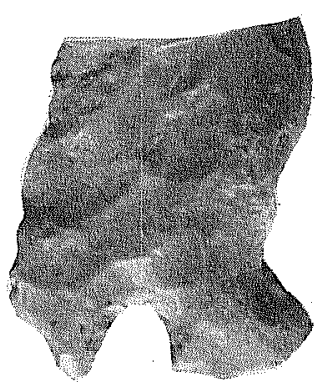

g

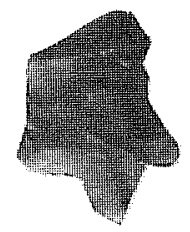

C

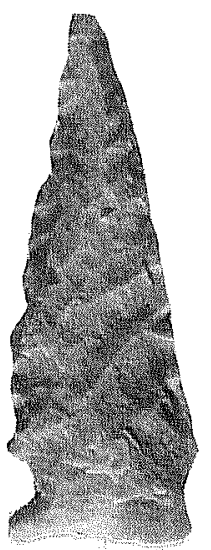

h
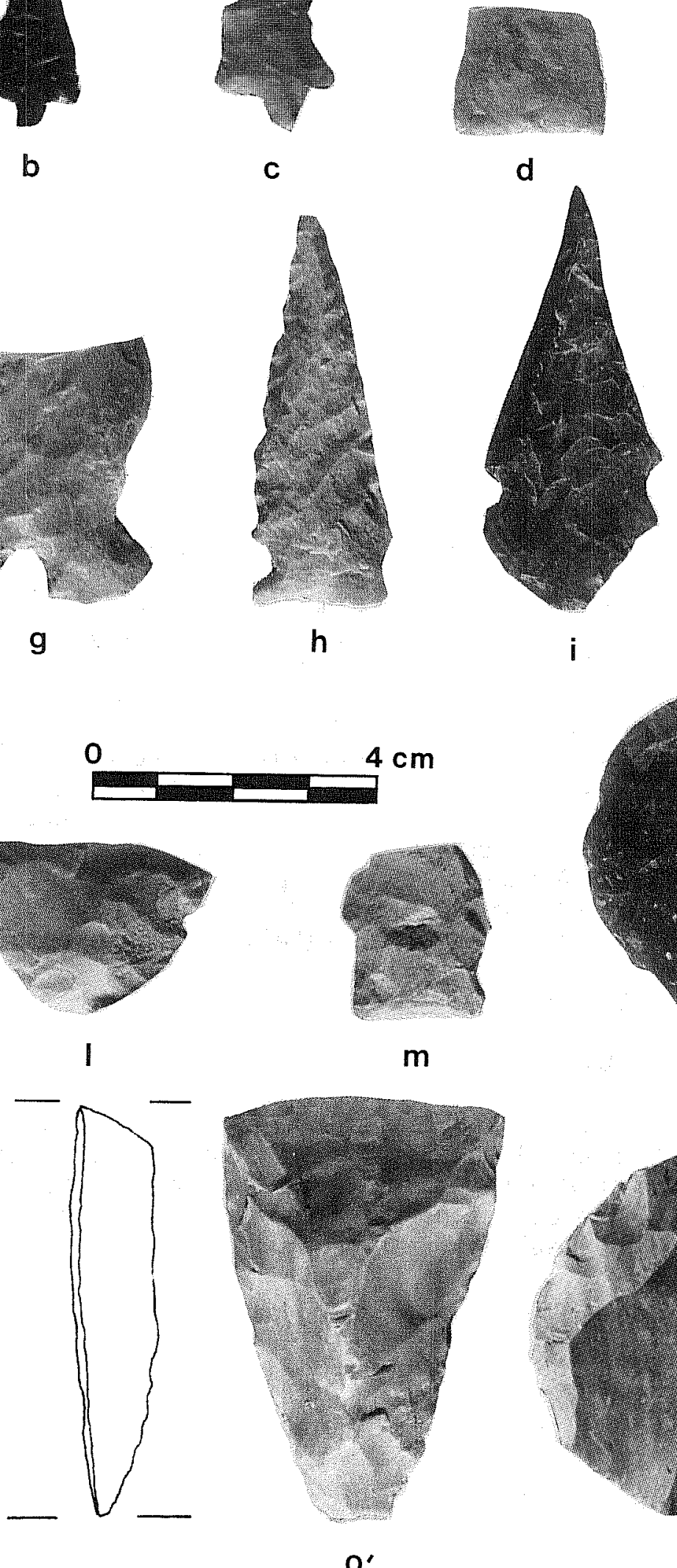

m
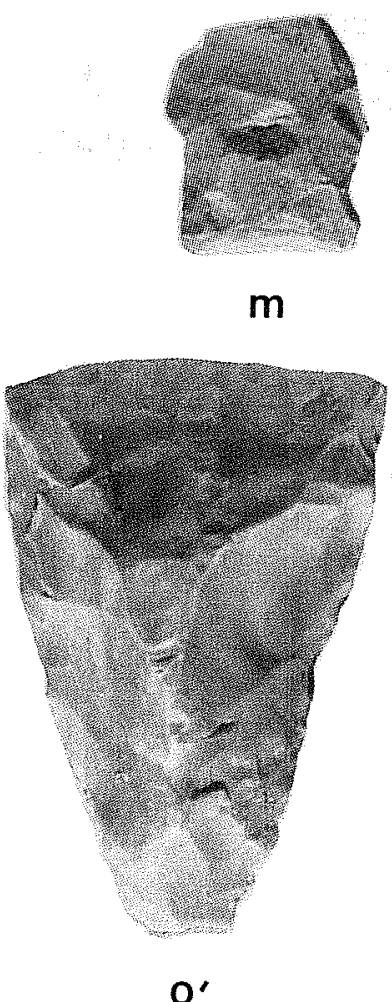

i
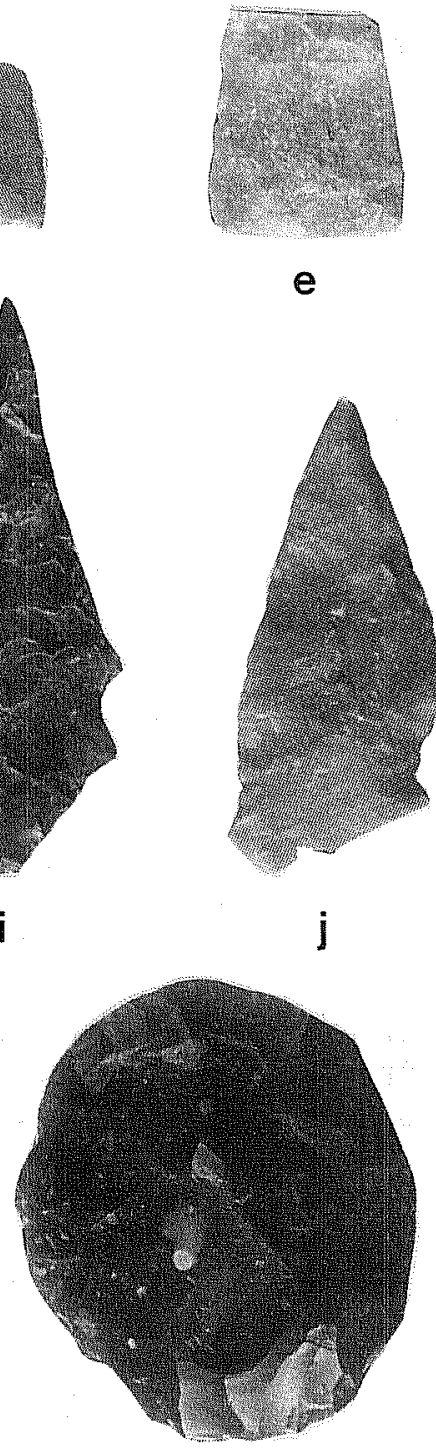

e

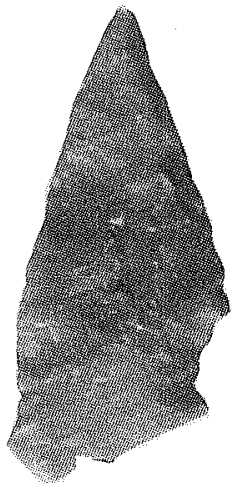

n

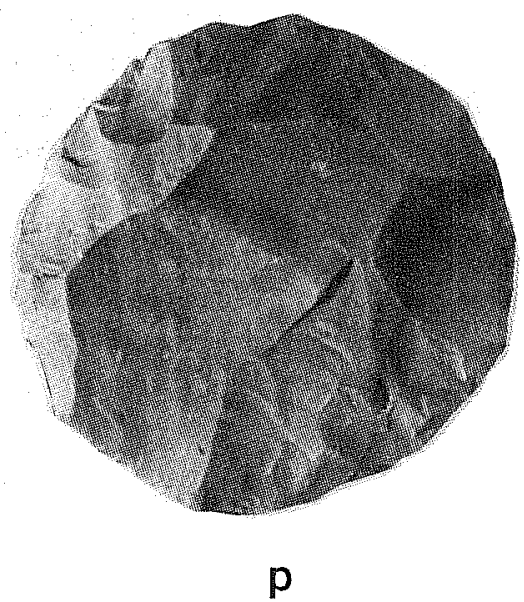


TK2. Group 2 - Elliptical

TK2:1. Form 1 - Narrow (width $<7.0 \mathrm{~cm} ; 1$ specimen; Fig. $51, \mathrm{c}$ )

Group 2, Form 1 thick biface specimen is suboval in out7ine. This artifact, unlike the others in the lithic collection, is chipped from petrified wood rather than chert. Extensive step fracturing is along the dorsal end. The angle of the working edges (about $85^{\circ}$ ) implies a gougelike function for the specimen, although the poor quality material and the crude workmanship would leave much to be desired in a functional tool.

L: $5.4 \mathrm{~cm} ; W: 3.7 \mathrm{~cm} ; \mathrm{T}: 1.9 \mathrm{~cm}$.

Provenience: $41 \mathrm{BX} 531$, surface.

TK4. Group 4 - Elongate

TK4:1. Form 1 - Sma11 (3 specimens; Figs. 51,b,d; 52,i)

Group 4, Form 1 thick biface specimens are small and elongated in outline with some hinge fracturing present on the surface. General morphology suggests unfinished, unidentifiable tool forms.

Specimen 1 (Fig. 52, $i$ ) is the remainder of a small, split chert cobble fragment. The dorsal side has semi-invasive retouch (flaking extends about one-third of the width across the face) on both edges. Cortex remains on unretouched surfaces. The distal end has been steeply beveled and has a working edge angle of about $80^{\circ}$. Ventral surfaces are lightly and randomly percussion flaked. A reddish tint on portions of the specimen suggests that it was heated or slightly burned at one time. Both dorsal and ventral surfaces of the distal end are moderately covered by small step fractures.

L: $5.6 \mathrm{~cm} ; W: 3.9 \mathrm{~cm} ; \mathrm{T}: 1.9 \mathrm{~cm}$.

Provenience: $41 \mathrm{BX} 526$, surface.

Specimen 2 (Fig. 51, b) is ovate in shape, but is 1 acking a portion of one edge. Numerous hinge fractures on both dorsal and ventral surfaces suggest that this artifact may have been discarded during the manufacturing process. A small but intense amount of minute step fracturing along a dorsal edge may indicate later informal utilization.

$\mathrm{L}: 5.4 \mathrm{~cm} ; W: 3.7 \mathrm{~cm} ; \mathrm{T}: 1.9 \mathrm{~cm}$.

Provenience: $41 \mathrm{BX} 531$, surface.

Specimen 3 (Fig. 51,d) is subovate in shape, thick, and extensively patinated. Alternate beveling along the edges gives the artifact a twisted appearance when viewed in cross section. Marginal and light semi-invasive retouch along the edges may indicate later re-use because these edges lack the patination that covers the rest of the surfaces. The degree of 
patination, the eccentricity of the tool, and the regularity of flaking indicate a specific tool form of unknown age.

L: $5.3 \mathrm{~cm} ; W: 1.49 \mathrm{~cm} ; \mathrm{T}: 1.49 \mathrm{~cm}$.

Provenience: 41 BX 539, surface.

TK11. Group 11 - Rounded Fragment (1 specimen; Fig. 52,g)

Group 11 thick biface specimen appears to be a broken, discarded, and later extensively utilized point fragment. The irregularly shaped artifact still has the remnants of a straight-sided, basally uncurved stem and a portion of one barb. Both faces are moderately patinated except for the edges. A11 edges reflect steep angle marginal retouch except for stem base and original snap fracture on blade. The distal blade portion, in cross section, shows numerous small step fractures. The original shape of the projectile point may have been similar to the type defined as Bulverde, but this is merely an estimate of the observer.

L: $4.2 \mathrm{~cm} ; W: 3.9 \mathrm{~cm} ; \mathrm{T}: 0.8 \mathrm{~cm}$.

Provenience: 41 BX 524, surface.

TK14. Group 14 - Pointed Fragments (2 specimens; Figs. $51, a ; 52, h$ )

Specimen 1 (Fig. 51 ,a) is subovate in shape, with the distal portion tapering to a narrow point. The actual distal end is broken. Cortex remains on portions of both dorsal and ventral surfaces. The proximal end is bifacially thinned. The remnant of the distal end appears more finely chipped than the rest of the artifact and is alternately beveled. The artifact is similar to types found in the region which are described as perforators.

\section{L: $6.5 \mathrm{~cm} ; W: 4.4 \mathrm{~cm} ; \mathrm{T}: 3.7 \mathrm{~cm}$.}

Provenience: 41 BX 528, surface.

Specimen 2 (Fig. 52,h), because of too much soft hammer(?) percussion flaking, may be an unfinished and perhaps discarded preform. Several large hinge fractures discouraged further thinning. The extensive amount of edge nicking and minute step fracturing suggests that the artifact was utilized at some time for purposes beyond its primary function.

L: $5.9 \mathrm{~cm} ; W: 3.4 \mathrm{~cm} ; \mathrm{T}: 1.3 \mathrm{~cm}$.

Provenience: $41 \mathrm{BX} 524$, surface. 
Figure 51. Collected Lithic Materials from Prehistoric Sites in Project Area.

a, TK14, pointed thick biface fragment (41 BX 528);

b. TK4:1, elongate, smal1 thick biface (41 BX 531);

c, TK2:1, elliptical, narrow thick biface (41 BX 531);

d. TK4:1, elongate, smal1 thick biface (41 BX 539);

e, D6:4, unstemmed triangular, convex base dart point (4I BX 528);

f, D2:5, Marcos (41 BX 532);

g, D6:3, "Thinned-Base Early Triangular" (41 BX 533);

h, D1:1, Frio (41 BX 535);

i, Dl:2, Ensor (4I BX 535);

$j$, D6:4, unstemmed triangular, convex base dart point (41 BX 540);

$k$, D6:5, unstemmed triangular, parallel edged dart point (41 BX 552);

1-p. Group 8, miscel 1 aneous unidentifiable fragments (41 BX 524, 41 BX 526, 41 BX 528, 41 BX 534, 41 BX 539);

q, D6:3 "Thinned-Base Early Triangular" (41 BX 274). 
Applewhite/Material Culture

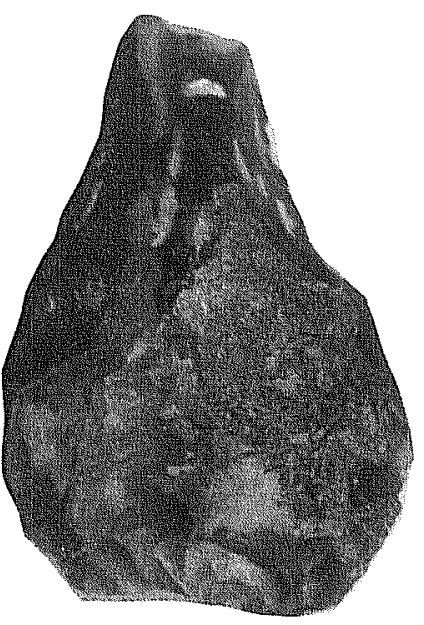

a

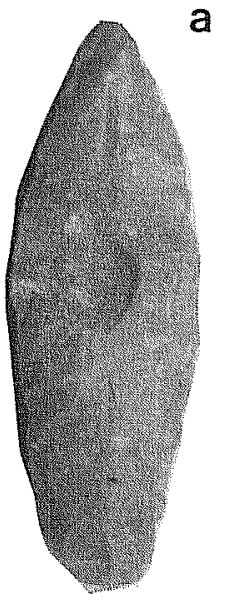

e

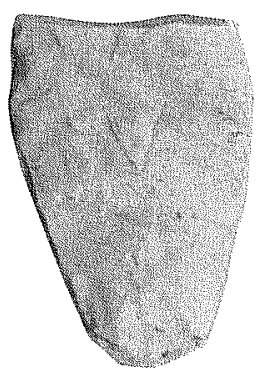

j

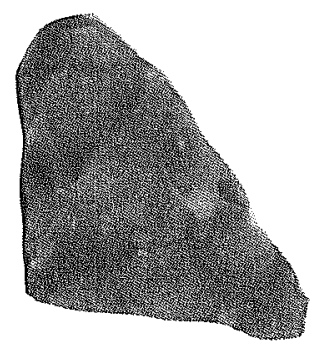

n

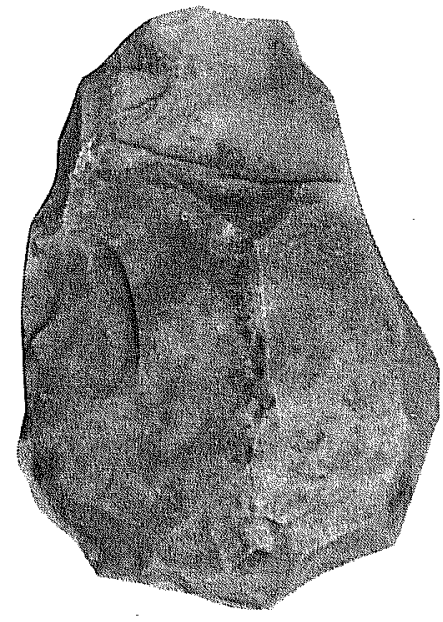

b

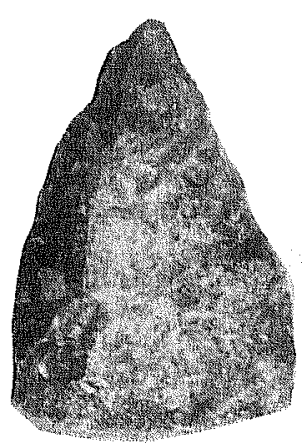

g

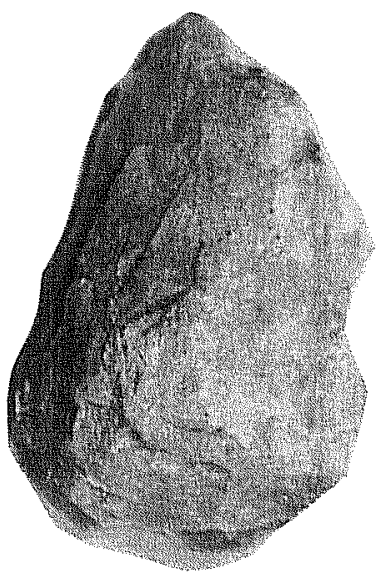

C

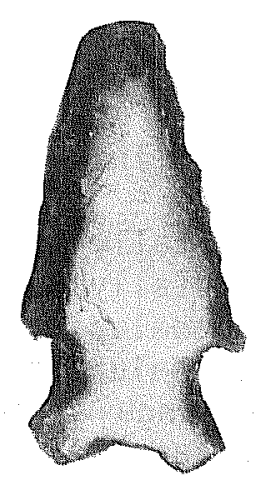

h
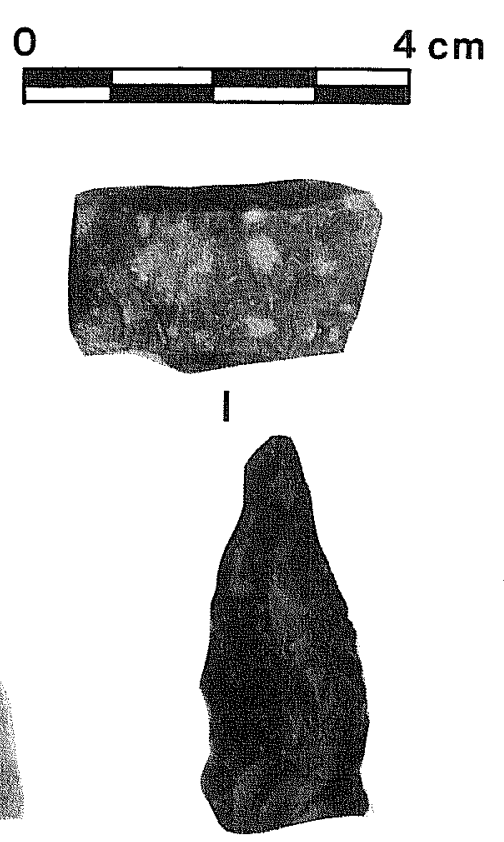

$p$

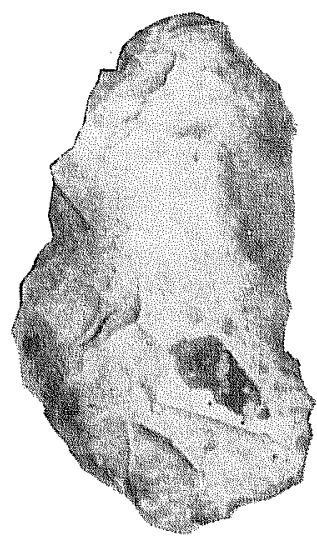

d

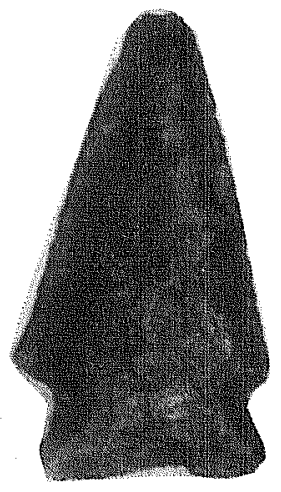

i

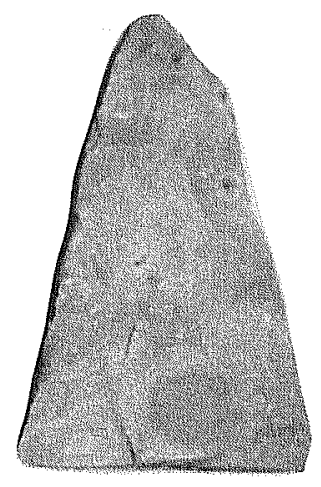

m

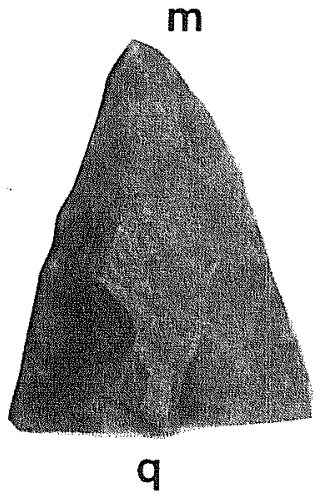


Figure 52. Thick Bifaces, Distally Beveled Tools, and Uniface.

a, DB4:1, distally beveled tool preform (41 BX 518);

b, DB4:2, distally beveled tool proximal fragment (41 BX 344);

c, DB2: 1, GuadaTupe tool (41 BX 554);

d, DB2:2, Guadalupe tool (41 BX 526);

e, DB3:4, triangular and unifacial distal1y beveled tool (41 BX 540);

f, Ul:4, uniface (4I BX 344);

g, TKII, rounded thick biface fragment (41 BX 524);

$h$, TK14, pointed thick biface fragment (4I BX 524);

$i$, TK4:l, elongate, small thick biface (4l BX 526). 
Applewhite/Material Culture

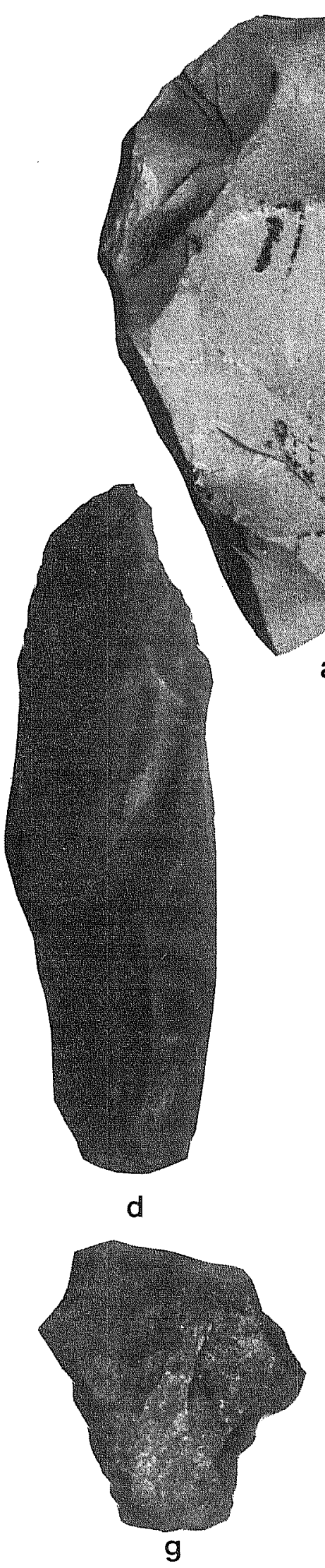

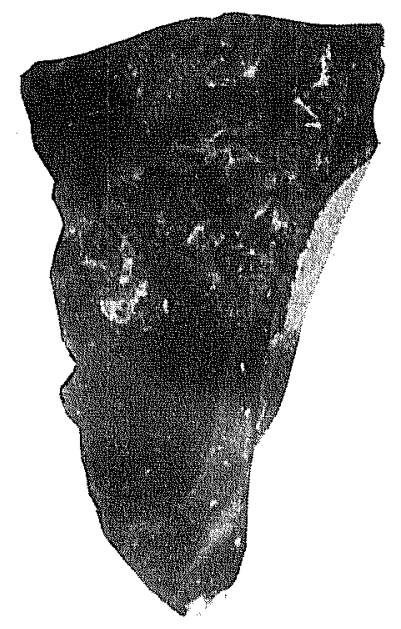

b
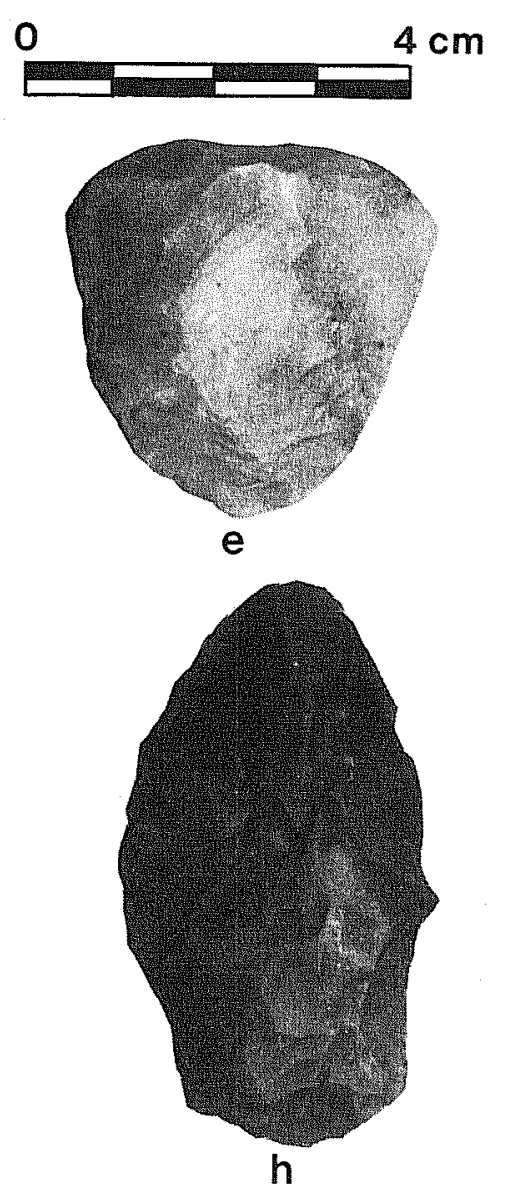

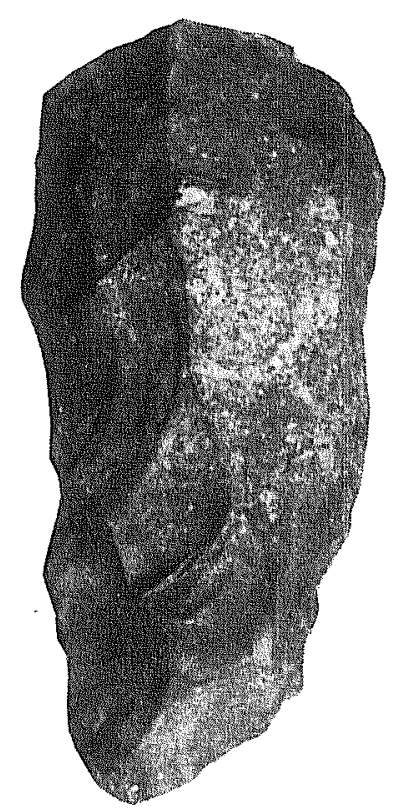

c
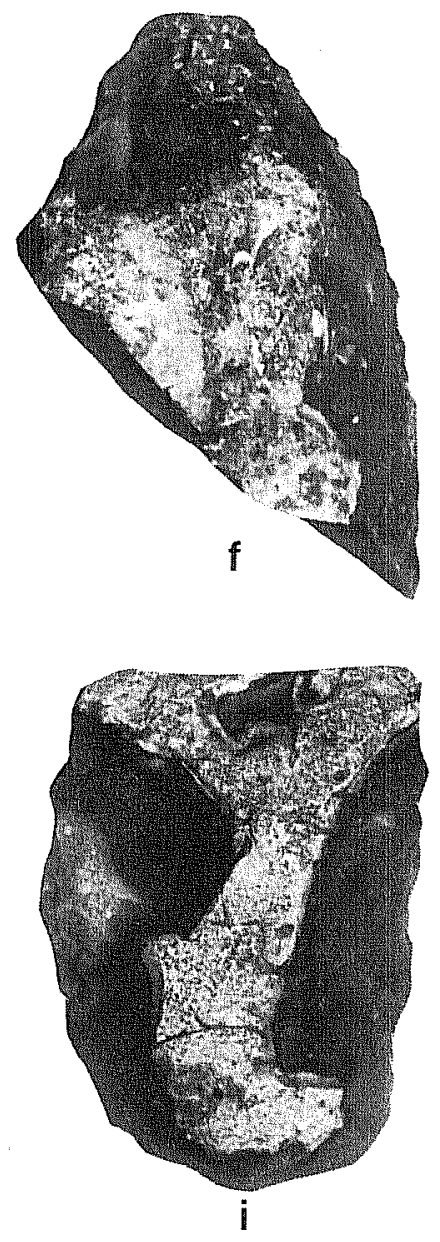
THIN BIFACES (TN; less than $1.5 \mathrm{~cm}$ in thickness; 11 specimens)

TN1. Group 1 - Lanceolate

TN1:1. Form 1 - Percussion Flaked (1 specimen; Fig. 53,e)

Group 1, Form 1 thin biface specimen has a lanceolate blade outline, and blade edges are parallel to slightly convex. The base is slightly convex, with a long and narrow blade.

$\mathrm{L}: \quad 8.1 \mathrm{~cm} ; W: 2.2 \mathrm{~cm} ; \mathrm{T}: 0.8 \mathrm{~cm}$.

Provenience: $41 \mathrm{BX} 665$, surface.

TN1:2. Form 2 - Pressure Flaked (1 specimen; Fig. 53,f)

Group 1, Form 2 thin biface specimen is characterized by a reworked distal end and may have been (much) longer when originally manufactured.

L: $5.2 \mathrm{~cm} ; W: 1.5 \mathrm{~cm} ; \mathrm{T}: 0.7 \mathrm{~cm}$.

Provenience: 41 BX 665, surface.

TN2. Group 2 - Narrow

TN2:2. Form 2 - Thin, Leaf Shaped (1 specimen; Fig. 54,f)

Group 2, Form 2 thin biface specimen has convex blade edges with a dulled distal end and a reworked blade.

L: $4.4 \mathrm{~cm} ; W: 2.01 \mathrm{~cm} ; \mathrm{T}: 1.05 \mathrm{~cm}$.

Provenience: 41 BX 274, E1000 N1001.

TN3. Group 3 - Leaf to Ovate

TN3:2. Form 2 - Medium (5-7 cm in 1ength; 3 specimens; Figs. 55, j; 56,b,f)

Specimen 1 (Fig. 55,j) is manufactured from a light brown, fine-grained chert. The thinness of the artifact gives it a translucent quality, and the lateral edges have been dulled and extensively pressure flaked. The bifacially worked artifact may be related to relatively late chronological contexts at the site as other collected artifacts include Late Prehistoric Scallorn and Perdiz arrow points, ceramics, and a possible historic Indian Guerrero point.

L: $5.20 \mathrm{~cm} ; W: 3.84 \mathrm{~cm} ; \mathrm{T}: 5.60 \mathrm{~cm}$.

Provenience: $41 \mathrm{BX} 528$, surface. 
Specimen 2 (Fig. $56, b$ )

L: $5.72 \mathrm{~cm} ; W: 2.05 \mathrm{~cm} ; \mathrm{T}: 0.72 \mathrm{~cm}$.

Provenience: $41 \mathrm{BX} 274$, surface.

Specimen 3 (Fig. 56,f)

L: $\quad 5.19 \mathrm{~cm} ; W: 2.94 \mathrm{~cm} ; \mathrm{T}: 0.78 \mathrm{~cm}$.

Provenience: $41 \mathrm{BX} 274$, surface.

\section{TN8. Group 8 - Stemmed}

TN8:2. Form 2 - Miscellaneous Contracting Stem (1 specimen; Fig. 50,i)

Group 8, Form 2 thin biface specimen is characterized by an alternately beveled blade slightly convex in outline. The unusual proximal end is expanding and at its median, strongly contracts. The biface is generally triangular with a convex base and side notched with the barbs in line with the upper stem outlines.

$\mathrm{L}: 6.2 \mathrm{~cm} ; W: 2.6 \mathrm{~cm} ; \mathrm{T}: 0.54 \mathrm{~cm}$.

Provenience: 41 BX 669, surface.

TN16. Group 16 - Miscellaneous Fragments

TN16:1. Form 1 - Distal Fragments (2 specimens; Figs. $50, j ; 55, i$ )

Specimen 1 (Fig. 50,j) is the distal portion of a small biface characterized by alternate beveling of the blade and asymmetrical side notching, assumed to be the result of extensive reworking. The width and thickness suggest possible morphological similarities to TN8:2, also recovered from the same site.

L: $4.86 \mathrm{~cm} ; W: 2.12 \mathrm{~cm} ; \mathrm{T}: 0.53 \mathrm{~cm}$.

Provenience: $41 \mathrm{BX} 669$, surface.

Specimen 2 (Fig. $55, i$ ) is also characterized by alternate beveling of the b7ade edges by soft-hammer percussion. Minute abrasion of portions of the edges reflect some dulling but this may represent only a manufacturing step of the lithic reduction. The cross section of the distal fragment shows a silica inclusion which may have contributed to the failure of the material during the manufacturing stage.

L: $4.79 \mathrm{~cm} ; W: 3.66 \mathrm{~cm} ; \mathrm{T}: 0.7 \mathrm{~cm}$.

Provenience: $41 \mathrm{BX} 528$, surface. 
Figure 53. Surface Collected Artifacts from 41 BX 665.

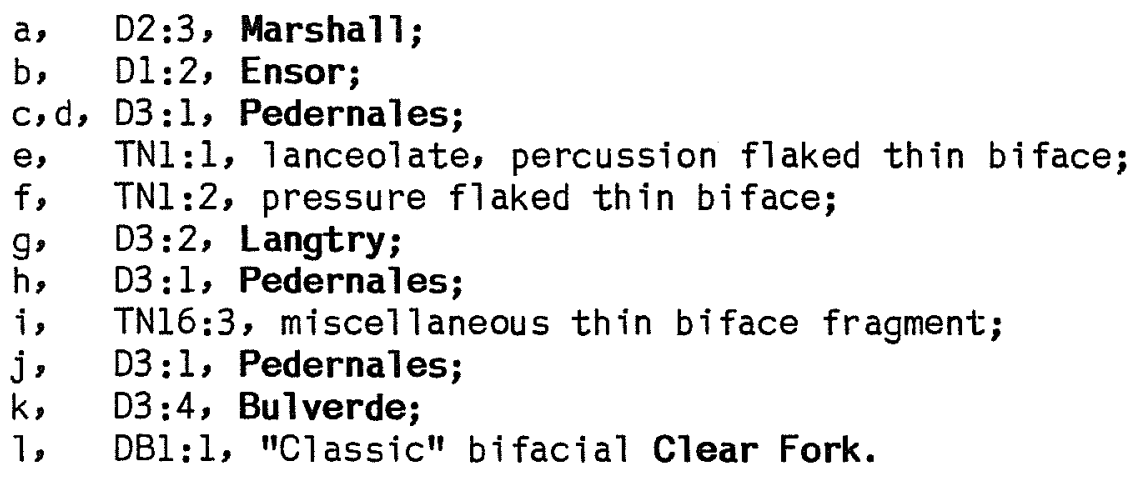




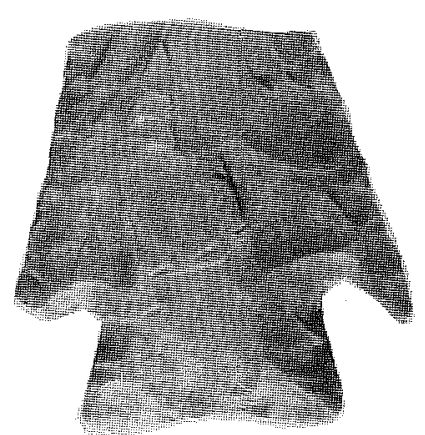

a

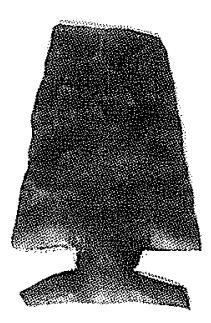

b

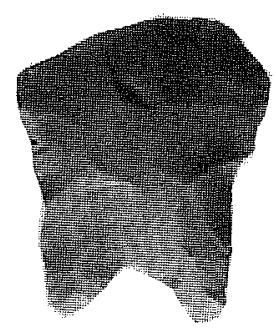

C

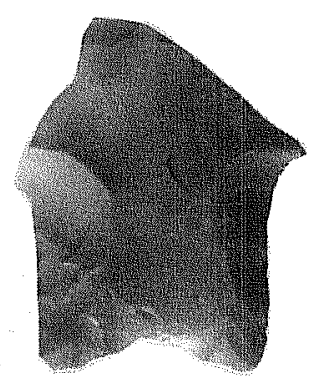

d

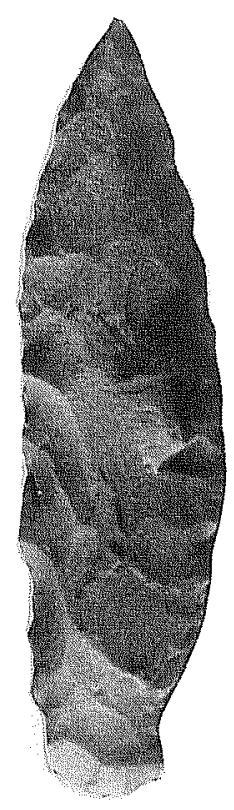

e

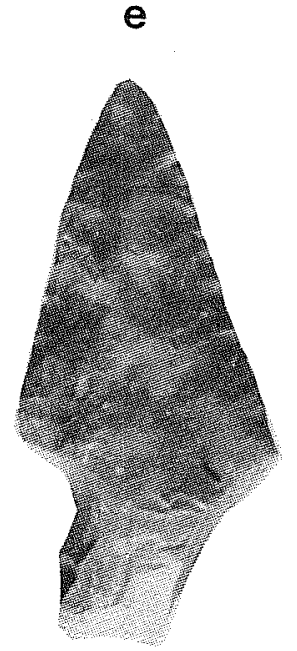

i

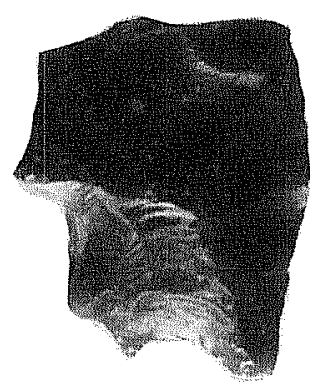

j

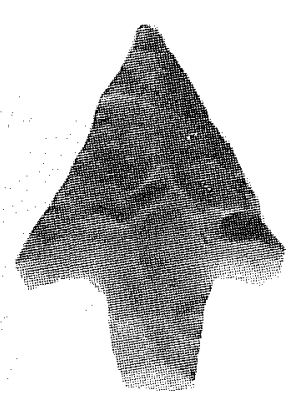

g
$4 \mathrm{~cm}$.

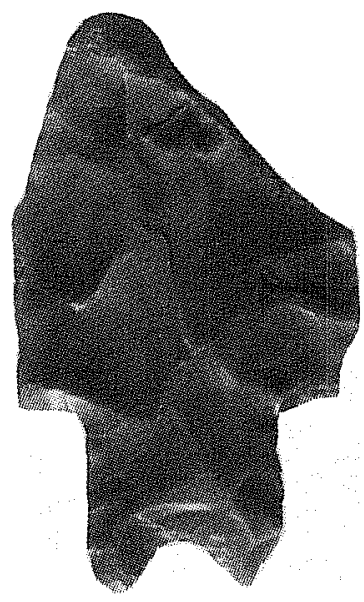

h 


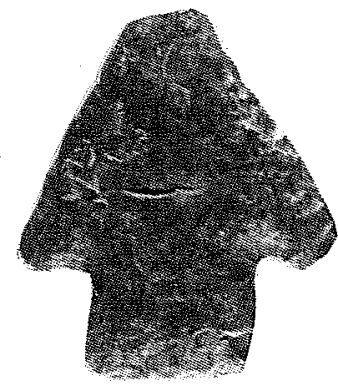

a

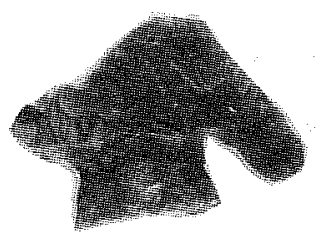

b

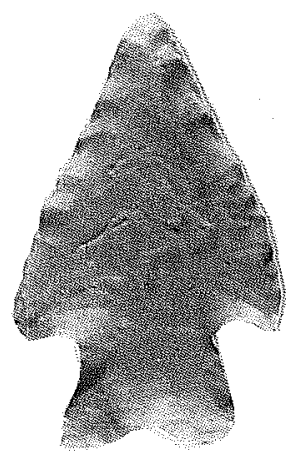

C

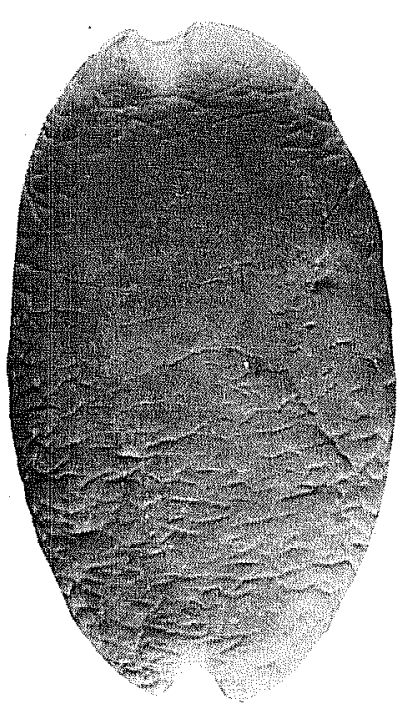

d

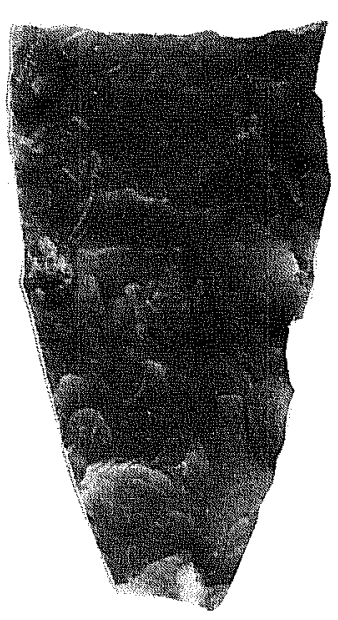

e
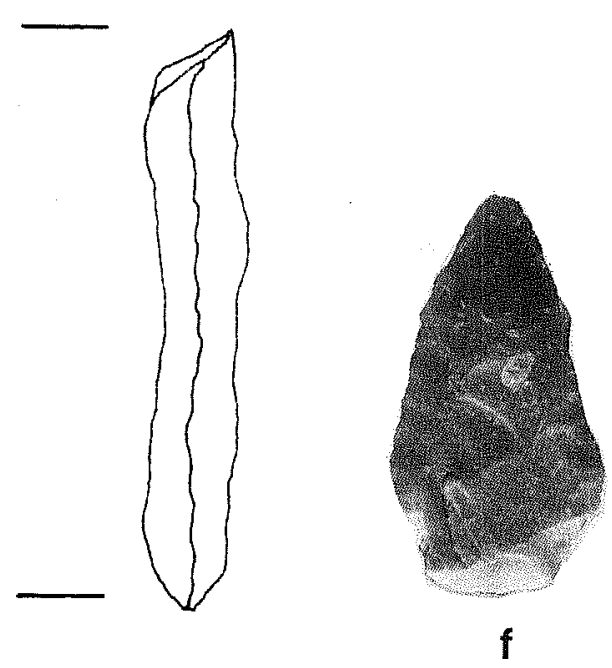

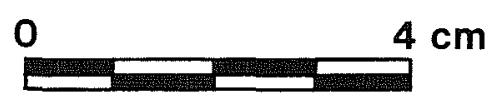

Figure 54. Artifacts from 41 BX 274. a,b, D3:11, Be1 1; C, D4:3, Martindale; d, quartzite pebb 1e; e, DBl:1, "Classic" bifacial Clear Fork (Specimen 3); f, TN2:2, thin, 1eaf-shaped thin biface. 
TN16:3. Form 3 - Misce11aneous Fragments (2 specimens; Figs. 50,1;53,i)

With an alternatively beveled blade, Specimen 1 (Fig. $53, i$ ) is the fragmented lateral edges of a lower blade and stem. Presumed to have functioned as a knife, identification of a more discrete type is precluded by the lack of an identifiable base.

$\mathrm{L}: \quad 6.0 \mathrm{~cm} ; \mathrm{W}: 2.80 \mathrm{~cm} ; \mathrm{T}: 0.87 \mathrm{~cm}$.

Provenience: $41 \mathrm{BX} 665$, surface.

Specimen 2 (Fig. 50,1) is characterized by a semiovate shape which has fractured 1atera71y. Burned and pot-1idded, the artifact may have functioned at one time as a small scraper as the rounded tip is distinctly beveled and shaped by minute pressure flaking.

$\mathrm{L}:$ (incomplete) $2.48 \mathrm{~cm} ; \mathrm{W}: 3.41 \mathrm{~cm} ; \mathrm{T}: 0.58 \mathrm{~cm}$.

Provenience: 41 BX 669, surface.

\section{PROJECTILE POINTS}

Projectile points are separated into arrow and dart points. Arrow points are generally identified as weighing less than $2.5 \mathrm{~g}$ and are associated with the Late Prehistoric or Historic period and the usage of the point with a bow. Dart points may include thrusting projectile points ("spear" points), but this distinction, as well as the possible (and probable) multifunctional use of these thin, hafted bifaces are beyond the scope of this work. Black and McGraw (1985:95-97) outline some of the contemporary problems and aspects of this typology, and the reader is referred to this work and its associated references for a more detailed background.

Following Black and McGraw (1985), arrow points were divided into three groups and dart points into eight groups. Not all of the projectile point types identified in the $41 \mathrm{BX} 228$ material collection are represented in the collection from the present study area. Additionally, several projectile points (e.g., convex based) not represented in the previous work but identified in this study have been added into the typological scheme with accompanying descriptions.

\section{Arrow Points (A; 11 specimens)}

The current study was characterized by a paucity of arrow points. Several factors are thought to contribute to this lack of arrow points: (1) the more difficult recovery of such small artifacts at potential Late Prehistoric site locations due to dense ground cover, modern surface alterations, or previous relic collecting; and (2) the relative infrequency of Late Prehistoric sites as compared to Archaic sites which predominate the prehistoric site record of the study area. The prehistoric ceramics observed and collected at various locations are contrasted to the lack of recovered arrow points. This strongly suggests that the paucity of arrow points is a surface 
Figure 55. Surface Collected Artifacts from 41 BX 528.

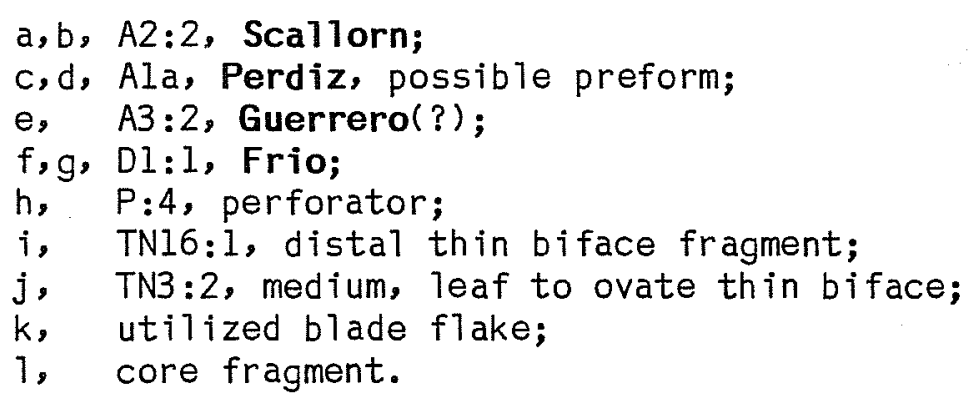


Applewhite/Material Culture

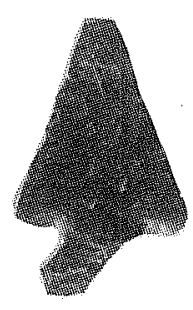

a

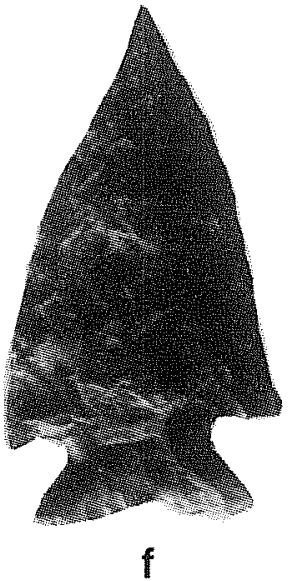

$f$

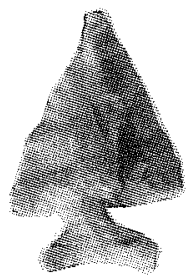

b

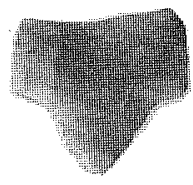

C
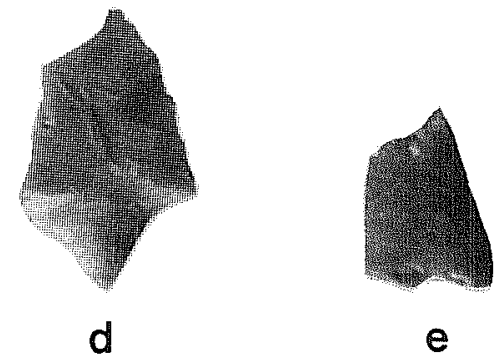
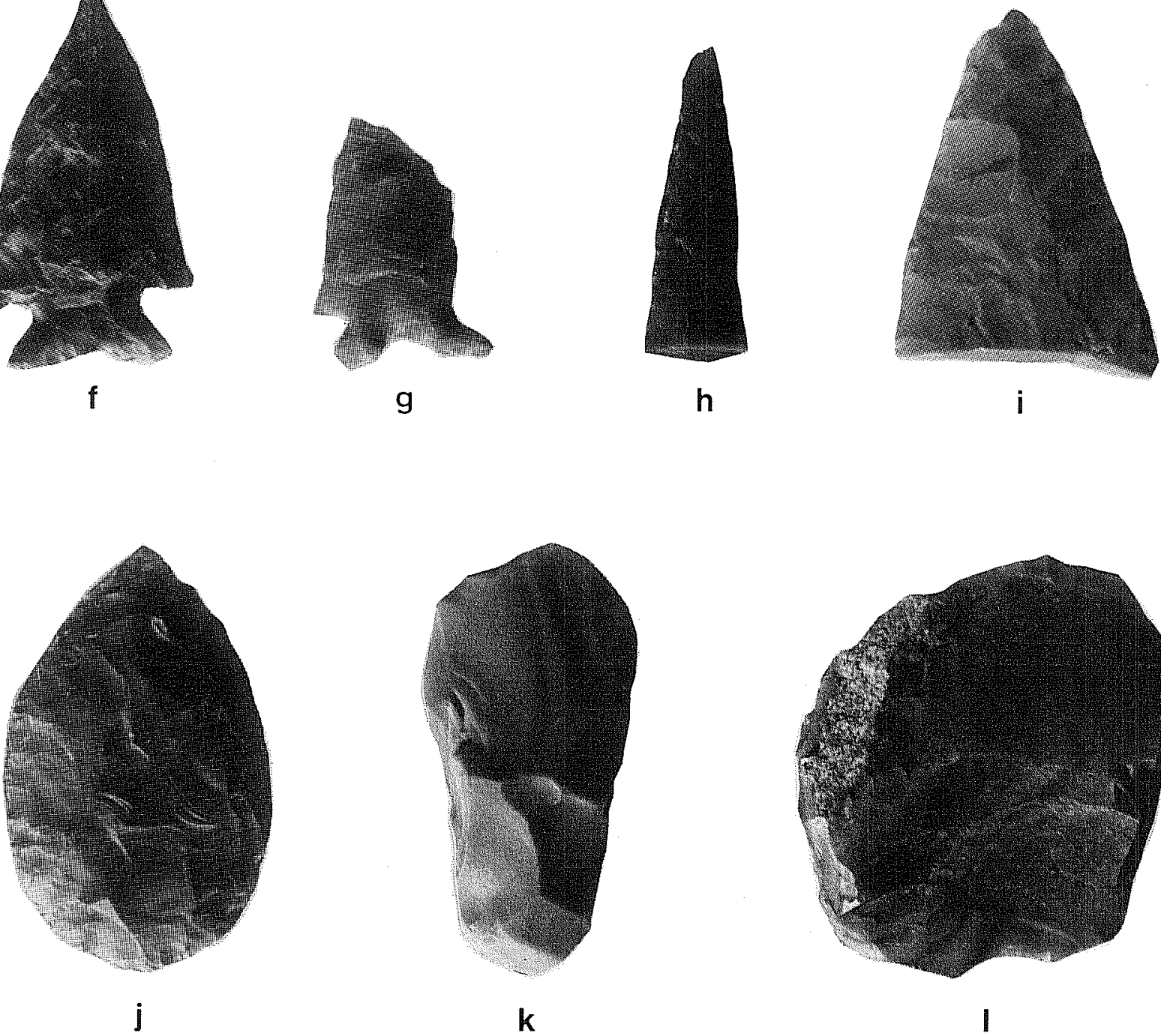

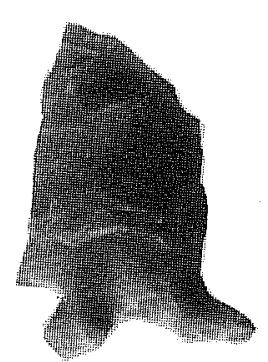

g

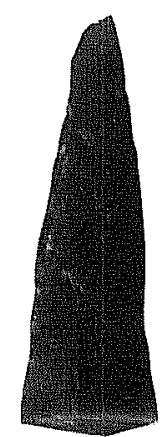

h

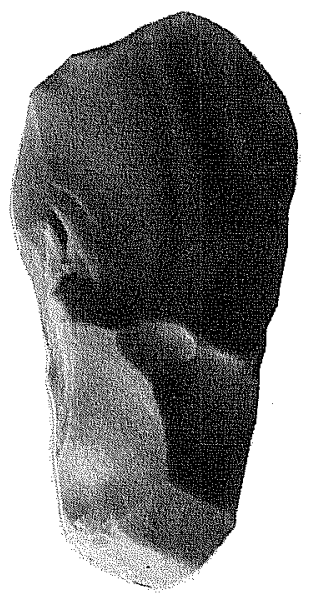

k
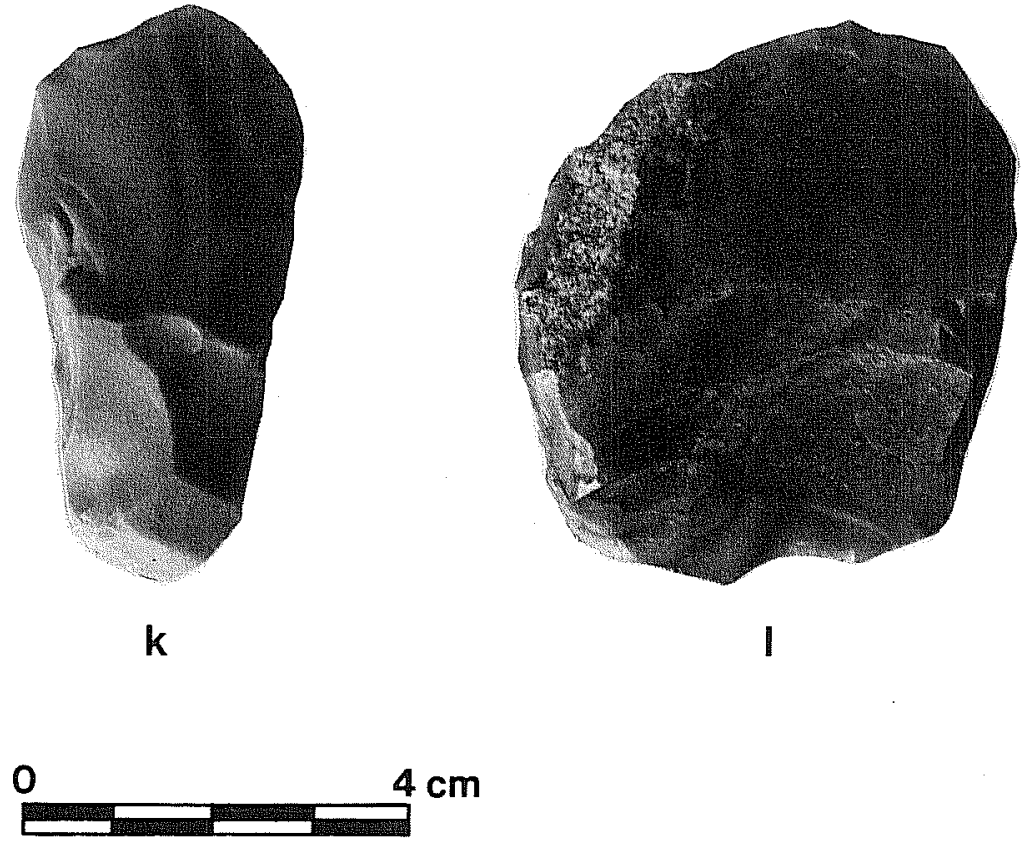
characteristic of the Late Prehistoric sites in the area rather than survey or collection difficulties.

A1. Group 1 - Contracting Stem Arrow Points, Perdiz (3 specimens; Fig. $50, a, b, c)$

Blade outlines of contracting stem arrow points are triangular, and vary widely in workmanship from finely made to crude. The type has radiocarbonassociated dates in the region from ca. A.D. 1300-1600 (Jelks 1962). These arrow points have been identified as belonging to Local Period 11 at 41 BX 228 in Bexar County (B1ack and McGraw 1985), with 1ocal radiocarbon dates of A.D. 1000-1610 (see Table 5). See Suhm and Jelks (1962), Hester (1980), and Turner and Hester (1985) for additional information on this type.

Specimen 1 is lacking the distal tip. It is dark gray in color and bifacially worked. The artifact is manufactured from extremely fine-grained chert. Moderate blade edge serration is noted.

L: $2.38 \mathrm{~cm} ; W: 1.40 \mathrm{~cm} ; \mathrm{T}: 0.85 \mathrm{~cm}$.

Provenience: 41 BX 669, surface.

Specimen 2 is more crudely worked and is unifacial in character. The chert is also dark gray in color but less fine grained.

L: $2.1 \mathrm{~cm} ; W: 1.65 \mathrm{~cm} ; \mathrm{T}: 0.25 \mathrm{~cm}$.

Provenience: 41 BX 669, surface.

Specimen 3 is a burned, bifacially worked artifact that lacks the distal tip and shows some marginal blade edge fracturing.

L: $2.78 \mathrm{~cm} ; W: 2.06 \mathrm{~cm} ; \mathrm{T}: 0.45 \mathrm{~cm}$.

Provenience: 41 BX 669, surface.

Ala. Group 1a - Contracting Stem Arrow Points, Perdiz; Possible Preform (2 specimens; Fig. $55, \mathrm{c}, \mathrm{d}$ )

These specimens, both unifacial, may be considered as Perdiz but are listed separately because of the crude workmanship. Additionally, as both specimens were surface collected from the same site, 41 BX 528, they may represent a cultural and/or chronological variant of the general type. Alternatively, they may simply be unfinished points. Manufactured from a fine-grained, tancolored chert, they reflect a minimum amount of workmanship in the form of pressure flaking. The relatively wide stems are the only portion of both specimens that are bifacially worked. Chronological contexts are thought to be similar to $A 1: 1$, although a historic Indian component is postulated for site 41 BX 528. 
Specimen 1 (Fig. 55,c) is a proximal fragment. This specimen, al though a basal end, is identified as a Perdiz variant because of its distinctive, contracting stem.

L: $1.68 \mathrm{~cm} ; W: 1.85 \mathrm{~cm} ; \mathrm{T}: 0.24 \mathrm{~cm}$.

Provenience: 41 BX 528.

Specimen 2 (Fig. 55,d) 1acks the distal tip and one blade edge.

L: $2.94 \mathrm{~cm} ; W: 1.83 \mathrm{~cm} ; \mathrm{T}: 0.19 \mathrm{~cm}$.

Provenience: 41 BX 528.

A2. Group 2 - Expanding Stem Arrow Points

A2:2. Form 2 - Scallorn (2 specimens; Fig. 55,a,b)

Collected from $41 \mathrm{BX} 528$, these two arrow points are similar to Black and McGraw's (1985:101-102) and Jelk's (1962:30) description of the Late Prehistoric Scallorn type. Characterized by a triangular blade shape and prominent shoulders, the stems are often deeply corner notched. Stems are often as wide as the blade, however, the two collected specimens have broken stem tips. Stem bases are usually straight or slightly curved (convex). These arrow points are associated with B Tack and McGraw's (1985:324) Local Period 10, ca. A.D. 900, although Prewitt (1981) suggests a slightly earlier time frame, ca. A.D. 700. As BTack and McGraw (1985:102) observe, there is some morphological overlap with the Edwards type.

Specimen 1 (Fig. 55,a)

L: (1acks distal tip) $2.9 \mathrm{~cm} ; W: 1.79 \mathrm{~cm} ; \mathrm{T}: 0.36 \mathrm{~cm}$.

Provenience: 41 BX 528.

Specimen 2 (Fig. 55, b)

L: $2.72 \mathrm{~cm} ; W: 1.81 \mathrm{~cm} ; \mathrm{T}: 0.37 \mathrm{~cm}$.

Provenience: 41 BX 528.

\section{A3. Group 3 - Misce1laneous Arrow Point Fragments}

A3:1. Form 1 - Distal Fragment (1 specimen; not i1lustrated)

Group 3, Form 1 arrow point specimen is a sma11, thin chipped distal portion of a biface. The fragment cannot be associated with a Late Prehistoric regionally defined phase or local period (as defined by Black and McGraw 1985), but it does indicate Late Prehistoric activity at this location.

L: $2.5 \mathrm{~cm} ; W: 2.2 \mathrm{~cm} ; \mathrm{T}: 0.42 \mathrm{~cm}$. 
Provenience: $41 \mathrm{BX} 274$, surface.

A3:2. Form 2 - Basal Fragments (3 specimens; Figs. 50,d,e; 55,e)

The authors believe that Specimen 1 (Fig. 55,e), a small, burned arrow point proximal fragment with a concave base, is a variant of the historic Indian Guerrero point type. Unfortunately, the fragmentation of the artifact makes this identification less than conclusive, therefore, it is identified as simply a miscellaneous basal fragment. The inferences behind the identification of this artifact as a possible historic Indian arrow point are quite significant, thus, a short discussion of the Guerrero point type is presented.

The Guerrero point type is a sma11, unstemmed triangular arrow point often characterized by parallel-oblique flaking and a slightly convex base. On some variants, this curve of the base is more pronounced, and a shallow, oblique angle is formed between the basal ends and the basal apex, or median point. This characteristic is best illustrated from a specimen collected at Mission San Antonio de Valero (Eaton 1980).

The cultural associations of this type are unclear, although they have been commonly identified at or near Spanish colonial mission sites in southern and south-central Texas and in northeastern Mexico. Hester (1977b:10) points out that researchers have confused this type with Fresno while others have suggested associations with Lipan Apache groups and a Plains origin.

In the San Antonio area, triangular unstemmed arrow points have been recovered at the mission sites. One exception to this is Mission Espada; information currently available to the authors does not indicate the presence of such points. However, Guerrero points have been recovered from Las Cabras, the outlying ranch of Mission Espada (Ivey and Fox 1981:37-38; Taylor and Fox 1985:32).

While research has shown the distribution of Guerrero points to include south-central and southern Texas as well as northeastern Coahuila, the type is similar in morphology and workmanship to variants of the east Texas Turney type thought to be historic Indian (Suhm and Jelks 1962:147). Different regional contexts notwithstanding, there does seem to be some cultural overlap as Scurlock and Fox (1977:Fig. 34,e) illustrate what appears to be a typical example of the Turney type. This specimen is presented with several other triangular points recovered from Mission Concepcion in San Antonio. The east Texas affiliations of the mission are real as it was withdrawn from that area and reestablished in San Antonio ca. 1729-1731.

Additionally, the triangular form associated with Guerrero points or Turney variants is widespread in the Protohistoric and Historic periods across much of the Plains area east of the Rocky Mountains. "Fresno" variants (triangular arrow points) dated at ca. A.D. 900-1370 occur as far south as Cueva de 1a Zona de Derrumbes and La Calsada, Mexico (Nance 1980:41-57).

Points similar to the morphology of Guerrero that occur with side-notched Washita arrow points are also common in south-central 0klahoma and are dated 
at Ca. A.D. 1000-1500 (see Brooks, Drass, and Swenson 1985). Baugh (1982:125) identifies such a type as "Fresno Variety I" in his discussion of southern plains adaptations in the Protohistoric period. Baugh (1982:43-44) also notes that the assemblages associated with the point type were once thought to be related to former Caddoan-speaking Witchita groups. More recent research indicates that the material evidence could be associated with several linguistically separate peoples who were interacting on the Southern Plains between A.D. 1500-1800. These include Witchita, Jumano, Kiowa, and most reasonable for the south-central Texas area, Apache (presumably, but not restricted to, Lipan).

Further research is necessary to more clearly define the cultural origins of the Guerrero type and the relationships to other similar, contemporaneous, triangular arrow points found in the southern plains and in northeastern Mexico. Current data cannot answer whether the artifact type represents the diffusion of a technological style across widely varying cultural ranges or the material reflection of a widespread nomadic migration pattern during the Protohistoric and early Historic periods.

L: (fragmented $1.96 \mathrm{~cm} ; \mathrm{W}: 1.40 \mathrm{~cm} ; \mathrm{T}: 0.27 \mathrm{~cm}$.

Provenience: $41 \mathrm{BX} 528$, surface.

Specimens 2 and 3 (Fig. 50,d,e) are the proximal portions of two triangular arrow points with straight bases. Bifacially worked and basally thinned, they may represent finished products broken through use, although the (pressure) flaking pattern along the blade edges does not compare to the technique or workmanship of Specimen 1, with the concave base from 41 BX 528. Alternatively, they may represent unfinished manufacturing failures. The artifacts, although inconclusive as a type, are nonetheless significant as other materials from site 41 BX 669 include a Tecovas jasper biface. It is possible these small arrow point fragments may be related to a Protohistoric or early Historic Indian component at this locale.

Specimen 1 (Fig. 50,d) may be heat treated.

$\mathrm{L}:$ (incomplete) $1.86 \mathrm{~cm} ; \mathrm{W}: 2.19 \mathrm{~cm} ; \mathrm{T}: 0.31 \mathrm{~cm}$.

Provenience: 41 BX 669, surface.

Specimen 2 (Fig. 50,e)

$\mathrm{L}:$ (incomplete) $2.90 \mathrm{~cm} ; W: 2.03 \mathrm{~cm} ; \mathrm{T}: 0.32 \mathrm{~cm}$.

Provenience: 41 BX 669, surface. 
Figure 56. Collected Lithic Materials from 41 BX 274.

a, $P: 1$, perforator;

b. TN3:2, thin biface (Specimen 2);

c, D5:3, Tanceolate/leaf-shaped dart point;

d, D6:3, "Thinned-Base Early Triangular";

e, DI:1, Frio;

f, TN3:2, thin biface (Specimen 3);

g, DBl:1, "Classic" bifacial Clear Fork (Specimen 1);

h, DB2:2 Guadalupe tool, narrow bit (Specimen 2). 
Applewhite/Material Culture

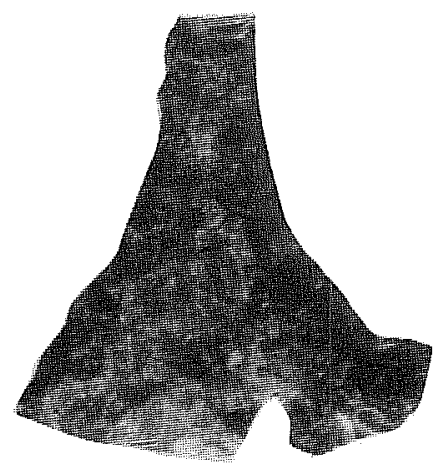

a

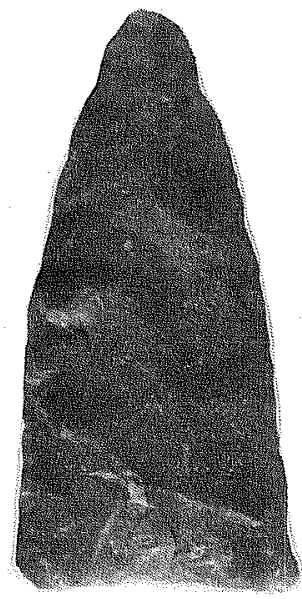

d

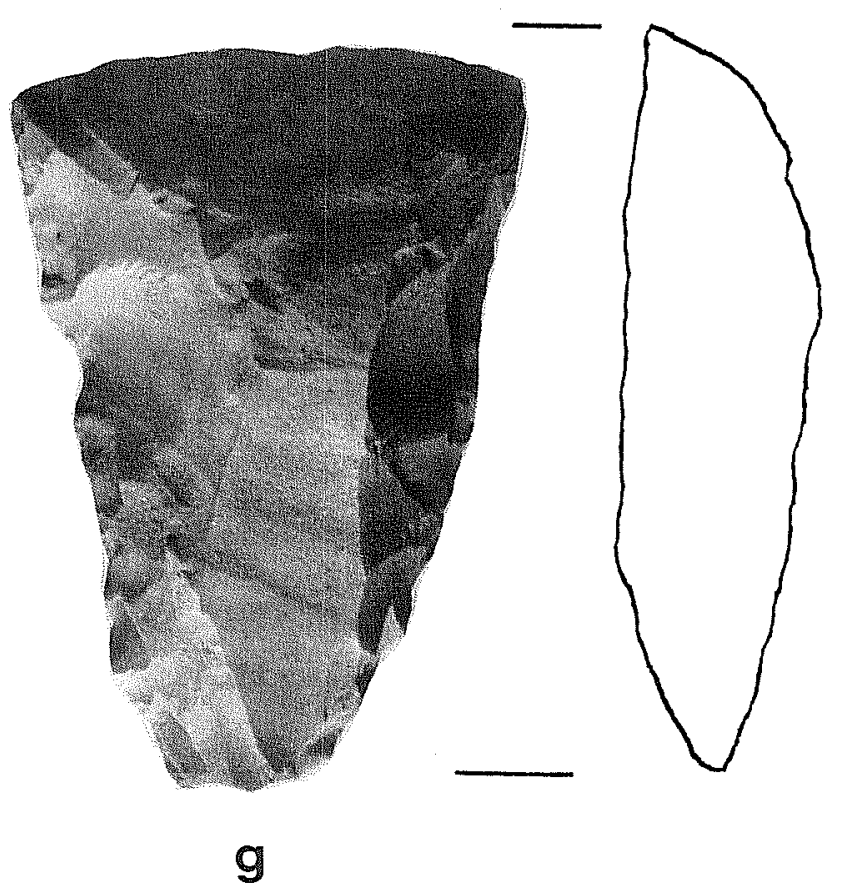

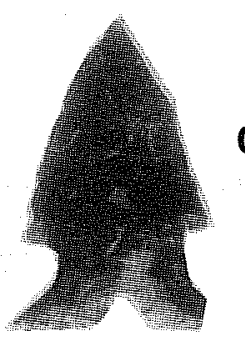

e

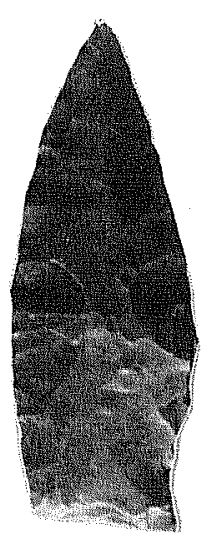

b

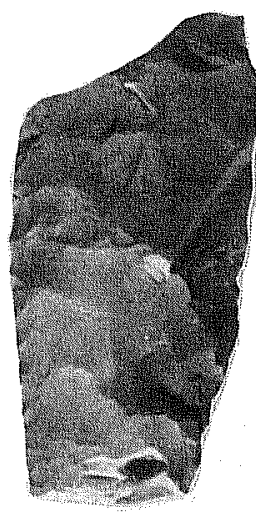

c
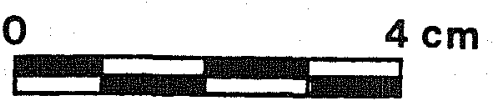
$4 \mathrm{~cm}$

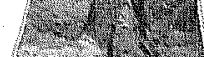

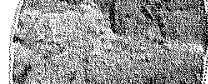

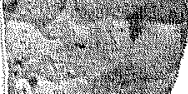

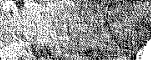

단존

$f$ 
Dart Points (D; 45 specimens)

\section{D1. Group 1 - Side and Corner-Notched Triangular \\ D1:1. Form 1 - Frio (4 specimens; Figs. 51,h; 55,f,g; 56,e)}

Specimen 1 (Fig. 51,h) is characterized by straight blade edges with alternate beveling along the right edge. One shoulder is weakly developed; the other is more noticeably barbed. The stem is formed by broad corner notching. The base is broadly notched, and the basal curve is shallow. One face is extensively patinated. This artifact is tentatively identified as a Frio, which is associated with Local Period 9 of the Transitional Archaic. Unfortunately, it also represents an interpretive dichotomy of site interpretation as its site context is considered to be related to the Early Archaic based on intersite distribution patterns and preliminary identification of fossil river movements. There are some (morphological) suggestions that this artifact is actually a variant of Black and McGraw's (1985:121-122, Fig. 22,a-f) unnamed Early Expanding Stem Form 1 (D4:1), a poorly described and defined type occasionally confused with much later Frio projectile points. The Early Archaic association is preferable for this study, in order to support interpretations of prehistoric site distributions; however, the variants of the Early Archaic Early Expanding Stem artifact require additional study before positive identification can be made simply on the basis of a surface collection.

L: $4.8 \mathrm{~cm} ; W: 2.4 \mathrm{~cm} ; \mathrm{T}: 0.68 \mathrm{~cm}$.

Provenience: 41 BX 535, surface.

Specimen 2 (Fig. 56,e) is characterized by slightly convex blade edges and a distinctive shallow, basal indentation. The artifact is manufactured from a medium tan chert. The blade has been reworked into an asymmetrical outline.

$\mathrm{L}: \quad 3.5 \mathrm{~cm} ; W: 2.3 \mathrm{~cm} ; \mathrm{T}: 0.68 \mathrm{~cm}$.

Provenience: 41 BX 274, surface.

Specimen 3 (Fig. $55, f$ ) has a distinctly asymmetric, reworked, and recurved blade. The specimen has been burned.

$L: \quad 5.30 \mathrm{~cm} ; W: 2.85 \mathrm{~cm} ; \mathrm{T}: 0.51 \mathrm{~cm}$.

Provenience: $41 \mathrm{BX} 528$, surface.

Specimen 4 (Fig. 55,g) lacks the distal tip and one blade edge, probably as a result of an impact fracture. Manufactured from a fine-grained, tan-colored chert, the artifact's blade is distinctly smaller than that of Specimen 3 , although the base is comparable in size.

L: (fragmented) $3.38 \mathrm{~cm}$; W: (1acks stem tip) $2.15 \mathrm{~cm} ; \mathrm{T}: 0.57 \mathrm{~cm}$.

Provenience: 41 BX 528, surface. 
D1:2. Form 2 - Ensor (3 specimens; Figs. 50,h; $51, \mathrm{i} ; 53, \mathrm{~b}$ )

Group 1, Form 2 dart point specimens are small and have narrow triangular blade outlines. An expanding base is formed by deep corner notching or side notching. The type is related to Local Period 9, ca. A.D. 250-900.

The blade edges of Specimen 1 (Fig. 51,i) are straight, and one edge may be marginally retouched on both faces. Shoulders are prominent and barbed, although the barb on the possibly reworked edge is slightly less prominent (resulting in asymmetric notching). The stem may have been formed by corner notching, and the base is slightly concave. Proximal portions of the point are similar in form to the Late Archaic Ensor point, although this is only tentative (see comments on D1:1, Specimen 1).

L: $4.98 \mathrm{~cm} ; W: 2.57 \mathrm{~cm} ; \mathrm{T}: 0.84 \mathrm{~cm}$.

Provenience: $41 \mathrm{BX} 535$, surface.

Specimen 2 has (Fig. 53,b) prominent shoulders with slightly convex lateral blade edges. The base is slightly curved. Deep corner notches characterize the specimen.

L: $3.0 \mathrm{~cm} ; W: 1.96 \mathrm{~cm} ; \mathrm{T}: 0.37 \mathrm{~cm}$.

Provenience: $41 \mathrm{BX} 665$, surface collection.

Specimen 3 (Fig. $50, \mathrm{~h}$ )

L: $5.34 \mathrm{~cm} ; W: 1.97 \mathrm{~cm} ; \mathrm{T}: 0.92 \mathrm{~cm}$.

Provenience: 41 BX 669, surface.

D1:10. Form 10 - Edgewood (1 specimen; Fig. 57,b)

Dart point Group 1, Form 10 has an uncertain association with Local Period 9. L: $3.38 \mathrm{~cm} ; W: 2.54 \mathrm{~cm} ; \mathrm{T}: 0.63 \mathrm{~cm}$.

Provenience: 41 BX 652, surface.

D2. Group 2- Broad Triangular with Expanding Stem

D2:1. Form 1 - Monte11 (2 specimens; Figs. 50,g; 57,g)

Specimen 1 (Fig. $57, g$ ) is a basal fragment with a distinctive bifurcated stem. The artifact is associated with Local Period 8, 650 B.C.-A.D. 250.

L: $3.89 \mathrm{~cm} ; \mathrm{L}: 0.68 \mathrm{~cm} ; \mathrm{T}: 0.58 \mathrm{~cm}$.

Provenience: $41 \mathrm{BX} 653$, surface. 
Figure 57. Collected Dart Points.

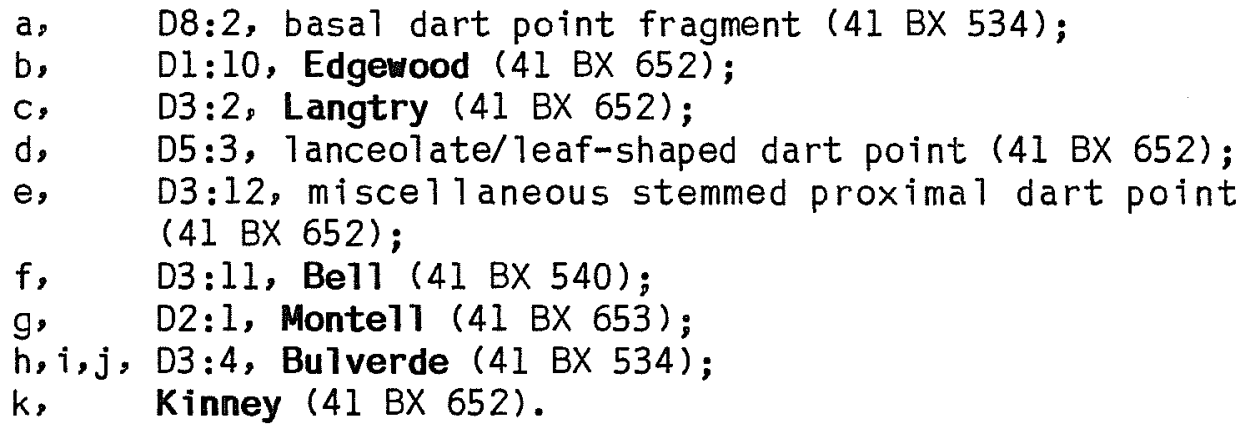




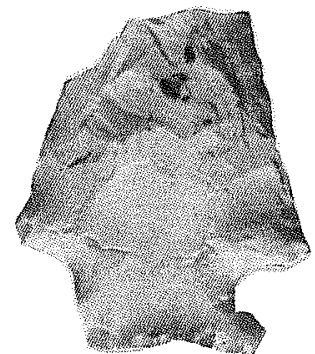

a

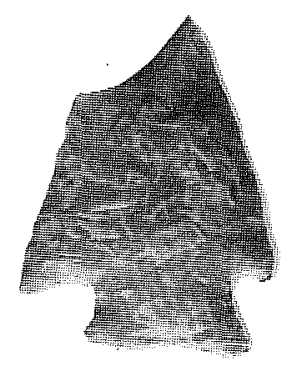

b
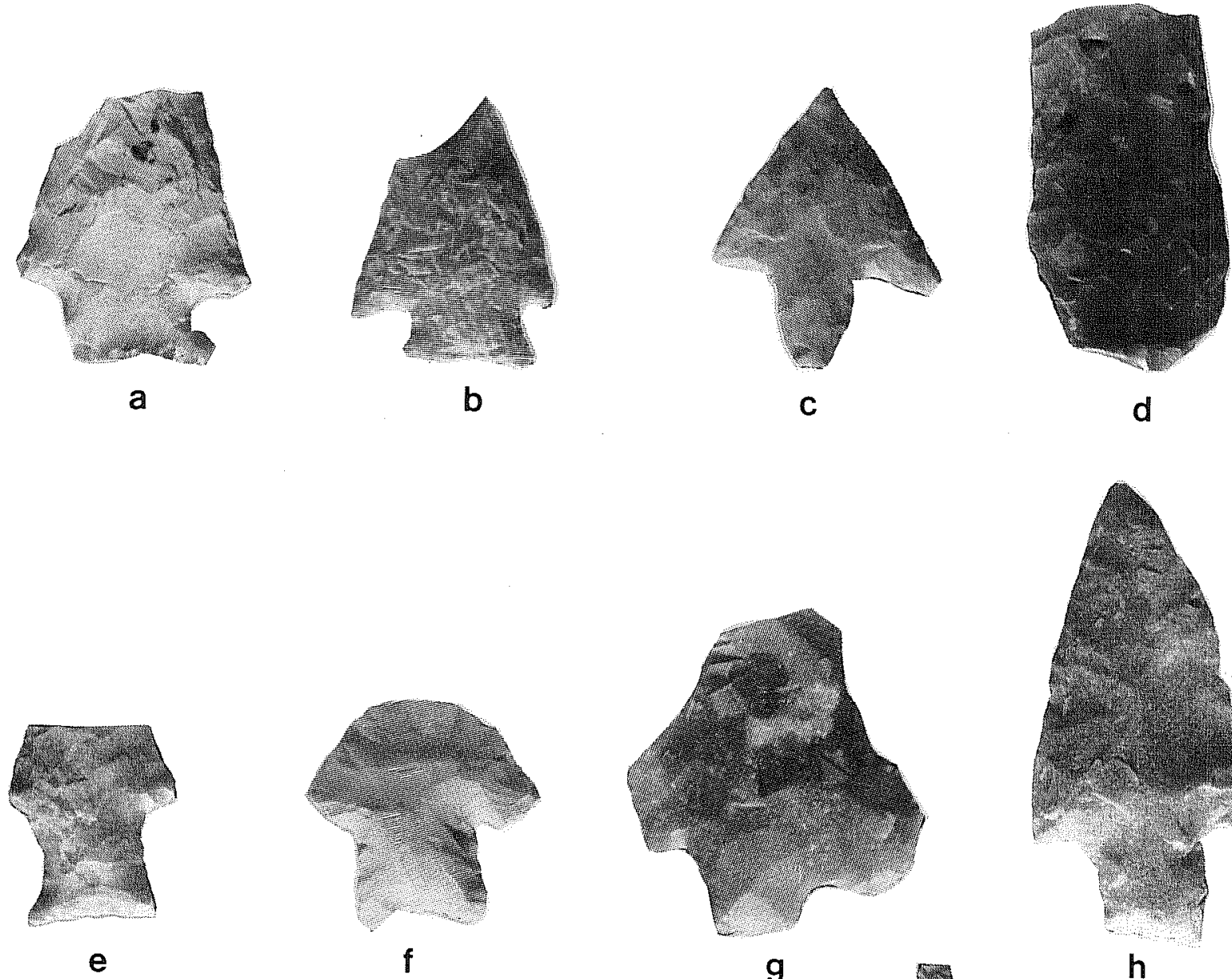

9
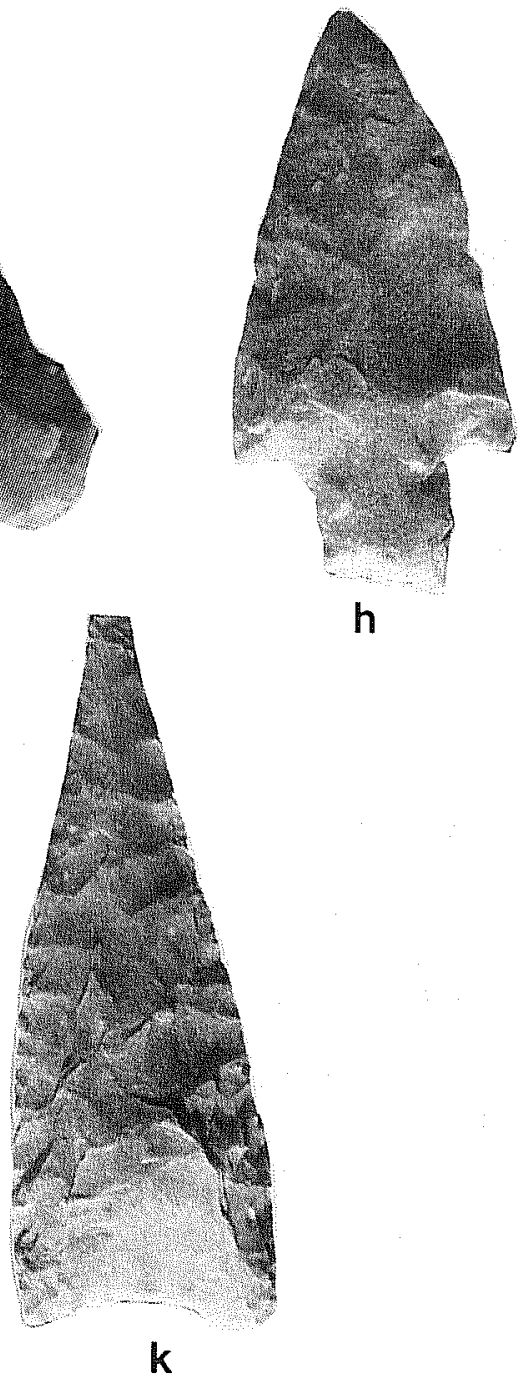

h
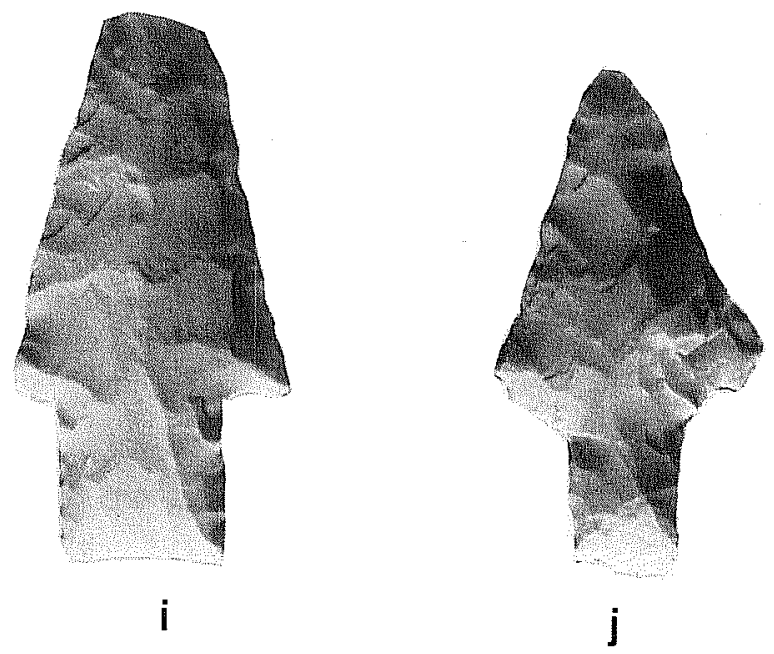

0 $4 \mathrm{~cm}$. 
Specimen 2 (basal fragment, Fig. 50,g)

L: $3.83 \mathrm{~cm} ; W: 3.12 \mathrm{~cm} ; \mathrm{T}: 1.0 \mathrm{~cm}$.

Provenience: 41 BX 669, surface.

D2:3. Form 3 - Marsha11 (1 specimen, proximal portion; Fig. 53,a)

Dart point Group 2, Form 3 specimen has straight blade edges, the stem is deeply corner notched, and the base is slightly concave.

L: $4.4 \mathrm{~cm} ; W: 4.5 \mathrm{~cm} ; \mathrm{T}: 0.6 \mathrm{~cm}$.

Provenience: $41 \mathrm{BX} 665$, surface.

D2:5. Form 5 - Marcos (1 specimen; Fig. 51,f)

Dart point Group 2, Form 5 specimen has a short, reworked blade with slightly convex edges and barbed shoulders. The base is slightly concave and exhibits some evidence of heat treatment. The artifact is chronologically associated with Local Period 8, 650 B.C.-A.D. 250 (Black and McGraw 1985:112).

L: $4.37 \mathrm{~cm} ; W: 3.15 \mathrm{~cm} ; \mathrm{T}: 0.81 \mathrm{~cm}$.

Provenience: 41 BX 532, surface.

\section{D3. Group 3 - Miscellaneous Stemmed}

D3:1. Form 1 - Pedernales ( 4 specimens; Fig. $53, c, d, h, j$ )

Dart point Group 3, Form 1 specimens are characterized by considerable blade variation and slight to prominent shoulders. All specimens reflect the distinguishing stem feature, a $U$-shaped basal concavity. The Pedernales type is probably the most common dart point found in Texas. It is associated with Local Period 7, ca. 2000-600 B.C. (Black and McGraw 1985:113).

Maximum L: $6.42 \mathrm{~cm}$ (proximal fragment); maximum $W: 3.61 \mathrm{~cm}$; maximum T: $0.94 \mathrm{~cm}$; minimum L: $3.72 \mathrm{~cm}$ (proximal fragment); minimum $W: 2.60 \mathrm{~cm}$; minimum $\mathrm{T}: 0.75 \mathrm{~cm}$.

Provenience: A11 four specimens were surface collected from 41 BX 665 .

D3:2. Form 2 - Langtry (2 specimens; Figs. 53,g; 57,C)

More common in the Trans-Pecos area, Langtry points are characterized by thin triangular blades, relatively long with contracting stems and prominent shoulders. The type is associated with Local Period 7, ca. 2000-650 B.C. (Black and McGraw 1985:113, 115). 
Specimen 1 (Fig. 53,g)

L: $3.75 \mathrm{~cm} ; W: 2.87 \mathrm{~cm} ; \mathrm{T}: 0.45 \mathrm{~cm}$.

Provenience: 41 BX 665, surface.

Specimen 2 (Fig. 57, C)

L: $3.65 \mathrm{~cm} ; W: 3.05 \mathrm{~cm} ; \mathrm{T}: 0.46 \mathrm{~cm}$.

Provenience: $41 \mathrm{BX} 652$, surface.

D3:4. Form 4 - Bulverde (4 specimens; Figs. $53, k ; 57, h, i, j$ )

Specimen 1 (Fig. 53,k) is a proximal fragment with a straight-edged blade and prominent shoulders. The stem edges and base are straight. This point type is not radiocarbon-dated locally; chronological associations are thought to be Local Period 6 or 7 (BTack and McGraw 1985:115-116).

\section{L: $3.87 \mathrm{~cm} ; W: 2.6 \mathrm{~cm} ; \mathrm{T}: 0.72 \mathrm{~cm}$.}

Provenience: $41 \mathrm{BX} 665$, surface.

Specimens 2-4 were surface collected from 41 BX 534 during a 1984 revisit to the site area first identified in 1981. Only one of these artifacts, Specimen 3, can be accurately identified as Bulverde; Specimen 2 reflects crude workmanship, and Specimen 4 has been extensively reworked along a 11 edges. However, as all these specimens were collected from a $5 \mathrm{~m}^{2}$ eroding burned rock cluster, they are thought to be feature and chronologically related. Given this context, the specimens are thought to represent the range (or variation) of this type from a site-specific perspective. (This should also give other researchers pause when considering the morphological variations of this type from a larger regional perspective.)

Specimen 2 (Fig. 57,h) is characterized by a triangular, asymmetric blade and is manufactured from a coarse-grained gray chert.

L: $5.92 \mathrm{~cm} ; W: 3.0 \mathrm{~cm} ; \mathrm{T}: 0.62 \mathrm{~cm}$.

Provenience: 41 BX 534, surface.

Specimen 3 (Fig. $57, i$ ) has a narrow, triangular blade and appears reworked. It is made of a fine-grained, tan chert.

L: (distal tip missing) $5.73 \mathrm{~cm}$; $: 2.87 \mathrm{~cm} ; \mathrm{T}: 0.66 \mathrm{~cm}$.

Provenience: 41 BX 534, surface.

Specimen 4 (Fig. $57, j$ ) is a fine-grained tan chert. All edges of this specimen have been reworked, and the blade is distinctly asymmetrical.

L: $\quad 5.19 \mathrm{~cm}$; $W$ (barb tips are broken) $2.74 \mathrm{~cm} ; \mathrm{T}: 0.63 \mathrm{~cm}$. 
Provenience: 41 BX 534, surface.

D3:11. Form 11 - Bel1 (3 specimens; Figs. 54,a,b; 57,f)

Group 3, Form 11 dart point specimens are characterized by reworked triangular blades with long barbs and extremely deep basal notches. Associated with the Early Archaic, they are identified with Local Period 5. They have been radiocarbon assayed 10cal1y at 41 BX 271 to 3600-3400 B.C. (BTack and McGraw 1985:120).

Specimen 1 (Fig. 54, b)

L: $2.42 \mathrm{~cm}$ (proximal fragment); W: $3.20 \mathrm{~cm} ; \mathrm{T}: 0.57 \mathrm{~cm}$.

Provenience: 41 BX 274, E998 N999.

Specimen 2 (Fig. $57, f$ )

L: $\quad 3.24 \mathrm{~cm}$ (proximal fragment); W: $3.52 \mathrm{~cm} ; \mathrm{T}: 0.63 \mathrm{~cm}$.

Provenience: 41 BX 540, erosional feature (surface).

Specimen 3 (Fig. 54,a) is characterized by a reworked, alternately beveled blade. Moderately patinated on both faces, it reflects the deeply cornernotched, U-shaped flake scar at the top of the stem notch, although the barb tips have been fractured. The point has a straight base and is similar to those described by Black and McGraw (1985:119-120) from 41 BX 228.

L: $\quad 3.86 \mathrm{~cm}$ (distal tip broken); $W: 3.32 \mathrm{~cm}$ (barb tips missing); $\mathrm{T}: \quad 0.62 \mathrm{~cm}$.

Provenience: $41 \mathrm{BX} 274$, surface.

D3:12. Form 12 - Miscellaneous Stemmed (Proximal) (1 specimen; Fig. 57,e)

Group 3, Form 2 specimen is a proximal fragment with recurved blade edges (reworked?) and a relatively long expanding stem. The basal end is slightly concave. The prominent shoulders appear to have had distinctive short barbs (now missing).

This dart point fragment does not fit into any previously identified types, perhaps due to the extent of blade reworking that has altered its morphology particularly along the blade shoulder and barb area. The long and slightly expanding stem is reminiscent of some varieties of Early Archaic associated Uvalde points but the specimen lacks the distinctive concave base. The recurved blade and expanding stem formed by wide notching are also characteristic of Val Verde points but usually these points are limited to the lower Pecos River area, the lower Rio Grande, and Coahuila, Mexico. Interestingly, a Langtry projectile point was surface collected from this same site (D3:2, Specimen 2). Further identifications, particularly in excavated contexts, 
are necessary to more accurately describe and define this unnamed (Early Archaic?) type.

L: $2.51 \mathrm{~cm}$ (proximal fragment); $W: 2.29 \mathrm{~cm} ; \mathrm{T}: 0.72 \mathrm{~cm}$.

Provenience: $41 \mathrm{BX} 652$, surface.

\section{D4. Group 4 - Early Expanding Stem}

D4:3. Form 3 - Martindale (1 specimen; Fig. 54,c)

The Martindale type is characterized by a triangular blade with slightly convex blade edges. The recurved base reflects the distinctive "fish-taij" appearance of the type. This point is associated with the Early Archaic Local Period 5, ca. 4000-3000(?) B.C. (B1ack and McGraw 1985:123).

L: $4.52 \mathrm{~cm} ; W: 3.02 \mathrm{~cm} ; \mathrm{T}: 0.53 \mathrm{~cm}$.

Provenience: 41 BX 274, E999 N999.

\section{D5. Group 5 - Lanceolate/Leaf Shaped}

D5:3. Form 3 - Miscellaneous Lanceolate to Leaf-Shaped (2 specimens;

Figs. 56, c;57,d)

Group 5, Form 3 dart point specimens have parallel blades. They are not readily identifiable as a described type, although they bear general similarities to Late Paleo-Indian Angostura points. Unfortunately, the extent of reworking and fragmentation precludes a more definitive assessment on original form or flaking.

Specimen 1 (Fig. 57,d)

L: $4.79 \mathrm{~cm}$ (distal[?] fragment); $W: 2.63 \mathrm{~cm} ; T: 0.84 \mathrm{~cm}$.

Provenience: 41 BX 652, surface.

Specimen 2 (Fig. 56,C) is ground $2.1 \mathrm{~cm}$ on each edge and is heavily patinated with remnant parallel flaking.

L: $\quad 5.02 \mathrm{~cm}$ (media1); $W: 2.55 \mathrm{~cm} ; \mathrm{T}: 0.95 \mathrm{~cm}$.

Provenience: $41 \mathrm{BX} 274$, surface.

D6. Group 6 - Unstemmed Triangular

D6:1. Form 1 - Kinney (1 specimen; Fig. 57, k)

The chronological placement of this artifact (tentatively identified as Kinney) is still unclear and is estimated at Local Period 7, ca. 2000- 
650 B.C. (B1ack and McGraw 1985:127). This triangular form has morphological similarities to other lithic forms, including triangular knives and poorly defined triangular projectile points.

L: $7.5 \mathrm{~cm} ; W: 2.37 \mathrm{~cm} ; \mathrm{T}: 0.81 \mathrm{~cm}$.

Provenience: $41 \mathrm{BX} 652$, surface.

D6:3. Form 3 - "Thinned-Base Early Triangular" (3 specimens; Figs. 51,g, q; $\overline{56, d)}$

Black and McGraw (1985:129-133) have described this triangular form in some detail and concluded its primary function was as a knife. Parallel flaking is seen on most specimens with alternate blade beveling or reworking. The form is associated with Local Period 6, ca. 4000-2500 B.C.

Specimen 1 (Fig. 51,g)

L: $4.16 \mathrm{~cm} ; W: 2.91 \mathrm{~cm} ; \mathrm{T}: 0.67 \mathrm{~cm}$.

Provenience: $41 \mathrm{BX} 533$, surface.

Specimen 2 (Fig. 56,d)

L: $6.02 \mathrm{~cm} ; W: 3.21 \mathrm{~cm} ; \mathrm{T}: 0.69 \mathrm{~cm}$.

Provenience: 41 BX 274, surface.

Specimen 3 (Fig. 51,q)

L: $4.40 \mathrm{~cm} ; W: 3.22 \mathrm{~cm} ; \mathrm{T}: 0.71 \mathrm{~cm}$.

Provenience: $41 \mathrm{BX} 274$, Feature 1.

D6:4. Form 4 - Unstemmed Triangular, Convex Base (3 specimens; Figs. 50,f; $51, e, j$ )

Three Group 6 dart point specimens are defined by a new form characterized by semicircular to convex bases which distinguishes them from other point types. While no real shoulders are present, the contracting proximal end distinguishes the hafting point. D6:4 forms are similar to the southern Texas Refugio or Abasolo types that are not definitively described.

Specimen 1 (Fig. 51,e)

L: $5.82 \mathrm{~cm} ; W: 2.23 \mathrm{~cm} ; \mathrm{T}: 0.71 \mathrm{~cm}$.

Provenience: $41 \mathrm{BX} 528$, surface.

Specimen 2 (Fig. $51, \mathrm{j}$ ) 
L: $3.71 \mathrm{~cm} ; W: 2.32 \mathrm{~cm} ; \mathrm{T}: 0.63 \mathrm{~cm}$.

Provenience: $41 \mathrm{BX} 540$, surface.

Specimen 3 (Fig. 50,f)

L: $5.30 \mathrm{~cm} ; W: 2.32 \mathrm{~cm} ; \mathrm{T}: 0.91 \mathrm{~cm}$.

Provenience: 41 BX 669, surface.

D6:5. Form 5 - Unstemmed Triangular, Parallel Edged (1 specimen; Fig. 51,k)

Group 6, Form 5 specimen is a reworked, unstemmed triangular biface with basal thinning, a straight base, and slightly contracting proximal edges. The extensive reworking of the artifact may indicate a modification of another point type, however, it is identified separately here because of the limited data currently available.

L: $4.52 \mathrm{~cm} ; W: 2.50 \mathrm{~cm} ; \mathrm{T}: 0.79 \mathrm{~cm}$.

Provenience: $41 \mathrm{BX} 552$, surface.

D7. Group 7 - Miscellaneous Form (1 specimen; Fig. 50,k)

Group 7 dart point specimen does not easily fit into previously described groups. The artifact, fire-reddened and pot-7idded, is unstemmed with a narrow, triangular blade. Blade edges are almost parallel. The distal portion is missing, and the base has been thinned by several small longitudinal flakes. Approximately a $10 \mathrm{~mm}$ length of the basal edge is slightly dulled. This may indicate an extensively reworked originally stemmed artifact, but this is only speculative.

$\mathrm{L}:$ (incomplete) $4.86 \mathrm{~cm} ; \mathrm{W}: 2.14 \mathrm{~cm} ; \mathrm{T}: 0.57 \mathrm{~cm}$.

Provenience: $41 \mathrm{BX} 669$, surface.

\section{D8. Group 8 - Miscellaneous Unidentifiable Fragments}

D8:1. Form 1 - Medial and Distal Fragments (5 specimens; Fig. 51,1-p)

Five untyped small biface fragments are thought to represent medial and distal portions of dart points. Although chronologically undiagnostic, their presence at various site locations indicates tertiary lithic reduction or reworking activities of estimated Archaic age. Of the five fragments, four are triangular to subtriangular, the fifth, from $41 \mathrm{BX} 528$, is irregular. Three specimens (collected from 41 BX 524, 41 BX 528, and 41 BX 539) are heat treated. The fragment from $41 \mathrm{BX} 534$ is the most complete as only the lower portion of the stem appears missing. The artifact is thick in cross section, blade shoulders are weak, and the stem appears to flare outward. 
Minimum width: $1.9 \mathrm{~cm}$; maximum width: $2.88 \mathrm{~cm}$.

Provenience: Surface collected from 41 BX 524, 41 BX 526, 41 BX 528, $41 \mathrm{BX} 534$, and $41 \mathrm{BX} 539$.

D8:2. Form 2 - Basal Fragments (2 specimens; Figs. 50, m; 57,a)

Specimen 1 (Fig. 57,a) is a patinated, heat-treated, proximal fragment thought to be a Late Archaic Marshal1 or Marcos dart point remnant, but stem and blade fracturing (as well as some overlapping morphological characteristics) precludes identification.

$\mathrm{L}:$ (incomplete) $3.53 \mathrm{~cm} ; \mathrm{W}: 3.14 \mathrm{~cm} ; \mathrm{T}: 0.76 \mathrm{~cm}$.

Provenience: 41 BX 534, surface.

Specimen 2 (Fig. $50, \mathrm{~m}$ )

L: $2.26 \mathrm{~cm} ; W: 2.10 \mathrm{~cm} ; \mathrm{T}: 0.61 \mathrm{~cm}$.

Provenience: 41 BX 669, surface.

\section{DISTALLY BEVELED TOOLS (DB; 20 specimens)}

Distally beveled tools are characterized by an elongated or triangular shape, usually bifacial with a beveled or sharply truncated distal end. often the widest portion of the artifact, the distal end, represents the functional tool edge. Black and Highley (1985:136-156), in analys is of the 41 BX 228 collection, concentrate on descriptions of Early Archaic Guadalupe and Clear Fork tools, but unfortunately lump a11 other distally beveled tools together under a (Group 3) miscellaneous category. This is contrasted to Hall, Black, and Graves' (1982:318-348) description of nine groups and 14 subgroups or forms for the distally beveled tool collection from Choke Canyon. Three groups and several forms of two additional groups were tentatively identified as having Early Archaic associations (ibid.:346-347).

The distally beveled tool descriptions follow the format of Black and Highley (1985:137-138) with some modifications. The reader is referred to Howard (1975), Hester (1980), Ha11, B1ack, and Graves (1982), and Black and McGraw (1985) for further discussions on this tool type and forms.

\section{DB1. Group 1 - Clear Fork Tools}

DB1:1. Form 1 - "Classic" Bifacial (3 specimens; Figs. 53,1; 54,e; 56,g)

Clear Fork tools are generally triangular in shape with convex edges. The wide geographical distribution and apparent variations may indicate a general form rather than a specific type. Black and Highley (1985:139) have identified bifacial, unifacial, and miscellaneous forms, but only three bifacial specimens were identified in this study area. Group 1, Form 1 of 
the distally beveled tool is associated with the Early Archaic (Local Period 3, ca. 8000-5000 B.C.).

Specimen 1 (Fig. 56,g)

L: $8.19 \mathrm{~cm} ; W: 5.48 \mathrm{~cm} ; \mathrm{T}: 1.75 \mathrm{~cm}$.

Provenience: $41 \mathrm{BX} 274$, surface.

Specimen 2 (Fig. 53,1 )

L: (distal fragment) $3.91 \mathrm{~cm} ; W: 4.01 \mathrm{~cm} ; \mathrm{T}: 1.44 \mathrm{~cm}$.

Provenience: $41 \mathrm{BX} 665$, surface.

Specimen 3 (Fig. 54,e), while complete, has been extensively fire-fractured and pot-1idded.

L: $6.04 \mathrm{~cm} ; W: 3.20 \mathrm{~cm} ; \mathrm{T}: 1.19 \mathrm{~cm}$.

Provenience: Backhoe trench, $41 \mathrm{BX} 274,98.51$, ca. $1 \mathrm{~m}$ below ground surface.

DB1:2. Form 2 - "Classic" Unifacial (3 specimens; Figs. 50,0,0'; 58,c; $\left.60, b, b^{\prime}\right)$

DB1:2 follows the morphological outline of specimens placed in the DB1:1 category, but is distinguished by the unifacial chipping pattern only on its dorsal surface. Cultural associations are thought to be similar to DB1:1 specimens. The reader is referred to Black and Highley (1985:138-142) for a more detailed discussion of this tool form.

Specimen 1 (Fig. 50,0, $0^{\circ}$ )

L: $6.22 \mathrm{~cm} ; W: 4.28 \mathrm{~cm} ; \mathrm{T}: 1.30 \mathrm{~cm}$.

Provenience: 41 BX 669, surface.

Specimen 2 (Fig. 60, b, $\mathrm{b}^{\prime}$ )

L: $5.90 \mathrm{~cm} ; W: 3.55 \mathrm{~cm} ; \mathrm{T}: 1.26 \mathrm{~cm}$.

Provenience: $41 \mathrm{BX} 274$, surface collection.

Specimen 3 (Fig. 58, C)

L: $7.39 \mathrm{~cm} ; W: 4.27 \mathrm{~cm} ; \mathrm{T}: 1.36 \mathrm{~cm}$.

Provenience: $41 \mathrm{BX} 274$, surface collection. 
Figure 58. Distally Beveled Tools from 41 BX 274.

a, DB2:2, Guadalupe tool, narrow bit (Specimen 3);

$b, b^{\prime}, \mathrm{DB} 2: 2$, Guadalupe tool, narrow bit (Specimen 4);

c, DBl:2, "Classic" unifacial Clear Fork;

d, DB3:2, miscellaneous distally beveled tool.

Artifacts are shown distal (bit) end up, dorsal and ventral views. Due to irregular thickness, $c$ and $d$ are shown in profile. 
Applewhite/Material Culture

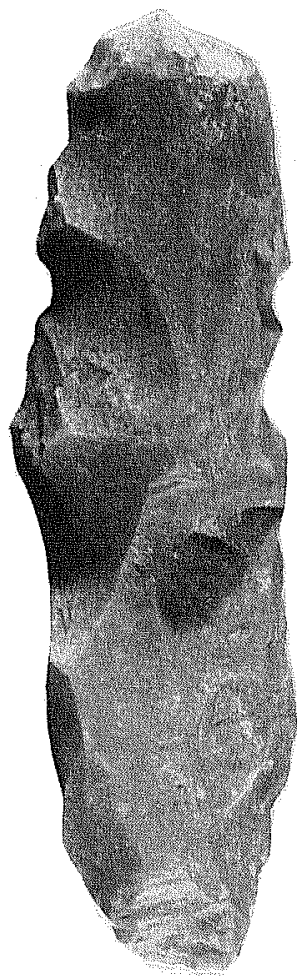

a

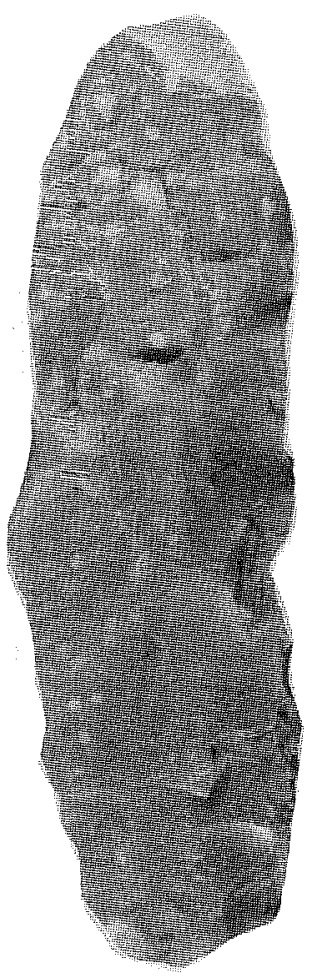

$a^{\prime}$
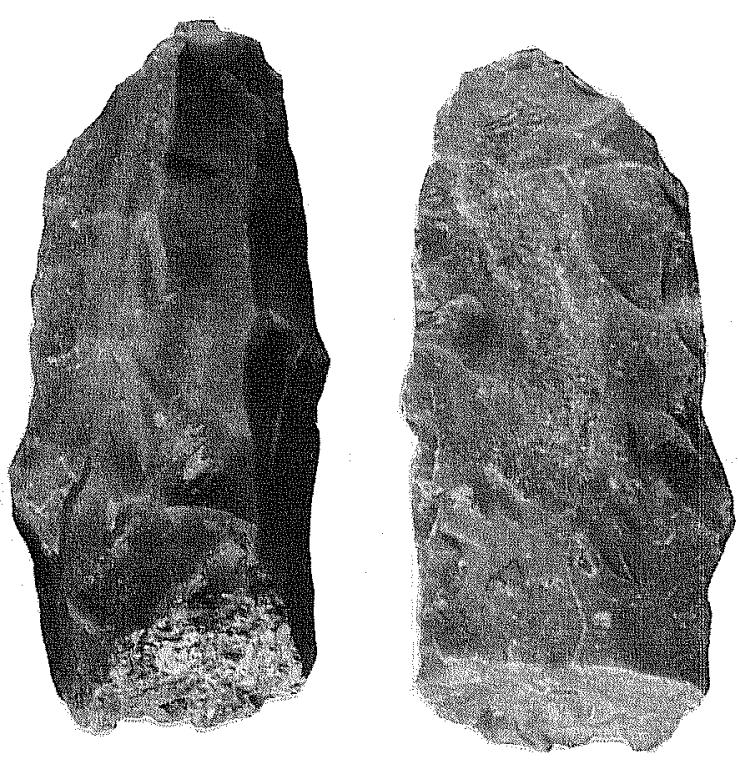

b

$b^{3}$
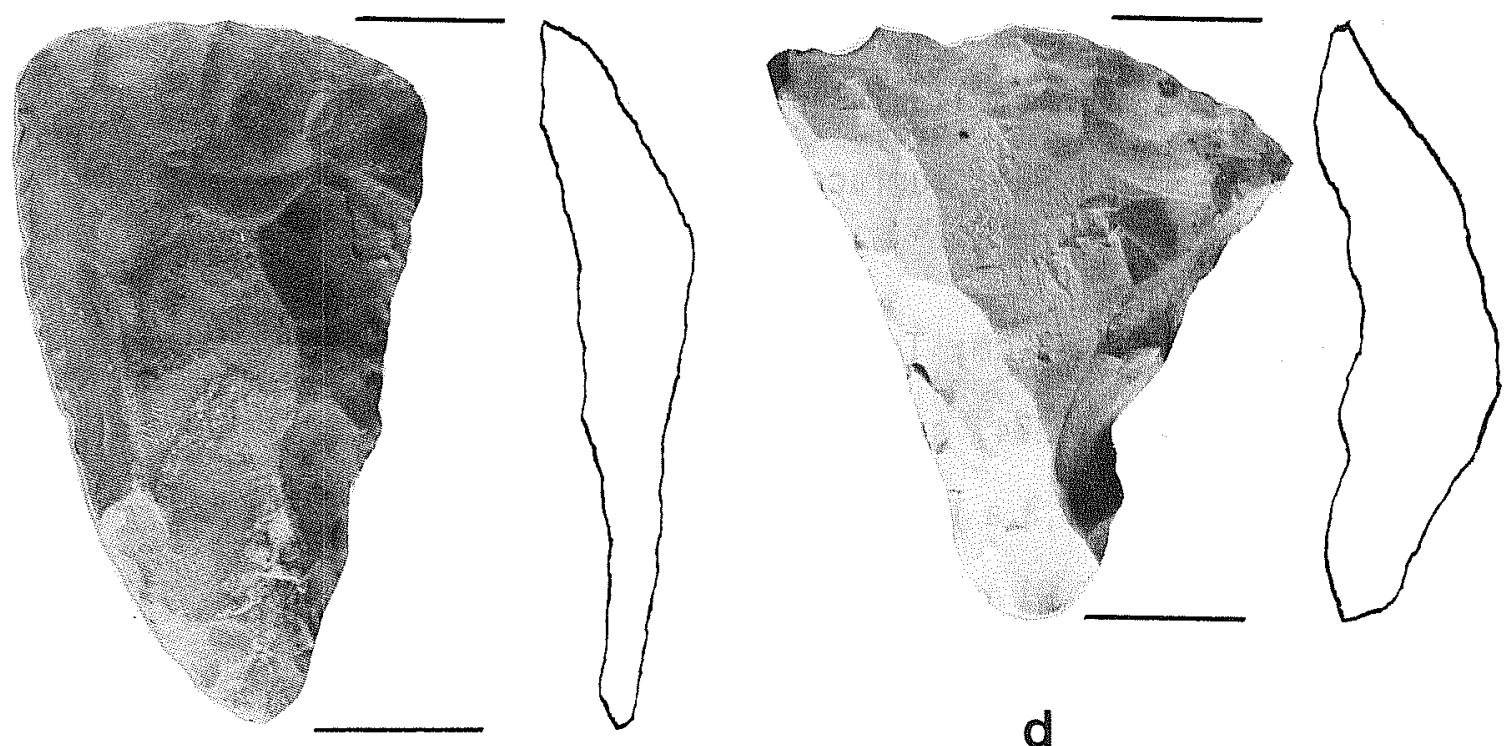

C 


\section{DB2. Group 2 - Guadalupe Tools}

Distinguished by its unusual morphology, the Guadalupe tool is recovered most frequently along the Guadalupe River drainage. The extent of distribution ranges from the eastern edge of the Edwards Plateau to the Rio Grande Valley in the south, and along the upper margins of the Nueces River drainage in the west. Data are currently 1imited on the northward distribution of the tool type, although the Colorado River drainage is identified as the current northern margins.

Guadalupe tools are distinguished by their elongated morphology and almost triangular cross sections. A steeply truncated bit angles from the dorsal edge to the ventral edge and proximal end. Form 1 indicates a steep, wide bit as opposed to Form 2, with a distinctly more narrow distal end. Guadalupe tools in the study area are associated with the Early Archaic (Local Period 5, ca. 3500 B.C.).

DB2:1. Form 1 - Steep, Wide Bit (6 specimens)

Specimen 1 appears to represent the most common variety of the Guadalupe tool type found within the Bexar County area. The ventral surface and sides are percussion flaked, and a small amount of cortex remains on the dorsal proximal tip and right ventral distal edge. A small amount of percussion retouch (resharpening) is along the dorsal distal end; seven step fractures of varying sizes (from small to less than $2 \mathrm{~cm}$ in length) may indicate extended tool usage. The artifact is made of coarse-grained chert and is very lightly patinated. The angle of the working edge in relation to the longitudinal axis of the tool is quite different from Specimen 3.

Specimen 1 (Fig. 52, C)

L: $8.2 \mathrm{~cm} ; W: 3.7 \mathrm{~cm} ; \mathrm{T}: 2.25 \mathrm{~cm}$; Distal $W: 2.91 \mathrm{~cm}$.

Provenience: 41 BX 554, surface.

Specimen 2 (Fig. 59,b)

L: $\quad 8.91 \mathrm{~cm}$; W: $3.52 \mathrm{~cm}$; T: $2.25 \mathrm{~cm}$; Distal W: $2.75 \mathrm{~cm}$.

Provenience: 41 BX 274, surface.

Specimen 3 (Fig. 59,a, á)

L: $\quad 10.30 \mathrm{~cm} ; W: 3.91 \mathrm{~cm} ; \mathrm{T}: 2.28 \mathrm{~cm}$; Distal $W: 3.0 \mathrm{~cm}$.

Provenience: 41 BX 274, surface.

Specimen 4 (Fig. 60,a, a) has a bit angle (measured from base of bit toward dorsal axis) of about $80^{\circ}$. The bit is almost perpendicular to the long axis. An unusual characteristic of this specimen is a patch of cortex on the right ventral distal corner. 


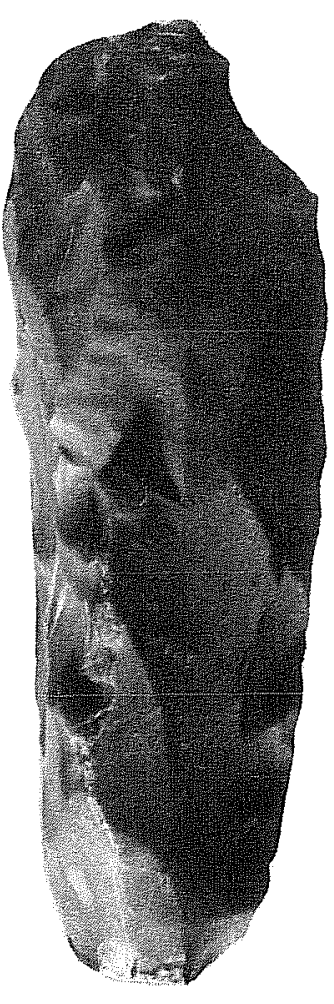

a

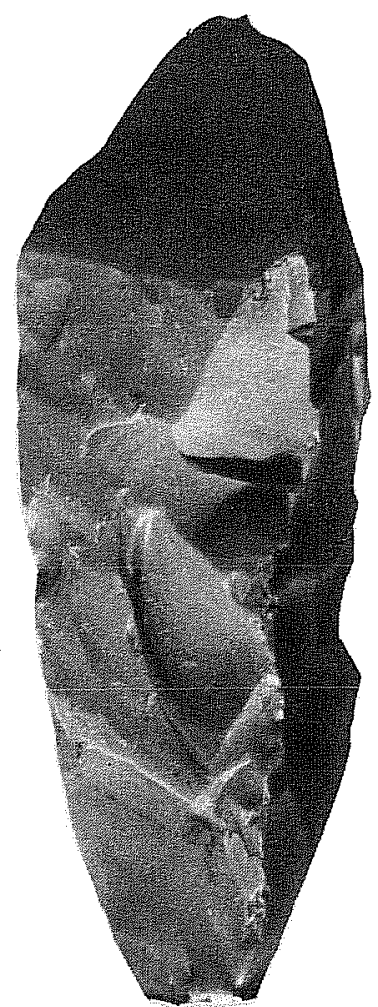

$a^{\prime}$
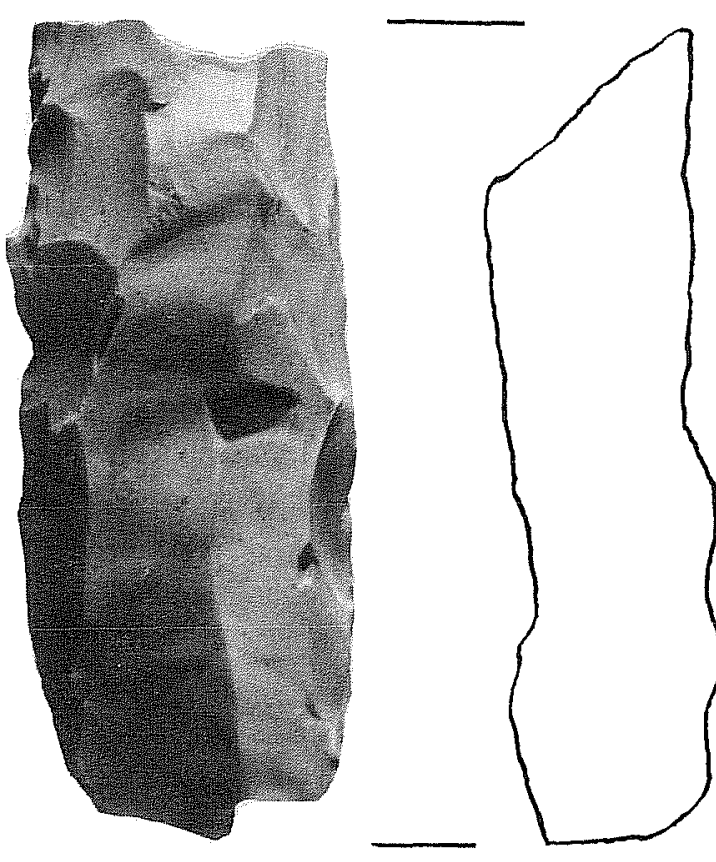

b

Figure 59. Surface Collected Dista11 y Beve1ed Too1s from 41 BX 274. a, a', DB2:1, Guada1upe tool (Specimen 3); b, DB2:1, Guadalupe tool (Specimen 2). Because of irregular thickness, this artifact is shown in profile. The artifacts are shown distal (bit) end up.

$4 \mathrm{~cm}$ 
Figure 60. Distal1y Beveled Tools Recovered from Limited Testing at $41 \mathrm{BX} 274$.

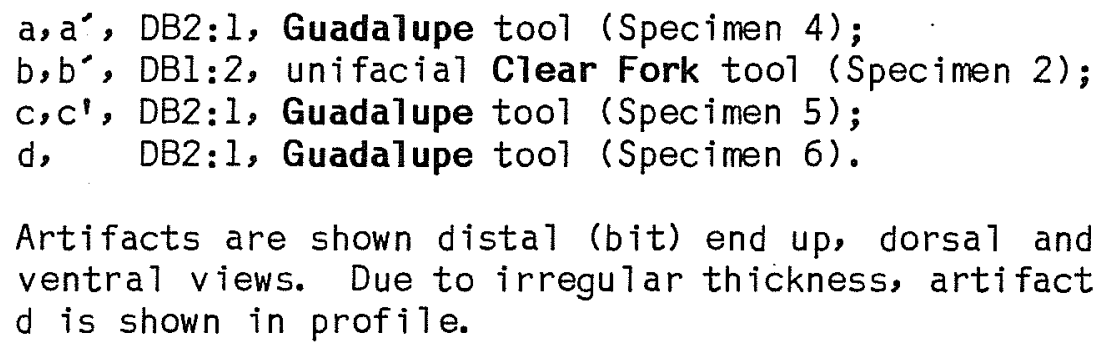


Applewhite/Material Culture

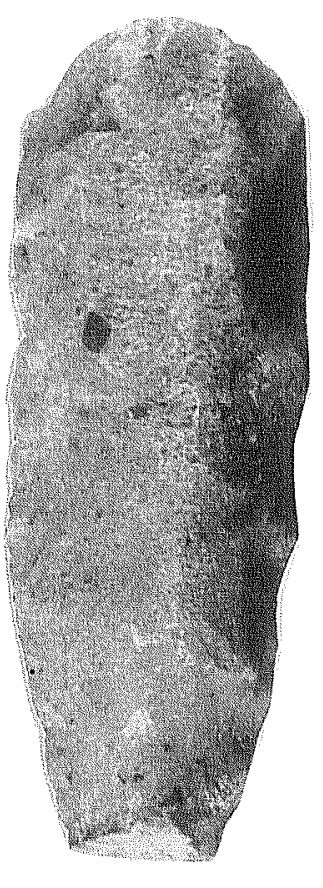

a

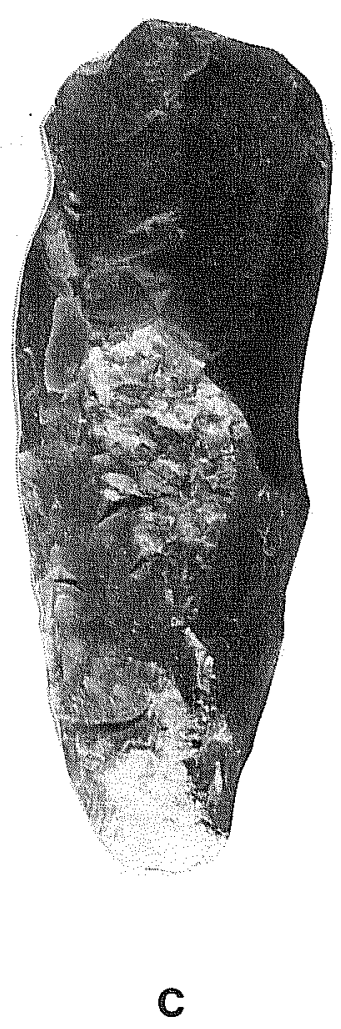

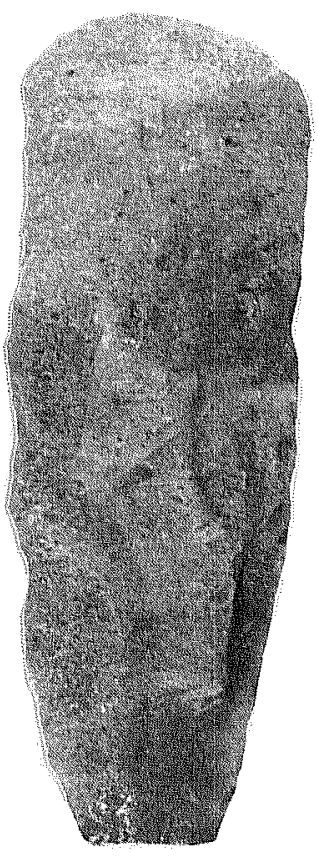

$a^{\prime}$

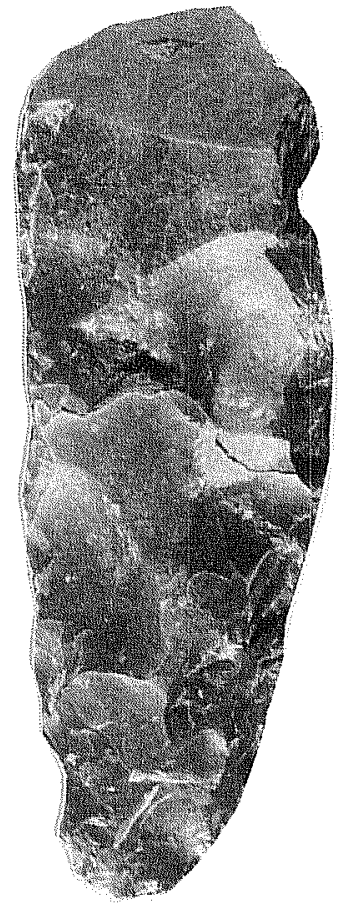

c'

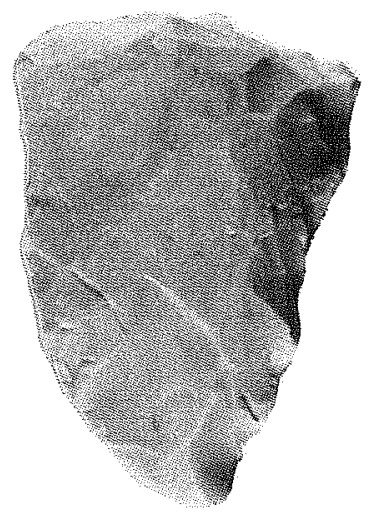

b

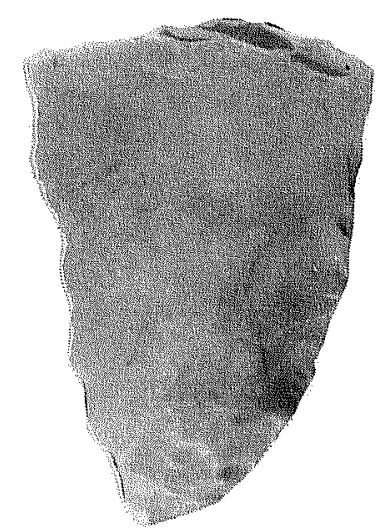

b'
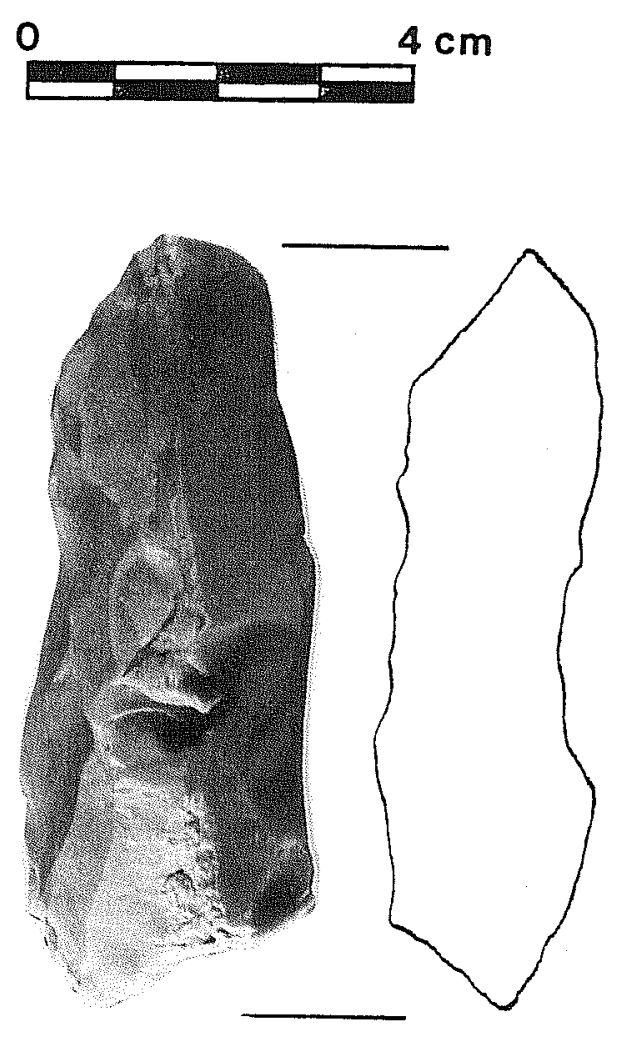

d 
L: $8.72 \mathrm{~cm} ; W: 3.18 \mathrm{~cm} ; \quad T: 2.23 \mathrm{~cm}$; Distal W: $3.0 \mathrm{~cm}$.

Provenience: 41 BX 274, E998 N998.

Specimen 5 (Fig. 60, c, $\mathrm{C}^{\circ}$ )

L: $9.17 \mathrm{~cm} ; W: 3.08 \mathrm{~cm} ; \quad T: 2.21 \mathrm{~cm} ;$ Distal $W: 2.91 \mathrm{~cm}$.

Provenience: 41 BX 274, E998 N999.

Specimen 6 (fragment; Fig. 60,d)

L: $6.89 \mathrm{~cm}$; W: $3.42 \mathrm{~cm} ; \mathrm{T}: 2.22 \mathrm{~cm}$; Distal W: $3.0 \mathrm{~cm}$.

Provenience: 41 BX 274, E996 N1013.

DB2:2. Form 2 - Narrow Bit (4 specimens)

Specimen 1 Fig. 52,d) is distinctly triangular in cross section. It is percussion flaked with cortex remaining on the dorsal proximal end. The right dorsal lateral distal end is missing, and this gives the otherwise complete tool a pointed appearance. A slight luster (gloss) is observable along the intact dorsal end from the distal edge to about $2 \mathrm{~cm}$ from the edge. The entire tool, excluding the apparent break along the right dorsal side is discolored(?) by a yellow brown tint on an otherwise banded gray chert. Whether this is the result of natural erosional and/or chemical processes or related to a specific type of prehistoric activity cannot be determined at this time. Working edge angle of the intact distal portion was measured by an SK goniometer to vary between $72^{\circ}$ and $80^{\circ}$. The distal dorsal edge is percussion flaked and reflects much more careful flaking than that noted elsewhere on the tool.

L: $\quad 10.05 \mathrm{~cm} ; W: 3.30 \mathrm{~cm} ; \mathrm{T}: 2.97 \mathrm{~cm}$; Distal $W: 2.90 \mathrm{~cm}$.

Provenience: $41 \mathrm{BX} 526$, surface.

Specimen 2 (fragment; Fig. 56,h)

L: $6.32 \mathrm{~cm}$; W: $3.38 \mathrm{~cm} ; \mathrm{T}: 2.27 \mathrm{~cm}$; Distal W: $2.69 \mathrm{~cm}$.

Provenience: $41 \mathrm{BX} 274$, surface.

Specimen 3 (Fig. 58,a)

L: $9.91 \mathrm{~cm} ; W: 3.12 \mathrm{~cm} ; \mathrm{T}: 2.80 \mathrm{~cm}$; Distal W: $2.34 \mathrm{~cm}$.

Provenience: 41 BX 274, E998 N998.

Specimen 4 (fragment; Fig. 58,b, b')

L: $7.37 \mathrm{~cm} ; W: 3.41 \mathrm{~cm}$; T: $2.57 \mathrm{~cm}$; Distal W: $2.78 \mathrm{~cm}$. 
Provenience: 41 BX 274, E999 N999.

DB3. Group 3 - Miscellaneous Distally Beveled Tools

DB3:2. Form 2 - "Shove1-Bit" (1 specimen; Fig. 58,d)

This specimen has a distinctly rounded distal working end that sharply contracts toward the proximal end.

L: $6.12 \mathrm{~cm} ; W: 5.41 \mathrm{~cm} ; \mathrm{T}: 1.47 \mathrm{~cm}$.

Provenience: 41 BX 274, E1000 N1001.

DB3:4. Form 4 - Triangular and Unifacial (1 specimen; Fig. 52,e)

A unifacial, triangular, gougelike artifact has a working edge angle of about $83^{\circ}$ and fits the general morphological characteristics of what Hester (1976) has described as Clear Fork artifacts. The specimen is plano-convex in cross section and generally subtriangular in outline. The artifact retains the bulb of percussion on the proximal ventral surface. For a further discussion of this type of artifact, the reader is referred to Hester, Gilbow, and Albee (1973). The specimen is also similar to Hall, Black, and Graves (1982:326) Group 3:1 which is distinguished from the "Nueces Scraper" type described by Turner and Hester (1985:221).

$\mathrm{L}: \quad 3.87 ; \mathrm{W}: 3.85 ; \mathrm{T}: 0.84$.

Provenience: $41 \mathrm{BX} 540$, surface.

DB4. Group 4 - Preforms and Proximal Fragments

DB4:1. Preform (1 specimen; Fig. 52,a)

The specimen appears to be an unfinished preform with no utilization or working edge noted. The artifact is distinctly triangular in cross section, but lacks any type of pressure flaking. Somewhat asymmetric in form, the specimen lacks the (distal?) tip. All faces have been flaked, including ventral.

L: $9.4 \mathrm{~cm} ; W: 4.2 \mathrm{~cm} ; \mathrm{T}: 2.7 \mathrm{~cm}$.

Provenience: $41 \mathrm{BX} 518$, surface.

DB4:2. Form 2 - Proximal Fragment (1 specimen; Fig. 52,b)

The proximal portion of a Guadalupe tool is biconvex in cross section, but this may be due to the location of the snap fracture on the complete tool; percussion flaking along the tool faces may also give the appearance of a biconvex shape at certain cross sectional locations. Several areas of cortex 
remain on the dorsal surface: one along the right edge and another on the proximal tip. The location of this artifact is quite significant (see 41 BX 344), since it appears in situ about $98 \mathrm{~cm}$ above a smal1 1 ithic debris and charcoal fleck concentration.

\section{L: $6.2 \mathrm{~cm} ; W: 3.75 \mathrm{~cm} ; \mathrm{T}: 2.45 \mathrm{~cm}$.}

Provenience: 41 BX 344 (eroding from bulldozer cut about $2.20 \mathrm{~m}$ below the surface).

UNIFACES (U; 1 specimen)

Unifaces, for the purposes of this report, are defined as chipped stone flakes which have been modified by flaking over two-thirds of their width across the dorsal surface. This surface flaking may be described as invasive retouch to distinguish it from other forms of tool shaping or resharpening such as marginat or semi-invasive retouch. It is necessary to define unifaces as discrete, formal, specifically manufactured tool types to separate them from the more common marginally and semi-invasively retouched flakes which are considered an informal tool type.

Only two unifacial artifacts were surface collected from the study area. One is discussed as a distally beveled tool (see DB3:4), and the other is a miscellaneous specimen.

\section{U1. Group 1 - Proximal (P1atform) Intact}

\section{U1:4. Form 4 - Miscellaneous (1 specimen; Fig. 52,f)}

Group 1, Form 4 specimen is the distal or proximal end of a steeply angled unifacial tool. Cortex still covers much of the dorsal surface. The fragment is subtriangular in outline, and the original shape cannot be determined. Very steep beveling which varies from 35 to $55^{\circ}$ is noted on the edges and end. Cross section is biconvex. There is a possibility that the tool snapped on impact at some point before completion, since some cortex still remains along the dorsal edges. This artifact was found more than $30 \mathrm{~cm}$ below a Guadalupe tool fragment (DB2:2, Guadalupe tool fragment). Both artifacts were apparently in situ.

\section{L: 6.33 (incomplete); W: 4.19 (incomplete); T: 0.62 .}

Provenience: $41 \mathrm{BX} 344$, about $260 \mathrm{~cm}$ below the surface. Collected from the wall of a bulldozer cut. 
PERFORATORS (P; 2 specimens; Figs. $55, \mathrm{~h} ; 56, \mathrm{a}$ )

P:1. Form 1 - Identifiable Base (1 specimen; Fig. 56,a)

A single corner-tanged perforator missing its distal end was surface collected from the study area. Bifacially worked, the working edges appear to be resharpened but not alternately beveled.

L: $4.6 \mathrm{~cm} ; W: 4.3 \mathrm{~cm} ; \mathrm{T}: 0.8 \mathrm{~cm}$.

Provenience: $41 \mathrm{BX} 274$.

P:4. Form 4 - Fragment (1 specimen; Fig. 55,h)

Although consisting of only the distal portion, the distinctive shape of this artifact makes it easily identifiable. It represents occupational activities at 41 BX 528 not directly associated with lithic reduction or food processing. Manufactured from a fine-grained medium brown chert, the specimen is alternately beveled and broken by a distinctive hinge fracture.

L: $4.34 \mathrm{~cm}$ (fragmented); $W: 1.48 \mathrm{~cm}$ (maximum); T: $0.62 \mathrm{~cm}$.

Provenience: 41 BX 528, surface.

UTILIZED AND/OR MODIFIED CHIPPED STONE (5 specimens; Figs. 61,a,b)

Several fragments of siliceous stone cobbles were collected which represent former utilization and/or modification of the artifact. The artifacts are characterized by percussion flaking along marginal edges to establish a particular or otherwise functional working edge.

Specimen 1 (Fig. 61,a) is a large chert cobble with one end bifacially trimmed by percussion flaking in a semi-invasive fashion.

Provenience: $41 \mathrm{BX} 526$, surface.

Specimen 2 (Fig. 61,b) is a small core remnant with a patch of cortex on the dorsal surface. The ventral surface is laterally flaked to produce a biconvex cross section. Extensive small step fractures were observed on the ventral face.

Provenience: 41 BX 526, surface.

Specimen 3 (Fig. 62,b) is a large, unifacially worked core tool with possible multi-angled working edges. Ovate in shape, part of the cortex remains on the dorsal surface. All edges reflect sma11, primarily dorsal edged, step fractures.

Provenience: $41 \mathrm{BX} 528$, surface. 


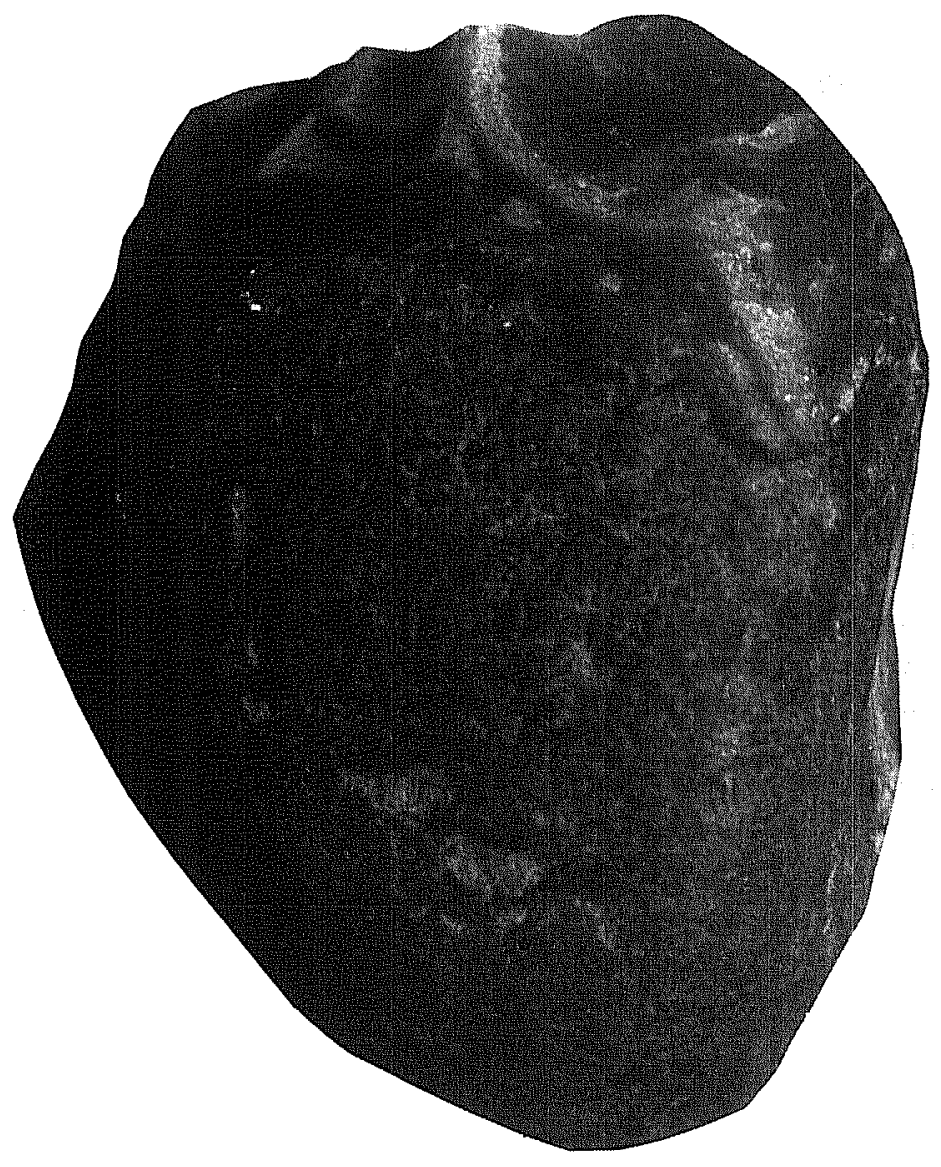

a

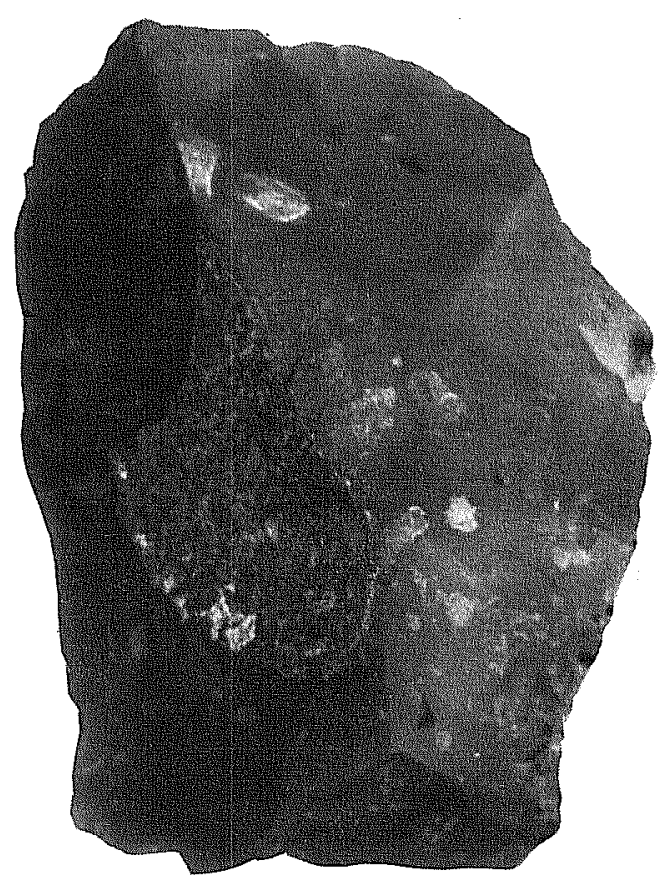

b
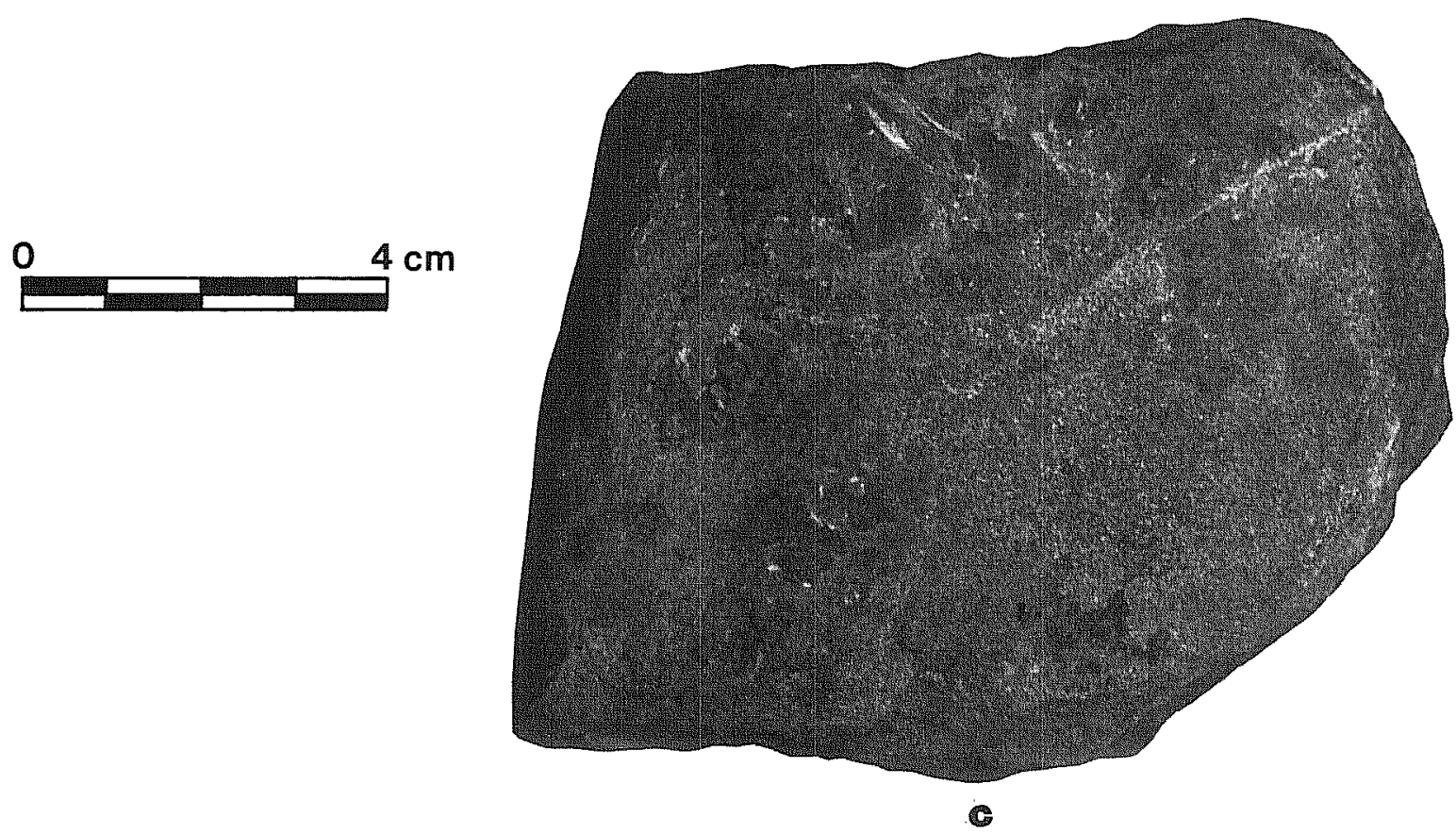

Figure 6l. Utilized/Modified Chipped Stone and Sandstone. a,b, utilized/ modified chipped stone (41 BX 526); C, sandstone (41 BX 536). 
Specimen 4 (Fig. $55, \mathrm{k}$ ) is a large modified blade flake manufactured from a fine-grained, tan-colored chert. The distal end and the right blade edge of the dorsal face (distal end up) has been modified by pressure flaking (marginal edge retouch) as well as more random (use-wear) nicking. The right lateral side of the ventral surface (distal end up) is characterized by semiinvasive retouch in the form of pressure flaking. These flake scars occur across the face of the blade to its long axis.

Other artifacts collected at this site indicate Late Prehistoric and possible historic Indian associations. It is possible (probable?) this specimen is representative of a blade technology known to have existed during this time period (see also Hester 1977).

Provenience: 41 BX 528, surface.

Specimen 5 (Fig. 55,1 ) is a small modified core fragment of medium brown chert. Cortex still remains on portions of the surfaces. The ventral face is unmodified. Somewhat irregular in shape, the thickest portion of the dorsal edge has been modified by soft-hammer flaking to form a steep, gougelike scraping edge. Nicking and minute hinge-fracturing along this edge indicate some use-wear.

Provenience: 41 BX 528, surface.

BATTERED, GROUND, PECKED, AND NOTCHED STONE (5 specimens)

Ground and pecked stone tools are artifacts which have been shaped either by rubbing or pounding actions for some specific purpose. Ground stone tools were fashioned by rubbing a stone surface with an abrasive and are often associated with food processing such as grinding seeds or grains (Joukowsky 1980). Grinding stones can be identified by their smooth, even surfaces. Pecked stone tools, on the other hand, can be easily recognized by tiny, often porelike, peck marks all over their surfaces (ibid.).

Five pieces of ground, pecked, or otherwise battered stone were collected during survey operations. These are listed and described as follows:

Site Provenience Source Material General Description Comments

41 BX 526 Surface limestone oblong; fragment grinding slab fragment, burned

(not i17ustrated)

41 BX 528 Surface limestone indeterminate; battered, probcobble fragment ably used as a hammerstone

(Fig. 62,a)

41 BX 534 Surface $\begin{aligned} & \text { 1imestone } \\ & \text { cobble }\end{aligned}$

subdiscoidal; complete

smooth top, pecked to shape around edges (Fig. 62, C) 
Applewhite/Material Culture

Figure 62. Miscellaneous Artifacts from 41 BX 528 and 41 BX 534.

a, limestone cobble, probably used as a hammerstone (4I BX 528);

b, core tool (4l BX 528);

c, limestone cobble (41 BX 534). 

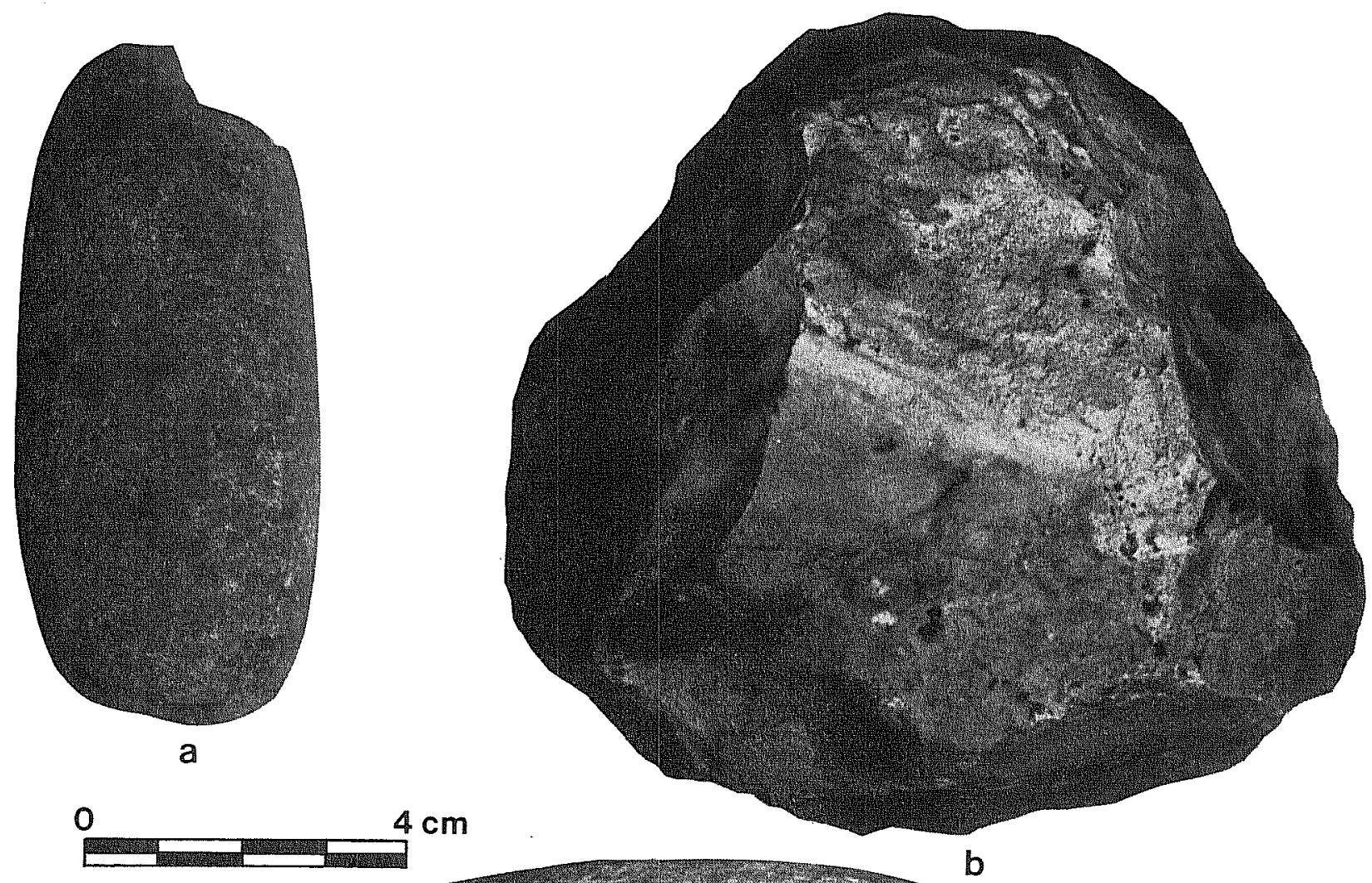

b

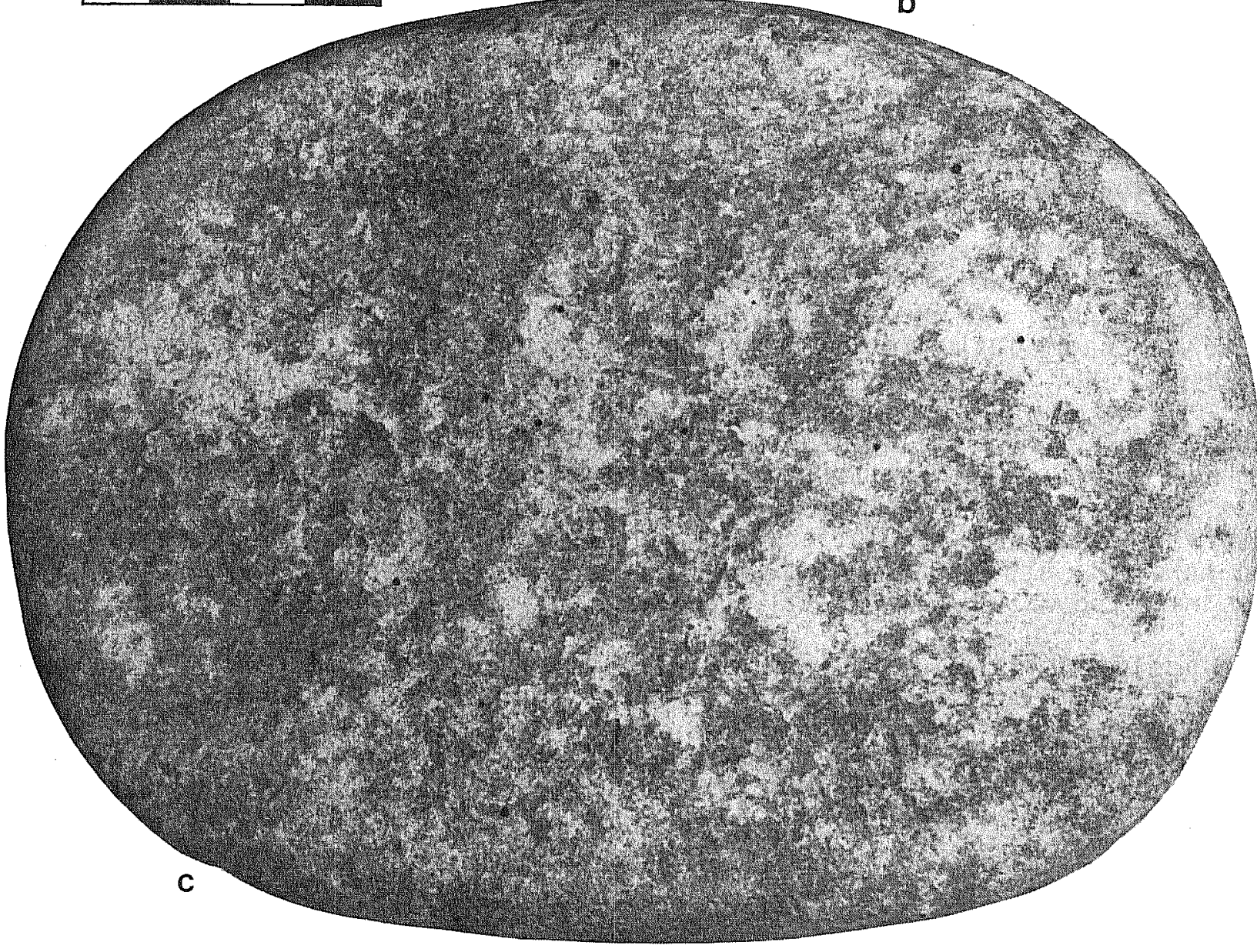




\begin{tabular}{|c|c|c|c|c|}
\hline Site & Provenience & Source Material & General Description & Comments \\
\hline $41 \mathrm{BX} 536$ & Surface & $\begin{array}{l}\text { sandstone with } \\
\text { iron oxidation }\end{array}$ & $\begin{array}{l}\text { irregular shape; } \\
\text { complete }\end{array}$ & $\begin{array}{l}\text { abraded } \\
\text { (Fig. } 61, c)\end{array}$ \\
\hline 41 BX 274 & Surface & $\begin{array}{l}\text { quartzite } \\
\text { pebble }\end{array}$ & $\begin{array}{l}\text { oblong, notched } \\
\text { along ends of } \\
\text { long axis }\end{array}$ & $\begin{array}{l}\text { The complete } \\
\text { specimen is } 7.1 \times \\
3.8 \mathrm{~cm} \text { and is } \\
\text { similar.to Turner } \\
\text { and Hester's } \\
\text { (1985:258-259) } \\
\text { description of } \\
\text { "Waco Sinkers." } \\
\text { Their use and } \\
\text { chronological } \\
\text { context are } \\
\text { currently } \\
\text { undetermined }\end{array}$ \\
\hline
\end{tabular}

(Fig. 54,d).

\section{LITHIC DEBRIS (not i17ustrated)}

Lithic debris, in the form of cores, core fragments, flakes, chips, and chunks, were noted on site survey forms, but generally not collected. However, at 41 BX 344, where subsurface materials were exposed in a bulldozer cut, a special collection was made. The materials were collected from a concentration about $301 \mathrm{~cm}$ below the surface, nearly $1 \mathrm{~m}$ lower than the Guadalupe tool fragment (see 41 BX 344) from the same site.

Debris, as defined for this report, may be described as the waste products from the manufacture or utilization and/or sharpening of siliceous stone tools. Debris can be categorized as remnants of the parent material (cores and/or fragments) or detached primary, secondary, or tertiary flakes from these cores. All flakes possess the remnants of a striking platform and bulb of percussion, and are categorized by the amount of original exterior surface (cortex) remaining on the dorsal face of the flake. The degree of cortex ranges from completely covering the exterior surface (a primary flake) to no cortex on the surface (a tertiary flake). Small stone fragments without a bulb of percussion or platform remnant are described as chips or chunks. For a more detailed discussion of lithic production, techniques, etc., the reader is referred to Crabtree (1972) and Tringham et al. (1974).

In addition to lithic debris, six pieces of burned limestone, five small pieces of burned sandstone, and numerous small gravels were present in the concentration at $41 \mathrm{BX} 344$. Since the concentration seems too haphazard to be considered a cache, and there is no evidence of rodent disturbance in the surrounding soils, it is possible that this concentration was formed by an erosional wash from surface run-off. 


\section{Flakes}

Secondary Flakes (5 specimens)

Three secondary flake specimens have a cortex striking platform, and two have a single-faceted decorticate platform. of the five specimens, two are heat treated, and one shows evidence of utilization on the dorsal edge.

\section{Tertiary Flakes (7 specimens)}

Two tertiary flake specimens have a single-faceted platform; three have small (1ess than $1 \mathrm{~cm}$ ) multifaceted $\mathrm{platforms}$ which may indicate some preparation of the platform surface before the blows that removed the flakes were struck; and two specimens have crushed platforms due to the force of the blows which separated them from the parent material. None of these flakes have been burned. One specimen has been utilized on all dorsal edges.

\section{Chips (13 specimens)}

Four specimens retain patches of exterior surface material and are defined as partially corticate. The remainder are decorticate (lacking cortex), including one which is fire reddened.

\section{Chunks ( 3 specimens)}

Two chunk specimens are partially corticate, and one has burned edges.

\section{CERAMICS}

The investigation of south-central and southern Texas prehistoric ceramics is a relatively recent focus of archaeological inquiry. Primary emphas is in past ceramic analyses has been on descriptive classifications (Story 1968; Hester and Parker 1970; Fawcett 1972), but 7 ittle has been done to define cultural and temporal relations. Hester (1968), Hester and Hi11 (1971), and, more recentiy, Black $(1982,1986)$ have presented discussions on regional ceramics.

The majority of prehistoric ceramics recorded in the area are known as a very broadly defined category, Leon Plain (Suhm and Jelks 1962; Heartfield 1966; Dulaney 1977). This coiled, bone-tempered, undecorated ware is found in small quantities at various Late Prehistoric sites throughout central and most of south Texas. Vessel shapes include more or less hemispherical bowls and jars with light vertical rims. For a further discussion of Leon Plain, the reader is referred to Dulaney (1977), B ack (1982, 1986), and Black and McGraw (1985).

Fifty small prehistoric sherds, including two previously collected from the Medio Creek survey (McGraw 1977), were analyzed to determine broad morphological characteristics. The ceramic sherds are discussed using the 
following criteria: (1) provenience; (2) general groups, if applicable; (3) associated materials, when possible; and (4) morphological characteristics, including color range as defined by a Munsell color chart, interior and exterior characteristics, and various treatments such as burnishing (polishing) and degree of burnishing. Ceramics were collected from six archaeological sites in the study area. Hardness on all specimens ranges from ca. 2.5 to 3.5 on the Moh scale.

\section{Site 41 BX 528}

Group 1 ( 3 sherds)

Provenience: The sherds were surface collected on the western section of the site.

Associations: No chronologically diagnostic artifacts were noted.

Morphological characteristics: Maximum 1ength: $0.9 \mathrm{~cm}$; maximum width: $0.8 \mathrm{~cm}$; maximum thickness: $0.45 \mathrm{~cm}$.

$$
\begin{array}{lll}
\text { Color range: } & \text { exterior surface } & 2.5 \text { YR } 5.8 \\
& \text { inner surface } & 10 \text { YR } 6 / 4
\end{array}
$$

Surface characteristics: Exterior surfaces are smoothed with a slight luster. No decorations were noted. Inner surfaces are tactually more rough. Paste is quite sandy with many small silicate inclusions. Core streak is negligible, but color of outer surface extends half-way across cross section of sherd.

Group 2 (24 sherds)

Provenience: Surface collected from western end of site, ca. $15 \mathrm{~m}$ from Group 1 fragments.

Associations: None.

Morphological characteristics: Maximum 1ength: $1.3 \mathrm{~cm}$; maximum width: $1.2 \mathrm{~cm}$; maximum thickness: $0.45 \mathrm{~cm}$.

$\begin{array}{lllll}\text { Color range: } & \text { exterior surface } & 5 \text { YR } 7 / 8-5 \quad \text { YR } 8 / 4 \\ & \text { inner surface } & 5 \text { YR } 6 / 8\end{array}$

Surface characteristics: Exterior surfaces are smoothed, but paint brush lines are traceable across the surface. Interiors are slightly curved and smoothed. No decoration is visible on either surface.

Remarks: No distinct core streak is visible on the cross section of the sherds, although the interior has a distinct mottled appearance of 1 ight and dark colors. Paste appears much more clayey than in Group 1. 
Group 3 (1 sherd)

Provenience: Surface collected from the eastern site margins.

Associations: No chronologically diagnostic associations were noted.

Morphological characteristics: Maximum 1ength: $8.0 \mathrm{~cm}$; maximum width: $7.5 \mathrm{~cm}$; maximum thickness: $0.50-0.75 \mathrm{~cm}$ (rim sherd).

$$
\begin{array}{lll}
\text { Color range: } & \text { exterior surface } & 10 \text { YR } 6 / 2.5 \\
& \text { inner surface } & 10 \text { YR } 7 / 2
\end{array}
$$

Surface characteristics: Exterior surfaces are smoothed but with no luster; this may be due to natural weathering. Inner surfaces are tactualiy rough and relatively unsmoothed. Rim is pinched and flares outward slightly, resulting in a small 7 ip around the edges of the vessel. Serrated edges give the appearance of breakage along original coil 1 ines.

Remarks: This unusual1y large ceramic fragment suggests more sherds may be buried beneath the surface at 41 BX 528 . Core streak appears across entire cross section of sherd; paste is somewhat clayey and bone tempered with fragments up to $1 \mathrm{~mm}$ in length.

\section{Site 41 BX 530}

Group 1 ( 7 sherds)

Provenience: Surface collected from eastern area of site.

Associations: No culturally diagnostic materials were observed.

Morphological characteristics: Maximum length: $4.9 \mathrm{~cm}$; maximum width: $3.9 \mathrm{~cm}$; maximum thickness: $0.78 \mathrm{~cm}$.

$$
\begin{array}{lll}
\text { Color range: } & \text { exterior surface } & 10 \text { YR } 6 / 6-10 \text { YR } 6 / 2 \\
& \text { inner surface } & 10 \text { YR } 7 / 4-10 \text { YR } 6 / 2
\end{array}
$$

Surface characteristics: The exterior surface of the sherds ranges from smoothed and somewhat weathered to a moderate degree of luster. A11 exterior surfaces are plain without indications of decoration or brush marks. Inner surfaces are tactualiy rough and unburnished (unpolished).

Remarks: Core streak on all specimens is quite distinct and covers the entire cross section of the sherds. Paste is somewhat clayey and has a laminated appearance. The sherds appear to be the fragments of a jarlike vesse1.

Group 2 (4 sherds)

Provenience: Within the immediate vicinity of Group 1. 
Associations: Group 1 ceramic sherds.

Morphological characteristics: Maximum length: $2.4 \mathrm{~cm}$; maximum width: $1.7 \mathrm{~cm}$; maximum thickness: ca. $0.7 \mathrm{~cm}$.

$$
\begin{array}{lll}
\text { Color range: } & \text { exterior surface } & 5 \text { YR 5/5 } \\
& \text { inner surface } & 7.5 \text { YR } 5 / 2
\end{array}
$$

Surface characteristics: Exterior surfaces are plain and smoothed; no evidence of brush marks was noted. Inner surfaces are tactually rough and similar in overall characteristics as Group 1.

Remarks: Core streak is slightly lighter than in Group 1, and paste appears to include a higher fraction of silicate materials; less clayey, more sandy. These four sherds may actually be from the same vessel as Group 1 but this can only be determined by more detailed ceramic analyses.

\section{Site 41 BX 531}

Group 1 (1 specimen)

Provenience: Surface collected during intensive survey operations along the sloping terrace margins in the central site area.

Associations: No close associations, but Perdiz arrow points have been found at adjacent sites.

Morphological characteristics: Length: $2.9 \mathrm{~cm}$; thickness: $0.5 \mathrm{~cm}$.

$$
\begin{array}{lll}
\text { Color range: } & \text { exterior surface } & 10 \text { YR } 6 / 6 \\
& \text { inner surface } & 10 \text { YR } 7 / 4
\end{array}
$$

Surface characteristics: Bone temper is visible in exterior surface, and pitting due to weathering is noted (as is the inner surface). The small sherd is badly weathered. Carbon core streak is more than two-thirds across the cross section of the sherd.

Remarks: The recovery of this single fragment precludes further interpretations, although it appears to have general morphological similarities to Group 1 sherds from 41 BX 530.

\section{Site $41 \mathrm{BX} 653$}

Group 1 (1 specimen)

Provenience: The sherd was recovered along the eroding, sloping margins in the eastern portion of the site area.

Associations: No diagnostic artifacts were directly associated with the sherd. 
Morphological characteristics: Length: $2.8 \mathrm{~cm}$; thickness: $0.65 \mathrm{~cm}$.

$\begin{array}{lll}\text { Color range: } & \text { exterior surface } & 10 \text { YR } 6.5 / 4 \\ & \text { inner surface } & 10 \text { YR } 3 / 2\end{array}$

Surface characteristics: The exterior surface is moderately pitted due to weathering; the inner surface is tactually smooth. Paste inclusions reflect very small bone (temper) fragments in a sandy matrix. No core streak is visible.

Remarks: The small sample precludes interpretations. A 1arger sample collected from future work will contribute significantly to morphological assessments.

\section{Site 41 BX 459}

Group 1 ( 6 sherds)

Provenience: Surface collected from the eroding top of a small crescentshaped midden ca. $5 \times 3 \mathrm{~m}$ and ca. $25 \mathrm{~cm}$ in height. These sherds were recovered during the work in 1977 (McGraw 1977).

Associations: The six sherds were associated with scattered Tithic debris in the form of chips and tertiary flakes. Fire-reddened and fire-cracked limestone cobbles were also noted on the small crescent-shaped midden.

Morphological characteristics: 0nly body sherds are represented, but they can be joined together to form part of one vessel. Interior surface smoothing may indicate a shallow bowllike vessel. Maximum and minimum thicknesses of sherds, respectively: 0.8 to $0.65 \mathrm{~cm}$. The length and width of the sherds when joined together are $7.8 \times 8.8 \mathrm{~cm}$,

$$
\begin{array}{lll}
\text { Color range: } & \text { exterior surface } & 10 \text { YR } 6.5 / 3-7.5 \text { YR } 5 / 4 \\
& \text { inner surface } & 10 \text { YR } 3 / 2-5 \text { YR } 4 / 6
\end{array}
$$

Surface characteristics: Exterior surfaces show distinct brush marks generally in one direction across the sherds. A faintly curved, incised line appears to diagonally cross these brush marks, unfortunately it is too shallow to determine whether this line was accidental or an attempt at decoration. Exterior texture is rough and generally reddish brown in color with exposed bone flecks. The inner surfaces are smoothed dark brownish gray, except for one corner which contrasts sharply by a red coloration. Core streak covers the entire cross section of the sherds. Bone fragments ca. $2 \mathrm{~mm}$ in length are noted. Very small hematitelike nodules are scattered throughout core cross section.

Remarks: No rim or lip sherds were collected, and the general vessel shape is indeterminate. The sherds are similar to Boothe Brushed pottery. The occurrence in south Bexar County of ceramics similar to Boothe Brushed, a minor central Texas ware, must be considered as an unusual phenomenon. The obvious question of whether these ceramics are intrusive cannot be answered, as Dee Ann Story of The University of Texas at Austin points out (personal 
communication) without a detailed study of past and local clays. Since studies involving thin sectioning and neutron activation are beyond the scope of this report, the origins of these ceramics cannot be determined. Dr. Story does observe that sherds of this type description combine a number of both Caddoan and plain central Texas ware characteristics. While ceramics at the central Texas site where Boothe Brushed was first defined were not closely related to diagnostic lithic artifacts, they were still clearly related to past Late Prehistoric occupations.

Group 2 (1 sherd)

Provenience: Directly associated with Group 1 ceramics.

Associations: See Group 1, site 41 BX 459.

Morphological characteristics: Length: $2.4 \mathrm{~cm}$; width: $1.4 \mathrm{~cm}$; maximum thickness: $0.80 \mathrm{~cm}$.

$$
\begin{aligned}
& \text { Color range: exterior surface } \quad 7.5 \text { YR } 5 / 8 \\
& \text { inner surface } \quad 5 \text { YR } 5 / 8
\end{aligned}
$$

Temper of sherd is finely to moderately crushed bone; largest bone fragment (unburned) is ca. $2 \mathrm{~mm}$ in length, most are $0.5 \mathrm{~mm}$ or 1 ess. Small red lumps (hematite or clay) are included in the paste.

Remarks: Eroding from the same small feature at 41 BX 459, both Groups 1 and 2 ceramics appear to be closely associated. Further testing will be necessary before more definite conclusions can be reached concerning the context and associations of these materials.

\section{Site 41 BX 463}

Two sherds, which can be joined together, were recovered from $41 \mathrm{BX} 463$, located on Medio Creek. As one of the Medio Creek sites under potential impact by the proposed Applewhite Reservoir, the site was revisited in 1981 and reassessed as to its archaeological potential. The resulting sherds are from this later visit.

Provenience: The sherds were collected on the eroding slopes along the western margins of the site.

Associations: No diagnostic materials are currently associated with the ceramics.

Morphological characteristics: Maximum length of both sherds joined together: $2.5 \mathrm{~cm}$; maximum width: $2.1 \mathrm{~cm}$; maximum thickness: $0.69 \mathrm{~cm}$.

$\begin{array}{lll}\text { Color range: } & \text { exterior surface } & 10 \text { YR } 7 / 4 \\ & \text { inner surface } & 10 \text { YR } 6 / 4\end{array}$


Surface characteristics: Outer surfaces are smoothed, undecorated, and lightly burnished. Inner surfaces are tactually rougher. Core streak extends across most of the cross section but stops short before inner surface margins. A transition of ca. 1-3 mm was noted between core streak and inner surface margins. Burned bone fragments ca. 0.5 to 3.0 in length were used as the tempering material.

Remarks: While 41 BX 463 is largely disturbed or eroded, the presence of ceramic materials indicates at least one cultural component of Late Prehistoric association at this locality. 


\section{SUMMARY AND INTERPRETATIONS}

\section{PROJECT SUMMARY}

A total of 85 sites (Table 13) has been documented in the area of the proposed Applewhite Reservoir in southwestern Bexar County, Texas. Seventyeight of these sites were identified during the 1981 and 1984 studies; an additional seven sites were previously identified in a 1977 Medio Creek survey (McGraw 1977). These seven sites were revisited and reassessed in both 1981 and 1984. Forty-nine sites are prehistoric, 26 are hiștoric, and 10 contain both prehistoric and historic components. The 10 sites containing both prehistoric and historic components are discussed and listed in both the prehistoric and historic summaries as the significance of these components vary. Those sites having both a prehistoric and historic component present are clearly identified on Table 13.

Forty sites (five of these have both a prehistoric and historic component) have been identified as being eligible or potentially eligible for listing on the National Register of Historic Places. Nineteen of these sites will require further work to determine their eligibility for listing on the National Register of Historic Places.

The significance of 21 sites is not known at this time. Eighteen of these sites will require further work to determine their potential eligibility or eligibility for listing on the National Register of Historic Places (three of these sites are not recommended for further work as they are out of the reservoir area). One additional site, $41 \mathrm{BX} 666$, has a historic component that has been determined eligible but the prehistoric component is unknown.

Fourteen sites are not recommended at this time for further work. These sites are listed for no further work at this time for two reasons: (1) they are severely eroded or extensively disturbed; or (2) they are out of the proposed reservoir area. Some of the sites which are in the maximum flood pool level might potentially contain deeply buried deposits. Should future testing at nearby sites reveal the presence of these deeply buried deposits, then a smal1 number of these sites might need reassessment. Ten sites are recommended for no further work.

To date, cumulative surveys have investigated approximately $98 \%$ of the proposed reservoir area based on the maximum flood pool level of 555.3 feet above msl. An extensive archival and historical background review has identified personalities, families, and events that have influenced both the development of the study area and the regional history. Historical research has also clarified the importance of many of the sites identified to date.

The results of cultural resources investigations have shown a study area with an archaeological significance that contrasts markedly with the relatively small physical proportions of the projected reservoir. As presented, this report has been, in some aspects, quite detailed. Given the area's projected impacts and the scope of its archaeological resources, such a perspective is considered a critical necessity for the responsible management of these cultural resources. 
TABLE 13. SUMMARY OF PREHISTORIC AND HISTORIC SITE RECOMMENDATIONS

\begin{tabular}{|c|c|c|c|c|c|c|c|}
\hline $\begin{array}{l}\text { Site } \\
\text { Number }\end{array}$ & $\begin{array}{l}\text { Field } \\
\text { Number } 1\end{array}$ & $\begin{array}{l}\text { Type of } \\
\text { Site }\end{array}$ & Elevation ${ }^{3}$ & Description & $\begin{array}{l}\text { National } \\
\text { Register Status } \\
\text { (In the op inion } \\
\text { of the authors) }\end{array}$ & $\begin{array}{l}\text { Further Work } \\
\text { Recommendatl ons }{ }^{5}\end{array}$ & Comments \\
\hline $41 \mathrm{BX} 273$ & $A W-38$ & H & $\begin{array}{l}540^{\prime}-550^{\prime} \\
(\mathrm{mfp} 1)\end{array}$ & $\begin{array}{l}\text { Munk home; late 19th- } \\
\text { century stone home } \\
\text { current'y occupted }\end{array}$ & $\begin{array}{l}\text { Potentlally } \\
\text { eligible }\end{array}$ & Yes & $\begin{array}{l}\text { Further archival research } \\
\text { and } 11 \mathrm{~m} \text { ted testing }\end{array}$ \\
\hline $41 \mathrm{BX} 274$ & $\begin{array}{c}\text { (P) AW-51 }(1981) \\
2 A W-11(1984) \\
\text { (H) } 2 A W-13 \text { (1984) } \\
\text { Former7y } \\
41 \text { BX } 663\end{array}$ & $\mathrm{P} / \mathrm{H}$ & $\begin{array}{l}\text { (P) } 500-550^{\prime} \\
\text { (cp } 1) \\
\text { (H) } 540-570^{\prime} \\
\text { (mfp1) }\end{array}$ & $\begin{array}{l}\text { (P) Late Paleo-Indian } \\
\text { through Late Prehistoric } \\
\text { (H) PErez's Rancho/"Stone } \\
\text { Rancho" }\end{array}$ & Elfgible & See text & $\begin{array}{l}\text { A determination of eligi- } \\
\text { bility should be sought }\end{array}$ \\
\hline $41 \quad B \times 277$ & $\begin{array}{r}A W-37(1981) \\
2 A W-12(1984)\end{array}$ & H & $\begin{array}{l}570^{\prime} \\
(a m f p 1)\end{array}$ & Pórez Chapel and Cemetery & Eligible & See text & $\begin{array}{l}\text { A determination of eligi- } \\
\text { bllity should be sought }\end{array}$ \\
\hline $41 \mathrm{BX} 343$ & $A W-1$ & $\mathrm{P}$ & $\begin{array}{l}550-570^{\prime} \\
(\mathrm{mfp} 1)\end{array}$ & $\begin{array}{l}\text { Small prehistoric 11thic } \\
\text { reduction site }\end{array}$ & $\begin{array}{l}\text { Not at this } \\
\text { time }\end{array}$ & Not at this time & $\begin{array}{l}\text { May contain deeply buried } \\
\text { deposits }\end{array}$ \\
\hline $41 \mathrm{BX} 344$ & $A W-2$ & $\mathrm{P} / \mathrm{H}$ & $\begin{array}{l}560-580 \\
(\text { amfpl })\end{array}$ & $\begin{array}{l}\text { (P) Early Archaic } \\
\text { (H) Francisco A. Ruiz } \\
\text { rancho complex }\end{array}$ & El $\lg 1 \mathrm{~b} l e$ & Yes & $\begin{array}{l}\text { A determination of eligi- } \\
\text { should be sought }\end{array}$ \\
\hline $41 \mathrm{BX} 346 \mathrm{~A}$ & $A W-5(1981)$ & $\mathrm{P} / \mathrm{H}$ & $\begin{array}{l}500-530^{\prime} \\
(\mathrm{cp} 1)\end{array}$ & $\begin{array}{l}\text { Large prehistoric occupa- } \\
\text { tion zone and recent } \\
\text { structures }\end{array}$ & Unknown & Yes & $\begin{array}{l}\text { May contain deeply buried } \\
\text { deposits. Historic con- } \\
\text { ponent redefined as modern }\end{array}$ \\
\hline $41 \mathrm{BX} 346 \mathrm{~B}$ & $\begin{array}{l}\text { AW-46 (1981) } \\
\text { Formerly } \\
41 \text { BX } 551\end{array}$ & $P$ & $\begin{array}{l}500-550^{\prime} \\
(c p 1)\end{array}$ & Middle to Late Archaic & Unknown & Yes & $\begin{array}{l}\text { May contain deeply buried } \\
\text { deposits }\end{array}$ \\
\hline 41 BX 347 & $A W-6$ & $P$ & $\begin{array}{l}530-540^{\prime} \\
(c p 1)\end{array}$ & Prehistoric occupation site & $\begin{array}{l}\text { Not at this } \\
\text { time }\end{array}$ & Not at this time & $\begin{array}{l}\text { Extensively disturbed, but } \\
\text { may contain deeply buried } \\
\text { materials; monitoring } \\
\text { recommended }\end{array}$ \\
\hline $41 \mathrm{BX} 348$ & $A W-7$ & $P$ & $\begin{array}{l}520^{\prime}-540^{\prime} \\
(\mathrm{cp} 1)^{\prime}\end{array}$ & $\begin{array}{l}\text { Lithic scatter; possible } \\
\text { temporary occupation site }\end{array}$ & $\begin{array}{l}\text { Not at this } \\
\text { time }\end{array}$ & Not at this time & $\begin{array}{l}\text { Severely eroded; monitoring } \\
\text { recommended to identify any } \\
\text { deeply buried materials }\end{array}$ \\
\hline $41 \mathrm{BX} 350$ & $A W-8$ & $P$ & $540^{\prime}(\operatorname{mfp} 1)$ & $\begin{array}{l}\text { Lithic scatter; possible } \\
\text { temporary occupation site }\end{array}$ & $\begin{array}{l}\text { Not at this } \\
\text { time }\end{array}$ & Not at this time & $\begin{array}{l}\text { Severely eroded; monitoring } \\
\text { recommended to identify } \\
\text { deeply burled materials }\end{array}$ \\
\hline $41 \mathrm{BX} 515$ & $A W-50$ & $\mathbf{P}$ & $\begin{array}{l}550-560^{\prime} \\
(m f p 1)\end{array}$ & Lithic scatter & Unknown & Yes & $\begin{array}{l}\text { May contain deeply buried } \\
\text { deposits }\end{array}$ \\
\hline $41 \mathrm{BX} 516$ & AW-9 & $\mathbf{P}$ & $\begin{array}{l}560-570^{\prime} \\
(\text { amfp } 1)\end{array}$ & $\begin{array}{l}\text { Prehistoric occupation } \\
\text { site }\end{array}$ & $\begin{array}{l}\text { Not at this } \\
\text { time }\end{array}$ & Not at this time & $\begin{array}{l}\text { Monitoring recommended to } \\
\text { identify deeply buried } \\
\text { deposits }\end{array}$ \\
\hline
\end{tabular}




\begin{tabular}{|c|c|c|c|c|c|c|c|}
\hline $\begin{array}{l}\text { Site } \\
\text { Number }\end{array}$ & $\begin{array}{l}\text { Field } \\
\text { Numberl }\end{array}$ & $\begin{array}{l}\text { Type of } \\
\text { Site }\end{array}$ & Elevation ${ }^{3}$ & Description & $\begin{array}{l}\text { National } \\
\text { egister Status } \\
\text { in the op infon } \\
\text { in the authors) }\end{array}$ & $\begin{array}{l}\text { Further Work } \\
\text { Recommendations } 5\end{array}$ & Comments \\
\hline $41 \mathrm{BX} 517$ & $A W-10$ & $P$ & $620 \cdot(\operatorname{amfp} 1)$ & $\begin{array}{l}\text { Possible lithic workshop/ } \\
\text { quarry area }\end{array}$ & $\begin{array}{l}\text { Potentialiy } \\
\text { elfible }\end{array}$ & No & Out of reservoir area \\
\hline $41 \mathrm{BX} 518$ & $A W-11$ & $P$ & $\begin{array}{l}550-570^{\prime} \\
(\mathrm{mfp} 1)\end{array}$ & Prehistoric occupation site & Unknown & Yes & $\begin{array}{l}\text { Deep } 7 \text { y buried deposits may } \\
\text { exist }\end{array}$ \\
\hline $41 B \times 519$ & $A W-12$ & $H$ & $510^{\prime}(\mathrm{cp} 1)$ & $\begin{array}{l}\text { Picard property, late } \\
\text { 19th-early } 20 \text { th-century } \\
\text { structures (2) }\end{array}$ & $\begin{array}{l}\text { Potentially } \\
\text { elfible }\end{array}$ & Yes & $\begin{array}{l}\text { Further archival/deed } \\
\text { research and } 11 \text { mited testing } \\
\text { are recommended }\end{array}$ \\
\hline $41 \mathrm{BX} 520$ & $A W-13$ & $H$ & $\begin{array}{l}530-540 ' \\
(\mathrm{cp} 1)\end{array}$ & $\begin{array}{l}\text { Estimated initial encounter } \\
\text { of the Battle of the Medina }\end{array}$ & Eligible & See text & $\begin{array}{l}\text { A determination of eligi- } \\
\text { bility should be sought }\end{array}$ \\
\hline $41 \mathrm{BX} 521$ & $A W-14$ & $H$ & $\begin{array}{l}550-570 ' \\
(\operatorname{mfp} 1)\end{array}$ & $\begin{array}{l}\text { Oak Island Methodist Church } \\
\text { and Cemetery }\end{array}$ & Eligible & See text & $\begin{array}{l}\text { A determination of ellgi- } \\
\text { bility should be sought }\end{array}$ \\
\hline $41 B \times 522$ & $A W-15$ & $\mathrm{P}$ & $590^{\prime}(\operatorname{amfpl})$ & $\begin{array}{l}\text { Lithic scatter; possible } \\
\text { temporary occupation }\end{array}$ & $\begin{array}{l}\text { Not at this } \\
\text { time }\end{array}$ & Not at this time & $\begin{array}{l}\text { Out of reservoir area. Site } \\
\text { may contain deeply buried } \\
\text { deposits }\end{array}$ \\
\hline $41 \mathrm{BX} 523$ & $A W-16$ & H & $560 \cdot(\operatorname{amfp} 1)$ & Historic occupation & No & No & Destroyed \\
\hline 41 BX 524 & AW-17 & $\mathrm{P} / \mathrm{H}$ & $\begin{array}{l}\text { (P) } 550-570^{\prime} \\
\text { (mfpl) } \\
\text { (H) } 634^{\prime} \\
\text { (amfp } 1 \text { ) }\end{array}$ & $\begin{array}{l}\text { (P) Lithic scatter } \\
\text { (H) Historic structure, } \\
\text { occupled }\end{array}$ & $\begin{array}{l}\text { Potentially } \\
\text { eligible }\end{array}$ & Yes & $\begin{array}{l}\text { (P) Buried deposits may exist } \\
\text { (H) Two-story structure, out } \\
\text { of reservoir area }\end{array}$ \\
\hline $41 \mathrm{BX} 525$ & AW-18 & $P$ & $\begin{array}{l}550^{\prime} \\
(\mathrm{mfp} 1)\end{array}$ & Prehistoric occupation site & Unknown & Yes & $\begin{array}{l}\text { May contain deeply burfed } \\
\text { deposits }\end{array}$ \\
\hline 41 BX 526 & $A K-19$ & $\mathbf{P}$ & $550^{\prime}(\mathrm{mfp} 1)$ & $\begin{array}{l}\text { Prehistoric occupation site; } \\
\text { Early Archaic }\end{array}$ & $\begin{array}{l}\text { Potentially } \\
\text { eligible }\end{array}$ & Yes & $\begin{array}{l}\text { May contain deepiy buried } \\
\text { deposits }\end{array}$ \\
\hline 41 BX 527 & $A W-20$ & H & $\begin{array}{l}550-5601 \\
(\operatorname{mfp} 1)\end{array}$ & $\begin{array}{l}\text { Late 19th-century histor 1c } \\
\text { structures ( } 2 \text { stone, } 1 \\
\text { frame; Mitchell property) }\end{array}$ & Eligible & See text & $\begin{array}{l}\text { A determination of eligi- } \\
\text { bility should be sought }\end{array}$ \\
\hline $41 \mathrm{BX} 528$ & $A W-21$ & $P$ & $\begin{array}{l}550-560 ' \\
(\mathrm{mfpl})\end{array}$ & $\begin{array}{l}\text { Extensive prehistoric occu- } \\
\text { pation zone; probable } \\
\text { historic Indian component }\end{array}$ & $\begin{array}{l}\text { Potentfally } \\
\text { eligible }\end{array}$ & Yes & $\begin{array}{l}\text { Prehistoric/historic Indian } \\
\text { pottery sherds recovered as } \\
\text { well as a probable Guerrero } \\
\text { point }\end{array}$ \\
\hline $41 B \times 529$ & $A W-22$ & H & $530^{\prime}(c p 1)$ & $\begin{array}{l}\text { Small historic cemetery } \\
\text { (A1 fred Heermann burlal) }\end{array}$ & Eligible & See text & $\begin{array}{l}\text { Additional graves may be } \\
\text { located here. A determina- } \\
\text { tlon of elfgibility should } \\
\text { be sought }\end{array}$ \\
\hline
\end{tabular}


TABLE 13. (continued)

\begin{tabular}{|c|c|c|c|c|c|c|c|}
\hline $\begin{array}{l}\text { Site } \\
\text { Number }\end{array}$ & $\begin{array}{l}\text { Field } \\
\text { Numberl }\end{array}$ & $\begin{array}{l}\text { Type of } \\
\text { Site }\end{array}$ & Elevation ${ }^{3}$ & Description & $\begin{array}{l}\text { National } \\
\text { Register Status } \\
\text { in the op inion } \\
\text { of the authors) }\end{array}$ & $\begin{array}{l}\text { Further Work } \\
\text { Recommendations } 5\end{array}$ & Comments \\
\hline 41 BX 530 & $A N-23$ & $P$ & $\begin{array}{l}530-540^{\prime} \\
(\mathrm{cpl})\end{array}$ & $\begin{array}{l}\text { Extensive prehistoric occu- } \\
\text { pation site. May contain } \\
\text { historic Indian component }\end{array}$ & $\begin{array}{l}\text { Potentially } \\
\text { eligible }\end{array}$ & Yes & $\begin{array}{l}\text { Deeply burled deposits may } \\
\text { exist }\end{array}$ \\
\hline $41 \mathrm{BX} 531$ & $A W-24$ & $P$ & $\begin{array}{l}500-520 \\
(\mathrm{CPI})\end{array}$ & Prehistoric occupation site & $\begin{array}{l}\text { Potentialiy } \\
\text { eligible }\end{array}$ & Yes & $\begin{array}{l}\text { Extensive erosion noted, but } \\
\text { may contain deeply burled } \\
\text { deposits }\end{array}$ \\
\hline 41 BX 532 & AW-25 & $\mathbf{P}$ & $530 \cdot(c p 1)$ & $\begin{array}{l}\text { Prehistoric lithic scatter; } \\
\text { possible occupation site; } \\
\text { Late Archalc }\end{array}$ & Unknown & Yes & $\begin{array}{l}\text { May contain intact sub- } \\
\text { surface deposits }\end{array}$ \\
\hline 41 BX 533 & AW- 26 & $P$ & $500^{\prime}(\mathrm{cp} 1)$ & $\begin{array}{l}\text { Prehistoric occupation site; } \\
\text { Early Archaic(?) }\end{array}$ & $\begin{array}{l}\text { Not at this } \\
\text { time }\end{array}$ & Not at this tim & $\begin{array}{l}95 \% \text { of site destroyed by } \\
\text { erosion }\end{array}$ \\
\hline 41 BX 534 & AW-27 & $P$ & $\begin{array}{l}540-550 \\
(m f p 1)\end{array}$ & $\begin{array}{l}\text { Prehistoric occupation site; } \\
\text { Early to Middle Archalc }\end{array}$ & $\begin{array}{l}\text { Potentially } \\
\text { elfiglele }\end{array}$ & Yes & $\begin{array}{l}\text { May contain intact sub- } \\
\text { surface deposits }\end{array}$ \\
\hline 41 BX 535 & AW-28 & $P$ & $\begin{array}{l}550-590 \\
(\mathrm{mfp} 1)\end{array}$ & $\begin{array}{l}\text { Prehistoric occupation site; } \\
\text { Early/Transitional Archaic }\end{array}$ & Unknown & Yes & May contain burled deposits \\
\hline $41 \mathrm{BX} 536$ & $A W-29$ & $P$ & $\begin{array}{l}560-600 \\
(\text { amfp } 1)\end{array}$ & Prehistoric occupation site & $\begin{array}{l}\text { Not at this } \\
\text { time }\end{array}$ & Not at this time & Out of reservolr area \\
\hline $41 \mathrm{BX} 537$ & $A W-30$ & $P$ & $510^{\prime}(\mathrm{cp} 1)$ & Lithic scatter & $\begin{array}{l}\text { Not at this } \\
\text { time }\end{array}$ & Not at this time & $\begin{array}{l}\text { May contain intact sub- } \\
\text { surface deposits }\end{array}$ \\
\hline $41 \mathrm{BX} 538$ & AW-31 & $H$ & $510^{\prime}(\mathrm{cp} 1)$ & Applewhite/Watson home & Eligible & See text & $\begin{array}{l}\text { A determination of eligi- } \\
\text { bility should be sought }\end{array}$ \\
\hline $41 \mathrm{BX} 539$ & $A W-32$ & $\mathrm{P}$ & $530^{\prime}(\mathrm{cp} 1)$ & $\begin{array}{l}\text { Sma11 prehistoric occupa- } \\
\text { tion site }\end{array}$ & Unknown & Yes & $\begin{array}{l}\text { May contain deeply buried } \\
\text { deposits }\end{array}$ \\
\hline $41 \mathrm{BX} 540$ & AW-33 & $P$ & $\begin{array}{l}530-550 ! \\
(c p 1)\end{array}$ & $\begin{array}{l}\text { Prehistoric occupation site; } \\
\text { Early Archaic }\end{array}$ & $\begin{array}{l}\text { Potentially } \\
\text { eligible }\end{array}$ & Yes & $\begin{array}{l}\text { Contains deeply buried } \\
\text { deposits }\end{array}$ \\
\hline $41 \mathrm{BX} 541$ & $A W-34$ & $P$ & $\begin{array}{l}550-570 \\
(\mathrm{mfp} 1)\end{array}$ & $\begin{array}{l}\text { Prehistoric temporary occu- } \\
\text { pation site }\end{array}$ & $\begin{array}{l}\text { Not at this } \\
\text { time }\end{array}$ & Not at this time & $\begin{array}{l}\text { May need to be reassessed } \\
\text { later }\end{array}$ \\
\hline $41 \mathrm{BX} 542$ & $A W-35$ & $\mathrm{H}$ & $580^{\prime}(\operatorname{amfp} 1)$ & Hernández Cemetery & $\begin{array}{l}\text { Potentially } \\
\text { eligible }\end{array}$ & Not at this time & Out of reservoir area \\
\hline $41 \mathrm{BX} 543$ & $A W-36$ & $\mathrm{H}$ & $570^{\prime}(a m f p 1)$ & Rú́z-Herrera Cemetery & Eltgible & See text & $\begin{array}{l}\text { A determination of eligi- } \\
\text { billty should be sought }\end{array}$ \\
\hline
\end{tabular}




\begin{tabular}{|c|c|c|c|c|c|c|c|}
\hline 41 BX 550 & AW -45 & $P$ & $540^{\prime}(\mathrm{mfpl})$ & $\begin{array}{l}\text { Prehistoric temporary occu- } \\
\text { pation site }\end{array}$ & Unknown & Yes & $\begin{array}{l}\text { May contain deeply buried } \\
\text { deposits }\end{array}$ \\
\hline 41 BX 552 & $A W-47$ & $P$ & $\begin{array}{l}550-570^{\prime} \\
(\mathrm{mfp} 1)\end{array}$ & $\begin{array}{l}\text { Prehistoric occupation site; } \\
\text { possibly Middle Archafc }\end{array}$ & Unknown & Yes & May contain buried deposits \\
\hline 41 BX 553 & $A W-48$ & $H$ & $620^{\prime}(a m f p 1)$ & $\begin{array}{l}\text { Hernández home; late 19th- } \\
\text { century occupation site }\end{array}$ & $\begin{array}{l}\text { Potentially } \\
\text { eligible }\end{array}$ & Not at this time & Out of reservolr area \\
\hline $41 \mathrm{BX} 554$ & $A W-49$ & $P$ & $\begin{array}{l}550-570^{\prime} \\
(\mathrm{mfp} 1)\end{array}$ & $\begin{array}{l}\text { Prehistoric occupation site; } \\
\text { possibly Early Archaic }\end{array}$ & Unknown & Yes & $\begin{array}{l}\text { May contain deeply buried } \\
\text { deposits }\end{array}$ \\
\hline 41 BX 568 & $A W-3$ & $\mathbf{P}$ & $\begin{array}{l}560-570^{\prime} \\
(\text { amfp } 1)\end{array}$ & $\begin{array}{l}\text { Prehistoric temporary occu- } \\
\text { pation site }\end{array}$ & Unknown & Not at this time & $\begin{array}{l}\text { Out of reservoir area; may } \\
\text { contain deeply buried } \\
\text { deposits }\end{array}$ \\
\hline 41 BX 569 & $A W-4$ & $\mathbf{P}$ & $\begin{array}{l}580-610^{\prime} \\
(\text { amfp } 7)\end{array}$ & $\begin{array}{l}\text { Small occupation site and } \\
\text { quarry/workshop area }\end{array}$ & $\begin{array}{l}\text { Not at this } \\
\text { time }\end{array}$ & Not at this time & Out of reservoir area \\
\hline 41 BX 652 & $2 A W-1$ & $\mathrm{P} / \mathrm{H}$ & $\begin{array}{l}510-530^{\prime} \\
(\mathrm{cp} 1)\end{array}$ & $\begin{array}{l}\text { Possibly Late Paleo-Indian } \\
\text { through Late Prehistoric; } \\
\text { Historic period }\end{array}$ & $\begin{array}{l}\text { Potentially } \\
\text { eligible }\end{array}$ & Yes & $\begin{array}{l}\text { Appears to contain a long } \\
\text { sequence of cultural deposits }\end{array}$ \\
\hline $41 \mathrm{BX} 653$ & $2 A W-2$ & $P$ & $\begin{array}{l}540^{\prime} \\
(\mathrm{mfp} 1)\end{array}$ & $\begin{array}{l}\text { Extensive occupation site; } \\
\text { Late Archaic }\end{array}$ & Unknown & Yes & $\begin{array}{l}\text { May contain deeply buried } \\
\text { deposits }\end{array}$ \\
\hline
\end{tabular}


TABLE 13. (continued)

\begin{tabular}{|c|c|c|c|c|c|c|c|}
\hline $\begin{array}{l}\text { Site } \\
\text { Number }\end{array}$ & $\begin{array}{l}\text { Field } \\
\text { Number }\end{array}$ & $\begin{array}{l}\text { Type of } \\
\text { Site }^{2}\end{array}$ & Elevation 3 & Description & $\begin{array}{l}\text { National } \\
\text { Register Status } 4 \\
\text { (in the opinion } \\
\text { of the authors) }\end{array}$ & $\begin{array}{l}\text { Further Work } \\
\text { Recommendations }\end{array}$ & Comments \\
\hline $41 \mathrm{BX} 654$ & $2 A W-3$ & $P$ & $\begin{array}{l}530-540 \\
(\mathrm{cp} 1)\end{array}$ & $\begin{array}{l}\text { Lithic workshop; possible } \\
\text { temporary occupation site }\end{array}$ & No & No & Severely eroded \\
\hline $41 \mathrm{BX} 655$ & $2 A W-4$ & $P$ & $\begin{array}{l}530-540^{\prime} \\
(\mathrm{mfp} 1)\end{array}$ & $\begin{array}{l}\text { Lithic processing/occupa- } \\
\text { tion site (possibly multi- } \\
\text { component) }\end{array}$ & Unknown & Yes & May contain buried deposits \\
\hline $41 \mathrm{BX} 656$ & $2 A W-5$ & $P$ & $\begin{array}{l}530-540^{\prime} \\
(\mathrm{cp} 1)\end{array}$ & $\begin{array}{l}\text { Prehistoric occupation site } \\
\text { (possibly multicomponent) }\end{array}$ & Unknown & Yes & May contaln burfed deposits \\
\hline $41 \mathrm{BX} 657$ & $2 A W-6$ & $P$ & $530^{\prime}(\mathrm{cp} 1)$ & $\begin{array}{l}\text { Prehistoric lithic workshop } \\
\text { site }\end{array}$ & No & No & Severely eroded \\
\hline $41 \mathrm{BX} 658$ & $2 A W-7$ & $P$ & $540 \cdot(m f p 1)$ & $\begin{array}{l}\text { Prehistoric temporary occu- } \\
\text { pation site }\end{array}$ & No & No & Severely eroded \\
\hline $41 B \times 659$ & $2 A W-8$ & $P$ & $\begin{array}{l}500-520^{\prime} \\
(\mathrm{cp} 1)\end{array}$ & $\begin{array}{l}\text { Prehistoric temporary occup- } \\
\text { tion site }\end{array}$ & No & No & Severely eroded \\
\hline $41 \mathrm{BX} 660$ & $2 A W-9$ & H & $570 \cdot(\operatorname{amfp} 1)$ & $\begin{array}{l}\text { Tenant house; early 20th } \\
\text { century }\end{array}$ & No & No & $\begin{array}{l}\text { Destroyed; out of reservolr } \\
\text { area }\end{array}$ \\
\hline $41 \mathrm{BX} 661$ & $2 A W-10$ & $\mathrm{P} / \mathrm{H}$ & $\begin{array}{l}530-540^{\prime} \\
(\mathrm{cp} 1)\end{array}$ & $\begin{array}{l}\text { (P) Temporary occupation } \\
\text { site } \\
\text { (H) Tenant home (ca. } 1880 \text { s- } \\
1930 \text { s) }\end{array}$ & $\begin{array}{l}\text { (P) No } \\
\text { (H) Potentially } \\
\text { eligible }\end{array}$ & $\begin{array}{l}\text { (P) No } \\
\text { (H) Yes }\end{array}$ & $\begin{array}{l}\text { (P) Severely eroded } \\
\text { (H) May contain intact } \\
\text { deposits }\end{array}$ \\
\hline $41 \mathrm{BX} 662$ & $2 A W-27$ & $H$ & $530^{\prime}(c p 1)$ & Domestic brick klln & $\begin{array}{l}\text { Potentially } \\
\text { eliglble }\end{array}$ & Yes & $\begin{array}{l}\text { Specialized historfcal } \\
\text { feature }\end{array}$ \\
\hline $41 \mathrm{BX} 664$ & $2 A W-14$ & $\mathrm{P} / \mathrm{H}$ & $\begin{array}{l}580-610^{\prime} \\
(\text { amfp } 7)\end{array}$ & $\begin{array}{l}\text { (P) Destroyed } \\
\text { (H) Enoch Jones complex } \\
\text { (house ca. 1858) }\end{array}$ & $\begin{array}{l}\text { (P) No } \\
\text { (H) Eligible }\end{array}$ & $\begin{array}{l}\text { (P) No } \\
\text { (H) See text }\end{array}$ & $\begin{array}{l}\text { (H) A determination of eligi- } \\
\text { bility should be sought }\end{array}$ \\
\hline $41 \mathrm{BX} 665$ & $2 A W-15$ & $\mathbf{P}$ & $\begin{array}{l}570-600 ' \\
(\operatorname{amfp} 1)\end{array}$ & $\begin{array}{l}\text { Extensive occupation zone; } \\
\text { Early Archaic to Late } \\
\text { Prehistoric }\end{array}$ & $\begin{array}{l}\text { Potentially } \\
\text { eligible }\end{array}$ & Not at this time & Out of reservoir area \\
\hline $41 \mathrm{BX} 666$ & $2 A W-16$ & $\mathrm{P} / \mathrm{H}$ & $\begin{array}{l}540-550^{\prime} \\
(m f p 1)\end{array}$ & $\begin{array}{l}\text { (P) Late Paleo-Indian } \\
\text { through Late Prehistoric } \\
\text { art facts } \\
\text { (H) Applewhite/Mullens } \\
\text { complex }\end{array}$ & $\begin{array}{l}\text { (P) Unknown } \\
\text { (H) Eligible }\end{array}$ & $\begin{array}{l}\text { (P) Yes } \\
\text { (H) See text }\end{array}$ & $\begin{array}{l}\text { (P) Contains deeply buried } \\
\text { deposits } \\
\text { (H) A determination of eligi- } \\
\text { bility should be sought }\end{array}$ \\
\hline
\end{tabular}




\begin{tabular}{|c|c|c|c|c|c|c|c|}
\hline $\begin{array}{l}\text { Site } \\
\text { Number }\end{array}$ & $\begin{array}{l}\text { Field } \\
\text { Number }\end{array}$ & $\begin{array}{l}\text { Type of } \\
\text { Site }\end{array}$ & Elevation ${ }^{3}$ & Description & $\begin{array}{l}\text { National } \\
\text { Register Status } \\
\text { (in the opinton. } \\
\text { of the authors) }\end{array}$ & $\begin{array}{l}\text { Further Work } \\
\text { Recommendations } 5\end{array}$ & Comments \\
\hline $41 \mathrm{BX} 667$ & $2 A W-17$ & $\mathbf{H}$ & $\begin{array}{l}550-570^{\prime} \\
(m f p 1)\end{array}$ & $\begin{array}{l}\text { Santisima Trinidad Church } \\
\text { and Cemetery (mid-19th } \\
\text { century to early 20th } \\
\text { century) }\end{array}$ & Elfgible & See text & $\begin{array}{l}\text { A determination of eligi- } \\
\text { blitity should be sought }\end{array}$ \\
\hline $41 \mathrm{BX} 668$ & $2 A W-18$ & $P$ & $\begin{array}{l}550-560^{\prime} \\
(\mathrm{mfp} T)\end{array}$ & Prehistoric occupation site & No & No & Deflated \\
\hline \multirow[t]{2}{*}{41 BX 669} & $2 A W-19$ & $\mathrm{P} / \mathrm{H}$ & $\begin{array}{l}500-530^{\prime} \\
(\mathrm{cp} 1)\end{array}$ & $\begin{array}{l}\text { (P) Extensive occupation } \\
\text { site; Late Archaic through } \\
\text { Late Prehistoric }\end{array}$ & $\begin{array}{l}\text { (P) Potentially } \\
\text { elfgible }\end{array}$ & (P) Yes & \\
\hline & & & & (H) Applewhite/Condra home & (H) Eligible & (H) See text & $\begin{array}{l}\text { (H) A determination of elfgi- } \\
\text { bility should be sought }\end{array}$ \\
\hline $41 \mathrm{BX} 670$ & $2 A W-20$ & $H$ & $\begin{array}{l}540-550 ' \\
(\mathrm{mfp} 1)\end{array}$ & $\begin{array}{l}\text { Blas Herrera/Maria Josefa } \\
\text { Ruiz home (mid 19th century) }\end{array}$ & Eligible & See text & $\begin{array}{l}\text { A determination of eligi- } \\
\text { bility should be sought }\end{array}$ \\
\hline $41 \mathrm{BX} 671$ & $2 A W-21$ & $\mathrm{H}$ & $\begin{array}{l}540-550^{\prime} \\
(\mathrm{mfp} 1)\end{array}$ & $\begin{array}{l}\text { Blas Herrera, Jr., and } \\
\text { Sabtna Salinas home }\end{array}$ & $\begin{array}{l}\text { Potentially } \\
\text { eligible }\end{array}$ & Yes & $\begin{array}{l}\text { Structural features may } \\
\text { exist; no standing structures }\end{array}$ \\
\hline $41 \mathrm{BX} 672$ & $2 A W-22$ & $\mathrm{P} / \mathrm{H}$ & $\begin{array}{l}550-570^{\prime} \\
(\mathrm{mfp} 1)\end{array}$ & $\begin{array}{l}\text { (P) Destroyed } \\
\text { (H) Blas Herrera/J ose Mar1a } \\
\text { Herrera home }\end{array}$ & $\begin{array}{l}\text { (P) No } \\
\text { (H) Eligible }\end{array}$ & $\begin{array}{l}\text { (P) No } \\
\text { (H) See text }\end{array}$ & $\begin{array}{l}\text { (H) A determination of eligi- } \\
\text { bility should be sought }\end{array}$ \\
\hline $41 \mathrm{BX} 673$ & $2 A W-23$ & H & $\begin{array}{l}540-550^{\prime} \\
(\mathrm{mfp} 1)\end{array}$ & Miguel de la Garza home & $\begin{array}{l}\text { Potentially } \\
\text { eligible }\end{array}$ & Yes & $\begin{array}{l}\text { Structural features may } \\
\text { exist; no standing structures }\end{array}$ \\
\hline $41 \mathrm{BX} 674$ & $2 A W-24$ & H & $\begin{array}{l}550-560 \\
(m f p 1)\end{array}$ & Early church location(?) & $\begin{array}{l}\text { Potentially } \\
\text { eligible }\end{array}$ & Yes & $\begin{array}{l}\text { Structural features may } \\
\text { exist; no standing structures }\end{array}$ \\
\hline 41 BX 675 & $2 A W-25$ & H & $\begin{array}{l}550-5701 \\
\text { (estimated) } \\
\text { (mfpl) }\end{array}$ & Historic cemetery & Unknown & Yes & $\begin{array}{l}\text { No access; Identified by oral } \\
\text { history interviews }\end{array}$ \\
\hline 41 BX 676 & $2 A W-26$ & H & $\begin{array}{l}540-550 ' \\
(m f p 1)\end{array}$ & Historic burial site & Unknown & Yes & $\begin{array}{l}\text { Assoclated with cholera } \\
\text { epidemic }\end{array}$ \\
\hline $41 \mathrm{BX} 680$ & $2 A W-28$ & $H$ & $\begin{array}{l}520-540 \\
(c p 1)\end{array}$ & Talon/Palo Alto Crossing & Eligible & See text & $\begin{array}{l}\text { A determination of eligi- } \\
\text { bility should be sought }\end{array}$ \\
\hline $41 \mathrm{BX} 681$ & $2 A W-29$ & $H$ & $\begin{array}{l}560-570^{\prime} \\
(\text { amfpl) }\end{array}$ & Historic Walsh home & $\begin{array}{l}\text { Potentially } \\
\text { eligible }\end{array}$ & Yes & $\begin{array}{l}\text { A determination of eligi- } \\
\text { bility should be sought. } \\
\text { Out of reservoir area }\end{array}$ \\
\hline $41 \mathrm{BX} 682$ & $2 \mathrm{AW}-30$ & H & $\begin{array}{l}490-550^{\prime} \\
(\mathrm{cp} 1)\end{array}$ & $\begin{array}{l}\text { Dolores/Perez/Applewhite } \\
\text { Crossing }\end{array}$ & Eligible & See text & $\begin{array}{l}\text { A determination of eligi- } \\
\text { bility should be sought }\end{array}$ \\
\hline
\end{tabular}


TABLE 13. (continued)

\begin{tabular}{|c|c|c|c|c|c|c|c|}
\hline $\begin{array}{l}\text { Site } \\
\text { Number }\end{array}$ & $\begin{array}{l}\text { Fleld } \\
\text { Number } 1\end{array}$ & $\begin{array}{l}\text { Type of } \\
\text { Site }\end{array}$ & Elevation ${ }^{3}$ & Description & $\begin{array}{l}\text { National } \\
\text { gister Status } 4 \\
\text { n the op inton } \\
\text { the authors) }\end{array}$ & $\begin{array}{l}\text { Further Work } \\
\text { Recommendations } 5\end{array}$ & Comments \\
\hline $41 \mathrm{BX} 697$ & $2 A W-31$ & $H$ & $\begin{array}{l}510-520^{\prime} \\
(c p 1)\end{array}$ & Paso de las Garza's Crossing & Eligible & See text & $\begin{array}{l}\text { A determination of eligi- } \\
\text { bility should be sought }\end{array}$ \\
\hline \multicolumn{8}{|c|}{ MEDIO CREEK SITES } \\
\hline $41 \mathrm{BX} 368$ & & $P$ & $\begin{array}{l}550-580^{\prime} \\
(\mathrm{mfp} 1)\end{array}$ & Prehistoric occupation site & No & No & Destroyed \\
\hline $41 \mathrm{BX} 459$ & & $P$ & $\begin{array}{l}550-580 \\
(\mathrm{mfp} 1)\end{array}$ & $\begin{array}{l}\text { Prehistorlc occupation site } \\
\text { (multicomponent); Early } \\
\text { Archafc through Late } \\
\text { Prehistoric }\end{array}$ & $\begin{array}{l}\text { Potentlally } \\
\text { eligible }\end{array}$ & Yes & $\begin{array}{l}\text { Testing did not reveal } \\
\text { significant deposits; deeply } \\
\text { buried deposits may exist. } \\
\text { however }\end{array}$ \\
\hline $41 \mathrm{BX} 460$ & & $P$ & $\begin{array}{l}550-570 \\
(m f p 1)\end{array}$ & $\begin{array}{l}\text { Prehistoric occupation site; } \\
\text { Late Prehistoric }\end{array}$ & Unknown & Yes & $\begin{array}{l}\text { May contain burfed deposits; } \\
80 \% \text { of site destroyed in } 1984\end{array}$ \\
\hline $41 \mathrm{BX} 461$ & & $P$ & $\begin{array}{l}560-570^{\prime} \\
(\text { amfp } 1)\end{array}$ & Prehistoric occupation site & Unknown & Not at this time & Out of reservolr area \\
\hline $41 \mathrm{BX} 462$ & & $P$ & $\begin{array}{l}560-570 ' \\
\text { (amfp } 7)\end{array}$ & Prehistoric occupation site & No & No & Destroyed \\
\hline $41 \mathrm{BX} 463$ & & $P$ & $\begin{array}{l}560-580 \\
(\operatorname{amfp} 1)\end{array}$ & $\begin{array}{l}\text { Prehistoric occupation site; } \\
\text { Late Prehistoric }\end{array}$ & Unknown & Not at this time & Out of reservolr area \\
\hline $41 \mathrm{BX} 464$ & & $P$ & $\begin{array}{l}560-580^{\prime} \\
(\operatorname{amfp} 7)\end{array}$ & Prehistoric occupation site & No & No & Destroyed \\
\hline
\end{tabular}

IField numbers are given to facilitate future research at these sites.

$2 \mathrm{H}=$ Historic; $\mathrm{P}=$ Prehistoric

${ }_{3}$ Elevation given as feet above mean sea level as well as location within the conservation pool level (cpl), the maximum flood pool level (mfpl), and adjacent to the maximum flood pool level (amfpl). Elevation of prehistoric and historfc component may vary.

4 National Register status may vary on multicomponent sites. National Register status determinations are the opinion of the authors.

5Further work needed to determine potential elfgibility or eligibility to the National Register of Historic Places. 
Applewhite/Summary and Interpretations

\section{PREHISTORIC SITES SUMMARY}

Forty-nine prehistoric sites (Table 14) have been identified in the area of the proposed Applewhite Reservoir. Of these, 10 sites have both prehistoric and historic components. These 10 sites are counted with the total for historic sites; the same trinomial numbers are used for both prehistoric and historic components. A total of 21 prehistoric sites (five of these also have a historic component) is within the conservation pool level of the proposed reservoir (Table 13). A total of 24 prehistoric sites (Table 14) is within the maximum flood pool level of the proposed reservoir (three of these also have a historic component). A total of 14 sites is adjacent to the maximum flood pool level.

Two prehistoric sites, $41 \mathrm{BX} 274$ and $41 \mathrm{BX} 344$, are believed to be eligible for the National Register of Historic Places (these sites also contain a historic component; Table 15). One of these sites, 41 BX 274, is within the conservation pool level of the proposed reservoir. Site 41 BX 344 is adjacent to the maximum flood pool level of the proposed reservoir.

Twelve sites (Table 16) are believed to be potentially eligible for the National Register of Historic Places: 41 BX 517, 41 BX 524, 41 BX 526, 41 BX 528, 41 BX 530, 41 BX 531, 41 BX 534, 41 BX 540, 41 BX 652, 41 BX 665, $41 \mathrm{BX} 669$, and $41 \mathrm{BX} 459$. Five of the 12 sites are with in the conservation pool level of the proposed reservoir: 41 BX 530, 41 BX 531, 41 BX 540, $41 \mathrm{BX} 652$, and $41 \mathrm{BX} 669$. Five of the 12 sites are within the maximum flood pool level of the proposed reservoir: 41 BX 524, 41 BX 526, 41 BX 528, $41 \mathrm{BX} 534$, and $41 \mathrm{BX} 459$.

The significance of twenty (Table 17) sites is not known (they will need further work to determine their significance): 41 BX 346, 41 BX 515, 41 BX 518, 41 BX 525, 41 BX 532, 41 BX 535, 41 BX 539, 41 BX 544, 41 BX 545, 41 BX 550, 41 BX 552, 41 BX 554, 41 BX 568, 41 BX 653, 41 BX 655, 41 BX 656, $41 \mathrm{BX} 666,41 \mathrm{BX} 460,41 \mathrm{BX} 461$, and $41 \mathrm{BX} 463$. Six of the 20 sites are within the conservation pool level of the proposed reservoir: $41 \mathrm{BX} 346$, 41 BX 552, 41 BX 539, 41 BX 544, 41 BX 545, and 41 BX 656. Eleven of the 20 sites are within the maximum flood pool level of the proposed reservoir: 41 BX 515, 41 BX 518, 41 BX 525, 41 BX 535, 41 BX 550, 41 BX 552, 41 BX 554, 41 BX 653, 41 BX 655, 41 BX 666, and 41 BX 460.

Fourteen prehistoric sites (Table 18) are not at this time believed to be potentially eligible for the National Register of Historic Places, and no further work is recommended at this time: $41 \mathrm{BX} 343,41 \mathrm{BX} 347,41 \mathrm{BX} 348$, 41 BX 350, 41 BX 516, 41 BX 522, 41 BX 533, 41 BX 536, 41 BX 537, 41 BX 541, $41 \mathrm{BX} 546,41 \mathrm{BX} 547,41 \mathrm{BX} 548$, and $41 \mathrm{BX} 569$. Five of the 14 sites are within the conservation pool level of the proposed reservoir: 41 BX 347, $41 \mathrm{BX} 348,41 \mathrm{BX} 533,41 \mathrm{BX} 537$, and $41 \mathrm{BX} 546$. Four of the 20 sites are in the maximum flood pool leve1: $41 \mathrm{BX} 343,41 \mathrm{BX} 350,41 \mathrm{BX} 541$, and 41 BX 548.

Eleven prehistoric sites (Table 19) are not eligible for 1 isting on the National Register of Historic P1aces: 41 BX 654, 41 BX 657, 41 BX 658, 41 BX 659, 41 BX 661, 41 BX 664, 41 BX 668, 41 BX 672, 41 BX 368, 41 BX 462, and 41 BX 464. 
TABLE 14. LISTING OF PREHISTORIC SITES IN THE CONSERVATION POOL LEVEL, MAXIMUM FLOOD POOL LEVEL, AND ADJACENT TO THE MAXIMUM FLOOD POOL LEVEL

\begin{tabular}{|c|c|c|c|}
\hline $\begin{array}{l}\text { Trinomial } \\
\text { Number }\end{array}$ & $\begin{array}{l}\text { Conservation } \\
\text { Pool Level ( } 536 \\
\text { feet above ms } 1 \text { ) }\end{array}$ & $\begin{array}{l}\text { Maximum Flood } \\
\text { Pool Level ( } 555.3 \\
\text { feet above msl) }\end{array}$ & $\begin{array}{l}\text { Adjacent to } \\
\text { Maximum Flood } \\
\text { Pool Level }\end{array}$ \\
\hline $41 \mathrm{BX} 274^{*}$ & $x$ & & \\
\hline $41 \mathrm{BX} 343$ & & $x$ & \\
\hline 41 BX $344^{*}$ & & & $x$ \\
\hline & $x$ & & \\
\hline 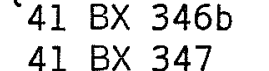 & & & \\
\hline & $x$ & & \\
\hline $41 \mathrm{BX} 348$ & $x$ & & \\
\hline $41 \mathrm{BX} 350$ & & $x$ & \\
\hline $41 \mathrm{BX} 515$ & & $x$ & \\
\hline $41 \mathrm{BX} 516$ & & & $x$ \\
\hline $41 \mathrm{BX} 517$ & & & $x$ \\
\hline $41 \mathrm{BX} 518$ & & $x$ & \\
\hline $41 \mathrm{BX} 522$ & & & $x$ \\
\hline $41 \mathrm{BX} 524 *$ & & $x$ & \\
\hline $41 \mathrm{BX} 525$ & & $x$ & \\
\hline $41 \mathrm{BX} 526$ & & $x$ & \\
\hline $41 \mathrm{BX} 528$ & & $x$ & \\
\hline $41 \mathrm{BX} 530$ & $x$ & & \\
\hline $41 \mathrm{BX} 531$ & $x$ & & \\
\hline $41 \mathrm{BX} 532$ & $x$ & & \\
\hline $41 \mathrm{~B} \times 533$ & $x$ & & \\
\hline $41 \mathrm{BX} 534$ & & $x$ & \\
\hline $41 \mathrm{BX} 535$ & & $x$ & \\
\hline 41 BX 536 & & & $x$ \\
\hline $41 \mathrm{BX} 537$ & $x$ & & \\
\hline $41 \mathrm{BX} 539$ & $x$ & & \\
\hline $41 \mathrm{BX} 540$ & $x$ & & \\
\hline $41 \mathrm{BX} 541$ & & $x$ & \\
\hline $41 \mathrm{~B} \times 544$ & $x$ & & \\
\hline $41 \mathrm{BX} 545$ & $x$ & & \\
\hline $41 \mathrm{BX} 546$ & $x$ & & \\
\hline $41 \mathrm{BX} 547$ & & & $x$ \\
\hline $41 \mathrm{~B} \times 548$ & & $x$ & \\
\hline $41 \mathrm{BX} 550$ & & $x$ & \\
\hline $41 \mathrm{BX} 552$ & & $x$ & \\
\hline $41 \mathrm{~B} \times 554$ & & $x$ & \\
\hline $41 \mathrm{BX} 568$ & & & $x$ \\
\hline $41 \mathrm{BX} 569$ & & & $x$ \\
\hline $41 \mathrm{BX} 652^{*}$ & $x$ & & \\
\hline $41 \mathrm{BX} 653$ & & $x$ & \\
\hline $41 \mathrm{BX} \quad 654$ & $x$ & & \\
\hline $41 \mathrm{BX} 655$ & & $x$ & \\
\hline
\end{tabular}


TABLE 14. (continued)

\begin{tabular}{|c|c|c|c|}
\hline $\begin{array}{l}\text { Trinomial } \\
\text { Number }\end{array}$ & $\begin{array}{l}\text { Conservation } \\
\text { Pool Level ( } 536 \\
\text { feet above msl) }\end{array}$ & $\begin{array}{l}\text { Maximum Flood } \\
\text { Pool Level ( } 555.3 \\
\text { feet above ms } 1)\end{array}$ & $\begin{array}{l}\text { Adjacent to } \\
\text { Maximum Flood } \\
\text { Pool Level }\end{array}$ \\
\hline $41 \mathrm{BX} 656$ & $x$ & & \\
\hline $41 \mathrm{BX} 657$ & $x$ & & \\
\hline $41 \mathrm{BX} 658$ & & $x$ & \\
\hline $41 B X 659$ & $x$ & & \\
\hline $41 \mathrm{BX} 661 *$ & $x$ & & \\
\hline $41 \mathrm{BX} 664^{*}$ & & & $x$ \\
\hline $41 \mathrm{BX} 665$ & & & $x$ \\
\hline $41 \mathrm{BX} 666^{*}$ & & $x$ & \\
\hline $41 \mathrm{BX} 668$ & & $x$ & \\
\hline $41 \mathrm{BX} 669 *$ & $x$ & & \\
\hline $41 \mathrm{BX} 672^{*}$ & & $x$ & \\
\hline
\end{tabular}

Medio Creek Sites
41 BX 368
41 BX 459
41 BX 460
41 BX 461
$41 \mathrm{BX} 462$
41 BX 463
$41 \mathrm{BX} 464$

$\begin{array}{ll}\times & \\ \times & \\ \times & \times \\ & \times \\ & \times \\ & x\end{array}$

*Prehistoric and historic component significance and elevation may vary.

Note: Fifty-nine sites are 1 isted on this table, 10 of these contain both prehistoric and historic components and are counted with the total for historic sites. 
TABLE 15. PREHISTORIC SITES BELIEVED TO BE ELIGIBLE FOR LISTING ON THE NATIONAL REGISTER OF HISTORIC PLACES, BY ELEVATION

\begin{tabular}{llll} 
& & & \\
& Conservation & Maximum Flood & Adjacent to \\
$\begin{array}{c}\text { Trinomial } \\
\text { Number }\end{array}$ & Pool Level (536 & Pool Leve1 (555.3 & Maximum Flood \\
& feet above ms7) & feet above ms1) & Pool Level \\
\hline
\end{tabular}

41 BX $274 *$

41 BX $344 *$

$x$

$x$

*Prehistoric and historic component significance and elevation may vary.

TABLE 16. PREHISTORIC SITES POTENTIALLY ELIGIBLE FOR LISTING ON THE NATIONAL REGISTER OF HISTORIC PLACES, BY ELEVATION

\begin{tabular}{llll} 
& & & \\
& Conservation & Maximum Flood & Adjacent to \\
Trinomial & Pool Level (536 & Pool Level (555.3 & Maximum Flood \\
Number & feet above ms7) & feet above ms 1$)$ & Pool Level \\
\hline
\end{tabular}

41 BX 517

41 BX 524*

41 BX 526

41 BX 528

41 BX 530

41 BX 531

41 BX 534

41 BX 540

41 BX $652 *$

41 BX 665

41 BX $669 *$

41 BX 459 (Medio Creek)

$\begin{array}{ll}\times & \times \\ \times & \times \\ \times & \times \\ \times & \\ \times & \\ \times & \\ & \\ \times & \end{array}$

*Prehistoric and historic component significance and elevation may vary. 
TABLE 17. PREHISTORIC SITES IN WHICH THE SITE SIGNIFICANCE IS UNKNOWN (FURTHER WORK NEEDED), BY ELEVATION

\begin{tabular}{llll} 
& & & \\
& Conservation & Maximum Flood & Adjacent to \\
$\begin{array}{c}\text { Trinomial } \\
\text { Number }\end{array}$ & Pool Level (536 & Pool Leve1 (555.3 & Maximum Flood \\
& feet above ms7) & feet above ms 1$)$ & Pool Leve1 \\
\hline
\end{tabular}

41 BX 346

41 BX 515

$41 \mathrm{BX} 518$

41 BX 525

41 BX 532

41 BX 535

41 BX 539

41 BX 544

41 BX 545

41 BX 550

41 BX 552

41 BX 554

41 BX 568

41 BX 653

41 BX 655

$41 \mathrm{BX} 656$

41 BX 666* $\times$

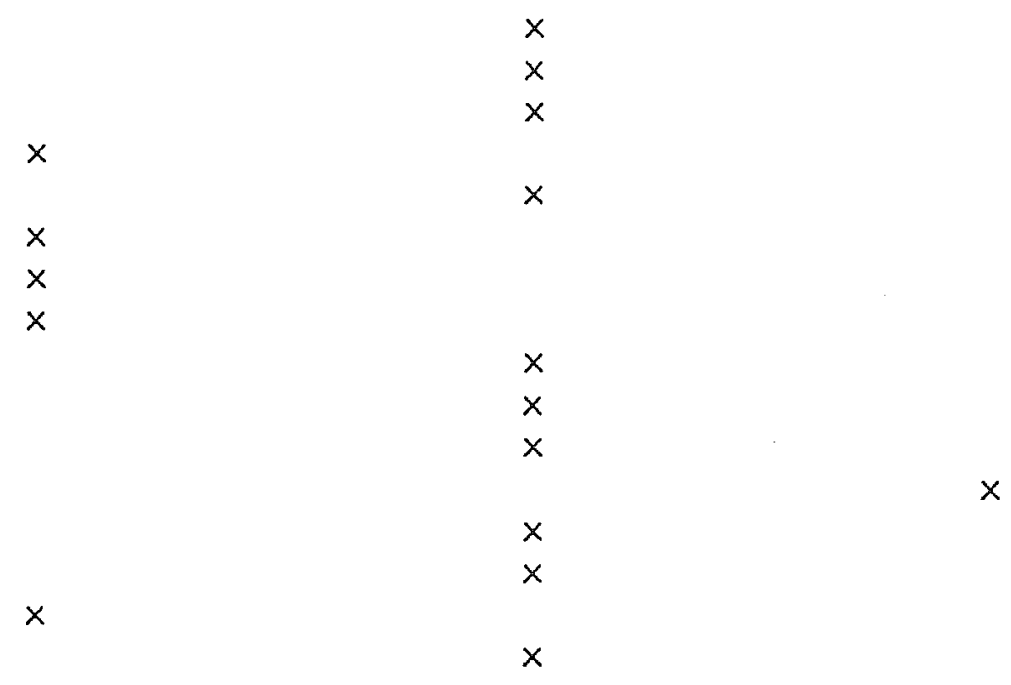

Medio Creek Sites

$41 \mathrm{BX} 460$

41 BX 461

41 BX 463

$x$

$x$

$x$

*Prehistoric and historic component significance and elevation may vary. 
TABLE 18. PREHISTORIC SITES NOT AT THIS TIME POTENTIALLY ELIGIBLE FOR THE NATIONAL REGISTER OF HISTORIC PLACES (NO FURTHER WORK RECOMMENDED), BY ELEVATION*

\begin{tabular}{llll}
\hline & Conservation & Maximum Flood & Adjacent to \\
$\begin{array}{l}\text { Trinomial } \\
\text { Number }\end{array}$ & $\begin{array}{l}\text { Pool Leve1 (536 } \\
\text { feet above ms7) }\end{array}$ & $\begin{array}{l}\text { Pool Leve1 (555.3 } \\
\text { feet above ms7) }\end{array}$ & $\begin{array}{l}\text { Maximum Flood } \\
\text { Pool Level }\end{array}$ \\
\hline
\end{tabular}

41 BX 343

41 BX 347

41 BX 348

41 BX 350

41 BX 516

41 BX 522

41 BX 533

41 BX 536

41 BX 537

41 BX 541

41 BX 546

41 BX 547

41. BX 548

41 BX 569 $\times$

$x$

$x$

$\times$

$\times$

$\times$

$x$

$x$ $x$

$x$

$x$
$x$

$\times$

$x$

$\times$

* Some of these sites may need reassessment after testing at nearby sites or when locations of a 11 ancillary facilities connected to the proposed reservoir are released. 
TABLE 19. PREHISTORIC SITES NOT ELIGIBLE FOR LISTING ON THE NATIONAL REGISTER OF HISTORIC PLACES, BY ELEVATION

\begin{tabular}{llll} 
& Conservation & Maximum Flood & Adjacent to \\
$\begin{array}{c}\text { Trinomial } \\
\text { Number }\end{array}$ & Pool Leve1 (536 & Pool Leve1 (555.3 & Maximum Flood \\
& feet above ms 1$)$ & feet above ms 1$)$ & Pool Leve1 \\
\hline
\end{tabular}

$41 \mathrm{BX} 654$

41 BX 657

$41 \mathrm{BX} 658$

41 BX 659

41 BX $661^{*}$

$\times$

$\times$

$x$

$41 \mathrm{BX} 664^{*}$

$x$

$x$

41 BX 668

41 BX $672 *$

$x$

$x$

$x$

Medio Creek Sites

41 BX 368

41 BX 462

41 BX 464

$x$

$x$

$x$

*Prehistoric and historic component significance and elevation may vary. 


\section{PREHISTORIC SITES INTERPRETATIONS}

Prehistoric sites identified during the 1981 and 1984 operations have contributed to a clearer understanding of intersite distributional patterns along the Medina River in southwestern Bexar County. Considered from both local and regional perspectives, the following discussion will briefly comment on elements of the geomorphological record as well as prehistoric activity patterns.

\section{GEOMORPHOLOGICAL AND PALEOENVIRONMENTAL CONSIDERATIONS}

Geomorphological changes of the Medina River and its mainstream tributaries, E1m, Medio, and Leon Creeks, have apparent7y profoundly altered not only the location but the intensity of prehistoric occupations. Major prehistoric occupation zones appear to be related to modern fossil confluence points. Portions of ancient river channels and their associated terraces, as well as former confluence locations, have been traced throughout segments of the modern river system; the earliest channels identified to date are approximately 5000-6000 years old (age is estimated by diagnostic artifacts on associated terraces). These results are preliminary in scope; research to date has been the result of detailed discussions between Dr. W. W. Hammond (UTSA), the authors, Vance Holliday (University of Wisconsin), and Glen Evans, consulting geomorphologist (Austin).

A major example of an extensive occupation zone related to shifting confluence points may be seen at site 41 BX 274, located near the confluence of Elm Creek and the Medina River. Diagnostic materials from this occupation site span a period of time of at least 5000 years, with Late Prehistoric and Historic Indian arrow points and ceramics as the most recent artifacts recovered. The deeply buried earlier cultural deposits, identified by hand and mechanical testing, are in excess of three meters below the present ground surface, and investigations suggest the possibility of more deeply buried materials.

A detailed review of aerial photographs, topographic maps, on-ground inspections, and soil deposits suggests the modern confluence of E7m Creek and the Medina River is a recent hydrological phenomenon which occurred much more recently than 3000 B.C. The earliest identifiable deposits (Early Archaic materials) at this site are related to a fossil confluence with Leon Creek, ca. $5 \mathrm{~km}$ west of its present location. This, in part, explains the unusually large floodplain-riparian zone adjacent to the modern confluence. Interestingly, the fossil channel remnants of old Leon Creek approximates the direction of the currently proposed reservoir diversion channel between Leon Creek and the Medina River. Additional geomorphological studies at sitespecific locales recommended for further work would more clearly define this complex pattern of erosional and depositional sequences within the study area.

Another identified archaeological feature related to local geomorphological changes is an early cultural deposit appearing in a soil contact zone between tan colored, sandy, unconsolidated soil and a more compacted, subangular blocky, clayey, red subsoil. These soil contacts occur throughout portions 
of the proposed reservoir at varying depths from two to four meters. Dr. Joel Gunn (paleoclimatologist specialist, UTSA, personal communication), on observing these deposits, suggested that the lower materials are an ancient, well-developed soil of late Pleistocene origins, closely related to a band of coastal soils that extend eastward along the Texas coast toward Louisiana. It is speculated that the distinctive red soil coloration may be in part due to soil chemical changes caused by a climax flora of pine forests that once flourished in many parts of Texas during the Pleistocene epoch. Diagnostic materials noted in the upper limits of this soil zone and at the point of contact with the other soil znr:a include Guadalupe tools from 41 BX 274 and an Early Archaic Bell project:" 'oint from 41 BX 540.

The potential for further geoarchaeological research relies upon the location, definition, and interpretation of fluvial deposits associated with prehistoric occupations within the study area. The identification of such localities can be accomplished by the recognition of chronologically diagnostic artifacts at individual sites recommended for further work and subjective interpretations of stratigraphic deposits (relative dating). optimal cultural deposit conditions, reflected by specific geomorphological features, such as point bars and levees, need to be recognized. Direct artifact associations or radiocarbon assays can be used to date such geoarchaeological deposits. Several individual site locations should be used to describe both depositional episodes and a cultural chronological sequence. This approach is considered critical for a synthesis of site-specific information into a broad-based regionally testable hypotheses for further research.

Two areas of future investigation are recommended: (1) a general perspective that considers the variations and complexities of the proposed reservoir location as a whole; and (2) an extraction of specific data from selected, specific sites. Geomorphological elements that form the basis of this research may be identified as Holocene fluvial locations, high alluvial remnants, and colluvial slopes. In general, the field methodology for such work is purposefully flexible and should utilize two major working hypotheses: (1) the recognition and evaluation of specific fluvial depositions with a high potential for further work; and (2) the identification of localities with both long depositional and erosional sequences that can be used to infer geomorphological patterns of development in the study area.

The long-range goal of such a comprehensive study is not limited to simply the identification of optimum locales for potentially significant buried cultural deposits. Instead, and as importantly, such research should contribute to a clearer understanding of past local as well as regional cultural-ecological episodes. The information derived from geomorphological research at the proposed reservoir should, most significantly, offer substantial insights into the reconstruction of the paleoenvironment.

Given the extensive natural resources available in the riparian zones of the lower Medina River valley, prehistoric site locations were apparently chosen to exploit specific localities within a broad resource area. 0ccupation sites are generally multicomponent. Occupation zones range in age from Early Archaic through Late Prehistoric, possibly Historic. Occupation sites (as 
compared to zones) are more chronologically discrete with a series of Early to Middle Archaic sites identified on old terraces well away from the modern river channel (invariably these sites are situated at the 530 to $550-$ foot contour in the eastern portion of the study area). Interestingly, sites in the western margins dating to the same time period are 10cated ca. 30 to 40 feet higher on terrace remnants. It is speculated that an ancient fault block upthrown in this area is the cause of this discrepancy.

\section{PREHISTORIC ACTIVITIES}

Late Archaic and Late Prehistoric materials were usually found adjacent to the modern river channel or mainstream tributaries. An unusual cultural phenomenon identified at Late Prehistoric and/or Historic sites associated with native peoples is the apparent increase in intrusive materials. This is reflected by the occurrence of Boothe Brushed ceramics found near the Medio Creek confluence and the recovery of a Quitaque jasper artifact at 41 BX 669 . Origins of these materials are thought to be from east-central Texas and the southern high plains of the Texas Panhandle, respectively. Although these artifacts represent only a very limited sample, both are identifiably intrusive from an interregional perspective. Given the artifacts cultural significance, general chronological associations, and origins, the authors postulate an expansion of cultural interaction during this period. Further work, particularly from excavation contexts, will be necessary to substantiate or refute this hypothesis.

Distribution of archaeological sites within the project area are generally similar to sites south of the Balcones Escarpment and often contain similar material elements. Prehistoric sites along the lower Medina River are typified by large (in excess of 150-250 $\mathrm{m}^{2}$ ) site areas, an extensive scatter (or intrasite concentrations) of burned limestone rock (not morphologically similar to central Texas burned rock middens), a moderate to dense scatter of 7 ithic debris (often fire reddened), and frequent deeply buried deposits. 0ccupation zones are located at the modern or fossil locations of drainage confluences, and site distributions generally appear to be linked to large riparian zones adjacent to these confluences.

The exploitation of these riparian zones implies a seasonal emphasis of occupations and activities, e.g., nuts from pecan groves are only available at specific times. Further seasonality interpretations must consider the possible influence of the nearby Balcones Escarpment and its own natural resources (including deer and acorns). Seasonality of specific site occupations are currently vague and lack the extensive background of excavation data needed for such inferences.

The most common site feature noted throughout the study area was the remains of burned rock clusters exposed during testing operations or observed in erosional contexts during surveys. Clusters, usually composed of limestone rocks, consisted of five identifiable configurations: (1) large circular clusters 2-5 $\mathrm{m}^{2}$ in diameter; (2) larger linear clusters over $2 \mathrm{~m}^{2}$ in length; (3) small circular features usually less than $1 \mathrm{~m}^{2}$ and composed of rocks less than $10 \mathrm{~cm}$ in individual length; and (4) small burned rock clusters usually less than $1 \mathrm{~m}^{2}$ but composed of individual rocks $15-30 \mathrm{~cm}$ in length. Another 
infrequent type of cluster appears to be the concentrated remains of burned chert cobbles, as these were used in place of the more common limestone rocks. All the identified clusters may be associated with a variety of Tithic debris and chronologically diagnostic lithic materials. The variability of configurations are presumably related to as yet unidentified activities that ranged from cooking to heating and other specialized functions. The authors suggest that an element of further research which could offer inter- as well as intra-regional insights could be a detailed comparison of these burned rock clusters to features of other Early Archaic archaeological sites within and adjacent to the Balcones Escarpment.

\section{Paleo-Indian 0ccupation}

While several lanceolate dart point fragments were collected, almost no significant Paleo-Indian artifacts were recovered. At this date, we believe this is in part due to several factors: (1) the inability to recognize former river channels and/or associated fossil terraces earlier than those dated to around 3000 B.C.; (2) extensive hydrological shifts that may have alternately buried or scoured very old terraces; (3) unrecognized PaleoIndian subsistence and/or occupation patterns which would have affected and altered ancient site distribution (perhaps beyond the 555-foot contour survey $1 \mathrm{imit)}$; and/or (4) the impact of changing environmental conditions which would have drastically altered the physiographic characteristics of the river system and its related resources. Perhaps influenced by all or a combination of these factors, Paleo-Indian site locations remain an enigma throughout the study area. It may be speculated that changing patterns of subsistence, perhaps related to an emphasis on herd fauna may have contributed to a distinct pattern of early site distributions. Paleo-Indian bands may have been mobile in pursuing this faunal resource, and the site of a preferred occupation may have been only as significant as its proximity to the faunal resource (exploitation). In this respect, it can be postulated that the diverse riparian resource zones within the drainage basin areas may have been less significant than the broad savanna adjacent to or south of the study area, which contained the forage necessary for large groups of herd animals. While several significant Paleo-Indian sites (41 BX 52, 41 BX 229) have been noted locally, ca. $50 \mathrm{~km}$ north of the study area, the most intense activity areas to date have been found ca. $100 \mathrm{~km}$ to the south along San Miguel Creek, the Frio River, and the drainages of Atascosa County. If such environmental postulations are accurate, a gradual climatic shift to drier, warmer seasons would eventually dry the shallow lakebeds known to have existed in portions of southern Texas during the late Pleistocene. The loss of such significant environmental features may have eventually influenced a population to a subsistence shift to localities of more reliable water sources.

An exploitation emphasis of large, permanent riparian zones of major drainage systems during this environmental transition could account for the manifestation of Early Archaic components which invariably underlie extensive occupation zones of the study area. 


\section{Archaic 0ccupation}

Archaic sites in the lower Medina River valley predominate the archaeological remains. The intensity and distribution of chronologically diagnostic materials suggest the related groups had specific and intensive interests in discrete and recognizable locations in the study area. Features 1 and 4 at 41 BX 274 represent distinctive intrasite activity patterns during the Early Archaic period. Feature 1 was a $1-x$ 4-m linear, very compact burned rock cluster associated with Early Triangular and Guadalupe tools. A distinct lack of charcoal, a small amount of bone and mussels, and no Tithic tools characterized this large, postulated single event, feature.

Perhaps related to plant food processing, Feature 1 is contrasted to Feature 4, less than $15 \mathrm{~m}$ south. Feature 4 was characterized by a 1 arge collection of lithic debris, a scattered burned rock cluster estimated to be $4 \mathrm{~m}^{2}$ or larger in size, and a collection of diagnostic lithics that relate it to the same time period as Feature 1 and perhaps even the same occupation as Feature 1 .

A review of the types of lithic debitage between the two features indicates the actual quarrying and/or collection and preliminary shaping (in the form of quarry blanks) of lithic materials took place away from the site area. Secondary and some tertiary 7 ithic reduction processes, as reflected by the occurrence and amounts of debitage, comprise $80-85 \%$ of the identified lithic activities. Multifacet tertiary flakes, usually indicating final tool preparation or reworking of already manufactured tools, compose the remainder of the lithic collection.

The lithic collection from these features indicates lithic processes related to either finishing or reworking of already manufactured tools in use at the site and feature. Given the unusual number of Guadalupe tools collected here (in varying stages of utilization), it is postulated that the activities which were centered around these features involved the processing of materials associated with Guadalupe tool usage, the reworking/resharpening of the same and other tool types, and other unidentified but perhaps related, contemporaneous activities. The mixture of Be11 and Martindale projectile points from Feature 4 suggests either a multiple occupational sequence or, more likely, given the discrete nature of Feature 4 and the shared context of Guadalupe tools, a contemporaneity of activities and possibly related groups.

\section{Late Prehistoric 0ccupation}

The paucity of associated materials and the limited sample size of Late Prehistoric sites preclude any detailed observations of site patterns or distributions during this period. However, several general inferences may be noted, especially when the study area is compared to the areal and regional archaeological record.

Archaeological sites containing evidences of Late Prehistoric ceramics and arrow points occur most frequently at or near modern confluence points within the project area. Invariably, along this portion of the Medina River, these confluence points are also associated with historic river crossings. 
Adjacent to these crossings, the Medina River represented a preferred locale for encampments.

The material evidence from Late Prehistoric activities is mixed with earlier and later components throughout the project area. As such, intensive surveys and 1 imited testing at these sites often prove inadequate to distinguish little more than the identification of fragmentary material evidence or relative chronological sequence. Utilizing early historical documentation with general references to native Indian camps along the lower Medina River, Late Prehistoric site locations are very similar (if not the same) as early Historic era Indian site locations. Only detailed studies and comparisons based on further data will more accurately describe site distributions and material evidences of the Late Prehistoric period in this area.

Using the early documented movements of Protohistoric/Historic Indian groups, as recorded in Campbel1 and Campbel1 (1981), general patterns of earlier prehistoric subsistence strategies may be noted. Historic Indian groups in portions of the Gulf Coastal Plain were concentrated in Tittoral zones or along the valleys of major drainages. Dependent upon the amount (or lack) of rainfall, relatively 1 ittle occupation occurred in inland locations (between major drainages) or in savanna areas (ibid.:15). Perhaps this prehistoric subsistence pattern could be described as a seminomadic bilobate riparian/ savanna adaptation.

Plant food collection appears to be the dominant subsistence regime, at least in documents related to the native Indians. Cabeza de Vaca (in Campbell and Campbe11 1981:17) noted occupation and/or foraging activities in certain river valleys were so intense that practically all large game animals (deer) had been killed or scared away. At least three of the four seasons were concerned with the recovery of $\mathrm{p} 7$ ant foods. Plant roots dominated food collection in the winter, the summer was the period for the annual migration to the prickly pear tuna fields of southern Texas, and fall was the collection time of pecans and other nuts along the riparian zones of the river valleys.

If such a subsistence pattern applicable to the local aspects of the Late Prehistoric period is projected into the Archaic, this should be reflected by distinctive material differences in the local archaeological record of Balcones Escarpment sites and those farther south (and including the study area) in the Gulf Coastal Plain. When major occupation sites from both areas are compared, coastal plain sites should show a smaller sample collection of recovered faunal remains as well as a more diversified faunal as semblage. Balcones Escarpment sites, situated in a different habitat, may indicate (as at 41 BX 228) a faunal collection dominated by deer remains. Gulf Coastal Plain sites should also reflect a greater variety and diversity of lithic tools that were utilized for foraging and/or gathering rather than hunting activities. The sites of the study area and southward should indicate a higher ratio of lithic tools to projectile points than those within the escarpment area.

Regardless of the eventual validity of these observations, which can only be resolved after more intensive studies, the identification of Protohistoric/ Historic Indian bilobate subsistence patterns indicates group territories 
were not limited to or defined by distinctive drainages in the area. Rather, these former territories crosscut vastiy different resource areas and physiographic boundaries (see Schiffer 1975). If this is a continuation of an earlier pattern of broad-spectrum resource exploitation, an understanding and a recognition of these transphysiographic exploitations are critical for a more refined view of regional aboriginal cultures.

\section{Historic Indian 0ccupation}

A number of linguistically unrelated groups occupied and exploited the lower Medina River valley from Protohistoric times through portions of the 19th century. The Coahuiltecan Payaya, because of their (relatively) numerous historical references, are thought to have frequented this drainage unti1 the middle of the 18th century. Campbe11 (1975:8-9) presents several examples of populous "Rancheria Grande" encampments throughout southern and east-central Texas that included Payaya. He points out that these camps were refugee in nature. The phenomenon of southern Texas Indians being pushed northward by encroaching Spanish pressures has not been addressed archaeologically and only identified broadly in the historical record. The authors suspect that this indigenous reaction to the Spanish presence was shortly overshadowed by southward and southeastward movements of Apache and other intrusive groups.

Boni11a (West 1904:4-78), in his 1772 history of Texas, notes that the Apache began increasingly frequent attacks (insultos) against the Spanish presence during the governorship of the Marques de San Miguel Aguayo (ending in 1723). Bonilla (ibid.:39) also observed that when Pedro de Rivera conducted his rivista (inspection) of Texas in 1729, there were no other (Spanish) enemies but the Apache who numbered approximate1y 100,000 persons divided into 13 groups.

By 1743, Apache groups and their Spanish adversaries encountered the Comanche over a slowly widening area of Texas. A short time later, in 1752, Bonilla (West 1904:50) relates that the Apache were actively seeking refuge in the Spanish missions. Cox (1902:85-100) notes that by the late 1750s, Apache chiefs were petitioning Spanish authorities to settle along the Medina River. It is assumed, and considered likely, that by this time local indigenous groups such as the Payaya were absorbed into the Spanish mission system or had been displaced (southeastward[?]) along the lower San Antonio River and Nueces River systems.

Historical accounts of the early 1800 s still noted the presence of Apache bands between San Antonio and Laredo (Berlandier 1826-1834), but the 19th century and an increased Anglo-European population rapidly contributed to the decline of these Apache groups as we11 as other intrusive groups.

\section{HISTORIC SITES SUMMARY}

Thirty-six historic sites have been documented in the area of the proposed Applewhite Reservoir. Ten of these sites also contain a prehistoric component (Table 20). These 10 sites are counted with the total of historic sites because it is felt the historic component is more evident than the 
TABLE 20. LISTING OF HISTORIC SITES/COMPONENTS IN THE CONSERVATION POOL LEVEL, MAXIMUM FLOOD POOL LEVEL, AND ADJACENT TO THE MAXIMUM FLOOD POOL LEVEL

$\begin{array}{lllll} & & & \\ & \text { Conservation } & \text { Maximum Flood } & \text { Adjacent to } & \text { In Area of } \\ \text { Trinomial } & \text { Pool Level (536 } & \text { Pool Level (555.3 } & \text { Maximum Flood } & \text { Leon Creek } \\ \text { Number } & \text { feet above ms7) } & \text { feet above ms7) } & \text { Pool Level } & \text { Diversion Dani }\end{array}$

41 BX 273

41 BX $274 *$

41 BX 277

$41 \mathrm{BX} 344 *$

$x$

41 BX 346a*

41 BX 519

41 BX 520

41 BX 521

41 BX 523

41 BX $524 *$

41 BX 527

41 BX 529

41 BX 538

41 BX 542

41 BX 543

41 BX 549

41 BX 552*

41 BX 553

41 BX 660

$41 \mathrm{BX} 661 *$

41 BX 662

41 BX $664 *$

41 BX 666*

41 BX 667

41 BX 669*

41 BX 670

41 BX 671

$x$

$x$

$x$

$x$

$x$

$\times$

$x$

$x$

$x$

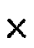

$x$

$x$ 
TABLE 20. (continued)

$\begin{array}{cllll} & & & \\ & \text { Conservation } & \text { Maximum Flood } & \text { Adjacent to } & \text { In Area of } \\ \text { Trinomial } & \text { Pool Level (536 } & \text { Pool Level (555.3 } & \text { Maximum Flood } & \text { Leon Creek } \\ \text { Number } & \text { feet above ms1) } & \text { feet above ms } 1) & \text { Pool Level } & \text { Diversion Dam }\end{array}$

41 BX $672 *$

41 BX 673

41 BX 674

41 BX 675

41 BX 676

$41 \mathrm{BX} 680$

41 BX 681

41 BX 682

41 BX 697

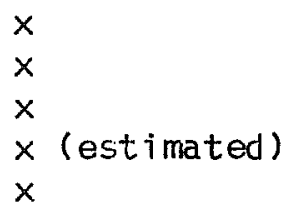

$x$

$x$

$x$

*Prehistoric and historic component significance and elevation may vary. 
prehistoric component. The same trinomial site number is used for both the prehistoric and historic component. A total of 12 historic sites and/or components (Table 20) is within the conservation pool level of the proposed reservoir. Thirteen historic sites and/or components (Table 20) are within the maximum flood pool level of the proposed reservoir. Ten historic sites are adjacent to the maximum flood pool level (Table 20).

Nineteen of the 36 sites (Table 21) are believed by the authors to be eligible for the National Register of Historic Places: 41 BX 274, 41 BX 277, 41 BX 344, 41 BX 520, 41 BX 521, 41 BX 527, 41 BX 529, 41 BX 538, 41 BX 543, 41 BX 549, 41 BX 664, 41 BX 666, 41 BX 667, 41 BX 669, 41 BX 670, 41 BX 672, $41 \mathrm{BX} 680,41 \mathrm{BX} 682$, and $41 \mathrm{BX} 697$. Seven of the 19 eligible sites are within the conservation pool level of the proposed reservoir: $41 \mathrm{BX} 520$, 41 BX 529, 41 BX 538, 41 BX 669, 41 BX 680, 41 BX 682, and 41 BX 697. Seven of the 19 eligible sites are within the maximum flood pool level of the proposed reservoir: 41 BX 274, 41 BX 521, 41 BX 527, 41 BX 666, 41 BX 667, $41 \mathrm{BX} 670$, and $41 \mathrm{BX} 672$. Five of the seven sites which are adjacent to the maximum flood pool level are estimated to suffer primary construction impact and/or secondary impacts: 41 BX 277, 41 BX 344, 41 BX 543, 41 BX 549, and 41 BX 664 (Table 22). One of these sites is located in the area of the proposed Leon Creek diversion dam (41 BX 549).

Twelve sites (Table 23) are believed to be potentially eligible for the National Register of Historic Places: 41 BX 273, 41 BX 519, 41 BX 524, 41 BX 542, 41 BX 553, 41 BX 652, 41 BX 661, 41 BX 662, 41 BX 671, 41 BX 673, $41 \mathrm{BX} 674$, and $41 \mathrm{BX} 681$. Four of the 12 sites are within the conservation pool leve1 of the proposed reservoir: 41 BX 519, 41 BX 652, 41 BX 661, and $41 \mathrm{BX} 662$. Four of the 12 sites are within the maximum flood pool level of the proposed reservoir: 41 BX 273, 41 BX 671, 41 BX 673, and 41 BX 674.

Sites 41 BX 523, 41 BX 346, 41 BX 660, and 41 BX 676 (Table 24) do not appear to be eligible or potentially eligible for listing on the National Register of Historic P1aces. No further work is recommended for sites 41 BX 523, $41 \mathrm{BX} 346$, and 41 BX 660 . Site 41 BX 676 apparently contains burials associated with a cholera epidemic and as such should be carefully considered by state and federal authorities. One site, 41 BX 675, has only been identified by oral history interviews and site inspection by the lessee of the 1and; access to the property has not been granted.

There are four historic churches (Table 25) in the area of the proposed reservoir: 41 BX 277, 41 BX 521, 41 BX 549, and 41 BX 667. One of these churches (41 BX 521, the Oak Island Methodist Church) has a State Historical Survey Committee marker as well as being a Methodist Landmark. One of these churches is within the maximum flood pool level of the proposed reservoir: 41 BX 667, the Santisima Trinidad Church. Two of these churches, 41 BX 277 and $41 \mathrm{BX} 549$, are in the vicinity of the proposed diversion dam and channe on/from Leon Creek to the reservoir. All of the churches are believed by the authors to be eligible for the National Register of Historic Places.

Nine cemeteries (Table 26) are in the area of the proposed reservoir (four of these are in conjunction with the churches): 41 BX 277, 41 BX 521, 41 BX 529, 41 BX 542, 41 BX 543, 41 BX 549, 41 BX 667, 41 BX 675, and $41 \mathrm{BX} 676$. One of these cemeteries (41 BX 529) is within the conservation 
TABLE 21. HISTORIC SITES BELIEVED TO BE ELIGIBLE FOR LISTING ON THE NATIONAL REGISTER OF HISTORIC PLACES

\begin{tabular}{|c|c|c|c|c|}
\hline $\begin{array}{l}\text { Trinomial } \\
\text { Number }\end{array}$ & Site Name & $\begin{array}{l}\text { Conservation } \\
\text { Pool Leve1 ( } 536 \\
\text { feet above ms } 1 \text { ) }\end{array}$ & $\begin{array}{l}\text { Maximum Flood } \\
\text { Pool Level ( } 555.3 \\
\text { feet above ms } 1)\end{array}$ & $\begin{array}{l}\text { Adjacent to } \\
\text { Maximum Flood } \\
\text { Pool Level }\end{array}$ \\
\hline $41 \mathrm{BX} 274^{*}$ & Pérez Rancho & & $x$ & \\
\hline $41 \mathrm{BX} 277$ & Pérez Chapel/Cemetery & & & $x$ \\
\hline 41 BX $344 *$ & Francisco A. Ruiz Site & & & $x$ \\
\hline $41 \mathrm{BX} 520$ & $\begin{array}{l}\text { Initial Encounter - } \\
\text { Battle of the Medina }\end{array}$ & $x$ & & \\
\hline $41 \mathrm{BX} 521$ & Oak Island Church/Cemetery & & $x$ & \\
\hline $41 \mathrm{BX} 527$ & Heermann Site & & $x$ & \\
\hline 41 BX 529 & Heermann Burial & $x$ & & \\
\hline $41 \mathrm{BX} 538$ & Applewhite/Watson Home & $x$ & & \\
\hline 41 BX 543 & Ru\{z-Herrera Cemetery & & & $x$ \\
\hline 41 BX 549 & $\begin{array}{l}\text { Linn Ranch Complex (Leon } \\
\text { Creek Area) }\end{array}$ & & & \\
\hline $41 \mathrm{BX} 664 *$ & Enoch Jones Complex & & & $x$ \\
\hline $41 \mathrm{BX} 666 *$ & Applewhite/Mullens Complex & & $x$ & \\
\hline $41 \mathrm{BX} 667$ & Santisima Trinidad Church/ & & & \\
\hline & Cemetery & & $x$ & \\
\hline $41 \mathrm{BX} 669 *$ & Applewhite/Condra Hone & $x$ & & \\
\hline 41 BX 670 & Blas Herrera Home $\# 1$ & & $x$ & \\
\hline $41 \mathrm{BX} 672 *$ & Blas Herrera Home $\# 2$ & & $x$ & \\
\hline $41 \mathrm{BX} 680$ & Talon/Palo Alto Crossing & $x$ & & \\
\hline $41 \mathrm{BX} 682$ & Dolores/Perez Applewhite & & & \\
\hline & Crossing & $x$ & & \\
\hline 41 BX 697 & Paso de las Garza"s & $x$ & & \\
\hline
\end{tabular}

*Prehistoric and historic component significance and elevation may vary. 
TABLE 22. HISTORIC SITES ADJACENT TO MAXIMUM FLOOD POOL OR IN AREA OF LEON CREEK DIVERSION DAM AND CHANNEL WITH ESTIMATED SECONDARY IMPACTS AND/OR PRIMARY IMPACT BY PROJECTED CONSTRUCTION*

Trinomial

Number

Site Name

Comments

41 BX 277

41 BX 344

41 BX 543

$41 \mathrm{BX} 549$

$41 \mathrm{BX} 664$
Perez Chape]/Cemetery

F. A. Ruiz site

Ru\{z-Herrera Cemetery

Linn home

Enoch Jones complex
At present, this site appears to 1 ie within the Leon Creek diversion dam and channel areas.

In the opinion of the authors and Glen Evans, consulting geomorphologist, this site, located on a bluff, will be undercut by wave action leading to slumping of the upper bluff.

In the opinion of the authors and Glen Evans, consulting geomorphologist, this site located on a bluff, will be undercut by wave action leading to slumping of the upper bluff.

At present, this site appears to 1 ie within the Leon Creek diversion dam and channel areas.

In the opinion of the authors and $G$ len Evans, consulting geomorphologist, this site, located on a bluff, will be undercut by wave action leading to slumping of the bluff.

* Primary impacts are identified as the estimated effects of accelerated erosional processes caused by water action on weak 1 y consolidated shorel ine soils. Such estimated processes may impact site locales located beyond the conservation pool but adjacent to maximum flood pool. Secondary impacts refers to sites beyond direct reservoir impacts that may occasional 1 y be affected by episodes of accelerated erosional processes on weak 1 y consolidated soils adjacent to site areas. 
TABLE 23. HISTORIC SITES POTENTIALLY ELIGIBLE FOR LISTING ON THE NATIONAL REGISTER OF HISTORIC PLACES

\begin{tabular}{|c|c|c|c|c|}
\hline $\begin{array}{l}\text { Trinomial } \\
\text { Number }\end{array}$ & Site Name & $\begin{array}{l}\text { Conservation } \\
\text { Pool Level ( } 536 \\
\text { feet above mis 1) }\end{array}$ & $\begin{array}{l}\text { Maximum Flood } \\
\text { Pool Level (555.3 } \\
\text { feet above ms } 7)\end{array}$ & $\begin{array}{l}\text { Adjacent to } \\
\text { Maximum Flood } \\
\text { Pool Leve1 }\end{array}$ \\
\hline
\end{tabular}

\begin{tabular}{lllll}
41 & BX 273 & Munk Home & $\times$ & $\times$ \\
41 & BX 519 & & & \\
41 & BX $524 *$ & & \\
41 & BX 542 & Hernández Cemetery & $\times$ & \\
41 & BX 553 & Hernández Home & $\times$ & \\
41 & BX $652^{*}$ & & $\times$ & \\
41 & BX $661^{*}$ & Tenant House & & $\times$ \\
41 & BX 662 & Domestic Brick Kiln & & $\times$ \\
41 & BX 671 & Blas Herrera, Jr., Hone & & $\times$ \\
41 & BX 673 & Miguel de 1a Garza Horne & & $\times$ \\
41 & BX 674 & Waish Home & & \\
41 & BX 681 & & & \\
\hline
\end{tabular}

*Prehistoric and historic component significance and elevation may vary 
TABLE 24. HISTORIC SITES/COMPONENTS NOT ELIGIBLE FOR LISTING ON THE NATIONAL REGISTER OF HISTORIC PLACES, BY ELEVATION

\begin{tabular}{llll} 
& & & \\
& Conservation & Maximum Flood & Adjacent to \\
$\begin{array}{c}\text { Trinomial } \\
\text { Number }\end{array}$ & Pool Leve1 (536 & Pool Leve1 (555.3 & Maximum Flood \\
& feet above ms1) & feet above ms1) & Pool Leve1 \\
\hline
\end{tabular}

41 BX 523

41 BX 346*

$\times$

$41 \mathrm{BX} 660$

41 BX 676

$x$

$x$

$x$

*Prehistoric and historic component significance and elevation may vary. 
TABLE 25. HISTORIC CHURCHES IN THE AREA OF THE PROPOSED APPLEWHITE RESERVOIR, BY ELEVATION

\begin{tabular}{|c|c|c|c|c|}
\hline $\begin{array}{c}\text { Trinomial } \\
\text { Number }\end{array}$ & Site Name & $\begin{array}{l}\text { Conservation } \\
\text { Pool Level ( } 536 \\
\text { feet above ms } 1 \text { ) }\end{array}$ & $\begin{array}{l}\text { Maximum Flood } \\
\text { Pool Level ( } 555.3 \\
\text { feet above ms } 7)\end{array}$ & $\begin{array}{l}\text { Adjacent to } \\
\text { Maximum Flood } \\
\text { Pool Level }\end{array}$ \\
\hline $\begin{array}{lll}41 & \text { BX } & 2771 \\
41 & \text { BX } & 5212 \\
41 & \text { BX } & 549^{3} \\
41 & \text { BX } & 667\end{array}$ & $\begin{array}{l}\text { Perez Chape1 } \\
\text { Oak Island Methodist Church } \\
\text { Purisima Concepción Chapel } \\
\text { Santisima Trinidad Church }\end{array}$ & & $x$ & $x$ \\
\hline
\end{tabular}

lThis site is adjacent to the maximum flood pool level of the proposed reservoir; however, the site appears to be in the area of the proposed diversion channel.

2 This site contains both a church and cemetery. While portions of the cemetery are within the maximum flood pool level, the church structure is well beyond this level.

${ }^{3}$ This site appears to be in the area of the proposed diversion dani on Leon Creek. 


\begin{tabular}{|c|c|c|c|c|}
\hline $\begin{array}{l}\text { Trinomial } \\
\text { Number }\end{array}$ & Site Name & $\begin{array}{l}\text { Conservation } \\
\text { Pool Level ( } 536 \\
\text { feet above mis })\end{array}$ & $\begin{array}{l}\text { Maximum Flood } \\
\text { Pool Level (555.3 } \\
\text { feet above mis } 1)\end{array}$ & $\begin{array}{l}\text { Adjacent to } \\
\text { Maximum Flood } \\
\text { Pool Level }\end{array}$ \\
\hline
\end{tabular}

41 BX $277^{1}$ Pérez Cemetery

41 BX $521 \quad$ Oak Island Cemetery

41 BX 529

41 BX 542

$41 \mathrm{BX} 543$

$41 \mathrm{BX} 549^{2}$

41 BX 667

41 BX 675

41 BX 676
Hernández Cenetery

Ruiz-Herrera Cemetery

Purisima Concepción Burials

Santisima Trinidad Cemetery

Thompson Burial

Cholera Burials
Conservation

feet above mis 7 )
Poot Leve1 (555.3

feet above ms 7 )

$x$

$x$

$x$

IThis site is adjacent to the maximum flood pool level; however, it appears that the site is within the area of the diversion channel from Leon Creek.

2 This site appears to be in the area of the Leon Creek diversion dam. 
pool level of the proposed reservoir. Three cemeteries are within the maximum flood pool leve1; 41 BX 521, 41 BX 667, and 41 BX 676, the known cholera burials. At this time, the elevation of $41 \mathrm{BX} 675$ is presumed to be within the conservation pool level or maximum flood pool level but has not been confirmed by on-site survey due to difficulties in access. Three of the cemeteries are adjacent to the maximum flood pool level (41 BX 277, 41 BX 542, and 41 BX 543); 41 BX 543, the Ruiz-Herrera Cemetery, has a State Historical Survey Committee marker. In the opinion of the authors and Glen Evans, consulting geomorphologist, this cemetery will suffer secondary impacts if the proposed reservoir is to be constructed; these impacts can be offset by judicious planning and consideration. Six of these cemeteries are believed by the authors to be eligible for the National Register of Historic P1aces: $41 \mathrm{BX} 521,41 \mathrm{BX} 529,41 \mathrm{BX} 543,41 \mathrm{BX} 277,41 \mathrm{BX} 549$, and $41 \mathrm{BX} 667$. One of these cemeteries is believed to be potential1y eligible for the National Register of Historic Places: 41 BX 542.

\section{HISTORIC SITES INTERPRETATIONS}

Historic sites in the area of the proposed Applewhite Reservoir are broadspectrumed. They provide an extremely unique situation in which the temporal, spatial, and relational associations of the early inhabitants could be examined while providing cross-cultural comparisons. Through archival research, oral history interviews, architectual evaluations, and archaeological field work, a framework for the history of the lower Medina River basin has been constructed. Future research should build upon this framework and expand our knowledge of this area.

The historic sites were evaluated on the basis of their potential eligibility to the National Register of Historic Places. These sites include early river crossings which were vital 1 inks in the transportation networks for the movement of goods and people; portions of an early battle site; haciendas and ranchos of original Spanish 1 and grantees and their descendants, some of whom were instrumental in the settlement and development of San Antonio and Texas; farm and ranch complexes of the later Anglo settlers, at least one of whom had achieved national prominence; as well as at least one tenant farm home. Also present are historic churches, one of which has a State Historical Survey Committee Marker, and cemeteries, some of which contain the graves of persons of transcendent importance in the history of San Antonio and Texas. One of these cemeteries contains a State Historical Survey Committee marker.

Of primary interest to researchers in the area of the proposed Applewhite Reservoir are the early fords/crossings and corresponding travel routes, the late Spanish colonial farming-ranching complex, the Antebellum "semiplantation" slave-owning commercial agriculturists-rancher as well as the subsistence farmer-rancher, and the rise and decline of Southern style sharecropping and full fledged tenant farming from the 1860 s to the 1930 s.

Temporal7y, the Spanish colonial and Mexican periods are represented by a historic rancho (41 BX 274), portions of an early battlefield (41 BX 520), and three early fords and/or river crossings (41 BX 680, 41 BX 682, and $41 \mathrm{BX} 697)$. Antebellum sites are best represented by four early slave-owning Anglo farm and ranch complexes (41 BX 666, 41 BX 669, 41 BX 664, and 
$41 \mathrm{BX} 538$ ) and five Mexican ranchos-farms (41 BX 344, 41 BX 670, 41 BX 671, $41 \mathrm{BX} 672$, and 41 BX 673). Post-Civil War/Industrialization is best represented by a small Anglo farm complex (41 BX 273), a domestic brick kiln (41 BX 662), and a 1ate 19th-early 20th-century tenant farm occupation (41 BX 661).

A total of 60 structures (standing and occupied, standing and unoccupied, standing ruins, and foundations only) was evaluated in the area of the proposed reservoir with 40 of these contributing to a more defined interpretation of the area. Standing buildings (or ruins) provided information on building types and styles, information on the socioeconomic status of the original occupants, and ethnic affiliations of the buildings.

The architectural sites represent both academic and vernacular (pioneer Anglo, ethnic Mexican, pioneer European) as well as mid-19th-century church styles. Site 41 BX 664, the Enoch Jones complex, is an outstanding example of academic architecture; site 41 BX 672, the Blas Herrera/Jose Maria Herrera home is an equally outstanding example of an ethnic Mexican adobe palisado technique; sites 41 BX 538, 41 BX 666, and 41 BX 674 are examples of pioneer Ang 10 and mid-19th-century church styles; additionally, site 41 BX 661 is representative of the wood frame (board and batten) style introduced after the arrival of the railroad in the area.

Stone was the most commonly used construction material in the area of the proposed reservoir. This is not unusual considering its availability to the early settlers. What is noticeable is the lack of log structures in this area--either these structures have not survived or more importantly may represent the ethnic affiliations of the earliest inhabitants. Methods of stone use varied widely; field stone, stuccoed stone, and cut/dressed stone were a17 used--usually dependent on the socioeconomic status of the builder. Adobe was generally used in association with stone. Wood frame structures replaced stone as the most commonly utilized material after the arrival of the railroad in the area. Glass (e.g., windows) also became widely available to the vast majority of citizens.

Settlement patterns in the study area were found to be influenced by two main factors: availability and distance to water and transportation networks, both of which are vital to the growth and development of an area. The routes established by the early travelers, including Alonso de Leon (1689), Domingo Terán (1691), Diego Ramón (1709), Domingo Ramón (1716), the Alarcon expedition (1718), the Marques de San Miguel de Aguayo (1718-1721), and Pedro de Rivera (1724-1728), became the basis for the permanent routes in the study area and adjacent to the study area. The opening of the Laredo Road, ca. 1750, and subsequent routes to Laredo profoundly affected the development of the study area. These roads became vital supply routes for military, economic, and cultural exchanges with Mexico and other areas. Sites $41 \mathrm{BX} 680,41 \mathrm{BX} 682$, and $41 \mathrm{BX} 697$ are three of the early crossings of the Medina River in the study area.

Site 41 BX 682 is postulated to have been the crossing to be utilized by General Arredondo in 1813 during the Battle of the Medina; site 41 BX 520 located west of the crossing contains artifactual evidence of this encounter. All three of the crossings are possible bivouac locations for members of 
Santa Anna's army prior to the Battle of the Alamo in 1836. A7though no artifactual evidence of this encampment was found in the study area, journals and diaries kept by various members of the Mexican army place the routes traveled in this vicinity. Further, an early map (Goeth 1913) identifies the road which crosses at 41 BX 697 as "Santa Anna's Trail" (see 41 BX 697).

At these crossings, the first smal1 "communities" were established. These communities were generally groupings of related families (Ruíz, Herrera, and Guzman). The arrival of the International and Great Northern and San Antonio Railroad in the last half of the 19th century would result in the shifting of small communities such as "Rio de Medina" closer to the railroad locations.

The availability of water was not necessarily a problem for the early settlers in the study area, but the distance to the source of water was an important factor for site location. We found that a majority of the early sites were located close to the river; preferably along a bluff or ridge. This location would put the settler in easy distance for procurement of water without the danger of flooding. These higher elevations (bluffs and ridges) were also the preferred locations for the earliest cemeteries in the study area. Later sites were found to be located somewhat farther away from the river as the need for a primary source of water should have been negated by the construction of secondary sources of water such as wells and cisterns. This movement is responsible for the lack of late sites in the study area.

Research to date has shown a long sequence of occupation along this section of the lower Medina River basin by the early settlers (both civilian and military) of San Antonio. Notable among those receiving large 1 and grants within the study area were Ruiz, Pérez, and Hernández. Adjacent to the study area were the Navarro, the de 1a Garza, and the Rodriquez families as well as lands belonging to the missions of San Jose and Espada.

The grants consisted of sitios de ganado mayor or large animals such as cattle, horses, burros, and mules, and sitios de ganado menor for smal1 animals such as sheep, goats, and hogs. Livestock owners such as Juan Ygnacio Pérez generally applied for multiple sitios at one time and in the case of Pérez controlled a large portion of the study area. Agricultural grants were divided into smaller units (generally a labor) with access to water or irrigation. Representative of these private ranches is 41 BX 274, the "Pérez Rancho." This ranch has been occupied and operated by members of the Pérez family for ca. 200 years. Originally containing some 22,000 acres, the ranch has been substantia77y reduced over the last 100 years.

Archival and archaeological work conducted to date at the rancho has allowed us to examine briefly a late Spanish colonial privately operated rancho complex. The complex originally extended over several acres and contained at least three structures: a main rock home, an associated jacal(?) structure, and a chapel with an associated cemetery (41 BX 277). Other probable structures such as corrals are postulated.

The ceramic artifactual material present at the ranch was predominantly an assemblage that has been dated to ca. 1820-1850 in the San Antonio area. This assemblage consists primarily of hard paste earthenwares (English) such as flow blue, handpainted, edged, transfer printed, etc. Occasional sherds 
of soft paste earthenwares such as Mexican lead-glazed pottery, Goliad ware, whee1-thrown, and tin-glazed pottery were recovered from limited testing. Archival research revealed that Perez was 1 iving on the rancho at least as early as 1800. Based on the predominance of the hard paste earthenwares and the known date of occupation, it could be hypothesized that Pérez, one of the most politically, economically, and socially influential persons in Spanish Texas, may have had access to these types of imported goods earlier than most residents. Conversely, the artifactual evidence may mean that the archival date is too early, although this seems improbable due to the fact that this information comes from legal affadavits.

The faunal analysis from the "Pérez Rancho" revealed that 22 taxa were present in the inventory. The largest groups of identifiable remains were caprines (sheep or goats) and Bos taurus (cow). Historical records indicate that cattle, sheep, possibly goats, pigs, and horses were raised by Pérez. While the large proportion of these animals were raised for sale, we can safely say that at least some of the cattle, sheep, and pigs were consumed by the occupants. The small proportion of species of animals such as deer, rabbit, turtle, and fish (gar) indicates that these animals played a supplementary role in the inhabitants diets. A comparison of the faunal material from the "Pérez Rancho" with the faunal materials from Rancho de las Cabras, the mission ranch of Mission Espada located in Wilson County, revealed that the same taxa predominated at Las Cabras; however, the caprines (sheep and goats) were present in much higher quantities at Las Cabras. A high number of Ictalurus sp. (catfish) and indeterminant fish bones were recovered from Rancho de las Cabras in comparison to the few gar (Lepisosteus sp.) and indeterminate fish bones found at the "Pérez Rancho" (41 BX 274). Three possible reasons were postulated by the authors of the analysis: (1) preference for fish; (2) poorer fishing along the Medina River; or (3) poorer preservation at $41 \mathrm{BX} 274$. Further investigations could address these differences.

The presence of large amounts of chipped stone at 41 BX 274 leads us to concur with Fox and Ivey (1981:37) that a chipped stone industry continued into the late 18th century/early 19th century in the San Antonio area. Together with the presence of historic Indian pottery at 41 BX 274 and archival evidence, we can hypothesize that this chipped stone tool production was perhaps being carried out by Indian laborers at the rancho.

The rancho was temporarily abandoned by the Pérez family from 1836 to 1847 , although relatives apparently lived there during this period. The reasons for the abandonment in the case of the Pérez family were somewhat unusual but the subsequent abandonment/loss/sale of much of the other property in the study area by the Mexican population during the Revolution and after the Revolution was not.

Local1y, the population remained predominantly Mexican, but thousands of acres in the study area were turned over to Anglo-Americans, sometimes by grant, headright, or script, but often by purchase from the Mexican population. Frequently these grants overlapped the old Spanish and Mexican grants. Of the 17 grants in the area obtained through the Republic, only four remained in Mexican hands, with many of these holdings greatly reduced. The Pérez family would eventua17y lose ca. 17,000 acres on the south side of 
the Medina River. Additionally, in the 1860 s, the old homesite would be abandoned and a new residence established on Leon Creek (41 BX 549).

From 1852 to 1861, the greatest wave of Ang7o-American immigration was to enter the study area--not as absentee landowners, but as homeowning residents: Theodore Heermann (41 BX 527, 41 BX 529); John, Stephen, and Jesse Applewhite (41 BX 538, 41 BX 666, and 41 BX 669); and Enoch Jones (41 BX 664). Other families which appeared in the area include Stanfield, Mudd, Avant, Macdona, Quesenbury (Quesenberry) Dever, Desmuke, and Mi17er.

The economic base of several of these families was derived from a "semiplantation" tradition utilizing slaves. The Applewhite family, emigrating from the South brought with them their customs, culture, as well as their architecture which was vernacular. Enoch Jones, an engineer of national prominence and a member of the elite mercantile class, also established a "semi-plantation" operation on the Medina River. Site 41 BX 664 is an excellent example of this "semi-plantation" contingent.

Sites 41 BX 538, 41 BX 666, 41 BX 669, and 41 BX 664, while being temporal as we11 as social contempories, offer a chance to compare and contrast minimum and maximum ranges of economic well being. The academic architecture of the Enoch Jones complex is polarized in relation to the vernacular architecture of the Applewhite complexes. This polarity is evidentiy a result of Jones' direct association with the mercantile class. He was able to secure scarce resources as early as 1858 (sawn lumber, window glass, plumbing fixtures, lighting devices, etc.) long before the other residents were able to obtain these items.

Contemporary with these "semi-plantation" sites were those of the smaller ranches and subsistence farmers. Site 41 BX 672, the Blas Herrera/José Maria Herrera home reflects the continued use of the Mexican vernacular adobe palisado style.

With the conclusion of the Civil War in 1865, falling cotton and land prices made planting acres valueless except for subsistence farming. Many of the farms and ranches (or portions) were sold, and survey maps get increasingly complex. Economically, from the large numbers of "longhorns" running wild, men would form the nucleus of the second great cattle industry when round-ups were conducted and drives were held to the northern markets. The great cattle trails would crisscross the state, with a portion of the Dodge Trail passing through and/or adjacent to the study area on the east. The great cattle drives would continue until the late 1870s, when the invention of barbed wire would be the cause and stimulus of the reorganization of ranching.

Sharecropping replaced slavery, thereby continuing the existence of some of the Targer farms and/or ranches. This system would include not only BTacks but Anglos and Mexicans as we11, and would subsequently evolve into fullfledged tenant farming which would not decline until the 1930 s and 1940 s. Families such as the Applewhites, the Pérez-Linn-Walshes would utilize this method. Site 41 BX 661 represents the remains of a tenant-occupied home in the study area. The wood frame structure is typical of those constructed after the arrival of the railroad in the area and is also an example of those 
homes occupied by tenant farmers. Work to date reveals that while the structure itself was indicative of the postulated economic status of tenantry, the artifactual evidence was not. Several hypotheses can be offered: (1) the material evidence is indicative of a prior economic status of the occupant; (2) the artifactual material is not associated with nor indicative of the original occupants; and (3) the economic status of some tenant farmers needs to be reevaluated.

Other sites representative of this period are a small farm complex (41 BX 273) and a domestic brick kiln (41 BX 662). Few 20th-century sites are located within the study area; these sites are generally beyond the 555.3 foot-contour (above mean sea level) of the proposed reservoir.

Developments during the mid to late 19th century included the addition of churches, schools, postal service, road development, and the founding of the community of Von Ormy, named after an East European Count Von Ormy, who had purchased the Enoch Jones complex, establishing a "royal court" at the home. Count Von Ormy did not stay long, but he so impressed the citizens that they named their community after him.

Twentieth-century developments in the study area centered around the discovery of oil and gas. Subsistence remained very much tied to the 1 and. A final "20th-century immigration" into the area resulted in new Mexican settlement with a resultant shift in social and political power to the predominantly Mexican-American population. Many of the residents are direct descendants of the early Spanish, Mexican, European, and Anglo-American settlers. 


\section{NOTES}

1 Spanish entradas (explorations) north of the Rio Grande into 17 th-century Texas identified two additional rivers of major importance. Both of these rivers, the Nueces (once called San Diego) and the Medina, were named by Alonso de León during his expedition of 1689 (Cox 1902:83). De León arrived on the banks of the Medina River on Lunes de Pascua, Apri1 11, or a day after Easter Sunday (Canedo 1968:94).

It is interesting to speculate whether this religious observance can be linked to the name he gave to the river. De Leon, in his diary a week earlier, wrote in some detail of Pedro de Medina (a 16th-century Italian astronomer), who produced a series of navigational tables that guided explorers such as De Leon throughout the late 17th century. A combination of the Easter observance, the discovery at that time of a "rio bien grande," and De Leon's recognition of his location (more or less) through the navigational tables (Canedo 1968) of Pedro de Medina may have all contributed to the naming of this river.

Sometime before 1721, the Medina River became the boundary between Texas (or Nuevas Filipinas) and Coahuila (or Nueva Estramadura). Cox (1902:85-88) identifies several primary sources that state this, including the Marques de Aguayo, governor of both provinces in 1721; the Marques de A7timira; and the cosmographer of the Kingdom of New Spain in 1746-1748. The province of Texas extended north and east from the Medina River for over 220 leagues in Tength and over 70 leagues in width, or more than 570 by 170 miles (ibid.).

The western boundary of the province was somewhat vaguely defined, dependent upon the attitude of usua77y hostile Indian groups (Apache) westward, beyond the Balcones Escarpment. By 1805, the western margins were more clearly described "beginning at the mouth of the Río Nueces, thence up that river to its junction with Moros Creek, thence in a northeasterly direction to near the Garza Crossing of the Medina River [within the present study area] thence up that river to its source" (Cox 1902:95).

The Medina River, as the southwestern boundary of the Spanish province of Texas, and later as the boundary between the Mexican department of Bexar and former Coahuila, gradualiy lost its importance by the first decade of the 19th century. By 1836, following Texas Independence, the new Republic officially declared its southwestern boundary as the Rio Grande, changing, as Cox (1902:100) notes, in a few months, what had been established for over a century.

2The estimate of leagues from the Celiz diary (Hoffman 1935) do not correspond with Tater estimates of distances as mapped by Austin (1828) of the Camino Pita in 1828.

${ }^{3}$ It is probable that while these early travelers may have followed the same or similar routes, the actual individual descriptions of the Medina River crossings may vary by a distance of several miles.

4The identification of the Lower Presidio Road just south of the Medina River is based on 1838 and 1847 field surveyor's notes of the Bruno Martinez grant 
(situated in this location) and not on Zivley's (1915-1916) survey of El Camino Real. The earlier records indicate the Lower Presidio Road formed the eastern boundary of this grant and, as such, is approximately $2 \mathrm{~km}$ west of Zivley's later estimates (see 41 BX 666).

5 The ranch headquarters of José Angel Navarro (as identified from archival research) were located on the Leon Creek northwest of the study area. It is not believed that the construction of the proposed reservoir will affect this locality; however, if any type of construction activities should take place in this vicinity, an intensive survey of the area should precede any work.

${ }^{6}$ In 1985, Mr. Robert (Bob) Thonoff published an extensive work dealing with the Battle of the Medina, Forgotten Battlefield of the First Texas Revolution: The Battle of Medina, August 18, 1813 (Schwarz 1985). While the authors agree with many of the assessments made by Mr. Thonoff, it must be pointed out that the Pérez Crossing was first known as Dolores Crossing and never as Paso Tranquitas. Paso Tranquitas was a later name for the La Barranca crossing which is known today as Cassin Crossing. Both Mr. Thonoff and Jack Jackson in his 1986 book, Los Mesteños have mistakenly identified some of the crossings on the Medina River within the Perez grant. The original 1808 grant to Pérez begins with the eastern boundary (La Barranca) and moves west; both Mr. Thonoff and Mr. Jackson have reversed the boundaries by having the survey move from west to east. Support for our analys is is borne out by a careful study of the field notes of a resurvey in 1847 of the Perez property and a study of the Medina River morphology. Additionally, Mr. Thonoff has stated that Arredondo planned on utilizing the Garza ranch ford (not the same crossing as Paso de las Garza's, 41 BX 697, but rather the crossing within the property of Jose Antonio de la Garza which lay adjacent to the Pérez property). José Antonio de 1a Garza was a staunch Republican and in fact had much of his property confiscated by Arredondo in 1ate 1813early 1814 after the battle. The authors of the present report do not believe that de 1a Garza would have, as Arredondo states, "arranged" for the crossing within his property to be utilized. Indeed, Pérez's Crossing within the 1 and of Ygnacio Perez, staunch Loyalist, is a much more realistic assessment.

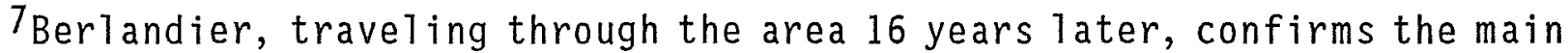
site of the Battle of the Medina as being south of the river.

${ }^{8}$ A study of José Enrique Peña's (Perry 1975) journal, an officer of Santa Anna's staff, sheds some light on these confusing episodes. Following the defeat of Mexican General Cos in late 1835 at Bejarr, Santa Anna reorganized his punitive expedition to Texas into two main divisions, the first commanded by General Ramirez y Sesma and the second by the (Italian) General Vicente Filosola. While mobilizing in Mexico, Santa Anna ordered Sesma to march northward to reinforce General Cos at San Antonio. Sesma delayed, Cos withdrew to Laredo and joined both Filosola and Sesma. Eventually, by midDecember 1835, Santa Anna had regrouped his divisions, including Cos' veterans, ca. 100 miles north of Laredo on the Rio Grande at Guerrero.

By early January 1836, Santa Anna, with an advance force, had entered Texas with his divisions following. According to the landmarks, de la Peña noted, the route corresponds closely to Berlandier's (1826-1834) road to San Juan 
Bautista in 1834 and Stephen F. Austin's "Camino Pita" of 1828 (Austin Papers n.d.). This eventually placed Santa Anna's forces at the Medina River in the vicinity of the present Medina County-Bexar County line or several miles southeastward (ca. 4-8 miles east of the study area) by February 20-21. Wi17iams (1933:12) noted that his army pitched camp on both sides of the river, the munition wagons being on the west bank. This comment is interesting as the Medina River generally flows southeastward. In the area of both Berlandier's and Austin's routes, the river flows almost north-south, with corresponding east and west banks. It is assumed that between February 21-23, as the Mexican army regrouped at the encampment, patrols were sent east and northward to control roads and fords in the vicinity; certainly such troops arrived in the vicinity of Garza's Crossing (within the study area) to place the alcalde, Ruiz, under arrest (see 41 BX 344).

${ }^{9}$ Author's note: The baptismal records of San Fernando Church do not contain the name of Francisco Antonio Ruiz. According to records, two children were born to José Francisco and Josepha Ruỉz--Marìa Lugarda de Jesús, born June 15, 1804; and Maria Antonia PauTa de 1a Concepción, born June 14, 1804. Either the priest failed to record the baptism, which is highly unlikely, or Francisco Antonio was an adopted child. If the birthdate of F. A. Ruiz was indeed 1804, the same as Maria Lugarda, then the latter hypothesis may be correct. 


\section{REFERENCES CITED}

Arneson, E. P.

1925 Early Art of Terrestrial Measurement and Its Practice. The Southwestern Historical Quarterly 29(1).

Asbury, S. E.

1944 The Private Journal of Juan Nepomuceno Almonte, Feb. 1-Apri1 6, 1836. The Southwestern Historical Quarterly 48(1).

Ashford, G.

1971 Spanish Texas. Jenkins Publishing Company, The Pemberton Press, Austin.

Assad, C.

1979 Archaeological Testing in the Devine Road Area North of 01 mos Dam, San Antonio, Texas. Center for Archaeological Research, The University of Texas at San Antonio, Archaeological Survey Report 53.

Aten, L. E.

1979 Indians of the Upper Texas Coast: Ethnohistoric and Archeological Frameworks. Unpublished Ph.D. dissertation, Department of Anthropology, The University of Texas at Austin.

Austin Papers

ca. 1828 Survey notes. SA 54, Series V. Barker Texas History Center, The University of Texas at Austin.

Austin, S. F.

ca. 1828 Sketch map of area between the Medina and Nueces Rivers. SA 57, Series V. Barker Texas History Center, The University of Texas at Austin.

Austin, G. L., L. M. Kacmarcik, D. E. Solomon, and S. E. Sweetser

1975 Environmental Inventory of the Guadalupe and San Antonio River Basins. Ecology Audits, Inc., Dallas, Texas.

Bacarisse, C. A.

1955 The Baron de Bastrop, Life and Times of Philip Hendrik Hering Bögel. Ph.D. dissertation, The University of Texas at Austin. On file at the Daughters of the Republic of Texas Research Library at the Alamo, San Antonio, Texas. 
Balverde, Acisclos

1767 Memorial Del R. P. Presidte al Cap. ${ }^{n}$ del Presidio de S. ${ }^{n}$ Antonio para $q^{e}$ va inserta a fin de averiguar a $q^{e}$ mision pertenecen unos indios $\mathrm{q}^{\mathrm{e}}$ los minros de la Mission de N. ${ }^{\circ}$ S.P.S. Franco de 1a Espada recogieron: Año de 1767. Santa Cruz de Querétaro, K, No. 19, Legajo 4. Dunn Transcripts, 1750-1767. Barker Texas History Center Archives, The University of Texas at Austin, 2Q237, Vol. 768:277-280.

Barber, E. A.

1908 The Maiolica of Mexico. Pennsylvania Museum and School of Industrial Art. Philadelphia.

Barnes, C. M.

1910 Combats and Conquests of Immortal Heroes. Guessay and Ferlet Co., San Antonio, Texas.

Barton, H. W.

1959 The Problem of Command in the Army of the Republic of Texas. The Southwestern Historical Quarterly 62(3).

Baugh, T. G.

1982 Edwards I (34 BK 2): Southern Plains Adaptations in the Protohistoric Period. 0klahoma Archaeological Society 8.

Behrends, J., editor and publisher

1859 Texas A7manac for 1860. San Antonio.

Berlandier, J. L.

1826- Journey to Mexico. Translated by S. M. Ohlendorf, J. M. 1834 Bigelow, and M. M. Standifer, with an Introduction by C. H. Muller. 2 volumes. The Texas State Historical Association in cooperation with the Center for Studies in Texas History, University of Texas at Austin.

1969 The Indians of Texas in 1830. Edited and introduced by John C. Evers. Smithsonian Institution Press, Washington, D.C.

Bexar Archives

Bexar Archives Translations (BAT)

Translations in the office of the Bexar County Archives, Bexar County Courthouse, San Antonio, Texas. 
Bexar Archives (continued)

Bexar Archives Microfilm Rolls (BAMR)

Microfilm rolls in the Special Collections, John Peace Library, The University of Texas at San Antonio.

Bexar County, Texas

Bexar County Archives (BCA)

Blas Herrera File.

Commissioner's Court Minutes.

El Carmen Church Records. Translated by John Ogden Leal. Headrights.

Land Grants and Sales.

List of Insurgents.

Marriage Certificates

Pérez Files.

Probate Records.

Records of Marks and Brands.

Ruíz Files (Pension Claim).

San Fernando Church Records. Translated by John Ogden Lea].

Santisima Trinidad Church Burial Records, 1867-1905. Translated by John Ogden Leal.

Spanish Land Grants and Sales No. 511.

Surveyor's Field Notes.

Wi11s.

1850 United States Census. Compiled by Laurette Russe11, 1966.

Bexar County Deed Records (BCDR)

Originals in Bexar County Courthouse, San Antonio, Texas. 
Bexar County, Texas (continued)

Bexar County Courthouse (BCCH)

Bexar County Tax Assessor-Collector Records. On file at the Bexar County Tax Assessor-Collector office, San Antonio, Texas.

Vital Statistics. Originals on file at the Bexar County Courthouse, San Antonio, Texas.

Wi11s and Probates. Originals on file at the Office of the County Clerk, Bexar County Courthouse, San Antonio, Texas.

Biesele, R. L., C. W. Hackett, and W. P. Webb, editors

1938 Colonel J. K. F. Mansfield's Report of the Inspection of the Department of Texas in 1856. The Southwestern Historical Quarterly 42(2).

1939a Copy of Arredondo's Report of the Battle of Medina Written August 18, 1813, from the Battlefield. The Southwestern Historical Quarterly 43(2).

1939b Laredo During the Texas Republic. The Southwestern Historical Quarterly 42.

Black, S. L.

1982 Prehistoric Ceramic Artifacts. In Archaeological Investigations at Choke Caynon Reservoir, South Texas: The Phase I Findings, by G. D. Ha71, S. L. B Tack, and C. Graves:390-453. Center for Archaeological Research, The University of Texas at San Antonio, Choke Canyon Series 5.

1985 Investigation of Prehistoric South Texas Ceramics. Unpublished manuscript on file, Center for Archaeological Research, The University of Texas at San Antonio.

1986 The Clemente and Herminia Hinojosa Site, 41 JW 8: A Toyah Horizon Campsite in Southern Texas. Center for Archaeological Research, The University of Texas at San Antonio, Special Report 18.

B7ack, S. L. and L. Hightey

1985 Distally Beveled Tools. In The Panther Springs Creek Site: Cultural Change and Continuity within the Upper Salado Creek Watershed, South-Central Texas, by S. L. Black and A. J. McGraw:136-156. Center for Archaeological Research, The University of Texas at San Antonio, Archaeological Survey Report 100 . 
Black, S. L. and A. J. McGraw

1985 The Panther Springs Creek Site: Cultural Change and Continuity in the Upper Salado Creek Watershed, South-Central Texas. Center for Archaeological Research, The University of Texas at San Antonio, Archaeological Survey Report 100.

Blair, W. F.

1950 The Biotic Provinces of Texas. The Texas Journal of Science. 2(1):93-117.

Bolton, H. E.

1910 Handbook of American Indians North of Mexico. F. W. Hodge, editor. Bureau of American Ethnology, Bulletin 30. Washington, D.C.

1916 Spanish Exploration in the Southwest, 1542-1706. New York.

1962 Texas in the Middle Eighteenth Century. University of Texas Press, Austin. Published in cooperation with The Texas State Historical Association.

Bracht, V.

1848 Texas in 1848. Translated by Charles F. Schmidt. Naylor Publishing Co., San Antonio.

Brooks, R. L., R. R. Drass, and F. E. Swenson

1985 Prehistoric Farmers of the Washita River Valley Settlement and Subsistence Patterns during the Plains Village Period. 0k1ahoma Archeology Survey Report 23, Norman, University of Oklahoma.

Brown, K. M., D. R. Potter, G. D. Hall, and S. L. Black

1982 Excavations at 41 LK 67, A Prehistoric Site in the Choke Canyon Reservoir, South Texas. Center for Archaeological Research, The University of Texas at San Antonio, Choke Canyon Series 7.

Bruseth, J. E. and J. P. Thurmond

1981 Report Content Guidelines. Section I in Guidelines for the Content of Cultural Resource Management Report. Draft 2. Committee on Report Standards. Council of Texas Archeologists. Austin. 
Bryant, V. M., Jr. and H. J. Shafer

1977 The Late Quaternary Paleo-Environment of Texas: A Model for the Archeologist. Bulletin of the Texas Archeological Society $48: 1-25$.

Campbe11, T. N.

1975 The Payaya Indians of Southern Texas. Southern Texas Archaeological Association, Special Publication 1. San Antonio.

Campbe11, T. N. and T. J. Campbe11

1981 Historic Indian Groups of the Choke Canyon Reservoir and Surrounding Area, Southern Texas. Center for Archaeollogical Research, The University of Texas at San Antonio, Choke Canyon Series 1 .

1985 Indian Groups Associated with Spanish Missions of the San Antonio Missions National Historical Park. Center for Archaeological Research, The University of Texas at San Antonio, Special Report 16.

Canedo, L. G.

1968 Primeras Exploraciónes y Poblamiento de Texas, 1686-1694. Publicaciones del Instituto Technológico y Estudios Superiores de Monterrey, Series Historia 6. Monterrey. Transcribed document.

Castañeda, C. E.

1938a The Mission Era: The Missions at Work, 1731-1761. Our Catholic Heritage in Texas, Vol. III. Von Boeckmann-Jones, Austin.

1938b The Mission Era: The Passing of the Missions, 1762-1782. Our Catholic Heritage in Texas, Vol. IV. Von Boeckmann-Jones, Austin.

1950 The Fight for Freedom. Our Catholic Heritage in Texas, Vol. VI. Von Boeckmann-Jones, Austin.

Castañeda, C. E., transiator

1971 The Mexican Side of the Texas Revolution. Documentary Publications, Washington, D. C.

Castro, M.

n.d. Von Ormy. On file, Center for Archaeological Research, The University of Texas at San Antonio. 
Chabot, F. C.

1936 San Antonio and its Beginnings. Naylor Publishing Co., San Antonio, Texas.

1937 With the Makers of San Antonio. Artes Graficas, San Antonio, Texas.

Chabot, F. C., transiator

1932 Excerpts from the Memorias for the History of the Province of Texas by Juan Agustin Morfi. Privately published.

1940 Texas Letters. Yanaguana Society Publications V, San Antonio. Collins, M. and V. Holliday

1984 Geomorphology at the Waco Lake Reservoir Project. Manuscript submitted to the U.S. Army Corps of Engineers, Fort Worth.

Corbin, J. E.

1974 A Model for Cultural Succession for the Coastal Bend Area of Texas. Bulletin of the Texas Archeological Society 45:29-54.

Corbin, J. E., T. C. Alex, and A. Kalina

1980 Mission Dolores de 10s Ais. Stephen F. Austin State University, Papers in Anthropology 2, Nacogdoches.

Corps of Engineers

1984 Summary of Known Environmental Elements in the Applewhite Dam, Reservoir, and Pump Station Project Area. Unpublished report, on file at the Center for Archaeological Research, The University of Texas at San Antonio.

Council of Texas Archeologists (CTA)

1981 Guidelines for Curation Standards and Procedures. Counci1 of Cox, I. J.

Texas Archeologists, Newsletter 5(2).

1902 The Southeast Boundary of Texas. Quarterly of the Texas Historical Association VI:81-102.

Coysch, A. W.

1970 Blue and White Transfer Ware 1780-1840. David and Charles, Newton Abbot Devon. 
Crabtree, D. E.

1972 An Introduction to Flintworking. Occasional Papers of the Idaho State University Museum 28. Pocate110, Idaho.

Crimmins, Colone

1931 Castle on the Medina Weathers Storms of Many Years. San Antonio Express, July 19. On file at the Daughters of the Republic of Texas Research Library at the Alamo, San Antonio, Texas.

Dabbs, J. A.

1940 The Texas Missions in 1785. Preliminary Studies of the Texas Catholic Historical Society 3(6). Austin.

Daughters of the Republic of Texas Research Library (DRT)

Each of the following documents are on file at the DRT, the Alamo, San Antonio, Texas.

Enoch Jones File.

Map Files - Oversized Folio Collection.

Steves Scrapbook.

Juan Nepomenco Seguin Deed, 1836.

Davis, E. M. and J. E. Corbin

1967 Archeological Investigations at Washington-on-the-Brazos State Park in 1966. State Building Commission, Archeological Program, Report 5, Austin.

Day, J. M., compiler

1967 The Texas Almanac 1857-1873. Texian Press, Waco.

Deetz, J.

1977 In Smal1 Things Forgotten. The Archeology of Early American Life. Anchor Press/Doubleday, New York.

Dibble, D. S.

1979 Archeological Reconnaissance in the Salado Creek Watershed, Bexar County, Texas. Texas Archeological Salvage Project, The University of Texas at Austin, Survey Report 9. 
Di1lehay, T.

1974 Late Quaternary Bison Population Changes on the Southern Plains. Plains Anthropologist 19(64):180-196.

Dobie, J.F.

1957 James Bowie, Big Dealer. The Southwestern Historical Quarterly 60(3).

Dobyns, H.

1967 Ethnographic Methodology, A Tri-chronic Study in Culture Change, Informant Reliability and Validity from the Southern Paiute. In Essays in Honor of Leslie Spier, by R. Euler:6267. Southern Illinois University Press, Carbonda7e.

Dulaney, A. R.

1977 Ceramics from the Fayette River Project. In Archeological Investigations at the Fayette Power Project, Fayette County, Texas, by D. W. Skelton:198-209. Texas Archeological Survey, The University of Texas at Austin, Research Report 60.

Eaton, J. D.

1980 Excavations at the Alamo Shrine (Mission San Antonio de Valero). Center for Archaeological Research, The University of Texas at San Antonio, Special Report 10.

Espinosa, Isidro Fèliz de

1930 The Espinosa-01ivares-Aguirre Expedition of 1709: Espinosa's Diary. Preliminary Studies of the Texas Catholic Historical Society $1(3)$. Translated by G. Tous.

Faulk, 0. B.

1964 The Last Years of Spanish Texas, 1778-1821. Mouton and Co., London.

Fawcett, W. B., Jr.

1972 The Prehistory of Bexar County: A Study of Previous Work in South Central Texas. Bulletin of the Lower Plains Archeological Society 2:23-43.

Fehrenbach, T. R.

1968 Lone Star. Macmillan Publishing Co., Inc., New York. 
Fields, R. C., M. C. Freeman, and S. M. Kotter

1983 Inventory and Assessment of Cultural Resources at Addicks Reservoir, Harris County, Texas. Prewitt and Associates, Inc., Reports of Investigations 22. Austin.

Fisher, W. L., director

1985 The Guadalupe-Lavaca-San Antonio-Nueces River Basins Regional Study. Bureau of Economic Geology, The University of Texas at Austin in cooperation with the Texas Department of Water Resources.

Ford, J. S.

1963 Rip Ford's Texas. University of Texas Press, Austin.

Forrestal, P. P., translator

1935 Peña's Diary of the Aguayo Expedition. Preliminary Studies of the Texas Catholic Historical Society 2(7). Austin.

Fox, A. A.

1977 The Archaeology and History of the Spanish Governor's Palace Park. Center for Archaeological Research, The University of Texas at San Antonio, Archaeological Survey Report 31.

1986 Ceramics. Chapter 5 in La Vi11ita Earthworks (41 BX 677): San Antonio, Texas, assembled by J. H. Labadie:107-127. Center for Archaeological Research, The University of Texas at San Antonio, Archaeological Survey Report 159.

Fox, A. A., F. A. Bass, Jr., and T. R. Hester

1975 The Archaeology and History of Alamo Plaza. Center for Archaeological Research, The University of Texas at San Antonio, Archaeological Survey Report 16.

Fox, A. A. and C. L. Highley

1985 History and Archaeology of the Hot Wells Hotel, 41 BX 237. Center for Archaeological Research, The University of Texas at San Antonio, Archaeological Survey Report 152.

Fox, D. E.

1983 Traces of Texas History. Corona Publishing Company, San Antonio, Texas.

n.d. The Rogers Site. Manuscript on file at the Center for Archaeological Research, The University of Texas at San Antonio. 
Fox, D. E., F. Valdez, Jr., and L. 0. Bobbitt

1978 An Archaeological Assessment of the Dolores Aldrete House Property, San Antonio, Texas. Center for Archaeological Research, The University of Texas at San Antonio, Archaeological Survey Report 58.

García, Bartholomé

1760 Manual para Administrar 1os Santos Sacramentos de Penitencia, Eucharista, Extrema-uncion, y Matrimonio. México.

Gerald, R. E.

1968 Spanish Presidios of the Late Eighteenth Century in Northern New Spain. Museum of New Mexico Research Records 7.

Gerstle, A., T. C. Kel1y, and C. Assad

1978 The Fort Sam Houston Project: An Archaeological and Historical Assessment. Center for Archaeological Research, The University of Texas at San Antonio, Archaeological Survey Report 40.

Goddard, I.

1979 The Languages of South Texas and the Lower Rio Grande. In The Languages of Native America: Historical and Comparative Assessment, edited by L. Campbe11 and M. Mithun:355-389. University of Texas Press, Austin.

Godden, G. A.

1975 British Pottery, an Illustrated Guide. Clarkson N. Potter, Inc., New York.

Goeldner, P. (compiled by)

1974 Texas Catalog. Historic American Buildings Survey. Edited by L. P. Wheeler and S. A. Chambers, Jr. Trinity University Press, San Antonio, Texas.

Goeth, R. A.

1913 San Antonio and Vicinity. Road Map. On file at the Center for Archaeological Research, The University of Texas at San Antonio. 
Goggin, J. M.

1970 The Spanish 01 ive Jar. In Introductory Study in Papers in Caribbean Anthropology, compiled by W. Mintz. Yale University Publications in Anthropology 57-64:3-40. Reprinted by Human Relations Area Files Press, New Haven.

Graham, R. W.

1976 Friesenhahn Cave Revisited (A Glimpse of Central Texas 20,000 Years Ago). The Mustang 18(5):1-7.

Greaser, A. and P. H. Greaser

n.d. Homespun Ceramics, A Study of Spatterware. Privately printed, Al lentown, Pa.

Gunn, J.

1986 Mobility Patterns in Central Texas. Paper submitted to University of Texas Press to be included in Aboriginal Central Texas: Culture Change Along the Central Texas Ecotone, edited by John Fox. Manuscript on file with author, The University of Texas at San Antonio.

Gunn, J. and F. A. Weir

1976 Tool Kit Hypotheses: A Case of Numerical Induction. Newsletter of Lithic Technology 5(3):131-135.

Gursky, K.

1964 The Linguistic Position of the Quinigua Indians. International Journal of Linguistics 30(4):325-327. Battimore.

Ha11, G. D., S. L. B1ack, and C. Graves

1982 Archaeological Investigations at Choke Canyon Reservoir, South Texas: The Phase I Findings. Center for Archaeological Research, The University of Texas at San Antonio, Choke Canyon Series 5 .

Hatcher, M. A.

1927 The Opening of Texas to Foreign Settlement. University of Texas Bulletin. University of Texas Press, Austin.

Hatcher, M. A., translator

1908 Joaquin de Arredondo's Report of the Battle of Medina, August 18, 1813. The Southwestern Historical Quarterly 11(3). 
Heartfield, L.

1966 An Analysis of Leon Plain Typology. Unpublished manuscript on file, Center for Archaeological Research, The University of Texas at San Antonio.

Heermann, Captain Theodore

1861 Texas Militia Muster Roll for Captain Theodore Heermann's Company, Medina Guards. Archive papers on file, Texas State Library, Austin.

Hester, T. R.

1968 Notes on Some Pottery-Bearing Sites in Southern Texas. The Bul1-Roarer, The University of Texas Anthropological Society Newsletter $3(2): 9-11$.

1976 The Archaic of South Texas. In The Texas Archaic: A Symposium, edited by T. R. Hester:83-90. Center for Archaeological Research, The University of Texas at San Antonio, Special Report 2.

1977a Archaeological Research at the Hinojosa Site (41 JW 8), Jim We1ls County, Southern Texas. Center for Archaeological Research, The University of Texas at San Antonio, Archaeological Survey Report 42.

1977b The Lithic Technology of Mission Indians in Texas and Northeastern Mexico. Lithic Technology 6(1-2):9-13.

1980 Digging Into South Texas Prehistory. Corona Publishing Company, San Antonio, Texas.

1981 Tradition and Diversity Among the Prehistoric Hunters and Gatherers of Southern Texas. Plains Anthropologist 26(92):119-128.

Hester, T. R., assembler

1975 Archaeological and Historical Resources in the San AntonioGuadalupe River Basins: A Preliminary Statement. Center for Archaeological Research, The University of Texas at San Antonio, Regional Studies 1.

Hester, T. R., J. D. Eaton, and A. J. McGraw

n.d. A Proposal for Phase II Archaeological and Historical Investigations of the Proposed Applewhite Reservoir Area. Submitted to Freese and Nichols, Inc., Center for Archaeological Research, The University of Texas at San Antonio. 
Hester, T. R., D. Gilbow, and A. D. Albee

1973 A Functional Analysis of "Clear Fork" Artifacts from the Rio Grande P1ain, Texas. American Antiquity 38(1):90-96.

Hester, T. R., R. F. Heizer, and J. A. Graham

1975 Field Methods in Archaeology. 6th edition. Mayfield Publishing Company, Palo Alto, California.

Hester, T. R. and T. C. Hi11, Jr.

1971 An Initial Study of a Prehistoric Ceramic Tradition in Southern Texas. Plains Anthropologist 16(52):195-203.

Hester, T. R. and R. C. Parker

1970 The Berclair Site: A Late Prehistoric Component in Goliad County, Southern Texas. Bulletin of the Texas Archeological Society 44:1-23.

Highley, C. L.

1986 Archaeological Investigations at 41 LK 201, Choke Canyon Reservoir, Southern Texas. Center for Archaeological Research, The University of Texas at San Antonio, Choke Canyon Series 11.

Hobson, R. L.

1976 Chinese Pottery and Porcelain. An Account of the Potter's Art in China From Primitive Times to the Present Day. Funk and Wagnalls Co., New York. Republication of 1915 edition by Dover Pubtications, Inc., New York.

Hoffman, F. L., transiator

1935 Diary of the Alarcon Expedition into Texas, 1718-1719, by Fray Francisco Celiz. The Quivira Society, Los Angeles.

1938 Mesquia Diary of Alarcon Expedition into Texas, 1718. The Southwestern Historical Quarterly 41(4).

Home Life of Early Ranches of Southwest Texas

ms. Manuscript on file at the Center for Archaeological Research, The University of Texas at San Antonio.

Howard, C. D.

1971 Paleo Surface Finds in Bexar County. Manuscript on file, Texas Archeological Research Laboratory, Balcones Research Center, Austin. 
Howard, C. D. (continued)

1973 A Study of the Clear Fork Gouge. Bulletin of the Texas Archeological Society 44:51-60.

Hudson, W. R., Jr., W. M. Lynn, and D. Scurlock

1974 Walker Ranch: An Archeological Reconnaissance and Excavations in Northern Bexar County, Texas. Texas Historical Commission, office of the State Archeologist, Report 26.

Hunter, J. W.

1925 Beltran's Narration of the Battle of the Medina. Frontier Times 3(3).

Ivey, J. E.

1983 Archaeological Testing at Rancho de 1 as Cabras, 41 WN 30, Wilson County, Texas. Second Season. Center for Archaeological Research, The University of Texas at San Antonio, Archaeological Survey Report 121.

Ivey, J. E. and A. A. Fox

1981 Archaeological Survey and Testing at Rancho de Tas Cabras, Wilson County, Texas. Center for Archaeological Research, The University of Texas at San Antonio, Archaeological Survey Report 104.

Jackson, J.

1986 Los Mesteñas Spanish Ranching in Texas, 1721-1821. Texas A\&M University Press, College Station.

Jelks, E. B.

1962 The Kyle Site, A Stratified Central Texas Aspect Site in Hill County, Texas. Department of Anthropology, The University of Texas at Austin, Archaeology Series 5.

Jones, C. J. and A. A. Fox

1983 Archaeological Testing at Rancho de las Cabras, Wilson County, Texas. Third Season. Center for Archaeological Research, The University of Texas at San Antonio, Archaeological Survey Report 123.

Joukowsky, M.

1980 A Complete Manual of Field Archaeology: Tools and Techniques of Field Work for Archaeologists. Prentice-Ha11, Englewood Cliffs, New Jersey. 
Kenda11, D. S.

1974 Gentilz: Artist of the 01d Southwest. University of Texas Press, Austin.

Labadie, J. H. (assembled by)

1986 La Villita Earthworks (41 BX 677): San Antonio, Texas: A Preliminary Report of Investigations of Mexican Siege Works at the Battle of the Alamo. Center for Archaeological Research, The University of Texas at San Antonio, Archaeological Survey Report 159.

Leibowitz, J.

1985 Yellow Ware, The Transitional Ceramic. Schiffer Publishing Co., Pennsylvania.

Lister, F. C. and R. H. Lister

1982 Sixteenth Century Maiolica Pottery in the Valley of Mexico. University of Arizona Press, Tucson.

Lord, W.

1961 A Time to Stand. Harper \& Row Publishers, New York.

Lukowski, P. D.

n.d. Archaeological Investigations at 41 BX 1, Bexar County, Texas. Center for Archaeological Research, The University of Texas at San Antonio, Archaeological Survey Report 135 (in preparation).

MacNeish, R. S.

1958 Preliminary Archaeological Investigations in the Sierra de Tamaulipas, Mexico. Transactions, American Philosophical Society $48(6)$.

Mallouf, R. J., B. Baskin, and K. L. Killen

1977 A Predictive Assessment of Cultural Resources in Hildalgo and Wi1lacy Counties, Texas. Texas Historical Commission, Austin.

Mallouf, R. J., H. Simons, R. L. Wilson, S. L. Andrews, J. B. Arnold III, and D. Moore

1981 Texas Heritage Conservation P1an Computerization Program Manue1. Texas Historical Commission, Austin. 
Martin, R. S. and J. C. Martin

1982 Contours of Discovery. Printed Maps Delineating the Texas and Southwestern Chapters in the Cartographic History of North America, 1513-1930. The Texas State Historical Association in cooperation with the Center for Studies in Texas History, The University of Texas at Austin.

McGraw, A. J.

1977 A Preliminary Archaeological Survey Along the Medio Creek Drainage, Southwestern Bexar County. Center for Archaeological Research, The University of Texas at San Antonio, Regional Studies 3.

1984 Archaeology in the South Texas Sand Sheet. Center for Archaeological Research, The University of Texas at San Antonio, Archaeological Survey Report 129.

n.d. The East Chacon Project: 11,000 Years of Prehistory Along the Upper Nueces River, Southern Texas. Center for Archaeological Research, The University of Texas at San Antonio, Archaeological Survey Report 125 (in preparation).

McGraw, A. J. and B. J. Marsha11 Van Note

1981 Chipped Stone and Adobe: A Survey of Cultural Resources Within Portions of the Proposed Applewhite Reservoir, Southwestern Bexar County, Texas. Draft report, Center for Archaeological Research, The University of Texas at San Antonio, Archaeological Survey Report 105. This draft report is now incorporated into McGraw and Hindes (1987), Chipped Stone and Adobe: A Cultural Resources Assessment of the Proposed Applewhite Reservoir, Bexar County, Texas. Center for Archaeological Research, The University of Texas at San Antonio, Archaeological Survey Report 163.

McGraw, A. J. and F. Valdez, Jr.

1978a Investigations of Prehistoric Rockshelter and Terrace Sites Along Portions of the Salado Creek Drainage, Northern Bexar County, Texas. Center for Archaeological Research, The University of Texas at San Antonio, Archaeological Survey Report 55.

1978b 41 BX 68: A Prehistoric Quarry-Workshop in Northern Bexar County, Texas. Center for Archaeological Research, The University of Texas at San Antonio, Archaeological Survey Report 56. 
McLean, M., editor

1974 Papers Concerning Robertson's Colony in Texas. Volume IV. Texas Christian University Press, Fort Worth.

Mi11er, T. L.

1967 Bounty and Donation Land Grants of Texas, 1835-1888. University of Texas Press, Austin.

Morfi, Fray Juan Agustin de

1935 History of Texas, 1673-1779. Translated and annotated by C. E. Castanẽda. 2 volumes. Quivira Society Publications 6. Albuquerque.

n.d. Viaje de Indios y Diarío del Nuevo Mexico. Translation by R. E. McDonald. San Antonio Conservation Society files, San Antonio, Texas.

Mullens, Mrs. Joe

n.d. Applewhite Papers. Private collection.

Murphy R.

1937 The Journey of Pedro de Rivera, 1724-1728. The Southwestern Historical Quarterly 41(2):125-141.

Myres, S. L.

1969 The Ranch in Spanish Texas 1691-1800. Texas Western Press, E1 Paso.

Nance, C. R.

1972 Cultural Evidence for the Altithermal in Texas and Mexico. Southwestern Journal of Anthropology 28:169-192.

1980 La Calsada and the Prehistoric Sequence in Northeast Mexico.

In Papers on the Prehistory of Northeastern Mexico and Adjacent Texas, by J. F. Epstein, T. R. Hester, and C. Graves:41-57. Center for Archaeological Research, The University of Texas at San Antonio, Special Report 9.

Nance, J. M.

1940 Joseph Eve Charge 'd'affaires to Texas. The Southwestern Historical Quarterly 43. 
Nelson, L. H.

1968 Nail Chronology as an Aid to Dating 07d Buildings. National

Park Service, Technical Leaflet 48. Originally pub7ished in 1963 in History News 24.

Noë1 Hume, I.

1963 Here Lies Virginia. Alfred A. Knopf, Inc., New York.

Norve11, Mrs. Lipscomb

1945 King's Highway.

01 ivares, Antonio de San Buenaventura

1720 Oposición a 1 a fund. ${ }^{n}$ de 1 a Miss. ${ }^{n}$ de $s^{n}$ Joseph del rio de $S .^{n}$ Ant. ${ }^{\circ}$ Ano de 1720. Archivo del Colegio de la Santa Cruz de Querétaro, KN 5, Leg. 4. Barker Texas History Center Archives, The University of Texas at Austin, 2Q237, Vol. $766: 9-11$.

01msted, F. L.

1857 A Journey through Texas, Or, A Saddle Trip on the Southwestern Frontier. University of Texas Press. Barker Texas History Center, The University of Texas at Austin, Series 2. Reprint of the 1857 edition published by Dix, Edwards, New York.

Orchard, C. D.

1938 Personal communication to A. T. Jackson, concerning Bexar County sites. Letter on file, Texas Archeological Research Laboratory, Balcones Research Center, Austin.

Orchard, C. D. and T. N. Campbe11

1954 Evidence of Early Man from the Vicinity of San Antonio, Texas. The Texas Journal of Science 6(4):454-465.

1960 Southwestern Pottery from Sites in the Vicinity of San Antonio, Texas. Texas Archeology 4(2):7-8.

Penrose, R. A., Jr.

1980 A Preliminary Report on the Geology of the Gulf Coast Tertiary of Texas from Red River to the Rio Grande, Texas. Geological Society Annual Report 1. 
Perry, C., translator

1975 With Santa Anna in Texas, A Personal Narrative of the Revolution, by Jose Enrique de la Pena. Texas A\&M University Press, College Station.

Pierce, G. A.

1969 Texas Under Arms. Encino Press, Austin.

Prewitt, E. R.

1981 Cultural Chronology in Central Texas. Bulletin of the Texas Archeological Society 52:65-89.

Ramsde11, C.

1948 House Built Forever. San Antonio Express Magazine December 19.

1959 San Antonio, A Historical and Pictorial Guide. University of Texas Press, Austin.

Robacker, E. F. and A. F. Robacker

1978 Spatterware and Sponge: Hardy Perennials of Ceramics. A. S. Barnes and Co., Inc., New Jersey.

Robinson, R.

1979 Biosilica and Climatic Change at 41 GD 21 and 41 GD $21 \mathrm{~A}$. Appendix IV in Archaeological Investigations of Two Prehistoric Sites on the Coleto Creek Drainage, Goliad County, Texas, by D. E. Fox:102-113. Center for Archaeological Research, The University of Texas at San Antonio, Archaeological Survey Report 69.

Roemer, F.

1935 Texas with Particular Reference to German Immigration and the Physical Appearance of the Country. Translated by 0swald Mueller. Standard Printing Co., San Antonio.

Santos, R., translator

1966 Letter from Columbia, Texas, Dec. 27, 1836, to Blas Herrera.

Published privately by W. Knight, County Clerk, Bexar County, Texas.

Sayles, E. B.

1935 An Archaeological Survey of Texas. Meda11ion Papers XVII:1164. Gila Pueblo, Globe, Arizona. 
Sayre, A. A.

1932- Geologic Map of Bexar County. Compiled from maps of the Corps

1933 of Engineers, U.S. Army, General Highway Maps, Texas Highway Department. Revised January 1, 1957.

Schiffer, M. B.

1975 An Alternative to Morse Dalton Settlement Pattern Hypothesis. P1ains Anthropologist 20-70:241:253.

Schuetz, M. K.

1960 Report on the Martinez Creek Survey. Manuscript on file, Witte Memorial Museum, San Antonio.

1966 The Granberg Site: An Archaic Habitation in Bexar County, Texas. Witte Memorial Museum Studies 1. San Antonio.

1969 The History and Archeology of Mission San Juan Capistrano, San Antonio, Texas. Vol. 2 (of two volumes): Description of the Artifacts and Ethno-History of the Coahuiltecan Indians. State Building Commission, Archeological Program, Report 11. Austin.

1970 Excavation of a Section of the Acequia Madre in Bexar County, Texas, and Archeological Investigations at Mission San José in Apri1, 1968. Texas Historical Survey Committee, Archeological Program, Report 19, Austin.

Schoen, $H$.

1936 The Free Negro in the Republic of Texas. The Southwestern Historical Quarterly 40(1).

Schwarz, T.

1985 Forgotten Battlefield of the First Texas Revolution: The Battle of Medina, August 18, 1813. Edited and annotated by Robert H. Thonoff. Eakin Press, Austin.

Scurlock, D., A. Benavides, Jr., D. Isham, and J. W. Clark, Jr.

1976 An Archeological and Historical Survey of the Proposed Mission Parkway, San Antonio, Texas. Office of the State Archeologist, Texas Historical Commission, Archeological Survey Report 17.

Scurlock, D. and D. E. Fox

1977 An Archeological Investigation of Mission Concepción, San Antonio, Texas. Office of the State Archeologist, Texas Historical Commission, Report 28. 
Scurlock, D. and W. R. Hudson, Jr.

1973 An Archeological Investigation of Walker Ranch. Office of the State Archeologist, Texas Historical Commission, Special Report 9.

Secretary of the Interior

1983 Standards and Guidelines for Archeology and Historic Preservation. Federal Register, September 29. United States Department of the Interior.

Sellards, E. H., W. S. Adkins, and F. B. Plummer

1958 The Geology of Texas. 4th printing. Bureau of Economic Geology, The University of Texas Bulletin 3232. Austin, Texas.

Sibley, M. M.

1967 Travelers in Texas, 1761-1860. University of Texas Press, Austin.

Story, D. A.

1968 Archeological Investigations at Two Central Texas Gulf Coast Sites. State Building Commission, Archeological Program Report 13.

1980 Adaptive Strategies of Archaic Cultures of the West Gulf Coast Plains. Unpublished manuscript on file, Center for Archaeological Research, The University of Texas at San Antonio.

Suhm, D. A. and E. B. Jelks

1962 Handbook of Texas Archeology: Type Descriptions. Texas Archeological Society, Special Publication 1, and Texas Memorial Museum, Bulletin 4. Austin.

Taylor, A. J. and A. A. Fox

1985 Archaeological Testing at Rancho de las Cabras, Wilson County, Texas. Fifth Season. Center for Archaeological Research, The University of Texas at San Antonio, Archaeological Survey Report 143.

Taylor, F. B., R. B. Hailey, and D. L. Richmond

1966 Soil Survey of Bexar County. U.S. Department of Agriculture, Soil Conservation Service Series 1962. 
Taylor, V. H.

1957 The Letters of Antonio Martinez. Texas State Library, Austin.

Texas General Land Office (TGLO)

Spanish Collection, Volumes 31,43 , and 49. Archives and Records Division, Texas General Land Office, Austin.

Paschal vs. Pérez. Court of $\mathrm{Cla}$ ams Collection, Archives and Records Division, Texas General Land Office, Austin.

Paul vs. Pérez. Court of Claims Collection. Archives and Records Division, Texas General Land Office, Austin.

Texas Historical Commission (THC)

1973 Historic Preservation in Texas: The Comprehensive Statewide Historic Preservation for Texas. Vol. I. Published jointly by the Texas Historical Commission and the Office of Archeology and Historic Preservation, U.S. Department of the Interior.

1981 Cultural Resource Information System. Pamphlet, Austin.

Thonoff, R. H.

1981 The Texas Connection With the American Revolution. Eakin Press, Burnet, Texas.

Tringham, R., G. Cooper, G. Ode11, B. Voytek, and A. Whitman

1974 Experimentation in the Form of Edge Damage: A New Approach to Lithic Analysis. Journal of Field Archaeology 1:171-196.

Tunne11, C. D. and W. W. Newcomb, Jr.

1969 A Lipan Apache Mission: San Lorenzo de 1a Santa Cruz, 17621771. Texas Memorial Museum, Bul1etin 14.

Turner, E. S. and T. R. Hester

1985 A Field Guide To Stone Artifacts. Texas Monthly Press, Austin, Texas.

Uecker, $H$.

ms. Unpublished manuscript on file, Center for Archaeological Research, The University of Texas at San Antonio. 
Valdéz, Juan

1720 Letter to the Marqués de Aguayo, giving an account of the founding of Mission San José. In Testimo de la Possn y Misson de Sn Joseph, AGN, Audiencia de Guadalajara, 67-3-11. Dunn Transcripts, 1750-1767. Barker Texas History Center Archives, The University of Texas at Austin, Vol. 23:12-25.

Walker, H. P., editor

1962 William McLane's Narrative of the Magee-Guiterrez Expedition 1812-1813. The Southwestern Historical Quarterly 66(2). Walker, J.W.

1971 Excavation of the Arkansas Post Branch of the Bank of the State of Arkansas. Southeast Archeological Center, Division of Archeology, Office of Archeology and Historic Preservation, National Park Service, U.S. Department of the Interior.

Walsh, M.

n.d. Pérez/Linn Papers. Private collection.

Webb, W. P.

1952 The Handbook of Texas. Two volumes. The Texas State Historical Association, Austin.

Weber, D. J.

1982 The Mexican Frontier, 1821-1846. University of New Mexico Press, Albuquerque.

Weddle, R. A. and R. H. Thonoff

1976 Drama and Conflict: The Texas Saga of 1776. Madrona Press, Austin.

Wedgewood, J. and T. H. Ormsbee

1947 Staffordshire Pottery. Robert M. McBride and Co., New York.

Weir, F. W.

1976 The Central Texas Archaic. Ph.D. dissertation, Department of Anthropology, Washington State University, Pul1man. University Microfilms, Ann Arbor.

Weniger, D.

1984 The Explorer's Texas: The Lands and Waters. Eakin Press, Austin. 
West, E. H. (translator)

1904 A Brief Compendum of the Events Which Have Occurred in the Province of Texas from its Conquest, or Reduction to the Present Day, written by Antonio Boni17a in 1772. Quarterly of the Texas State Historical Association VIII(1):1-78.

White, A., editor

1966 The 1840 Census of the Republic of Texas. Pemberton Press, Austin.

Willey, G. R. and P. Phillips

1958 Method and Theory in American Archaeology. The University of Chicago Press, Chicago.

Williams, A.

1933 A Critical Study of the Siege of the Alamo and of the Personnel of its Defenders. The Southwestern Historical Quarterly 36(4).

Wi17iams, J. W.

1979 01d Texas Trails. Eakin Press, Burnet, Texas.

Ziviey, V. N.

1915- Field Notes and Detail Map of the King's Highway from 1916 Pendleton's Ferry on the Sabine River to Paso de Francia on the Rio Grande. On file at the Daughters of the Republic of Texas Research Library at the Alamo, San Antonio. 


\section{APPENDIX I \\ FEDERAL AND STATE CRITERIA FOR THE SELECTION OF NATIONAL REGISTER SITES AND TEXAS HISTORIC LANDMARKS}

There have been a series of federal mandates affecting resources preservation, but only those which are considered applicable to the specific recommendations in this report are discussed.

\section{THE NATIONAL HISTORIC PRESERVATION ACT OF 1966}

The National Historic Preservation Act of 1966 (16 USC 470, as amended) authorized the Secretary of the Interior to expand and maintain a National Register of districts, sites, structures, and objects that have been determined to be significant to American history, architecture, archaeology, or culture. Such properties may be part of the National Park System or any cultural resource that has been declared eligible for an Official Texas Historical Marker by the Texas Historical Commission and is a Recorded Texas Historic Landmark. The Act of 1966 also provides a means for states to nominate properties of state and local significance to the National Register of Historic Places regardless of location within the state and whether publically or privately owned (36 CFR 800 ).

The National Historic Preservation Act of 1966 is an expanded version of the Historic Sites Preservation Act of 1935 which authorized extensive responsibilities to the federal government to determine a policy of historical (cultura1) preservation. The Act of 1966 called for a broadened program of preservation for a 11 cultural property, and noted that the National Register was designed to be, and is administered as, a planning tool without restraint upon private property interests (36 CFR 800).

Such a listing in the National Register (a) provides protection through comment by the Advisory Council on Historic Preservation on the effect of federal1y financed, assisted, or licensed undertakings on prehistoric or historic properties (stated in Section 106 of the National Historic Preservation Act of 1966 and Executive Order 11593); and (b) in some instances, makes private property owners eligible to be considered for federal grants-in-aid for historic preservation through state programs.

\section{ADDITIONAL FEDERAL MANDATES}

In 1969, the National Environmental Policy Act (NEPA) set forth a comprehensive program for governmental policies toward cultural resources management and land-use planning. The impacts of NEPA and its Environmental Impact Statements for documenting land modification projects have had a major influence on cultural resources management in the last ten years.

The role of the federal government towards cultural resources preservation was further emphasized in 1971 with the signing of Executive Order 11593 entitled "Protection and Enhancement of the Cultural Environment." The purpose of this Executive Order was to bring together earlier diverse pieces 
of preservation legislation that affected cultural resources. Section 2(a) of this order states that:

. . with the advice of the Secretary of the Interior, and in cooperation with the liaison office for historic preservation for the state or territory involved, locate, nominate, inventory, and nominate to the Secretary of the Interior all sites, buildings, districts, and objects under their jurisdiction or control that appear to qualify for listing in the National Register of Historic Places.

\section{CRITERIA FOR EVALUATION OF NATIONAL REGISTER ELIGIBILITY}

The following quotation is taken from the National Historic Preservation Act of 1966 (36 CFR 60.4):

The following criteria are designed to guide the States, Federal agencies, and the Secretary of the Interior in evaluating potential entries (other than areas of the National Park System and National Historic Landmarks) for the National Register;

The quality of significance in American history, architecture, archeology, and culture is present in districts, sites, buildings, structures, and objects that possess integrity of location, design, setting, materials, workmanship, feeling, and association, and:

A. that are associated with events that have made a significant contribution to the broad patterns of our history; or

B. that are associated with the lives of persons significant in our past; or

C. that embody the distinctive characteristics of a type, period, or method of construction, or that represent the work of a master, or that possess high artistic values, or that represent a significant and distinguishable entity whose components may lack individual distinction; or

D. that have yielded, or may be likely to yield, information important in prehistory or history. 


\section{APPENDIX II}

\section{GLOSSARY}

adobe palisado - A type/method of construction in which vertical poles are placed in the ground chinked with adobe, then plastered.

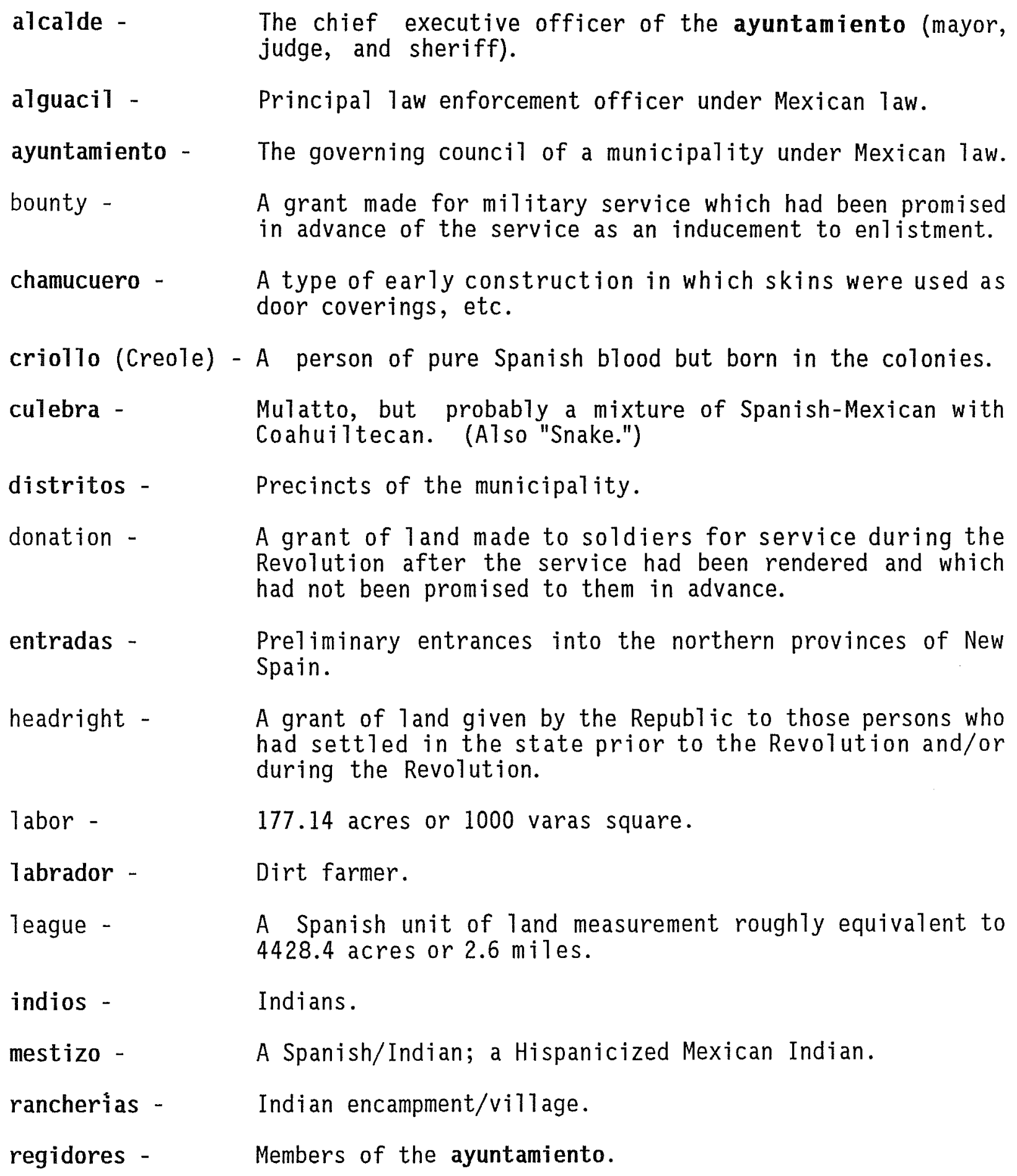
had settled in the state prior to the Revolution and/or during the Revolution.

1abor - $\quad 177.14$ acres or 1000 varas square.

labrador - Dirt farmer.

league - A Spanish unit of land measurement roughly equivalent to 4428.4 acres or $2.6 \mathrm{miles}$.

indios - Indians.

mestizo - A Spanish/Indian; a Hispanicized Mexican Indian.

rancherias - Indian encampment/village.

regidores - Members of the ayuntamiento. 


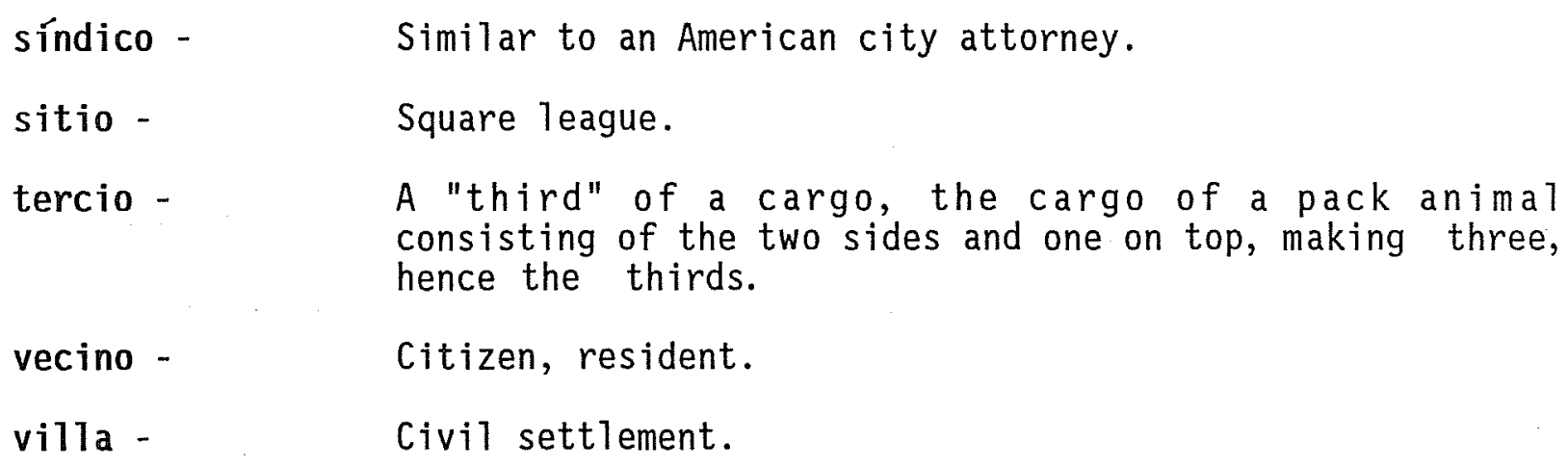
consisting of the two sides and one on top, making three, hence the thirds.

vecino - $\quad$ Citizen, resident.

villa - Civil settlement. 


\section{APPENDIX III \\ IDENTIFIED HEADRIGHTS AND/OR \\ GRANTS IN THE STUDY AREA}

\section{INTRODUCTION}

Archival research, including genealogical and biographical information, is presented on Luciano Navarro, John W. Smith, Henry Peace, Bernardino Ruiz, and Franklin Lafitte Paschal. These men were identified from research as having been early property owners in the study area. Field work did not locate or identify any historic sites associated with these individuals. This information is included in this report with the belief that it might be of some benefit to future researchers.

\section{LUCIANO NAVARRO/ASSIGNEE OF CRUZ LANDIN}

Luciano Navarro received the headright (BCA Headrights, No. 56) of Cruz Landin on August 10, 1838; said headright was surveyed for Navarro on the north bank of the Medina River, being survey No. 46 (BCA Surveyor's Field Notes, Book A1:12). In 1841, the one league and one 1 abor were patented to Navarro, and on February 7, 1847, Navarro (a brother of José Antonio Navarro) and his wife Teodora Carabajal de Navarro, and José Angel Navarro, sold 1158 acres of the survey to Miguel Calvo for $\$ 1158$ (BCDR Vol. D2:372). Subsequent7y, Calvo sold the 1 and to George F. Howard for $\$ 1447.25$ on December 11, 1850 (BCDR Vo1. 12:103).

\section{JOHN W. SMITH}

John W. Smith, known as El Colorado or "Red Head," came to San Antonio from Missouri in 1826. In 1832, he married Maria de Jesus Curbelo (a member of the Delgado-Curbelo family; Chabot 1937:157). He was a scout and guide, and knew the Texas territory exceedingly we11. After the American occupation, he was elected the first mayor of San Antonio (1837); he held this office until March 9, 1838. John W. Smith also was mayor from January 8, 1840, to January 9, 1841, and succeeded the Juan M. Seguin administration, from Apri1 18, 1842, to March 30, 1844 (Chabot 1937:274).

John W. Smith was a representative from Bexar in the Congress of the Republic in Washington-on-the-Brazos. He died there in 1844 (Chabot 1937:275-105).

In 1840, Smith owned 9406 acres under a completed title; 31,284 acres under survey, based on a grant, but without a final title confirmed by the Texas General Land Office; 11 town lots; and two slaves.

\section{HENRY PEACE}

Henry Peace received a headright of one league and one labor of 1 and by virtue of certificate No. 44 issued by the land commissioners for the county 
of Jefferson (BCA Headrights, No. 44). The headright was surveyed on August 4, 1838, on the south bank of the Medina River; said survey being No. 37 in Section No. 2. This survey contained eight (original document illegible here) of arable land and 18 labors of pastureland (BCA Surveyor's Field Notes, Book A1). In 1846, the grant was sold to Robert Lockhart and patented to him on March 17, 1852 (TGLO Spanish Collection).

Henry Peace received donation certificate No. 641 for 640 acres on November 23, 1854, for being in the Siege of Bexar. The 640 acres were patented to his assignee, William P. Normandie, in Travis County. He also received bounty warrant for 320 acres on December 7, 1837 (Miller 1967).

\section{BERNARDINO RUIZ}

Bernardino, the oldest son of Salvador de Castañeda Ruiz (sometimes referred to as Luis) and Maria Ignacia Robleau of Natchitoches and Nacogdoches, was born on May 19, 1803, at Mission San José. The Ruiz family was originally from Andalusia, Spain, and settled in Zacatecas; here Salvador was sent to Louisiana with a herd of horses. He returned as far as San Antonio and settled (Chabot 1937:201).

Other children of Salvador and María Robleau Ruiz were María Concepción, born December 7, 1806; José Ignacio, born August 1, 1808; José Lino de Jesus, born September 22, 1811; José Hermerigildo, born Apri1 22, 1814; Juan Francisco, born January 29, 1817; and Guadalupe, date not known for birth, but her second marriage was to Erastus "Deaf" Smith, a scout (Chabot 1937).

Bernardino married Maria del Carmen Góngora, and to this union seven children were born: (1) José Antonio Andres, born November 29, 1832, died September 26, 1833; (2) José de Jesus, born November 4, 1833; (3) Francisco, born Apri1 2, 1841; (5) María de1 Carmen, born December 15, 1848; (6) Santiago de 1a Encarnacion, born February 2, 1851; and (7) Concepción, born February 7, 1854.

On March 6, 1838, Ruiz received a headright of one league and one labor of 1and (BCA Headrights, No. 343). On August 12, 1838, Wi11 iam Lindsey surveyed the said league and labor for Ruiz; the survey contained five labors and 99,250 square varas of arable land (BCA Surveyor's Field Notes, Book A1:40).

Some confusion surrounds the Ruiz family. Chabot (1937) wrote that Salvador de Castañeda was sometimes known as Bernardino; however, upon examination of the baptismal records of San Fernando (BCA San Fernando Church Records), Salvador is often referred to as Luis, but never as Bernardino.

\section{FRANKLIN LAFITTE PASCHAL}

Franklin Lafitte Paschal was born January 15, 1810, at Lexington, Oglethorpe County, Georgia, the son of George and Agnes (Brewer) Paschal. His early education was provided at home by his mother, and he clerked for a time in a store. He taught school for a while, but when his father became $i 11$ he returned home to be with his family. In 1836, when news of the Goliad 
massacre of the Georgia Battalion reached him, Paschal, as a lieutenant, joined with the forces of Major Augustus Parker and came to Texas to join in the fight for independence. Shortly thereafter, he became commissary chief of Green's Brigade. He later became a member of Jack Hays' company of scouts, and was severely wounded at Leon Springs while on a scouting expedition. He returned home to Georgia to recuperate, and in 1839, he arrived back in San Antonio (Chabot 1937:315-316). For his services from December 10,1836 , to November 4, 1837, Paschal received Bounty Warrant 37 for 960 acres (patented to John P. Davie, assignee in Tyler County) and Bounty Warrant 1174 for 640 acres. The 640 acres in Bexar County were patented to Paschal on January 27, 1841 (Miller 1967:517).

The 1840 census 1 ists $F$. L. Paschal as owning 4605 acres of 1 and under a completed title from the Texas General Land Office and 2116 acres of 1 and under survey based on a grant but without a final title confirmed by the Texas General Land Office (White 1966:16). Paschal evidently had extensive land holdings in the San Antonio area other than those he received for bounty warrants.

In 1842, Paschal married Miss Frances Roach in the first marriage of Americans performed in the City of San Antonio. From this union, seven children were born (Chabot 1937:316).

Paschal was the first sheriff of Bexar County during the Texas Republic. He was a member of the City Council, and his last service was that of crier of the United States district and circuit court. He was a member of the Association of Texas Veterans (ibid.:316).

The 1850 census (BCA) for Bexar County lists Paschal as a dry goods merchant. He died on February 13, 1884, from pneumonia. The funeral took place at the First Presbyterian Church on February 14, 1884 (Chabot 1937:316).

\section{REFERENCES CITED}

Bexar County, Texas

Bexar County Archives (BCA)

Headrights, Nos. 44, 56, 343. Bexar County Courthouse, San Antonio, Texas.

San Fernando Church Records. Translated by John Ogden Leal. Bexar County Courthouse, San Antonio, Texas.

Surveyor's Field Notes, Book A1. Bexar County Courthouse, San Antonio, Texas.

1850 Census. Compiled in 1966 by L. Russell. On file at the Bexar County Courthouse, San Antonio, Texas. 
Bexar County Deed Records (BCDR)

Volumes D2 and 12. Originals and microfilm in Bexar County Chabot, F. C. Courthouse, San Antonio, Texas.

1937 With the Makers of San Antonio. Artes Graficas Press, San Antonio, Texas.

Miller, T. L.

1967 Bounty and Donation Land Grants of Texas, 1835-1888. University of Texas Press, Austin.

Texas Genera7 Land Office (TGLO)

Spanish Collection. Archives and Records Division, Austin, Texas.

White, A., editor

1966 The 1840 Census of the Republic of Texas. Pemberton Press, Austin. 
APPENDIX IV

SITE SURVEY FORMS FOR 1981 AND 1984 


\section{SITE SURVEY FORM}

THE UNIVERSITY OF TEXAS AT SAN ANTONIO

Center for Archaeological Research

Site Survey Record

Applewhite Reservoir Survey

Recorder

County

Map Coordinates

Map Name

Location:

Description of Site:

size Shape Type

Permanent Number

Field Number

Site Name

Project

Nature of Archaeological Evidence:

Features:

Vegetation:

Soils:

Topography:

Present Condition:

Name and address of owner (include county portion \#, if applicable):

Activities of Recorder at Site (describe the nature of the investigations, what was done and methods used):

Materials from Site (list artifacts and other materials collected or observed at site, sketches should be made on a continuation sheet)

Photographic Records type camera:

No. of Bags

No Collection made

Black and White

Ro11 \# Color

Recommendations

Disposition of notes and collections

Date

Center for Archaeological Research, The University of Texas at San Antonio, unless otherwise noted. 
State of Texas

ARCHEOLOGICAL SITE DATA FORM

Instructions: Answer all questions. Be specific in distinguishing between "none" and "none observed" or "unknown"; if in doubt, enter "unknown." Where question is followed by (Yes) (No), simply circle answer. Enter measurements in metric. Attachments may be used to complete any question: at question, write "See Attachment __ " and number attachments consecutively. List all attachments at end of this form.

\section{GENERAL INFORMATION}

Temporary Site No.

Permanent Site No.

Site Name

Project Name

$\overline{\text { Project Funding Source(s) }}$

Owner and Address

Informant and Address

Additional Sources of Information

Previous Investigations

Who

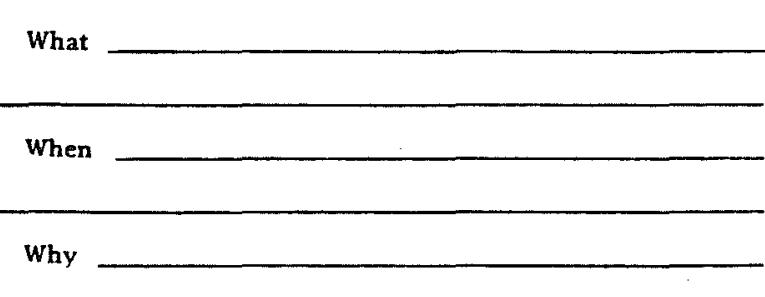

Name of Original Recorder of Site

\section{RECORDING INFORMATION}

Name of Recorder

Institutional Affiliation, if any

Date

\section{LOCATIONAL INFORMATION}

County

USGS Map Name \& No.

Elevation

UTM: Zone

Easting —_- - - - - -

Northing _- - - - - - - -

Latitude $\_-1-1-{ }_{-}$

Longitude $-1-1-1-$

Description of Location (include nearby USGS topographic landmarks as well as on-site references; note mileages, distances, etc.) 


\section{WORK PERFORMED BY FIELD PERSONNEL}

\begin{tabular}{lll}
$\begin{array}{l}\text { Survey } \\
\text { Testing }\end{array}$ & (Yes) & (No) \\
Method & (Yes) & (No) \\
\cline { 2 - 3 } & & \\
\hline Excavation & (Yes) & (No) \\
Method & & \\
\hline & & \\
\hline Notes & (Yes) & (No)
\end{tabular}

Where Housed

\begin{tabular}{|c|c|c|}
\hline \multicolumn{3}{|l|}{ Photographs } \\
\hline Slides-Color & (Yes) & (No) \\
\hline Blacis \& White & (Yes) & (No) \\
\hline Prints-Color & (Yes) & (No) \\
\hline Black \& White & (Yes) & (No) \\
\hline \multicolumn{3}{|l|}{ Where Housed } \\
\hline Collections & (Yes) & $(\mathrm{No})$ \\
\hline
\end{tabular}

Collection Techniques (e.g., controlled, noncontrolled, select, random, arbitrary; describe)

Kinds of Materials Collected

Special Samples (e.g., carbon, archeomagnetic, plant; list and describe)

How Collected

\section{ENVIRONMENTAL LOCATION}

Nearest Natural Water Source

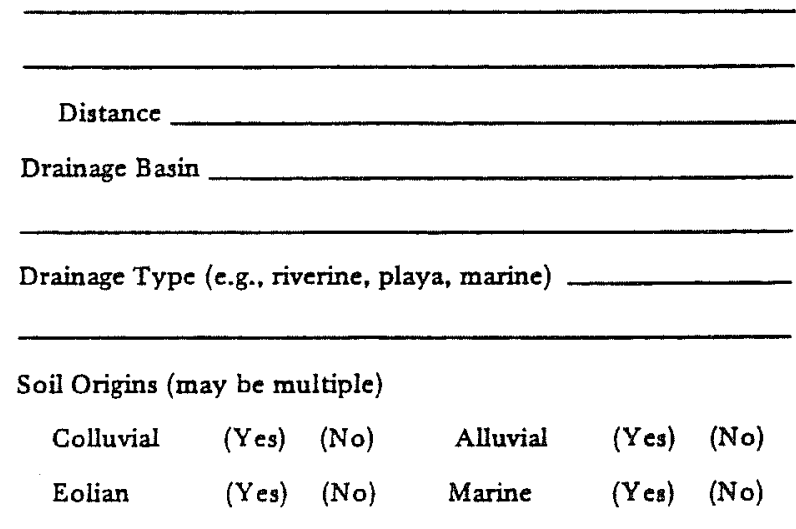

Soil Type (e.g., clay loam, sand)

Vegetation (list dominant, others if known)

Ground Surface Visibility

Environmental Setting of Site (include pertinent landforms, slope, visible landmarks, etc.)

Additional Comments 


\section{CULTURAL MANIFESTATIONS}

Site Size (estimate if necessary)

At Present

\section{At Original Occupation}

Basis for Determination

Circumstances of Observation

Depth of Cultural Deposit

Basis for Determination

Time Periods of Occupation (e.g., Prehistoric-Early Archaic; may be multiple)

Components (refers to discreet occupations)

$\begin{array}{ccrrr}\text { Single } & \text { (Yes) }(\mathrm{No}) & \text { Multiple } & \text { (Yes) } \\ & \text { Unknown } & (\mathrm{Nes}) & (\mathrm{No}) & \end{array}$

Basis for Determination

Site Type (e.g., open campsite, military post, rockshelter)

Cultural Features (If present, describe: e.g., bumed rock midden, bearth, structural remains; how do they relate to components, time periods, physiography ; how many are there. spatial distribution, size, contents, etc.)

(Continued)
Artifactual Materials Present (kinds of materials. distribution across site, relationship to features, etc.)

Discussion of Site (comments, observations, impressions) 
Permanent Site No.

\section{SITE CONDITION AND RECOMMENDATIONS}

Approximate percentage of site remaining intact

Natural Impacts (include erosion. spalling. sloughing, etc.)

Artificial Impacts (include construction, plowing, etc.)

Known or Perceived Future Impacts

Potential for State Archeological Landmark

$$
\text { (Yes) (No) }
$$

Potential for National Register of Historic Places

(Yes) (No)

Submitted?

Uncertain/Unknown?

\section{Current Registration}

State Archeological Landmark

(Yes) (No)

National Register of Historic Places

(Yes) (No)

Other

Recommended Actions (regional and project specific research. management. preservation)

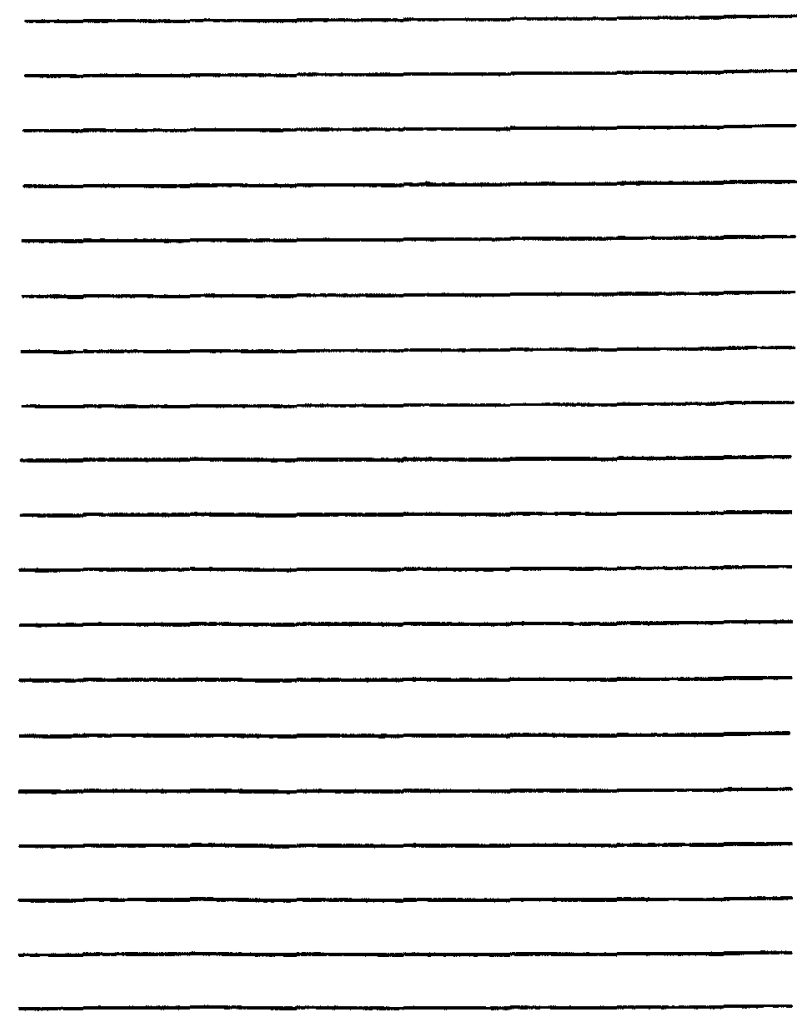

LIST ALL ATTACHMENTS (Where applicable, refer to question that is being supplemented)

1.

2.

3.

4.

5.

6.

7.

8.

8.
9.

10.

11

12.

13.

14.

15.

Other (give numbers) 
Permanent Site No.

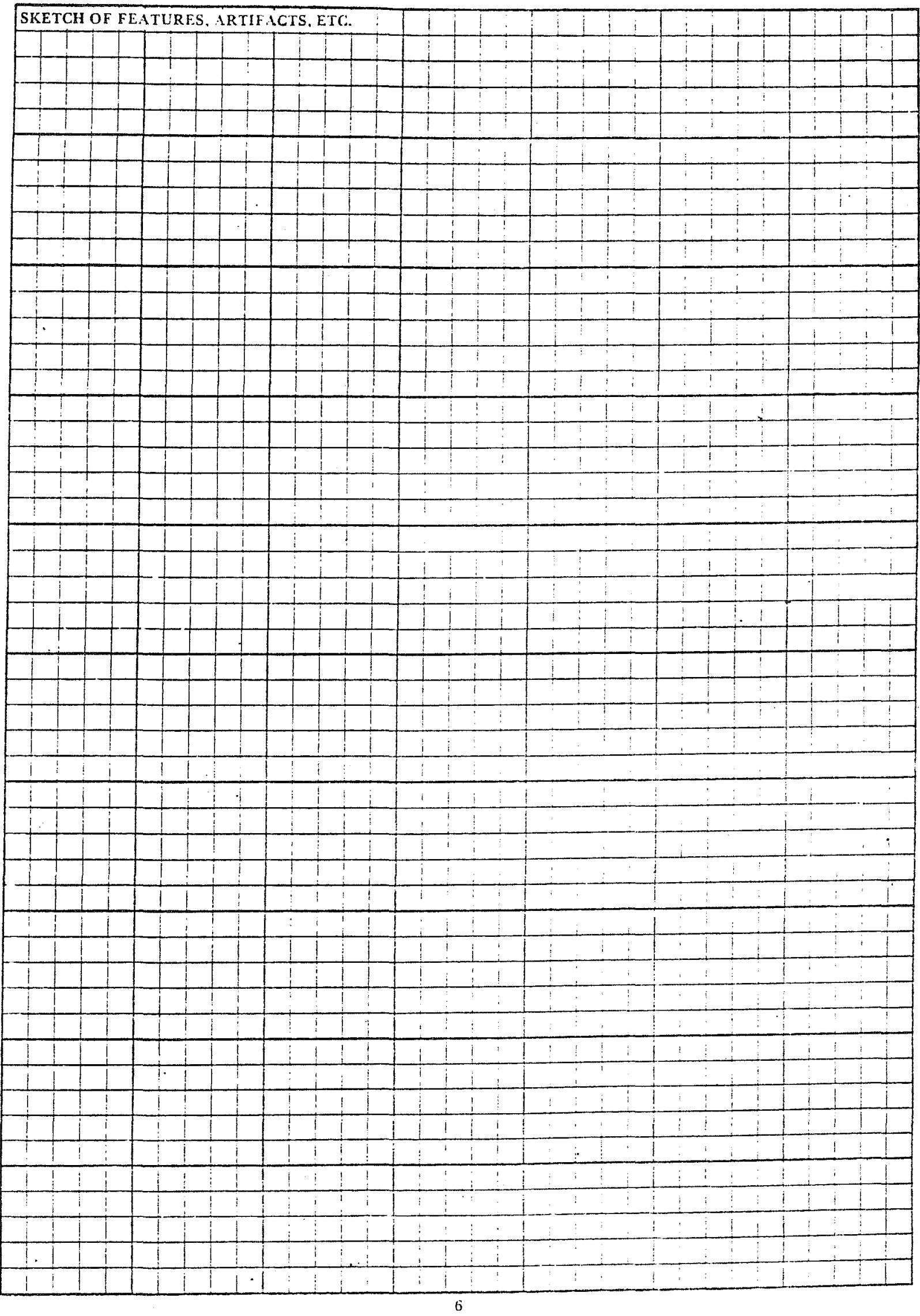


Permanent Site No.

SKETCH MAP OF SITE AND SURROUNDING TOPOGRAPHIC FEATURES (include North arrow and scale; note if map was not made on site). Attach photocopy of topographic map showing site location. 


\section{APPENDIX $y$}

\section{PREVIOUSLY IDENTIFIED SITES ALONG MEDIO CREEK*}

\section{INTRODUCTION}

In the spring of 1977 , fifteen prehistoric sites were discovered by $A . J$. McGraw along Medio Creek in southwestern Bexar County. The sites were designated as 41 BX 368, 41 BX 459, 41 BX 460, 41 BX 461, 41 BX 462, 41 BX 463, 41 BX 464, 41 BX 465, 41 BX 466, 41 BX 467, 41 BX 468, 41 BX 469, $41 \mathrm{BX} 470,41$ BX 471, and 41 BX 472. A preliminary survey report of these sites was presented by McGraw (1977) with additional intensive survey and limited testing at 41 BX 459 being performed in 1977-1978. In 1981, a reassessment of the Medio Creek data was conducted in conjunction with a study of the proposed Applewhite Reservoir. At this time a reevaluation of elevational data was undertaken, and portions of seven of the sites were found to be within the maximum flood pool level ( 555.3 feet above mean sea leve1) of the proposed reservoir. These included the following: $41 \mathrm{BX} 368$, 41 BX 459, 41 BX 460, 41 BX 461, 41 BX 462, 41 BX 463, 41 BX 464. During the 1984 study, the seven previously identified sites were revisited and reassessed. Table 27 contains the 1984 reassessed data for the seven sites and this appendix presents site-specific information adapted from the 1977 (McGraw) study, including the 1977-1978 intensive survey/limited testing data at $41 \mathrm{BX} 459$. The descriptions do not follow the newly revised site survey forms.

Site designations follow a trinominal identification in which the first two numbers represent Texas, the next two letters the county, and the last numbers a specific site. Locational information is given only to locate the site in a general environmental and geographic context. Specific locations are not generally given, in order to forestall improper use of such information (Nunley and Hester 1975:11). Detailed maps are on file at the Center for Archaeological Research, The University of Texas at San Antonio.

Site descriptions will be presented as follows:

Location: Viewed from a general geographic and environmental context and in respect to known geographic features.

Elevation: Elevation above mean sea level (msl) as identified on USGS topographic maps.

Description: Brief, specific statements concerning the site occupation, depth, extent, and condition.

Type of site: Occupational (campsite), quarry, workshop, temporary occupation, stream terrace, multifunctional, etc.

*Adapted from McGraw (1977). 
41 BX 459 Prehistor Ic occupati

\section{Originally est imated at} $300 \times 100 \mathrm{~m}$ ca. $1 \mathrm{~km}^{2}$

41 BX 460 Prehistorfc occupation

ca. $200 m^{2}$

41 BX 461 Prehistoric occupation

ca. $275 \times$ $200 \mathrm{~m}$

41 BX 462 Prehistoric occupation

$120 \times 100 \mathrm{~m}$

$50 \times 75 \mathrm{~m}$; posstbly larger

41 BX 463 Originally described a lithic workshop;

redefined as

a prehistoric occupation in 1981

41 BX 464 Prehistoric occupation

ca. $400 \times$ $300 \mathrm{~m}$
550-580 feet

ca. $70 \%$ of site is severely damaged by topsoll removal. natural erosion by naturat
1984

550-570 feet

ca. $80 \%$ of site area destroyed by modern alterations in 1984

Intrusive Boothe Brushed ceramics; Ensor, Frio, Gower projectlle points: Clear Fork tool

Leon Plain ceramic sherd, thick and thin biface fragments

560-570 feet

ca. $70 \%$ of site area destroyed by modern alterations in 198

Leon Plain ceramics arrow point distal fragments

None Identifled

Over 90\% of site destroyed by bul1-

$75 \%$ destroyed by earth moving 19831984

\section{Leon Plain ceramics}

None identiffed
560-580 feet

Extensively damaged

by $l$ and clearing and

earth moving in 1983-
Management Recommendations

Continual natural erosion, land clearing and recent topsoll removal has destroyed the site area; testing at 41 BX 459 .

Potential National Register eligibility; systematic testeliglbinty; systenatic testing along relatively undiscomments on 11 mited testing.

Testing of northern site area along and north of fence 1 ine to determine National Register potential.

Limited testing in undisturbed areas to assess National Register potential. Site is above maximum flood pool level.

No further work, due to severity of site damage.

Limfted testing of und $15-$ turbed site margins to determ ine subsurface

deposits. Site is above maximum flood pool elevation. destruction precludes the site's eligibility potential for nomination to National Register status; no further work is recommended. 
Environmental characteristics: A brief geographic and environmental description.

Interpretation/remarks: A preliminary analysis of the extent, importance, and condition of the site.

\section{SITE 41 BX 368 (Cindy Mae Site)}

Location: Site 41 BX 368 follows the contours of a former stream terrace behind the entrance to Hidden Valley Recreational Park, southwestern Bexar County.

Elevation: $550-580$ feet above ms1.

Description: Physically, the site follows the contours of the ridgeline and culminates in a large, relatively high bluff to the south; the northern end is bounded by a large eroded area consisting of 7 ight calcareous marl interspersed with cobbles of varying size. The site extends north-south ca. $300 \mathrm{~m}$ and slopes westward and downward ca. $250 \mathrm{~m}$ toward Medio Creek. Two artifact concentrations were located on the southern bluff, and at least three fire-burned rock scatters were situated atop eroded knolls on the ridge below the concentrations.

Type of site: Archaeological evidence in the form of finished bifaces, scrapers, a projectile point, lithic debris, and fire-burned rocks suggests a multifunctional site, including habitation and workshop areas.

Environmental characteristics: The site area is generally covered by high grasses and, as of 1977, was used as a horse pasture. Uplands extend northeastward away from the creek area. The soil is characterized by heavy gully erosion on slopes, dark gray loam on uplands, and eroded calcareous marl mixed with cobbles on slopes. Vegetation along the stream channel includes high grasses; oak, pecan, elm, and mesquite trees; and often dense brush.

Interpretation/remarks: Heavy erosion has badly damaged slope sections of the site, especially near the base of the bluff, but the presence of some half-buried material on the bluff area itself suggests that some controlled surface collection may be feasible at this site.

\section{SITE 41 BX 459}

Location: Site $41 \mathrm{BX} 459$ is located ca. 400 m northwest of 41 BX 368 on the fringes of a high ridge adjacent to a former crescent-shaped channel and floodplain of Medio Creek. Located on the eastern bank of the stream, the site overlooks a bowl-shaped depression ca. $275 \mathrm{~m}$ in diameter.

Elevation: $550-560$ feet above ms 1 .

Description: An "extensive" rather than intensive area, the site can best be described as an extensive preferred occupational zone rather than a locally 
defined and limited area. Lithic debris is scattered frequently along the high ground for more than $300 \mathrm{~m}$ and ranges at least $100 \mathrm{~m}$ eastward away from the waterway into dense brush. A small, crescent-shaped midden ca. $5 \mathrm{~m} \times 3 \mathrm{~m}$ and $25 \mathrm{~m}$ in height is ca. $12 \mathrm{~m}$ north of the fence line on the southern boundary of the site. Several fragments of a large brushed potsherd have been found eroding from this feature. Bifaces and two projectile points, identified as Frio and Gower, have also been found within $5 \mathrm{~m}$ of this area. Fire-cracked rocks are scattered throughout.

Type of site: The site is possibly multifunctional, but primarily occupational, as a "base area."

Environmental characteristics: High, dense brush obscures much of the site. Site 41 BX 459 is located on the edge of an upland ridge complex liberally overgrown with thorny bushes, tall grasses, and mesquite trees. The soil is dark gray, but the eroding slope is tan calcareous marl.

Interpretation/remarks: In the course of the original survey, a major feature, a sma11, crescent-shaped midden ca. $5 \times 3 \mathrm{~m}$ and $25 \mathrm{~m}$ in height was discovered $12 \mathrm{~m}$ north of a fence line that comprises the southern site boundary. Several fragments of a large brushed potsherd were found eroding from this feature, and five bifaces were surface collected in the immediate vicinity. Diagnostic Tithic materials included Ensor, Frio, and Gower projectile points and fragments, and a unifacially worked Clear Fork tool. The site's significance was greatly increased following the identification of the pottery fragments as Boothe Brushed, a minor central Texas ware rarely found in south-central Texas (Dee Ann Story, personal communication). The ceramic fragments reflect unsuspected intercultural contacts in the Late Prehistoric period between central and south-central Texas.

The area was intensively surveyed, and limited subsurface examination in the form of a $1-\mathrm{m}^{2}$ and a $50-\mathrm{cm}^{2}$ pit was conducted. The results of these observations are briefly summarized.

The primary purpose of the 1-m² unit and the subsurface examination was not to identify the horizontal extent or vertical depth of cultural materials but to locate one component (the pottery-bearing cultural level) and assess its context and artifacts. This was done by locating a 1 -m unit directly over the eroding midden location. Vertical depth of the test square extended to $30 \mathrm{~cm}$, and all materials were screened through 1/4-inch wire mesh. Surprisingly, no other ceramic sherds were recovered, and only a moderate collection of fire-reddened, tertiary flakes, chert chips, and themrally-fractured cobbles were observed. Soil coloration throughout the $10-\mathrm{cm}$ levels was composed of a sandy, medium gray loam, although soil excavated near the bottom of the unit was distinctly lighter in color. No cultural or stratigraphic levels were identified in the small midden area, and preliminary subsurface examination revealed little other than lithic debris to a depth of ca. $25 \mathrm{~cm}$.

Approximately $15-\mathrm{m}$ eastward along the ridgeline, a $50-\mathrm{cm}^{2}$ unit was excavated to a depth of $45 \mathrm{~cm}$ primarily to identify an undisturbed soil deposition for comparison with the former $1-\mathrm{m}^{2}$ unit. Medium to dark gray soil along the slope extended to a depth of $12-17 \mathrm{~cm}$. Below this, a calcareous transition 
zone changed the color and content of the soil to increasingly lighter shades of yellow-colored materials. Chert cobbles first appeared in the transition zone and became increasingly larger as depth increased. The light soil cover of the upper soil zones suggests erosion and possibly deflation across much of the site area. This erosion is contrasted, however, to a much more extensive topsoil observed several hundred meters northeastward. Bul1dozer activity in that area reflected a dark gray loam, possibly of the HoustonHouston-Black soil association, to a depth exceeding $80 \mathrm{~cm}$.

Intensive survey throughout the densely wooded area established a much larger surface distribution of 1ithic materials than originally suspected. Lithic debris, usually cores and secondary flakes, were often observed almost a kilometer north from the defined main activity area. This was most apparent in the bulldozed localities. Several heavily patinated tertiary flakes and chert chips were discovered just below the surface of the bul1dozed area (ca. $80 \mathrm{~cm}$ below actual surface) ca. 330 m north of nearby site 41 BX 368 . This debitage was found in a light tan, clayey calcareous marl below the darker topsoil.

Several diagnostic artifacts and a number of irregular tertiary blade flakes and fragments as well as the presence of Gower, Frio, and Ensor projectile points and prehistoric ceramic sherds imply the site location was used throughout portions of the Archaic and Late Prehistoric time periods. The presence of central Texas associated ceramics into south and south-central Texas may be explained by several possibilities: the obtainment of vessels by centrat Texas groups through trade with intermediaries or the migration of central Texas groups into south-central and south Texas.

\section{SITE 41 BX 460}

Location: Site $41 \mathrm{BX} 460$ is located ca. $200 \mathrm{~m}$ directly southwest and across the stream channel from 41 BX 368 , on flat, high ground, ca. $11 \mathrm{~m}$ above the west bank of Medio Creek.

\section{Elevation: $550-570$ feet above ms1.}

Description: The site covers an area of ca. $200 \mathrm{~m}$ east-west and over $200 \mathrm{~m}$ north-south. The area has been critically altered by chain-dragging and bulldozing. Very few artifacts have been found on the open level ground, but there are frequent scatterings of heat-fractured rocks, chert flakes, and biface fragments along the northern boundary of the site, a fence line which separates the open area from heavy brush beyond. The presence of archaeological evidence beyond the fence line implies the site may extend farther to the north where it may be less damaged. Artifacts from 41 BX 460 include a 1 arge, thin, finely worked biface ca. $10 \mathrm{~cm}$ in length, several 1 arge burned rocks, and a predominance of secondary and tertiary flakes. No features were noted in the open area.

Type of site: Finished tools and heat-fractured rocks suggest a moderately occupied habitation site. 
Environmental characteristics: As observed in 1977, erosion has taken place along the slopes of the site, and the site area itself has been modified by land clearing. The area just to the north consists of heavy brush, mesquite trees, and other upland vegetation. The soil is a dark to medium gray loam, and on the eroding slopes, a lighter gray and a tan calcareous marl.

Interpretation/remarks: Site $41 \mathrm{BX} 460$ has been extensively damaged, but the frequency of artifacts along the northern fence line suggests the site may extend undamaged farther north into the brush. The relative closeness of 41 BX 368 to the east, especially to the bluff areas, may indicate some relationship. Without further diagnostic evidence, however, such a relationship is unknown.

\section{SITE 41 BX 461}

Location: Site 41 BX 461 is located $300 \mathrm{~m}$ southwest of 41 BX 460 on the same ridge complex but separated from it by an ca. 100-m-wide, deeply eroded gul1y. The site is bounded on the north by a common fence 1 ine, ca. $80 \mathrm{~m}$ from the southern slopes of the site.

Elevation: 560-570 feet above msl.

Description: Site $41 \mathrm{BX} 461$ is very similar to $41 \mathrm{BX} 460$ in shape, and they al so share a common northern boundary, an east-west running fence 1 ine. Unfortunately, even in the early spring, the entire site area, ca. $275 \mathrm{~m}$ in length, is heavily overgrown with high tall grasses (sometimes called buffalo grass). This vegetation tenaciously resists any attempts to clear the ground cover (short of burning or plowing) and obscures over $90 \%$ of the site area. This condition precludes any attempt at defining site boundaries, although lithic debris found in widely scattered, ant-cleared, circular spaces across the site suggest the site may extend north into uncleared brush. No features were noted, but an intense lithic debris concentration ca. $15 \mathrm{~m}$ in diameter was located just east of, and in part into, an unpaved road which winds its way up the steep southern slope from the floodplain below. The concentration contained primary, secondary, and tertiary flakes; several thin biface fragments; and one small pottery fragment. Although only $1 \mathrm{~cm}$ in length, the exterior surface of the ceramic artifact is plainly visible and shows no evidence of any of the brush strokes found on the sherds from $41 \mathrm{BX} 459$. The exterior surface of this small fragment is smooth and undecorated. No features were noted at the site.

Type of site: Multifunctional; occupational and/or workshop.

Environmental characteristics: As mentioned, high grasses hide much of the ground surface. Otherwise, the area is clear of any large trees or other types of vegetation. As of 1977, erosion was evident on the eastern and southern slopes. Beyond the northern fence line lies dense brush of upland vegetation. Site 41 BX 461 itself is located on a flat, high ridge system adjacent to a former channel of Medio Creek but over $30 \mathrm{~m}$ above the floodplain. 
Interpretation/remarks: Like nearby $41 \mathrm{BX} 460$, this site has been heavily damaged by chain-dragging and bulldozing. However, the presence of eroding artifact concentrations along the southern slope suggests portions of the site may still be intact. Site 41 BX 461 is unique in that its steep southern slope overlooks a former channel and floodplain area of Medio Creek. Today, this location is simply a small valley in an eroded ridge-valley complex; the creek has been rechanneled to flow farther south and west behind another set of ridges. Ceramic evidence at this site may warrant a more intensive survey of the southern slope area and into the dense brush to the north.

\section{SITE 41 BX 462 (Pool Ha11 Site)}

Location: Site 41 BX 462 is within the confines of the Hidden Valley Recreation Park, south of Fischer Road, southern Bexar County. Situated atop a high, flat ridge and overlooking not only the roadway and structures but much of the park as well, it is bounded on the east by a north-south fence 1ine. Upland continues to the north and east, and a heavily eroded, steep ridge is located to the west and south.

Elevation: $560-570$ feet above ms 1 .

Description: Site 41 BX 462 overlooks the floodplain of Medio Creek. The entire high ground area atop the ridge, ca. $120 \mathrm{~m} \times 100 \mathrm{~m}$, contains a scattering of lithic debris, some characterized by potlids, heat fractures, and fire-reddened discolorations. A small but scattered concentration occurs just above and to the northeast of the building structures below. No evidence of features or finished artifacts occurred, but there were occasional samples of fire-fractured cobbles.

Type of site: Light to moderate occupation, but the amount of lithic debris suggests primary use of the area as a Tithic workshop.

Environmental characteristics: High grasses grow on most of the surface with an occasional mesquite tree. The slope to the south and west is heavily eroded, exposing frequent chert cobbles. At least the southern half of the site has been altered by brush clearance and/or bulldozing. The soil is medium gray, turning lighter on the slopes.

Interpretation/remarks: Site 41 BX 462, located on a high ground area adjacent to a waterway, appears to be a 1 ightly occupied area in which the primary function was some degree of lithic activity. Due to the absence of diagnostic tool types, projectile points, or other artifacts associated with habitation, further survey work here is considered unnecessary.

\section{SITE 41 BX 463}

Location: Site 41 BX 463 is directly east of an unpaved roadway, situated atop a high knoll in Hidden Valley Recreation Park, south Bexar County. Distance from park entrance along roadway to knoll is one-half of a mile. 
Elevation: $560-580$ feet above msl.

Description: The site is roughly oval, ca. 50 m east-west $x 75 \mathrm{~m}$ northsouth. This unusually high ground has a light scattering of lithic debris along the edges of its eastern and western slopes. Artifact evidence consisted of an occasional fire-reddened rock and generally secondary or tertiary flakes. No finished artifacts or features were noted. This site was revisited in 1981; fire-fractured rock and a small Leon Plain sherd were noted.

Type of site: Lithic workshop.

Environmental characteristics: The vegetation is dense in the form of thorny bushes, mesquite trees, prickly pear cactus, and assorted high grasses. One of the higher elevations in the vicinity, this site overlooks much of the surrounding area. The soil is medium gray ranging to darker shades.

Interpretation/remarks: From preliminary estimates, 41 BX 463 is identified as a lightly used lithic workshop site with few artifactual remains. Whether this is due to previous erosion or 1 ack of aboriginal use cannot now be determined.

\section{SITE 41 BX 464}

Location: Site 41 BX 464 is in the area of Hidden Valley Recreation Park, south Bexar County. The site area extends 400 to $450 \mathrm{~m}$ along a steep ridgeline that runs parallel and to the east of Medio Creek.

Elevation: $560-580$ feet above ms 1 .

Description: The site area extends ca. 400-450 m north-south along the upland ridge to the east of Medio Creek and at an approximate distance of 15$20 \mathrm{~m}$ up a steep slope. Archaeological evidence in the form of lithic debris gradual1y disappears by traveling ca. $70 \mathrm{~m}$ east away from the edge of the ridgeline. The unusually large site contains primary, secondary, and tertiary flakes in a large and frequent scattering along its entire length without any particular concentrations. There are occasional traces of sma11, solitary fire-cracked rocks, chunks, and cores. Al though covered by heavy brush, thorny bushes, mesquite trees, and tall grasses, an exploration of the area produced no evidence of finished artifacts or features. The soil is medium to dark gray, with numerous cobbles eroding from the gullies and washes to the west of the ridge.

Type of site: Lithic workshop, possibly lightly occupied.

Environmental characteristics: Site 41 BX 464 is characterized by an extensive ridge system bordered on the west by a steep slope and overlooking Medio Creek. The western slope often exposes deeply eroded gullies and washes with large amounts of chert cobbles. The ridge climaxes to the south in a high bluff overlooking the mergence of Medio Creek and the Medina River. 
Toward the north, upland topography predominates with heavy brush covering much of the highly elevated areas. Of the upland area, 30-40\% 1acks tree vegetation and is covered only by tall grasses.

\section{REFERENCES CITED}

McGraw, A. J.

1977 A Preliminary Archaeological Survey Along the Medio Creek Drainage, Southwestern Bexar County. Center for Archaeological Research, The University of Texas at San Antonio, Regional Studies 3.

Nunley, J. P. and T. R. Hester

1975 Assessment of Archaeological Resources in Portions of Starr County, Texas. Center for Archaeological Research, The University of Texas at San Antonio, Archaeological Survey Report 7. 


\title{
APPENDIX VI
}

\section{FAUNAL REMAINS FROM 41 BX 274}

\author{
Cristi Assad Hunter and Jana Hellier
}

\section{INTRODUCTION}

The historic component of 41 BX 274, the Pérez's Rancho" or "Stone Rancho," was confirmed in 1984 through field inspection and was supported by archival research, which indicates the historic importance of the site. Site $41 \mathrm{BX} 274$ is situated close to the terrace bluffs of the Elm Creek and Medina River confluence. The historic component of the site represents a frontier ranch complex which was first occupied during the Spanish colonial period of Texas by a politically, socially, and economically prominent family, the Ygnacio Pérez family. The duration of the site's occupation ranged from the early 19th century to the mid 1800s.

This frontier ranch complex has been impacted by modern farming and ranching activities, resulting in damage to approximately $70 \%$ of the site, leaving the scattered remains of a stone dwelling and probably the remains of outbuildings and other ranching features.

Archival research of the site's occupants (see previous sections of this report) indicates that the Pérez family ran several thousand head of cattle, sheep, horses, and possibly other stock throughout the site's occupation.

The presence of some aboriginal pottery in the site area suggests that a historic Indian component may be associated with the Spanish occupation of the site, as well.

\section{EXCAVATION AND RECOVERY METHODS}

The majority of the faunal remains were recovered from sixteen $50-\mathrm{cm}^{2}$ shovel tests which were excavated from the surface to sterile soil without division by artificial or stratigraphic level (Table 28). In addition to the shovel tests, faunal remains were recovered from three other excavation units. A11 of the excavated materials were screened through $1 / 4$-inch screen mesh.

Because the faunal remains were recovered through $1 / 4$-inch screen mesh, it is likely that a bias exists in the sample; the bones of very small animals would probably be lost through the large screen size. This situation does not necessarily alter the results concerning the faunal resources procured for consumption by the site's occupants, unless rodents and small rabbits were a major food resource. Small vertebrates are often sensitive or restricted to specific climates or habitats, such as some insectivores and rodents, and the inability to recover specimens of small taxa precludes the possibility of paleoecological reconstruction at the site. 
TABLE 28. FAUNAL REMAINS FROM 41 BX 274

\begin{tabular}{|c|c|c|c|c|c|c|c|c|}
\hline Unit & Class & Order & Taxon & Quantity & $\operatorname{sid\theta }$ & Element & Part & Comments \\
\hline$B-11$ & Indeterminate & Indeterminate & Indeterminate & 1 & & Long bone, indeterminate & Dtaphyseal fragment & \\
\hline$B-11$ & Mamma Ira & Indeterminate & Medium/Large Mamma 1 & 4 & & Mamma 1 bone, fragment & $\begin{array}{l}\text { Unidentif fable bone } \\
\text { fragment }\end{array}$ & Burned \\
\hline$B-11$ & Mamma 1 1a & Indeterminate & Medium/Large Mammal & 19 & & Mammal bone, fragment & $\begin{array}{l}\text { Unidentifiable bone } \\
\text { fragment }\end{array}$ & \\
\hline $\begin{array}{l}B-11 \\
B-11\end{array}$ & $\begin{array}{l}\text { Mamnial1a } \\
\text { Aves }\end{array}$ & $\begin{array}{l}\text { Artiodactyla } \\
\text { Galliformes }\end{array}$ & $\begin{array}{l}\text { Caprine } \\
\text { cf. Gallus gallus }\end{array}$ & $\begin{array}{l}1 \\
1\end{array}$ & Right & $\begin{array}{l}\text { Tooth } \\
\text { Furculum }\end{array}$ & $\begin{array}{l}M_{1} \text { lower } \\
\text { Fragment }\end{array}$ & \\
\hline$B-14$ & Indeterminate & Indeterminate & Indeterminate & 5 & & Indeterm1 nate fragment & $\begin{array}{l}\text { Unidentifiable bone } \\
\text { fragment }\end{array}$ & \\
\hline$B-7 A$ & Mamma lía & Indeterminate & Medium/Large Mamma 7 & 11 & & Mammal bone, fragment & $\begin{array}{l}\text { Unidentiffable bone } \\
\text { fragment }\end{array}$ & Burned \\
\hline$B-7 A$ & Mamma 71 a & Indeterminate & Med Ium/Large Mammal & 16 & & Mammal bone, fragment & $\begin{array}{l}\text { Unidentiffable bone } \\
\text { fragment }\end{array}$ & \\
\hline$B-7 A$ & Mammalia & Artiodactyla & Bos taurus & 1 & & Tooth & Tooth fragment & In poor condition \\
\hline$B-7 A$ & Mamma lia & Artiodactyla & Caprine & 1 & Left & Astragulas & Entire bone & Cut mark \\
\hline$B-7 A$ & Aves & Galliformes & cf. Gallus gallus & $\tilde{l}$ & Right & Radius & Proximal epiphysis & \\
\hline$B-7 B$ & Indeterm1nate & Indeterminate & Indeterminate & 27 & & Indeterminate fragment & $\begin{array}{l}\text { Un } 1 \text { dentiffable bone } \\
\text { fragment }\end{array}$ & \\
\hline$B-7 B$ & Mammalta & Indeterminate & Medtum/Large Mammai & 35 & & Mammal bone, fragment & $\begin{array}{l}\text { Unidentifiable bone } \\
\text { fragment }\end{array}$ & \\
\hline$B-7 B$ & Mammalia & Artiodactyla & Bos taurus & 1 & & Sesamoid & Entire bone & \\
\hline$B-7 B$ & Mamma 7 la & Artfodactyla & Bos taurus & 1 & Left & Calcaneus & Entire bone & Weathered \\
\hline$B-7 B$ & Mammalfa & Artiodactyla & Caprine & 1 & Right & Astragulas & Entire bone & \\
\hline $\mathrm{B}-7 \mathrm{~B}$ & Mamma $11 \mathrm{a}$ & Artiodactyla & Caprine & 1 & Left & Humerus & Distal epiphysis & Possible cut/hack \\
\hline$B-7 B$ & Mammalia & Artlodactyla & Large Mamma] & 3 & & Tooth & Tooth fragment & \\
\hline$B-78$ & Mamma 1 i a & Artiodactyla & Med fum Mamma 1 & 2 & & Rib & Rib fragment. & \\
\hline$B-7 B$ & Mammalia & Artiodactyla & Medfum/Large Mamma 1 & 9 & & Mammal bone, fragment & $\begin{array}{l}\text { Unidentifiable bone } \\
\text { fragment }\end{array}$ & Burned \\
\hline$B-7 B$ & Osteichthyes & Indeterminate & Fish & 1 & & Indeterminate fragment & $\begin{array}{l}\text { Unidentifiable bone } \\
\text { fragment }\end{array}$ & \\
\hline$B-7 B$ & Reptifia & Testudines & Turtle & 1 & & Carapace fragment & $\begin{array}{l}\text { Unidentiffable bone } \\
\text { fragment }\end{array}$ & \\
\hline$c-10$ & Mammalia & Indeterminate & Large Mammal & 4 & & Mammal bone, fragment & $\begin{array}{l}\text { Unidentifiable bone } \\
\text { fragment }\end{array}$ & \\
\hline$C-10$ & Mamma 1 ia & Indeterminate & Medium/Large Mammal & 27 & & Mammal bone, fragment & $\begin{array}{l}\text { Unidentifiable bone } \\
\text { fragment }\end{array}$ & \\
\hline$c-10$ & Mammalfa & Indeterminate & Indeterminate & 11 & & Mammal bone, fragment & $\begin{array}{l}\text { Unidentifiable bone } \\
\text { fragment }\end{array}$ & Burned \\
\hline $\begin{array}{l}C-10 \\
C-5 / B-5\end{array}$ & $\begin{array}{l}\text { Mammalia } \\
\text { Mamma lia }\end{array}$ & $\begin{array}{l}\text { Artlodactyia } \\
\text { Indeterminate }\end{array}$ & $\begin{array}{l}\text { Bos taurus } \\
\text { Large Mamma } 7\end{array}$ & $\begin{array}{l}1 \\
1\end{array}$ & & $\begin{array}{l}\text { Phalange, fndeterminate } \\
\text { Mammal bone, fragment }\end{array}$ & $\begin{array}{l}\text { Distal epiphysis } \\
\text { Unfdentifiable bone } \\
\text { fragment }\end{array}$ & $\begin{array}{l}\text { Burned } \\
\text { Burned }\end{array}$ \\
\hline$c-6$ & Mamma 1 ia & Indeterminate & Medium/Large Mammal & 3 & & Mammal bone, fragment & $\begin{array}{l}\text { Unidentifiable bone } \\
\text { fragment }\end{array}$ & Burned \\
\hline
\end{tabular}


TABLE 28. (continued)

\begin{tabular}{|c|c|c|c|c|c|c|c|c|}
\hline Unit & Class & Order & Taxon & Quantity & Side & Element & Part & Comments \\
\hline $\mathrm{C}-6$ & Mamma lia & Indeterminate & Medium/Large Mammal & 24 & & Mammal bone, fragment & $\begin{array}{l}\text { Unidentifiable bone } \\
\text { fragment }\end{array}$ & \\
\hline$c-6$ & Osteichthyes & $\begin{array}{l}\text { Lep Isostei- } \\
\text { formes }\end{array}$ & Lepisosteus sp. & 3 & & Mandible & Body & Same individual \\
\hline$c-7$ & Mamma 11 a & Indeterminate & Medium/Large Mammal & 4 & & Mammal bone, fragment & $\begin{array}{l}\text { Unfdentiffable bone } \\
\text { fragment }\end{array}$ & Burned \\
\hline$c-7$ & Mamma $1 \mathrm{ia}$ & Indeterminate & Med tum/Large Mammat & 31 & & Mammal bone, fragment & $\begin{array}{l}\text { Unidentiffable bone } \\
\text { fragment }\end{array}$ & \\
\hline$c-7$ & Mammalia & Artiodactyla & Bos taurus & 1 & & Sesamold & Entire bone & Weathered \\
\hline $\mathrm{c}-7$ & Mammalia & Artlodactyla & Bos taurus & 1 & Left & Carpal & Entire bone & Weathered \\
\hline$c-7$ & Mammalfa & Artlodactyla & Sus scrofa & 1 & Right & Humerus & Distal epiphysis & Possible cut/hack \\
\hline$c-7$ & Mamma 1 ta & Artiodactyla & Caprine & 1 & Right & Tooth & $p^{4}$ upper & Deciduous \\
\hline$c-9$ & Indeterminate & Indeterminate & Indeterminate & i & & Long bone, indeterminate & Diaphyseal fragment & \\
\hline$c-9$ & Mamma lia & Indeterminate & Largo Mamma 1 & 6 & & Mamma 1 bone, fragment & $\begin{array}{l}\text { Unidentifiable bone } \\
\text { fragment }\end{array}$ & \\
\hline$c-9$ & Mamma11a & Indeterminate & Medium/Large Mammal & 18 & & Mammal bone, fragment & $\begin{array}{l}\text { Unidentifiable bone } \\
\text { fragment }\end{array}$ & Burned \\
\hline$c-9$ & Mammal la & Indeterminate & Medium/Large Mammal & 46 & & Mammal bone, fragment & $\begin{array}{l}\text { Unidentifiable bone } \\
\text { fragment }\end{array}$ & \\
\hline$C-9$ & Mammal la & Artiodactyla & Caprine & 1 & Right & Metatarsa 1 & Proximal epiphysis & \\
\hline$c-9$ & Mammalia & Artiodactyla & Med fum Mamma 1 & 3 & & Vertebrae, indeterminate & Fragment & \\
\hline$c-9$ & Mammal fa & Artlodactyla & Medium/Large Mammal & 10 & & Tooth & Tooth fragment & \\
\hline$c-9$ & Ostelchthyes & Indeterminate & Fish & 3 & & Vertebrae, indeterminate & Centrum broken & Same individual \\
\hline$c-9$ & Aves & Falconiformes & cf. Cathartes sp. & 1 & Right & Carpometacarpus & Fragment & \\
\hline $0-11$ & Mamma 1 la & Indeterminate & Med fum/Large Mamma 1 & 4 & & Mammal bone, fragment & $\begin{array}{l}\text { Unidentff lable bone } \\
\text { fragment }\end{array}$ & Burned \\
\hline$D-11$ & Mammalfa & Indeterminate & Medium/Large Mammal & 29 & & Mamma1 bone, fragment & $\begin{array}{l}\text { Unidentiffable bone } \\
\text { fragment }\end{array}$ & \\
\hline$D-11$ & Mammalia & Lagomorpha & Sylvilagus sp. & 1 & & Radius & Diaphyseal fragment & Rodent chewed \\
\hline$D-11$ & Mammalia & Lagomorpha & Sylvilagus sp. & 1 & Left & Mandible & Anterior half & \\
\hline$D-11$ & Mammal fa & Lagomorpha & Lepus cal Ifornicus & $i$ & Left & Pelvis & Innominate fragment & \\
\hline$D-11$ & Mammalla & Rodentia & Sigmodon hisplidus & 1 & Left & Mand tb $7 \theta$ & Anterfor half & \\
\hline D-11 & Marnmal fa & Rodentia & Rattus sp. & $i$ & Right & Tibia & Entire bone & \\
\hline D-11 & Mamma 1 ia & Carnivora & Canis sp. & 1 & Right & Metatarsal & Diaphysis & Rodent chewed \\
\hline $\mathrm{D}-11$ & Marmal la & Artiodactyla & Med 1um/Large Mammal & 2 & & Tooth & Tooth fragment & \\
\hline D-11 & Mammalfa & Artiodactyla & Medfum/Large Mamma 1 & 2 & & Rib & Rib fragment & \\
\hline$D-11$ & Rept111a & Testudines & Chelydra serpentina & I & & Carapace fragment & $\begin{array}{l}\text { Unidentiffable bone } \\
\text { fragment }\end{array}$ & Rodent chewed \\
\hline$D-6$ & Mammalia & Artiodactyla & Bos taurus & 1 & & Sesamold & Entire bone & \\
\hline$D-7$ & Mamma 11 a & Indeterminate & Large Mamma 1 & 4 & & Mammal bone, fragment & $\begin{array}{l}\text { Unidentifiable bone } \\
\text { fragment }\end{array}$ & Burned \\
\hline$D-7$ & Manmalia & Indeterminate & Medium/Large Mammal & 1 & & $R+b$ & Rib fragment & \\
\hline
\end{tabular}


TABLE 28. (continued)

\begin{tabular}{|c|c|c|c|c|c|c|c|c|}
\hline Unit & Class & Order & Taxon & Quantity & Side & Element & Part & Comments \\
\hline$D-7$ & Mammalta & Indeterminate & Medfum/Large Mammal & 23 & & Mammal bone, fragment & $\begin{array}{l}\text { Unidentiffable bone } \\
\text { fragment }\end{array}$ & \\
\hline$D-7$ & Aves & Indeterminate & Aves & 1 & & Indeterminate fragment & $\begin{array}{l}\text { Unidentifiable bone } \\
\text { fragment }\end{array}$ & \\
\hline $0-8$ & Indeterminate & Indeterminate & Indeterminate & 2 & & Indeterminate fragment & $\begin{array}{l}\text { Unidentif fable bone } \\
\text { fragment }\end{array}$ & \\
\hline$D-8$ & Mammal la & Indeterminate & Medium/Large Mammal & 13 & & Mammal bone, fragment & $\begin{array}{l}\text { Unfdentifiable bone } \\
\text { fragment }\end{array}$ & Burned \\
\hline $\mathrm{D}-8$ & Mamma7la & Indeterminate & Medium/Large Mammal & 97 & & Mamma7 bone, fragment & $\begin{array}{l}\text { Unidentiflable bone } \\
\text { fragment }\end{array}$ & \\
\hline$D-8$ & Mamma 11 a & Artiodactyla & Bos taurus & 5 & & Tooth & Molar, indeterminate & Same Individual \\
\hline $\begin{array}{l}\mathrm{D}-8 \\
\mathrm{D}-8\end{array}$ & $\begin{array}{l}\text { Mammalla } \\
\text { Mammalla }\end{array}$ & $\begin{array}{l}\text { Artiodactyla } \\
\text { Artiodactyla }\end{array}$ & $\begin{array}{l}\text { Bos taurus } \\
\text { Caprine }\end{array}$ & $\begin{array}{l}1 \\
1\end{array}$ & & $\begin{array}{l}\text { Rib } \\
\text { Tooth }\end{array}$ & $\begin{array}{l}\text { Rib fragment } \\
\text { Tooth fragment }\end{array}$ & Saw mark \\
\hline$D-8$ & Mamma 11 a & Artiodactyla & Caprine & 1 & Right & Humerus & Distal epiphysis & $\begin{array}{l}\text { Possible carnivore } \\
\text { puncture }\end{array}$ \\
\hline$D-8$ & Mammalia & Artlodactyla & Medfum Mammal & 2 & & Scapula & Spine fragment & \\
\hline$D-8$ & Mammalia & Artiodactyla & Medium/Large Mammal & 2 & Pelvis & Innominate fragment & & \\
\hline D-8 & Mammalia & Artiodactyla & Odocolleus sp. & 1 & Right & Tooth & Molar, indeterminate & \\
\hline $0-8$ & Osteichthyes & $\begin{array}{l}\text { Lep isoste1- } \\
\text { formes }\end{array}$ & Lepisosteus sp. & 2 & & Scale, fish & Entíre bone & \\
\hline$E-7$ & Mammalia & Indeterminate & Medfum/Large Mammal & 11 & & Mamma 1 bone, fragment & $\begin{array}{l}\text { Unidentifiable bone } \\
\text { fragment }\end{array}$ & Burned \\
\hline$E-7$ & Mammalta & Indeterminate & Medium/Large Mammal & 27 & & Mammal bone, fragment & $\begin{array}{l}\text { Unidentif } f \text { able bone } \\
\text { fragment }\end{array}$ & \\
\hline$E-7$ & Mammal la & Artiodactyla & Bos taurus & 1 & & Phalanx, proxtmal & Diaphysis & \\
\hline$E-7$ & Mamma $1 \mathrm{ia}$ & Artlodactyla & Medfum Mamma 1 & 1 & & Ulna & Proximal epiphysis & \\
\hline E-7 & Marnmal1a & Artiodactyla & Medfum Mammal & 1 & & Carpat & Fragment & \\
\hline$E-7$ & Manimalia & Artlodactyla & Odocolleus sp. & 1 & & Tooth & Indeterminate & \\
\hline$E-7$ & Osteich thyes & Indeterminato & Fish & 1 & & Indeterminate fragment & $\begin{array}{l}\text { Unidentiffable bone } \\
\text { fragment }\end{array}$ & \\
\hline$E-8$ & Indeterminate & Indeterminate & Indeterminate & 1 & & Indeterminate fragment & $\begin{array}{l}\text { Unidentff } f \text { able bone } \\
\text { fragment }\end{array}$ & \\
\hline $\begin{array}{l}E-8 \\
E-8\end{array}$ & $\begin{array}{l}\text { Mammal fa } \\
\text { Mamma lia }\end{array}$ & $\begin{array}{l}\text { Indeterminate } \\
\text { Indeterminate }\end{array}$ & $\begin{array}{l}\text { Medium Mamma\} } \\
\text { Medium/Large Mammal }\end{array}$ & $\begin{array}{r}3 \\
11\end{array}$ & & $\begin{array}{l}\text { Vertebrae, indeterminate } \\
\text { Mamma } 1 \text { bone, fragment }\end{array}$ & $\begin{array}{l}\text { Fragment of process } \\
\text { Unidentifiable bone } \\
\text { fragment }\end{array}$ & \\
\hline$E-8$ & Mammalia & Indeterminate & Indeterminate & 10 & & Mammal bone, fragment & $\begin{array}{l}\text { Unidentifiable bone } \\
\text { fragment }\end{array}$ & Burned \\
\hline$E-8$ & Mammaila & Indeterminate & Indeterminate & 55 & & Mammal bone, fragment & $\begin{array}{l}\text { Unidentiffable bone } \\
\text { fragment }\end{array}$ & \\
\hline$E-8$ & Marnma 71 a & Indetermfnate & Indeterminate & 11 & & Mammal bone, fragment & $\begin{array}{l}\text { Unidentifiable bone } \\
\text { fragment }\end{array}$ & Burned \\
\hline$E-8$ & Mamma Tla & Indeterminate & Indeterminate & 100 & & Mammal bone, fragment & $\begin{array}{l}\text { Unidentiflable bone } \\
\text { fragment }\end{array}$ & \\
\hline
\end{tabular}


TABLE 28. (continued)

\begin{tabular}{|c|c|c|c|c|c|c|c|c|}
\hline Unit & Class & Order & Taxon & Quantity & Side & Element & Part & Comments \\
\hline$E-8$ & Mamma $11 a$ & Artlodactyla & Bos taurus & 3 & & Tooth & Tooth fragment & \\
\hline$E-B$ & Manima 71 a & Artlodactyla & Bos taurus & 1 & & Rib & Rib fragment & Cut mark \\
\hline$E-8$ & Mammal ia & Artiodactyla & Bos taurus & 1 & & Phalange, proximal & Entire bone & \\
\hline$E-8$ & Mamma lla & Artiodactyla & Bos taurus & 1 & Right & Tibla & Proximal epiphysis & \\
\hline$E-8$ & Mamma 1 Ia & Artlodactyla & Caprine & 4 & & Tooth & Tooth fragment & \\
\hline$E-8$ & Mamma 71 a & Artiodactyla & Caprine & 1 & Right & Mand tble & Posterior half & \\
\hline$E-8$ & Mamma 7 ia & Artiodactyla & Caprine & 1 & Right & Tooth & Premolar, indeterminate & \\
\hline $\mathrm{E}-8$ & Mamma $11 \mathrm{a}$ & Artlodactyla & Caprine & 1 & Right & Tooth & $M^{2}$ upper & \\
\hline$E-8$ & Mamma $7 \mathrm{a}$ & Artiodactyla & Caprine & 1 & Right & Ulna & Proximal eptphysis & \\
\hline$E-8$ & Manma ila & Artiodactyla & Caprine & 1 & Right & Pelvis & Pubis & Saw mark \\
\hline$E-8$ & Mammal ia & Artiodactyla & Caprine & 1 & Right & Femur & Pubis & $\begin{array}{l}\text { Possible carnivore } \\
\text { puncture }\end{array}$ \\
\hline$E-8$ & Mamma 11a & Artiodactyla & Caprine & 1 & Left & Mand tble & Body & \\
\hline$E-8$ & Mamma $71 \mathrm{a}$ & Artlodactyla & Caprine & 1 & Left & Mand tble & Body & \\
\hline$E-8$ & Mamma 7 ia & Artiodactyla & Caprine & 1 & Left & Mand tble & Body & \\
\hline$E-B$ & Mamma 11 a & Artiodactyla & Caprine & 1 & Left & Mand tble & Posterior half & \\
\hline$E-8$ & Mamma $7 \mathrm{fa}$ & Artiodactyla & Caprine & 1 & Left & Mand tble & Mand fble condyle & Same individual \\
\hline$E-8$ & Mammal la & Artiodactyla & Caprine & 1 & Left & Tooth & $M_{2}$ lower & \\
\hline$E-8$ & Mammal fa & Artiodactyla & Caprine & 1 & Left & Radius & Dfaphysis & \\
\hline$E-8$ & Mammalia & Artiodactyla & Caprine & 1 & Left & Uina & Diaphyseal fragment & \\
\hline$E-8$ & Mammalia & Artiodactyla & Medlum Mammal & 3 & & Pelvis & Pubis & \\
\hline$E-8$ & Mamma 1 ia & Artiodactyla & Medium Mamma & 1 & & Vertebrae, indeterminate & Fragment of process & \\
\hline$E-8$ & Mammalia & Artfodactyla & Medium Mamma & 2 & & Thoracic vertebra & Complete & \\
\hline$E-B$ & Mamma lia & Artiodactyla & Medfum Mamma 1 & 1 & & $\mathrm{R} 1 \mathrm{~b}$ & Rib fragment & $\begin{array}{l}\text { Chop mark/ } \\
\text { carnivore gnaw }\end{array}$ \\
\hline$E-8$ & Manma 71 a & Artiodactyla & Medium Mamma1 & 5 & & Rib & Rib fragment & Cut mark \\
\hline$E-8$ & Mamma lia & Artiodactyla & Medlum/Large Mamma 7 & 2 & & Rib & Rib fragment & \\
\hline$E-8$ & Mammalia & Artiodactyla & Medium/Large Mammal & 8 & & Tooth & Tooth fragment & \\
\hline$E-8$ & Osteichthyes & Indeterminate & Fish & 1 & & Vertebrae, indeterminate & Centrum & \\
\hline$E-8$ & Osteichthyes & Indeterminate & Fish & 2 & & Indeterminate fragment & $\begin{array}{l}\text { Unidentifiable bone } \\
\text { fragment }\end{array}$ & \\
\hline$E-8$ & Aves & Indeterminate & Aves & 1 & & Phalanx, Indeterminate & Distal epiphysis & Large individual \\
\hline$E-8$ & Aves & Galliformes & cf. Gallus gallus & 1 & & Tarsometatarsus & Spur & \\
\hline$E-8$ & Aves & Galliformes & cf. Meleagris gallopavo & 101 & & Radius & Diaphysear fragment & \\
\hline$E-8$ & Reptilia & Testudines & Trionyx sp. & 1 & & Pelvis & Pubis & Large individual \\
\hline$E-8$ & Reptilla & Testudines & Trtonyx sp. & 1 & & Carapace fragment & $\begin{array}{l}\text { Unidentifiable bone } \\
\text { fragment }\end{array}$ & \\
\hline$F-11$ & Mamma 7 ia & Indeterminate & Indeterminate & 4 & & Mammal bone, fragment & $\begin{array}{l}\text { Unidentifiable bone } \\
\text { fragment }\end{array}$ & Burned \\
\hline$F-11$ & Mamma 1 la & Indeterminate & Indeterminate & 6 & & Mammal bone, fragment & $\begin{array}{l}\text { Unidentif iable bone } \\
\text { fragment }\end{array}$ & \\
\hline$F-11$ & Mamnalia & Artiodactyla & Medtum/Large Mammal & 2 & & Tooth & $\begin{array}{l}\text { Tooth fragment } \\
\text { fragment }\end{array}$ & \\
\hline
\end{tabular}


TABLE 28. (continued)

\begin{tabular}{|c|c|c|c|c|c|c|c|c|}
\hline Unit & Class & Order & Taxon & Quantity & $\operatorname{sid} \theta$ & Element & Part & Comments \\
\hline \multicolumn{9}{|l|}{ Shovel } \\
\hline Test 1 & Mamma 1 ia & Indeterminate & Indeterminate & 8 & & Mamma I bone, fragment & $\begin{array}{l}\text { Unfdentifiable bone } \\
\text { fragment }\end{array}$ & \\
\hline Shove 1 & & & & & & & & \\
\hline $\begin{array}{l}\text { Test } 1 \\
\text { Shovel }\end{array}$ & Mammalta & Indeterminate & Indeterminate & 99 & & Mamma l bone, fragment & $\begin{array}{l}\text { Unidentifiable bone } \\
\text { fragment }\end{array}$ & \\
\hline Test i & Mamma lía & Artiodactyla & Bos taurus & 1 & & Sku17 & $\begin{array}{l}\text { Skuj fragment } \\
\text { indeterminate }\end{array}$ & \\
\hline $\begin{array}{l}\text { Shove } 1 \\
\text { Test 1 } \\
\text { Shove 1 }\end{array}$ & Mamma lia & Artiodactyla & Bos taurus & I & Left & Tooth & Incisor, lower & \\
\hline $\begin{array}{l}\text { Test } 1 \\
\text { Shove1 }\end{array}$ & Mamma 1 i a & Artiodactyla & Sus scrofa & 1 & Right & Tooth & Incisor, lower & \\
\hline $\begin{array}{l}\text { Test } 1 \\
\text { Shove1 }\end{array}$ & Mammalia & Artiodactyla & Med fum Mamma ] & 1 & & Scapula & Spine fragment & \\
\hline $\begin{array}{l}\text { Test } 1 \\
\text { Shove } 1\end{array}$ & Mammatia & Artiodactyla & Medfum/Large Mamma 1 & 2 & & Tooth & Tooth fragment & \\
\hline $\begin{array}{l}\text { Test } 1 \\
\text { Shovel }\end{array}$ & Mamma 1 ia & Artiodactyla & Medfum/Large Mamma 1 & 1 & & Long bone, indeterminate & Diaphyseal fragment & \\
\hline Test 2 & Mammalia & IndetermInate & Medfum/Large Mamma 1 & 3 & & Mamima 1 bone, fragment & $\begin{array}{l}\text { Unfdentifiable bone } \\
\text { fragment }\end{array}$ & Burned \\
\hline $\begin{array}{l}\text { Shovel } \\
\text { Test } 2\end{array}$ & Mamma li a & Indeterminate & Medfum/Large Mamma 7 & 28 & & Mamma 1 bone, fragment & $\begin{array}{l}\text { Unidentifiable bone } \\
\text { fragment }\end{array}$ & \\
\hline $\begin{array}{l}\text { Shove } 1 \\
\text { Test } 2 \\
\text { Shovel }\end{array}$ & Mamma lia & Artiodactyla & Caprine & 1 & Left & Mand ible & Posterior half & \\
\hline $\begin{array}{l}\text { Test } 2 \\
\text { Shovel }\end{array}$ & Manimalia & Artiodactyla & Large Mamma 1 & 4 & & Rib & Rib fragment & \\
\hline $\begin{array}{l}\text { Test } 2 \\
\text { Shovel }\end{array}$ & Mamma 11 a & Artfodactyla & Medfum Mamma 1 & 3 & & Rib & Rib fragment & \\
\hline Test 2 & Aves & GaTliformes & cf. Gallus gallus & 1 & & FurcuTum & Fragment & \\
\hline $3-A$ & Marmalia & Indeterminate & Large mammal & 2 & & $\mathrm{R} F \mathrm{~b}$ & Rib fragment & \\
\hline $3-A$ & Mammalia & Indeterminate & Medium Mammal & 2 & & Rib & Rib fragment & \\
\hline $3-A$ & Manmal fa & Indeterminate & Medium/Large Mammal & 2 & & Mammal bone, fragment & & Burned \\
\hline $3-A$ & Mammalia & Indeterminate & Med ium/Large Mamma 1 & 7 & & Mamma 1 bone, fragment & & \\
\hline $3-A$ & Mammalia & Artiodactyla & Bos taurus & 1 & Right & Tooth & Inctsor, Tower & \\
\hline $3-A$ & Mammalia & Artiodactyla & Bos taurus & 1 & Right & Tooth & $M_{2}$ lower & \\
\hline $3-A$ & Mammal ia & Artiodactyla & Bos taurus & 1 & Left & Tooth & $M_{3}^{2}$ lower & \\
\hline $3-A$ & Aves & Indeterminate & Aves & $i$ & & Long bone, Indeterminate & Dfaphyseal fragment & \\
\hline
\end{tabular}




\section{THE FAUNAL SAMPLE}

A total of 1017 vertebrate bone fragments was recovered from the excavations of the historic component at 41 BX 274 . The weight of the faunal sample is $1381.8 \mathrm{~g}$. All of the faunal remains were examined and identified to the closest taxonomic level, which ideally is to species. Twenty-two taxa have been identified from this material, including identification to species, genus, and grosser categories such as order, class, and generalized groupings (e.g., "medium mammal," etc.). Table 29 provides data on the identified taxa and the frequencies and percentages of the faunal remains.

Both domestic and native species were identified from the 41 BX 274 faunal sample. Of these 22 taxa, four are domestic animals, including three mammals and one bird; ten are native animals, including four mammals, two fish, three turtles, and one bird; the remaining eight taxa represent generalized categories, and the specimens placed in them could represent either native or domestic forms, including mammals and birds.

\section{DIETARY AND BUTCHERING PRACTICES}

of the 22 taxa identified from the 41 BX 274 faunal remains, four categories were probabiy not present as food items: the dog (Canis sp.), the hispid cotton rat (Sigmodon hispidus), the old world rat (Rattus sp.), and the vulture (Cathartes sp.). It is very probable that the bone from the remaining categories were present at the site as food refuse, possibly excepting specimens placed within such a broad taxa as Class Indeterminate.

Historic records concerning $41 \mathrm{BX} 274$ indicate that many cattle, sheep, and possibly goats were raised by the occupants. Undoubtedly, many of these animals were raised for sale elsewhere; however, it is reasonable to assume that these animals also were consumed by the site's occupants. Very few pig bones were recovered from the faunal sample, suggesting that they may not have been raised for sale like the cattle and sheep. The small proportion of species of wild animals such as deer, rabbit, fish, and turtle indicates that these animals played a supplementary role in the inhabitant's diets.

Very little evidence of butchery, such as cut marks or saw or hack marks, was found on the bones of the faunal sample. All of the taxa with such evidence are domesticates or of the medium mammal category which probably consists mostly of caprines or pigs. There is too little bone with butchery marks to provide information on the butchering practices of the people of the site.

As mentioned previously, there is a possibility that some aboriginal people lived at or near $41 \mathrm{BX} 274$. It is impossible to determine, however, if the Spanish occupants and these people had the same or a different diet based on the current faunal sample.

\section{TAPHONOMY}

of 1017 bone fragments, 76 could be identified to genus (7.5\%). Much of the bone from this site is very comminuted and cannot be identified beyond the 
TABLE 29. FREQUENCIES AND PERCENTAGES OF THE TAXA FROM 41 BX 274

\begin{tabular}{|c|c|c|c|}
\hline Class & Taxon & Number & Percentage \\
\hline Indeterminate & Indeterminate & 37 & 3.6 \\
\hline Mammalia & $\begin{array}{l}\text { Indeterminate } \\
\text { Large mammal } \\
\text { Medium mammal } \\
\text { Medium/large mammal } \\
\text { Bos taurus } \\
\text { Sus scrofa } \\
\text { Caprine } \\
\text { Odocoileus sp. } \\
\text { Sylvilagus sp. } \\
\text { Lepus ca Tifornicus } \\
\text { Sigmodon hispidus } \\
\text { Canis sp. } \\
\text { Rattus sp. }\end{array}$ & $\begin{array}{r}304 \\
24 \\
30 \\
534 \\
25 \\
2 \\
27 \\
2 \\
2 \\
1 \\
1 \\
1 \\
1\end{array}$ & $\begin{array}{r}29.9 \\
2.4 \\
2.9 \\
52.5 \\
2.5 \\
0.2 \\
2.7 \\
0.2 \\
0.2 \\
0.1 \\
0.1 \\
0.1 \\
0.1\end{array}$ \\
\hline Aves & $\begin{array}{l}\text { Indeterminate } \\
\text { cf. Ga17us ga11us } \\
\text { cf. Cathartes sp. } \\
\text { cf. Meleagris gailopavo }\end{array}$ & $\begin{array}{l}3 \\
4 \\
1 \\
1\end{array}$ & $\begin{array}{l}0.3 \\
0.4 \\
0.1 \\
0.1\end{array}$ \\
\hline Osteichthyes & $\begin{array}{l}\text { Indeterminate } \\
\text { Lepisosteus } \mathrm{sp} .\end{array}$ & $\begin{array}{l}8 \\
5\end{array}$ & $\begin{array}{l}0.8 \\
0.5\end{array}$ \\
\hline Reptilia & $\begin{array}{l}\text { Turtle--Indeterminate } \\
\text { Chelydra serpentina } \\
\text { Trionyx spinniferus }\end{array}$ & $\begin{array}{l}1 \\
1 \\
2\end{array}$ & $\begin{array}{l}0.1 \\
0.1 \\
0.2\end{array}$ \\
\hline Total & & 1017 & 100.0 \\
\hline
\end{tabular}

level of class $(88.9 \%)$. This poor condition could be due to one or more factors: (1) the site was farmed when the Pérez family owned the 1and, and for an unknown length of time afterward; (2) humans break, hack, cut, and otherwise destroy bone while processing animals for food or other reasons; (3) other animals may gnaw bone; and (4) environmental weathering wears down and alters bone through time. 
Farming methods such as tilling and plowing severely disturb the ground to a depth of several inches. In addition, planting can cause damage to bone. The action of the roots and fertilization during growth can etch and break bone. Over a considerable length of time, this land was used for farming, and severe damage to bone due to these conditions could have occurred.

The largest group of identifiable remains belongs to the caprines and to Bos taurus (68.4\% of bone identified to genus), and $11.5 \%$ of the bone fragments of these domesticates shows evidence of human modification by either hacking, cutting, or sawing (Table 30). This sample is too small to make any conclusions about butchery patterns, but the elements with modifications are ones that are commonly disarticulated by humans while butchering animals. Additionally, one humerus fragment identifiable to Sus scrofa shows evidence of cutting or hacking marks, as do three of the medium mammal fragments.

A sma11 percentage, $0.7 \%$, of a11 the bone showed evidence of either rodent or carnivore gnawing (Table 30). Only three of the recovered bones are identified as being rodents or carnivores. This low number could be due to the disturbance of the site because of farming, or because of the recovery methods used.

The vast majority of burned bone cannot be identified past the level of class. Of the entire assemblage, $12.2 \%$ is burned to some degree. The cause of this burning is unknown, and could be attributable to humans or to nature. Consequently, the significance of this cannot be determined.

It is evident that the distribution of bone across the site is quite uneven, when examining the frequency, weight, and average weight of the bone by excavation unit. This information is provided in Table 31, where the average weight of the bone recovered ranges from $0.2 \mathrm{~g}$ in Unit B-14 to $7.0 \mathrm{~g}$ in Units $C-5 / B-5$, while the frequency of bone ranges from one specimen in Units $C-5 / B-$ 5 and $D-6$ to 245 specimens in Unit E-8. It should be noted that Units $B$ through $F$ are $50 \mathrm{~cm}^{2}$ in size and excavated to a varied depth, while Test Unit 1, Shovel Test 2, and Unit 3-A varied in size and depth.

\section{COMPARISON OF THE FAUNAL REMAINS FROM 41 BX 274 AND RANCHO DE LAS CABRAS}

Rancho de las Cabras, Wilson County, Texas, is another archaeological site representing a Spanish frontier ranching complex. Both the variety of taxa found and the skeletal elements of the most numerous domestic animals, the cows and caprines, from 41 BX 274 and Rancho de las Cabras will be compared. A11 of the information on Rancho de 1 as Cabras was taken from the faunal analysis of that site by Steele and DeMarcay (1985).

The taxa frequency data for the two sites are provided in Table 32 . The only information for the 1982 Rancho de 1 as Cabras excavation is given as presence/absence in Steele and DeMarcay (1985), allowing for very 1 imited interpretation of the data from that season. Among the mammals, the domestic taxa are represented at both sites with the caprines present in much higher quantity at Rancho de las Cabras. No horse bone was found at $41 \mathrm{BX} 274$, although historic records document their presence at the ranch. From the number of bones present, it appears that caprines played a more prominent 
TABLE 30. EVIDENCE OF MODIFICATIONS FOUND ON THE TAXA

\begin{tabular}{|c|c|c|c|c|c|c|c|c|}
\hline Taxa & Burned & $\begin{array}{l}\text { Cutt } \\
\text { Mark }\end{array}$ & $\begin{array}{l}\text { Possibly Cut } \\
\text { or Hacked }\end{array}$ & $\begin{array}{l}\text { Chop } \\
\text { Mark }\end{array}$ & $\begin{array}{l}\text { Saw } \\
\text { Mark }\end{array}$ & $\begin{array}{l}\text { Rodent } \\
\text { Chewed }\end{array}$ & $\begin{array}{l}\text { Carnivore } \\
\text { Chewed }\end{array}$ & Weathered \\
\hline $\begin{array}{l}\text { Class Mammalia } \\
\text { Medium Mamma } 7 \\
\text { Medium/Large Mammal } \\
\text { Large Mamma } 1 \\
\text { Indeterminate Mammal } \\
\text { Bos taurus } \\
\text { Caprine } \\
\text { Sus scrofa } \\
\text { Canis sp. } \\
\text { Sylvilagus sp. }\end{array}$ & $\begin{array}{r}82 \\
5 \\
36 \\
1\end{array}$ & $\begin{array}{l}1 \\
1\end{array}$ & $\begin{array}{l}1 \\
1\end{array}$ & 2 & $\begin{array}{l}1 \\
1\end{array}$ & $\begin{array}{l}1 \\
1\end{array}$ & 2 & 3 \\
\hline $\begin{array}{l}\text { Class Reptilia } \\
\text { Chelydra serpentina }\end{array}$ & & & & & & & 1 & \\
\hline
\end{tabular}


TABLE 31. THE FREQUENCY, WEIGHT IN GRAMS, AND AVERAGE SPECIMEN WEIGHT BY UNIT OF THE FAUNAL REMAINS

\begin{tabular}{lrrr}
\hline Unit & Frequency & Weight $(\mathrm{g})$ & $\begin{array}{c}\text { Average } \\
\text { Weight }(\mathrm{g})^{*}\end{array}$ \\
\hline B-7A & & & 1.3 \\
B-7B & 30 & 40.1 & 2.6 \\
B-11 & 82 & 212.1 & 0.9 \\
B-14 & 26 & 24.0 & 0.2 \\
C-5/B-5 & 5 & 1.0 & 7.0 \\
C-6 & 1 & 7.0 & 0.8 \\
C-7 & 30 & 25.4 & 1.1 \\
C-9 & 39 & 44.7 & 0.5 \\
C-10 & 89 & 44.7 & 1.6 \\
D-6 & 43 & 66.8 & 0.9 \\
D-7 & 1 & 3.4 & 1.2 \\
D-8 & 29 & 26.6 & 1.0 \\
D-11 & 127 & 150.0 & 1.8 \\
E-7 & 44 & 42.6 & 1.8 \\
E-8 & 43 & 79.0 & 0.9 \\
F-11 & 245 & 433.4 & 3.3 \\
3-A Unit 1 & 12 & 10.9 & 0.8 \\
Test Unit & 17 & 56.9 & 0.6 \\
Shove1 Test 2 & 114 & 89.3 & \\
& 40 & 23.9 & \\
\hline
\end{tabular}

*Average weight is obtained by dividing the weight of bone per unit by the frequency of bone in the unit.

role than cow did in the diet of the Rancho de las Cabras occupants; however, it must be kept in mind that a cow carcass would provide considerably more edible meat than a sheep or goat. The frequency of cow and caprine bone present at $41 \mathrm{BX} 274$ is more even, and the majority of bone placed in the medium, large, and medium/large mammal categories probably was from cows and caprines but they were too fragmented for positive identification.

The other two domesticates present at both sites are the pig and probably domestic dog (Canis sp.). These canid specimens could also represent coyotes or wolves but since there are so few specimens, it is not possible to make such a determination.

Rodent disturbance in the form of rodent bones recovered from the sample is much more prevalent at Rancho de las Cabras than at 41 BX 274 . The remainder of the mammals occurring at both sites are present with only a few specimens per taxa. 
In the fish class, a very high number of catfish bones (Ictalurus sp.) and indeterminate fish bones were recovered at Rancho de las Cabras in comparison to the few gar (Lepisosteus sp.) and the indeterminate fish bones found at 41 BX 274. Three possible reasons for this difference are the residents of Rancho de las Cabras had a much higher preference for fish than the residents of 41 BX 274, or there was poorer fishing along the waterways of the 41 BX 274 ranch, or the preservation of fish remains at 41 BX 274 may be much poorer than at Rancho de las Cabras.

Very few bird bones were recovered from either site, possibly due to poor preservation of these relatively fragile bones. Turkey and chicken are present at both sites; however, the specimens representing the turkey could not be separated as to domestic form or wild native form. Vulture specimens are present in both of the samples also. This bird is a common scavenger in many areas of Texas, and it is very doubtful that they represent a food item at either site.

The only reptile common to both sites are aquatic turtles. All of these animals are present in small quantities, indicating that although they could have been consumed by the site's occupants, they played a limited role in their diets.

Comparison of the cow and caprine skeletal elements may provide information on the differences or similarities in the role of these domesticates in the diets of the 41 BX 274 ranch inhabitants and the Rancho de 7 as Cabras inhabitants. The cow and caprine skeletal elements from the two sites are compared in Table 33.

When examining the cow skeletal elements found at 41 BX 274 and Rancho de las Cabras, the common elements include the loose teeth, rib fragments, carpals, and phalanges, or four of the twelve cow elements found at both sites. It is not surprising to find loose teeth at both sites because teeth tend to survive better than the other skeletal remains. There is less of a variety of cow skeletal elements found at 41 BX 274 when compared to skeletal elements found at Rancho de las Cabras, although neither site has a large quantity of cow bones present.

The majority of cow elements present at 41 BX 274 represent cranial fragments, and distal limb elements such as a carpal, calcanei, sesamoids, and phalanges. These skeletal elements tend to be butchering waste materials, therefore indicating that the animals were butchered at the site area where the bones were discarded. The remaining cow elements found at 41 BX 274 which would be meat-bearing are a tibia and rib fragments. With so 1ittle information about the meat-bearing bones found at $41 \mathrm{BX} 274$, it is not possible to discuss exactly how important beef was in the diet of the site's occupants. It is possible that the majority of the cow carcasses were taken elsewhere after the cows were killed and the heads and feet were removed. In addition, the lack of major cow skeletal elements at 41 BX 274 may have been caused by the removal of the bones from the cuts of meat, with disposal of the bones occurring elsewhere. 
TABLE 32. COMPARISON OF THE TAXA FOUND AT 41 BX 274 AND RANCHO DE LAS CABRAS

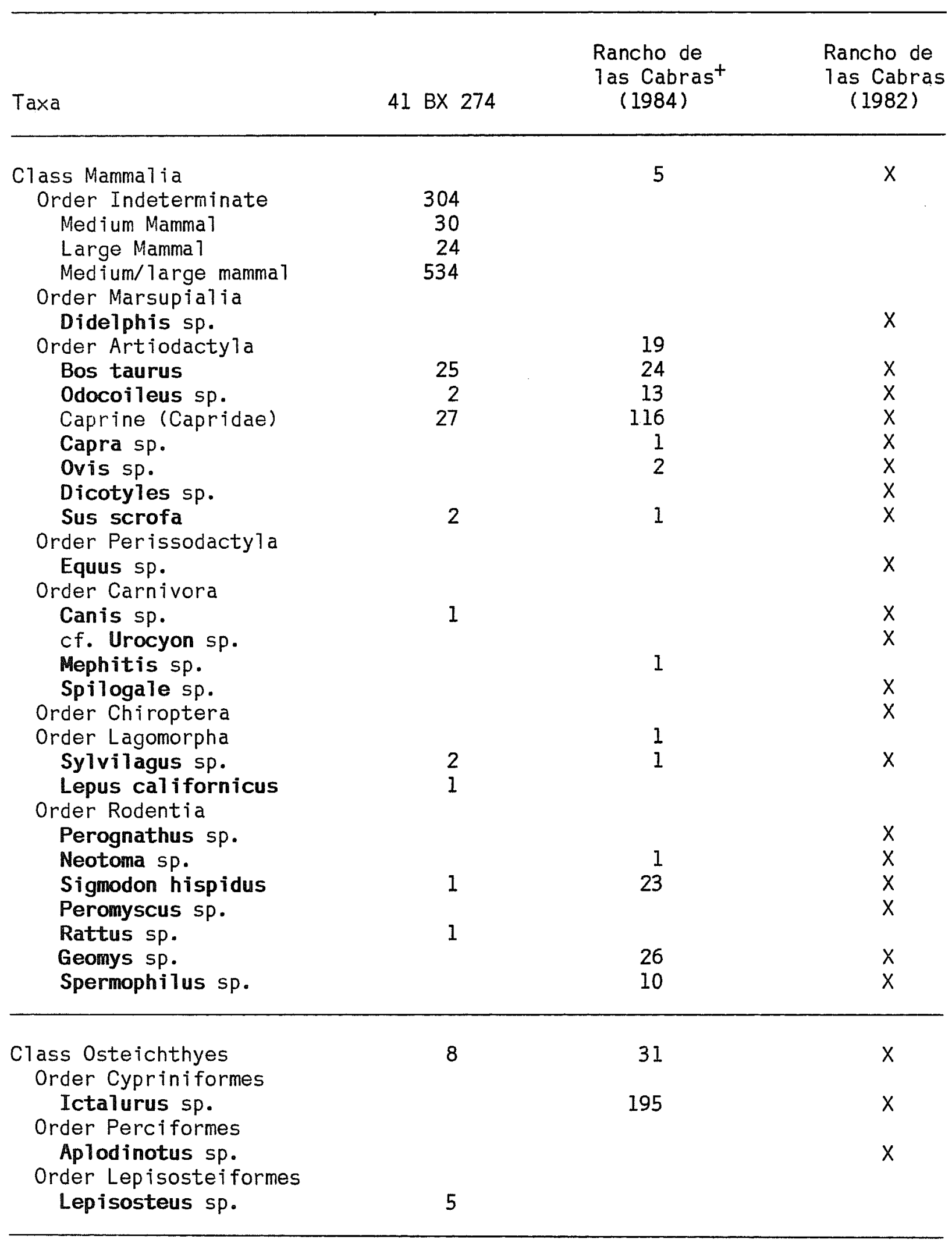


TABLE 32. (continued)

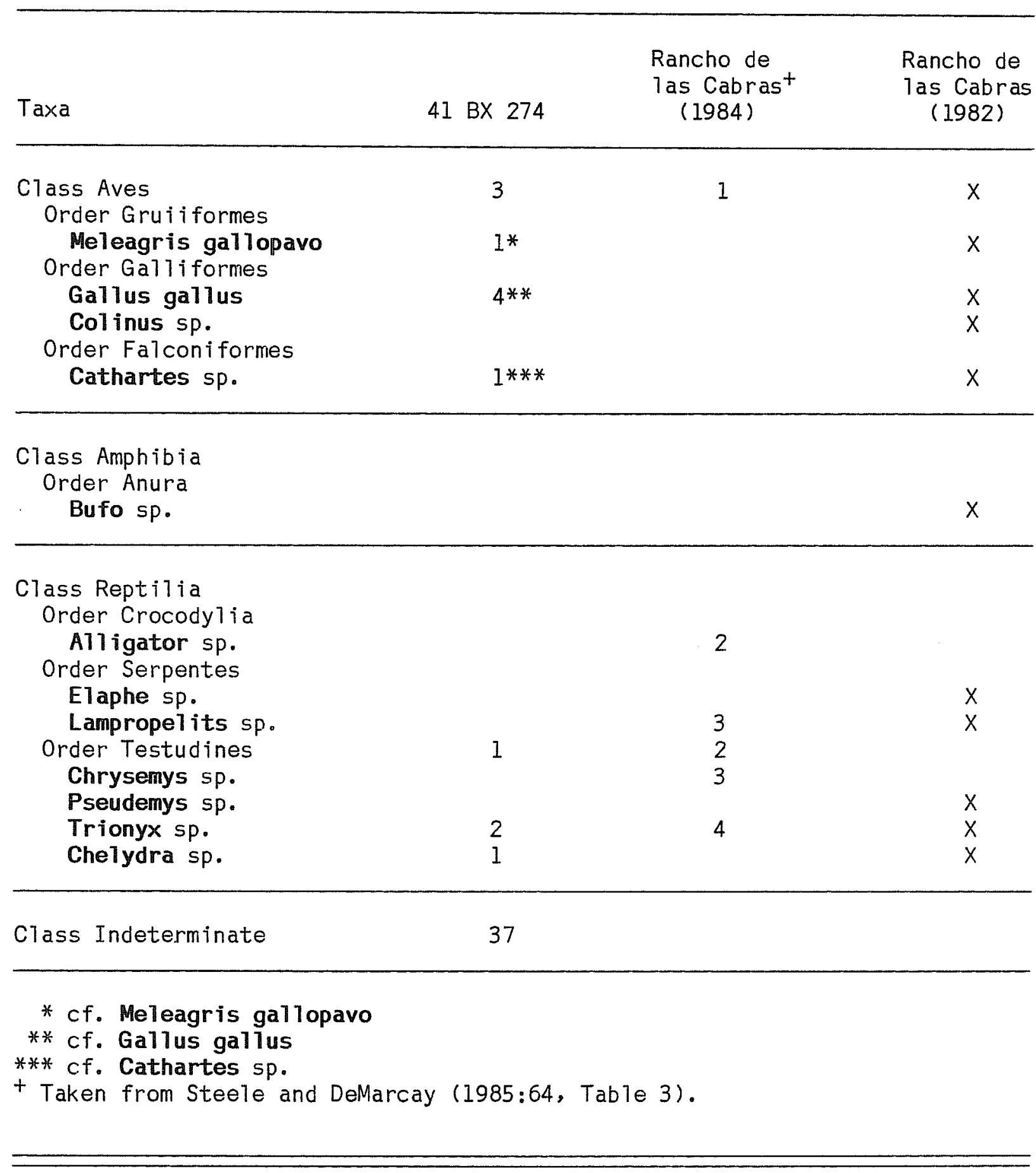


TABLE 33. COMPARISON OF THE 41 BX 274 AND RANCHO DE LAS CABRAS BOS AND CAPRINE ELEMENTS

\begin{tabular}{|c|c|c|c|c|}
\hline \multirow[b]{2}{*}{ Element } & \multicolumn{2}{|c|}{ Bos } & \multicolumn{2}{|c|}{ Caprine } \\
\hline & 41 BX 274 & $\begin{array}{l}\text { Rancho de } \\
\text { las Cabras* }\end{array}$ & 41 BX 274 & $\begin{array}{l}\text { Rancho de } \\
\text { las Cabras* }\end{array}$ \\
\hline Cranial & 1 & & & \\
\hline Mandible & & & 6 & 1 \\
\hline Teeth & 13 & 5 & 10 & 7 \\
\hline Cervical vertebra & & 1 & & 5 \\
\hline Thoracic vertebra & & 2 & & 5 \\
\hline Ribs & 2 & 6 & & 8 \\
\hline Scapula & & 1 & & \\
\hline Humerus & & & 2 & \\
\hline Radius & & 2 & 1 & 3 \\
\hline UIna & & & 2 & \\
\hline Carpals & 1 & 1 & & \\
\hline Pelvis & & & 2 & \\
\hline Femur & & & 1 & \\
\hline Tibia & 1 & & & 1 \\
\hline Metatarsal & & & 1 & 3 \\
\hline Sesamoid & 3 & & & \\
\hline Astragalus & & 1 & 2 & 1 \\
\hline Calcaneus & 2 & & & \\
\hline Phal anges & 2 & 2 & & 19 \\
\hline
\end{tabular}

*The information for this table was taken from Steele and DeMarcay (1985:67, Table 5), and is for the 1984 season only.

A wider variety of cow skeletal elements was found at Rancho de las Cabras, where butchering waste bones are present, as well as meat-bearing bones. Only a scapula, ribs, vertebrae, and radii represent the meat-bearing bones, providing little information about the dietary preference for beef at Rancho de las Cabras. Perhaps the situations suggested for the lack of cow bones at 41 BX 274 existed at this site also.

When comparing the caprine skeletal elements, only the mandibles, loose teeth, radius, metatarsal, and astragalus categories are represented at both sites. The caprine bones present at $41 \mathrm{BX} 274$, but not at Rancho de 1 as Cabras, include the humerus, ulna, femur, and pelvis categories; while elements present at Rancho de 1 as Cabras, but not at 41 BX 274, are cervical and thoracic vertebrae, ribs, tibia, and phalange categories (see Table 33). 
Both cranial and distal limb elements are present at both sites, indicating that butchering of the caprines occurred 10cally. In addition, meat-bearing bones were present at both sites.

At Rancho de Tas Cabras, it has been suggested by Steele and DeMarcay (1985) that the age of slaughter for both the cows and caprines was during the subadult stage where complete fusion of the long bones has not occurred. It appears that the same situation occurred at 41 BX 274 where slaughter of the cows and caprines tended to occur when the animals were younger, more tender animals. This idea needs to be further substantiated by a larger sample of faunal remains from the site, however.

The faunal remains recovered from 41 BX 274 and from Rancho de 1 as Cabras were badly broken. At 41 BX 274, 588 specimens were placed into the 1 arge, medium, and medium/large mammal categories, although the majority of these bones are probably cow or caprine, but are too fragmented for positive identification. This overly efficient reduction of the bones by the original inhabitants plus the ensuing reduction of the bone by carnivores, rodents, and other taphonomic agents has greatly reduced our ability to determine data such as dietary habits and food preference, butchering patterns, and the age and sex profiles of the slaughtered animals.

\section{DESCRIPTION OF TAXA}

The following presents a description by taxon of the faunal remains recovered from 41 BX 274. A 7isting of the provenience of each element recovered and its condition is provided. Also included is information for interpreting environmental indications and human behavior. Classification of the fishes follows Blair et a1. (1968). Classification of the reptiles follows Conant (1975). Robbins, Brunn, and Zim (1966) was followed for the birds, and classification for the mammals follows Davis (1974).

PHYLUM: Chordata

SUBPHYLUM: Vertebrata

CLASS: Indeterminate

Referred Material: Material consists of all vertebrate remains that could not be identified to more specific taxonomic categories. Specimens include both unidentifiable bone fragments and diaphyseal fragments of long bones.

Tota1: 37

Horizonta1 Distribution: Units B-7B, B-11, B-14, C-9, D-8, and E-8. 


\section{CLASS: Mammalia}

ORDER: Indeterminate

Referred Material: Material consists of unidentifiable bone fragments representing medium and large-sized mammals as well as rib and vertebral fragments. The medium mammal category would include remains of animals such as carnivores, deer, caprines, and pigs, while the large mammal category would include the specimens that are cow and horse sized. Those specimens that cannot be determined to be only large or medium were placed in the medium/large mammal group.

Total: 892

Horizontal Distribution: A11 units.

ORDER: Artiodactyla

FAMILY: Bovidae

GENUS-SPECIES: Bos taurus (cattle)

Referred Material: Material consists of one skull fragment, nine tooth fragments, two lower incisors, one $M_{2}$, one $M_{3}$, two rib fragments, one tibia fragment, three sesamoids, one proximal phalange, one indeterminate phalange fragment, two calcanei, and one carpal.

\section{Total: 25}

Horizontal Distribution: Units B-7A, B-7B, C-7, C-10, D-6, D8, E-7, E-8, 3-A, and Test Unit 1.

Remarks: Although bison and cattle bones are too similar to differentiate morphologically from the historic context of this site, we can assume the material is cattle. Bos taurus is a valuable domesticate with many uses: labor, dairy products, food resource, fertilizer source, and a source of leather.

GENUS: Capra and Ovis (sheep and goats)

Referred Material: Material consists of six mandible fragments, five tooth fragments, one indeterminate premolar, one $P^{4}$, one $M^{2}$, one $M_{1}$, one $M_{2}$, two humeri epiphyses, one radius diaphysis, two ulna fragments, two innominate fragments, one femur fragment, one metatarsal fragment, and two astragali.

Total: 27. 
Horizontal Distribution: Units B-7A, B-7B, B-11, C-7, D-8, E8, and Shovel Test 2.

Remarks: With a small comminuted sample, the bones of the caprines are hard to distinguish from one another. Sheep and goats are valuable food resources and also produce wool and dairy products.

GENUS-SPECIES: Sus scrofa ( $p i g$ )

Referred Material: Material consists of one lower incisor and one humerus epiphysis.

Total: 2

Horizontal Distribution: Unit C-7 and Shovel Test 1.

Remarks: Pigs are another valuable domesticate, providing food, leather, and fat for use as 1ard, tallow, and soap.

FAMILY: Cervidae

GENUS-SPECIES: Odocoileus sp. (deer)

Referred Materia1: Material consists of two teeth fragments.

Total: 2.

Horizontal Distribution: Units D-8 and E-7.

Remarks: Deer are native species and are widely distributed across North America. They tend to prefer the edge of forest/wooded habitats.

ORDER: Carnivora

FAMILY: Canidae

GENUS-SPECIES: Canis sp. (coyotes, wotves, and dogs)

Referred Material: Material consists of the diaphys is of a rodent-chewed right metatarsal.

Total: 1 .

Horizontal Distribution: Unit D-11.

Remarks: Coyotes, wolves, and dogs were probably al1 in the region throughout the occupation of the site. 
ORDER: Lagomorpha

FAMILY: Leporidae

GENUS-SPECIES: Sylvilagus sp. (cottontail rabbit)

Referred Material: Material consists of a rodent-chewed radius fragment and the anterior half of a left mandible.

Total: 2 .

Horizontal Distribution: Unit D-11.

Remarks: Sylvilagus floridanus, the eastern cottontail rabbit and S. aquaticus, the swamp rabbit, are sympatric in this region, but because of the large size difference between the two, these fragments are more than likely those of the eastern cottontail rabbit. This lagomorph prefers brushland and marginal areas such as abandoned fields (Davis 1974).

GENUS-SPECIES: Lepus californicus (black-tailed jackrabbit)

Referred Material: Material consists of an innominate fragment.

Tota7: 1 .

Horizontal Distribution: Unit D-11.

Remarks: The black-tailed jackrabbit is common throughout a11 of Texas except the eastern portion. This jackrabbit prefers thinly vegetated areas such as overgrazed pastures (Davis 1974).

ORDER: Rodentia

FAMILY: Muridae

GENUS-SPECIES: Sigmodon hispidus (hispid cotton rat)

Referred Material: Material consists of the anterior half of a left mandible.

Tota $: 1$

Horizontal Distribution: Unit D-11.

Remarks: This, the most common species of the genus Sigmodon is ubiquitous throughout the state, consequently it is of little use in reconstructing environmental conditions. 
GENUS-SPECIES: Rattus sp. (01d World rat)

Referred Material: Material consists of an entire right tibia.

Total: 1 .

Horizontal Distribution: Unit D-11.

Remarks: With the small sample we have, it is impossible to distinguish between $R$. norvequicus and $R$. rattus. Both are post-Columbian, and both are commensal with humans.

\section{CLASS: Aves}

ORDER: Indeterminate

Referred Material: Material consists of one phalanx fragment, one diaphyseal fragment, and one unidentifiable fragment.

Total: 3 .

Horizontal Distribution: Units D-7, E-8, and 3-A.

Remarks: The phalanx fragment (a distal epiphysis), although distinctive, could not be identified to species. It was from a large individual ranging in size between a large owl and a turkey.

ORDER: Falconiformes

FAMILY: Cathartidae

GENUS: Cathartes (vulture)

Referred Material: Material consists of one carpometacarpus fragment.

Total: 1 .

Horizontal Distribution: Unit C-9.

Remarks: Vultures are diurnal carrion eaters and are common throughout this region (Robbins, Brunn, and Zim 1966). 
ORDER: Galliformes

GENUS-SPECIES: cf. Gallus gallus (chicken)

Referred Material: Material consists of one spur, two furcula fragments, and the proximal epiphys is of a radius. The presence of the spur indicates that the specimen was from a male bird.

Total: 4 .

Horizontal Distribution: Units B7-A, B-11, E-8, and Shove1 Test 2.

Remarks: Chickens are a valuable domesticated fowl. Besides providing eggs and meat, their feathers can be practically used as ticking or as decorative items.

FAMILY: Meleagridae

GENUS-SPECIES: Meleagris gallopavo (turkey)

Referred Material: Material consists of one radius fragment.

Total: 1 .

Horizontal Distribution: Unit E-8.

Remarks: Wild turkeys Tive in a variety of habitats and conditions (0lson 1968); while the domestic turkey is dependent on its raisers for its survival. With such a small sample, it is impossible to assign this fragment to the wild or domesticated version.

CLASS: Osteichthyes

ORDER: Indeterminate

Referred Material: Material consists of four indeterminate fragments and four vertebral fragments.

Tota7: 8 .

Horizontal Distribution: Units B-7B, C-9, E-7, and E-8.

Remarks: These specimens could not be further identified due to their poor condition. 
ORDER: Lepisosteiformes

FAMILY: Lepisosteidae

GENUS-SPECIES: Lepisosteus sp. (gar)

Referred Material: Material consists of two fish scales and three mandibular fragments.

Total: 5 .

Horizontal Distribution: Units $C-6$ and D-8.

Remarks: Three different species of gar live in the waters of Texas. These fragments could not be assigned to a specific species.

CLASS: Reptilia

ORDER: Testudines

FAMILY: Indeterminate (turtTes)

Referred Material: Material consists of one carapace fragment.

Total: 1 .

Horizontal Distribution: Unit B-7B.

Remarks: Due to the fragmentary nature of this fragment, it could not be identified further.

FAMILY: Chelydridae

GENUS-SPECIES: Chelydra serpentina (snapping turtle)

Referred Material: Material consists of one carapace fragment.

Total: 1 .

Horizontal Distribution: Unit D-11.

Remarks: Snapping turtles live in or near any permanent body of freshwater. They are known to have been used in soups and stews in historic contexts, and turtle has been included as a food resource at other Spanish colonial sites in North America (Reitz and Cumbaa 1983). 
FAMILY: Trionychidae

GENUS-SPECIES: Trionyx spiniferous (spiny softshe11 turtle)

Referred Material: Material consists of one carapace fragment and one pubis from a very large individual.

Total: 2.

Horizontal Distribution: Unit E-8.

Remarks: This riverine species is found throughout Texas, and the females can reach a length of approximately 18 inches (Conant 1975).

\section{REFERENCES CITED}

Blair, W. F., A. P. Blair, P. Brodkorb, F. R. Cagle, and G. A. Moore

1968 Vertebrates of the United States. McGraw-Hi11 Book Company, Inc., New York.

Conant, R.

1950 A Field Guide to Reptiles and Amphibians of Eastern and Central North America. 2nd edition. Houghton Mifflin Company, Boston.

Davis, W. B.

1974 The Mammals of Texas. Texas Parks and Wildlife Department, Bulletin 41. Austin, Texas.

01 sen, S. J.

1968 The 0steology of the Wild Turkey. Appendix in Fish, Amphibian and Reptile Remains from Archaeological Sites Part I Southeastern and Southwestern United States. Papers of the Peabody Museum of Archaeology and Ethnology 56(2):107-137.

Reitz, E. J. and S. L. Cumbaa

1983 Diet and Foodways of Eighteenth-Century Spanish St. Augustine. In Spanish St. Augustine the Archaeology of a Colonial Creole Community, edited by Kathleen Deagan:151-185. Academic Press, New York.

Robbins, C. S., B. Brunn, and H. S. Zim

1966 A Guide to Field Identification Birds of North America. Golden Press, New York. 
Steele, D. G. and G. B. DeMarcay

1985 Analysis of Faunal Remains Recovered during the 1984 Excavations at Rancho de 7 as Cabras. Appendix $C$ in Archaeological Survey and Testing at Rancho de 1 as Cabras, 41 WN 30, Wilson County, Texas, Fifth Season, by A. J. Taylor and A. A. Fox:62-75. Center for Archaeological Research, The University of Texas at San Antonio, Archaeological Survey Report 144 . 


\section{APPENDIX VII}

\section{AN EXPERIMENTAL DATING OF A POSSIBLE SPANISH COLONIAL BUILDING IN THE PROPOSED APPLEWHITE RESERVOIR AREA}

Joel Gunn

\section{INTRODUCTION}

According to Bail1ie (1982), Leonardo da Vinci understood that there was a relationship between moisture and the annual widths of tree rings. There are indications that ancient Greeks surmised the annual character of tree rings, a matter which was expounded upon by Theophrastus, a student of Aristotle. From the 1700s, there are published notes observing the relationship between certain tree ring characters and severe frosts. Serious investigations of tree rings appear to have started in Europe in the early 1800s, so interest in the study of tree ring science, or dendrochronology, developed simultaneously with the other fields of science.

Given the interest in tree rings in Europe, it is no surprise to learn that a German immigrant to Texas was using tree rings to a purpose in the $1850 \mathrm{~s}$. Jacob Kuechler (Campbe11 1949) immigrated to Texas in 1847 from Germany. He was trained at either the University of Heidelberg or Giessen as a forester, and in 1859 he published an article in the Texas Staats-Zeitung, called "Das Clima von Texas" (The Climate of Texas). In his article Kuechler notes that ". . Texas lies on the border of an area which has a variable climate, and it extends into an area which has a regular climate, the trade winds bringing dry summers and wet winter." Droughts in the 1850 s had discouraged German immigrants to settle in central Texas, and Kuechler cut and studied three post oaks to show that drought was an intermittent condition in Texas, thus the farmers should not be unduly discouraged by the presumably temporary misfortune.

The present author had been thinking about continuing Kuechler's studies, which by 1984 had been neglected for over 120 years when Andrew Korus of Stockdale, Texas, volunteered a 242-year-old post oak slab for study (Gunn 1985). In 1985, a second post oak with 277 rings (A.D. 1709) was studied by the author. These rings were measured and computerized for climate studies.

In the fall of 1985, Al McGraw suggested that perhaps tree rings could be used to date a building of possible Spanish colonial architecture in the proposed Applewhite Reservoir area. A visit was made to the building on September 2, 1985, in the company of Andrew Korus, who identified the wood from three beams which were recovered from the walls of the building. These rings were prepared and measured, and a computer program written to compare the ring sets and to determine possible dates.

\section{TERMINOLOGY}

In order to present the findings, certain terminology definitions are presented. 
Rings -

Additions to the radius of a tree consisting of light colored and vesseled spring wood and unvesseled and darker summer wood. The spring wood develops in February or March and carries water and nutrients stored in the roots up the tree to start the year's growth. The summer wood develops after the leaves have begun to supply energy and nutrients.

Rays (medullar rays) - Lines radiating from the center to the outside of the tree.

Sapwood -

Younger, outer wood with many visible vessels. The cells are not yet filled with deposits so the wood is more porous.

Heartwood -

01der wood closer to the center of the tree. The cells and vessels are filled in with deposits, resins, etc., and so it is less porous and more solid.

Master -

An extended set of rings for which the dates are known. In this study, two trees from the same hi11 were used that were very 01d, 250-300 years, and were cut at known years.

Target - A limited set of rings whose date is not known. In this case, three samples taken from a building of unknown age.

\section{SETTING}

The three specimens dated in this study are from the inside of the walls of a long, two-story building located on the Enoch Jones Complex (41 BX 664) described elsewhere in this report. The building is divided into an east, middle, and west room. The specimens were a11 found in the west room. They were probably floor supports for a now-removed second floor. The room in which the specimens were found contained a large fireplace of different architectural style from that of the building and the fireplace in the middle room.

\section{SAMPLES}

Three samples were taken from the western room in the building (Fig. 39). Two (Live 0aks \#1 and \#3) were in the north wall and penetrated the wall from outside to inside. The other (Hickory \#2) was in the inside wall in the southwest corner of the room. They were about eight feet from the floor and probably served as the underpinnings of a second floor at one time. At some point in the history of the building, the second floor was removed, and the sawn stumps were left sticking out a few inches. The wood was rotten on the outside of the building but was in very good condition on the inside. The specimens (usually 3.5 inches) were taken from the inside. All of the specimens had bark on the outside. 


\section{APPLEWHITE LIVE OAK \#1}

The specimen was $110 \mathrm{~cm}$ (4-1/2 inches) $10 \mathrm{ng}$ and $100 \mathrm{~cm}$ (4 inches) in its greatest diameter. It was located along the north wall closest to the western door. It contained 41 rings.

Live oaks may not be we1l-suited to tree ring studies. They are a tropical evergreen, and as a consequence do not stop growing in the winter season. Under certain severe conditions, they may put on more than one ring a year. However, once prepared, there were rings of vessels to be found, usually one vessel wide. This suggests some sort of seasonality. It seems likely, however, that live oaks may skip rings in mild winters. The rings that could be observed were occasionally discontinuous around the tree suggesting caution with imcomplete specimens.

\section{APPLEWHITE HICKORY \#2}

The specimen was the most interesting of the three. It was located in the interior wall in the southeast corner of the room. It was $45 \mathrm{~mm}(1-3 / 4$ inches) long and $90 \mathrm{~mm}$ (3-1/2 inches) in longest diameter. It exhibited 28 rings. The rays in hickories are not visible to the unaided eye as they are in the oaks, but they can be seen under the microscope. Andrew Korus grew up in the Las Gallinas area near the proposed Applewhite Reservoir and remembers that there were numerous large hickories in the area until the 1950s. They grew in deeper sand than the post oaks, though not in the river bottoms which are too clayey for the hickories. Pecan trees grow in the bottoms. They died out in the 1950s, possibly because of the severe drought that plagued Texas in the early 1950s, but he also thinks there may have been some sort of root disease problem.

There may be some question as to whether dating across species is advisable. However, the somewhat similar habitats of the post oak masters and the hickories, e.g., sands, and the demands of necessity conspired to suggest trying. As will become apparent, the results are, at the very least, interesting. Dating across species is commonly practiced in the southwest (J. Dean, personal communication).

The wood was generally in good condition though there were some worm holes in it. There was no problem finding a ray that could be followed all the way from the center to the outside ring. The rings are variable, not complacent, and in general appearance resemble the post oak master specimens more closely than the live oaks do.

\section{APPLEWHITE LIVE OAK \#3}

The third specimen, a live oak, was found a few feet east of \# 1 along the north exterior wa11. It was $130 \mathrm{~mm}$ (5 inches) 7 ong and $95 \mathrm{~mm}$ (3-3/4 inches) in broadest diameter. Twenty-six rings were found. 


\section{DATA RECOVERY METHODS}

Several steps were followed consistently in preparing the specimens and measuring the rings.

1. A piece about $40 \mathrm{~mm}$ thick was sawn from the ends of specimens \#1 and \#3. A11 of specimen \#2 was of the standard $40 \mathrm{~mm}$ length as it was recovered. The end of each specimen was sanded even and smooth with a belt sander (grit 120). The sanding was finished with very fine sand paper (grit 220) to remove the scratches of the medium sanding belt.

2. The surface was dampened with a moist cloth. This removes the dust from the sanding. It also causes the vessels in the spring wood to swell and stand out a little, making the spring wood more apparent to observation.

3. The rings were measured using the graduations on the right ocular of a binocular microscope. The oculars were 10X, and the adjustable power of the microscope was set at 1.5X. The rings were measured from end of summer (EOS) to end of summer. The boundary between the end of summer wood and the beginning of spring wood is generally very sharp and serves as a good point of reference. The boundary between the spring and summer wood is very indistinct. The hickory conformed to this methodology very well, in much the same fashion as the post oak masters, but the live oaks had little to distinguish between spring and summer wood, as would be expected.

4. The resulting measurements were entered on a microcomputer by use of a spread sheet program (UP-PIanner, an inexpensive Lotus 1-2-3). The spread sheet environment makes data entry easy and also facilitates moving the columns of numbers around and basic statistical determinations. Once properly formatted the spead sheet was written to a text file.

5. The text file was read by program TREEDATE.PAS, a Turbo-Pascal program which made exhaustive comparison of the long master trees and the short ring sequence specimens from the building. The program was written specifically for this project.

\section{DATA ANALYSIS METHODS}

Program TREEDATE performed the following functions.

1. It read the data in from the spread sheet output file.

2. It calculated the mean and standard deviations of the tree to be dated, the "target" tree, converted the original tree ring values to standardized deviations from the mean, Z-scores, and cumulatively summed them from the outer to the inner rings. The profile of the cumulative deviations was compared to the master trees.

Cumulative deviations were used for a number of reasons. As Bailile (1982) points out, many numerical and statistical methods have been used to correlate tree rings. Most of them have failings which the cumulative deviations seem to overcome. Cumulative deviations provide a very 
informative visual representation of the data (Bel1 1981). The curve changes direction when the trend in growth changes. Also, the calculations of cumulative deviations waste no rings, a particularly important consideration when dealing with a few rings as in this study. Additionally, it allows the determination of the difference between two ring sets by subtracting one from the other after difference in size (mean) and variance (standard deviation) has been removed, this is Z-scores. Subtracting raw deviation scores always results in zero since the sum of the $Z$-scores is always zero.

3. For every ring in the master, a sequence of equal length to the target ring set was calculated, and the cumulative deviations of the master subtracted from the target. A comparison of the summed absolute differences between the two sets of rings suggested the most likely dates. Those sequences which were most like the target ring set were considered to be the most likely dates.

4. A second means of determining similarity of the ring sets was made by determining if each ring was larger or smaller than the one before it. The sequence of larger and smaller rings was compared between the target and master sequences. A percentage of agreement was calculated. The highest percentages of agreement were considered to be the most likely dates. The second method still requires some refinement, so the dates given here are considered secondary in importance to the cumulative deviations differences.

Both of the methods described resemble more those used by Europeans on oaks than the cross-dating techniques which are standard in the southwestern United States. In conversations subsequent to this study, David Jurney indicated to the author that the cross-dating technique may also be applicable to post oaks. Also, a future study should examine the relationship between the post oaks from south Texas presented in this study and those collected from north Texas by Stahle et al. (1984).

\section{RESULTS}

Table 34 is a 1 ist of all the tree ring measurements in half millimeters. The first ring in each specimen was not used in analysis since the thickness would vary with the time of year the tree or limb was cut.

If the specimens were all cut during the same year to build the structure, then they should all show comparable ring sequences. On the right side of the table the measurements are converted to standard deviations from the mean to make comparison easier. The likely peaks and valleys of deviation are joined with lines.

In the live oaks it appears that error creeps into the sequence at the 14 th ring. The sequences are, however, in general agreement given the theoretical liabilities of reading live oak rings (see previous discussion of Live Oak \#1 specimen). The hickory sequence generally agrees with the 1 ive oaks but occasional rings differ substantially. These are marked with $+^{\prime} s$.

The second rings are particularly deviant. Since the cumulative deviation technique is especially sensitive to the first ring in the series, it sets 
TABLE 34. RING MEASUREMENTS IN APPROXIMATELY HALF MILLIMETERS AND STANDARD DEVIATIONS FROM THE MEAN

\begin{tabular}{|c|c|c|c|c|c|c|c|}
\hline \multicolumn{2}{|c|}{$\begin{array}{l}\text { Ring } \\
\text { Number }\end{array}$} & $\begin{array}{r}\text { Aplwh2 } \\
\text { EOS } \\
\text { Hickory }\end{array}$ & $\begin{array}{r}\text { Ap lwh3 } \\
\text { EOS } \\
\text { Live Oak }\end{array}$ & $\begin{array}{r}\text { Aplwhl } \\
\text { EOS } \\
\text { Live Oak }\end{array}$ & $\begin{array}{c}\text { Aplwh2 } \\
\text { Z-Scores }\end{array}$ & Ap 1 wh3 & Aplwhl \\
\hline \multirow[t]{40}{*}{ outer } & 1 & 38 & 25 & 20 & $<-\infty$ Not & Used in $A$ & alysis \\
\hline & 2 & 20 & 37 & 37 & $-1.0+$ & 0.2 & $1.4^{*}$ not use \\
\hline & 3 & 37 & 48 & 34 & 0.7 & 0.9 & 1.1 \\
\hline & 4 & 42 & 46 & 65 & 1.2 & 0.8 & $3.7 *$ \\
\hline & 5 & 21 & 41 & 25 & $-0.9+$ & 0.4 & 0.4 \\
\hline & 6 & 42 & 56 & 34 & 1.2 & 1.4 & 1.1 \\
\hline & 7 & 36 & 49 & 19 & 0.6 & 0.9 & -0.1 \\
\hline & 8 & 41 & 35 & 12 & 1. . $1+$ & .0 & -0.7 \\
\hline & 9 & 20 & 12 & 14 & -1.0 & -1.5 & -0.5 \\
\hline & 10 & 9 & 49 & 25 & $-2.1+$ & 0.9 & 0.4 \\
\hline & 11 & 39 & 26 & 20 & 0.9 & -0.5 & .0 \\
\hline & 12 & 32 & 26 & 14 & 0.2 & -0.5 & -0.5 \\
\hline & 13 & 33 & 29 & 16 & 0.3 & -0.4 & -0.4 \\
\hline & 14 & 49 & 56 & 12 & 1.9 & 1.4 & $-0.7 * ?$ \\
\hline & 15 & 16 & II & 26 & -1.4 & -1.5 & $0.5 *$ \\
\hline & 16 & 18 & 32 & 11 & -1.2 & -0.2 & -0.8 \\
\hline & 17 & 29 & 30 & 9 & -0.1 & -0.3 & -0.9 \\
\hline & 18 & 22 & 12 & 18 & -0.8 & -1.5 & $-0.2^{*}$ \\
\hline & 19 & 40 & 19 & 6 & $1.0+$ & -1.0 & -1.2 \\
\hline & 20 & 30 & 33 & 10 & .0 & -0.1 & -0.8 \\
\hline & 21 & 34 & 45 & 17 & 0.4 & 0.7 & $-0.3 *$ \\
\hline & 22 & 36 & 12 & 24 & $0.6+$ & -1.5 & $0.3 *$ \\
\hline & 23 & 25 & 45 & 15 & -0.5 & 0.7 & $-0.4 *$ \\
\hline & 24 & 23 & 56 & 12 & -0.7 & 1.4 & $-0.7 *$ \\
\hline & 25 & 24 & 21 & 11 & -0.6 & -0.9 & -0.8 \\
\hline & 26 & 22 & 60 & 30 & $----\infty-\infty$ & - & $-\infty-\infty$ \\
\hline & 27 & 7 & & 23 & 29.9 & 34.4 & 20.3 Mean \\
\hline & 28 & 25 & & 22 & 9.8 & 15. & 12. I Standard \\
\hline & 29 & & & 22 & & & Deviation \\
\hline & 30 & & & 34 & & & \\
\hline & 31 & & & 26 & & & \\
\hline & 32 & & & 40 & & & \\
\hline & 33 & & & 27 & & & \\
\hline & 34 & & & 16 & & & \\
\hline & 35 & & & 21 & & & \\
\hline & 36 & & & 22 & & & \\
\hline & 37 & & & 30 & & & \\
\hline & 38 & & & 16 & & & \\
\hline & 39 & & & 29 & & & \\
\hline & 40 & & & 20 & & & \\
\hline inner 4 & 41 & & & 50 & & & \\
\hline
\end{tabular}

* Mismatch $>1.0$ Standard Deviation

? Probably Extra Ring 
the location of the rest of the curve immediately. It seemed advisable to not use the second rings as well in the search for a match with the master tree ring sequences.

Table 351 ists the best five matches from six runs of the program. One run was made with the first 23 rings from each target specimen, and one run was made with each specimen with a different number of rings to test the stability of the solution. The number of rings is the last item in each row of the table.

TABLE 35. TREE RING DATES BY VARIOUS METHODS

\begin{tabular}{|c|c|c|c|c|c|c|}
\hline & & & Tree & Dif & Ring & \\
\hline & 1978 & 1.0 & L01 & 22.69 & 23 & \\
\hline & 1977 & 1.0 & L01 & 23.05 & 23 & \\
\hline \multirow[t]{5}{*}{$1970 \mathrm{~s}$} & 1977 & 1.0 & L01 & 23.10 & 23 & Discounted \\
\hline & 1974 & 1.1 & L01 & 25.04 & 23 & \\
\hline & 1973 & 1.1 & LOI & 25.01 & 23 & \\
\hline & 1942 & 0.7 & $\llcorner 03$ & 16.13 & 23 & \\
\hline & 1941 & 0.7 & L03 & 16.96 & 23 & \\
\hline \multirow[t]{4}{*}{$1940 \mathrm{~s}$} & 1940 & 0.9 & L03 & 20.07 & 23 & Discounted \\
\hline & 1939 & 0.9 & L03 & 21.53 & 23 & \\
\hline & 1926 & 1.0 & L03 & 22.99 & 23 & \\
\hline & 1925 & 0.8 & $\mathrm{Hi} 2$ & 17.75 & 23 & \\
\hline \multirow[t]{7}{*}{$1920 \mathrm{~s}$} & 1924 & 0.9 & $\mathrm{Hi2}$ & 20.01 & 23 & Prohibition \\
\hline & 1924 & 0.9 & $\mathrm{Hi} 2$ & 21.28 & 23 & \\
\hline & 1892 & 1.0 & $\mathrm{Hi} 2$ & 23.20 & 23 & \\
\hline & 1889 & 1.0 & $\mathrm{Hi} 2$ & 23.80 & 23 & \\
\hline & 1878 & 1.9 & L01 & 72.06 & 38 & \\
\hline & 1873 & 2.0 & L01 & 74.55 & 38 & \\
\hline & 1872 & 2.0 & LOI & 76.59 & 38 & \\
\hline \multirow[t]{5}{*}{$1870 \mathrm{~s}$} & 1872 & 2.1 & L01 & 80.27 & 38 & Enoch Jones Complex \\
\hline & 1871 & 2.1 & LO1 & 80.33 & 38 & \\
\hline & 1869 & 0.6 & LO3 & 10.15 & 18 & \\
\hline & 1866 & 0.7 & L03 & 11.99 & 18 & \\
\hline & 1865 & 0.7 & L03 & 12.51 & 18 & \\
\hline \multirow[t]{5}{*}{$1860 \mathrm{~s}$} & 1865 & 0.9 & $\mathrm{LO3}$ & 15.34 & 18 & End of Civil War \\
\hline & 1864 & 0.9 & L03 & 15.65 & 18 & \\
\hline & 1792 & 1.0 & $\mathrm{Hi} 2$ & 24.29 & 25 & \\
\hline & 1777 & 1.0 & $\mathrm{Hi} 2$ & 25.03 & 25 & \\
\hline & 1776 & 1.0 & $\mathrm{Hi} 2$ & 26.19 & 25 & \\
\hline $1770 \mathrm{~s}$ & 1775 & 1.1 & $\mathrm{Hi} 2$ & 27.92 & 25 & Spanish Land Grants \\
\hline & 1774 & 1.2 & $\mathrm{Hi} 2$ & 29.06 & 25 & \\
\hline
\end{tabular}


Each of the ring sets shows a distinct bias toward some part of the scale with perhaps one or two exceptions. For example, all five best determinations for 25 rings of Hickory \#2 (Hi2) fall in the late 1700s. With 23 rings the determinations fall in the early 20 th century for the most part. The indication is that the solutions are not stable, and further investigations are necessary.

Further work is also required on the masters. The \#1 and \#3 post oak specimens are not yet perfectly correlated with each other. Very tentative suggestions indicate a four-year discrepancy in the 1880 s and a six-year discrepancy in the late 1700s. The fact of good cumulative deviation matches in 1799 in specimen \#3 and 1804 in specimen \#1, five years apart, favors the 1799 date as the most likely and the middle 1880 s as second most likely.

As a preliminary result, the 1870s are suggested as the most likely date for the building of the second floor. Six determinations fall in the nine-year period from 1869 to 1878. This is the only cluster of dates which involves more than one tree, which adds certain credibility to the date.

Judging from what is known about the building, the 1870 s dates are not unreasonable since this is the period of occupation of the Enoch Jones family, who may have built the building or modified it. It is recommended that an attempt be made to determine if the holes were made at the time of construction or added at a later date.

other date sets are not unreasonable. It is reported that the building was used as a place of entertainment during the Prohibition era, so adding an upstairs during the 1920 s is logical. The 1770 s were a period of Spanish land grants and so those dates might be good as we11. The 1770 s seem to agree with the architectural assessment of the building.

\section{CONCLUSIONS}

While there are obvious problems with the dating of the specimens, the determinations do suggest some logical time ranges. It is difficult to date oaks, especially with such short ring sequences. Baillie (1982) prefers to date sequences of 100 years. However, there are additional methods that could be used to refine the technique and narrow the possibilities. These are listed in the Recommendations section which follows.

At the present state of the investigation, the most likely date for the construction of the barn structure seems to be in the early 1870 s.

\section{RECOMMENDATIONS}

Several recommendations are made to assure the accuracy of further tree ring date studies.

1. A percentage agreement method is already in the program in a preliminary form and could be brought to use. The program could be made more sophisticated by eliminating rings of equal width from consideration. 
2. Spline curve fitting could be applied to the tree ring series to remove growth effects.

3. Experiment with parts of tree ring series to check the stability of the solutions found.

4. See if any of the old hickories mentioned by Korus are still standing or can be found under protection in the project area and use it as a master.

5. Work out the correlation of the \#1 and \#3 live oaks more closely. Insert blanks where the missing rings can be identified. It may be possible to code the rings in more detail and produce a nonsequence dependent correlation of the rings by clustering them. Some possible attributes are color of segments of the rings, vessel thickness, and chemical analysis of the rings such as those done by Libby (1983).

6. Make live oak sequence the same by eliminating extra ring in L01.

\section{TREE RING MEASUREMENTS AND STATISTICS}

The following is an example of output from program TREEDATE.PAS. The output is so voluminous as to prohibit complete presentation.

\section{TREERING DATING BY SEQUENTIAL CUMULATIVE DEVIATIONS TTTTTTTTTTTTTTTTTTTTTTTTTTTTTTTTTTTTTTTTTTTTTTTTTTTTTT}

Korus \#3 Post Oak and Applewhite \#2 Hickory

274 records (rings) will be taken from file tApple.dat. 25 rings in the $r t$ col are the target rings.

RiNo Korus\#1 Korus\#3 Aplwh\#2 Hick

$\begin{array}{llll}1 & 0.0 & 25.0 & 37.0 \\ 2 & 0.0 & 28.0 & 42.0 \\ 3 & 0.0 & 25.0 & 21.0 \\ 4 & 0.0 & 41.0 & 42.0 \\ 5 & 0.0 & 39.0 & 36.0\end{array}$

Calculating Cumulative Deviations of Target Tree

Sum $=727.0 \mathrm{Avg}=29.1 \mathrm{StD}=10.60$

Calculating Cumulative Sequences of Master Tree

Differences based on cutting year, last outer ring

\begin{tabular}{|c|c|c|c|c|c|c|c|}
\hline Pass & Date & Mean & StD & TotDif & LgstDif & SumDir & Original \\
\hline 1 & $\begin{array}{l}1982 \\
1981\end{array}$ & $\begin{array}{l}33.8 \\
34.2\end{array}$ & $\begin{array}{l}10.80 \\
10.65\end{array}$ & $\begin{array}{l}43.83 \\
41.44\end{array}$ & $\begin{array}{l}4.30 \\
3.82\end{array}$ & $\begin{array}{l}15 \\
13\end{array}$ & $0 \%$ \\
\hline
\end{tabular}




\begin{tabular}{|c|c|c|c|c|c|c|c|c|c|}
\hline 3 & 1980 & 34.3 & 10.61 & 41.64 & 3.77 & 11 & $44 \%$ & 25 & 21 \\
\hline 4 & 1979 & 34.1 & 10.78 & 43.36 & 4.65 & 12 & $48 \%$ & 41 & 42 \\
\hline 5 & 1978 & 33.0 & 11.37 & 39.20 & 4.79 & 16 & $64 \%$ & 39 & 36 \\
\hline 6 & 1977 & 32.8 & 11.31 & 38.78 & 5.41 & 10 & $40 \%$ & 44 & 41 \\
\hline 7 & 1976 & 31.9 & 11.26 & 34.91 & 3.58 & 13 & $52 \%$ & 47 & 20 \\
\hline 8 & 1975 & 30.6 & 11.29 & 29.45 & 3.24 & 13 & $52 \%$ & 45 & 9 \\
\hline 9 & 1974 & 29.3 & 11.52 & 29.06 & 3.22 & 11 & $44 \%$ & 38 & 39 \\
\hline 10 & 1973 & 28.7 & 11.44 & 32.76 & 3.84 & 11 & $44 \%$ & 42 & 32 \\
\hline 11 & 1972 & 28.2 & 11.12 & 34.02 & 3.03 & 10 & $40 \%$ & 30 & 33 \\
\hline 12 & 1971 & 27.7 & 11.25 & 34.15 & 3.60 & 15 & $60 \%$ & 42 & 49 \\
\hline 13 & 1970 & 27.4 & 10.98 & 33.29 & 3.46 & 11 & $44 \%$ & 52 & 16 \\
\hline 14 & 1969 & 26.9 & 10.07 & 48.75 & 5.23 & 10 & $40 \%$ & 16 & 18 \\
\hline 15 & 1968 & 27.2 & 9.86 & 36.82 & 5.10 & 11 & $44 \%$ & 32 & 29 \\
\hline 16 & 1967 & 27.5 & 10.09 & 48.89 & 6.39 & 17 & $68 \%$ & 36 & 22 \\
\hline 17 & 1966 & 27.4 & 10.03 & 68.34 & 7.48 & 6 & $24 \%$ & 40 & 40 \\
\hline 18 & 1965 & 27.4 & 9.98 & 96.67 & 8.03 & 13 & $52 \%$ & 15 & 30 \\
\hline 19 & 1964 & 27.9 & 9.66 & 85.87 & 7.48 & 12 & $48 \%$ & 40 & 34 \\
\hline 20 & 1963 & 27.2 & 9.40 & 93.78 & 7.50 & 12 & $48 \%$ & 38 & 36 \\
\hline 21 & 1962 & 27.9 & 10.68 & 134.01 & 8.49 & 13 & $52 \%$ & 15 & 25 \\
\hline 22 & 1961 & 28.2 & 10.43 & 112.79 & 8.93 & 11 & $44 \%$ & 13 & 23 \\
\hline 23 & 1960 & 29.2 & 10.20 & 109.00 & 9.31 & 13 & $52 \%$ & 32 & 24 \\
\hline 24 & 1959 & 30.1 & 11.29 & 135.32 & 10.08 & 13 & $52 \%$ & 45 & 22 \\
\hline 25 & 1958 & 29.9 & 11.03 & 162.73 & 12.30 & 11 & $44 \%$ & 26 & 7 \\
\hline 26 & 1957 & 29.8 & 11.07 & 151.50 & 11.38 & 14 & $56 \%$ & 34 & \\
\hline 27 & 1956 & 30.2 & 11.44 & 169.51 & 11.19 & 13 & $52 \%$ & 30 & \\
\hline 28 & 1955 & 29.8 & 11.65 & 155.83 & 11.23 & 7 & $28 \%$ & 21 & \\
\hline 29 & 1954 & 30.0 & 11.54 & 142.80 & 9.94 & 18 & $72 \%$ & 14 & \\
\hline 30 & 1953 & 30.5 & 11.09 & 123.82 & 8.90 & 8 & $32 \%$ & 33 & \\
\hline 31 & 1952 & 29.9 & 11.34 & 112.18 & 9.54 & 10 & $40 \%$ & 22 & \\
\hline 32 & 1951 & 30.1 & 11.26 & 99.18 & 8.51 & 15 & $60 \%$ & 15 & \\
\hline 33 & 1950 & 30.7 & 10.83 & 82.41 & 7.32 & 6 & $24 \%$ & 11 & \\
\hline 34 & 1949 & 31.8 & 10.19 & 72.37 & 6.46 & 14 & $56 \%$ & 23 & \\
\hline 35 & 1948 & 32.0 & 10.11 & 58.91 & 4.97 & 15 & $60 \%$ & 29 & \\
\hline 36 & 1947 & 32.0 & 10.10 & 54.47 & 4.50 & 6 & $24 \%$ & 19 & \\
\hline 37 & 1946 & 32.3 & 9.80 & 37.99 & 3.31 & 17 & $68 \%$ & 35 & \\
\hline 38 & 1945 & 33.1 & 10.76 & 55.46 & 5.34 & 11 & $44 \%$ & 39 & \\
\hline 39 & 1944 & 32.7 & 10.73 & 55.78 & 5.14 & 11 & $44 \%$ & 23 & \\
\hline 40 & 1943 & 32.1 & 11.56 & 31.30 & 3.18 & 16 & $64 \%$ & 39 & \\
\hline 41 & 1942 & 30.9 & 12.38 & 27.92 & 2.93 & 10 & $40 \%$ & 34 & \\
\hline 42 & 1941 & 30.1 & 12.75 & 24.29 & 3.18 & 12 & $48 \%$ & 39 & \\
\hline 43 & 1940 & 29.5 & 12.67 & 03 & 2.69 & 13 & $52 \%$ & 29 & \\
\hline 44 & 1939 & 29.7 & 12.69 & 26.19 & 3.56 & 14 & $56 \%$ & 22 & \\
\hline 45 & 1938 & 29.6 & 12.74 & 35.71 & 3.35 & 9 & $36 \%$ & 55 & \\
\hline 46 & 1937 & 28.2 & 11.73 & 31.76 & 2.81 & 14 & $56 \%$ & 22 & \\
\hline 47 & 1936 & 28.3 & 11.71 & 36.07 & 4.32 & 8 & $32 \%$ & 40 & \\
\hline 48 & 1935 & 27.2 & 11.78 & 33.51 & 4.68 & 15 & $60 \%$ & 54 & \\
\hline 49 & 1934 & 25.8 & 10.59 & 29.83 & 4.33 & 12 & $48 \%$ & 39 & \\
\hline 50 & 1933 & 25.1 & 10.25 & 32.30 & 4.14 & 9 & $36 \%$ & 24 & \\
\hline 51 & 1932 & 25.0 & 10.28 & 33.71 & 3.33 & 10 & $40 \%$ & 45 & \\
\hline 52 & 1931 & 23.8 & 9.57 & & 3.89 & 16 & $64 \%$ & 19 & \\
\hline 53 & 1930 & 24.2 & 9.56 & & 3.91 & 10 & $40 \%$ & 26 & \\
\hline 5 & 1929 & 24.0 & 9.58 & & 4.29 & 11 & $44 \%$ & 27 & \\
\hline 55 & 1928 & 24.2 & 9.69 & & 4.55 & 16 & $64 \%$ & 18 & \\
\hline
\end{tabular}




\begin{tabular}{|c|c|c|c|c|c|c|c|}
\hline 56 & 1927 & 24.2 & 9.75 & 41.36 & 5.60 & 9 & $36 \%$ \\
\hline 57 & 1926 & 24.0 & 9.74 & 37.70 & 4.27 & 17 & $68 \%$ \\
\hline 58 & 1925 & 23.9 & 9.68 & 41.88 & 4.04 & 9 & $36 \%$ \\
\hline 59 & 1924 & 22.8 & 9.36 & 35.98 & 3.68 & 13 & $52 \%$ \\
\hline 60 & 1923 & 22.7 & 9.34 & 45.05 & 3.50 & 13 & $52 \%$ \\
\hline 61 & 1922 & 22.4 & 9.22 & 54.20 & 4.02 & 11 & $44 \%$ \\
\hline 62 & 1921 & 22.1 & 9.20 & 56.07 & 4.69 & 10 & $40 \%$ \\
\hline 63 & 1920 & 20.5 & 6.34 & 87.54 & 6.68 & 18 & $72 \%$ \\
\hline 64 & 1919 & 19.7 & 6.68 & 76.00 & 6.13 & 8 & $32 \%$ \\
\hline 65 & 1918 & 20.3 & 6.39 & 64.63 & 6.29 & 13 & $52 \%$ \\
\hline 66 & 1917 & 20.6 & 6.02 & 32.87 & 3.37 & 14 & $56 \%$ \\
\hline 67 & 1916 & 21.3 & 6.45 & 45.67 & 4.63 & 10 & $40 \%$ \\
\hline 68 & 1915 & 21.5 & 6.57 & 62.36 & 6.10 & 13 & $52 \%$ \\
\hline 69 & 1914 & 20.8 & 6.21 & 72.91 & 6.28 & 13 & $52 \%$ \\
\hline 70 & 1913 & 21.1 & 6.36 & 84.73 & 7.18 & 11 & $44 \%$ \\
\hline 71 & 1912 & 21.2 & 6.37 & 86.13 & 7.67 & 14 & $56 \%$ \\
\hline 72 & 1911 & 20.7 & 6.60 & 72.46 & 5.91 & 12 & $48 \%$ \\
\hline 73 & 1910 & 21.2 & 6.53 & 68.83 & 5.77 & 12 & $48 \%$ \\
\hline 74 & 1909 & 21.7 & 6.64 & 74.69 & 6.23 & 10 & $40 \%$ \\
\hline 75 & 1908 & 21.4 & 6.70 & 69.64 & 4.89 & 10 & $40 \%$ \\
\hline 76 & 1907 & 21.5 & 6.71 & 70.75 & 6.03 & 15 & $60 \%$ \\
\hline 77 & 1906 & 21.7 & 6.62 & 60.62 & 6.75 & 6 & $24 \%$ \\
\hline 78 & 1905 & 21.1 & 6.61 & 57.62 & 6.26 & 16 & $64 \%$ \\
\hline 79 & 1904 & 20.6 & 6.96 & 40.85 & 6.44 & 13 & $52 \%$ \\
\hline 80 & 1903 & 19.9 & 6.67 & 48.26 & 5.15 & 10 & $40 \%$ \\
\hline 81 & 1902 & 19.9 & 6.70 & 33.83 & 4.12 & 16 & $64 \%$ \\
\hline 82 & 1901 & 19.6 & 6.73 & 38.07 & 4.82 & 9 & $36 \%$ \\
\hline 83 & 1900 & 19.1 & 6.65 & 45.98 & 6.26 & 13 & $52 \%$ \\
\hline 84 & 1899 & 19.2 & 6.61 & 37.11 & 4.34 & 14 & $56 \%$ \\
\hline 85 & 1898 & 18.7 & 6.64 & 43.55 & 5.45 & 8 & $32 \%$ \\
\hline 86 & 1897 & 18.4 & 6.60 & 45.28 & 4.77 & 17 & $68 \%$ \\
\hline 87 & 1896 & 18.3 & 6.62 & 46.19 & 4.13 & 11 & $44 \%$ \\
\hline 88 & 1895 & 18.4 & 6.60 & 45.89 & 3.94 & 12 & $48 \%$ \\
\hline 89 & 1894 & 19.0 & 6.23 & 54.22 & 4.34 & 10 & $40 \%$ \\
\hline 90 & 1893 & 18.8 & 6.12 & 51.84 & 4.07 & 12 & $48 \%$ \\
\hline 91 & 1892 & 18.8 & 6.19 & 59.68 & 5.81 & 13 & $52 \%$ \\
\hline 92 & 1891 & 17.9 & 5.49 & 47.76 & 5.03 & 11 & $44 \%$ \\
\hline 93 & 1890 & 17.1 & 5.35 & 36.40 & 5.29 & 11 & $44 \%$ \\
\hline 94 & 1889 & 17.3 & 5.39 & 41.37 & 5.68 & 15 & $60 \%$ \\
\hline 95 & 1888 & 16.7 & 4.99 & 36.68 & 4.41 & 11 & $44 \%$ \\
\hline 96 & 1887 & 16.3 & 4.99 & 31.81 & 2.71 & 13 & $52 \%$ \\
\hline 97 & 1886 & 16.2 & 5.08 & 37.50 & 3.62 & 14 & $56 \%$ \\
\hline 98 & 1885 & 16.0 & 4.82 & 40.63 & 3.76 & 6 & $24 \%$ \\
\hline 99 & 1884 & 15.3 & 4.13 & 41.73 & 4.63 & 16 & $64 \%$ \\
\hline 100 & 1883 & 15.0 & 4.24 & 38.18 & 4.08 & 15 & $60 \%$ \\
\hline 101 & 1882 & 14.5 & 4.02 & 41.25 & 3.98 & 9 & $36 \%$ \\
\hline 102 & 1881 & 14.3 & 3.86 & 49.31 & 4.89 & 14 & $56 \%$ \\
\hline 103 & 1880 & 14.0 & 4.05 & 37.50 & 4.75 & 10 & $40 \%$ \\
\hline 104 & 1879 & 14.2 & 3.97 & 35.28 & 4.31 & 14 & $56 \%$ \\
\hline 105 & 1878 & 14.1 & 4.02 & 38.19 & 3.63 & 11 & $44 \%$ \\
\hline 106 & 1877 & 13.8 & 4.25 & 41.08 & 3.45 & 9 & $36 \%$ \\
\hline 107 & 1876 & 13.5 & 4.39 & 39.78 & 4.43 & 12 & $48 \%$ \\
\hline 108 & 1875 & 13.4 & 4.41 & 40.19 & 4.02 & 11 & $44 \%$ \\
\hline
\end{tabular}




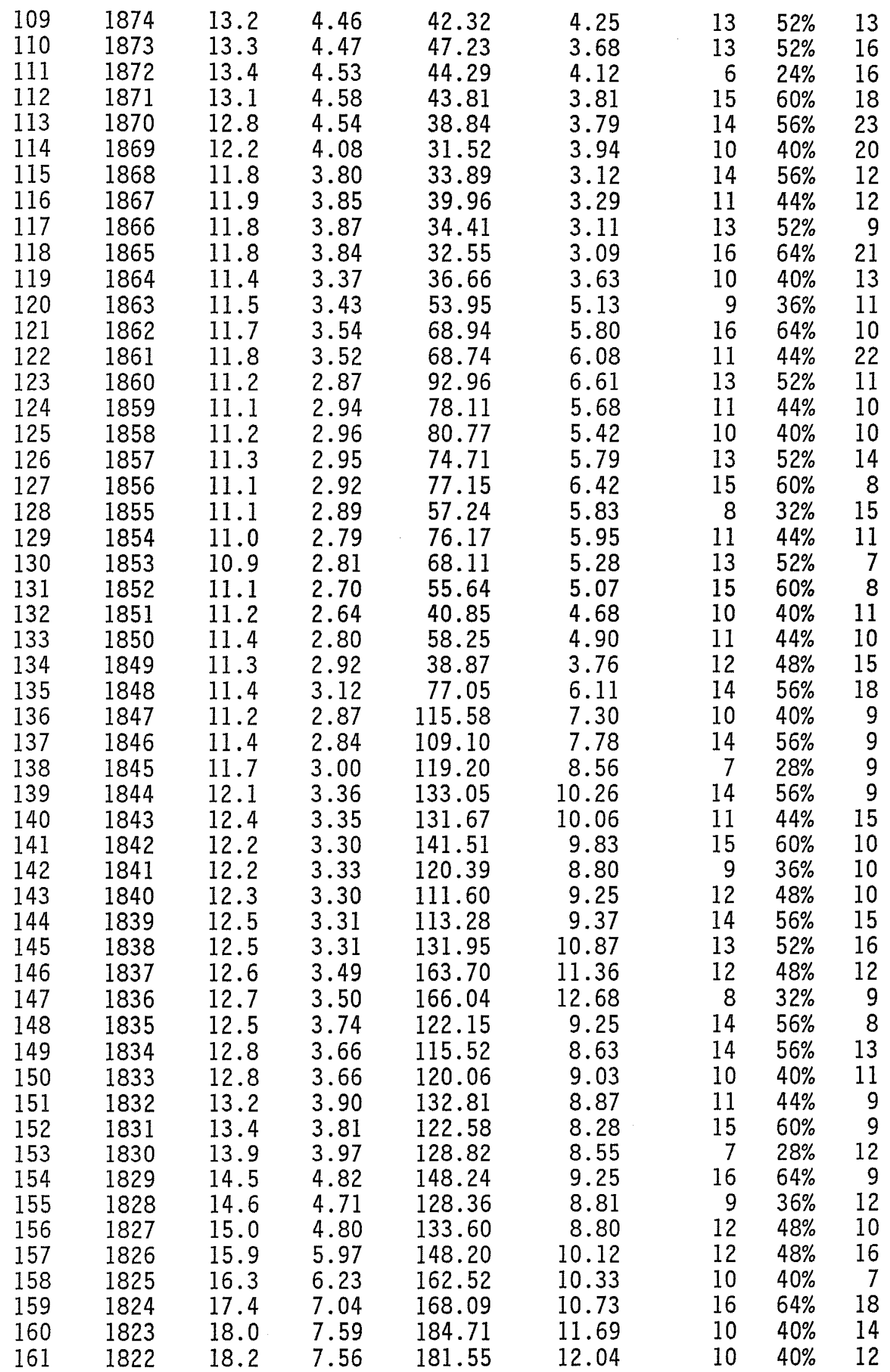




\begin{tabular}{|c|c|c|c|c|c|c|c|}
\hline 162 & 1821 & 18.6 & 7.47 & 176.52 & 12.30 & 16 & $64 \%$ \\
\hline 163 & 1820 & 18.5 & 7.52 & 165.71 & 12.46 & 9 & $36 \%$ \\
\hline 164 & 1819 & 18.0 & 7.78 & 148.74 & 11.46 & 15 & $60 \%$ \\
\hline 165 & 1818 & 18.4 & 7.87 & 153.51 & 12.12 & 14 & $56 \%$ \\
\hline 166 & 1817 & 18.5 & 7.80 & 138.44 & 11.22 & 6 & $24 \%$ \\
\hline 167 & 1816 & 18.5 & 7.80 & 107.92 & 8.79 & 21 & $84 \%$ \\
\hline 168 & 1815 & 18.4 & 7.92 & 84.31 & 8.55 & 10 & $40 \%$ \\
\hline 169 & 1814 & 19.2 & 8.45 & 98.43 & 8.80 & 9 & $36 \%$ \\
\hline 170 & 1813 & 19.6 & 8.48 & 99.99 & 7.78 & 18 & $72 \%$ \\
\hline 171 & 1812 & 20.0 & 8.72 & 112.63 & 8.56 & 7 & $28 \%$ \\
\hline 172 & 1811 & 19.9 & 8.82 & 91.03 & 7.63 & 13 & $52 \%$ \\
\hline 173 & 1810 & 20.2 & 8.38 & 62.43 & 5.72 & 13 & $52 \%$ \\
\hline 174 & 1809 & 20.2 & 8.44 & 48.15 & 5.62 & 7 & $28 \%$ \\
\hline 175 & 1808 & 20.2 & 8.44 & 37.80 & 4.91 & 15 & $60 \%$ \\
\hline 176 & 1807 & 19.7 & 8.77 & 33.48 & 3.46 & 11 & $44 \%$ \\
\hline 177 & 1806 & 19.5 & 8.91 & 31.07 & 4.37 & 11 & $44 \%$ \\
\hline 178 & 1805 & 19.3 & 8.93 & 31.60 & 4.42 & 11 & $44 \%$ \\
\hline 179 & 1804 & 18.9 & 8.75 & 35.80 & 4.11 & 12 & $48 \%$ \\
\hline 180 & 1803 & 19.0 & 8.68 & 45.44 & 4.28 & 11 & $44 \%$ \\
\hline 181 & 1802 & 18.6 & 8.89 & 49.60 & 3.90 & 14 & $56 \%$ \\
\hline 182 & 1801 & 17.9 & 8.32 & 41.29 & 3.63 & 9 & $36 \%$ \\
\hline 183 & 1800 & 17.6 & 8.20 & 40.71 & 3.08 & 13 & $52 \%$ \\
\hline 184 & 1799 & 16.7 & 7.33 & 34.05 & 2.94 & 13 & $52 \%$ \\
\hline 185 & 1798 & 16.0 & 6.64 & 39.70 & 3.63 & 14 & $56 \%$ \\
\hline 186 & 1797 & 15.8 & 6.59 & 44.77 & 4.84 & 9 & $36 \%$ \\
\hline 187 & 1796 & 15.4 & 6.57 & 48.19 & 6.12 & 13 & $52 \%$ \\
\hline 188 & 1795 & 15.5 & 6.56 & 47.73 & 4.81 & 14 & $56 \%$ \\
\hline 189 & 1794 & 15.6 & 6.42 & 37.81 & 3.67 & 11 & $44 \%$ \\
\hline 190 & 1793 & 15.2 & 6.13 & 41.28 & 3.42 & 14 & $56 \%$ \\
\hline 191 & 1792 & 15.4 & 6.20 & 47.56 & 4.04 & 9 & $36 \%$ \\
\hline 192 & 1791 & 15.9 & 6.12 & 53.18 & 4.61 & 13 & $52 \%$ \\
\hline 193 & 1790 & 16.2 & 5.96 & 57.20 & 5.60 & 14 & $56 \%$ \\
\hline 194 & 1789 & 15.4 & 4.72 & 67.54 & 6.10 & 12 & $48 \%$ \\
\hline 195 & 1788 & 14.8 & 4.40 & 70.40 & 5.78 & 9 & $36 \%$ \\
\hline 196 & 1787 & 14.2 & 3.14 & 126.19 & 9.12 & 18 & $72 \%$ \\
\hline 197 & 1786 & 14.2 & 3.19 & 96.15 & 7.40 & 7 & $28 \%$ \\
\hline 198 & 1785 & 14.0 & 3.29 & 79.15 & 5.87 & 17 & $68 \%$ \\
\hline 199 & 1784 & 14.0 & 3.31 & 67.61 & 5.76 & 11 & $44 \%$ \\
\hline 200 & 1783 & 13.7 & 3.66 & 51.89 & 5.86 & 7 & $28 \%$ \\
\hline 201 & 1782 & 13.6 & 3.81 & 39.80 & 3.67 & 18 & $72 \%$ \\
\hline 202 & 1781 & 13.6 & 3.85 & 42.59 & 5.33 & 12 & $48 \%$ \\
\hline 203 & 1780 & 13.6 & 3.85 & 40.09 & 5.07 & 6 & $24 \%$ \\
\hline 20 & 1779 & 13.5 & 3.77 & 45.91 & 4.09 & 18 & $72 \%$ \\
\hline 20 & 1778 & 13.5 & 3.80 & 48.87 & 5.19 & 10 & $40 \%$ \\
\hline 20 & 1777 & 13.7 & 3.68 & 46.76 & 5.74 & 11 & $44 \%$ \\
\hline 207 & 1776 & 13.4 & 3.78 & 47.37 & 5.03 & 14 & $56 \%$ \\
\hline 208 & 1775 & 13.1 & 3.69 & 51.12 & 4.22 & 9 & $36 \%$ \\
\hline 209 & 1774 & 12.9 & 3.77 & 45.19 & 3.91 & 14 & $56 \%$ \\
\hline 21 & 1773 & 12.7 & 3.79 & 40.75 & 4.42 & 13 & $52 \%$ \\
\hline 2. & 1772 & 12.9 & 4.03 & 51.17 & 3.84 & 8 & $32 \%$ \\
\hline 1 & 177 & 13.5 & 4.65 & 69.10 & 6.63 & 12 & $48 \%$ \\
\hline & 177 & 14.3 & 6.28 & 106.84 & 9.15 & 13 & $52 \%$ \\
\hline & 1769 & 14.2 & 6.32 & 95.07 & 9.06 & 10 & $40 \%$ \\
\hline
\end{tabular}




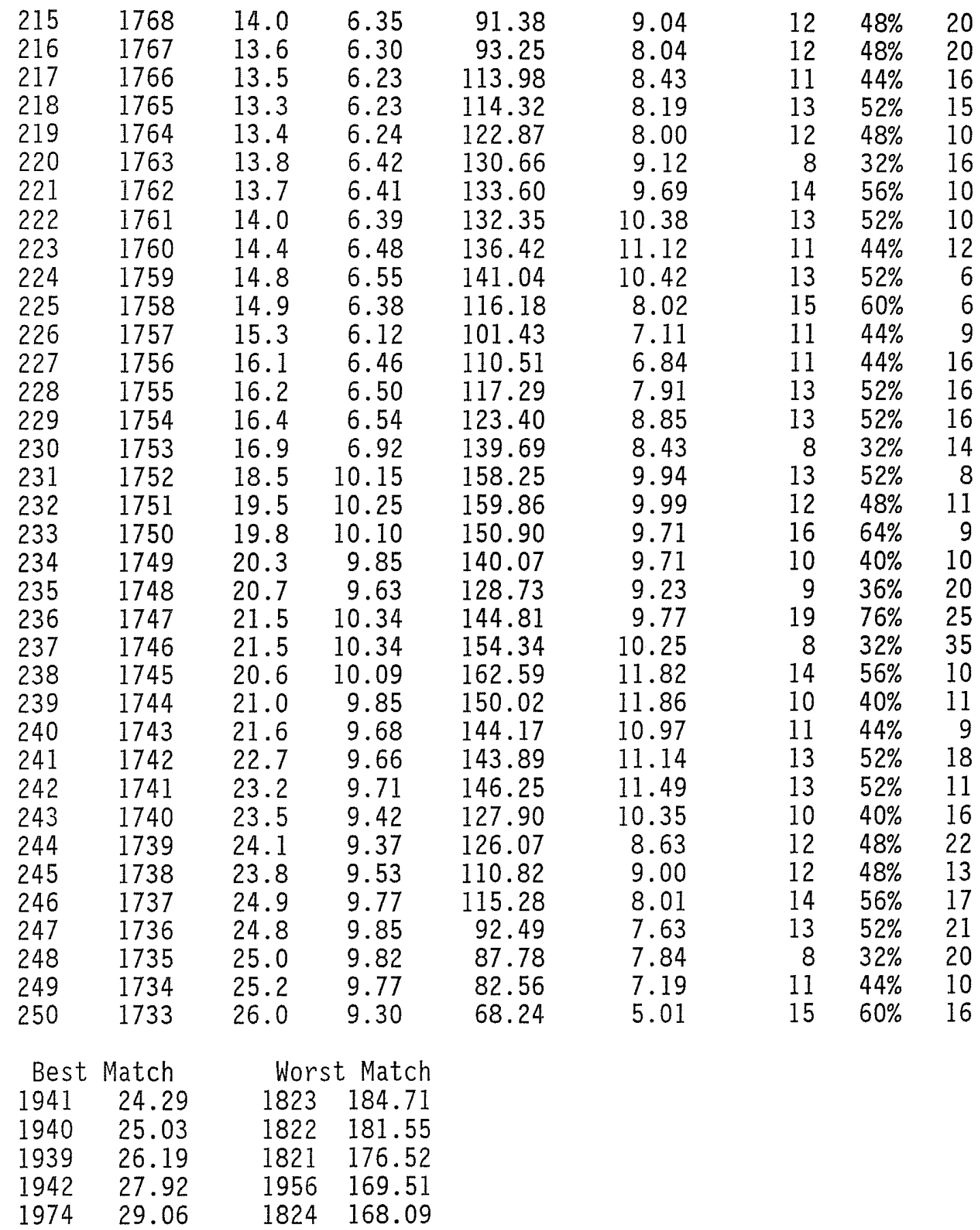

Accumulated Trajectories of the Five Best Matched Ring Sequences

\begin{tabular}{|c|c|c|c|c|c|c|}
\hline & Target & First & Second & Third & Fourth & Fifth \\
\hline & $?$ & 1941 & 1940 & 1939 & 1942 & 1974 \\
\hline 1 & 0.7 & 0.7 & -0.0 & -0.6 & 0.3 & 0.8 \\
\hline 2 & 2.0 & 0.6 & -0.6 & 1.4 & 0.9 & 1.9 \\
\hline 3 & 1.2 & -0.0 & 1.4 & 0.8 & 0.8 & 1.9 \\
\hline$A$ & 2.4 & 1.9 & 0.8 & 1.6 & 0.0 & 3.0 \\
\hline
\end{tabular}




$\begin{array}{rrrrrrr}5 & 3.1 & 1.3 & 1.6 & 3.5 & 2.0 & 5.0 \\ 6 & 4.2 & 2.1 & 3.5 & 4.3 & 1.3 & 3.8 \\ 7 & 3.3 & 3.9 & 4.3 & 3.8 & 2.0 & 4.1 \\ 8 & 1.4 & 4.6 & 3.9 & 5.0 & 3.9 & 4.7 \\ 9 & 2.4 & 4.2 & 5.1 & 4.2 & 4.5 & 5.6 \\ 10 & 2.7 & 5.3 & 4.2 & 3.9 & 4.0 & 4.4 \\ 11 & 3.0 & 4.4 & 4.0 & 3.7 & 5.1 & 5.3 \\ 12 & 4.9 & 4.1 & 3.8 & 2.7 & 4.2 & 6.0 \\ 13 & 3.7 & 3.9 & 2.9 & 2.5 & 3.8 & 4.8 \\ 14 & 2.6 & 2.9 & 2.6 & 2.5 & 3.4 & 3.4 \\ 15 & 2.6 & 2.6 & 2.6 & 3.3 & 2.4 & 3.6 \\ 16 & 2.0 & 2.6 & 3.4 & 3.0 & 2.0 & 5.0 \\ 17 & 3.0 & 3.4 & 3.2 & 3.0 & 1.9 & 4.7 \\ 18 & 3.1 & 3.0 & 3.2 & 2.8 & 2.7 & 5.1 \\ 19 & 3.5 & 3.0 & 3.0 & 4.8 & 2.3 & 5.2 \\ 20 & 4.2 & 2.8 & 5.0 & 4.7 & 2.2 & 4.5 \\ 21 & 3.8 & 4.7 & 4.9 & 3.1 & 1.9 & 3.1 \\ 22 & 3.2 & 4.6 & 3.3 & 1.3 & 3.8 & 3.5 \\ 23 & 2.8 & 2.9 & 1.6 & 0.2 & 3.6 & 2.8 \\ 24 & 2.1 & 1.2 & 0.4 & & & \end{array}$

\{IIIIIIIIIIIIIIIIIIIIIIIIIIIIIIIIIIIIIIIIIIIIIIIIIIIIIIIIIIIIIIIIIIIII\} PROGRAM TREEDATE; \{Converts Lotus Text file to Numeric and compares a TARGET treering set to a MASTER long period tree.

The program is currently set to use the Korus \#3 and \#1 Post 0aks as the master, see TEXAS CLIMATE BULLETIN, fal1 1985 issue.

Program treedate was written by Joel Gunn, PhD, Center for Archaeological Research, The University of Texas at San Antonio SAT 78285, 512-691-5709.

V1 DEC85

$\{\$ R+\}$ \{Turn on Run Time range checking\}

$\left\{\$ U_{+}\right\}$\{User Abort with $\left.{ }^{\wedge} \mathrm{C}\right\}$

\{?P255\} \{A7ter Output Device\}

\begin{tabular}{|c|c|c|}
\hline \multirow{14}{*}{ const } & \multicolumn{2}{|c|}{$(* * * * *$ THE FOLLOWING CONSTANTS MUST BE SET ACCORDING TO PROBLEM******) } \\
\hline & rings & \{number of rings in tallest tree \\
\hline & ringspl & \{number of rings in tallest tree + \\
\hline & newrings & \{number of rings in tree to be date \\
\hline & middle & \{between the hi \& lo cumulative dev \\
\hline & infile & $=$ 'tApple.dat'; input file name \\
\hline & outfile & \{output file or device \\
\hline & method & $\{1=$ use means, $0=$ use standardization \\
\hline & $\begin{array}{l}\text { Job } \\
\text { Taranama }\end{array}$ & $=$ 'Korus \#3 Post Oak and Applewhite \#2 Hickory'; \\
\hline & StartColumn & $\begin{array}{l}=\text { Aplwh\#2 Hick'; }\{\text { Name of target ringset } \\
=17 .\end{array}$ \\
\hline & SColWidth & \{column width of field of Targ Riset \\
\hline & Startyear & YYear of ring on which master starts \\
\hline & 0 & \\
\hline & $\mathrm{s}$ & $=\# 32$ \\
\hline
\end{tabular}




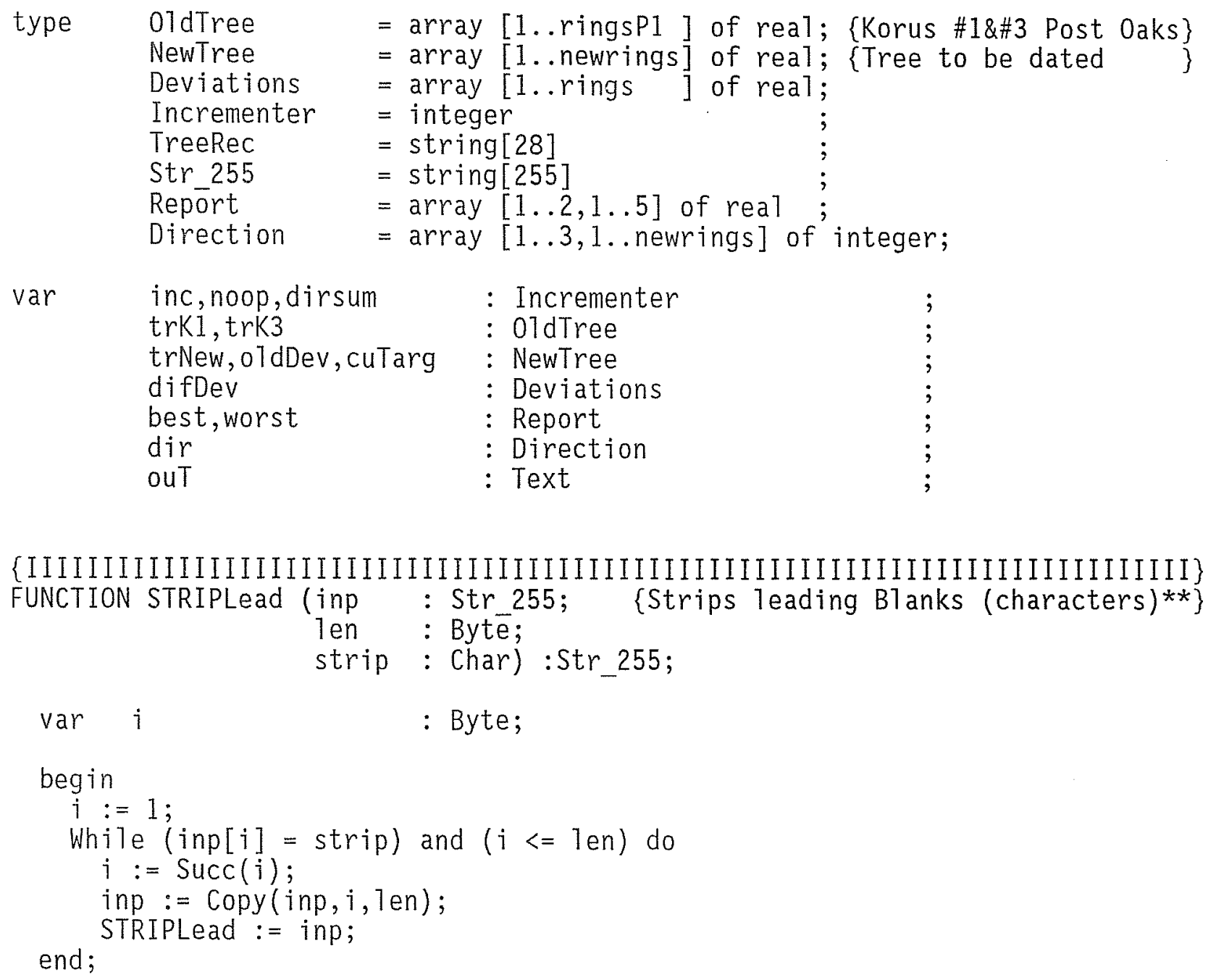


for $i:=1$ to newrings do sum := sum+trNew $[i]$

avg := sum / newrings;

sumsq :=0;

for $i:=1$ to newrings do sumsq := sumsq+((trNew[i]-avg)*(trNew[i]-avg));

stD : = sqrt (sumsq / newrings);

if method $=1$ then stD $:=1$;

Writeln(ouT,' Sum= ', sum:5:1,' $\mathrm{Avg}={ }^{\prime}$, avg:5:1,' StD=', stD:5:2);

$\operatorname{dir}[2,1]:=0$;

for $i:=1$ to newrings do

begin

if $i>=2$ then $\quad$ determinal direction of ring size change begin

$\operatorname{dir}[2, i]:=-1$

if $\operatorname{trNew}[i]>\operatorname{trNew}[i-1]$ then $\operatorname{dir}[2, i]:=1$; end;

cuTarg[i] :=(trNew[i]-avg) / stD;

if $(i>=2)$ and (method $=0$ ) then

end;

cuTarg $[i]:=\operatorname{cuTarg}[i]+\operatorname{cuTarg}[i-1]$;

end ;

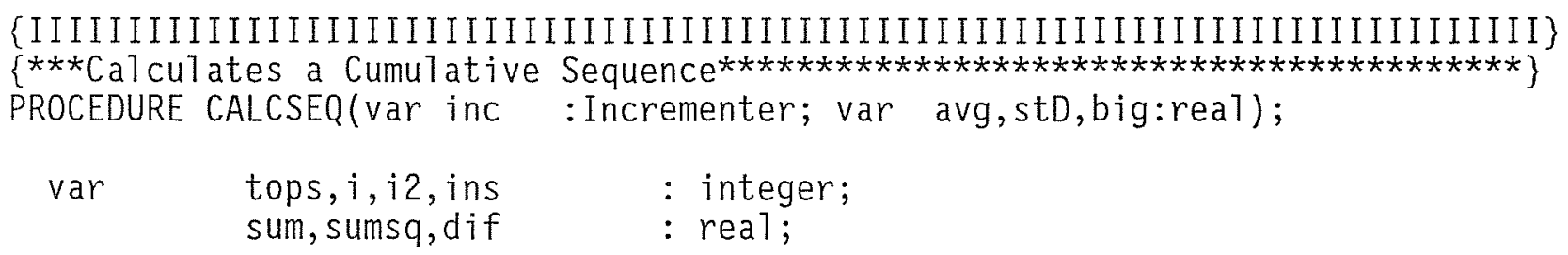

begin

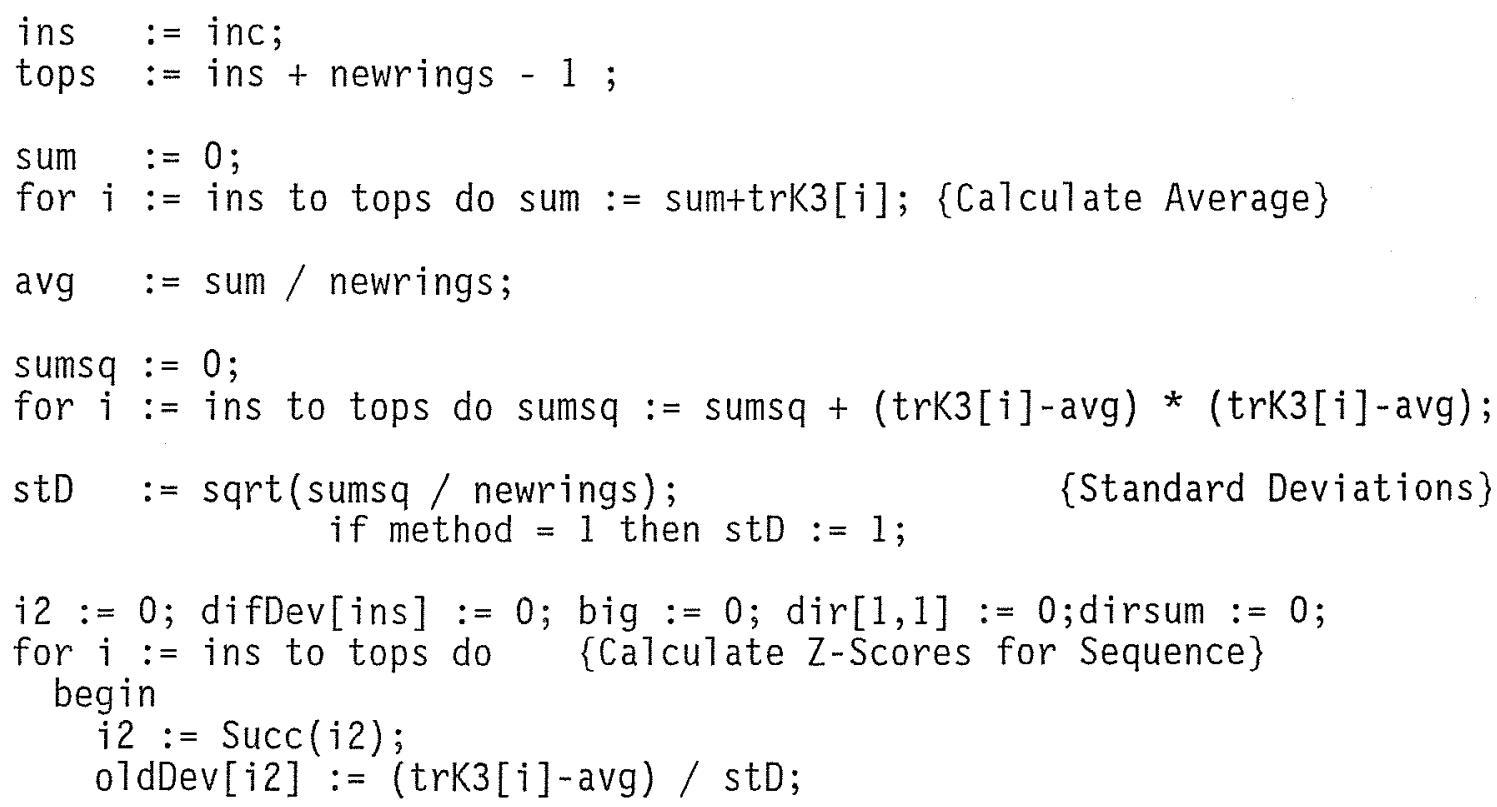


begin

$\operatorname{dir}[1, \mathrm{i} 2]:=-1$

if oldDev[i2] $>((\operatorname{trk} 3[i-1]-\mathrm{avg}) / \mathrm{stD})$ then $\operatorname{dir}[1, i 2]:=1$;

$\operatorname{dir}[3, \mathrm{i} 2]:=0$;

if $\operatorname{dir}[1, i 2]=\operatorname{dir}[2, i 2]$ then $\operatorname{dir}[3, i 2]:=1$;

end;

dirsum $:=\operatorname{dirsum}+\operatorname{dir}[3, i 2]$;

if $(i 2>=2)$ and (method $=0)$ then

oldDev[i2]:= oldDev[i2] + oldDev[i2-1];

dif $:=\operatorname{abs}($ (cuTarg[i2]) - (oldDev[i2]) ) ;

$\operatorname{difDev}[$ ins $]:=\operatorname{difDev}[$ ins $]+$ dif; \{accumulate differences

if abs(dif) > big then big := abs(dif);

if noop $=1$ then $\quad$ if 1 , writes all profiles, a bunch of stuff $\}$

Writeln (ouT, ins:4,s,' ', i:4, s, i2:4, s, StartYear- $i$, $s, \operatorname{trk} 3[i]: 6: 1, s, 0] \operatorname{dDev}[i 2]: 6: 2, s, \operatorname{cuTarg}[i 2]: 6: 2$, s, difDev[ins]:7:2, $s, \operatorname{dir}[1, i 2]: 3, s, \operatorname{dir}[2, i 2]: 3, s, \operatorname{dir}[3, i 2]: 3)$;

end;

end;

\{IIIIIIIIIIIIIIIIIIIIIIIIIIIIIIIIIIIIIIIIIIIIIIIIIIIIIIIIIIIIII $\{* * *$ Calculate sequential deviations for Master and Target tree****************$\}$ PROCEDURE CALCOLD;

$\begin{array}{cl}\text { var } & \text { avg,stD,big,dirper : real; } \\ \text { ins } & \text { integer; }\end{array}$

begin

writeln (ouT);

writeln(ouT, 'Calculating Cumulative Sequences of Master Tree'); writeln (ouT); writeln(ouT);

writeln(ouT, 'Differences based on cutting year, last outer ring'); writeln(ouT); writeln (ouT,

' Pass Date Mean StD TotDif LgstDif SumDir Origina7');

ins $:=1 ; \quad$ Major 10op to control sequential comparisons

while (trk3 [ ins + newrings - 1 ] $<0$ ) do

begin

if noop $=1$ then

writeln(ouT, StartYear-ins,

' Trajectory-.........--Master-MasDev--TargDev--Dif-.....-_');

CALCSEQ (ins, avg, stD, big);

dirper $:=$ (dirsum / newrings) $* 100$;

Write(ouT, ins: 4, ' ', StartYear-ins:5,' ', avg:5:1,

', stD:5:2,' ', difDev[ins]:7:2,' ', big:7:2,' ',

dirsum: $4, s$, dirper: $4: 0,{ }^{\prime} \%$, s, trk3 [ins] $\left.: 4: 0\right)$;

if ins $<=$ newrings then write(ouT, trNew[ins]:4:0); writeln(ouT); 
end; end;

$$
\text { ins := Succ(ins); }
$$

\{IIIIIIIIIIIIIIIIIIIIIIIIIIIIIIIIIIIIIIIIIIIIIIIIIIIIIIIIIIIIIIIII\}

\{***Find the best and worst matches $* * * * * * * * * * * * * * * * * * * * * * * * * * * * * * * * * * * * * * * * * * *\}$ PROCEDURE CALCBEST;

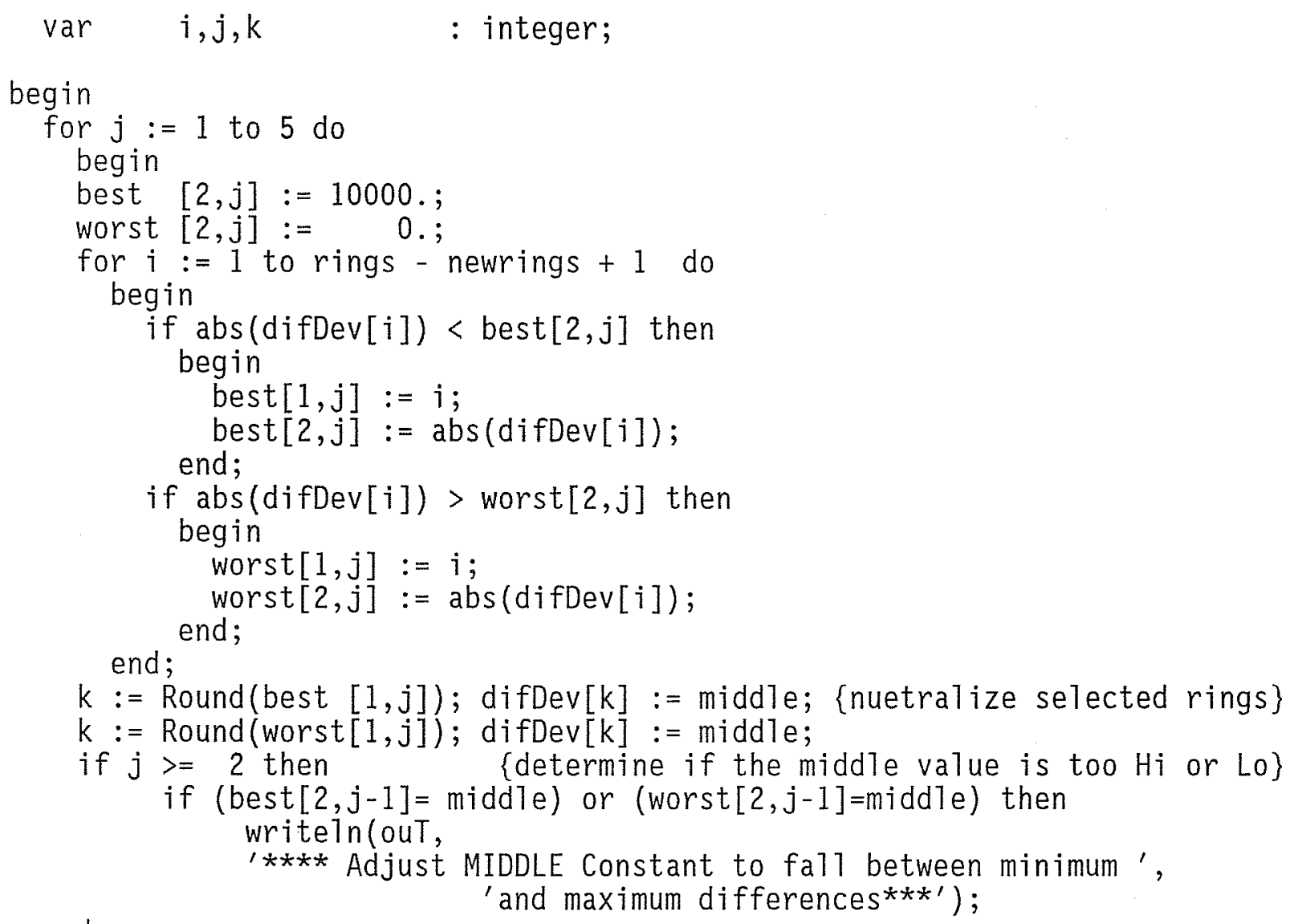

end ;

end;

\{IIIIIIIIIIIIIIIIIIIIIIIIIIIIIIIIIIIIIIIIIIIIIIIIIIIIIIIIIIIIIIII\}

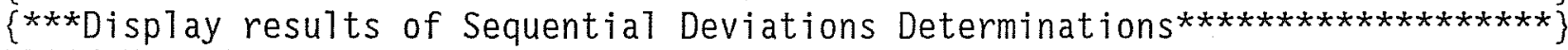
PROCEDURE DISPLAY;

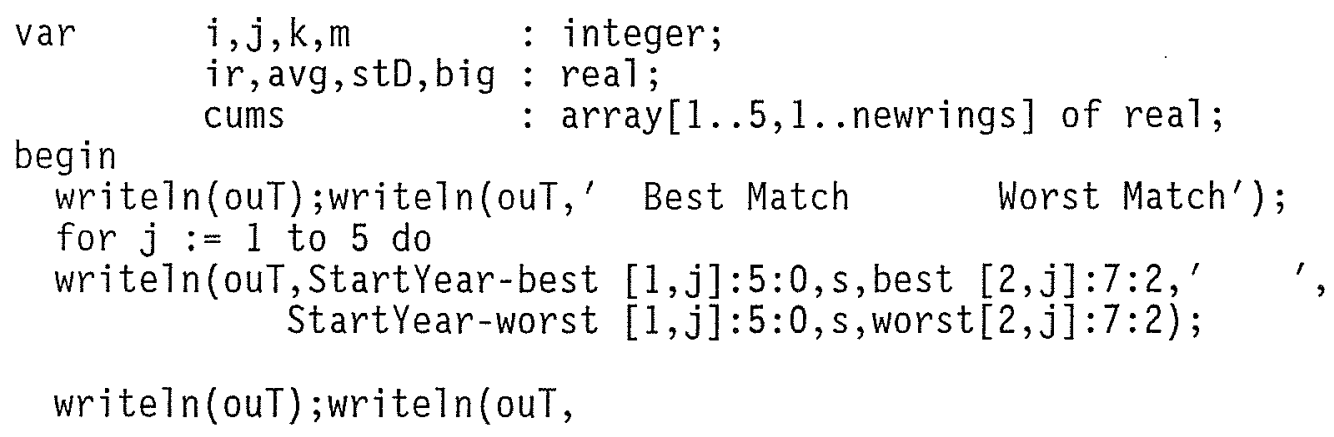




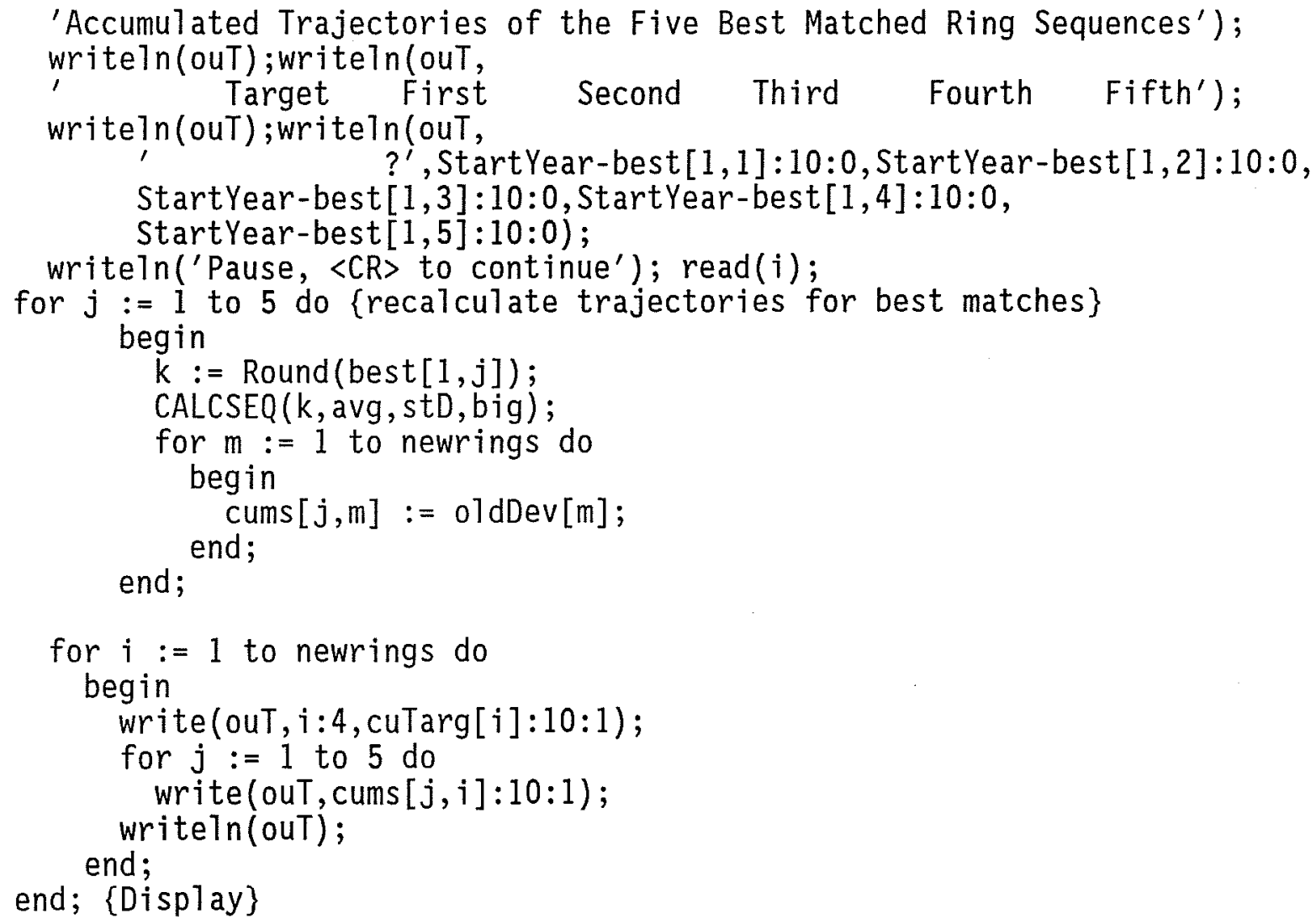

\section{\{IIIIIIIIIIIIIIIIIIIIIIIIIIIIIIIIIIIIIIIIIIIIIIIIIIIIIIIIIIIII\}} BEGIN \{MAIN PROGRAM\}

noop : $=0 ;\{1=$ output each sequence, $0=$ do not output each sequence $\}$

assign(ouT, outfile);

rewrite (ouT);

Extract;

CalcNew;

Calc0ld;

CalcBest;

noop :=0;

Display ;

end.

\{IIIIIIIIIIIIIIIIIIIIIIIIIIIIIIIIIIIIIIIIIIIIIIIIIIIII\}

\section{ACKNOWLEDGMENTS}

David Jurney critiqued the draft of this paper. Numerous conversations with David Jurney during the 1986 Tree Ring Symposium at Fort Burgwin furthered the author's knowledge of the status of tree ring research in the southeast. 


\section{REFERENCES CITED}

Baillie, M. G. L.

1982 Tree-Ring Dating and Archaeology. The Chicago Press, Chicago.

Be 11, B.

1981 An Analysis of Viticultural Data by Cumulative Deviations. In Climate and History: Studies in Interdisciplinary History, edited by R. Rotberg and T. Rabb. Princeton Press, New Jersey.

Campbe11, T. N.

1949 The Pioneer Tree-Ring Work of Jacob Kuechler. Tree-Ring Bulletin 15(3):16-20.

Gunn, J.

1985 Tree Ring Study 1: Korus \#3 Post Oak. Texas Climate Bulletin September 1985:7-10.

Kuechler, J.

1859 Das C1ima von Texas. Texas Staats-Zeitung.

Libby, L. M.

1983 Past C1imates. Texas University Press, Austin.

Stahle, D. W., J. G. Hehr, G. G. Hawks, Jr., M. K. Cleavel and, and J. R. Baldwin

1984 Tree-Ring Chronologies for the Southcentral United States. Department of Geography, University of Arkansas. Final technical report submitted to the Climate Dynamics Program, National Science Foundation, Washington, D.C., under grant number ATM-8120615. 
